\title{
Effects of Grit Roughness and Pitch Oscillations on the S815 Airfoil
}

R. Reuss Ramsay

M. J. Hoffman

G. M. Gregorek

The Ohio State University

Columbus, Ohio

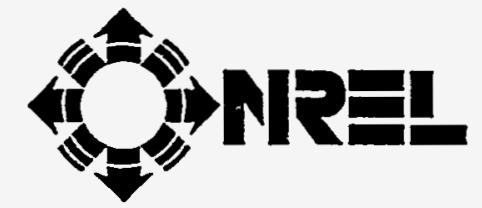

National Renewable Energy Laboratory 1617 Cole Boulevard Golden, Colorado 80401-3393

A national laboratory of the U.S. Department of Energy Managed by Midwest Research Institute for the U.S. Department of Energy under Contract No. DE-AC36-83CH10093 



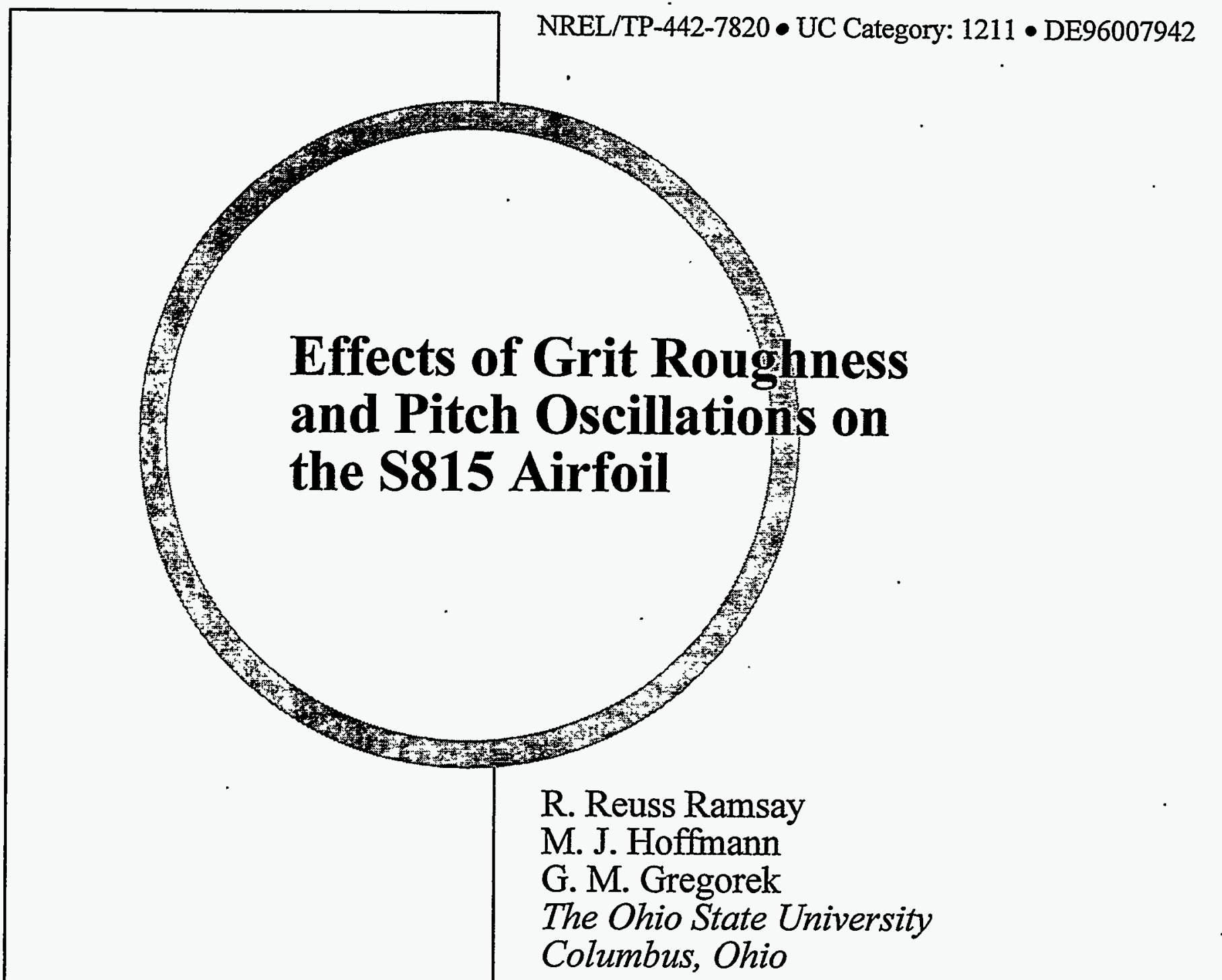

NREL Technical Monitor:

C. P. Butterfield

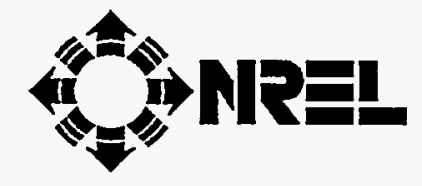

National Renewable Energy Laboratory 1617 Cole Boulevard

Golden, Colorado 80401-3393

A national laboratory of the U.S. Department of Energy Managed by Midwest Research Institute for the U.S. Department of Energy under contract No. DE-AC36-83CH10093

Prepared under Subcontract No. XF-1-11009-3

July 1996 


\section{NOTICE}

This report was prepared as an account of work sponsored by an agency of the United States government. Neither the United States government nor any agency thereof, nor any of their employees, makes any warranty, express or implied, or assumes any legal liability or responsibility for the accuracy, completeness, or usefulness of any information, apparatus, product, or process disclosed, or represents that its use would not infringe privately owned rights. Reference herein to any specific commercial product, process, or service by trade name, trademark, manufacturer, or otherwise does not necessarily constitute or imply its endorsement, recommendation, or favoring by the United States govemment or any agency thereof. The views and opinions of authors expressed herein do not necessarily state or reflect those of the United States govemment or any agency thereof.

Available to DOE and DOE contractors from:

Office of Scientific and Technical Information (OSTI)

P.O. Box 62

Oak Ridge, TN 37831

Prices available by calling (423) $576-8401$

Available to the public from:

National Technical Information Service (NTIS)

U.S. Department of Commerce

5285 Port Royal Road

Springfield, VA 22161

(703) $487-4650$ 


\section{DISCLAIMER}

Portions of this document may be illegible in electronic image products. Images are produced from the best available original document. 


\section{Foreword}

Airfoils for wind turbines have been selected by comparing data from different wind tunnels, tested under different conditions, making it difficult to make accurate comparisons. Most wind tunnel data sets do not contain airfoil performance in stall commonly experienced by turbines operating in the field. Wind turbines commonly experience extreme roughness for which there is very little data. Finally, recent tests have shown that dynamic stall is a common occurrence for most wind turbines operating in yawed, stall or turbulent conditions. Very little dynamic stall data exists for the airfoils of interest to a wind turbine designer. In summary, very little airfoil performance data exists which is appropriate for wind turbine design.

Recognizing the need for a wind turbine airfoil performance data base, the National Renewable Energy Laboratory (NREL), funded by the U.S. Department of Energy, awarded a contract to Ohio State University (OSU) to conduct a wind tunnel test program. Under this program, OSU tested a series of popular wind turbine airfoils. A standard test matrix was developed to assure that each airfoil was tested under the same conditions. The test matrix was developed in partnership with industry and is intended to include all of the operating conditions experienced by wind turbines. These conditions include airfoil performance at high angles of attack, rough leading edge (bug simulation), steady and unsteady angles of attack.

Special care has been taken to report as much of the test conditions and raw data as practical so that designers can make their own comparisons and focus on details of the data relevant to their design goals. Some of the airfoil coordinates are proprietary to NREL or an industry partner. To protect the information which defines the exact shape of the airfoil, the coordinates have not been included in the report. Instructions on how to obtain these coordinates may be obtained by contacting C.P. (Sandy) Butterfield at NREL.

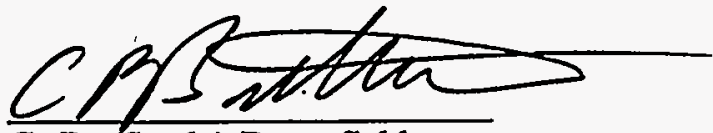

C. P. (Sandy) Butterfield

Wind Technology Division

National Renewable Energy Laboratory

1617 Cole Blvd.

Golden, Colorado, 80401 USA

Internet Address: Sandy_Butterfield@NREL.GOV

Phone 303-384-6902

FAX 303-384-6901 


\section{Preface}

The Ohio State University Aeronautical and Astronautical Research Laboratory is conducting a series of steady state and unsteady wind tunnel tests on a set of airfoils that have been or will be used for horizontal axis wind turbines. The purpose of these tests is to investigate the effect of pitch oscillations and leading edge grit roughness (LEGR) on airfoil performance. The study of pitch oscillation effects can help to understand the behavior of horizontal axis wind turbines in yaw. The results of these tests will aid in the development of new airfoil performance codes that account for unsteady behavior and also aid in the design of new airfoils for wind turbines. The application of LEGR simulates surface irregularities that occur on wind turbines. These irregularities on the blades are caused by the accumulation of insect debris, ice, and the aging process and can significantly reduce the output of horizontal-axis wind turbines. The experimental results from the application of LEGR will promote the development of airfoils that are less sensitive to roughness.

This work was made possible by the efforts and financial support of two other organizations. The National Renewable Energy Laboratory provided major funding and technical monitoring, the U.S. Department of Energy is credited for its funding of this document through the National Renewable Energy Laboratory under contract number DE-AC36-83CH10093 and KENETECH, Windpower Inc. provided technical assistance. The staff of The Ohio State University Aeronautical and Astronautical Research Laboratory appreciate the contributions made by personnel from both organizations. In addition the authors would like to recognize the efforts of the following student research assistants, Fernando Falasca, Jolanta M. Janiszewska, and Monica Angelats i Coll. 


\section{Summary}

A S815 airfoil model was tested in The Ohio State University Aeronautical and Astronautical Research Laboratory $3 \times 5$ subsonic wind tunnel under steady state and unsteady conditions. The test defined baseline conditions for steady state angles of attack from $-20^{\circ}$ to $+40^{\circ}$ and examined unsteady behavior by oscillating the model about its pitch axis for three mean angles, three frequencies, and two amplitudes. For all cases, Reynolds numbers of $0.75,1,1.25$, and 1.4 million were used. In addition, these conditions were repeated after the application of leading edge grit roughness (LEGR) to determine contamination effects on airfoil performance.

Typical steady state results of the S815 testing at Reynolds number of 1.25 million showed a baseline maximum lift coefficient of 1.27 at $12.1^{\circ}$ angle of attack. The application of LEGR reduced the maximum lift coefficient by $27 \%$ and increased the 0.0134 minimum drag coefficient value by $42 \%$. The zero lift pitching moment of -0.1268 showed a $71 \%$ reduction in magnitude to -0.0364 with LEGR applied.

Data were also obtained for two pitch oscillation amplitudes: $\pm 5.5^{\circ}$ and $\pm 10^{\circ}$. The larger amplitude consistently gave a higher maximum lift coefficient than the smaller amplitude, and both sets of unsteady maximum lift coefficients were greater than the steady state values. Stall is delayed on the airfoil while the angle of attack is increasing, thereby causing an increase in maximum lift coefficient. A hysteresis behavior was exhibited for all the unsteady test cases. The hysteresis loops were larger for the higher reduced frequencies and for the larger amplitude oscillations. As in the steady case, the effect of LEGR in the unsteady case was to reduce the lift coefficient at high angles of attack. In addition, with LEGR, the hysteresis behavior persisted into lower angles of attack than for the clean case.

In general, the unsteady maximum lift coefficient was $7 \%$ to $53 \%$ higher than the steady state maximum lift coefficient, and variation in the quarter chord pitching moment coefficient magnitude was from $13 \%$ to $137 \%$ larger than the steady state values at high angles of attack. These findings indicate the importance of considering the unsteady flow behavior occurring in wind turbine operation in order to obtain accurate load estimates. 


\section{Contents}

Preface iv

Summary $\mathrm{v}$

List of Symbols ix

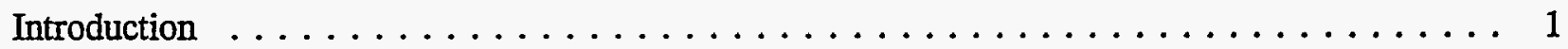

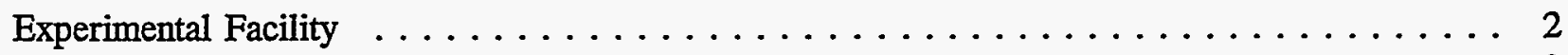

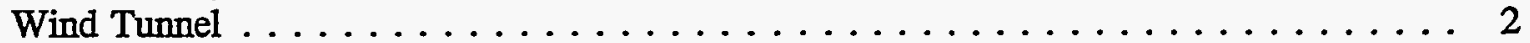

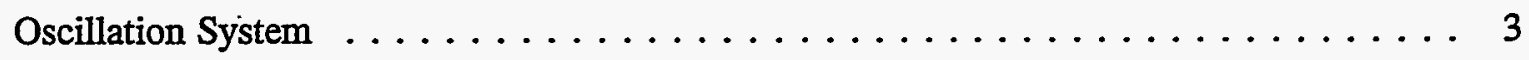

Model Details $\ldots \ldots \ldots \ldots \ldots \ldots \ldots \ldots \ldots \ldots \ldots \ldots \ldots \ldots \ldots$

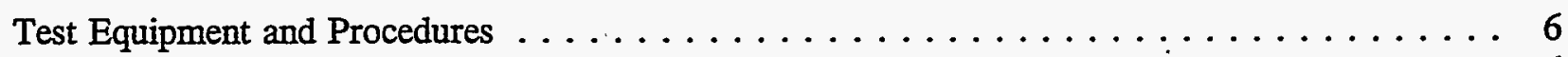

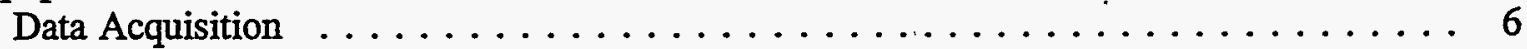

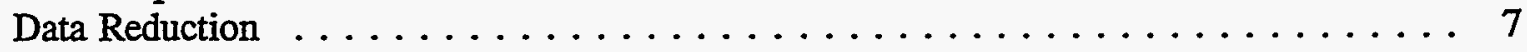

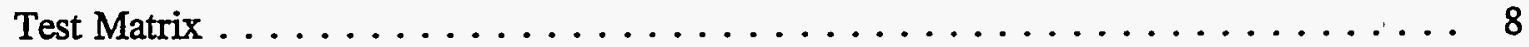

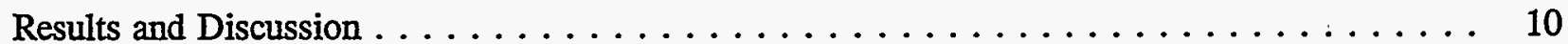

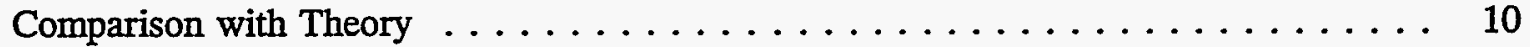

Steady State Data . . . . . . . . . . . . . . . . . . . . 11

Unsteady Data . . . . . . . . . . . . . . . . . . . . 13

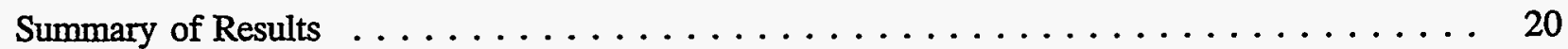

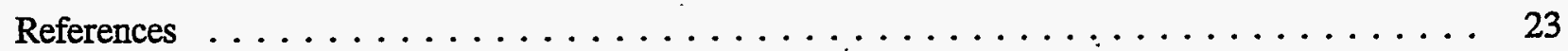

Appendix A: Surface Pressure Tap Coordinates $\ldots \ldots \ldots \ldots \ldots \ldots \ldots \ldots \ldots \ldots$

Appendix B: Steady State Data . . . . . . . . . . . . . . . . . B-1

Appendix C: Unsteady Integrated Coefficients $\ldots \ldots \ldots \ldots \ldots \ldots \ldots \ldots \ldots \ldots$ 
1. $3 \times 5$ Subsonic wind tunnel, top view ...................... 2

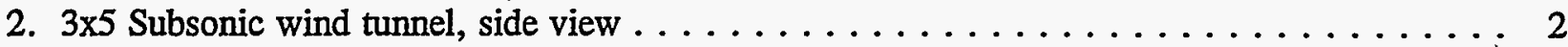

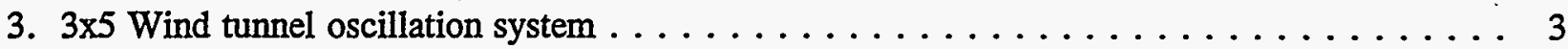

4. $\$ 815$ airfoil section $\ldots \ldots \ldots \ldots \ldots \ldots \ldots \ldots \ldots \ldots \ldots \ldots \ldots \ldots$

5. Measured-to-desired model coordinates difference curves. . . . . . . . . . . . 4

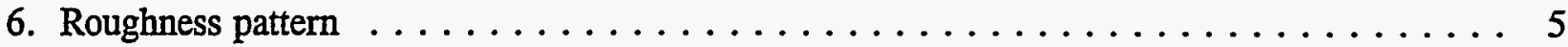

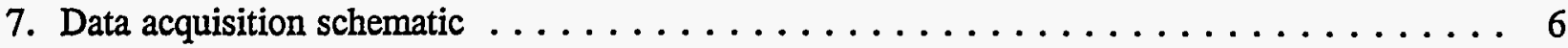

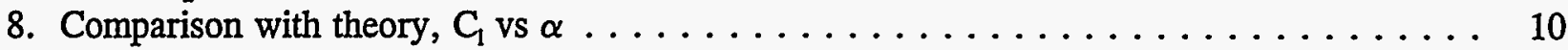

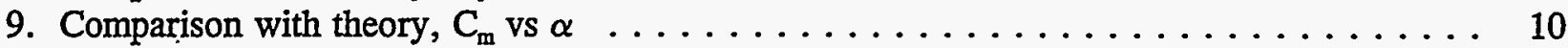

10. Comparison with theory, $\mathrm{C}_{\mathrm{p}} \mathrm{vs \textrm {x } / \mathrm { c } , \alpha = - 0 . 1 \ldots \ldots \ldots \ldots \ldots \ldots \ldots \ldots \ldots \ldots \ldots \ldots \ldots \ldots \ldots}$

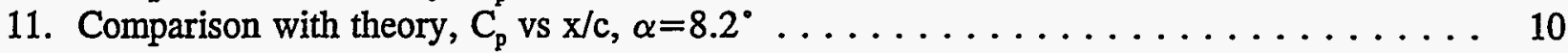

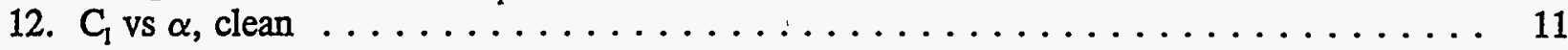

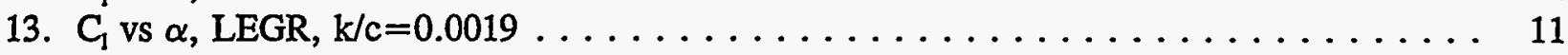

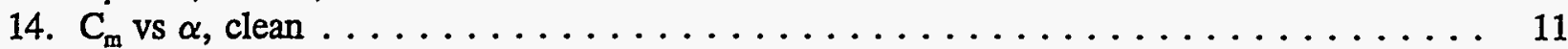

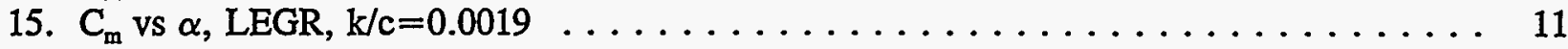

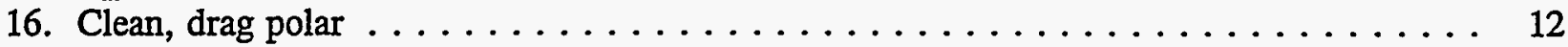

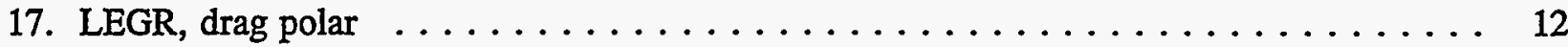

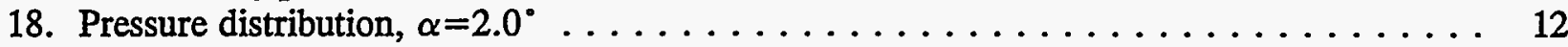

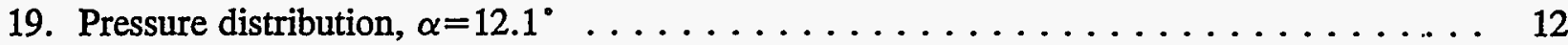

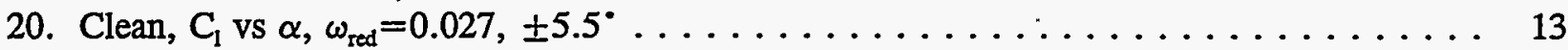

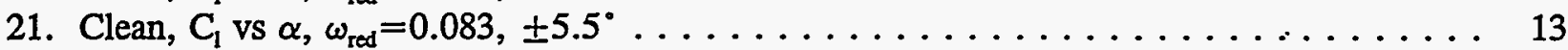

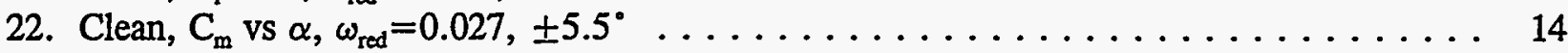

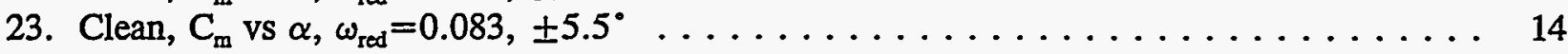

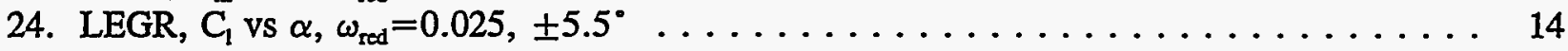

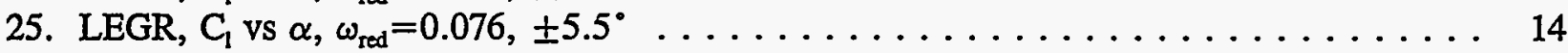

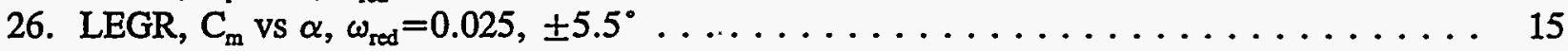

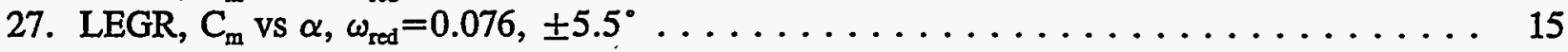

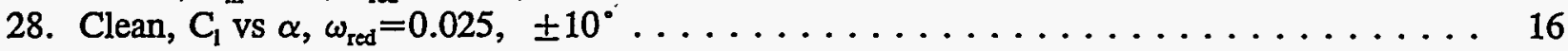

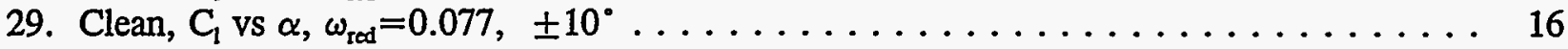

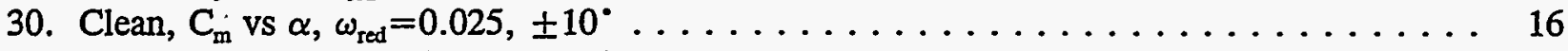

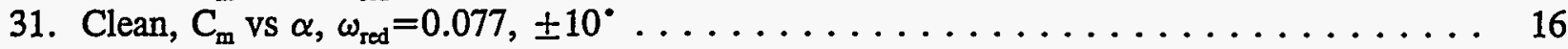

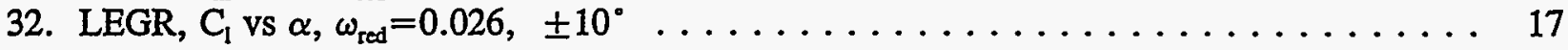

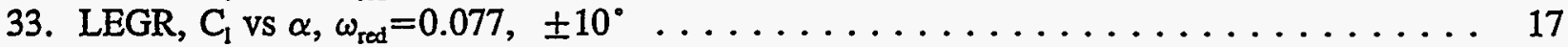

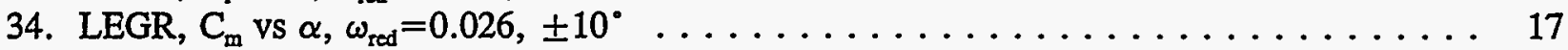

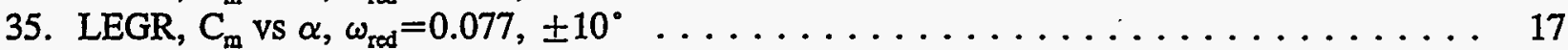

36. Unsteady pressure distribution, clean, $\omega_{\text {red }}=0.054,14 \pm 10^{\circ} \ldots \ldots \ldots \ldots \ldots$

37. Unsteady pressure distribution, LEGR, $\omega_{\text {red }}=0.055,14 \pm 10^{\circ} \ldots \ldots \ldots \ldots \ldots \ldots$

38. Unsteady pressure distribution, clean, $\omega_{\text {red }}=0.054,20 \pm 10^{\circ} \ldots \ldots \ldots \ldots \ldots$

39. Unsteady pressure distribution, clean, $\omega_{\text {red }}=0.054,14 \pm 5.5^{\circ} \ldots \ldots \ldots \ldots \ldots$ 


\section{List of Tables}

1. S815 Steady State Parameters Summary . . . . . . . . . . . . . . . 20

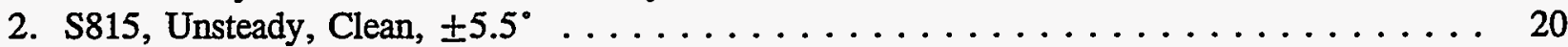

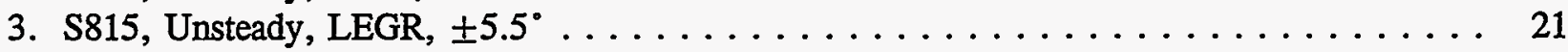

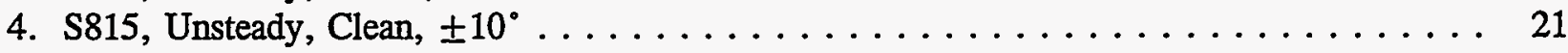

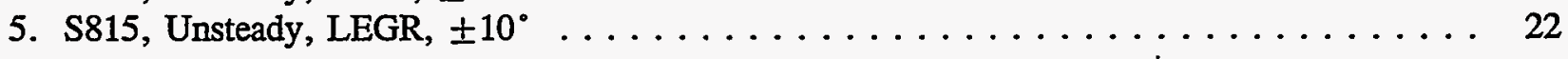




\section{List of Symbols}

AOA

$A / C$, a.c.

C

$\mathrm{C}_{\mathrm{d}}$

$\mathrm{C}_{\mathrm{dmin}}$

$\mathrm{C}_{\mathrm{dp}}$

$\mathrm{C}_{\mathrm{dw}}$

$\mathrm{C}_{\text {du }}$

$\mathrm{C}_{1}$

$\mathrm{C}_{\operatorname{lmax}}$

$\mathrm{C}_{\mathrm{l} \text { dec }}$

$\mathrm{C}_{\mathrm{Iu}}$

$\mathrm{C}_{\mathrm{m}}, \mathrm{C}_{\mathrm{m} / \mathrm{k}}$

$C_{m \text { dec }}$

$\mathrm{C}_{\mathrm{m} \text { inc }}$

$\mathrm{C}_{\mathrm{mo}}$

$\mathrm{C}_{\mathrm{m}^{1 / \mathrm{u}}}$

$\mathrm{C}_{\mathrm{p}}$

$\mathrm{C}_{\text {pmin }}$

f

h

hp, Hp, HP

$\mathrm{Hz}$

$\mathrm{k}$

$\mathrm{k} / \mathrm{c}$

$\mathrm{p}$

q

$\mathrm{q}_{\mathrm{u}}$

$\mathrm{q}_{w}$

$q_{\infty}$

$\operatorname{Re}$

$\mathrm{Re}_{\mathrm{u}}$

t

$\mathrm{U}_{\infty}$

$\mathrm{V}$

$\mathrm{V}_{\mathrm{u}}$

$\mathrm{X}$

y

Angle of attack

Alternating current

Model chord length

Drag coefficient

Minimum drag coefficient

Pressure drag coefficient

Wake drag coefficient

Uncorrected drag coefficient

Lift coefficient

Maximum lift coefficient

Lift coefficient at angle of maximum lift, but with angle of attack decreasing .

Uncorrected lift coefficient

Pitching moment coefficient about the quarter chord

Pitching moment coefficient at angle of maximum lift, but with angle of attack decreasing

Pitching moment coefficient at angle of maximum lift, but with angle of attack increasing

Pitching moment coefficient about the quarter chord, at zero lift

Uncorrected pitching moment coefficient about the quarter chord

Pressure coefficient, $\left(p-p_{\infty}\right) / q_{\infty}$

Minimum pressure coefficient

Frequency

Wind tunnel test section height

Horsepower

Hertz

Grit particle size

Grit particle size divided by airfoil model chord length

Pressure

Dynamic pressure

Uncorrected dynamic pressure

Dynamic pressure through the model wake

Free stream dynamic pressure

Reynolds number

Uncorrected Reynolds number

Time

Corrected free stream velocity

Velocity

Uncorrected velocity

Axis parallel to model reference line

Axis perpendicular to model reference line 
$\alpha$

$\alpha_{\text {dec }}$

$\alpha_{\text {inc }}$

$\alpha_{m}$

$\alpha_{\text {mean }}$

$\alpha_{\mathrm{u}}$

$\epsilon$

$\epsilon_{\mathrm{sb}}$

$\epsilon_{w b}$

$\Lambda$

$\pi$

$\sigma$

$\omega_{\text {redi }}, \omega_{\text {reduced }}$
Angle of attack

Decreasing angle of attack

Increasing angle of attack

Median angle of attack

Mean angle of attack

Uncorrected angle of attack

Tunnel solid wall correction scalar

Solid blockage correction scalar

Wake blockage correction scalar

Body-shape factor

3.1416

Tunnel solid wall correction parameter

Reduced frequency, $\pi \mathrm{fc} / \mathrm{U}_{\infty}$ 


\section{Introduction}

Horizontal axis wind turbine rotors experience unsteady aerodynamics due to wind shear when the rotor is yawed, when rotor blades pass through the support tower wake, and when the wind is gusting. An understanding of this unsteady behavior is necessary to assist in the calculation of rotor performance and loads. The rotors also experience performance degradation due to surface roughness. These surface irregularities are cause by the accumulation of insect debris, ice, and the aging process. Wind tunnel studies that examine both the steady and unsteady behavior of airfoils can help define pertinent flow phenomena, and the resultant data can be used to validate analytical computer codes.

A S815 airfoil model was tested in The Ohio State University Aeronautical and Astronautical Research Laboratory (OSU/AARL) $3 \times 5$ subsonic wind tunnel $(3 \times 5)$ under steady flow and stationary model conditions, as well as with the model undergoing pitch oscillations. To study the possible extent of performance loss due to surface roughness, a standard grit pattern (LEGR) was used to simulate leading edge contamination. After baseline cases were completed, the LEGR was applied for both steady state and model pitch oscillation cases. The Reynolds numbers used for steady state conditions were $0.75,1$, 1.25 , and 1.4 million, while the angle of attack ranged from $-20^{\circ}$ to $+40^{\circ}$. With the model undergoing pitch oscillations, data were acquired at Reynolds numbers of $0.75,1,1.25$, and 1.4 million, at frequencies of $0.6,1.2$, and $1.8 \mathrm{~Hz}$. Two sine wave forcing functions were used; $\pm 5.5^{\circ}$ and $\pm 10^{\circ}$, at mean angles of attack of $8^{\circ}, 14^{\circ}$, and $20^{\circ}$. For purposes herein, any reference to unsteady conditions means that the model was in pitch oscillation about the quarter chord. 


\section{Experimental Facility}

\section{Wind Tunnel}

The OSU/AARL $3 \times 5$ was used to conduct tests on the S815 airfoil section. Schematics of the top and side views of the tunnel are shown in Figure 1 and Figure 2, respectively. This open-circuit tunnel has a velocity range of $0-55-\mathrm{m} / \mathrm{s}(180-\mathrm{ft} / \mathrm{s})$ produced by a 2.4 -meter $(8-\mathrm{ft})$ diameter, six-bladed fan. The

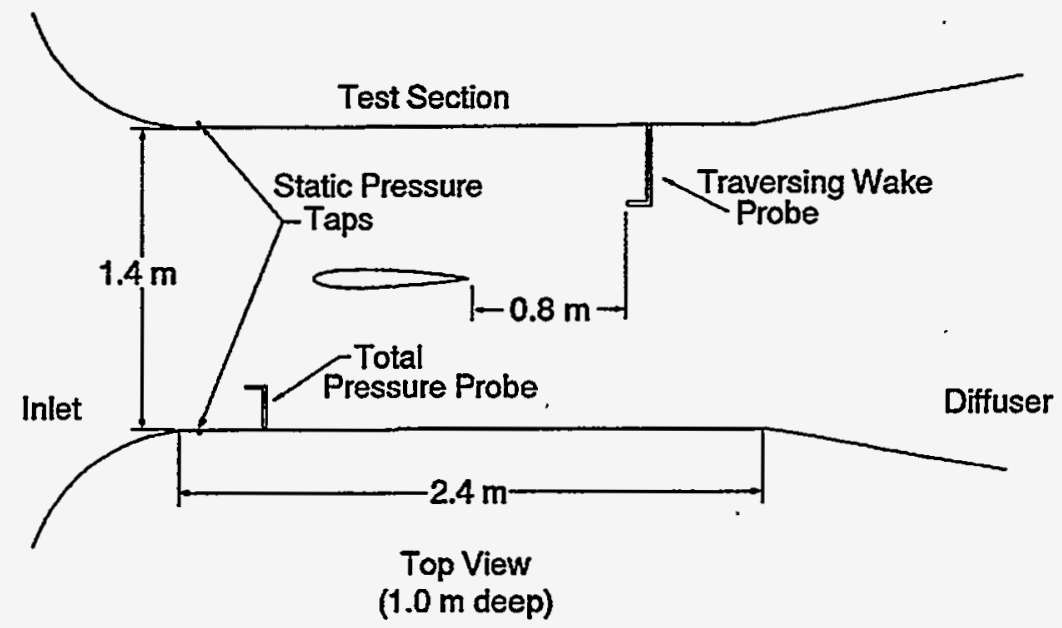

Figure 1. $3 \times 5$ Subsonic wind tunnel, top view

fan is belt driven by a $93.2-\mathrm{kw}$ (125-hp) three phase a.c. motor connected to a variable frequency motor controller. Nominal test section dimensions are $1.0-\mathrm{m}$ (39-in) high by $1.4-\mathrm{m}$ (55-inch) wide by $2.4-\mathrm{m}$ (96-in) long. The 457-mm (18-in) chord airfoil model was mounted vertically in the test section. A steel

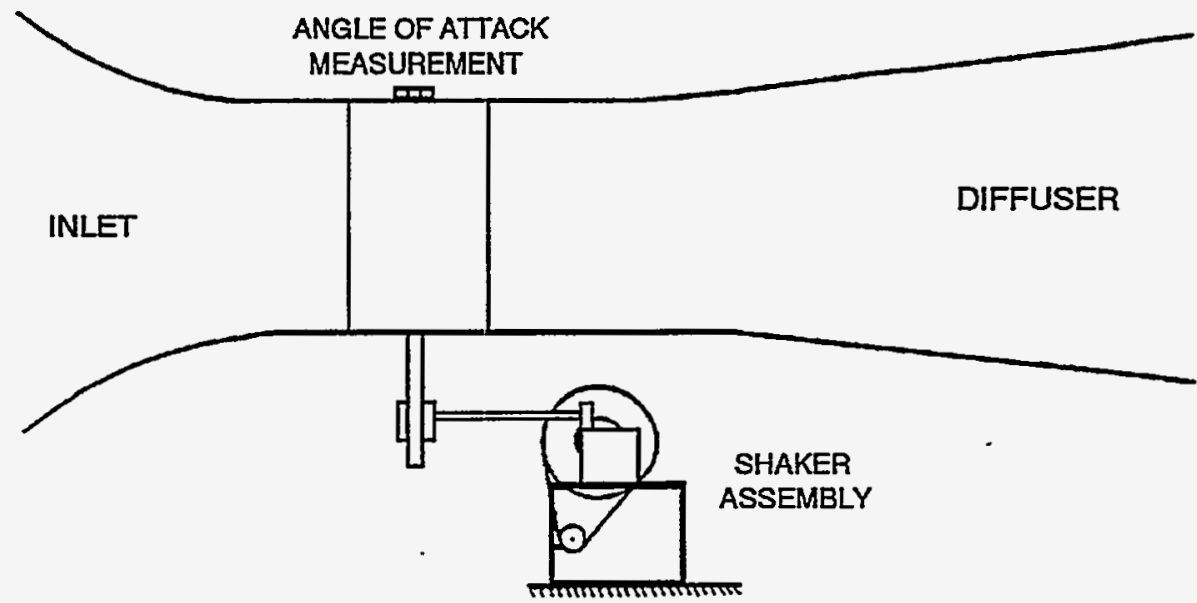

Figure 2. $3 \times 5$ Subsonic wind tunnel, side view

tube through the quarter chord of the model attached the model to the tunnel during testing. An angle of attack potentiometer was fastened to the model at the top of the tunnel, as shown in Figure 2. The steady state angle of attack was adjusted with a worm gear drive attached to the model strut below the tunnel floor. 


\section{Oscillation System}

Portions of the airfoil model testing required the use of a reliable pitch oscillation system. The OSU/AARL "shaker" system incorporated a face cam and follower arm attached to the model support tube below the wind tunnel floor, as shown in Figure 3. The choice of cam governed the type and amplitude of the wave form produced. Sine wave forms with amplitudes of $\pm 5.5^{\circ}$ and $\pm 10^{\circ}$ were used for these tests. The wave form is defined by the equation

$$
\alpha=\alpha_{m}+A \sin (2 \pi f t)
$$

where $A$ is the respective amplitude. The shaker system was powered by a 5-hp a.c. motor with variable line frequency controller. The useable oscillating frequency range was $0.1-2.0-\mathrm{Hz}$, with three frequencies used for this test: $0.6,1.2$, and $1.8 \mathrm{~Hz}$.

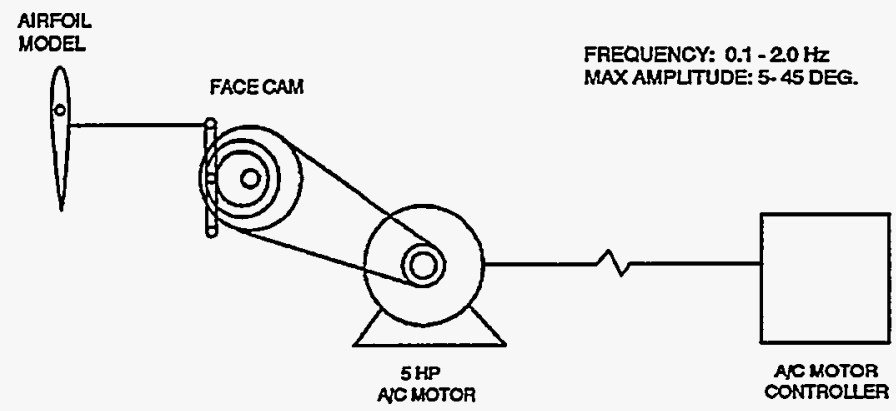

Figure 3. $3 \times 5$ Wind tunnel oscillation system 


\section{Model Details}

A 457-mm (18-in) constant chord S815 airfoil model was designed by OSU/AARL personnel and manufactured by others. Figure 4 shows the airfoil section. Due to their proprietary nature, model coordinates are not presented in tabular form. The trailing edge was thickened to $1.25 \mathrm{~mm}$ (0.05 inch)

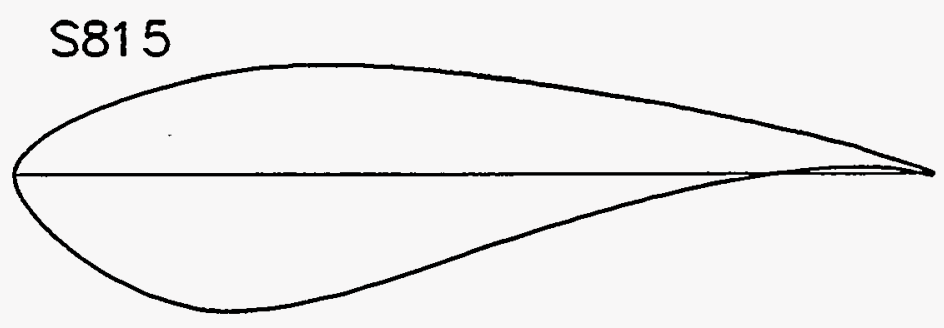

Figure 4. $\$ 815$ airfoil section

for fabrication purposes. This thickness was added to the upper surface over the last $10 \%$ of the chord. The model was made of a laminated fiberglass skin over ribs and filled with foam. The main load bearing member was a 38-mm (1.5-in) diameter steel tube which passed through the model quarter chord station. Ribs and end plates were used to transfer loads from the skin to the steel tube. The final surface was hand finished using templates to attain given coordinates within a requested tolerance of $\pm 0.25-\mathrm{mm}$ ( \pm 0.01 -in). The completed model was measured at three spanwise locations using a Sheffield-Cordax coordinate measurement machine. Measurements were made in English units and later converted to metric. Figure 5 shows the results of comparing measured-to-desired coordinates by calculating differences normal to the profiled surface at three stations on the model. The "spikes" apparent near the trailing edge are due to the numerical methods used and are not real.

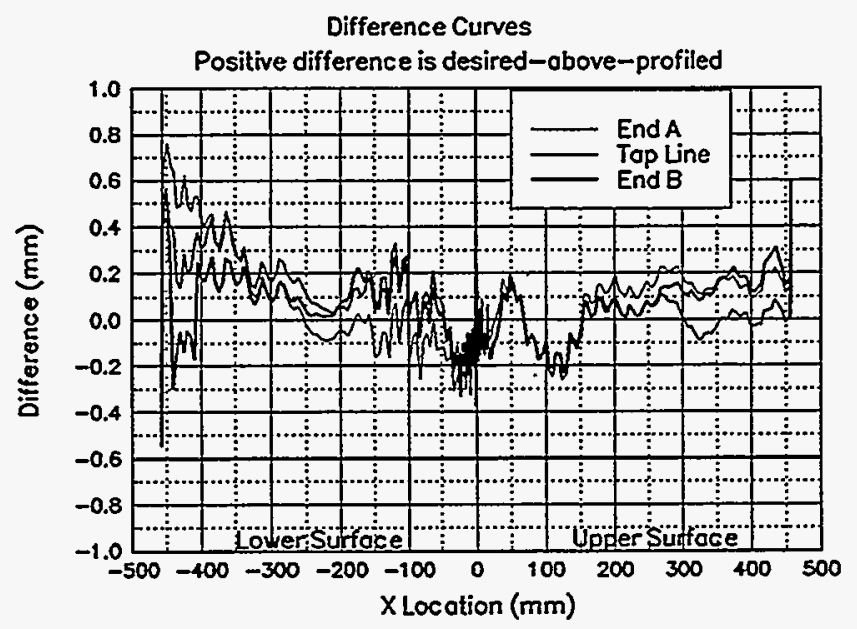

Figure 5. Measured-to-desired model coordinates difference curves.

To minimize pressure response times, which is important for the unsteady testing, the surface pressure tap lead-out lines had to be as short as possible. Consequently, a compartment was built into the model so pressure scanning modules could be installed inside the model. This compartment was accessed through a panel door fitted flush with the model contour on the lower (pressure) surface. 
For test cases involving roughness, a standard, repeatable pattern with grit as roughness elements was desired. The roughness pattern used was jointly developed by OSU/AARL and KENETECH, Windpower personnel from a molded insect pattern taken from a wind turbine in the field by personnel at the University of Texas Permian Basin. The particle density was 5 particles per $\mathrm{cm}^{2}$ (32 particles per square inch) in the middle of the pattern, thinning to 1.25 particles per $\mathrm{cm}^{2}$ ( 8 particles per square inch) at the edge of the pattern. Figure 6 shows the pattern. To make a usable template, the pattern was repeatedly

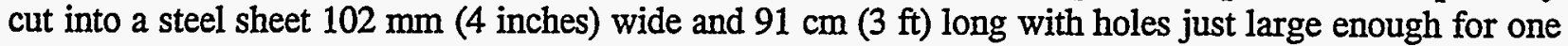
piece of grit. Based on average particle size from the field specimen, standard \#40 lapidary grit was chosen for the roughness elements, giving $\mathrm{k} / \mathrm{c}=0.0019$ for a $457 \mathrm{~mm}$ (18 inch) chord model.

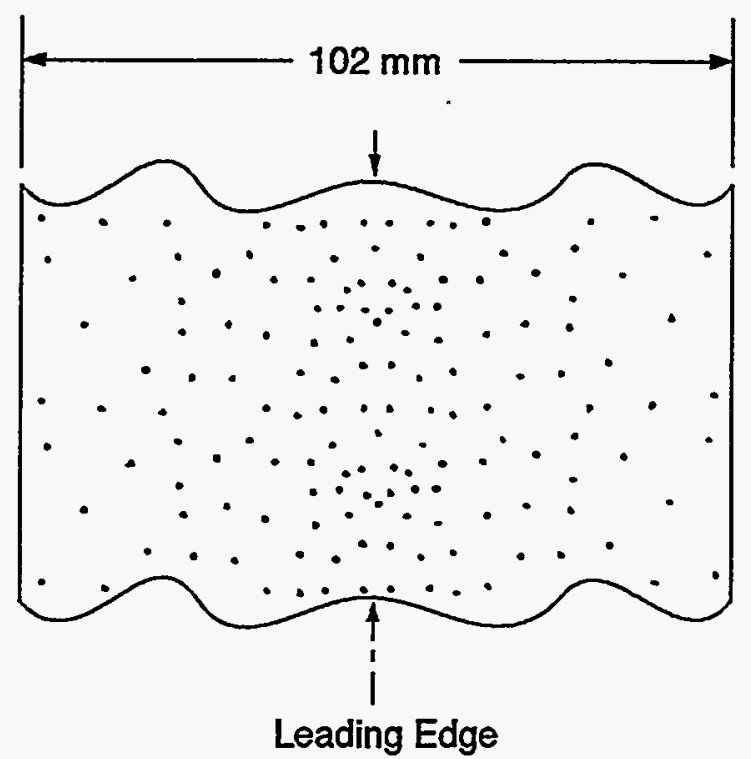

Figure 6. Roughness pattern

To use the template, 102-mm (4-in) wide double-tack tape was applied to one side of the template and grit was poured and brushed from the opposite side. The tape was then removed from the template and transferred to the model. This method allowed the same roughness pattern to be replicated for any test. 


\section{Test Equipment and Procedures}

\section{Data Acquisition}

Data were acquired and processed from 60 surface pressure taps, four individual tunnel pressure transducers, an angle of attack potentiometer, a wake probe position potentiometer, and a tunnel thermocouple. The data acquisition system included an IBM PC compatible 80486-based computer connected to a Pressure Systems Incorporated (PSI) data scanning system. The PSI system included a 780B Data Acquisition and Control Unit (DACU), 780B Pressure Calibration Unit (PCU), 81-IFC scanning module interface, two 2.5 psid pressure scanning modules (ESPs), one 20-in water column range pressure scanning module, and a 30 channel Remotely Addressed Millivolt Module (RAMM-30). Figure 7 is a schematic of the data acquisition system.

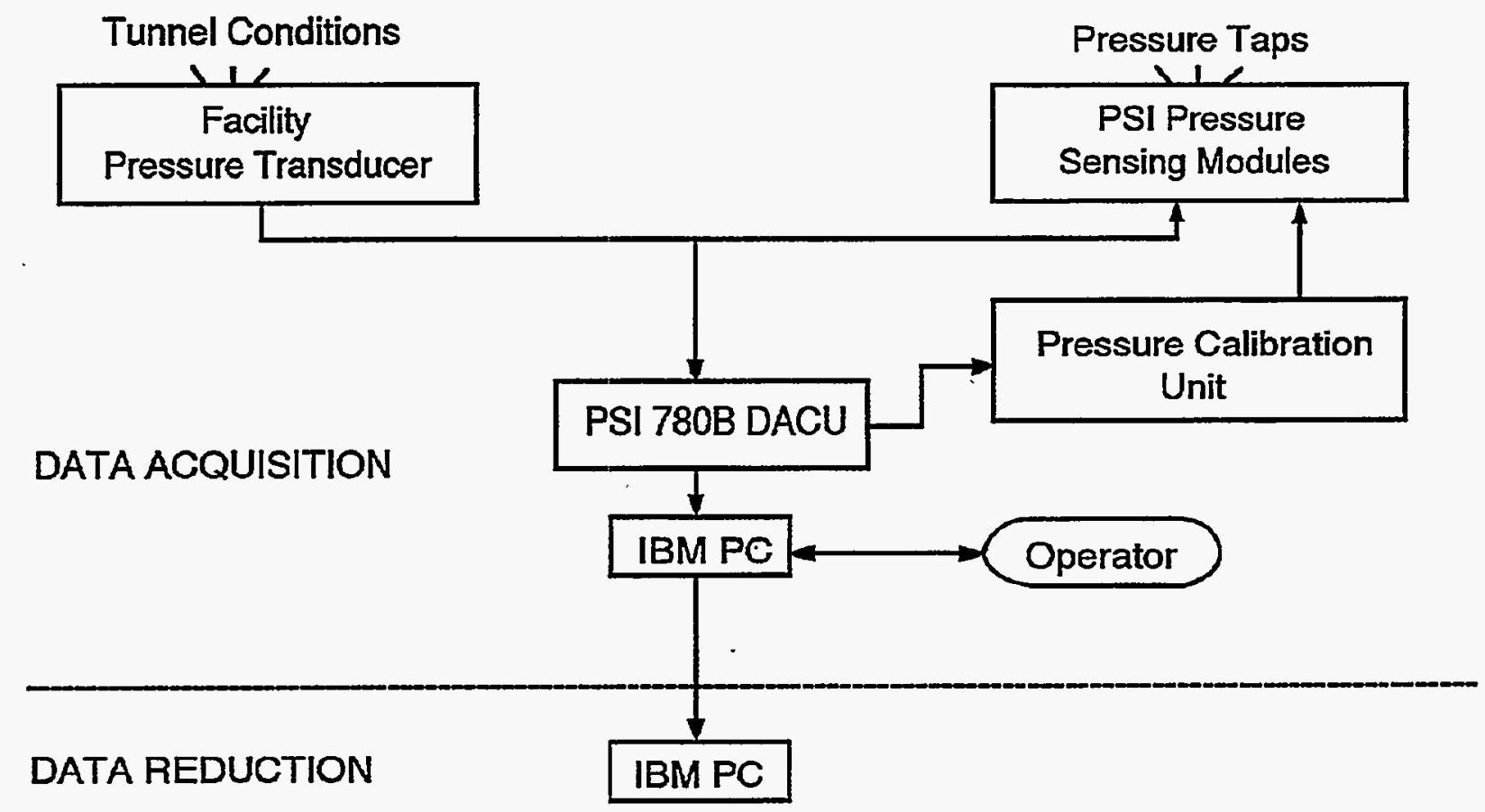

Figure 7. Data acquisition schematic

Four individual pressure transducers read tunnel total pressure, tunnel north static pressure, tunnel south static pressure, and wake dynamic pressure. Before the test began, these transducers were bench calibrated using a water manometer to determine their sensitivities and offsets. Related values were entered into the data acquisition and reduction program so the transducers could be shunt resistor calibrated before each series of wind tunnel runs.

The rotary angle of attack potentiometer of $0.5 \%$ linearity was regularly calibrated during the tunnel pressure transducers shunt calibration. The angle of attack calibration was accomplished by taking voltage readings at known values of set angle of attack. This calibration method gave angle of attack readings within $\pm 0.25^{\circ}$ over the entire angle range. The wake probe position potentiometer was a linear potentiometer, and it was also regularly calibrated during the shunt calibration of the tunnel pressure transducers.

Calibration of the three ESPs was done simultaneously using the DACU and PCU. At operator request, the DACU commanded the PCU to apply known regulated pressures to the ESPs and read the output 
voltages from each integrated pressure sensor. From these values, the DACU calculated the calibration coefficients and stored them internally until the coefficients were requested by the controlling computer. This calibration was done several times during a run set because the ESPs were installed inside the model and their outputs tended to drift with temperature changes during a test sequence. Frequent on-line calibrations minimized the effect.

For steady state cases, the model was set to angle of attack and the tunnel conditions were adjusted. At operator request, pressure measurements from the airfoil surface taps and all other channels of information were acquired and stored by the DACU and subsequently passed to the controlling computer for final processing. The angles of attack were always set in the same progression from negative to positive values.

For model oscillating cases, the tunnel conditions were set while the model was stationary at the desired mean angle of attack. The "shaker" was started, after approximately 10 seconds the model surface pressure and tunnel condition data were acquired. Generally, 120 data scans were acquired over three model oscillation cycles. Since surface pressures were scanned sequentially, the data rate was set so the model rotated through less than $0.50^{\circ}$ during any data burst. Finally, due to the unsteady and complex nature of the pitch oscillation cases, model wake surveys (for drag) were not conducted.

\section{Data Reduction}

The data reduction routine was included as a section of the data acquisition program. This combination of data acquisition and reduction routines allowed data to be reduced on-line during a test. By quickly reducing selected runs, integrity checks could be made to ensure the equipment was working properly and to allow timely decisions about the test matrix.

The ambient pressure was manually input into the computer and was updated regularly. This value, along with the measurements from the tunnel pressure transducers and the tunnel thermocouple, were used to calculate tunnel airspeed. As a continuous check of readings, the tunnel total and static pressures were read by both the tunnel individual pressure transducers and the 20 -inch water column ESP.

A typical steady state datum point was derived by acquiring 10 data scans of all channels over a 10 second window at each angle of attack and tunnel condition. The reduction portion of the program processed each data scan to coefficients $\left(C_{p}, C_{l}, C_{m 1 k}\right.$, and $\left.C_{d p}\right)$ using the measured surface pressure voltages, calibration coefficients, tap locations and wind tunnel conditions. All scan sets for a given condition were then ensemble averaged to provide one data set and that data set was corrected for the effects of solid tunnel walls. All data were saved in electronic form.

Corrections due to solid tunnel sidewalls were applied to the wind tunnel data. As described by Pope and Harper (1966), tunnel conditions are represented by the following equations:

$$
\begin{gathered}
q=q_{u}(1+2 \epsilon) \\
V=V_{u}(1+\epsilon) \\
R_{e}=R_{e_{u}}(1+\epsilon)
\end{gathered}
$$

Airfoil aerodynamic characteristics are then corrected by: 


$$
\begin{gathered}
\alpha=\alpha_{u}+\frac{57.3 \sigma}{2 \pi}\left(C_{l_{u}}+4 C_{m \frac{1}{4}}\right) \\
C_{l}=C_{l_{u}}(1-\sigma-2 \epsilon) \\
C_{m_{\frac{1}{4}}}=C_{m_{\frac{1}{4}}}(1-2 \epsilon)+\frac{\sigma C_{l}}{4} \\
C_{d}=C_{d_{u}}\left(1-3 \epsilon_{s b}-2 \epsilon_{w b}\right)
\end{gathered}
$$

where

$$
\begin{aligned}
& \sigma=\frac{\pi^{2}}{48}\left(\frac{c}{h}\right)^{2} \\
& \epsilon=\epsilon_{s b}+\epsilon_{w b} \\
& \epsilon_{s b}=\Lambda \sigma \\
& \epsilon_{w b}=\frac{c}{h 4} C_{d_{u}}
\end{aligned}
$$

Model wake data were taken for steady state cases when the wake could be completely traversed. Pressures were acquired from a pitot-static probe which was connected to measure incompressible dynamic pressure through the wake. These pressure measurements were used to calculate drag coefficient using a form of the Jones equation derived from Schlichting (1979).

$$
C_{d w}=\frac{2}{c} \int \sqrt{\frac{q_{w}}{q_{\infty}}}\left(1-\sqrt{\frac{q_{w}}{q_{\infty}}}\right) d y
$$

This equation assumes that static pressure at the measurement site is the free-stream value. The integration was done automatically, except the computer operator chose the end points of the integration from a plot of the wake survey displayed on the computer screen.

For pitch oscillation cases, model surface pressures were reduced to pressure coefficient form with subsequent integrations and angle of attack considerations giving lift, moment and pressure drag coefficients. The wind tunnel was not calibrated for unsteady model pitch conditions; therefore, the unsteady pressure data were not corrected for any possible effects due to time dependent pitching or solid tunnel walls. Also, for these cases, the wind tunnel contraction pressures (used for steady state cases) could not be used to calculate instantaneous freestream conditions due to slow response. The tunnel conditions were obtained from a total pressure probe and the average of opposing static taps in the test section entrance. This gave nearly instantaneous flow pressure conditions for the pitching frequencies used.

\section{Test Matrix}

The test was designed to study steady state and unsteady pitch oscillation data. Steady state data were acquired at Reynolds numbers of $0.75,1,1.25$, and 1.4 million with and without LEGR. During testing of this model, it became apparent that there was steady state hysteresis at 0.75 million Reynolds number. When the tunnel speed was increased from zero to 0.75 million, there was separation on the model 
surface such that it was not possible to acquire wake data. However, if the tunnel speed was increased beyond this Reynolds number to 1 million and then reduced to the desired 0.75 million Reynolds number, the flow field .was established and it was possible to take wake data. Therefore, tunnel speeds for the 0.75 million Reynolds number cases were, set by increasing the tunnel speed beyond the desired value to 1 million Reynolds number and then back to 0.75 million. Refer to the tabular data in Appendix B for the actual Reynolds number for each steady state angle of attack. The angle of attack increment was two degrees when $-20^{\circ}<\alpha<+10^{\circ}$ or $+20^{\circ}<\alpha<+40^{\circ}$ and one degree when $+10^{\circ}<\alpha<+20^{\circ}$. Wake surveys were conducted to find total airfoil drag over an approximate angle of attack range of $-10^{\circ}$ to $+10^{\circ}$. Unsteady data were taken for Reynolds numbers of $0.75,1,1.25$, and 1.4 million. Sine wave cams with amplitudes $\pm 5.5^{\circ}$ and $\pm 10^{\circ}$ were used for pitch oscillations, and the mean angles for both these amplitudes were $8^{\circ}, 14^{\circ}$, and $20^{\circ}$. For all these conditions, the frequencies were varied to 0.6 , 1.2 , and $1.8 \mathrm{~Hz}$. All data points for the unsteady cases were acquired for both clean and LEGR cases. 


\section{Results and Discussion}

The S815 airfoil model was tested under steady state and pitch oscillation conditions. A brief discussion of the results follows, beginning with a comparison of experimental data and computational predictions.

\section{Comparison with Theory}

The wind tunnel steady state data collected in this study were compared with computed predictions made using the North Carolina State Airfoil Analysis Code. This analysis code has proven to be accurate for moderate angles of attack. The analysis was made with specifications set to allow free transition from laminar to turbulent flow, and the pressure distribution comparisons were matched to the same angle of attack as the wind tunnel cases.

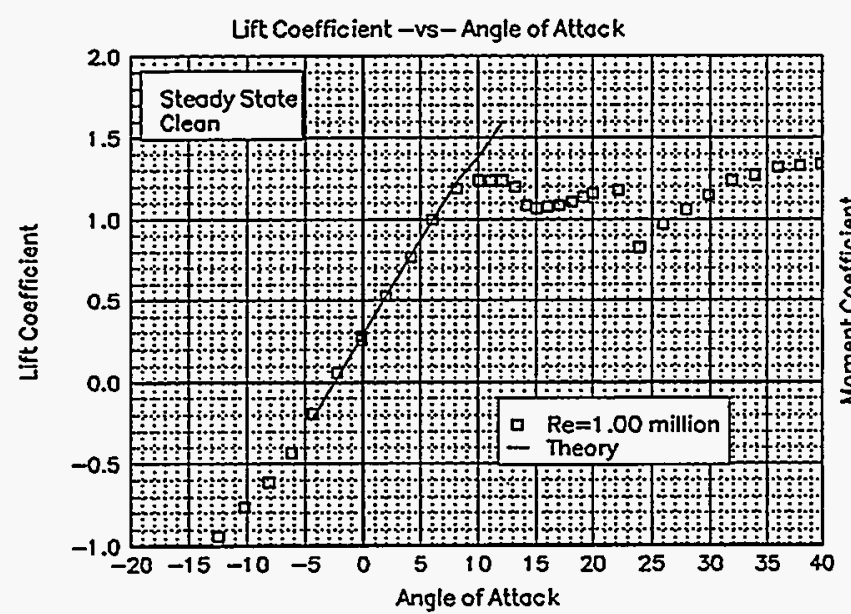

Figure 8. Comparison with theory, $\mathrm{C}_{1}$ vs $a$

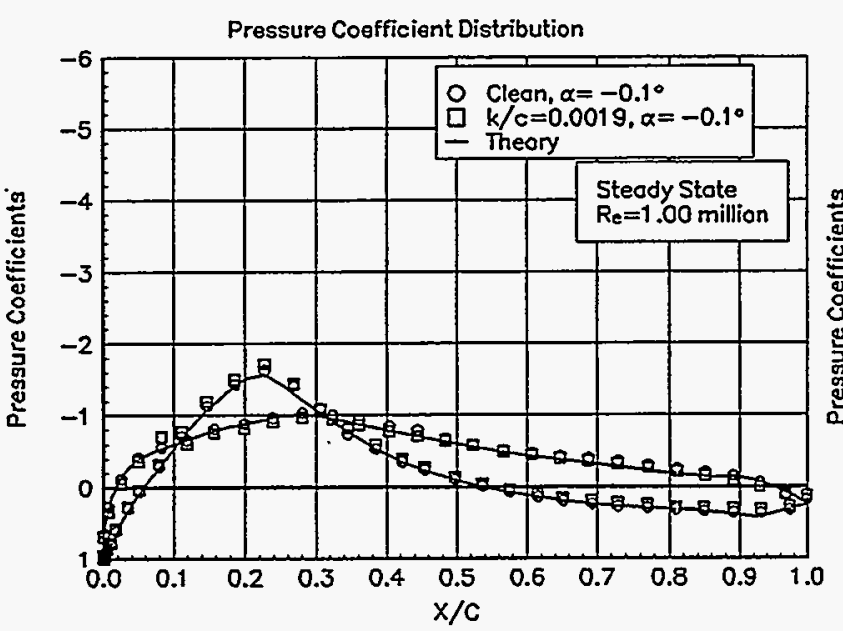

Figure 10. Comparison with theory, $C_{p}$ vs $x / c, a=-0.1^{\circ}$

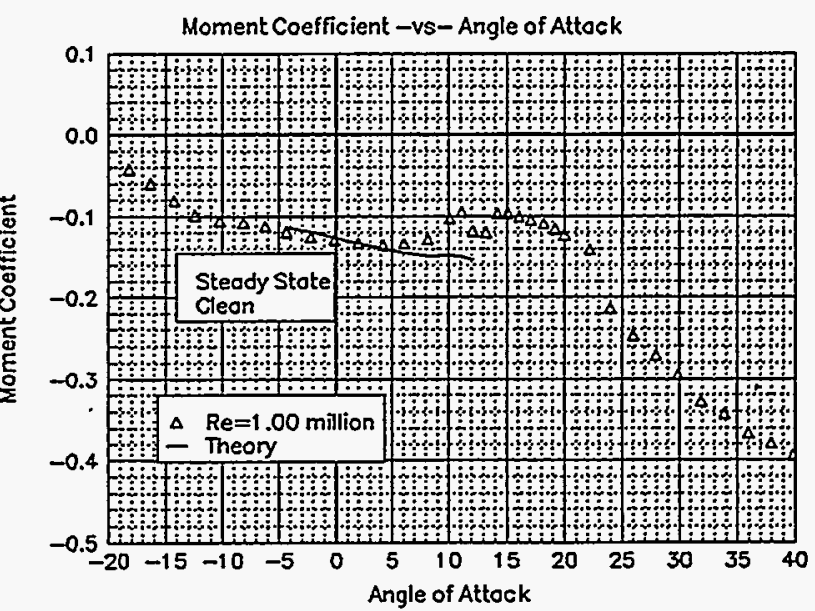

Figure 9. Comparison with theory, $C_{m}$ vs $a$

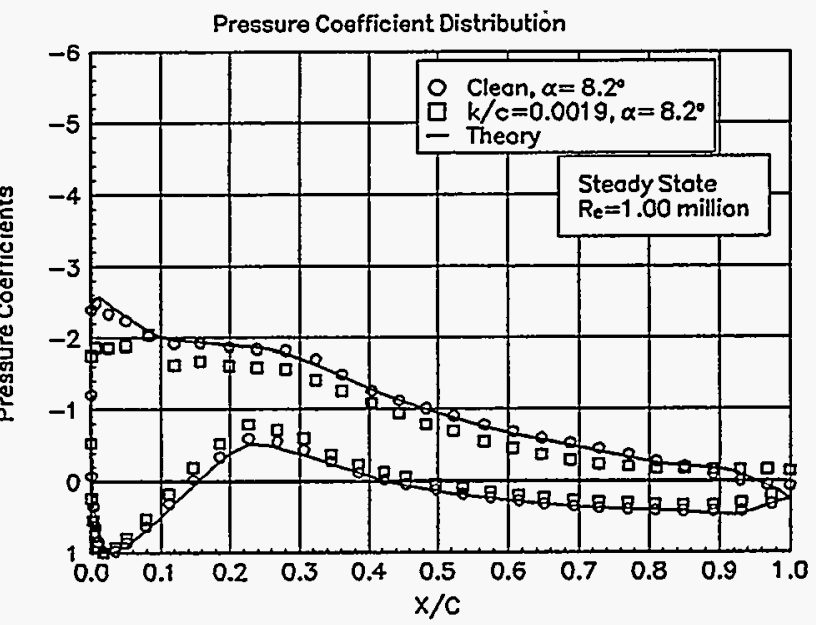

Figure 11. Comparison with theory, $C_{p}$ vs $x / c, a=8.2^{\circ}$

Figure 8 shows the lift coefficient versus angle of attack for the 1 million Reynolds number case. For moderate angles of attack, where the analysis code is valid, the comparison shows good agreement. The pitching moment about the quarter chord, Figure 9, also shows good agreement for angles of attack from $-5^{\circ}$ to $+5^{\circ}$. The pressure distributions shown in Figure 10 and Figure 11 are for angles of attack of 
$-0.1^{\circ}$ and $8.2^{\circ}$, respectively, and include clean and LEGR wind tunnel data as compared to computed free transition pressure distributions. For both angles of attack, there is reasonable correlation between the experimental and predicted values.

\section{Steady State Data}

The S815 airfoil model was tested at four Reynolds numbers at nominal angles of attack from $-20^{\circ}$ to $+40^{\circ}$. Figure 12 and Figure 13 show lift coefficients for all the test Reynolds numbers for a clean model

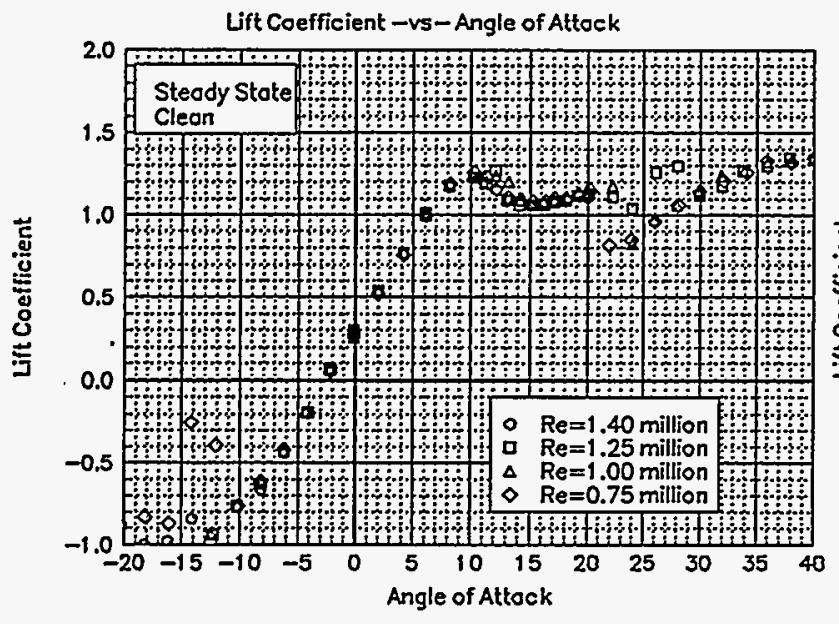

Figure 12. $\mathrm{C}_{1}$ vs $a$, clean

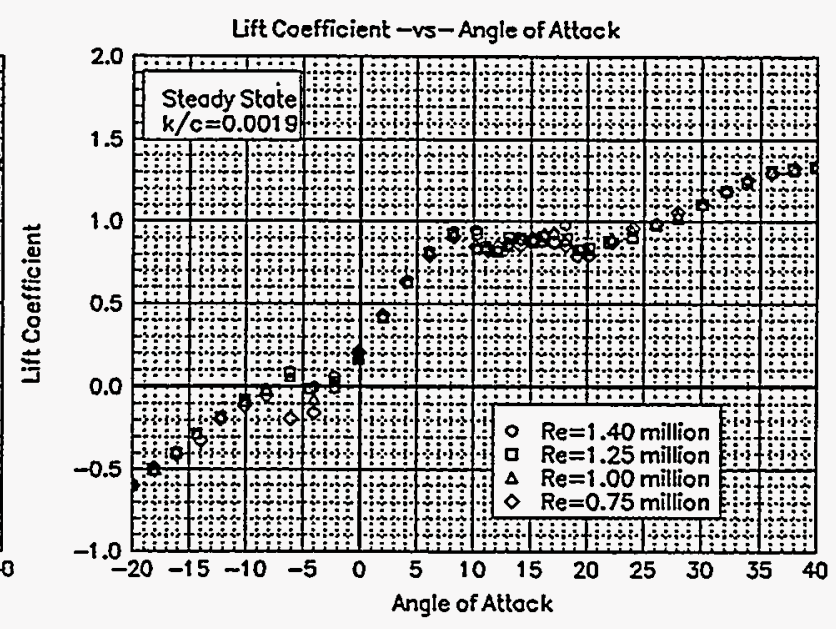

Figure 13. $C_{1}$ vs $a, L E G R, k / c=0.0019$

and with LEGR applied, respectively. The maximum positive lift coefficient for the clean cases is about 1.27 and about 0.93 for the LEGR cases, a 27\% reduction. The clean cases have positive stall between $10^{\circ}$ to $12^{\circ}$ angle of attack, while the LEGR cases stall between $8^{\circ}$ to $10^{\circ}$ angle of attack. Also, negative stall occurs much earlier for the LEGR case, thereby reducing the linear portion of the lift curve significantly. Finally, the average lift curve slope for clean data is about 0.116 ; it is slightly lower for the LEGR case at 0.104 . The associated average lift coefficients at zero angle of attack are 0.28 for the clean case and 0.19 for the LEGR case.

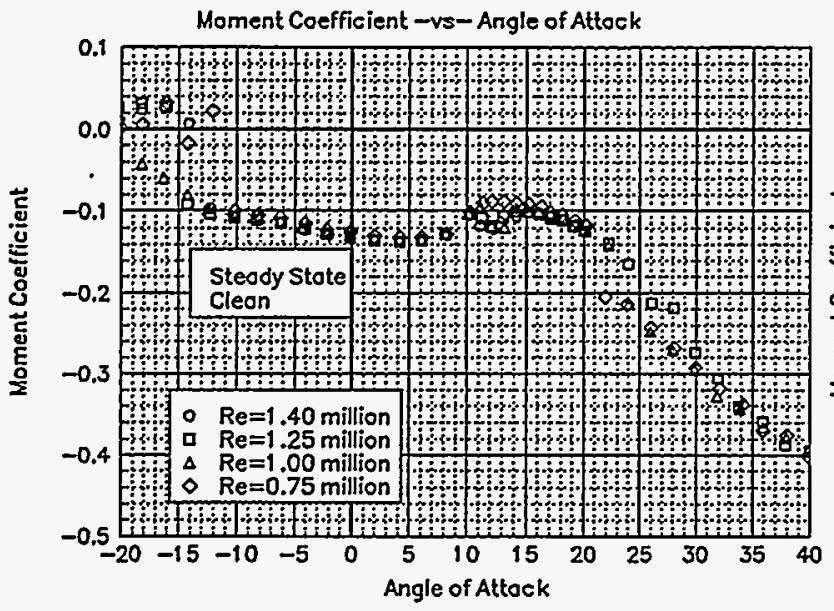

Figure 14. $\mathrm{C}_{\mathrm{m}}$ vs $a$, clean

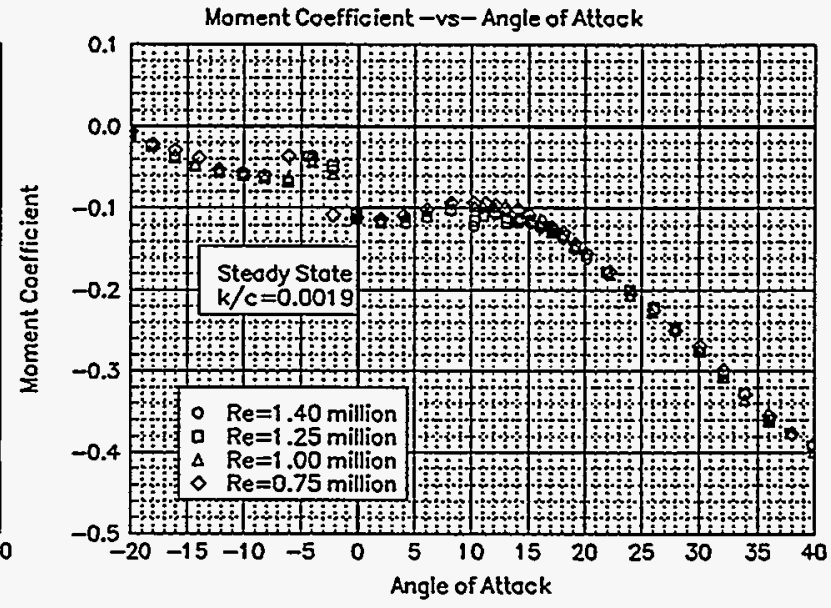

Figure 15. $C_{m}$ vs $a, L E G R, k / c=0.0019$ 
Figure 14 shows the pitching moment about the quarter chord for the clean cases and Figure 15 shows the same for the LEGR cases. The LEGR data show a jump in the curve between $0^{\circ}$ and $-5^{\circ}$ that corresponds to the negative stall angle of attack. The clean data show this behavior at a much lower angle of attack again corresponding with negative stall. The zero lift pitching moment coefficient about the quarter chord for the 1.25 million Reynolds number, is -0.1268 for the clean case and -0.0364 for the LEGR case.

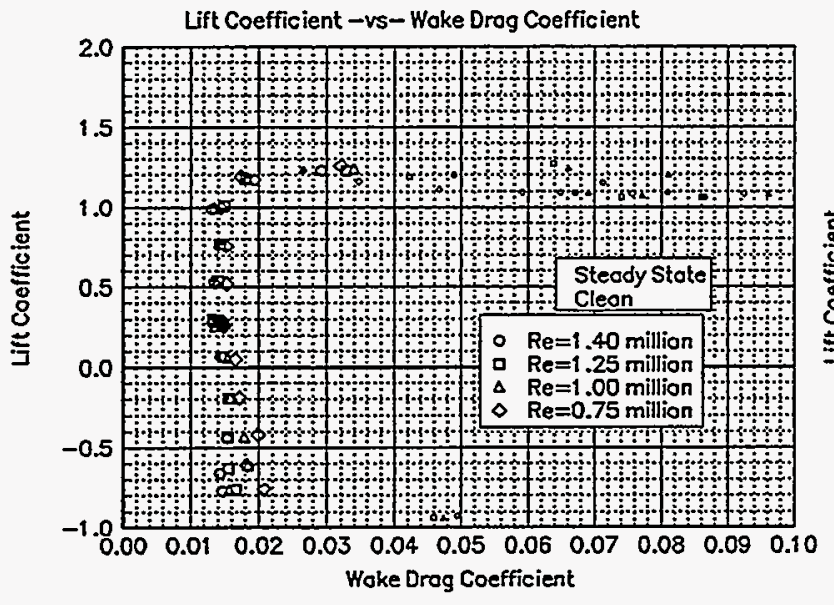

Figure 16. Clean, drag polar

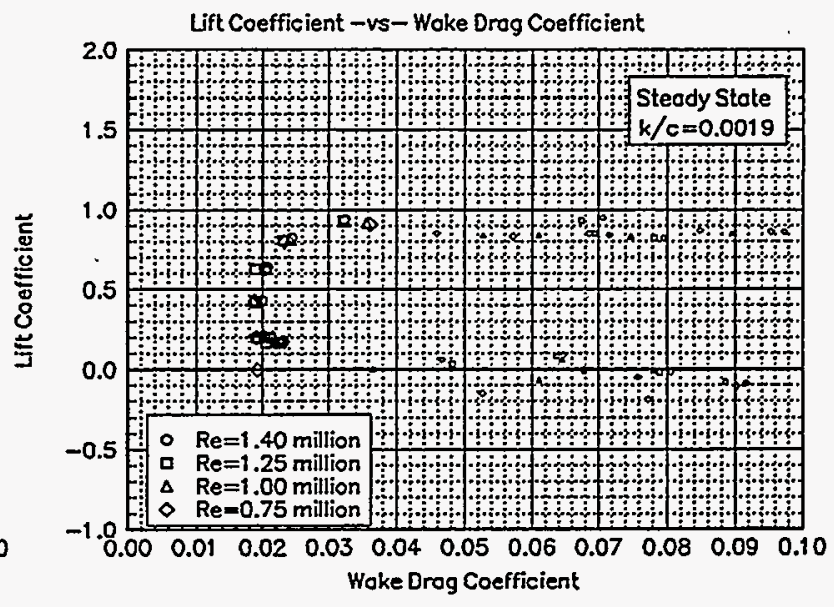

Figure 17. LEGR, drag polar

Total wake drag data were obtained for the clean cases over an angle of attack range of $-10^{\circ}$ to $+10^{\circ}$ and over a range of $0^{\circ}$ to $8^{\circ}$ for the LEGR cases. A pitot-static probe was used to describe the wake profile. This method is reliable when there is relatively low turbulence in the wake flow; therefore, only moderate angles of attack have reliable total drag coefficient data. At angles of attack other than those indicated above, surface pressure data were integrated to give $C_{d p}$ and are shown in the drag polars as small symbols. The model clean drag data are shown in Figure 16, and the LEGR case is shown in Figure 17. The LEGR data show the drag bucket for a narrower band of lift coefficients than do the clean data. Again, this is an effect of early negative stall. It is apparent that LEGR causes much of the model lower surface to separate at even moderate negative angles of attack; this does not occur in the clean cases. At 1 million Reynolds number, minimum drag coefficient for the clean cases was measured as 0.0136 , and 0.0186 for LEGR; a $37 \%$ increase.

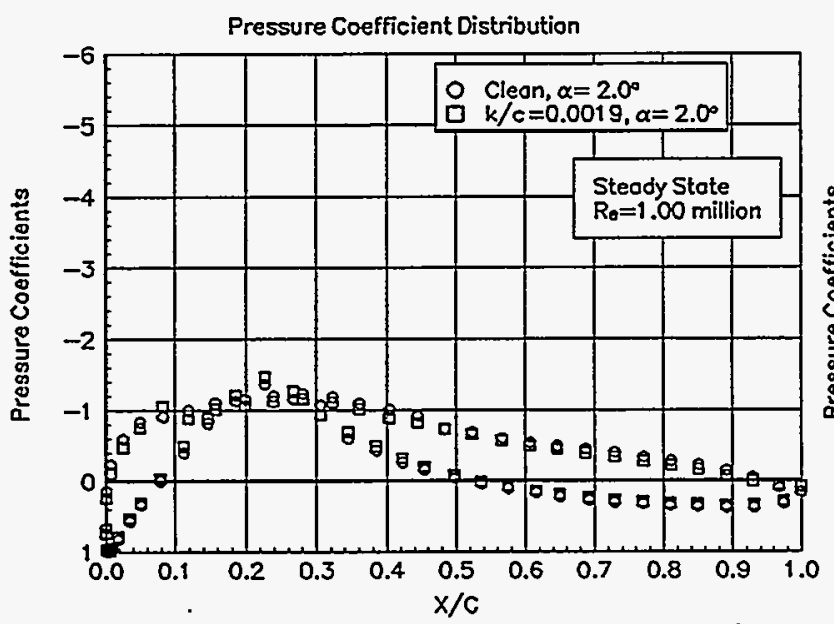

Figure 18. Pressure distribution, $a=2.0^{\circ}$

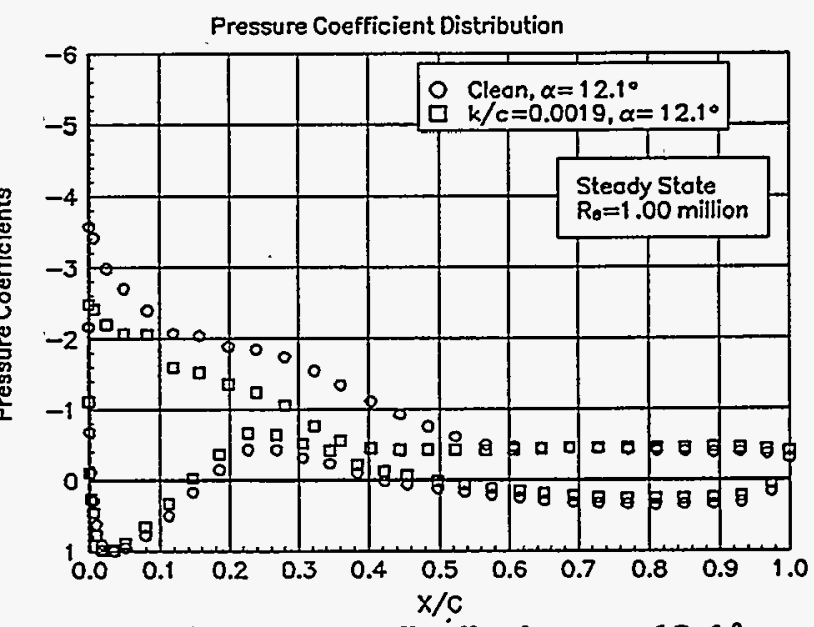

Figure 19. Pressure distribution, $a=12.1^{\circ}$ 
Two examples of the surface pressure distributions are shown in Figure 18 and Figure 19 for $2.0^{\circ}$ and $12.1^{\circ}$, respectively, for 1 million Reynolds number. At the angles of attack close to zero degrees, LEGR does not appear to significantly change the pressure distribution comparing to the clean case distribution. However, there is an effect apparent in the lift coefficient with values of 0.43 for the LEGR case and 0.53 for the clean case. For the higher angle of attack case, Figure 19, the effect of LEGR is to reduce the magnitude of the pressure peak from -3.6 to -2.5 and to increase the pressures on the upper (suction) surface over the forward $60 \%$ of the chord. On the lower surface, the LEGR case shows a slightly lower. pressure through the high curvature region of the model, which indicates a higher pressure gradient. The net effect is a reduction in lift coefficient from 1.24 to 0.83 , a $33 \%$ decrease.

\section{Unsteady Data}

Unsteady experimental data were obtained for the S815 airfoil model undergoing sinusoidal pitch oscillations. As mentioned earlier, no attempt was made to calibrate the wind tunnel for the unsteady oscillating model conditions; the steady state tunnel calibration was used to set the flow conditions while the model was stationary at its mean angle of attack. The use of the unsteady data should be limited to comparisons with other models tested in this same facility and can be used to detect possible trends. A comprehensive set of test conditions was used to describe unsteady behavior of an airfoil, including two angle of attack amplitudes, $\pm 5.5^{\circ}$ and $\pm 10^{\circ}$; four Reynolds numbers, $0.75,1,1.25$, and 1.4 million; three pitch oscillation frequencies, $0.6,1.2$, and 1.8; and three mean angles of attack, $8^{\circ}, 14^{\circ}$, and $20^{\circ}$.

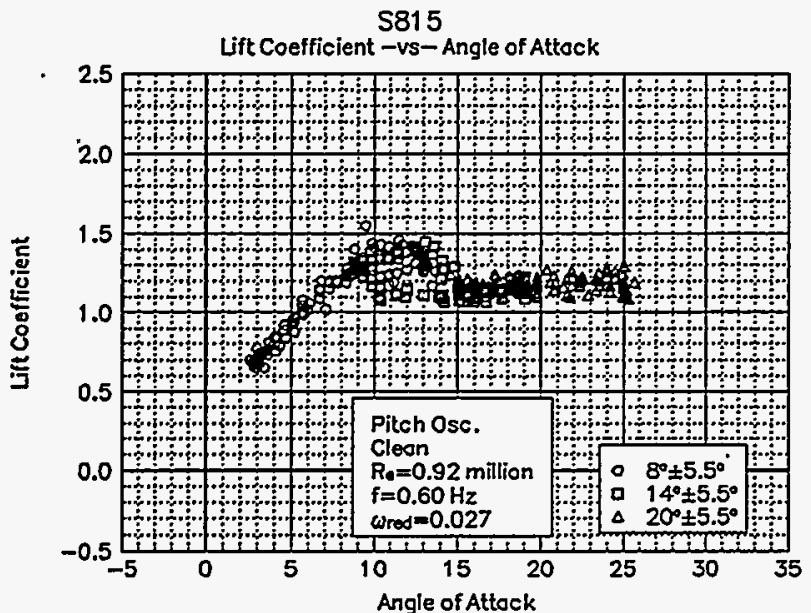

Figure 20. Clean, $C_{1}$ vs $a, \omega_{\text {red }}=0.027, \pm 5.5^{\circ}$

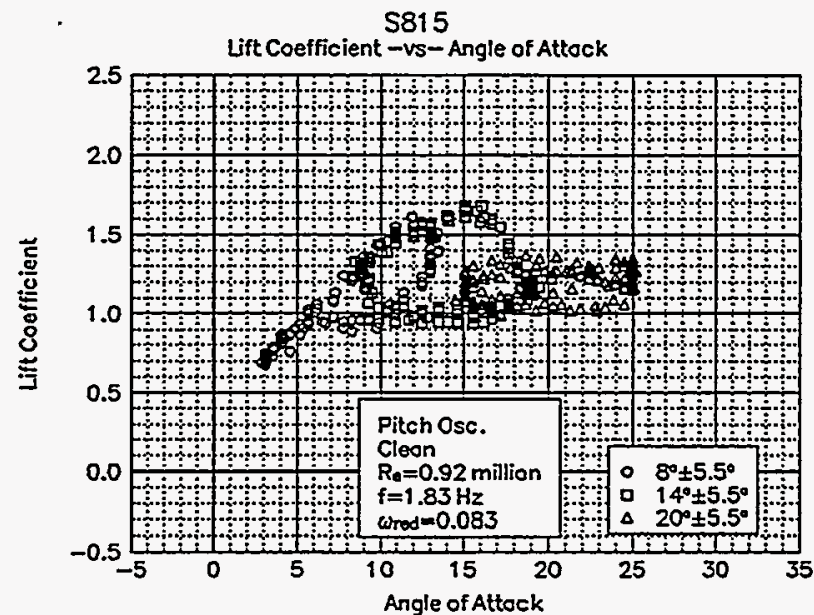

Figure 21. Clean, $C_{1}$ vs $a, \omega_{\text {red }}=0.083, \pm 5.5^{\circ}$

Figure 20 shows the lift coefficient versus angle of attack for the $\pm 5.5^{\circ}$ amplitude, model clean case, at reduced frequency of 0.027 and 1 million Reynolds number. Note that all three mean angles of attack are plotted on the same figure. The maximum pre-stall lift coefficient for this case is near 1.45 and occurs when the airfoil is traveling with the angle of attack increasing. In contrast, when the model is traveling through decreasing angles of attack, the stall recovery is delayed and a hysteresis behavior is exhibited in the lift coefficient that can be seen throughout all the unsteady data. To obtain some measure of this hysteresis behavior, the lift coefficient on the "return" portion of the curve, at the angle of attack where maximum lift coefficient occurs, can be used. For the case discussed here, the hysteresis lift coefficient is 1.11 , a $23 \%$ decrease from the 1.45 unsteady maximum value. In comparison, the steady state maximum lift coefficient is 1.24 . At higher reduced frequency of 0.083 , the hysteresis behavior is more pronounced, as seen in Figure 21. In addition to greater hysteresis, the maximum lift coefficient is increased to about 1.68 , a $35 \%$ increase over the steady state value. The corresponding hysteresis lift 
coefficient is 0.94 . This difference between steady state behavior and unsteady hysteresis behavior is a main reason that unsteady testing should be required for airfoils used in wind turbine applications.

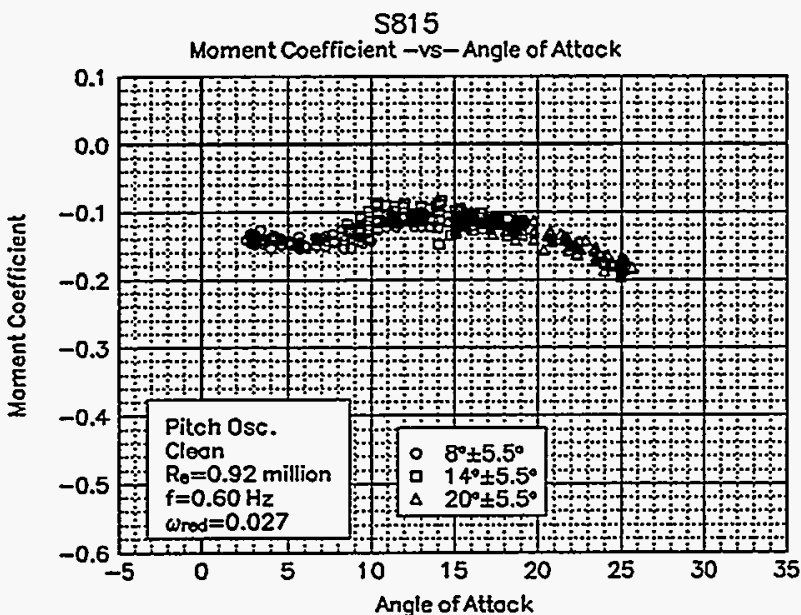

Figure 22. Clean, $C_{\mathrm{m}}$ vs $a, \omega_{\text {red }}=0.027, \pm 5.5^{\circ}$

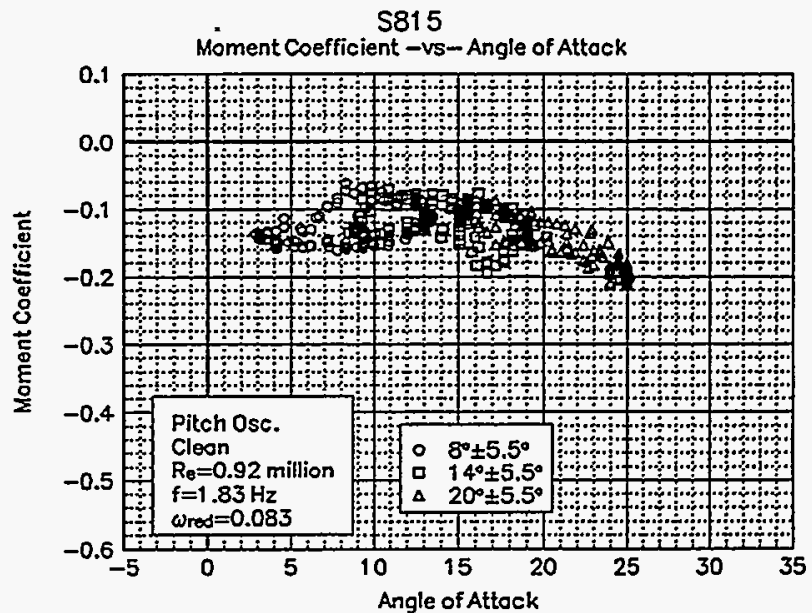

Figure 23. Clean, $\mathrm{C}_{\mathrm{m}}$ vs $a, \omega_{\text {red }}=0.083, \pm 5.5^{\circ}$

The pitching moment shown in Figure 22 and Figure 23 corresponds to the same conditions as the two lift coefficient plots previously discussed. Hysteresis behavior is indicated, but it is not as apparent as in the lift coefficient plots. However, the higher reduced frequency case does show more hysteresis than the lower reduced frequency case. For reference, the steady state maximum lift occurs near $12^{\circ}$ angle of attack, and the steady state pitching moment at this maximum lift point is -0.1179 . In comparison, when the airfoil is undergoing pitch oscillation at the lower frequency, pitching moment varies from -0.1119 to -0.0937 (at the angle of attack where maximum lift occurs), a $5 \%$ to $21 \%$ decrease in magnitude from the steady state value. Note the angle of attack where the maximum lift coefficient occurs does not necessarily show the greatest hysteresis behavior but does give a relative indication of the effect.

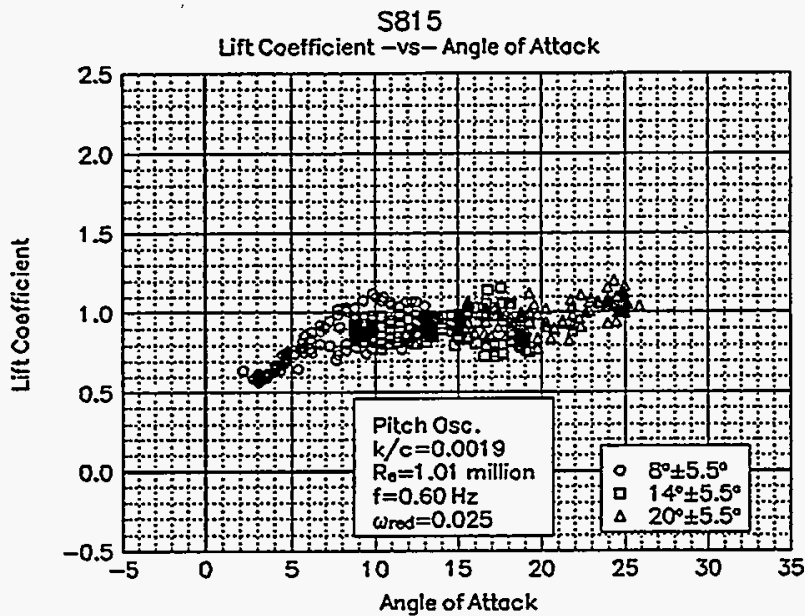

Figure 24. LEGR, $C_{1}$ vs $a, \omega_{\text {red }}=0.025, \pm 5.5^{\circ}$

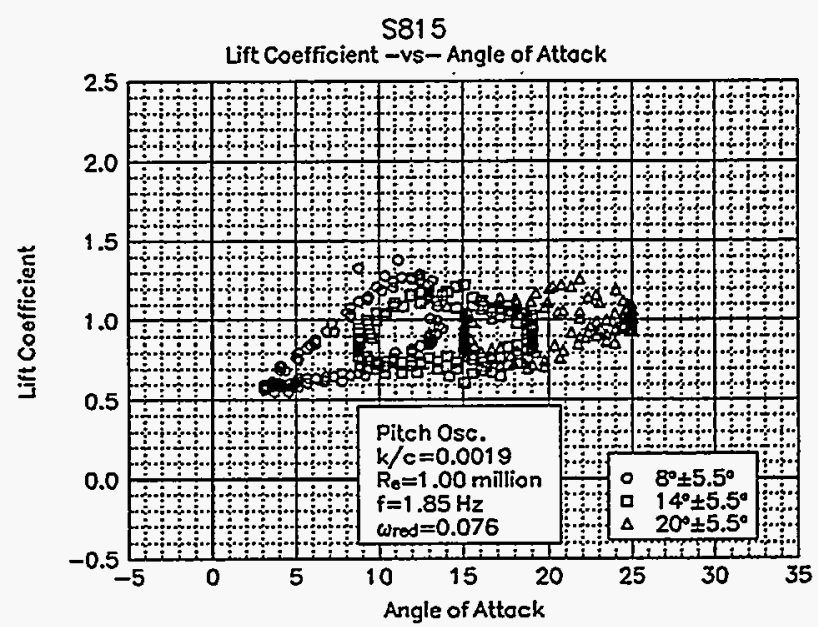

Figure 25. LEGR, $C_{1}$ vs $a, \omega_{\text {red }}=0.076, \pm 5.5^{\circ}$

Compared to the clean data, the application of LEGR reduces the maximum lift coefficient in the pitch oscillation cases. Lift coefficient versus angle of attack with LEGR applied is shown in Figure 24 for the 0.025 reduced frequency case. The 0.076 reduced frequency case is shown in Figure 25 . Both correspond to the same run conditions described earlier for the clean cases. For the lower reduced 
frequency, the maximum unsteady lift coefficient is reduced to 1.12 from the corresponding clean case of 1.45 , a $23 \%$ decrease. Hysteresis behavior is apparent at this frequency and is of similar order as the clean case; the corresponding hysteresis lift coefficient is 0.78 when LEGR is applied. In contrast, the higher frequency LEGR case has a maximum lift coefficient of 1.29 while the model is increasing in angle of attack and the corresponding decreasing angle of attack lift coefficient is 0.84 . In this case, the application of LEGR reduced the hysteresis loop behavior through the stall region compared to the clean case at the same run conditions.

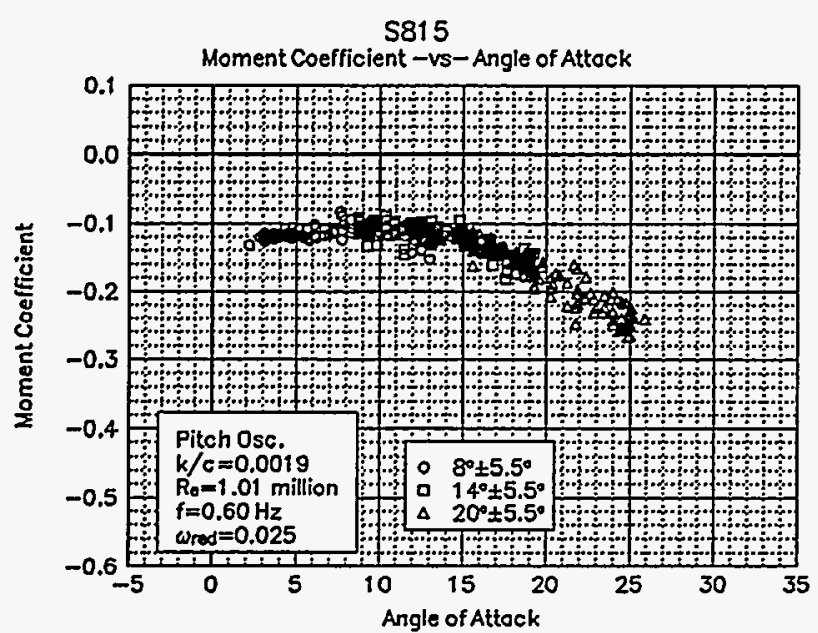

Figure 26. LEGR, $c_{m}$ vs $a, \omega_{\text {red }}=0.025, \pm 5.5^{\circ}$

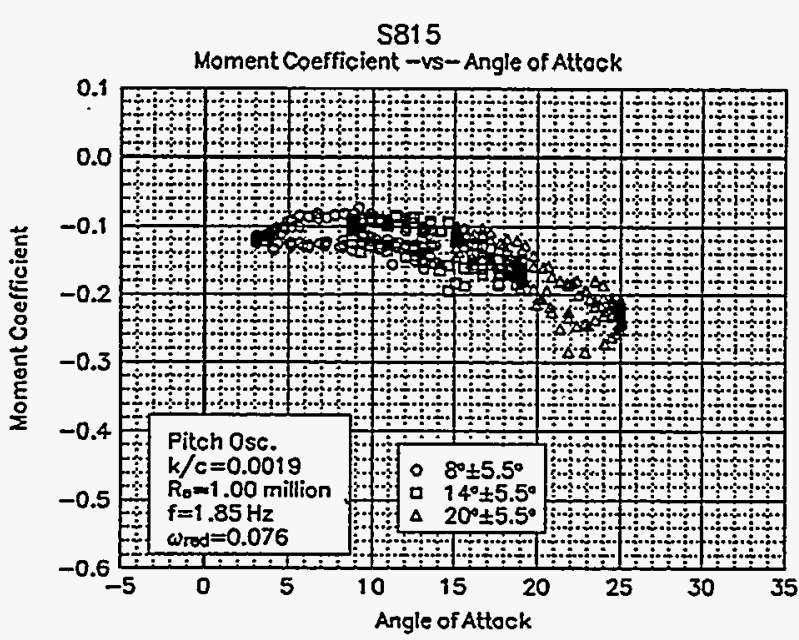

Figure 27. LEGR, $C_{m}$ vs $\alpha, \omega_{\text {red }}=0.076, \pm 5.5^{\circ}$

The pitching moment coefficient shown in Figure 26 is for 0.025 reduced frequency with LEGR applied. At the angle of unsteady maximum lift, the pitching moment ranges from -0.1189 to -0.0956 , while the steady state LEGR pitching moment is -0.0941 at the steady state stall angle of attack $\left(8.2^{\circ}\right)$. The higher reduced frequency of 0.076 with LEGR applied is shown in Figure 27. As was seen with the lift coefficient, pitching moment hysteresis is more apparent at the higher reduced frequency than in the corresponding low reduced frequency case. Unsteady maximum lift angle of attack for this reduced frequency occurs at $12.5^{\circ}$, and the pitching moment ranges from -0.1499 to -0.0942 at that angle. Throughout the higher angle of attack range, the magnitude of the unsteady pitching moment can be very different from the steady state clean case (steady state pitching moment at maximum lift is -0.1179). It seems these differences can have an impact on the fatigue life predictions of a wind turbine system.

In addition to the $\pm 5.5^{\circ}$ unsteady experimental data, $\pm 10^{\circ}$ unsteady data were obtained with and without LEGR. The data used were taken at 1 million Reynolds number using the same mean angles and frequencies as the $5.5^{\circ}$ amplitude cases. Figure 28 and Figure 29 show the $\pm 10^{\circ}$, unsteady, clean, lift coefficient for the reduced frequencies of 0.025 and 0.077 , respectively. The maximum lift coefficient for the lower frequency is 1.53 and occurs, as expected, when the airfoil is traveling through increasing angles of attack. The hysteresis lift coefficient (at $14.5^{\circ}$ ) is 1.02 . At the higher reduced frequency, the maximum lift coefficient occurs at a higher angle of attack, $17.6^{\circ}$, and is 2.01 . The corresponding hysteresis lift coefficient is 0.86 . The difference between the maximum lift coefficient and the hysteresis lift coefficient indicates a much greater hysteresis response than experienced for the lower reduced frequency. The steady state, clean, maximum lift coefficient is 1.24 ; therefore, the unsteady behavior created lift coefficients up to $62 \%$ higher than the steady state conditions.

The quarter chord pitching moments with the same reduced frequencies as the lift coefficient cases are shown in Figure 30 and Figure 31. The hysteresis behavior observed in the lift coefficient plots is also reflected in this pitching moment data. Near the maximum lift angle, $14.5^{\circ}$ for the lower frequency, the 


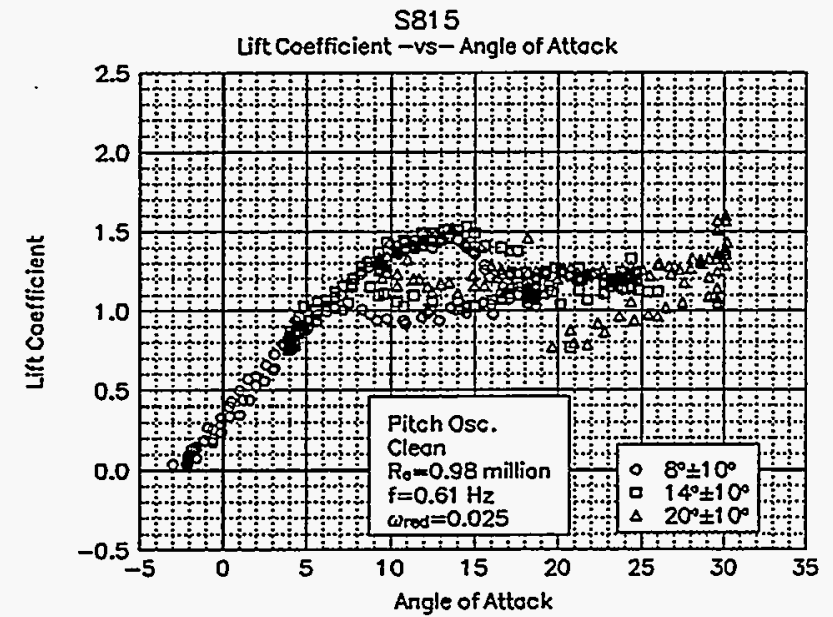

Figure 28. Clean, $C_{1}$ vs $a, \omega_{\text {red }}=0.025, \pm 10^{\circ}$

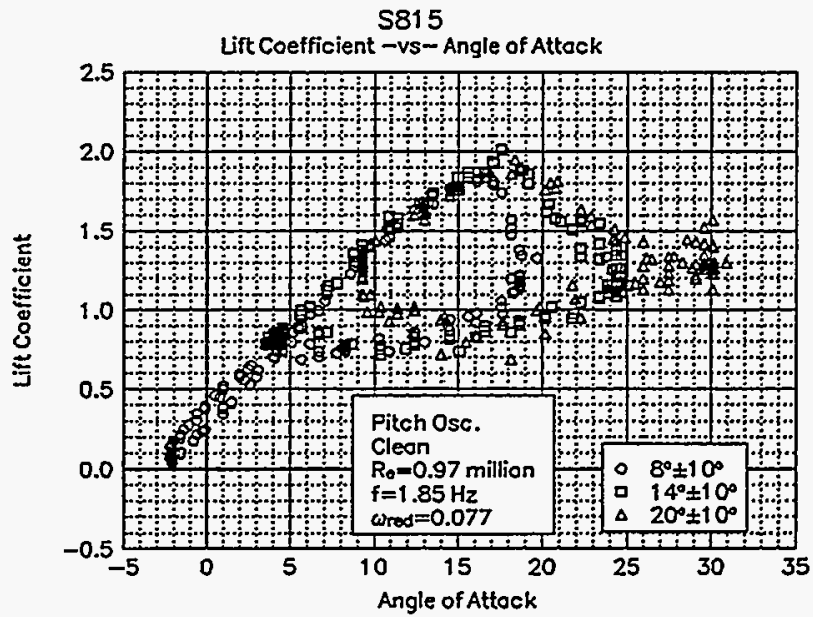

Figure 29. Clean, $\mathrm{C}_{\mathrm{v}}$ vs $a, \omega_{\text {red }}=0.077, \pm 10^{\circ}$

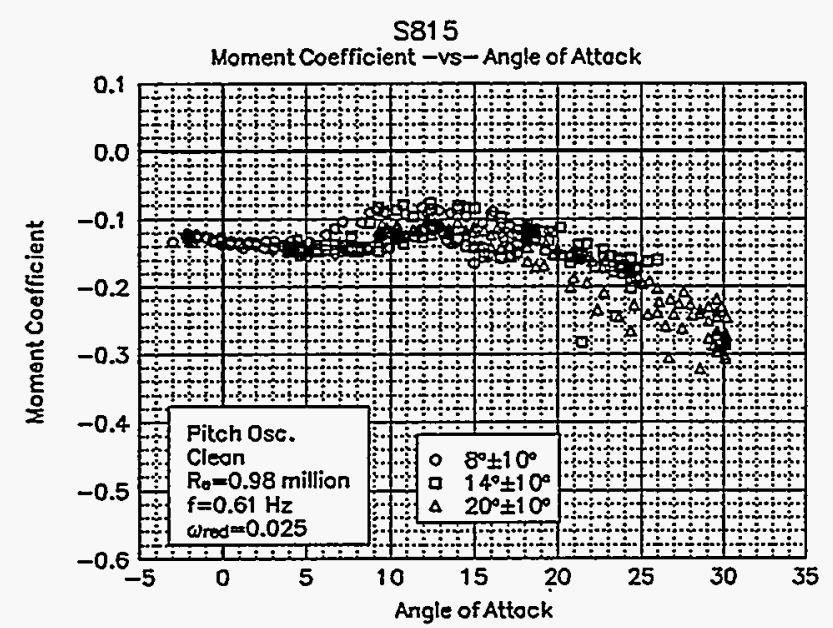

Figure 30. Clean, $\mathrm{C}_{\mathrm{m}}$ vs $a, \omega_{\text {red }}=0.025, \pm 10^{\circ}$

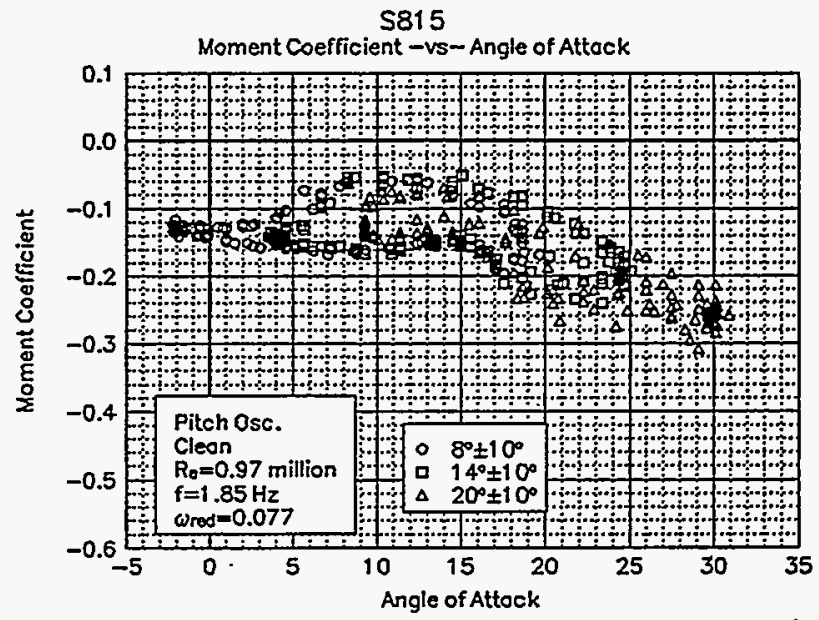

Figure 31. Clean, $c_{m}$ vs $a, \omega_{\text {red }}=0.077, \pm 10^{\circ}$

pitching moment coefficient ranges from -0.1389 to -0.0826 ; the 0.077 reduced frequency case has maximum lift near $17.6^{\circ}$ and pitching moment ranges from -0.2109 to -0.0822 . In comparison, the steady state pitching moment is -0.1179 near the steady state maximum lift coefficient angle of attack of $12^{\circ}$. The higher reduced frequency again shows large hysteresis loops for all three mean angles of attack.

The application of LEGR degrades the lift performance of the airfoil, as would be expected from the results discussed previously. The LEGR lift coefficient data for reduced frequencies of 0.026 and 0.077 are shown in Figure 32 and Figure 33, respectively. The maximum lift coefficient is reduced to 1.24 from 1.53 for the low frequency clean case. Although there is a reduction, this value is still significantly higher than the LEGR steady state case, which has a maximum lift coefficient of 0.92 at $8.2^{\circ}$ angle of attack. The higher reduced frequency has a maximum lift coefficient of 1.71 , which occurs near $17^{\circ}$ angle of attack. The corresponding lift coefficient at $17^{\circ}$ for the airfoil traveling with decreasing angle of attack is 0.74 , a $57 \%$ reduction from the maximum.

Figure 34 and Figure 35 show the corresponding pitching moment coefficients for the LEGR cases at reduced frequencies of 0.026 and 0.077 . For the 0.026 reduced frequency case, the pitching moment varies from -0.1406 to -0.0939 at $12.5^{\circ}$ (where the maximum lift occurs). The hysteresis behavior is 


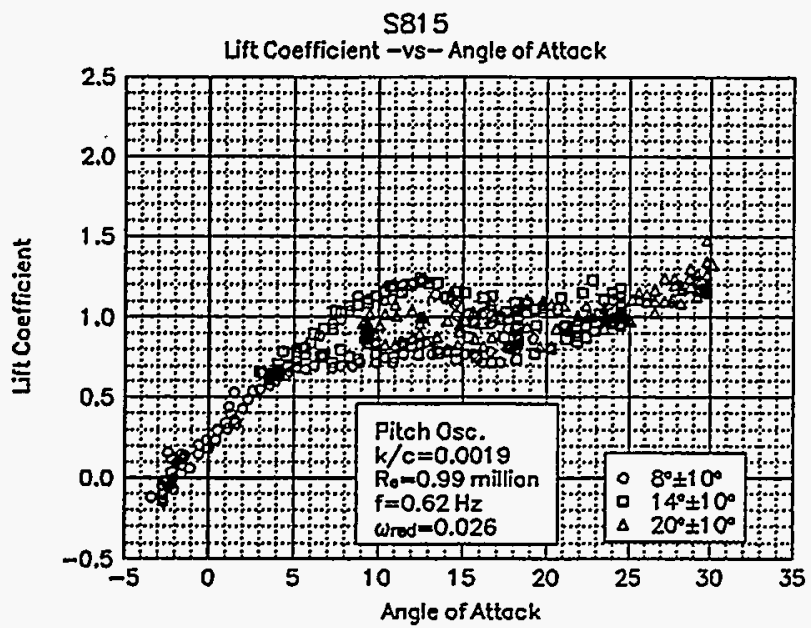

Figure 32. LEGR, $C_{1}$ vs $a, \omega_{\text {red }}=0.026, \pm 10^{\circ}$

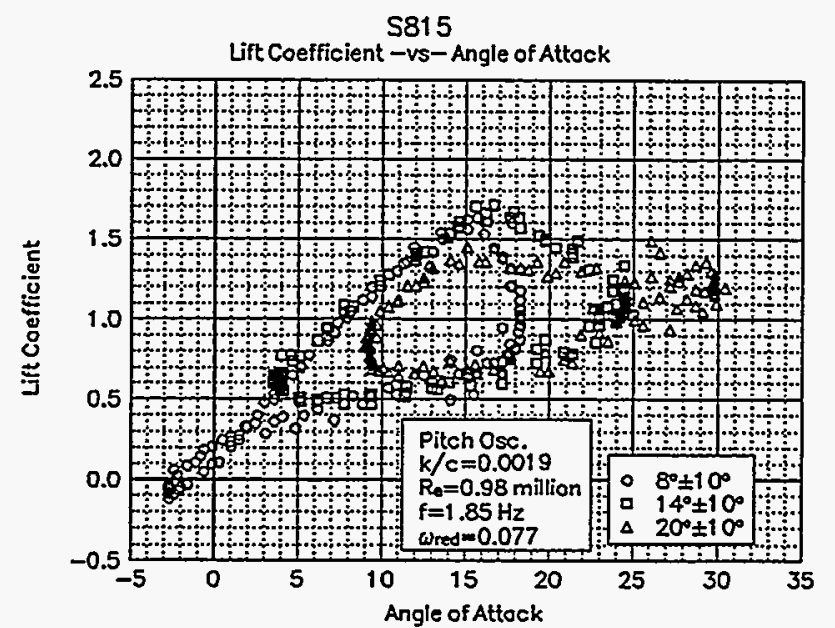

Figure 33. $L E G R, C_{1}$ vs $\alpha, \omega_{\text {red }}=0.077, \pm 10^{\circ}$

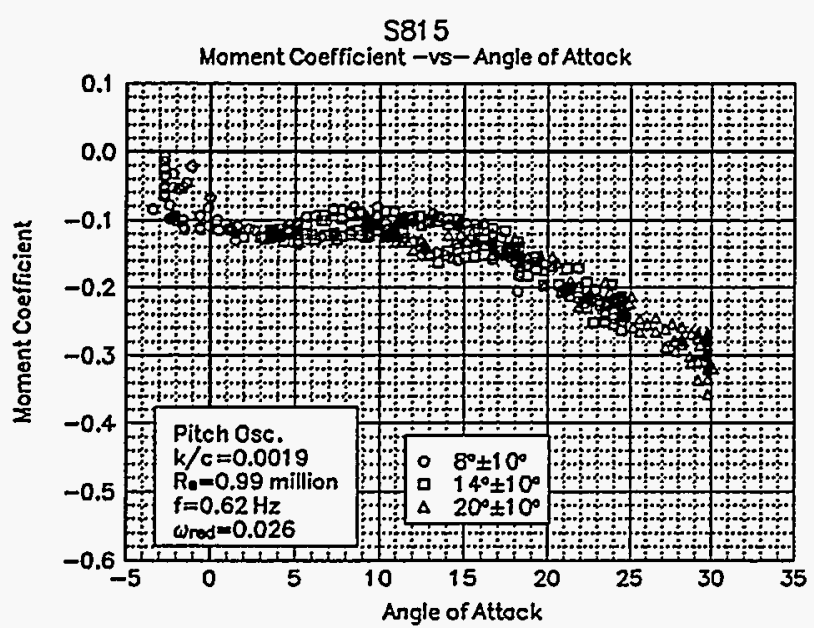

Figure 34. LEGR, $C_{m}$ vs $a, \omega_{\text {red }}=0.026, \pm 10^{\circ}$

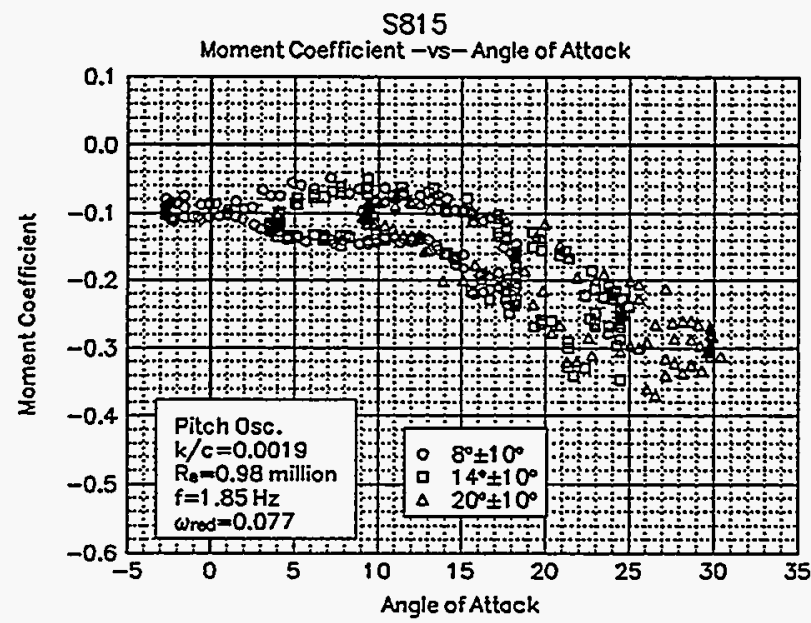

Figure 35. LEGR, $\mathrm{C}_{\mathrm{m}}$ vs $a, \omega_{\text {red }}=0.077, \pm 10^{\circ}$

more pronounced for the higher reduced frequency case, where the range of pitching moments at the maximum lift angle of $16.7^{\circ}$ is from -0.2280 to -0.1287 . These values can then be compared to the steady state LEGR value of -0.0941 .

Although all the unsteady data have not been discussed here, the previous discussion included typical examples of the wind tunnel data. The remaining cases of the $\pm 5.5^{\circ}$ and $\pm 10^{\circ}$ oscillation data for all the Reynolds numbers are included in Appendix C.

The following four unsteady pressure distributions show examples of the data used to calculate the lift, pressure drag, and the pitching moment coefficients. Figure 36 shows the distribution for a clean model with a reduced frequency of 0.054 , mean angle of attack of $14^{\circ}$, and $\pm 10^{\circ}$ pitch oscillation. For plotting clarity, the model pressures were "unwrapped" about the trailing edge. The upper surface pressures are depicted on the right side of the surface plot; lower surface values are on the left. The trailing edge is at the midpoint of the $\mathrm{x}$-axis, with the leading edge at each extreme. For clarification of the irregularities in the pressure distribution, an equally spaced grid was used. The pressure coefficients were linearly interpolated to the specified number of evenly spaced $x$ positions. The time scale corresponds to angle of attack. For this case, the separated flow area is defined by the irregular, "rough" areas of the upper surface trailing edge portion of the plot. The lower surface stays attached through all of the airfoil travel. 


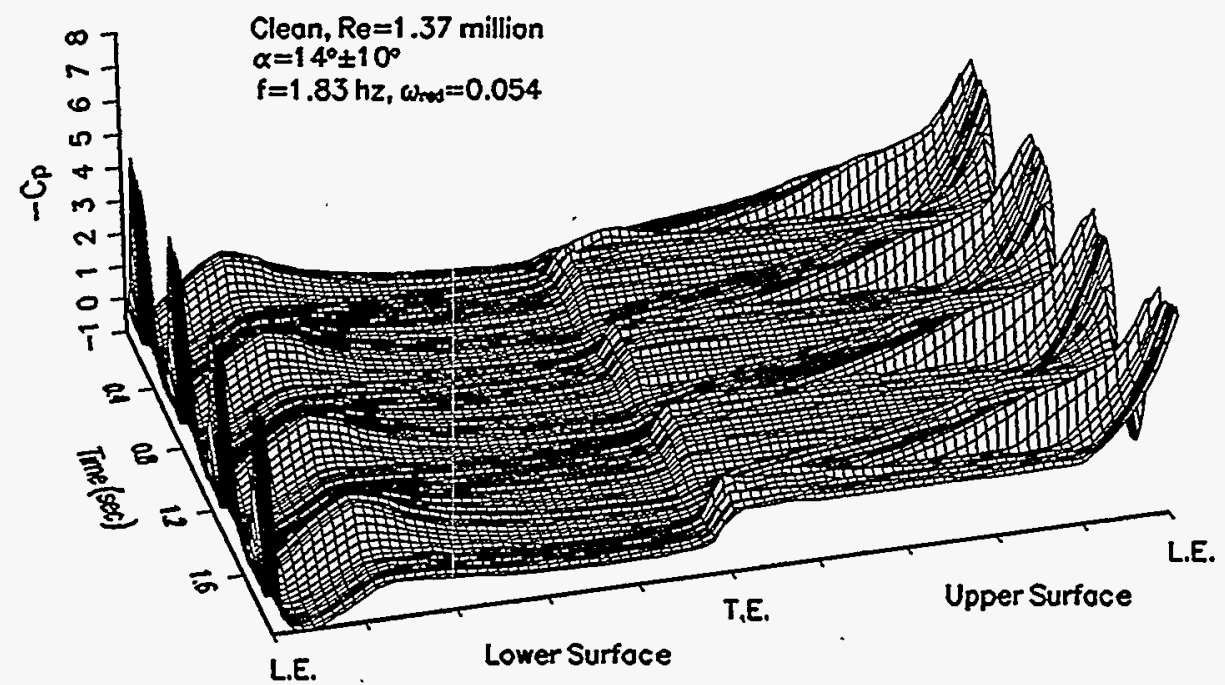

Figure 36. Unsteady pressure distribution, clean, $\omega_{\text {red }}=0.054,14 \pm 10^{\circ}$

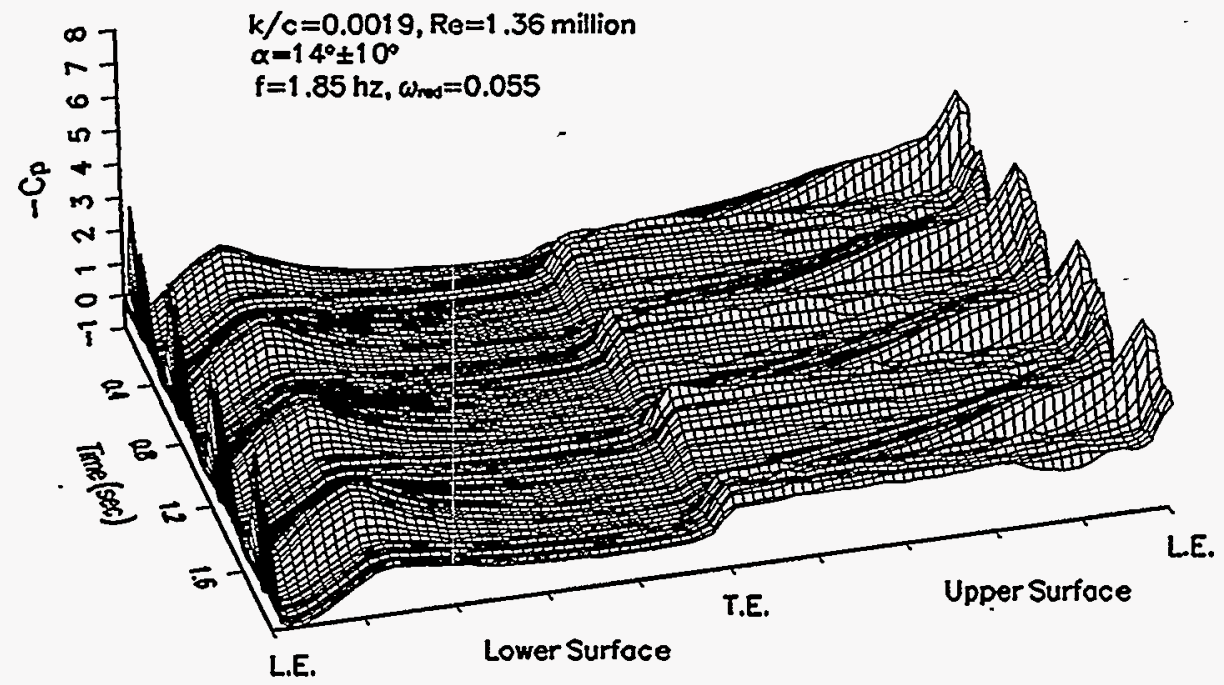

Figure 37. Unsteady pressure distribution, LEGR, $\omega_{\text {red }}=0.055,14 \pm 10^{\circ}$

Figure 37 shows the LEGR case for the same test conditions as the previous figure. In this case, the pressure peaks were not as high or over as wide a range of angles of attack as for the clean case, and the stall behavior is more pronounced.

Figure 38 shows the same clean run conditions at a higher mean angle of attack. This case is characterized by significant portions of separated flow on the upper surface of the model. The pressure coefficient peaks are near -4 , which correspond to where maximum lift occurs. 


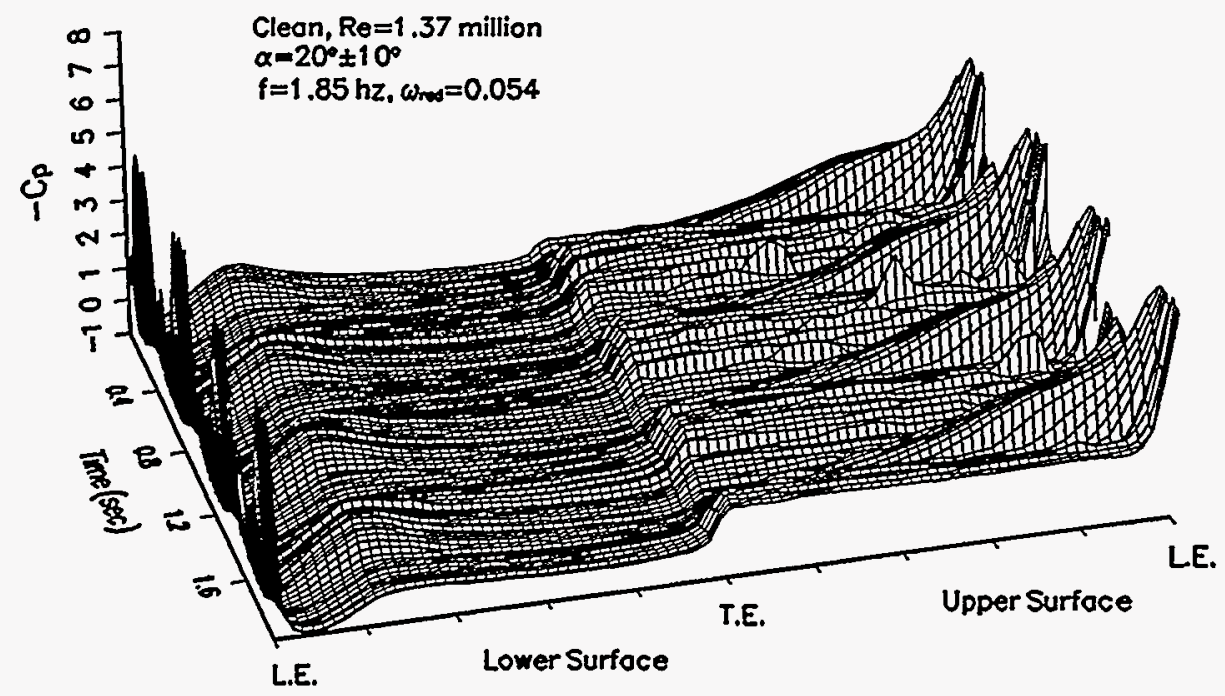

Figure 38. Unsteady pressure distribution, clean, $\omega_{\text {red }}=0.054,20 \pm 10^{\circ}$

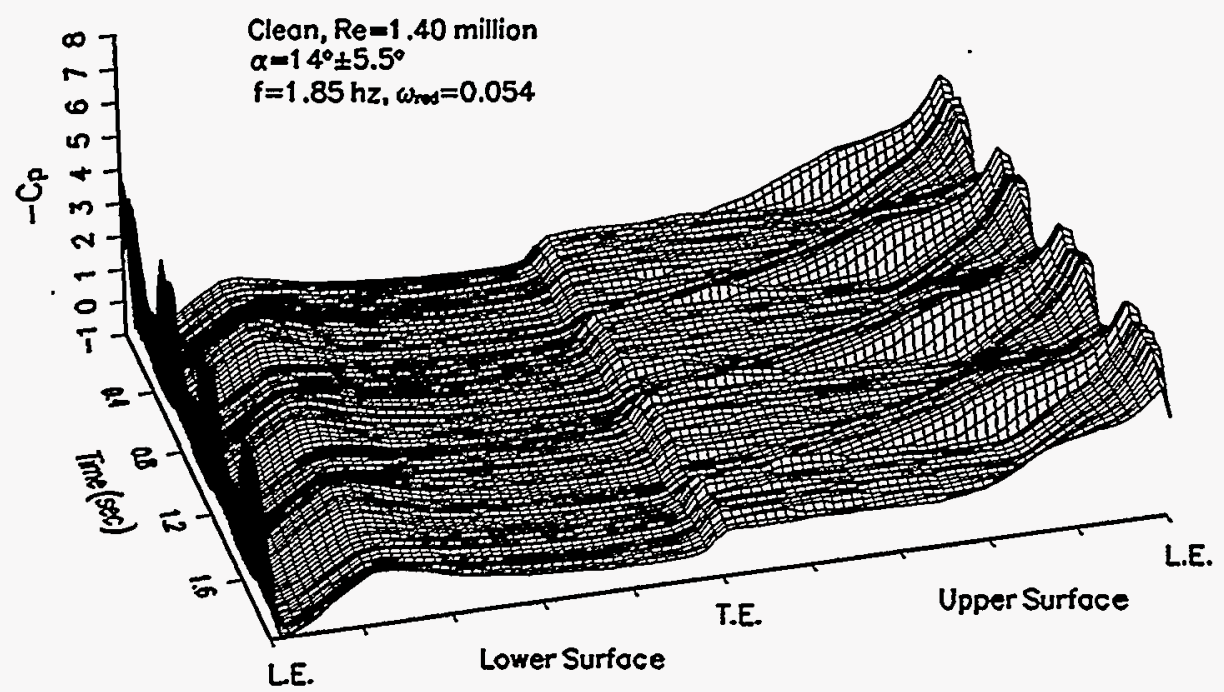

Figure 39. Unsteady pressure distribution, clean, $\omega_{\text {red }}=0.054,14 \pm 5.5^{\circ}$

Figure 39 shows the clean run conditions for a $\pm 5.5^{\circ}$ pitch oscillation at 1.4 million Reynolds number and 0.054 reduced frequency. The structure is similar to Figure 36 , but less of the upper surface flow was separated, a consequence of lower angles of attack. 


\section{Summary of Results}

A S815 airfoil model was tested under steady state and pitch oscillation conditions. Baseline tests were made while the model was clean, and then corresponding tests were conducted with LEGR applied.

A summary of the steady state aerodynamic parameters is shown in Table 1. As observed, the application of LEGR reduced the maximum lift of the airfoil up to $28 \%$, and the minimum drag coefficient increased up to 51\%. LEGR also affects the zero lift pitching moment coefficient reducing the magnitude by more than $70 \%$ in some cases.

Table 1. S815 Steady State Parameters Summary

\begin{tabular}{ccccc}
\hline Grit Pattern & $\mathrm{Re} \times 10^{-6}$ & $\mathrm{C}_{\max }$ & $\mathrm{C}_{\text {dmin }}$ & $\mathrm{C}_{\mathrm{mo}}$ \\
\hline Clean & 0.75 & $1.26 @ 10.3^{\circ}$ & 0.0147 & -0.1213 \\
$\mathrm{k} / \mathrm{c}=0.0019$ & 0.75 & $0.91 @ 8.2^{\circ}$ & 0.0188 & -0.1078 \\
Clean & 1.00 & $1.24 @ 12.1^{\circ}$ & 0.0136 & -0.1248 \\
$\mathrm{k} / \mathrm{c}=0.0019$ & 1.00 & $0.92 @ 8.2^{\circ}$ & 0.0186 & -0.0584 \\
Clean & 1.25 & $1.27 @ 12.1^{\circ}$ & 0.0134 & -0.1268 \\
$\mathrm{k} / \mathrm{c}=0.0019$ & 1.25 & $0.93 @ 10.3^{\circ}$ & 0.0190 & -0.0364 \\
Clean & 1.40 & $1.23 @ 10.2^{\circ}$ & 0.0132 & -0.1279 \\
$\mathrm{k} / \mathrm{c}=0.0019$ & 1.40 & $0.95 @ 10.2^{\circ}$ & 0.0199 & -0.0358 \\
\hline
\end{tabular}

Table 2. S815, Unsteady, Clean, $\pm 5.5^{\circ}$

\begin{tabular}{cccccccc}
\hline$\omega_{\text {red }}$ & $\operatorname{Re} \times 10^{-6}$ & $\mathrm{f}$ & $\mathrm{C}_{\operatorname{lmax}}$ & $\alpha_{\max }$ & $\mathrm{C}_{1 \text { dec }}$ & $\mathrm{C}_{\mathrm{m} \text { inc }}$ & $\mathrm{C}_{\mathrm{m} \mathrm{dec}}$ \\
\hline 0.033 & 0.76 & 0.61 & 1.48 & 16.1 & 1.14 & -0.1378 & -0.1041 \\
0.065 & 0.76 & 1.18 & 1.58 & 15.6 & 0.99 & -0.1524 & -0.0764 \\
0.100 & 0.76 & 1.83 & 1.75 & 16.7 & 1.06 & -0.1850 & -0.0972 \\
\hline 0.027 & 0.92 & 0.60 & 1.45 & 13.1 & 1.11 & -0.1119 & -0.0937 \\
0.054 & 0.92 & 1.18 & 1.53 & 14.0 & 0.99 & -0.1317 & -0.0812 \\
0.083 & 0.92 & 1.83 & 1.68 & 15.1 & 0.94 & -0.1464 & -0.0845 \\
\hline 0.020 & 1.25 & 0.60 & 1.43 & 12.0 & 1.08 & -0.1229 & -0.0979 \\
0.040 & 1.25 & 1.21 & 1.49 & 13.5 & 1.10 & -0.1214 & -0.1025 \\
0.061 & 1.25 & 1.85 & 1.62 & 15.1 & 0.99 & -0.1512 & -0.0963 \\
\hline 0.018 & 1.40 & 0.61 & 1.42 & 12.2 & 1.07 & -0.1171 & -0.0921 \\
0.038 & 1.40 & 1.19 & 1.48 & 13.0 & 1.02 & -0.1246 & -0.0876 \\
0.054 & 1.40 & 1.85 & 1.55 & 14.1 & 1.08 & -0.1364 & -0.1155 \\
\hline
\end{tabular}

The pitch oscillation data can be divided into two groups, the $\pm 5.5^{\circ}$ amplitude and $\pm 10^{\circ}$ amplitude oscillations, which show similar trends. For both $\pm 5.5^{\circ}$ and $\pm 10^{\circ}$, the unsteady test conditions and some parameters are listed in Tables $2,3,4$, and 5 . As the reduced frequency, which takes oscillation and tunnel speed into account, is increased, the maximum lift coefficient also increases. In addition, the hysteresis behavior becomes increasingly apparent with increased reduced frequency. 
Table 3. S815, Unsteady, LEGR, $\pm 5.5^{\circ}$

\begin{tabular}{cccccccc}
\hline$\omega_{\text {red }}$ & $\operatorname{Re} \times 10^{-6}$ & $\mathrm{f}$ & $\mathrm{C}_{\operatorname{lmax}}$ & $\alpha_{\max }$ & $\mathrm{C}_{1 \text { dec }}$ & $\mathrm{C}_{\mathrm{m} \text { inc }}$ & $\mathrm{C}_{\mathrm{m} \text { dec }}$ \\
\hline 0.033 & 0.75 & 0.59 & 1.15 & 10.4 & 0.80 & -0.1246 & -0.0825 \\
0.066 & 0.75 & 1.21 & 1.28 & 11.5 & 0.72 & -0.1349 & -0.0898 \\
0.101 & 0.75 & 1.85 & 1.34 & 13.0 & 0.83 & -0.1407 & -0.1082 \\
\hline 0.025 & 1.01 & 0.60 & 1.12 & 9.9 & 0.78 & -0.1189 & -0.0956 \\
0.049 & 1.00 & 1.19 & 1.20 & 12.0 & 0.79 & -0.1395 & -0.1036 \\
0.076 & 1.00 & 1.85 & 1.29 & 12.5 & 0.84 & -0.1499 & -0.0942 \\
\hline 0.019 & 1.26 & 0.60 & 1.10 & 10.9 & 0.86 & -0.1295 & -0.0983 \\
0.039 & 1.26 & 1.21 & 1.19 & 11.2 & 0.73 & -0.1267 & -0.0861 \\
0.060 & 1.25 & 1.83 & 1.26 & 11.9 & 0.80 & -0.1338 & -0.1046 \\
\hline 0.018 & 1.39 & 0.61 & 1.08 & 9.9 & 0.88 & -0.1193 & -0.1093 \\
0.035 & 1.38 & 1.19 & 1.14 & 11.5 & 0.81 & -0.1316 & -0.1036 \\
0.053 & 1.38 & 1.81 & 1.22 & 11.4 & 0.82 & -0.1342 & -0.1116 \\
\hline
\end{tabular}

Table 4. S815, Unsteady, Clean, $\pm 10^{\circ}$

\begin{tabular}{cccccccc}
\hline$\omega_{\text {red }}$ & $\operatorname{Re} \times 10^{-6}$ & $\mathrm{f}$ & $\mathrm{C}_{\operatorname{lmax}}$ & $\alpha_{\max }$ & $\mathrm{C}_{1 \text { dec }}$ & $\mathrm{C}_{\mathrm{m} \text { inc }}$ & $\mathrm{C}_{\mathrm{m} \text { dec }}$ \\
\hline 0.033 & 0.73 & 0.59 & 1.62 & 15.1 & 1.09 & -0.1476 & -0.0965 \\
0.067 & 0.73 & 1.19 & 1.93 & 17.6 & 0.94 & -0.2038 & -0.0916 \\
0.103 & 0.72 & 1.83 & 2.18 & 18.9 & 0.64 & -0.2274 & -0.1674 \\
\hline 0.025 & 0.98 & 0.61 & 1.53 & 14.5 & 1.02 & -0.1389 & -0.0826 \\
0.051 & 0.98 & 1.21 & 1.73 & 16.1 & 0.91 & -0.1491 & -0.0768 \\
0.077 & 0.97 & 1.85 & 2.01 & 17.6 & 0.86 & -0.2109 & -0.0822 \\
\hline 0.020 & 1.23 & 0.60 & 1.49 & 14.0 & 1.08 & -0.1453 & -0.1040 \\
0.040 & 1.22 & 1.21 & 1.64 & 14.0 & 0.94 & -0.1335 & -0.0789 \\
0.060 & 1.22 & 1.83 & 1.86 & 17.1 & 0.91 & -0.2038 & -0.0847 \\
\hline 0.017 & 1.38 & 0.59 & 1.49 & 12.5 & 1.04 & -0.1220 & -0.0815 \\
0.035 & 1.37 & 1.19 & 1.63 & 15.0 & 0.99 & -0.1642 & -0.0799 \\
0.054 & 1.37 & 1.85 & 1.77 & 16.1 & 0.96 & -0.1617 & -0.0799 \\
\hline
\end{tabular}

As expected, the application of LEGR reduces the aerodynamic performance of the airfoil. The maximum lift coefficient is reduced by $19 \%-24 \%$ for the $\pm 5.5^{\circ}$ case and $14 \%-21 \%$ for the $\pm 10^{\circ}$ case. In addition to following the same trends as the clean, unsteady data discussed previously, the LEGR causes the hysteresis behavior to persist into lower angles of attack than for the clean cases. Overall, the unsteady wind tunnel data show hysteresis behavior that becomes more apparent with increased reduced frequency. The maximum unsteady lift coefficient can be up to $47 \%$ higher for the $\pm 5.5^{\circ}$ amplitude and up to $103 \%$ higher for the $\pm 10^{\circ}$ amplitude than the steady state maximum lift coefficient. Variation in the quarter chord pitching moment coefficient can be more than one and a half times greater than that indicated by steady state results. These findings indicate that it is important to 
consider the unsteady loading that will occur in wind turbine operation because steady state results can greatly underestimate the forces.

Table 5. S815, Unsteady, LEGR, $\pm 10^{\circ}$

\begin{tabular}{cccccccc}
\hline$\omega_{\text {red }}$ & $\operatorname{Re} \times 10^{-6}$ & $\mathrm{f}$ & $\mathrm{C}_{\max }$ & $\alpha_{\max }$ & $\mathrm{C}_{1 \text { dec }}$ & $\mathrm{C}_{\operatorname{minc}}$ & $\mathrm{C}_{\mathrm{m} \text { dec }}$ \\
\hline 0.034 & 0.73 & 0.60 & 1.30 & 12.5 & 0.70 & -0.1378 & -0.0829 \\
0.069 & 0.73 & 1.22 & 1.61 & 16.2 & 0.64 & -0.2153 & -0.1186 \\
0.104 & 0.73 & 1.85 & 1.85 & 17.7 & 0.71 & -0.2311 & -0.1059 \\
\hline 0.026 & 0.99 & 0.62 & 1.24 & 12.5 & 0.77 & -0.1406 & -0.0939 \\
0.051 & 0.98 & 1.21 & 1.47 & 14.6 & 0.59 & -0.1760 & -0.0829 \\
0.077 & 0.98 & 1.85 & 1.71 & 16.7 & 0.74 & -0.2280 & -0.1287 \\
\hline 0.019 & 1.23 & 0.59 & 1.17 & 12.0 & 0.82 & -0.1350 & -0.1006 \\
0.039 & 1.23 & 1.18 & 1.37 & 13.0 & 0.66 & -0.1573 & -0.0998 \\
0.061 & 1.23 & 1.83 & 1.57 & 15.1 & 0.69 & -0.1943 & -0.0904 \\
\hline 0.018 & 1.37 & 0.61 & 1.18 & 12.0 & 0.83 & -0.1549 & -0.0993 \\
0.036 & 1.36 & 1.19 & 1.36 & 13.0 & 0.87 & -0.1602 & -0.1188 \\
0.055 & 1.36 & 1.85 & 1.52 & 14.8 & 0.67 & -0.1862 & -0.0889 \\
\hline
\end{tabular}




\section{References}

Pope, A.; Harper, J.J. 1966. Low Speed Wind Tunnel Testing. New York, NY: John Wiley \& Sons, Inc. Schlichting, H. 1979. Boundary Layer Theory. New York, NY: McGraw-Hill Inc.

Smetana, F. Summey D., et-al. 1975. Light Aircraft Lift, Drag, Moment Prediction - a Review and Analysis. North Carolina State University. NASA-CR2523. 

Appendix A: Surface Pressure Tap Coordinates 


\section{List of Tables}

A1. S815 Surface Pressure Taps, Non-Diminsional Coordinates $\ldots \ldots \ldots \ldots \ldots \ldots$ 


\begin{tabular}{|c|c|c|}
\hline Tap Number & Chord Station & Ordinate \\
\hline 1 & 1.0004 & - \\
\hline 2 & 0.9738 & - \\
\hline 3 & 0.9311 & - \\
\hline 4 & 0.8910 & -- \\
\hline 5 & 0.8492 & - \\
\hline 6 & 0.8093 & - \\
\hline 7 & 0.7697 & - \\
\hline 8 & 0.7295 & -- \\
\hline 9 & 0.6926 & - \\
\hline 10 & 0.6515 & - \\
\hline 11 & 0.6146 & - \\
\hline 12 & 0.5747 & - \\
\hline 13 & 0.5364 & - \\
\hline 14 & 0.4976 & - \\
\hline 15 & 0.4552 & -- \\
\hline 16 & 0.4225 & - \\
\hline 17 & 0.3846 & -- \\
\hline 18 & 0.3455 & _- \\
\hline 19 & 0.3061 & - \\
\hline 20 & 0.2678 & - \\
\hline 21 & 0.2271 & - \\
\hline 22 & 0.1864 & - \\
\hline 23 & 0.1471 & - \\
\hline 24 & 0.1122 & - \\
\hline 25 & 0.0788 & - \\
\hline 26 & 0.0512 & - \\
\hline 27 & 0.0349 & - \\
\hline 28 & 0.0182 & - \\
\hline 29 & 0.0096 & - \\
\hline 30 & 0.0056 & - \\
\hline 31 & 0.0030 & - \\
\hline 32 & 0.0012 & - \\
\hline 33 & -0.0003 & - \\
\hline 34 & 0.0009 & - \\
\hline 35 & 0.0071 & - \\
\hline 36 & 0.0247 & - \\
\hline
\end{tabular}




\begin{tabular}{||c|c|c||}
\hline \multicolumn{3}{|c|}{$\begin{array}{c}\text { Table A1. S815 Surface Pressure Taps, } \\
\text { Non-Diminsional Coordinates }\end{array}$} \\
\hline \hline Tap Number & Chord Station & Ordinate \\
\hline 37 & 0.0500 & - \\
38 & 0.0829 & - \\
39 & 0.1193 & - \\
40 & 0.1568 & - \\
41 & 0.1994 & - \\
42 & 0.2387 & - \\
43 & 0.2803 & - \\
44 & 0.3227 & - \\
45 & 0.3613 & - \\
46 & 0.4040 & - \\
47 & 0.4449 & - \\
48 & 0.4835 & - \\
49 & 0.5230 & - \\
50 & 0.5663 & - \\
51 & 0.6068 & - \\
52 & 0.6474 & - \\
53 & 0.6884 & - \\
54 & 0.7291 & - \\
55 & 0.7711 & - \\
56 & 0.8114 & - \\
57 & 0.8513 & - \\
58 & 0.8908 & - \\
59 & 0.9294 & - \\
60 & 0.9685 & - \\
\hline & End of Table A1 & - \\
\hline
\end{tabular}




\section{Appendix B: Steady State Data Integrated Coefficients and Pressure Distributions}




\section{List of Figures}

Pressure Distributions, Steady State, $\operatorname{Re}=0.75$ million $\ldots \ldots \ldots \ldots \ldots \ldots$. . . . . B-20

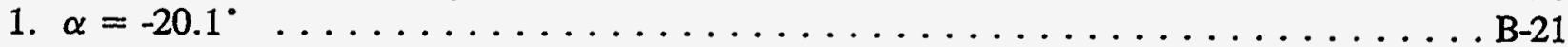

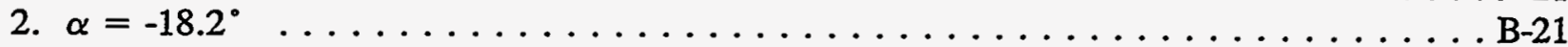

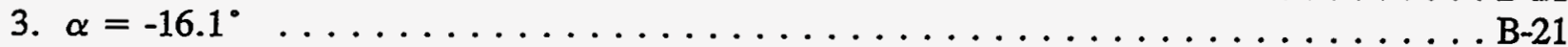

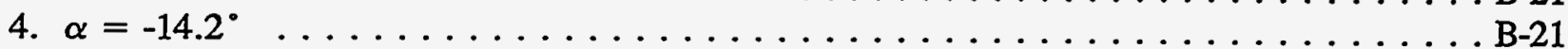

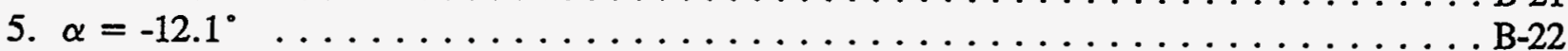

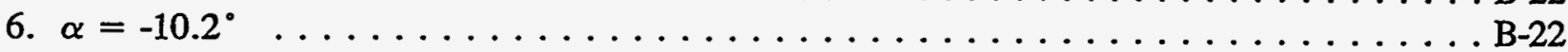

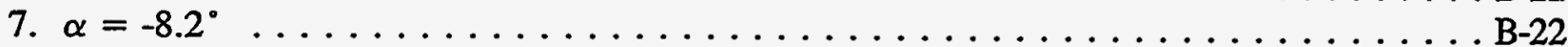

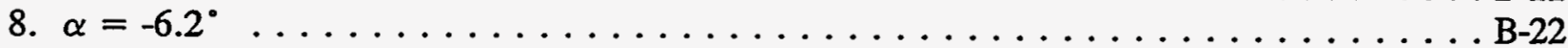

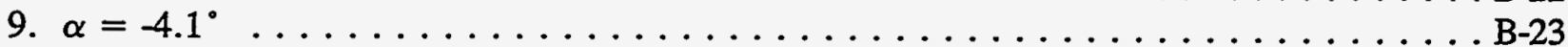

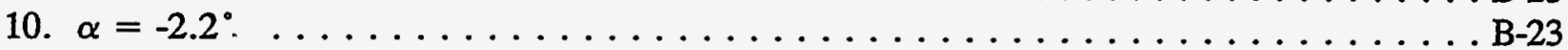

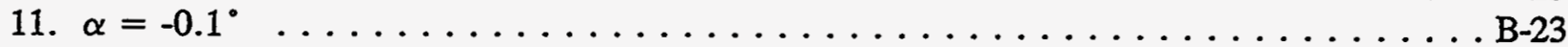

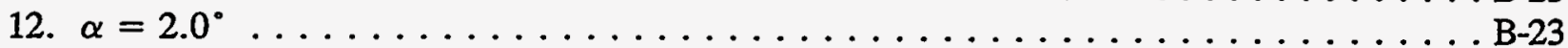

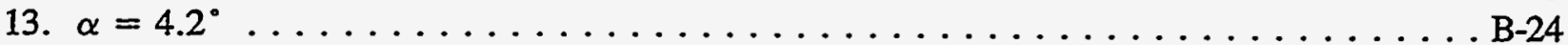

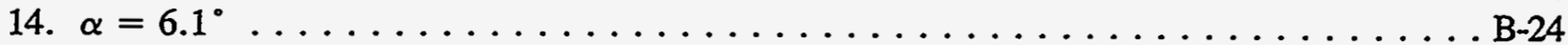

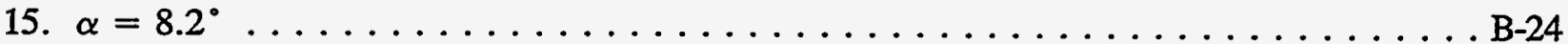

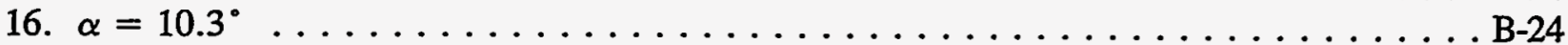

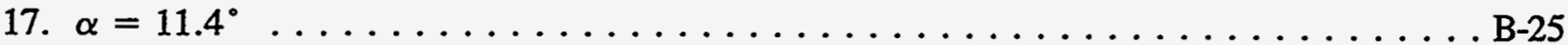

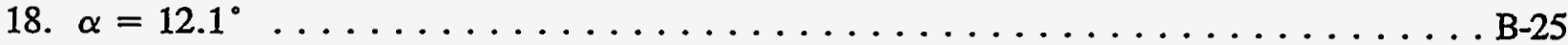

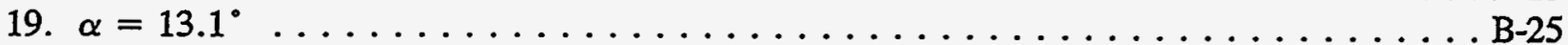

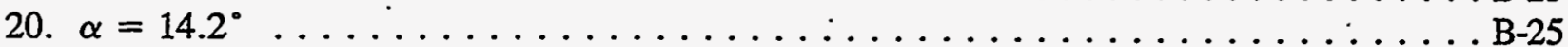

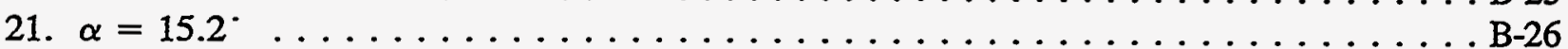

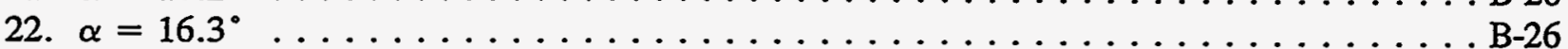

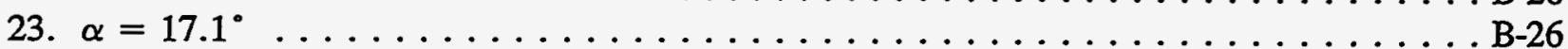

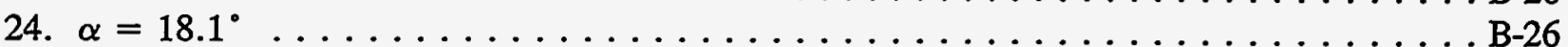

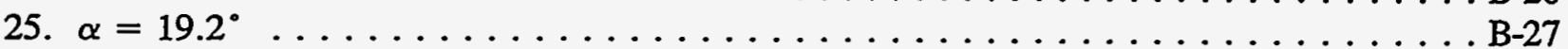

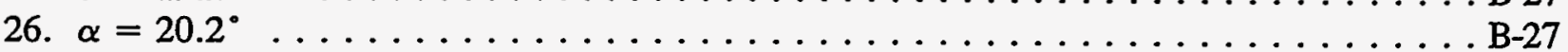

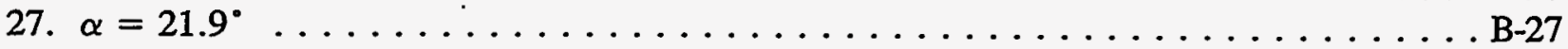

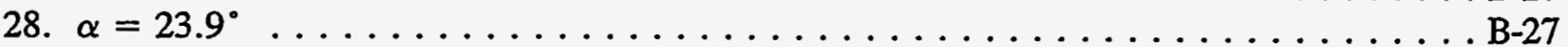

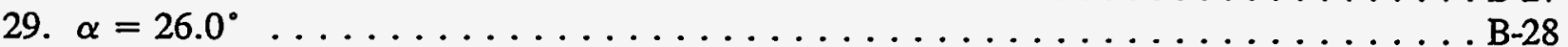

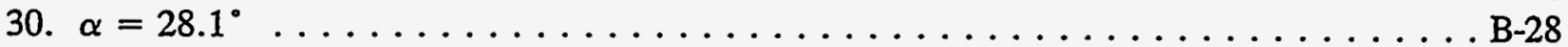

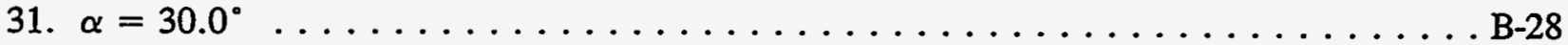

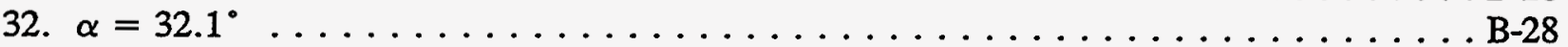

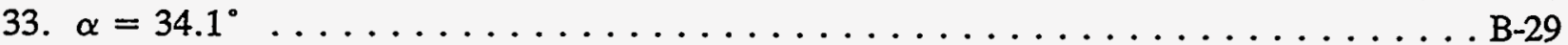

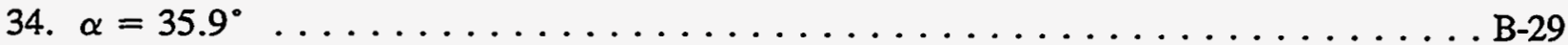

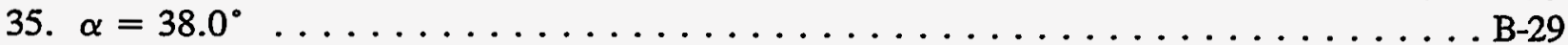

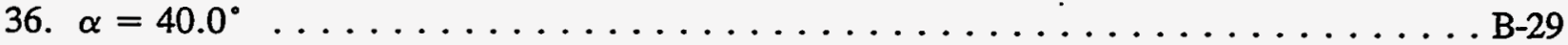

Pressure Distributions, Steady State, $\operatorname{Re}=1$ million $\ldots \ldots \ldots \ldots \ldots \ldots$

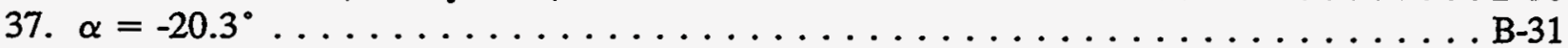

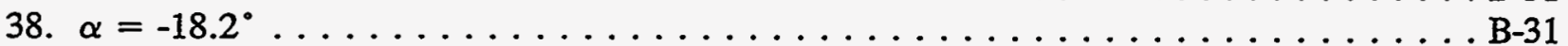

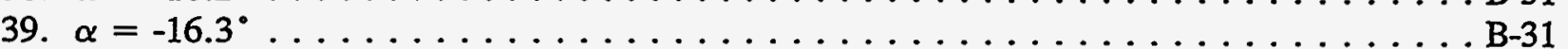

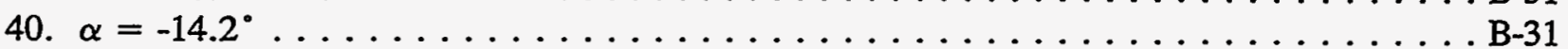

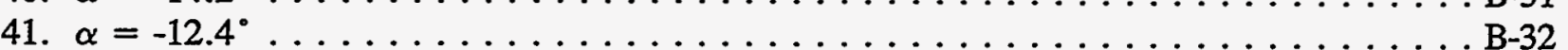

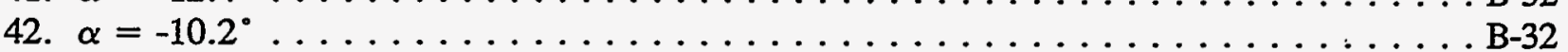

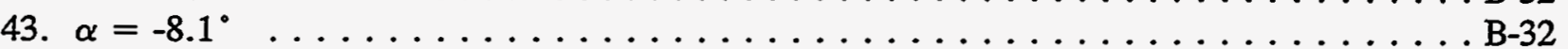

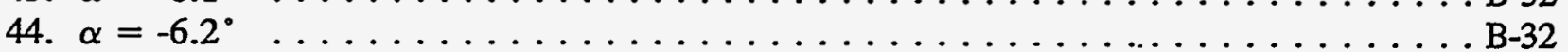


45. $\alpha=-4.3^{\circ}$

B-33

46. $\alpha=-2.2^{\circ}$

B-33

47. $\alpha=-0.1^{\circ}$

B-33

48. $\alpha=2.0^{\circ}$

B-33

49. $\alpha=4.2^{\circ}$

B-34

50. $\alpha=6.1^{\circ}$

B-34

51. $\alpha=8.2^{\circ}$

B-34

52. $\alpha=10.1^{\circ}$

B-34

53. $\alpha=11.1^{\circ}$

B-35

54. $\alpha=12.1^{\circ}$

B-35

55. $\alpha=13.2^{\circ}$

B-35

56. $\alpha=14.2^{\circ}$

B-35

57. $\alpha=15.1^{\circ}$

B-36

58. $\alpha=16.1^{\circ}$

B-36

59. $\alpha=17.1^{\circ}$

B-36

60. $\alpha=18.2^{\circ}$

B-36

61. $\alpha=19.2^{\circ}$

B-37

62. $\alpha=20.0^{\circ}$

B-37

63. $\alpha=22.2^{\circ}$

B-37

64. $\alpha=24.0^{\circ}$

B-37

65. $\alpha=26.0^{\circ}$

B-38

66. $\alpha=28.0^{\circ}$

B-38

67. $\alpha=29.9^{\circ}$

B-38

68. $\alpha=31.9^{\circ}$

B-38

69. $\alpha=33.9^{\circ}$

B-39

70. $\alpha=36.0^{\circ}$

B-39

71. $\alpha=38.0^{\circ}$

B-39

72. $\alpha=39.9^{\circ}$

B-39

Pressure Distributions, Steady State, $\operatorname{Re}=1.25$ million $\ldots \ldots \ldots \ldots \ldots$. . . . . B-40

73. $\alpha=-20.3^{\circ}$

B-41

74. $\alpha=-18.2^{\circ}$

B-41

75. $\alpha=-16.1^{\circ}$

B-41

76. $\alpha=-14.2^{\circ}$

$\mathrm{B}-41$

77. $\alpha=-12.3^{\circ}$

$\mathrm{B}-42$

78. $\alpha=-10.2^{\circ}$

B-42

79. $\alpha=-8.3^{\circ}$

B -42

80. $\alpha=-6.2^{\circ}$

$\mathrm{B}-42$

81. $\alpha=-4.1^{\circ}$

B- 43

82. $\alpha=-2.2^{\circ}$

$\mathrm{B}-43$

83. $\alpha=-0.1^{\circ}$

B- 43

84. $\alpha=2.0^{\circ}$

B-43

85. $\alpha=4.2^{\circ}$

B-44

86. $\alpha=6.1^{\circ}$

B-44

87. $\alpha=8.2^{\circ}$

B- 44

88. $\alpha=10.3^{\circ}$

B- 44

89. $\alpha=11.3^{\circ}$

B-45

90. $\alpha=12.1^{\circ}$

B- 45

91. $\alpha=13.1^{\circ}$

B-45

92. $\alpha=14.1^{\circ}$

B-45 


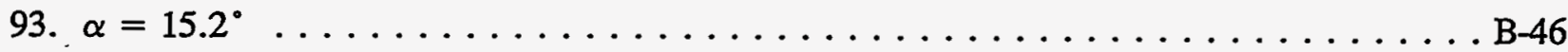

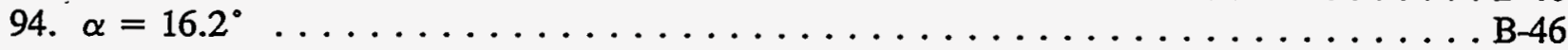

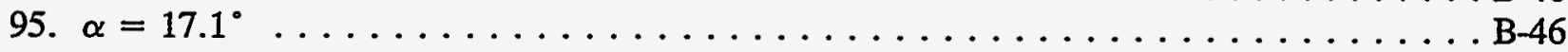

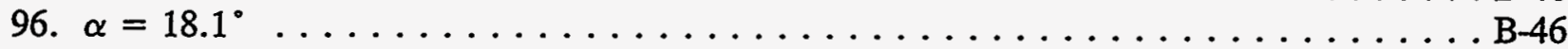

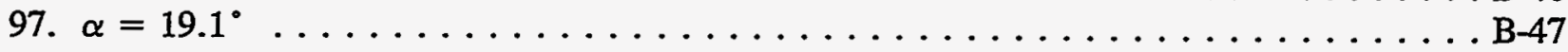

98. $\alpha=20.2^{\circ} \ldots \ldots \ldots \ldots \ldots \ldots \ldots \ldots \ldots \ldots \ldots \ldots \ldots \ldots \ldots \ldots \ldots \ldots$

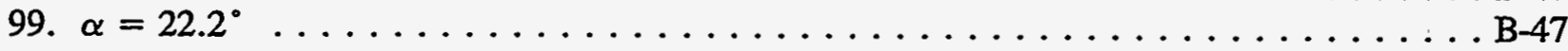

100. $\alpha=24.0^{\circ} \ldots \ldots \ldots \ldots \ldots \ldots \ldots \ldots \ldots \ldots \ldots \ldots \ldots \ldots \ldots \ldots \ldots \ldots \ldots$

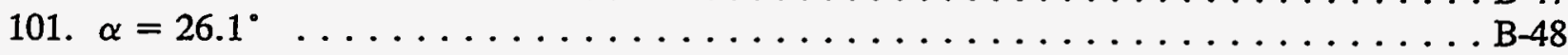

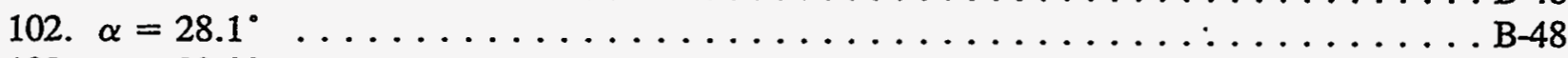

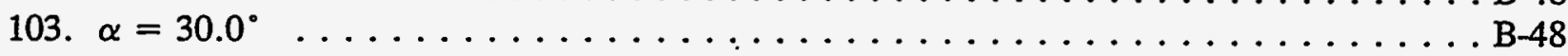

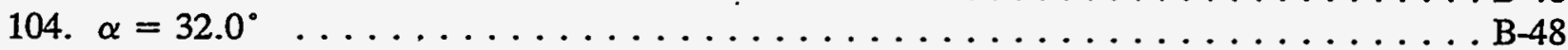

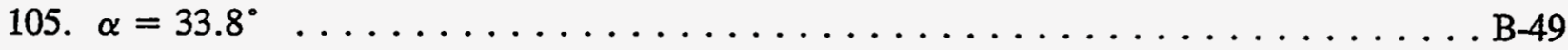

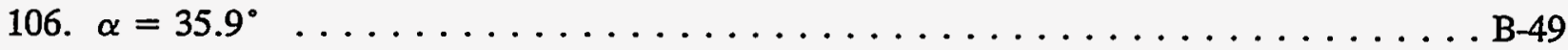

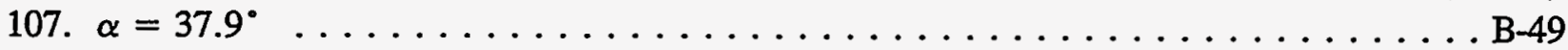

108. $\alpha=40.0^{\circ} \ldots \ldots \ldots \ldots \ldots \ldots \ldots \ldots \ldots \ldots \ldots \ldots \ldots \ldots \ldots \ldots$

Pressure Distributions, Steady State, $\operatorname{Re}=1.4$ million $\ldots \ldots \ldots \ldots \ldots \ldots$

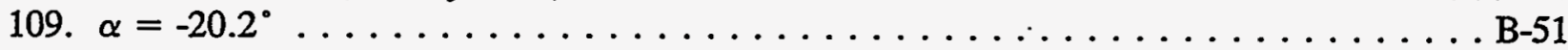

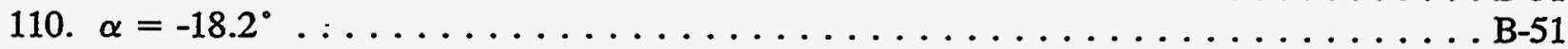

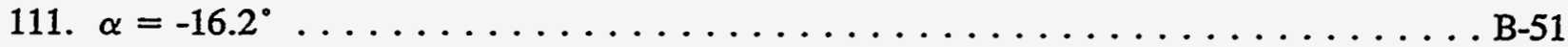

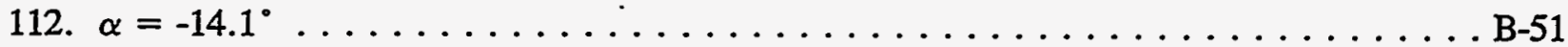

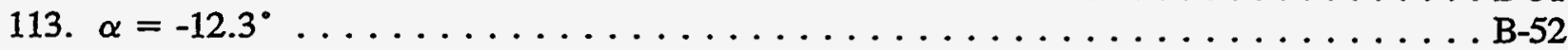

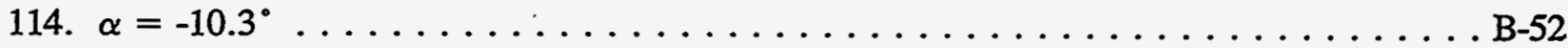

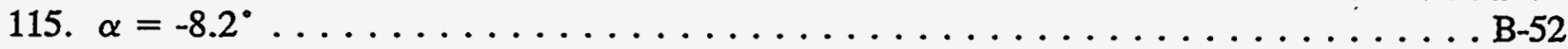

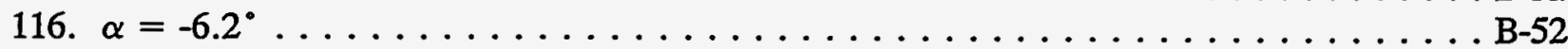

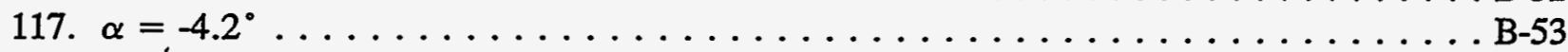

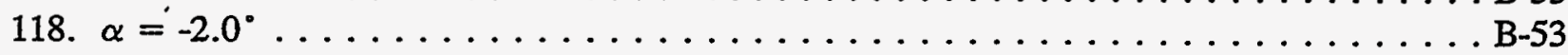

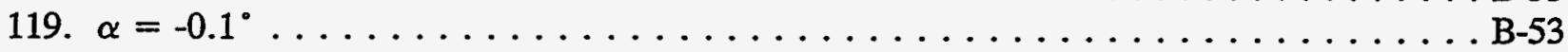

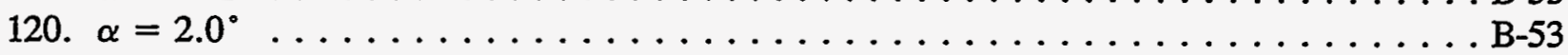

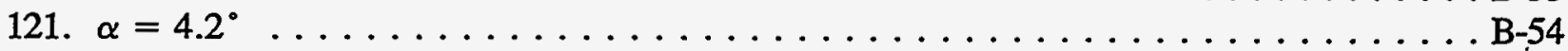

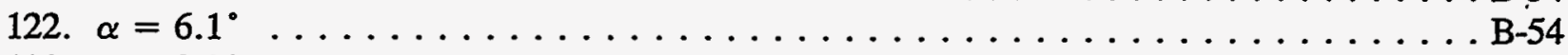

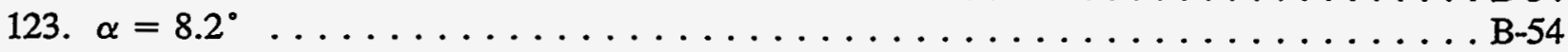

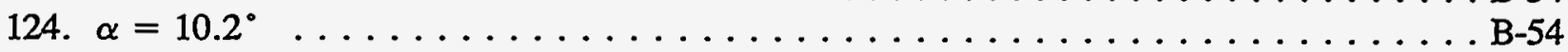

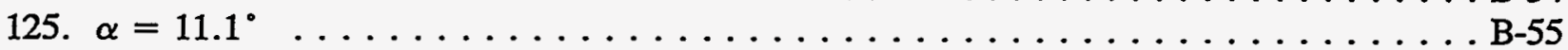

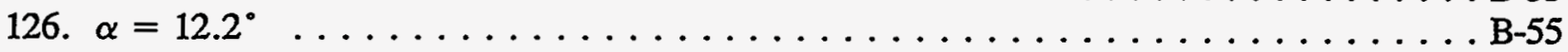

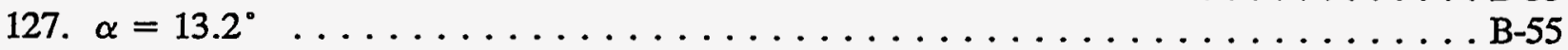

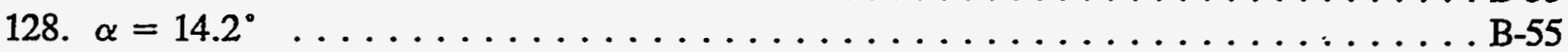

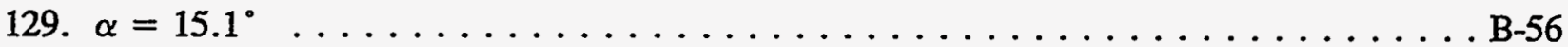

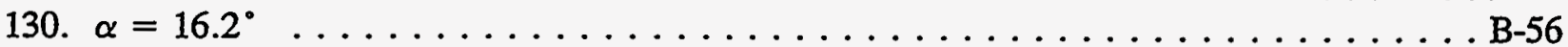

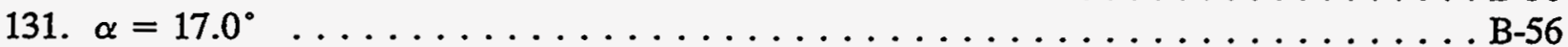

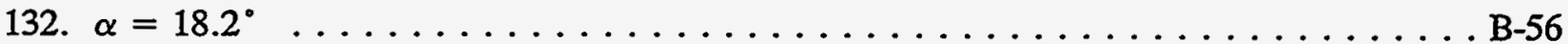

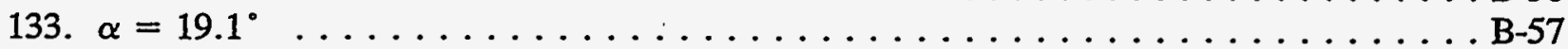

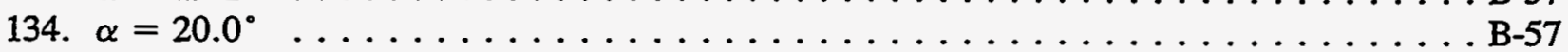




\section{List of Tables}

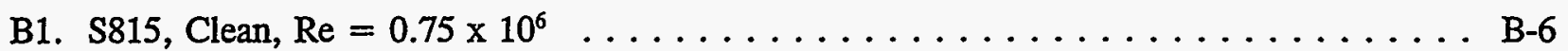

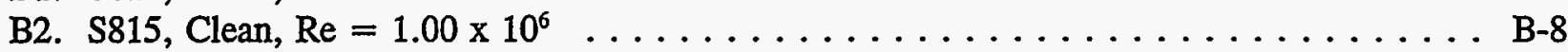

B3. $\mathrm{S} 815$, Clean, $\mathrm{Re}=1.25 \times 10^{6} \ldots \ldots \ldots \ldots \ldots \ldots \ldots \ldots \ldots \ldots \ldots$

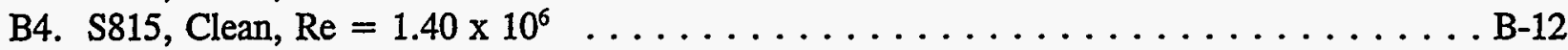

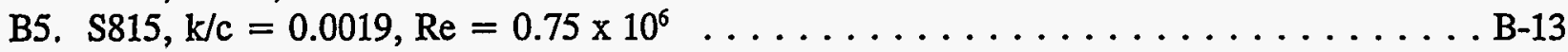

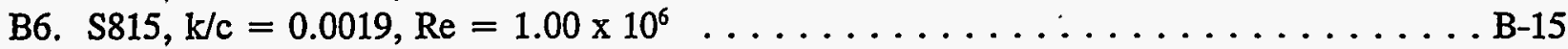

B7. $\mathrm{S} 815, \mathrm{k} / \mathrm{c}=0.0019, \mathrm{Re}=1.25 \times 10^{6} \ldots \ldots \ldots \ldots \ldots \ldots \ldots \ldots \ldots \ldots \ldots \ldots$

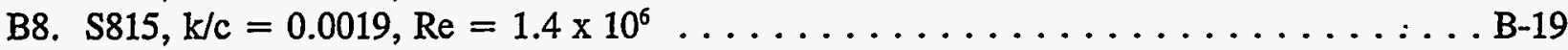




\begin{tabular}{|c|c|c|c|c|c|c|}
\hline \multicolumn{7}{|c|}{ Table B1. S815, Clean, $R e=0.75 \times 10^{6}$} \\
\hline RUN & $\mathrm{AOA}$ & $\mathrm{C}_{1}$ & $\mathrm{C}_{\mathrm{dp}}$ & $\mathrm{C}_{\mathrm{m} / \mathrm{s}}$ & $\operatorname{Re} \times 10^{-6}$ & $\mathrm{C}_{\mathrm{dw}}$ \\
\hline 191 & -20.1 & -1.12 & 0.1742 & 0.0025 & 0.75 & - \\
\hline 190 & -18.2 & -0.83 & 0.1756 & 0.0066 & 0.75 & - \\
\hline 189 & -16.1 & -0.87 & 0.2106 & 0.0330 & 0.75 & - \\
\hline 188 & -14.2 & -0.25 & 0.1759 & -0.0161 & 0.75 & - \\
\hline 187 & -12.1 & -0.39 & 0.1956 & 0.0222 & 0.76 & - \\
\hline 186 & -10.2 & -0.76 & 0.0313 & -0.1000 & 0.75 & 0.0208 \\
\hline 185 & -8.2 & -0.61 & 0.0159 & -0.1048 & 0.75 & 0.0183 \\
\hline 184 & -6.2 & -0.42 & 0.0088 & -0.1081 & 0.75 & 0.0198 \\
\hline 183 & -4.1 & -0.19 & 0.0098 & -0.1150 & 0.75 & 0.0171 \\
\hline 182 & -2.2 & 0.05 & 0.0098 & -0.1213 & 0.75 & 0.0165 \\
\hline 181 & -0.1 & 0.28 & 0.0116 & -0.1251 & 0.75 & 0.0147 \\
\hline 192 & -0.1 & 0.26 & 0.0130 & -0.1245 & 0.75 & 0.0149 \\
\hline 218 & -0.1 & 0.26 & 0.0114 & -0.1233 & 0.75 & 0.0147 \\
\hline 193 & 2.0 & 0.52 & 0.0128 & -0.1294 & 0.75 & 0.0153 \\
\hline 194 & 4.2 & 0.76 & 0.0149 & -0.1311 & 0.75 & 0.0151 \\
\hline 195 & 6.1 & 1.00 & 0.0154 & -0.1311 & 0.75 & 0.0144 \\
\hline 196 & 8.2 & 1.19 & 0.0191 & -0.1274 & 0.75 & 0.0174 \\
\hline 197 & 10.3 & 1.26 & 0.0213 & -0.1016 & 0.75 & 0.0321 \\
\hline 198 & 11.4 & 1.23 & 0.0265 & -0.0900 & 0.75 & - \\
\hline 199 & 12.1 & 1.16 & 0.0347 & -0.0880 & 0.75 & - \\
\hline 200 & 13.1 & 1.11 & 0.0467 & -0.0884 & 0.74 & - \\
\hline 201 & 14.2 & 1.09 & 0.0591 & -0.0901 & 0.74 & - \\
\hline 202 & 15.2 & 1.08 & 0.0756 & -0.0914 & 0.75 & - \\
\hline 203 & 16.3 & 1.08 & 0.0924 & -0.0945 & 0.75 & - \\
\hline 204 & 17.1 & 1.10 & 0.1097 & -0.1016 & 0.75 & - \\
\hline 205 & 18.1 & 1.10 & 0.1269 & -0.1047 & 0.75 & - \\
\hline 206 & 19.2 & 1.12 & 0.1472 & -0.1111 & 0.75 & - \\
\hline 207 & 20.2 & 1.15 & 0.1683 & -0.1175 & 0.75 & - \\
\hline
\end{tabular}




\begin{tabular}{||c|c|c|c|c|c|c||}
\hline \multicolumn{7}{|c|}{ Table B1. S815, Clean, Re $=0.75 \times 10^{6}$} \\
\hline \hline RUN & AOA & $\mathrm{C}_{1}$ & $\mathrm{C}_{\mathrm{dp}}$ & $\mathrm{C}_{\mathrm{m} / \mathrm{k}}$ & $\operatorname{Re} \times 10^{-6}$ & $\mathrm{C}_{\mathrm{dw}}$ \\
\hline 208 & 21.9 & 0.82 & 0.4131 & -0.2041 & 0.76 & - \\
\hline 209 & 23.9 & 0.85 & 0.4706 & -0.2140 & 0.76 & - \\
\hline 210 & 26.0 & 0.96 & 0.5607 & -0.2425 & 0.75 & - \\
\hline 211 & 28.1 & 1.06 & 0.6506 & -0.2681 & 0.75 & - \\
\hline 212 & 30.0 & 1.14 & 0.7382 & -0.2930 & 0.74 & - \\
\hline 213 & 32.1 & 1.21 & 0.8333 & -0.3183 & 0.75 & - \\
\hline 214 & 34.1 & 1.26 & 0.9169 & -0.3378 & 0.74 & - \\
\hline 215 & 35.9 & 1.33 & 1.0193 & -0.3691 & 0.74 & - \\
\hline 216 & 38.0 & 1.32 & 1.0750 & -0.3752 & 0.73 & - \\
\hline 217 & 40.0 & 1.35 & 1.1717 & -0.4023 & 0.73 & - \\
\hline & & & End of Table B1 & & \\
\hline
\end{tabular}




\begin{tabular}{|c|c|c|c|c|c|c|}
\hline \multicolumn{7}{|c|}{ Table B2. S815, Clean, $R e=1.00 \times 10^{6}$} \\
\hline RUN & $\mathrm{AOA}$ & $\mathrm{C}_{1}$ & $\mathrm{C}_{\mathrm{dp}}$ & $\mathrm{C}_{\mathrm{m} / \mathrm{k}}$ & $\operatorname{Re} \times 10^{-6}$ & $\mathrm{C}_{\mathrm{dw}}$ \\
\hline 153 & -20.3 & -1.46 & 0.1754 & -0.0345 & 0.99 & - \\
\hline 152 & -18.2 & -1.41 & 0.1337 & -0.0419 & 1.00 & - \\
\hline 151 & -16.3 & -1.31 & 0.1017 & -0.0594 & 1.00 & - \\
\hline 150 & -14.2 & -1.14 & 0.0692 & -0.0806 & 1.01 & - \\
\hline 149 & -12.4 & -0.94 & 0.0473 & -0.0980 & 1.00 & - \\
\hline 148 & -10.2 & -0.76 & 0.0295 & -0.1053 & 1.00 & 0.0157 \\
\hline 147 & -8.1 & -0.61 & 0.0141 & -0.1074 & 1.00 & 0.0185 \\
\hline 146 & -6.2 & -0.43 & 0.0069 & -0.1119 & 0.99 & 0.0179 \\
\hline 145 & -4.3 & -0.19 & 0.0071 & -0.1188 & 1.00 & 0.0158 \\
\hline 144 & -2.2 & 0.06 & 0.0080 & -0.1248 & 1.00 & 0.0154 \\
\hline 143 & -0.1 & 0.28 & 0.0100 & -0.1285 & 1.00 & 0.0142 \\
\hline 154 & -0.1 & 0.28 & 0.0092 & -0.1289 & 1.00 & 0.0137 \\
\hline 180 & -0.1 & 0.26 & 0.0099 & -0.1290 & 1.00 & 0.0136 \\
\hline 155 & 2.0 & 0.53 & 0.0126 & -0.1322 & 1.00 & 0.0139 \\
\hline 156 & 4.2 & 0.77 & 0.0153 & -0.1349 & 0.99 & 0.0145 \\
\hline 157 & 6.1 & 1.00 & 0.0148 & -0.1337 & 0.99 & 0.0135 \\
\hline 158 & 8.2 & 1.19 & 0.0193 & -0.1278 & 1.00 & 0.0182 \\
\hline 159 & 10.1 & 1.24 & 0.0210 & -0.1028 & 1.00 & 0.0340 \\
\hline 160 & 11.1 & 1.24 & 0.0265 & -0.0944 & 1.00 & - \\
\hline 161 & 12.1 & 1.24 & 0.0661 & -0.1179 & 1.00 & - \\
\hline 162 & 13.2 & 1.20 & 0.0810 & -0.1194 & 1.00 & - \\
\hline 163 & 14.2 & 1.09 & 0.0691 & -0.0969 & 0.99 & - \\
\hline 164 & 15.1 & 1.07 & 0.0771 & -0.0961 & 1.00 & - \\
\hline 165 & 16.1 & 1.08 & 0.0961 & -0.1002 & 0.99 & - \\
\hline 166 & 17.1 & 1.09 & 0.1122 & -0.1043 & 1.00 & - \\
\hline 167 & 18.2 & 1.11 & 0.1320 & -0.1090 & 1.00 & - \\
\hline 168 & 19.2 & 1.14 & 0.1533 & -0.1156 & 1.00 & - \\
\hline 169 & 20.0 & 1.16 & 0.1705 & -0.1228 & 1.00 & - \\
\hline
\end{tabular}




\begin{tabular}{||c|c|c|c|c|c|c||}
\hline \multicolumn{7}{|c|}{ Table B2. S815, Clean, Re $=1.00 \times 10^{6}$} \\
\hline \hline RUN & AOA & $C_{1}$ & $C_{d p}$ & $C_{\text {m/4 }}$ & $\operatorname{Re} \times 10^{-6}$ & $C_{d w}$ \\
\hline 170 & 22.2 & 1.18 & 0.2265 & -0.1406 & 0.98 & - \\
\hline 171 & 24.0 & 0.83 & 0.4636 & -0.2134 & 1.01 & - \\
\hline 172 & 26.0 & 0.97 & 0.5672 & -0.2469 & 1.00 & - \\
\hline 173 & 28.0 & 1.06 & 0.6517 & -0.2706 & 1.00 & - \\
\hline 174 & 29.9 & 1.15 & 0.7380 & -0.2945 & 0.99 & - \\
\hline 175 & 31.9 & 1.24 & 0.8444 & -0.3274 & 1.00 & - \\
\hline 176 & 33.9 & 1.27 & 0.9199 & -0.3430 & 0.98 & - \\
\hline 177 & 36.0 & 1.32 & 1.0136 & -0.3659 & 0.98 & - \\
\hline 178 & 38.0 & 1.33 & 1.0808 & -0.3781 & 0.98 & - \\
\hline 179 & 39.9 & 1.34 & 1.1563 & -0.3933 & 0.99 & - \\
\hline & & & End of Table B2 & & \\
\hline \hline
\end{tabular}




\begin{tabular}{|c|c|c|c|c|c|c|}
\hline \multicolumn{7}{|c|}{ Table B3. S815, Clean, Re $=1.25 \times 10^{6}$} \\
\hline RUN & $\mathrm{AOA}$ & $\mathrm{C}_{1}$ & $\mathrm{C}_{\mathrm{dp}}$ & $\mathrm{C}_{\mathrm{m}^{3 / 4}}$ & $\operatorname{Re} \times 10^{-6}$ & $\mathrm{C}_{\mathrm{dw}}$ \\
\hline 115 & -20.3 & -1.08 & 0.2105 & 0.0272 & 1.24 & - \\
\hline 114 & -18.2 & -1.07 & 0.1976 & 0.0318 & 1.25 & - \\
\hline 113 & -16.1 & -1.03 & 0.1777 & 0.0286 & 1.25 & - \\
\hline 112 & -14.2 & -1.11 & 0.0659 & -0.0912 & 1.24 & - \\
\hline 111 & -12.3 & -0.94 & 0.0459 & -0.1026 & 1.24 & - \\
\hline 110 & -10.2 & -0.76 & 0.0281 & -0.1071 & 1.24 & 0.0167 \\
\hline 109 & -8.3 & -0.63 & 0.0143 & -0.1103 & 1.25 & 0.0156 \\
\hline 108 & -6.2 & -0.43 & 0.0063 & -0.1132 & 1.26 & 0.0154 \\
\hline 107 & -4.1 & -0.19 & 0.0059 & -0.1200 & 1.26 & 0.0156 \\
\hline 106 & -2.2 & 0.07 & 0.0070 & -0.1268 & 1.25 & 0.0150 \\
\hline 105 & -0.1 & 0.30 & 0.0078 & -0.1301 & 1.25 & 0.0135 \\
\hline 116 & -0.1 & 0.29 & 0.0088 & -0.1302 & 1.25 & 0.0139 \\
\hline 142 & -0.1 & 0.30 & 0.0088 & -0.1313 & 1.26 & 0.0134 \\
\hline 117 & 2.0 & 0.54 & 0.0115 & -0.1348 & 1.25 & 0.0140 \\
\hline 118 & 4.2 & 0.77 & 0.0156 & -0.1363 & .1 .25 & 0.0143 \\
\hline 119 & 6.1 & 1.01 & 0.0143 & -0.1352 & $1.25^{\circ}$ & 0.0149 \\
\hline 120 & 8.2 & 1.18 & 0.0189 & -0.1256 & 1.25 & 0.0181 \\
\hline 121 & 10.3 & 1.23 & 0.0269 & -0.1042 & 1.25 & 0.0328 \\
\hline 122 & 11.3 & 1.19 & 0.0422 & -0.1080 & 1.25 & - \\
\hline 123 & 12.1 & 1.27 & 0.0639 & -0.1172 & 1.25 & - \\
\hline 124 & 13.1 & 1.09 & 0.0672 & -0.1065 & 1.25 & - \\
\hline 125 & 14.1 & 1.06 & 0.0740 & -0.1011 & 1.24 & - \\
\hline 126 & 15.2 & 1.06 & 0.0861 & -0.1012 & 1.25 & - \\
\hline 127 & 16.2 & 1.06 & 0.1017 & -0.1036 & 1.25 & - \\
\hline 128 & 17.1 & 1.08 & 0.1167 & -0.1074 & 1.25 & - \\
\hline 129 & 18.1 & 1.09 & 0.1312 & -0.1098 & 1.25 & - \\
\hline 130 & 19.1 & 1.12 & 0.1526 & -0.1168 & 1.24 & - \\
\hline 131 & 20.2 & 1.13 & 0.1744 & -0.1232 & 1.25 & - \\
\hline
\end{tabular}




\begin{tabular}{||c|c|c|c|c|c|c||}
\hline \multicolumn{7}{|c|}{ Table B3. S815, Clean, Re $=1.25 \times 10^{6}$} \\
\hline \hline RUN & AOA & $C_{1}$ & $C_{d p}$ & $C_{\text {m\% }}$ & $\operatorname{Re} \times 10^{-6}$ & $C_{d w}$ \\
\hline 132 & 22.2 & 1.11 & 0.2198 & -0.1383 & 1.24 & - \\
\hline 133 & 24.0 & 1.04 & 0.2852 & -0.1637 & 1.24 & - \\
\hline 134 & 26.1 & 1.26 & 0.4322 & -0.2122 & 1.23 & - \\
\hline 135 & 28.1 & 1.30 & 0.4711 & -0.2180 & 1.23 & - \\
\hline 136 & 30.0 & 1.12 & 0.7014 & -0.2734 & 1.22 & - \\
\hline 137 & 32.0 & 1.18 & 0.8045 & -0.3054 & 1.24 & - \\
\hline 138 & 33.8 & 1.27 & 0.9136 & -0.3401 & 1.24 & - \\
\hline 139 & 35.9 & 1.30 & 0.9936 & -0.3589 & 1.24 & - \\
\hline 140 & 37.9 & 1.35 & 1.0940 & -0.3868 & 1.22 & - \\
\hline 141 & 40.0 & 1.34 & 1.1604 & -0.3951 & 1.20 & - \\
\hline & & & End of Table B3 & & \\
\hline
\end{tabular}




\begin{tabular}{|c|c|c|c|c|c|c|}
\hline \multicolumn{7}{|c|}{ Table B4. S815, Clean, $R e=1.40 \times 10^{6}$} \\
\hline RUN & AOA & $\mathrm{C}_{1}$ & $\mathrm{C}_{\mathrm{dp}}$ & $\mathrm{C}_{\mathrm{m} / 4}$ & $\operatorname{Re} \times 10^{-6}$ & $\mathrm{C}_{\mathrm{dw}}$ \\
\hline 87 & -20.2 & -0.88 & 0.1813 & 0.0111 & 1.41 & - \\
\hline 86 & -18.2 & -1.00 & 0.1810 & 0.0246 & 1.42 & - \\
\hline 85 & -16.2 & -0.98 & 0.1681 & 0.0265 & 1.43 & - \\
\hline 84 & -14.1 & -0.84 & 0.1322 & 0.0074 & 1.41 & - \\
\hline 83 & -12.3 & -0.93 & 0.0494 & -0.0966 & 1.40 & - \\
\hline 82 & -10.3 & -0.77 & 0.0306 & -0.1048 & 1.40 & 0.0147 \\
\hline 81 & -8.2 & -0.66 & 0.0131 & -0.1049 & 1.40 & 0.0143 \\
\hline 80 & -6.2 & -0.44 & 0.0061 & -0.1136 & 1.41 & 0.0153 \\
\hline 79 & -4.2 & -0.19 & 0.0071 & -0.1214 & 1.41 & 0.0158 \\
\hline 78 & -2.0 & 0.07 & 0.0066 & -0.1279 & 1.41 & 0.0145 \\
\hline 77 & -0.1 & 0.30 & 0.0082 & -0.1315 & 1.40 & 0.0141 \\
\hline 88 & -0.1 & 0.28 & 0.0090 & -0.1312 & 1.40 & 0.0132 \\
\hline 104 & -0.1 & 0.27 & 0.0088 & -0.1311 & 1.40 & 0.0142 \\
\hline 89 & 2.0 & 0.53 & 0.0124 & -0.1347 & 1.40 & 0.0135 \\
\hline 90 & 4.2 & 0.77 & 0.0156 & -0.1368 & 1.41 & 0.0144 \\
\hline 91 & 6.1 & 0.99 & 0.0164 & -0.1340 & 1.40 & 0.0131 \\
\hline 92 & 8.2 & 1.17 & 0.0199 & -0.1261 & 1.40 & 0.0194 \\
\hline 93 & 10.2 & 1.23 & 0.0257 & -0.1053 & 1.40 & 0.0292 \\
\hline 94 & 11.1 & 1.20 & 0.0489 & -0.1165 & 1.40 & - \\
\hline 95 & 12.2 & 1.15 & 0.0712 & -0.1209 & 1.41 & - \\
\hline 96 & 13.2 & 1.09 & 0.0649 & -0.1037 & 1.41 & - \\
\hline 97 & 14.2 & 1.09 & 0.0809 & -0.1064 & 1.40 & - \\
\hline 98 & 15.1 & 1.06 & 0.0865 & -0.1012 & 1.40 & - \\
\hline 99 & 16.2 & 1.06 & 0.1016 & -0.1035 & 1.40 & - \\
\hline 100 & 17.0 & 1.09 & 0.1147 & -0.1064 & 1.40 & - \\
\hline 101 & 18.2 & 1.09 & 0.1330 & -0.1100 & 1.40 & - \\
\hline 102 & 19.1 & 1.12 & 0.1545 & -0.1180 & 1.39 & - \\
\hline 103 & 20.0 & 1.11 & 0.1702 & -0.1233 & 1.40 & - \\
\hline
\end{tabular}




\begin{tabular}{|c|c|c|c|c|c|c|}
\hline \multicolumn{7}{|c|}{ Table B5. S815, $\mathrm{k} / \mathrm{c}=0.0019, \mathrm{Re}=0.75 \times 10^{6}$} \\
\hline RUN & $\mathrm{AOA}$ & $\underline{C_{1}}$ & $\mathrm{C}_{\mathrm{dp}}$ & $\mathrm{C}_{\mathrm{m}^{1 / 2}}$ & $\operatorname{Re} \times 10_{-6}$ & $\mathrm{C}_{\mathrm{dw}}$ \\
\hline 265 & -20.0 & -0.60 & 0.2107 & -0.0055 & 0.75 & - \\
\hline 264 & -18.1 & -0.49 & 0.1742 & -0.0219 & 0.75 & - \\
\hline 263 & -16.1 & -0.41 & 0.1536 & -0.0291 & 0.76 & - \\
\hline 262 & -14.0 & -0.32 & 0.1315 & -0.0377 & 0.75 & - \\
\hline 261 & -12.2 & -0.19 & 0.1071 & -0.0517 & 0.75 & - \\
\hline 260 & -10.1 & -0.11 & 0.0902 & -0.0560 & 0.75 & - \\
\hline 259 & -8.2 & -0.05 & 0.0758 & -0.0599 & 0.75 & - \\
\hline 258 & -6.1 & -0.19 & 0.0773 & -0.0355 & 0.75 & - \\
\hline 257 & -4.0 & -0.15 & 0.0526 & -0.0398 & 0.76 & - \\
\hline 256 & -2.2 & 0.00 & 0.0103 & -0.1078 & 0.75 & 0.0192 \\
\hline 255 & -0.1 & 0.20 & 0.0110 & -0.1109 & 0.75 & 0.0192 \\
\hline 266 & -0.1 & 0.20 & 0.0114 & -0.1108 & 0.75 & 0.0190 \\
\hline 292 & -0.1 & 0.21 & 0.0127 & -0.1119 & 0.75 & 0.0201 \\
\hline 267 & 2.0 & 0.43 & 0.0129 & -0.1125 & 0.75 & 0.0188 \\
\hline 268 & 4.0 & 0.63 & 0.0130 & -0.1086 & 0.75 & 0.0204 \\
\hline 269 & 6.1 & 0.80 & 0.0164 & -0.1016 & 0.74 & 0.0233 \\
\hline 270 & 8.2 & 0.91 & 0.0254 & -0.0937 & 0.75 & 0.0361 \\
\hline 271 & 10.2 & 0.85 & 0.0459 & -0.0936 & 0.75 & - \\
\hline 272 & 11.2 & 0.83 & 0.0572 & -0.0937 & 0.74 & - \\
\hline 273 & 12.1 & 0.85 & 0.0686 & -0.0962 & 0.75 & - \\
\hline 274 & 13.0 & 0.87 & 0.0848 & -0.1006 & 0.75 & - \\
\hline 275 & 14.1 & 0.86 & 0.0953 & -0.1013 & 0.75 & - \\
\hline 276 & 15.1 & 0.90 & 0.1154 & -0.1081 & 0.75 & - \\
\hline 277 & 16.2 & 0.92 & 0.1373 & -0.1160 & 0.76 & - \\
\hline 278 & 17.1 & 0.88 & 0.1536 & -0.1215 & 0.76 & - \\
\hline 279 & 18.1 & 0.86 & 0.1767 & -0.1288 & 0.75 & - \\
\hline 280 & 19.1 & 0.80 & 0.2155 & -0.1424 & 0.76 & - \\
\hline 281 & 20.1 & 0.80 & 0.2513 & -0.1539 & 0.76 & - \\
\hline
\end{tabular}




\begin{tabular}{|c|c|c|c|c|c|c|}
\hline \multicolumn{7}{|c|}{ Table B5. s815, $\mathrm{k} / \mathrm{c}=0.0019, \mathrm{Re}=0.75 \times 10^{6}$} \\
\hline RUN & $\mathrm{AOA}$ & $\mathrm{C}_{1}$ & $\mathrm{C}_{\mathrm{dp}}$ & $\mathrm{C}_{\mathrm{m} / \mathrm{k}}$ & $\operatorname{Re} \times 10_{-6}$ & $\mathrm{C}_{\mathrm{dw}}$ \\
\hline 282 & 22.2 & 0.88 & 0.3201 & -0.1762 & 0.76 & - \\
\hline 283 & 24.0 & 0.96 & 0.3996 & -0.2041 & 0.76 & - \\
\hline 284 & 26.1 & 0.99 & 0.4759 & -0.2234 & 0.75 & - \\
\hline 285 & 28.0 & 1.06 & 0.5638 & -0.2494 & 0.74 & - \\
\hline 286 & 30.1 & 1.11 & 0.6521 & -0.2686 & 0.74 & - \\
\hline 287 & 32.1 & 1.19 & 0.7616 & -0.2989 & 0.75 & - \\
\hline 288 & 33.9 & 1.26 & 0.8682 & -0.3286 & 0.74 & - \\
\hline 289 & 36.0 & 1.30 & 0.9661 & -0.3550 & 0.73 & - \\
\hline 290 & 38.0 & 1.33 & 1.0559 & -0.3762 & 0.73 & - \\
\hline 291 & 40.0 & 1.34 & 1.1270 & -0.3906 & 0.74 & - \\
\hline \multicolumn{7}{|c|}{ End of Table B5 } \\
\hline
\end{tabular}




\begin{tabular}{|c|c|c|c|c|c|c|}
\hline \multicolumn{7}{|c|}{ Table B6. S815, k/c $=0.0019, \mathrm{Re}=1.00 \times 10^{6}$} \\
\hline RUN & $\mathrm{AOA}$ & $\mathrm{C}_{1}$ & $C_{d p}$ & $C_{\text {m/ }}$ & $\operatorname{Re} \times 10_{-6}$ & $C_{d w}$ \\
\hline 303 & -20.0 & -0.57 & 0.2064 & -0.0117 & 0.99 & - \\
\hline 302 & -17.9 & -0.50 & 0.1783 & -0.0204 & 1.00 & - \\
\hline 301 & -16.1 & -0.39 & 0.1498 & -0.0338 & 1.00 & - \\
\hline 300 & -14.3 & -0.28 & 0.1256 & -0.0460 & 1.00 & - \\
\hline 299 & -12.2 & -0.18 & 0.1061 & -0.0546 & 1.00 & - \\
\hline 298 & -10.0 & -0.09 & 0.0913 & -0.0564 & 1.00 & - \\
\hline 297 & -8.2 & -0.01 & 0.0781 & -0.0625 & 1.00 & - \\
\hline 296 & -6.1 & 0.06 & 0.0645 & -0.0626 & 1.00 & - \\
\hline 295 & -4.0 & -0.07 & 0.0610 & -0.0429 & 1.00 & - \\
\hline 294 & -2.2 & 0.00 & 0.0365 & -0.0584 & 1.01 & - \\
\hline 293 & -0.1 & 0.20 & 0.0114 & -0.1107 & 1.01 & 0.0192 \\
\hline 304 & -0.1 & 0.21 & 0.0118 & -0.1113 & 1.00 & 0.0216 \\
\hline 330 & -0.1 & 0.21 & 0.0108 & -0.1103 & 1.00 & 0.0202 \\
\hline 305 & 2.0 & 0.43 & 0.0118 & -0.1140 & 1.00 & 0.0186 \\
\hline 306 & 4.2 & 0.63 & 0.0162 & -0.1099 & 1.00 & 0.0207 \\
\hline 307 & 6.1 & 0.81 & 0.0180 & -0.1045 & 1.00 & 0.0242 \\
\hline 308 & 8.2 & 0.92 & 0.0263 & -0.0941 & 1.00 & 0.0357 \\
\hline 309 & 10.3 & 0.84 & 0.0527 & -0.0971 & 1.00 & - \\
\hline 310 & 11.0 & 0.84 & 0.0610 & -0.0972 & 1.00 & - \\
\hline 311 & 12.1 & 0.83 & 0.0747 & -0.0992 & 1.00 & - \\
\hline 312 & 13.1 & 0.85 & 0.0895 & -0.1022 & 1.00 & - \\
\hline 313 & 14.2 & 0.90 & 0.1117 & -0.1110 & 0.99 & - \\
\hline 314 & 15.2 & 0.89 & 0.1252 & -0.1131 & 0.99 & - \\
\hline 315 & 16.0 & 0.89 & 0.1387 & -0.1156 & 0.99 & - \\
\hline 316 & 17.1 & 0.94 & 0.1680 & -0.1284 & 0.99 & - \\
\hline 317 & 18.1 & 0.89 & 0.1891 & -0.1329 & 0.99 & - \\
\hline 318 & 19.1 & 0.83 & 0.2200 & -0.1440 & 1.00 & - \\
\hline 319 & 20.1 & 0.83 & 0.2531 & -0.1540 & 1.00 & - \\
\hline
\end{tabular}




\begin{tabular}{|c|c|c|c|c|c|c||}
\hline \multicolumn{7}{|c|}{ Table B6. S815, k/c $=0.0019, \mathrm{Re}=1.00 \times 10^{6}$} \\
\hline \hline RUN & AOA & $\mathrm{C}_{1}$ & $\mathrm{C}_{\mathrm{dp}}$ & $\mathrm{C}_{\mathrm{m} / \mathrm{k}}$ & $\operatorname{Re} \times 10_{-6}$ & $\mathrm{C}_{\mathrm{dw}}$ \\
\hline 320 & 22.2 & 0.90 & 0.3277 & -0.1804 & 0.99 & - \\
\hline 321 & 24.0 & 0.95 & 0.4041 & -0.2061 & 0.99 & - \\
\hline 322 & 26.0 & 0.99 & 0.4848 & -0.2267 & 1.00 & - \\
\hline 323 & 28.0 & 1.05 & 0.5665 & -0.2488 & 1.00 & - \\
\hline 324 & 30.1 & 1.11 & 0.6581 & -0.2726 & 0.99 & - \\
\hline 325 & 32.1 & 1.20 & 0.7801 & -0.3074 & 0.99 & - \\
\hline 326 & 33.9 & 1.27 & 0.8787 & -0.3345 & 0.99 & - \\
\hline 327 & 36.0 & 1.31 & 0.9792 & -0.3612 & 0.97 & - \\
\hline 328 & 38.0 & 1.32 & 1.0520 & -0.3758 & 0.97 & - \\
\hline 329 & 40.0 & 1.35 & 1.1430 & -0.3998 & 0.98 & - \\
\hline & & & \multicolumn{7}{|c|}{ End of Table B6 } & & \\
\hline
\end{tabular}




\begin{tabular}{|c|c|c|c|c|c|c|}
\hline RUN & AOA & $\mathrm{C}_{1}$ & $\mathrm{C}_{\mathrm{dp}}$ & $\mathrm{C}_{\mathrm{m}^{1 / 4}}$ & $\operatorname{Re} \times 10_{-6}$ & $\mathrm{C}_{\mathrm{dw}}$ \\
\hline 369 & -20.1 & -0.60 & 0.2032 & -0.0096 & 1.24 & - \\
\hline 368 & -18.2 & -0.50 & 0.1729 & -0.0246 & 1.24 & - \\
\hline 367 & -16.1 & -0.40 & 0.1443 & -0.0377 & 1.24 & - \\
\hline 366 & -14.3 & -0.28 & 0.1223 & -0.0488 & 1.25 & - \\
\hline 365 & -12.2 & -0.18 & 0.1040 & -0.0560 & 1.25 & - \\
\hline 364 & -10.1 & -0.08 & 0.0885 & -0.0603 & 1.25 & - \\
\hline 363 & -8.2 & -0.02 & 0.0790 & -0.0610 & 1.26 & - \\
\hline 362 & -6.1 & 0.08 & 0.0637 & -0.0677 & 1.25 & - \\
\hline 361 & -4.3 & -0.01 & 0.0678 & -0.0364 & 1.25 & - \\
\hline 360 & -2.2 & 0.03 & 0.0481 & -0.0474 & 1.25 & - \\
\hline 359 & -0.1 & 0.20 & 0.0124 & -0.1071 & 1.25 & 0.0211 \\
\hline 370 & -0.1 & 0.17 & 0.0135 & -0.1054 & 1.26 & 0.0205 \\
\hline 396 & -0.1 & 0.17 & 0.0132 & -0.1048 & 1.25 & 0.0228 \\
\hline 371 & 2.0 & 0.42 & 0.0149 & -0.1164 & 1.25 & 0.0191 \\
\hline 372 & 4.2 & 0.63 & 0.0188 & -0.1152 & 1.25 & 0.0190 \\
\hline 373 & 6.1 & 0.81 & 0.0204 & -0.1092 & 1.25 & 0.0231 \\
\hline 374 & 8.2 & 0.93 & 0.0303 & -0.1008 & 1.26 & 0.0322 \\
\hline 375 & 10.3 & 0.93 & 0.0674 & -0.1149 & 1.25 & - \\
\hline 376 & 11.0 & 0.85 & 0.0694 & -0.1074 & 1.25 & - \\
\hline 377 & 12.1 & 0.82 & 0.0782 & -0.1036 & 1.26 & - \\
\hline 378 & 13.1 & 0.90 & 0.1048 & -0.1157 & 1.26 & - \\
\hline 379 & 14.1 & 0.90 & 0.1162 & -0.1154 & 1.26 & - \\
\hline 380 & 15.2 & 0.88 & 0.1252 & -0.1139 & 1.25 & - \\
\hline 381 & 16.1 & 0.91 & 0.1432 & -0.1204 & 1.25 & - \\
\hline 382 & 17.1 & 0.88 & 0.1607 & -0.1250 & 1.25 & - \\
\hline 383 & 18.2 & 0.90 & 0.1869 & -0.1323 & 1.26 & - \\
\hline 384 & 19.2 & 0.83 & 0.2227 & -0.1458 & 1.25 & - \\
\hline 385 & 20.2 & 0.84 & 0.2546 & -0.1553 & 1.26 & - \\
\hline
\end{tabular}




\begin{tabular}{||c|c|c|c|c|c|c||}
\hline \multicolumn{7}{|c|}{ Table B7. S815, k/c $=0.0019, \mathrm{Re}=1.25 \times 10^{6}$} \\
\hline \hline RUN & AOA & $\mathrm{C}_{1}$ & $\mathrm{C}_{\mathrm{dp}}$ & $\mathrm{C}_{\mathrm{m} / \mathrm{k}}$ & $\operatorname{Re} \times 10_{-6}$ & $\mathrm{C}_{\mathrm{dw}}$ \\
\hline 386 & 22.0 & 0.88 & 0.3203 & -0.1769 & 1.26 & - \\
\hline 387 & 24.0 & 0.91 & 0.4003 & -0.1995 & 1.25 & - \\
\hline 388 & 26.1 & 0.98 & 0.4825 & -0.2218 & 1.24 & - \\
\hline 389 & 28.0 & 1.02 & 0.5806 & -0.2462 & 1.24 & - \\
\hline 390 & 30.1 & 1.11 & 0.6823 & -0.2754 & 1.23 & - \\
\hline 391 & 32.1 & 1.19 & 0.7827 & -0.3031 & 1.24 & - \\
\hline 392 & 33.9 & 1.24 & 0.8693 & -0.3267 & 1.22 & - \\
\hline 393 & 36.0 & 1.31 & 0.9814 & -0.3595 & 1.19 & - \\
\hline 394 & 37.9 & 1.33 & 1.0600 & -0.3765 & 1.18 & - \\
\hline 395 & 39.9 & 1.34 & 1.1346 & -0.3919 & 1.16 & - \\
\hline & & & \multicolumn{6}{|c|}{ End of Table B7 } & & \\
\hline
\end{tabular}




\begin{tabular}{|c|c|c|c|c|c|c|}
\hline \multicolumn{7}{|c|}{ Table B8. S815, k/c $=0.0019, R e=1.4 \times 10^{6}$} \\
\hline RUN & AOA & $\mathrm{C}_{1}$ & $\mathrm{C}_{\mathrm{dp}}$ & $\mathrm{C}_{\mathrm{m} / \mathrm{k}}$ & $\operatorname{Re} \times 10^{-6}$ & $\mathrm{C}_{\mathrm{dw}}$ \\
\hline 341 & -20.3 & -0.61 & 0.2052 & -0.0092 & 1.39 & - \\
\hline 340 & -18.2 & -0.51 & 0.1748 & -0.0216 & 1.40 & - \\
\hline 339 & -16.1 & -0.39 & 0.1440 & -0.0373 & 1.41 & - \\
\hline 338 & -14.3 & -0.28 & 0.1233 & -0.0483 & 1.41 & - \\
\hline 337 & -12.2 & -0.18 & 0.1064 & -0.0548 & 1.41 & - \\
\hline 336 & -10.0 & -0.09 & 0.0917 & -0.0573 & 1.42 & - \\
\hline 335 & -8.2 & -0.02 & 0.0806 & -0.0598 & 1.40 & - \\
\hline 334 & -6.1 & 0.09 & 0.0647 & -0.0667 & 1.41 & - \\
\hline 333 & -4.0 & 0.00 & 0.0678 & -0.0358 & 1.40 & - \\
\hline 332 & -2.2 & 0.06 & 0.0466 & -0.0530 & 1.41 & - \\
\hline 331 & -0.1 & 0.17 & 0.0136 & -0.1053 & 1.40 & 0.0224 \\
\hline 342 & -0.1 & 0.18 & 0.0133 & -0.1054 & 1.41 & 0.0232 \\
\hline 358 & -0.1 & 0.17 & 0.0137 & -0.1042 & 1.39 & 0.0219 \\
\hline 343 & 2.0 & 0.43 & 0.0145 & -0.1152 & 1.40 & 0.0199 \\
\hline 344 & 4.2 & 0.64 & 0.0178 & -0.1165 & 1.40 & 0.0208 \\
\hline 345 & 6.1 & 0.82 & 0.0205 & -0.1101 & 1.40 & 0.0244 \\
\hline 346 & 8.2 & 0.94 & 0.0306 & -0.1023 & 1.40 & 0.0323 \\
\hline 347 & 10.2 & 0.95 & 0.0706 & -0.1206 & 1.41 & - \\
\hline 348 & 11.2 & 0.84 & 0.0716 & -0.1084 & 1.41 & - \\
\hline 349 & 12.1 & 0.82 & 0.0795 & -0.1057 & 1.40 & - \\
\hline 350 & 13.1 & 0.86 & 0.0973 & -0.1109 & 1.40 & - \\
\hline 351 & 14.1 & 0.89 & 0.1125 & -0.1143 & 1.40 & - \\
\hline 352 & 15.2 & 0.90 & 0.1300 & -0.1173 & 1.41 & - \\
\hline 353 & 16.1 & 0.91 & 0.1451 & -0.1222 & 1.40 & - \\
\hline 354 & 17.1 & 0.93 & 0.1660 & -0.1280 & 1.40 & - \\
\hline 355 & 18.1 & 0.98 & 0.1925 & -0.1362 & 1.40 & - \\
\hline 356 & 19.1 & 0.79 & 0.2286 & -0.1492 & 1.40 & - \\
\hline 357 & 20.2 & 0.80 & 0.2641 & -0.1599 & 1.40 & - \\
\hline \multicolumn{7}{|c|}{ End of Table B8 } \\
\hline
\end{tabular}




\section{S815}

Pressure Distributions, Steady State, $R e=0.75$ million 

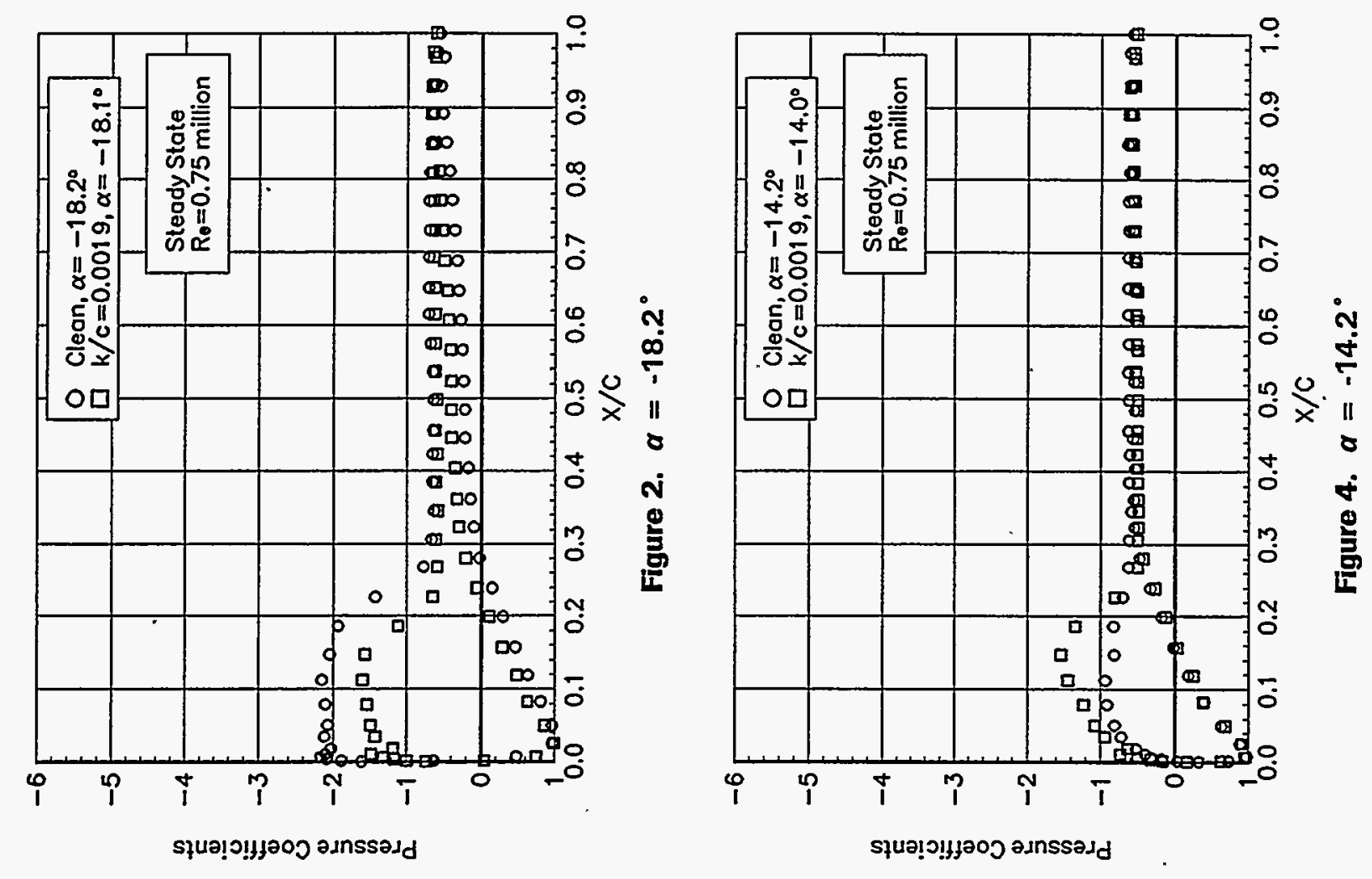

๓े
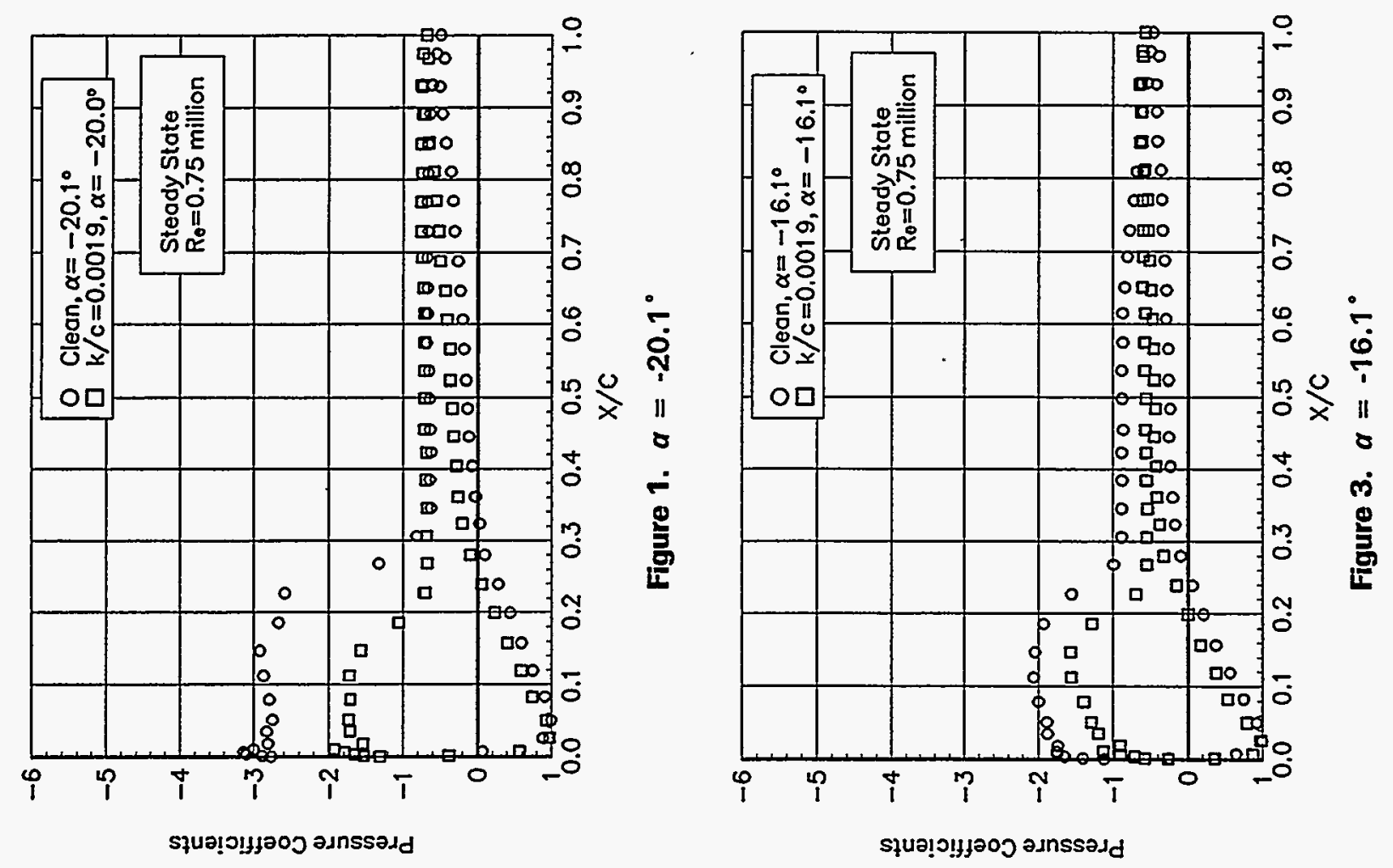


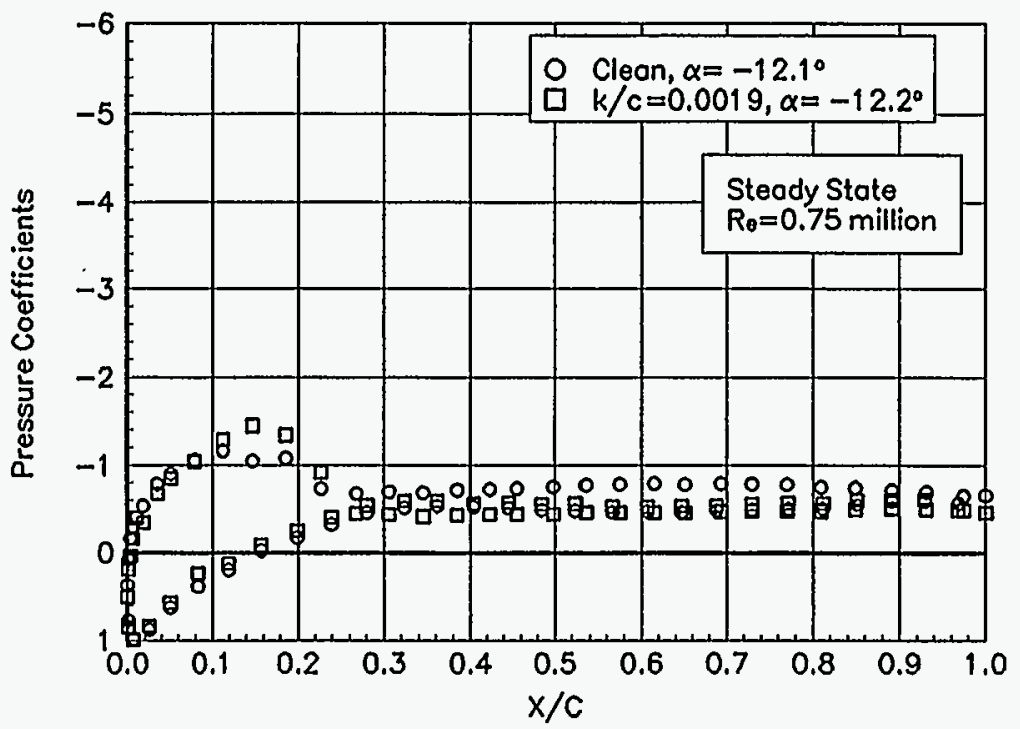

Figure 5. $a=-12.1^{\circ}$

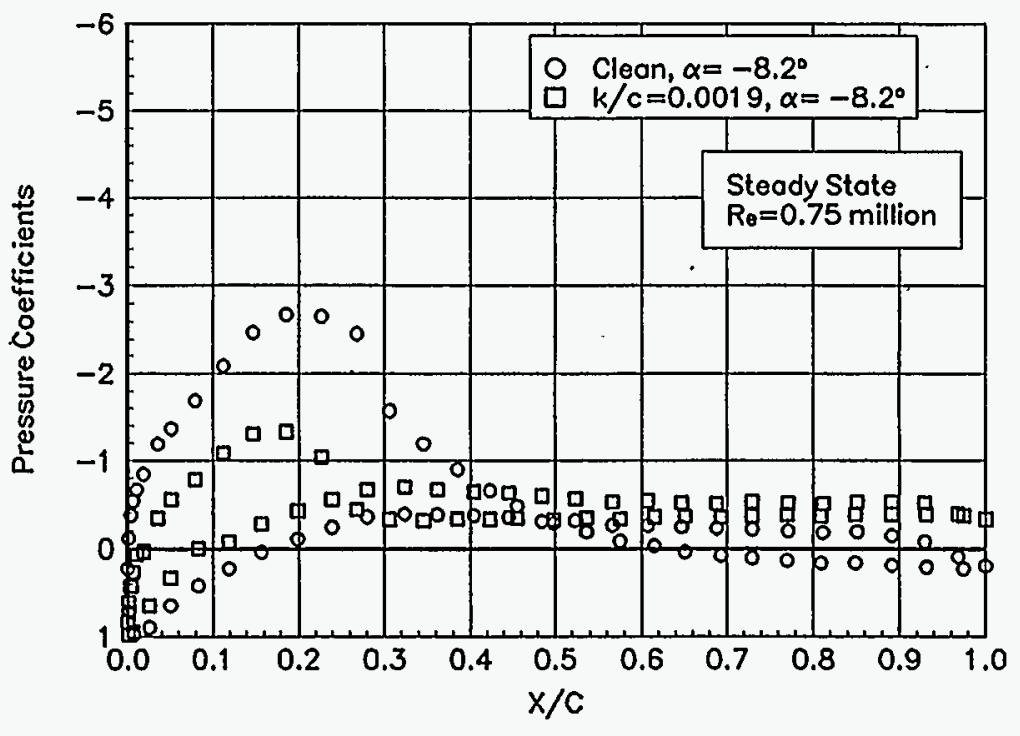

Figure 7. $\alpha=-8.2^{\circ}$

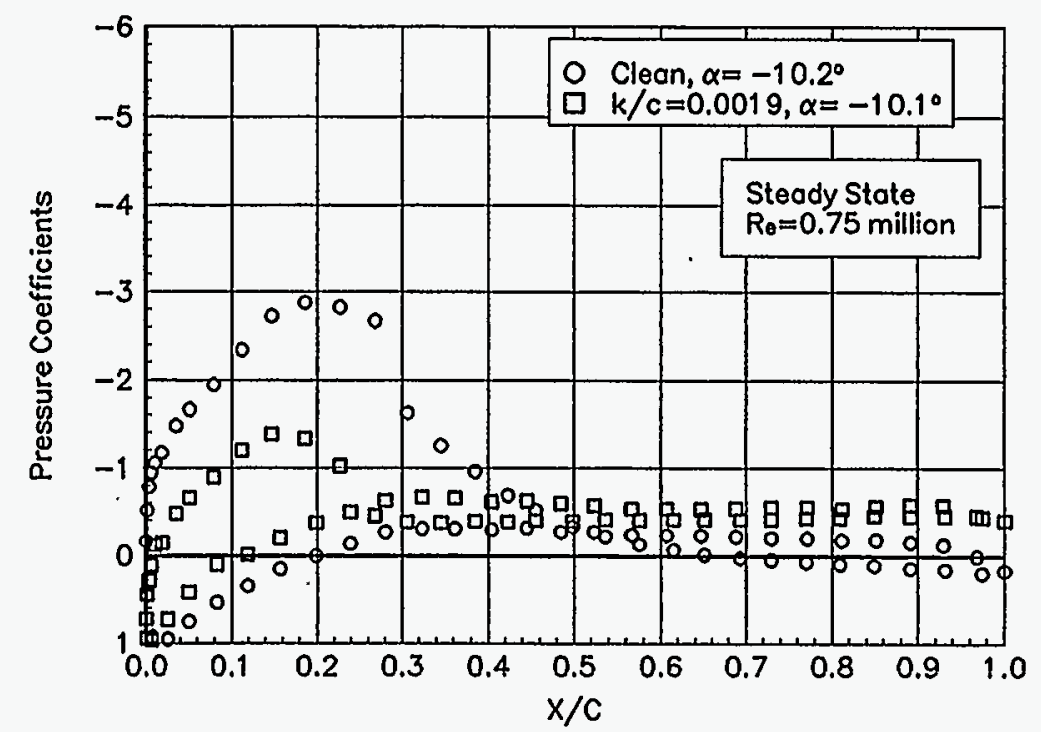

Figure 6. $a=-10.2^{\circ}$

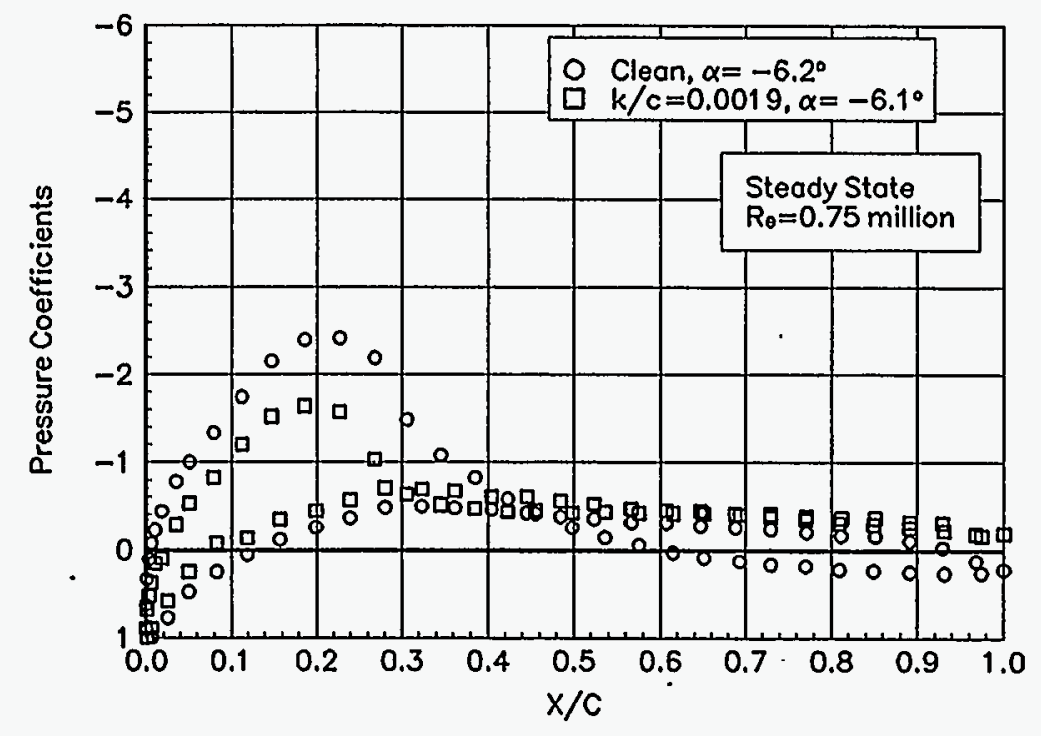

Figure 8. $a=-6.2^{\circ}$ 

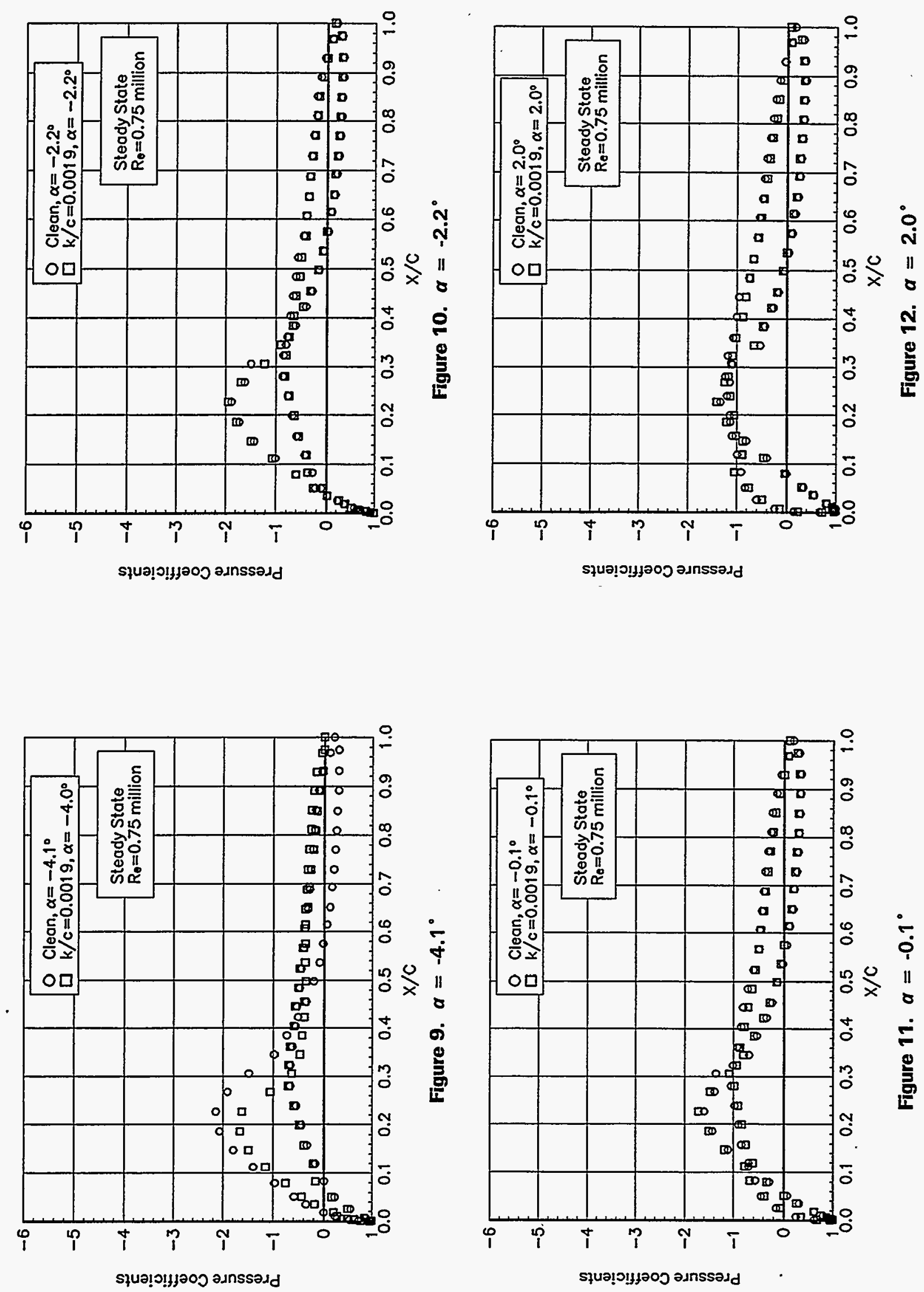
Pressure Coefficients

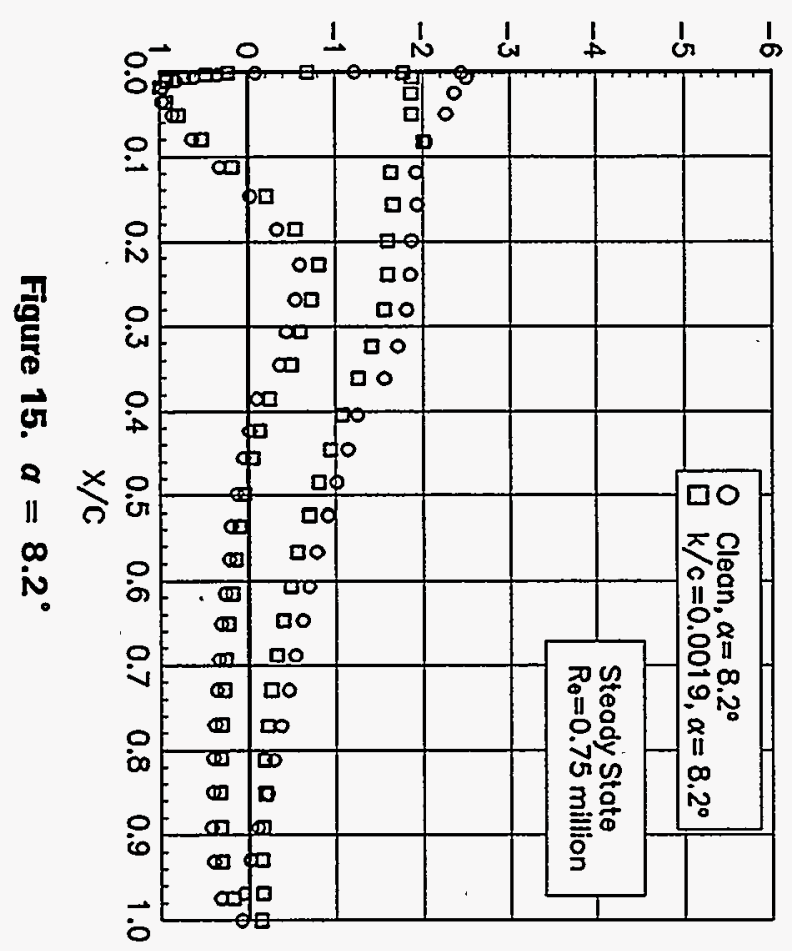

$\mathbb{1}$
$\mathbb{A}$
Pressure Coefficients

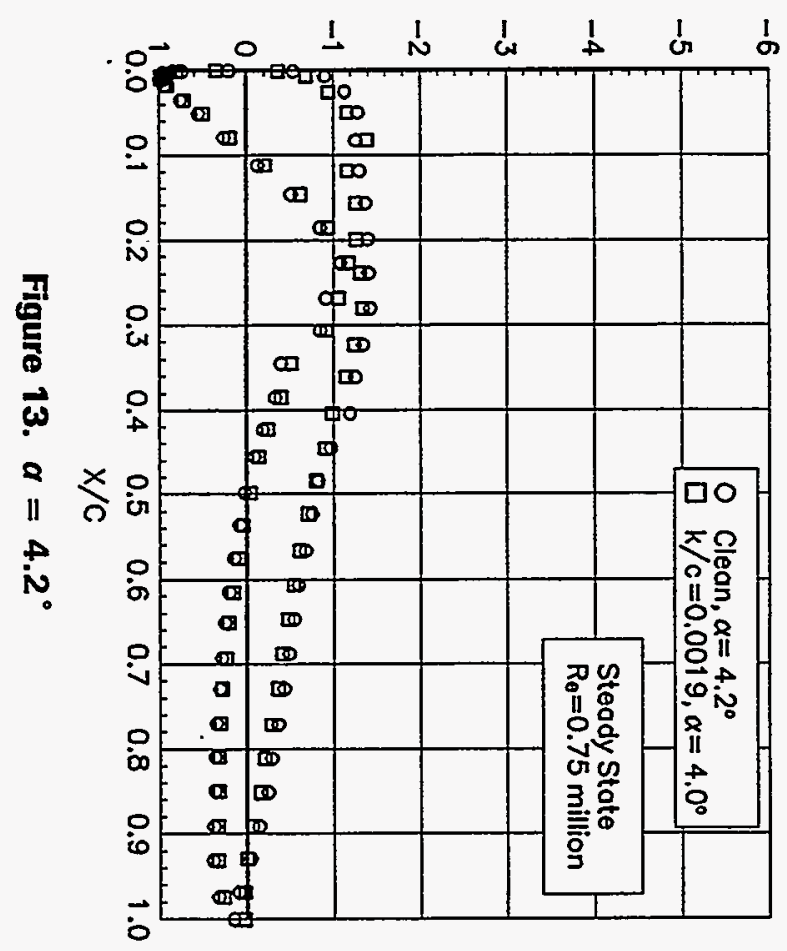

Pressure Coefficients

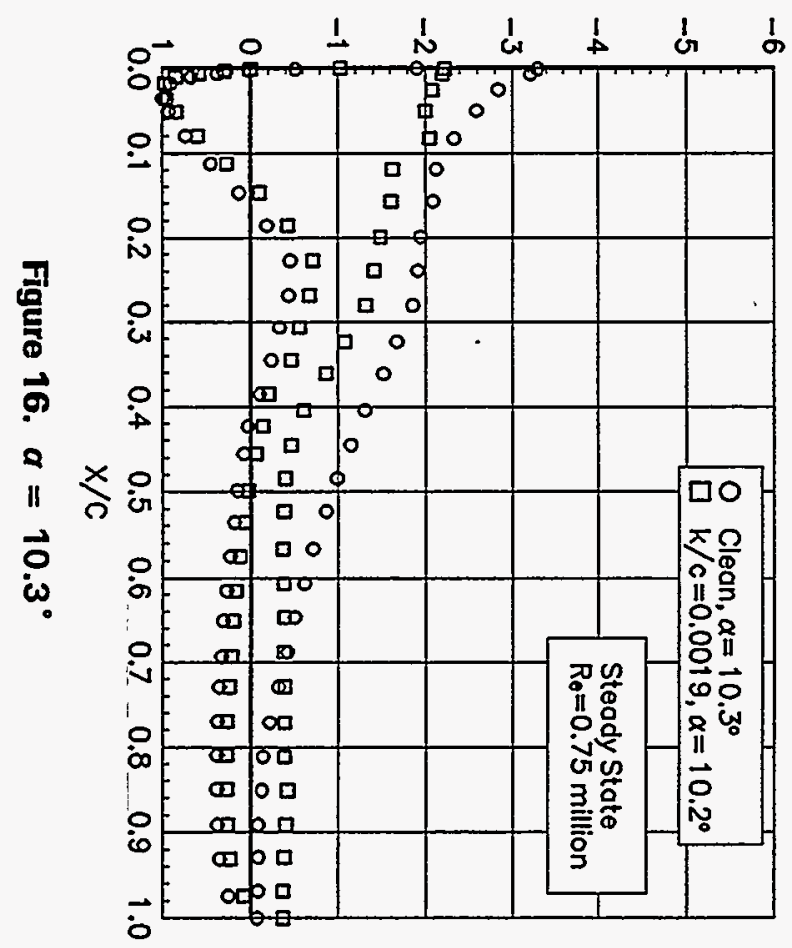

Pressure Coefficients

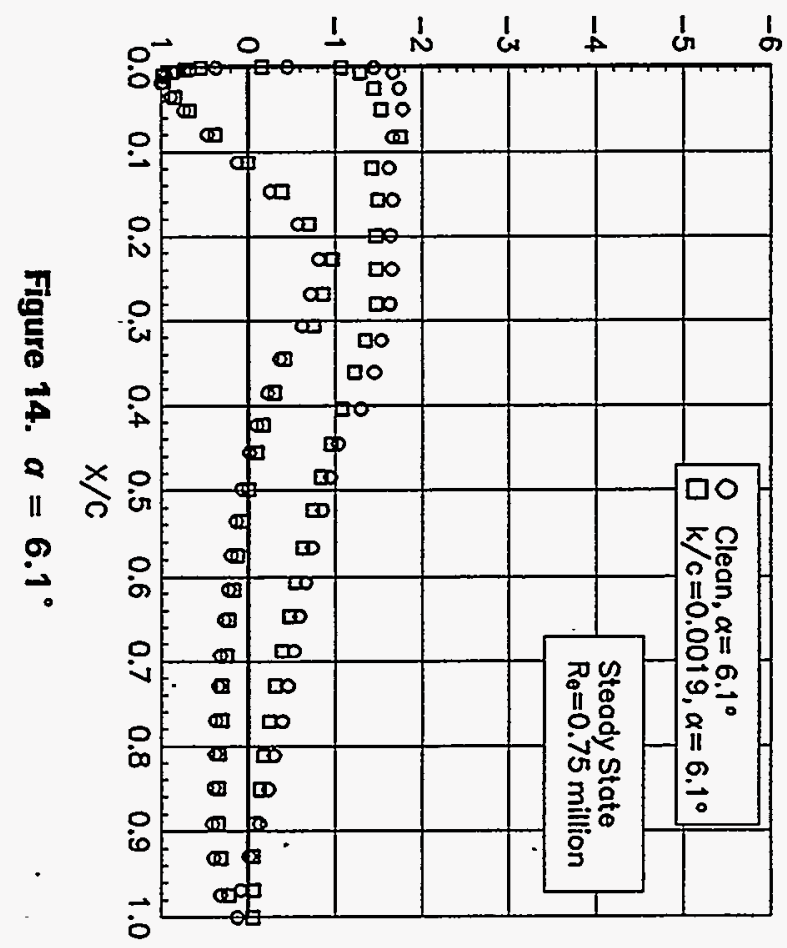




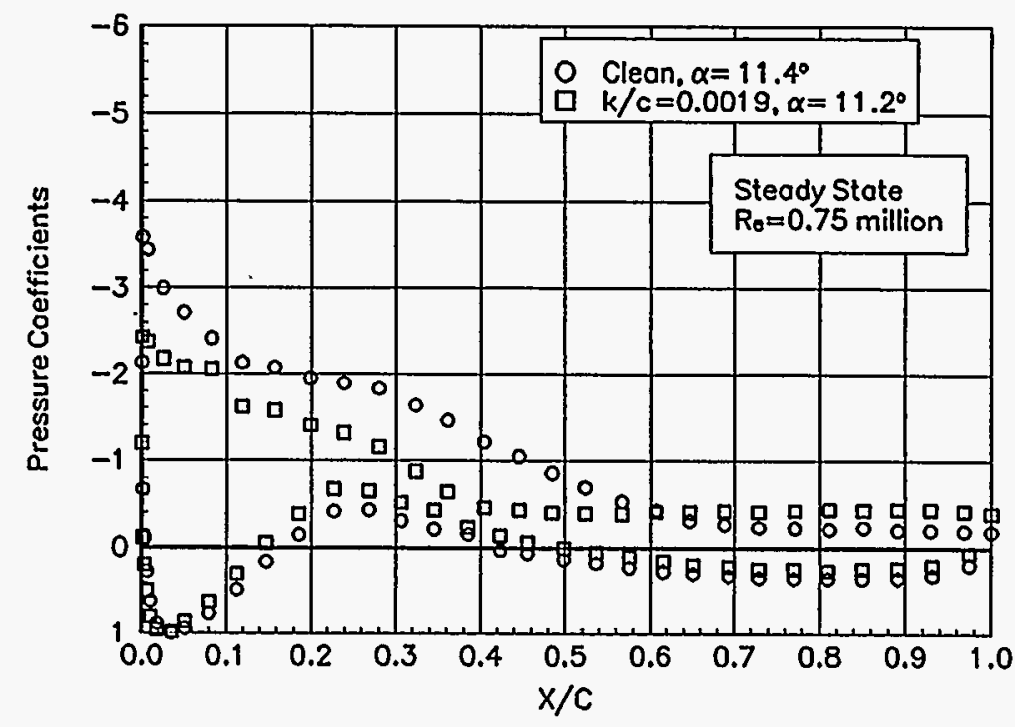

Figure 17. $a=11.4^{\circ}$

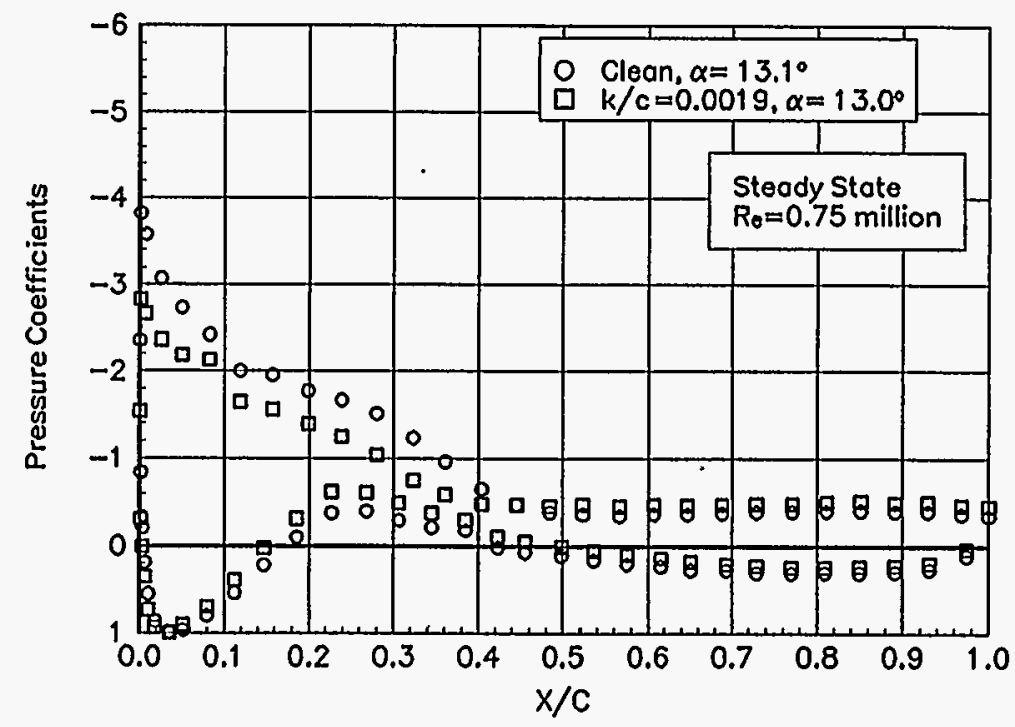

Figure 19. $a=13.1^{\circ}$

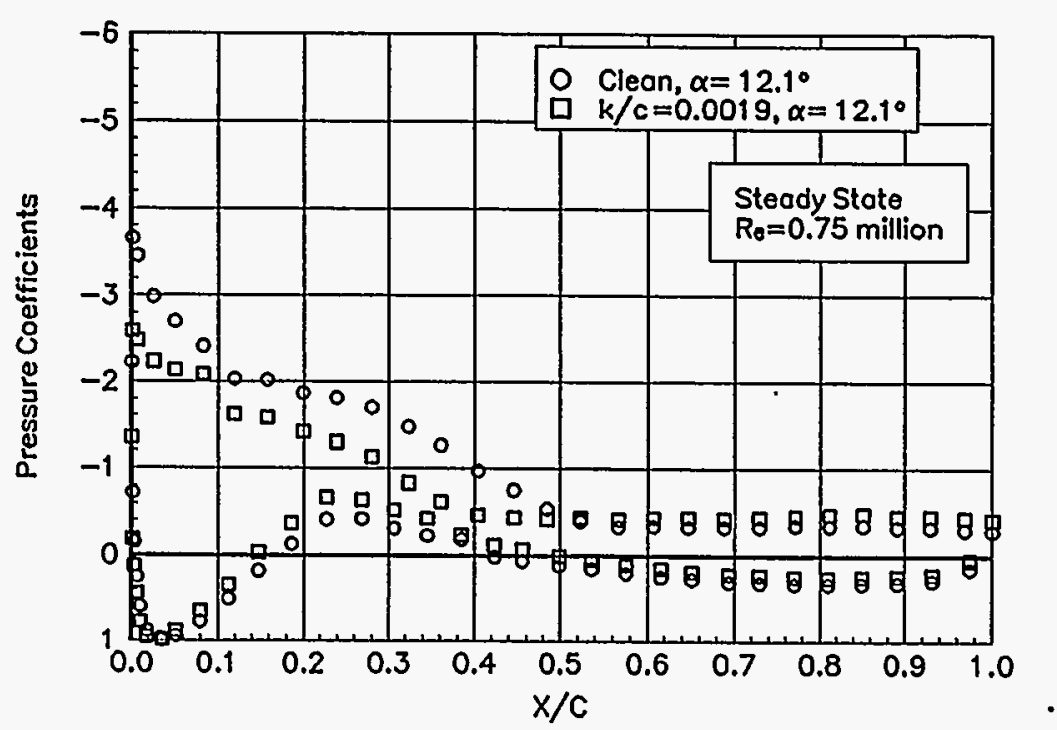

Figure 18. $a=12.1^{\circ}$

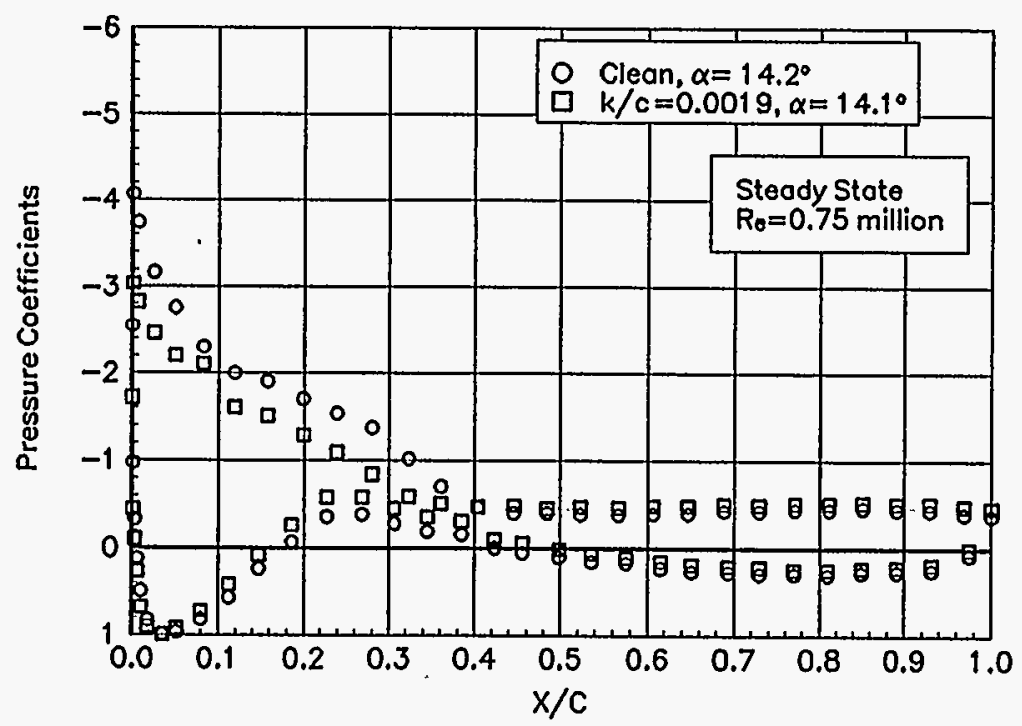

Figure 20. $a=14.2^{\circ}$ 


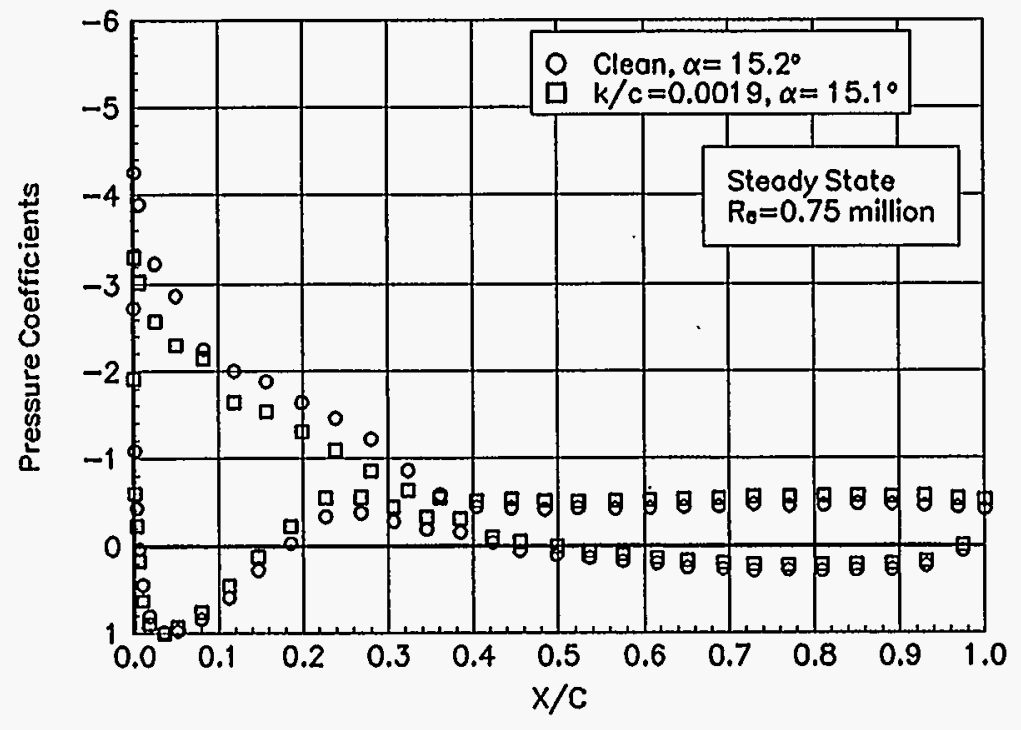

Figure 21. $a=15.2^{\circ}$

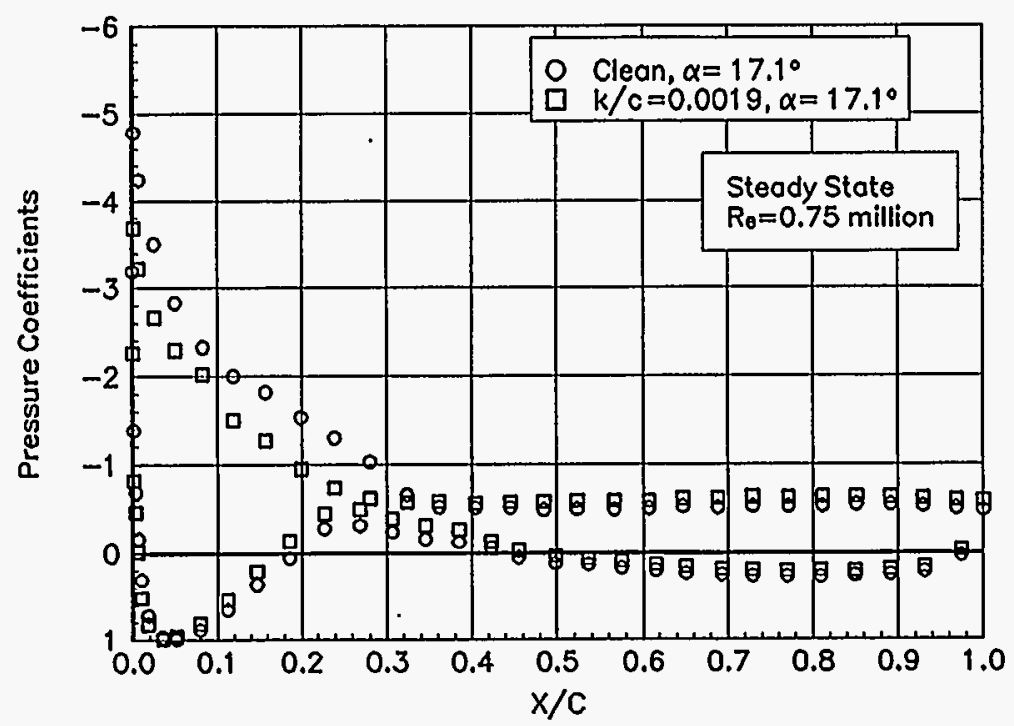

Figure 23. $a=17.1^{\circ}$

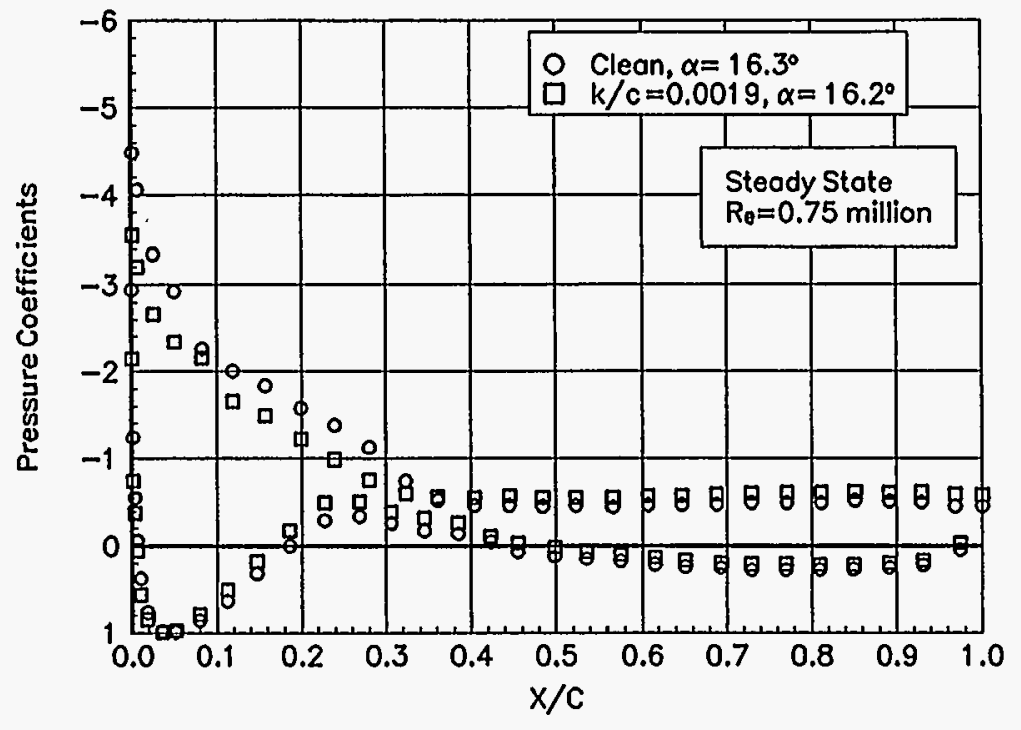

Figure 22. $a=16.3^{\circ}$

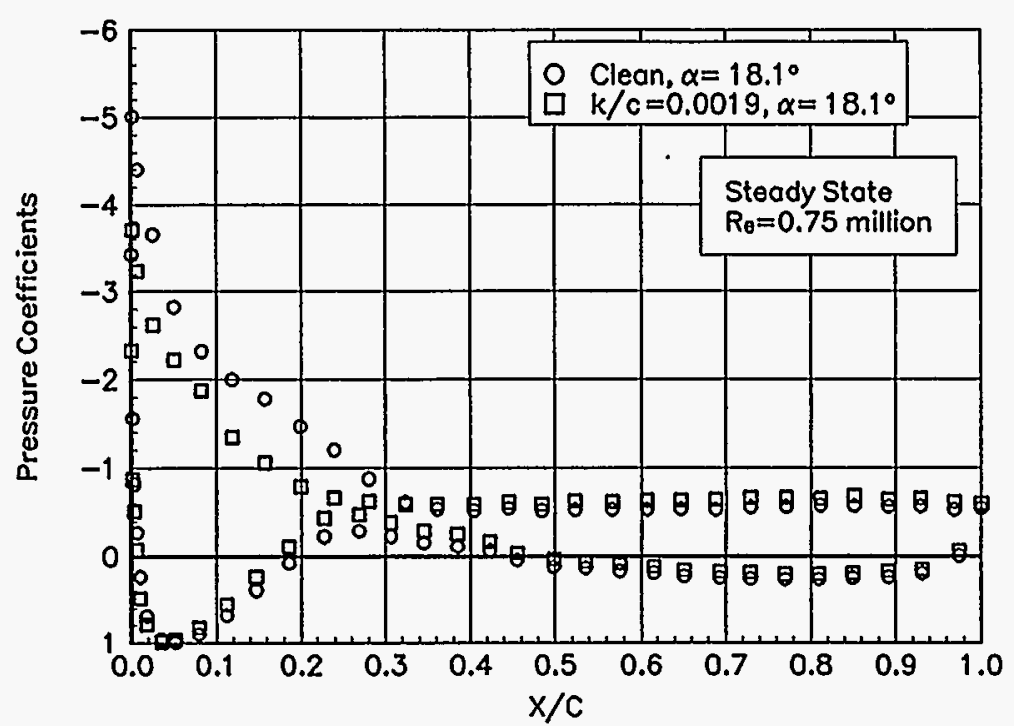

Figure 24. $a=18.1^{\circ}$ 

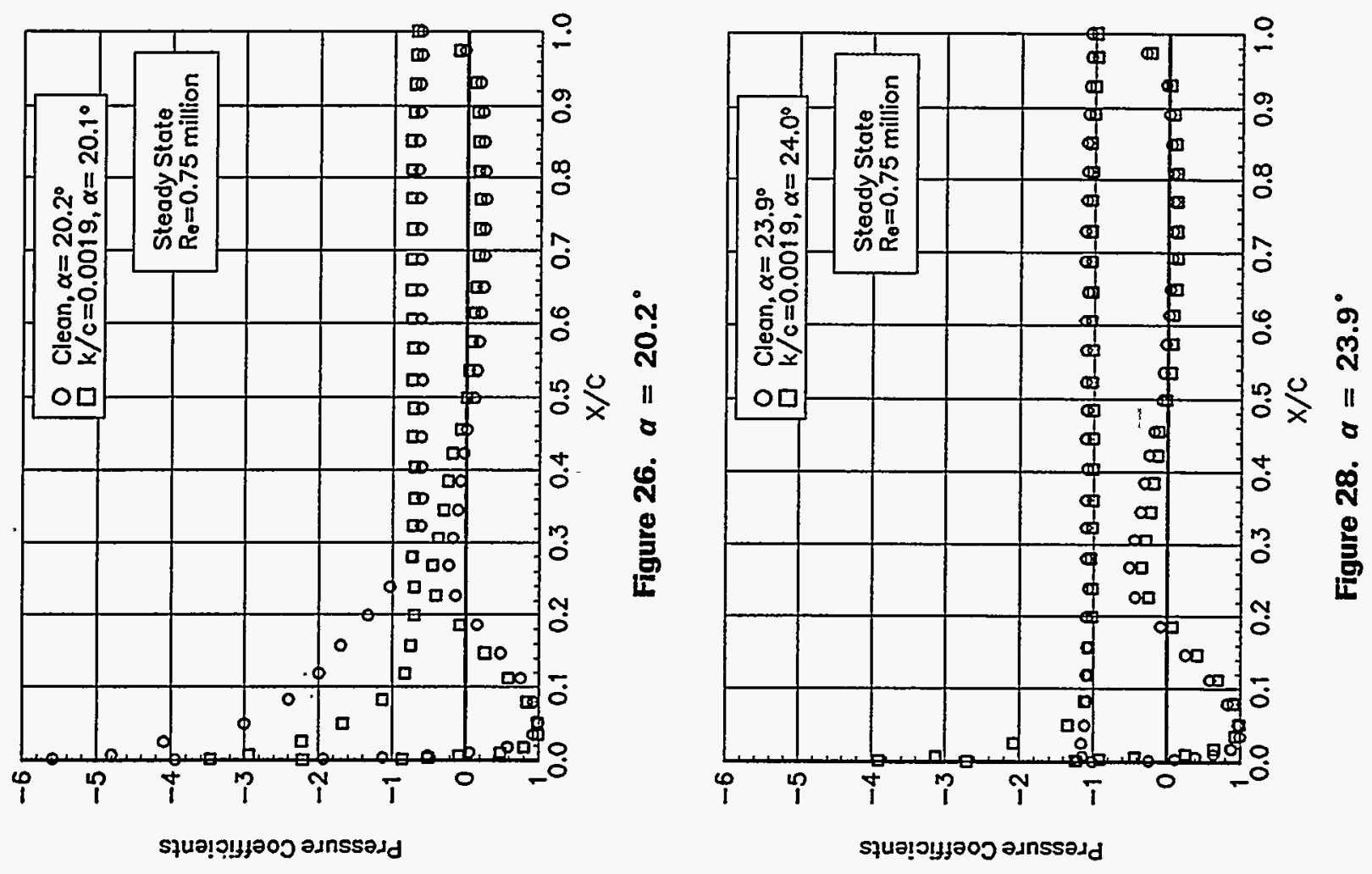

กิ
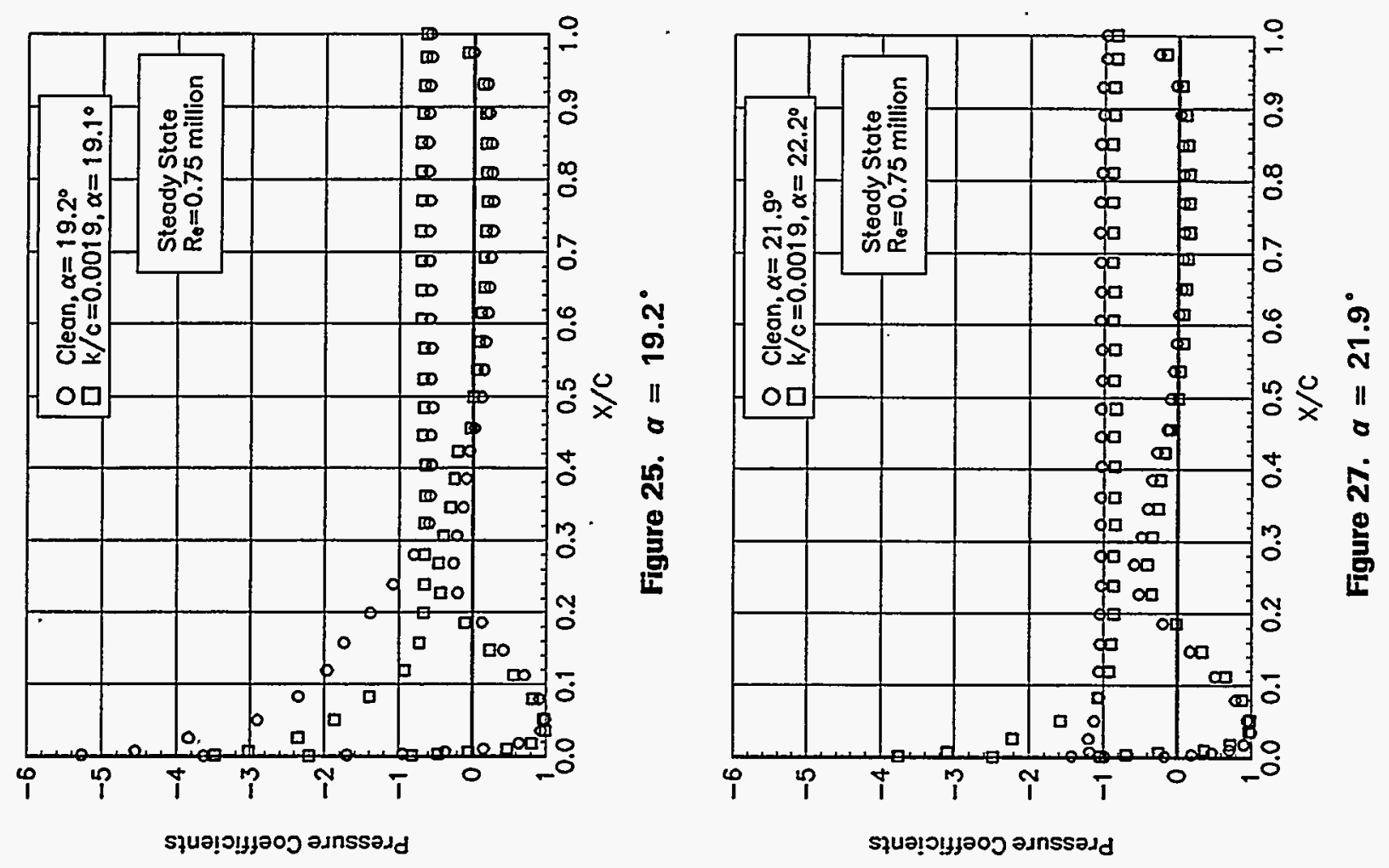


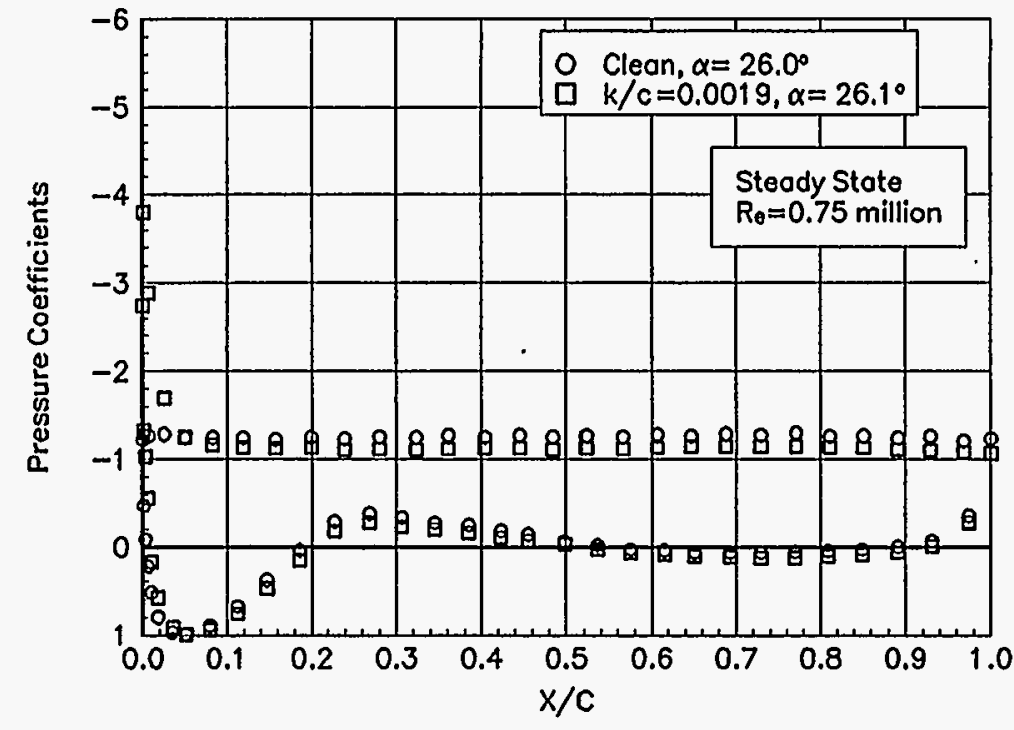

Figure 29. $a=26.0^{\circ}$

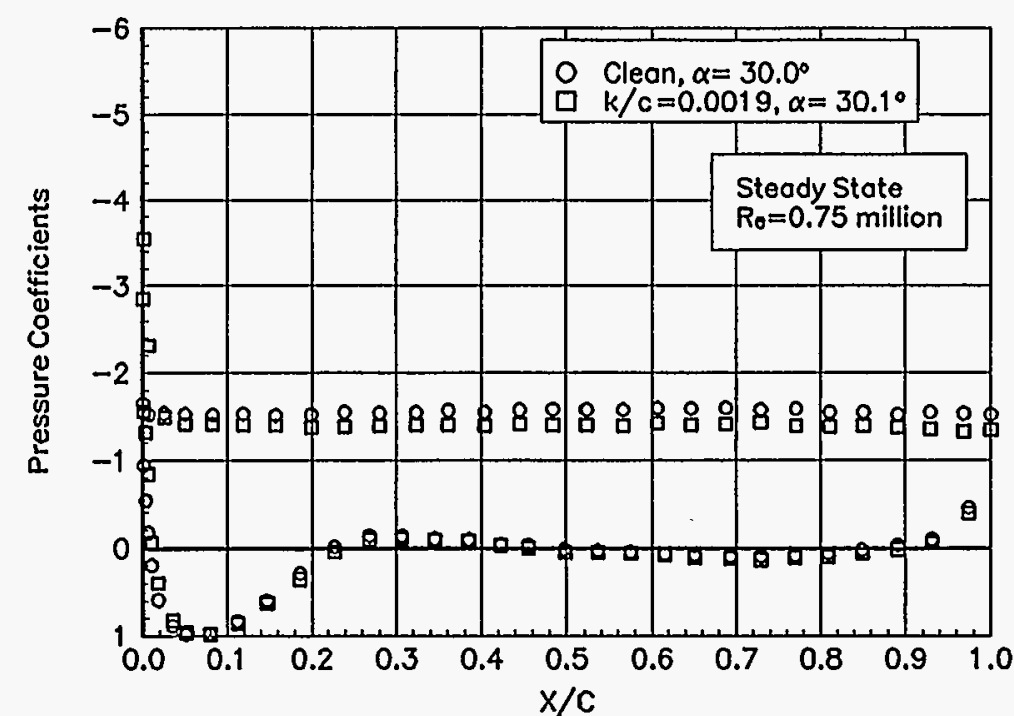

Figure 31. $a=30.0^{\circ}$

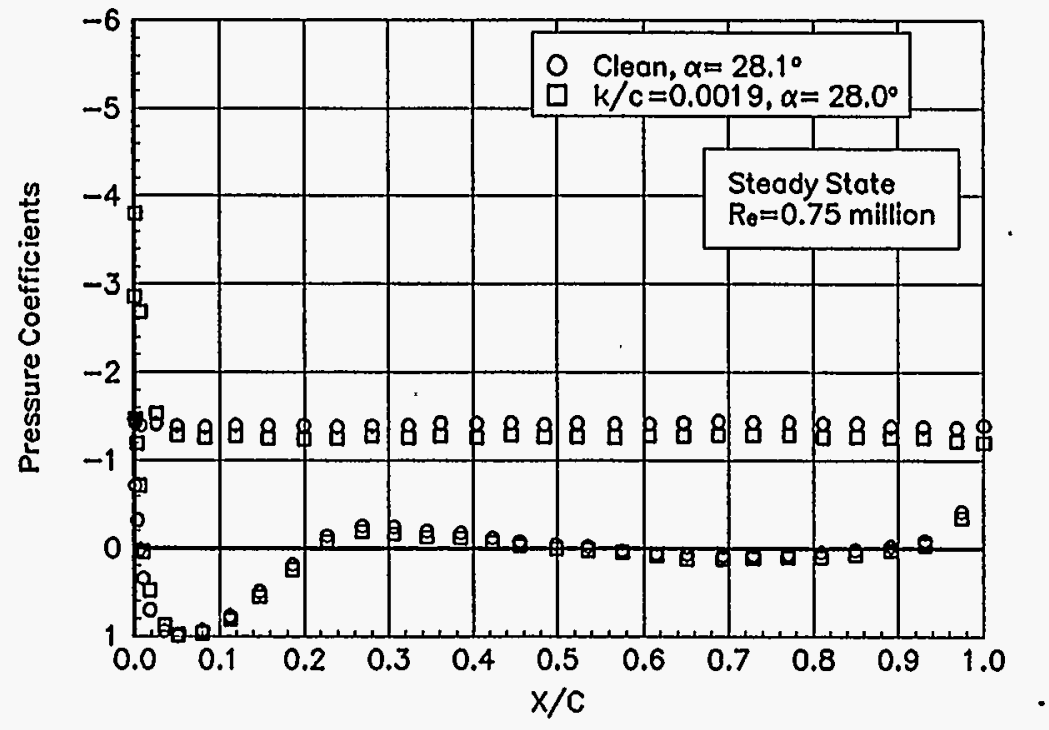

Figure 30. $a=28.1^{\circ}$

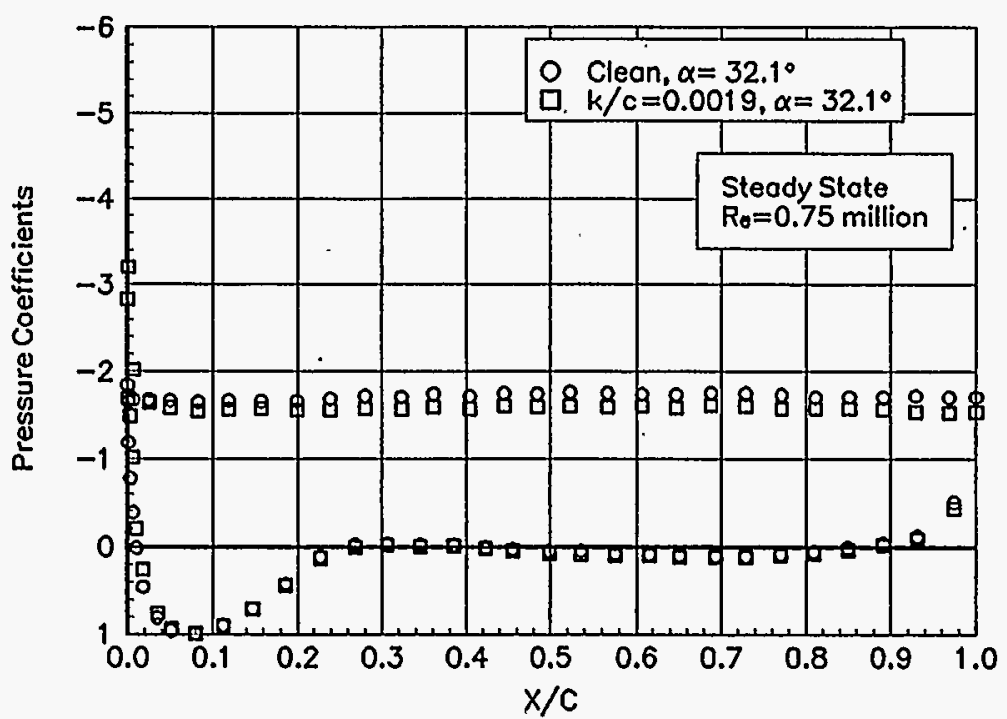

Figure 32. $a=32.1^{\circ}$ 


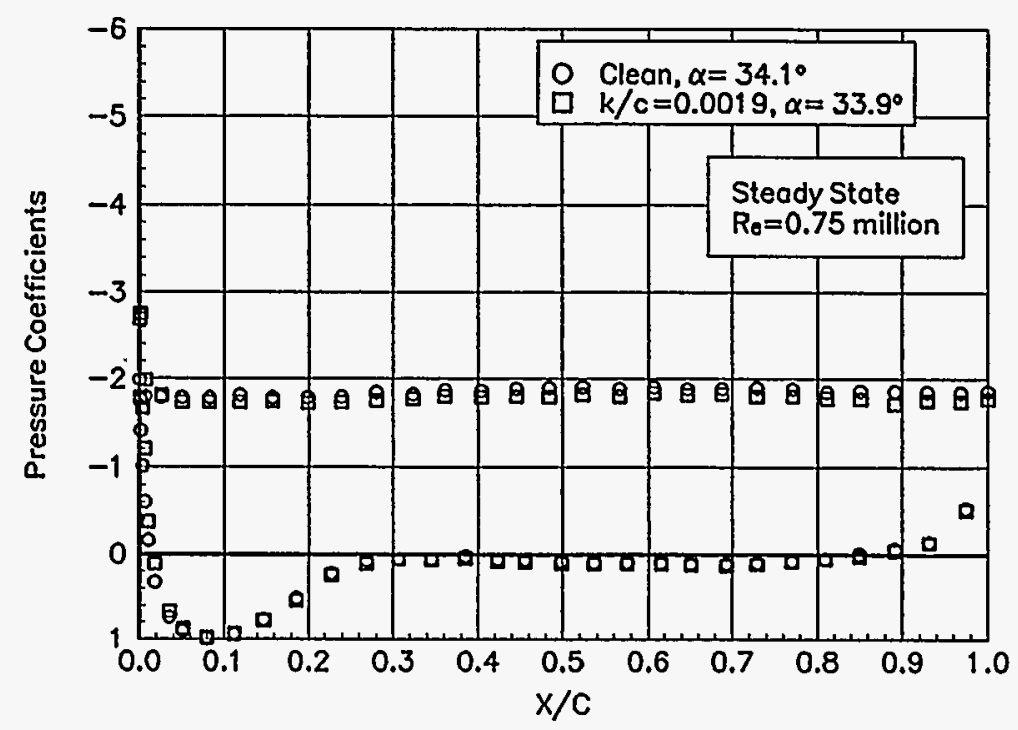

Figure 33. $a=34.1^{\circ}$

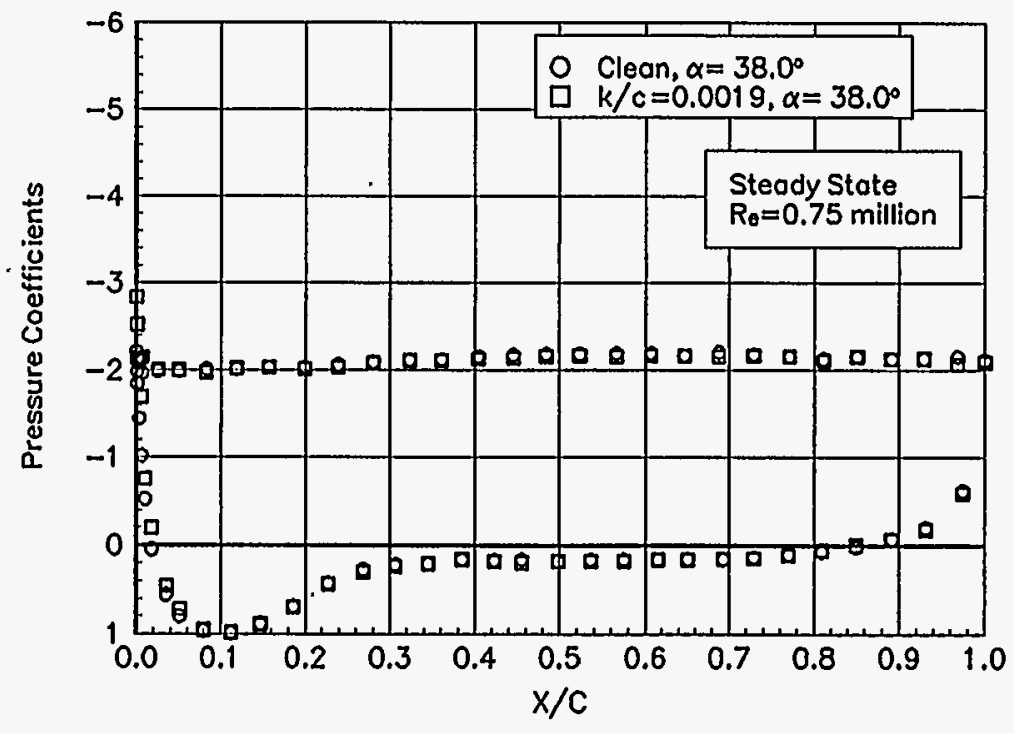

Figure 35. $a=38.0^{\circ}$

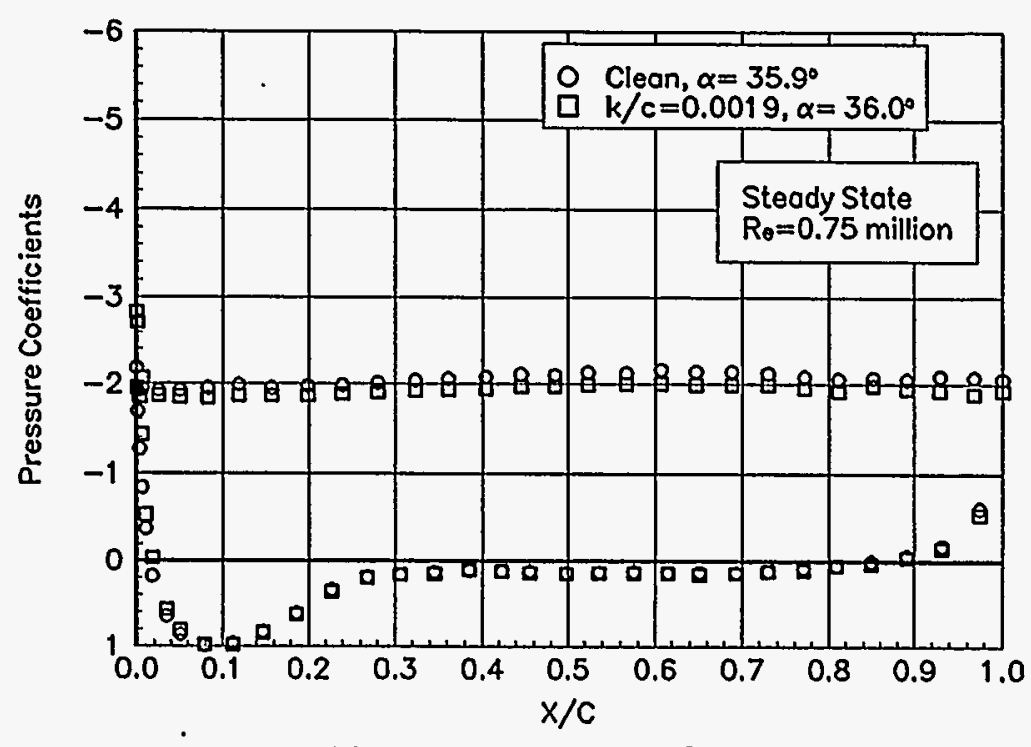

Figure 34. $a=35.9^{\circ}$

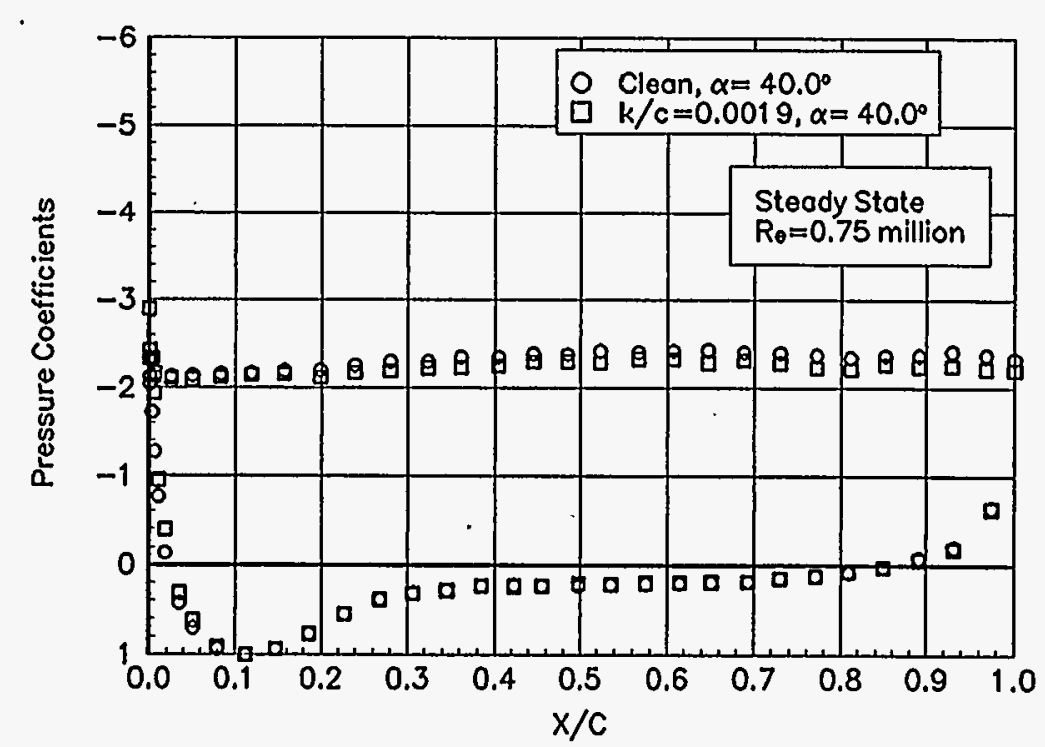

Figure 36. $a=40.0^{\circ}$ 
S815

Pressure Distributions, Steady State, $R e=1$ million 


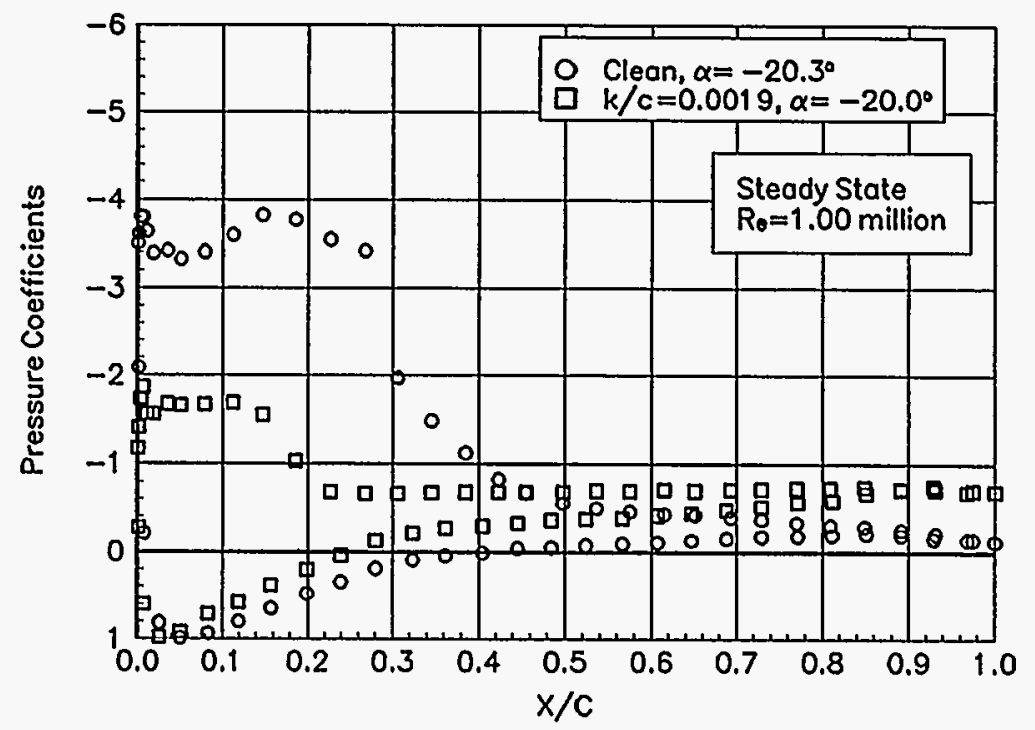

Figure 37. $a=-20.3^{\circ}$

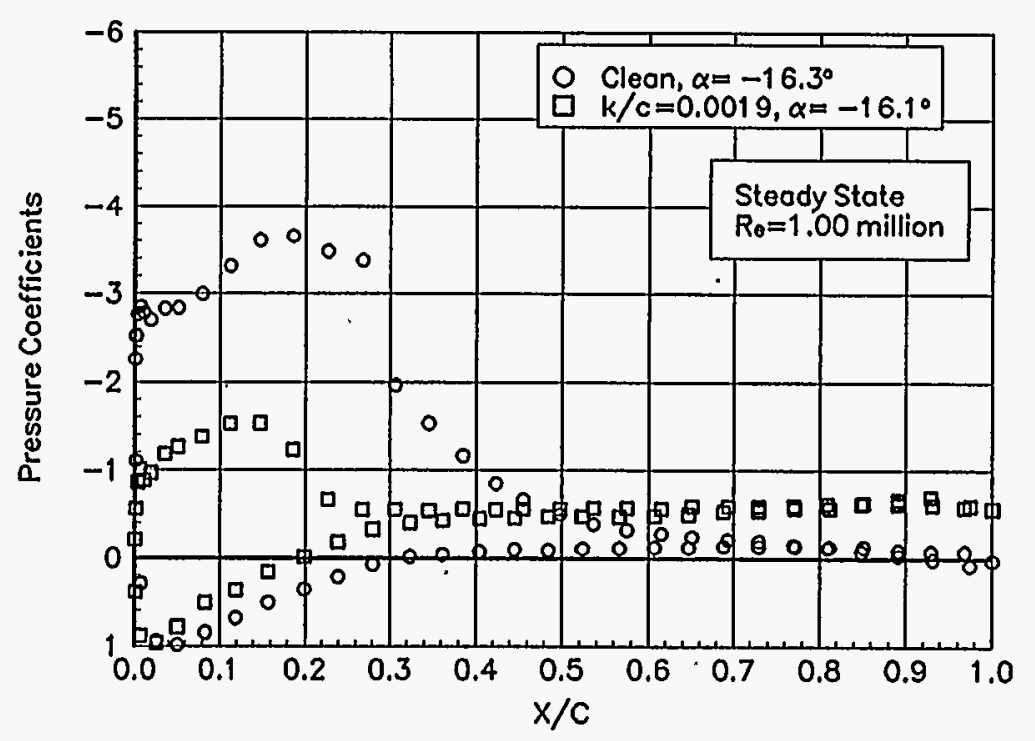

Figure 39. $a=-16.3^{\circ}$

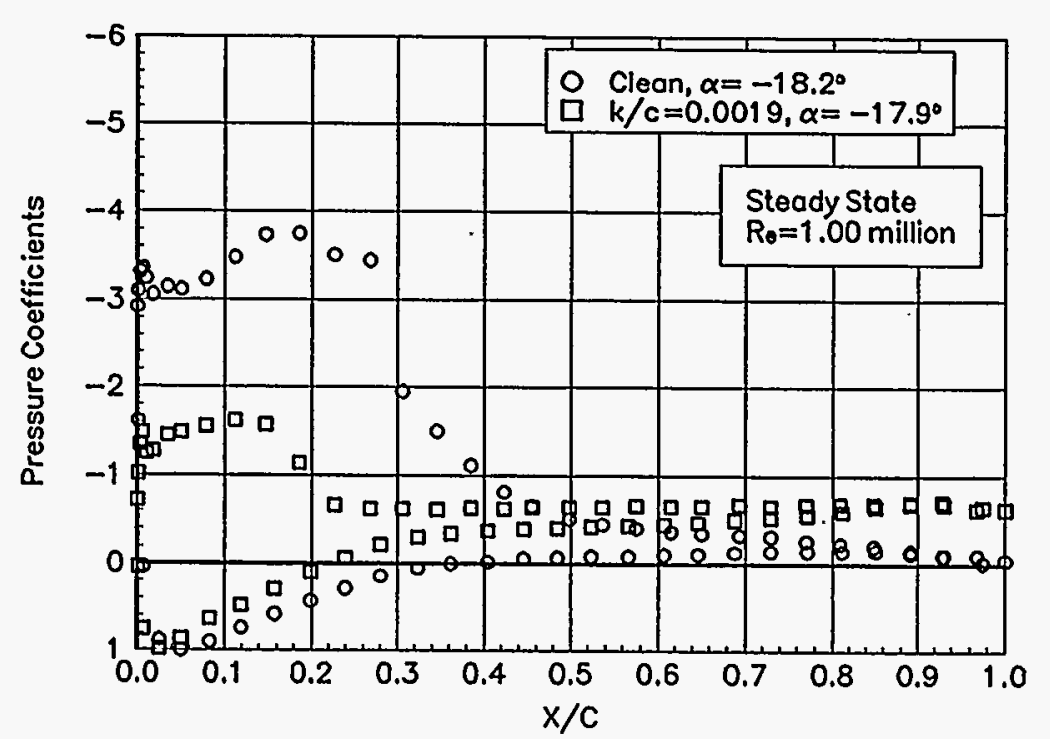

Figure 38. $a=-18.2^{\circ}$

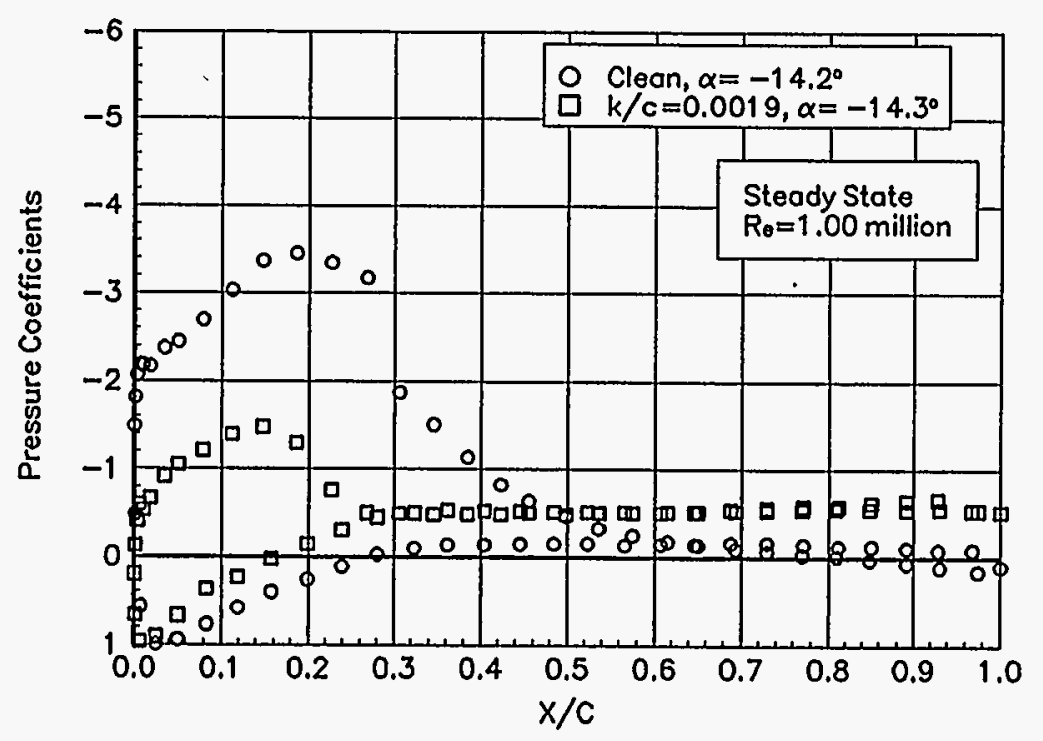

Figure 40. $a=-14.2^{\circ}$ 


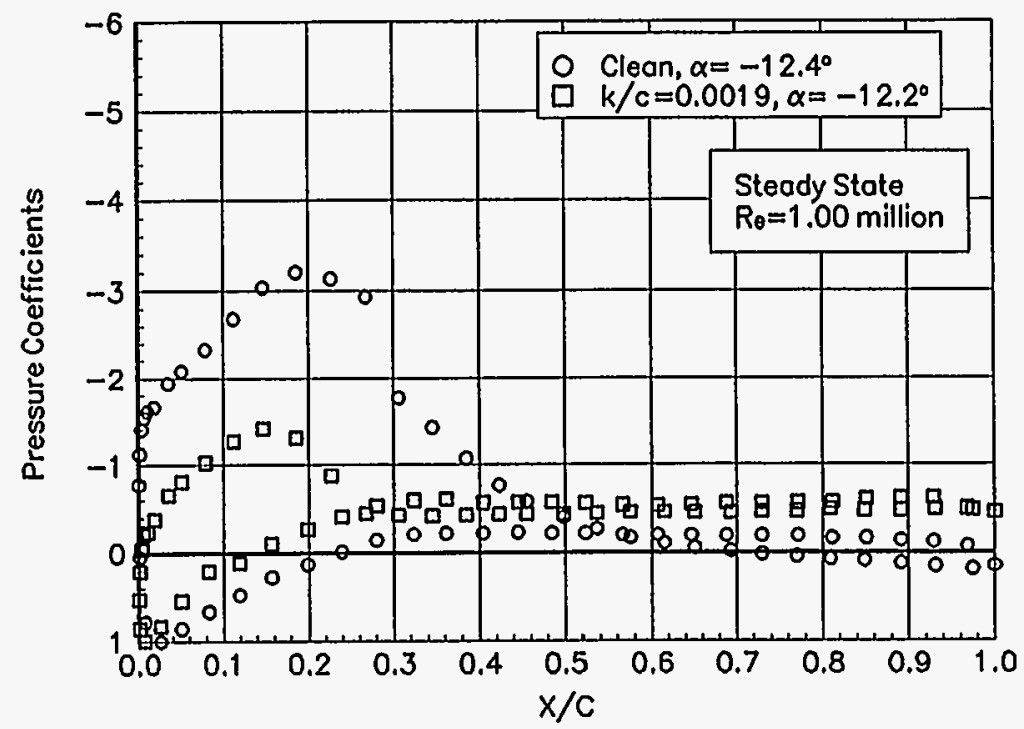

Figure 41. $a=-12.4^{\circ}$

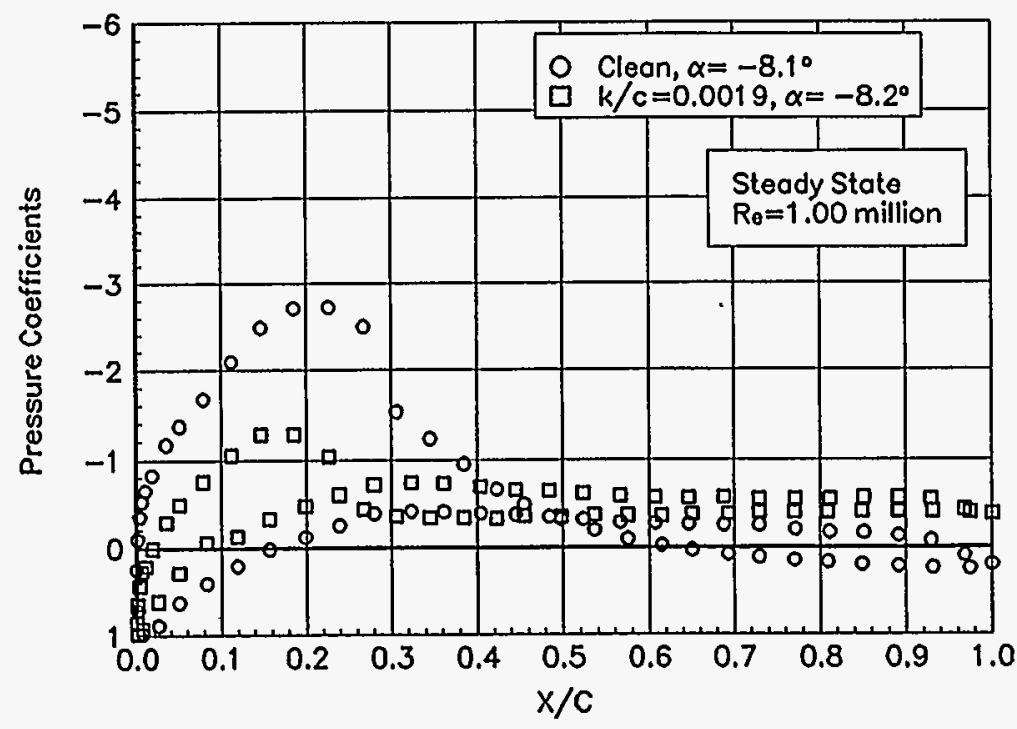

Figure 43. $a=-8.1^{\circ}$

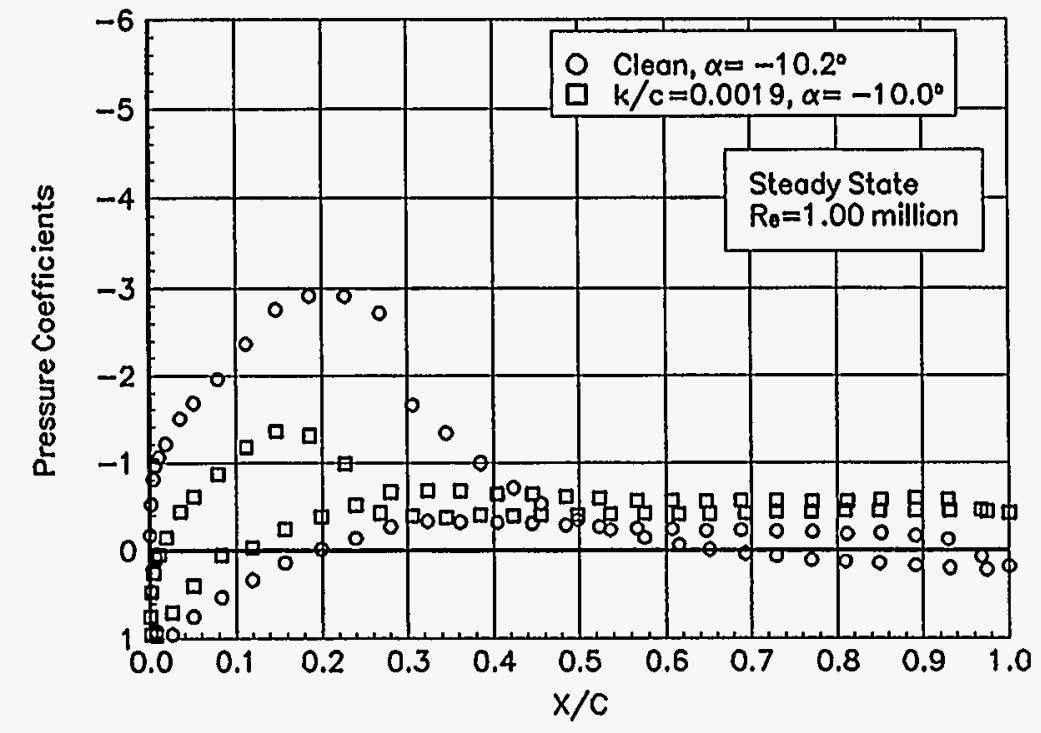

Figure 42. $a=-10.2^{\circ}$

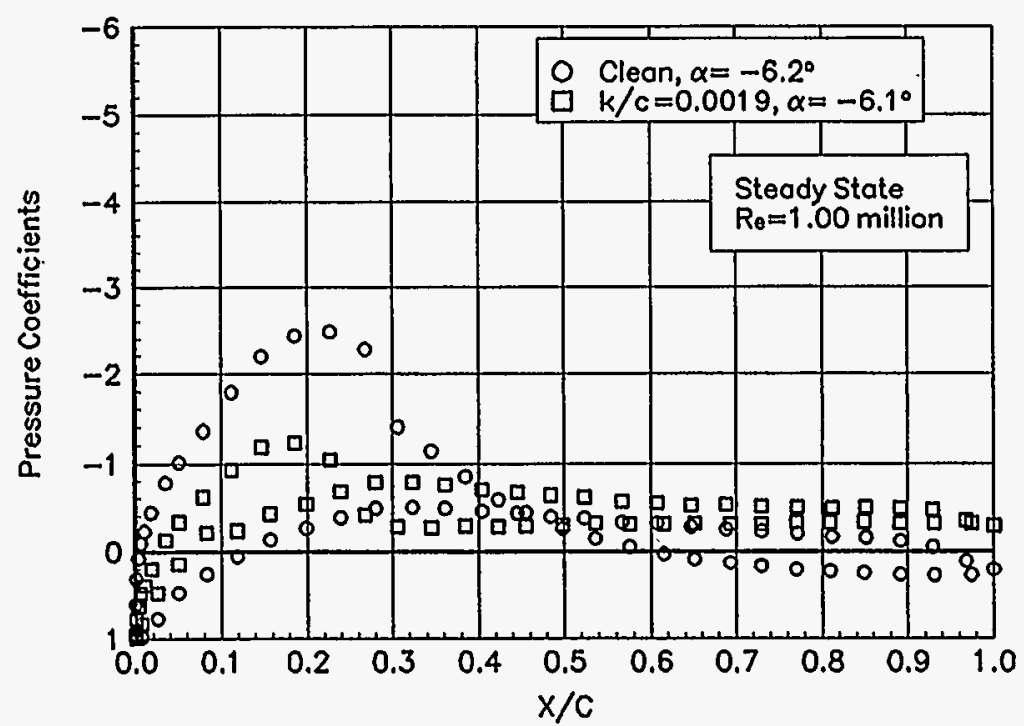

Figure 44. $a=-6.2^{\circ}$ 


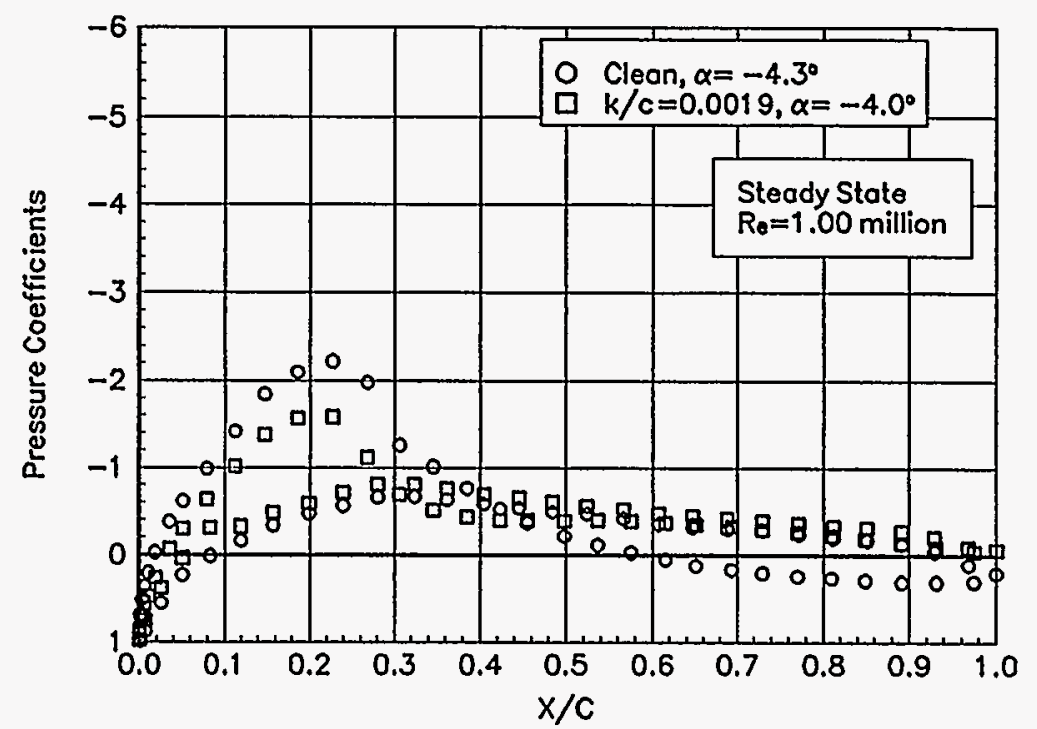

Figure 45. $a=-4.3^{\circ}$

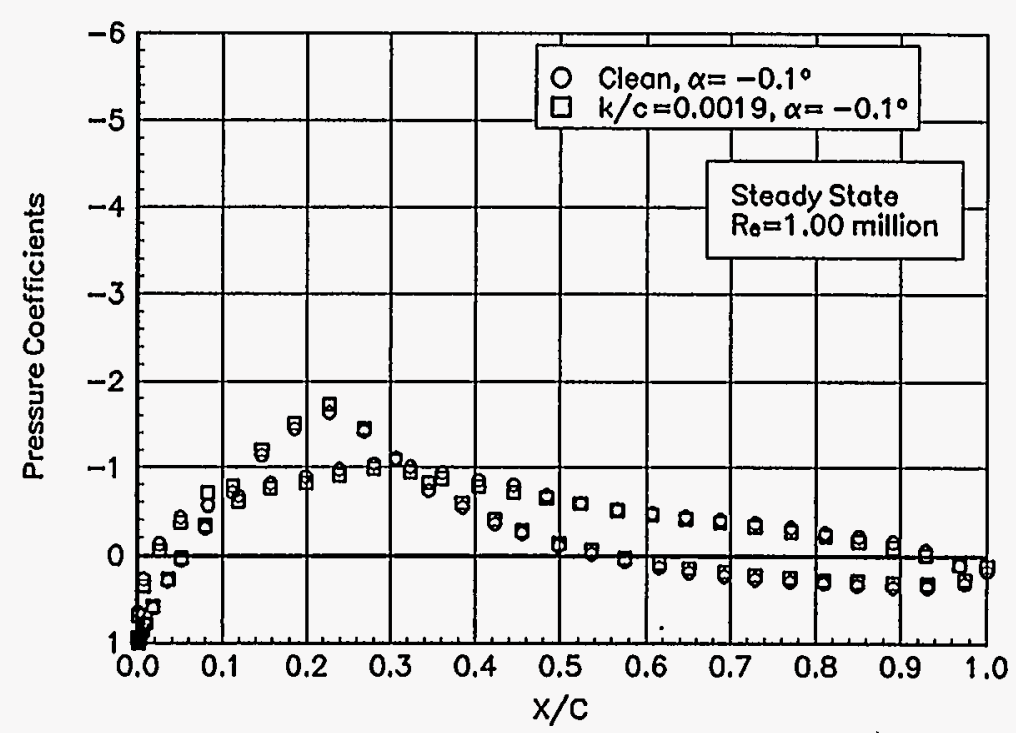

Figure 47. $a=-0.1^{\circ}$

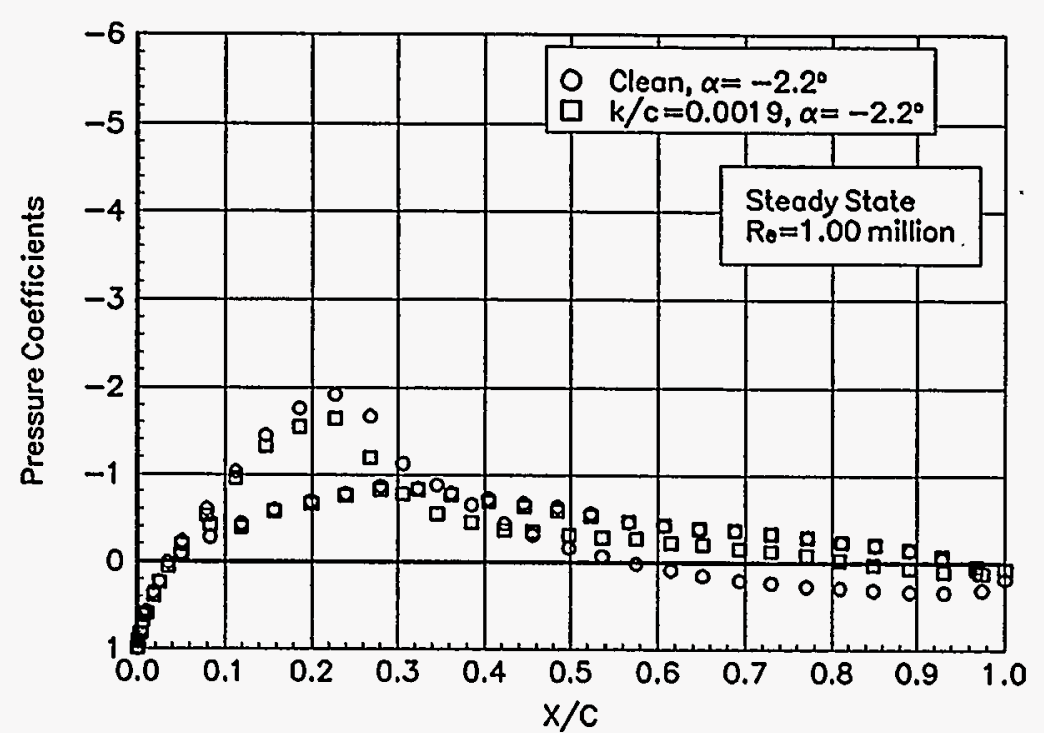

Figure 46. $a=-2.2^{\circ}$

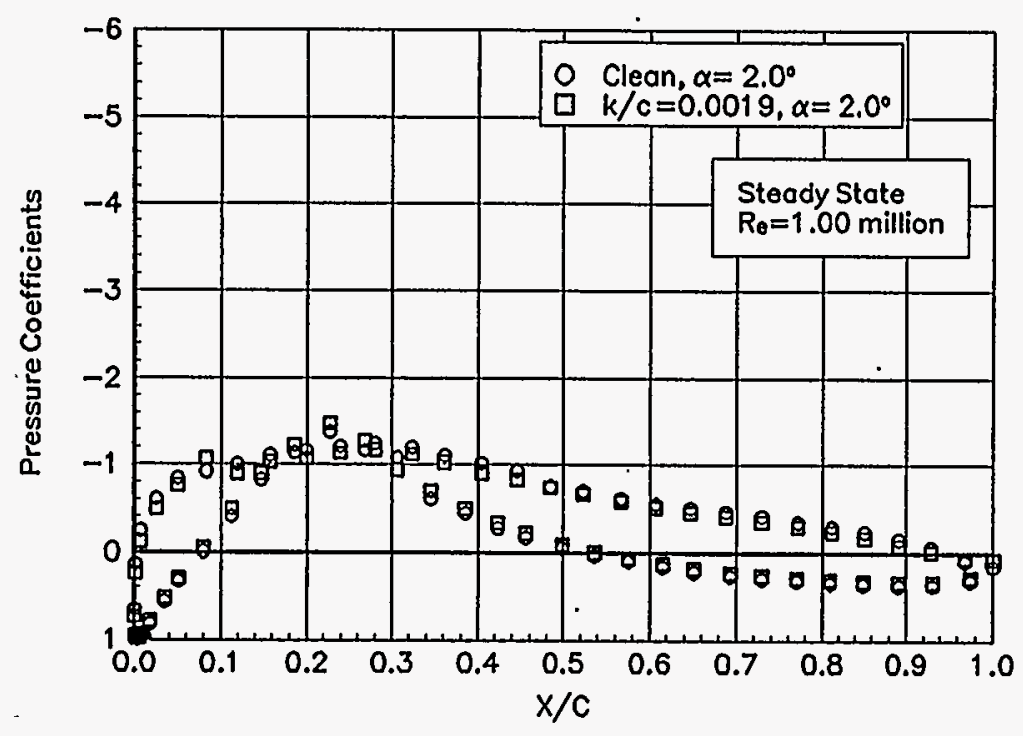

Figure 48. $a=2.0^{\circ}$ 
Pressure Coefficients

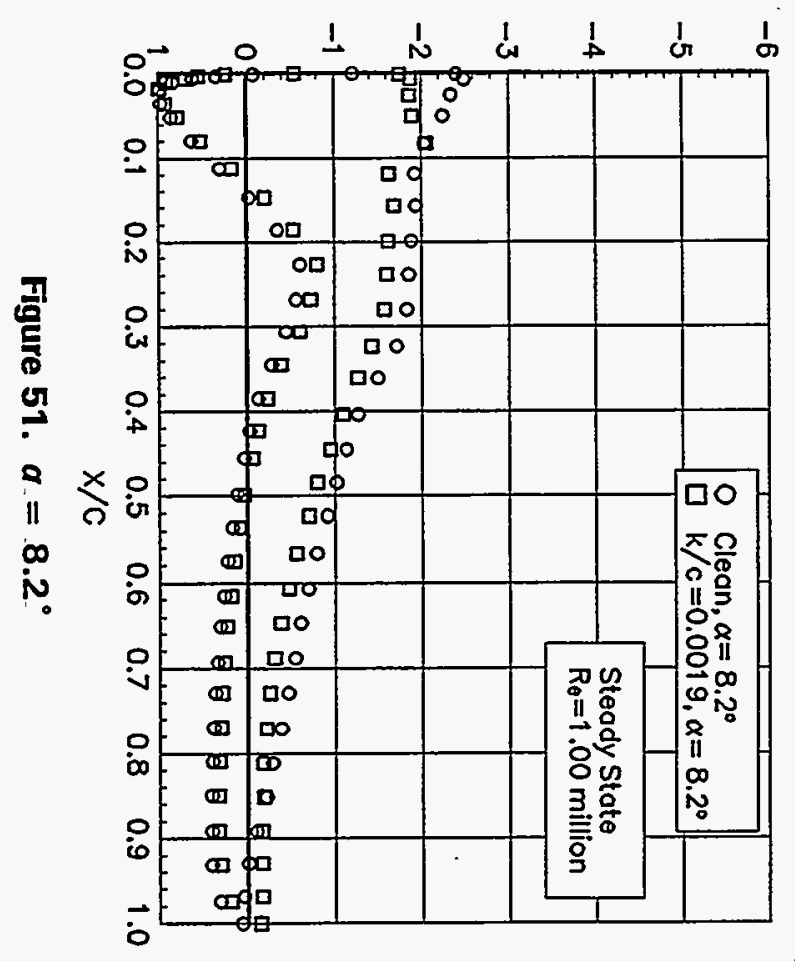

Pressure Coefficients

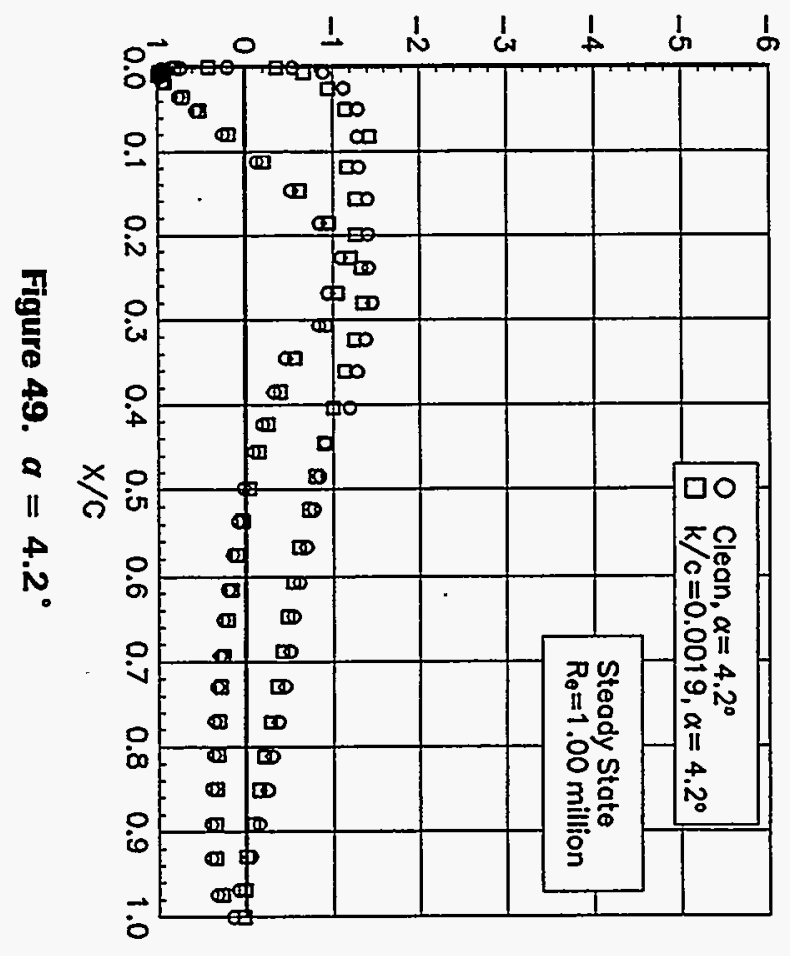

$\underset{+}{\stackrel{4}{+}}$

Pressure Coefficients

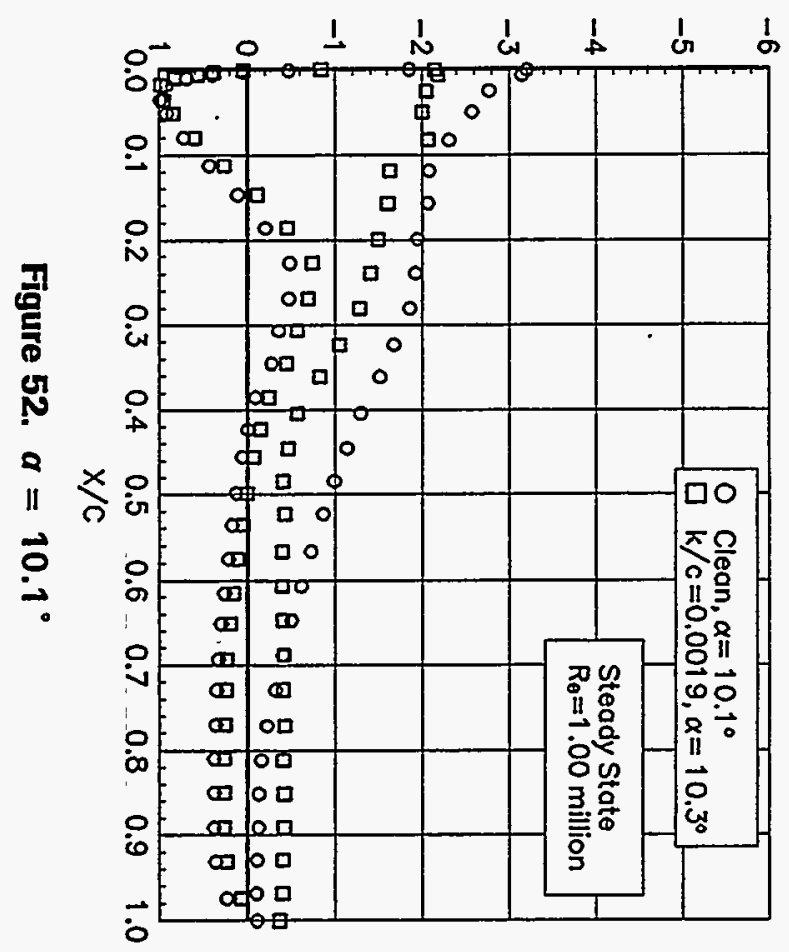

Pressure Coefficients

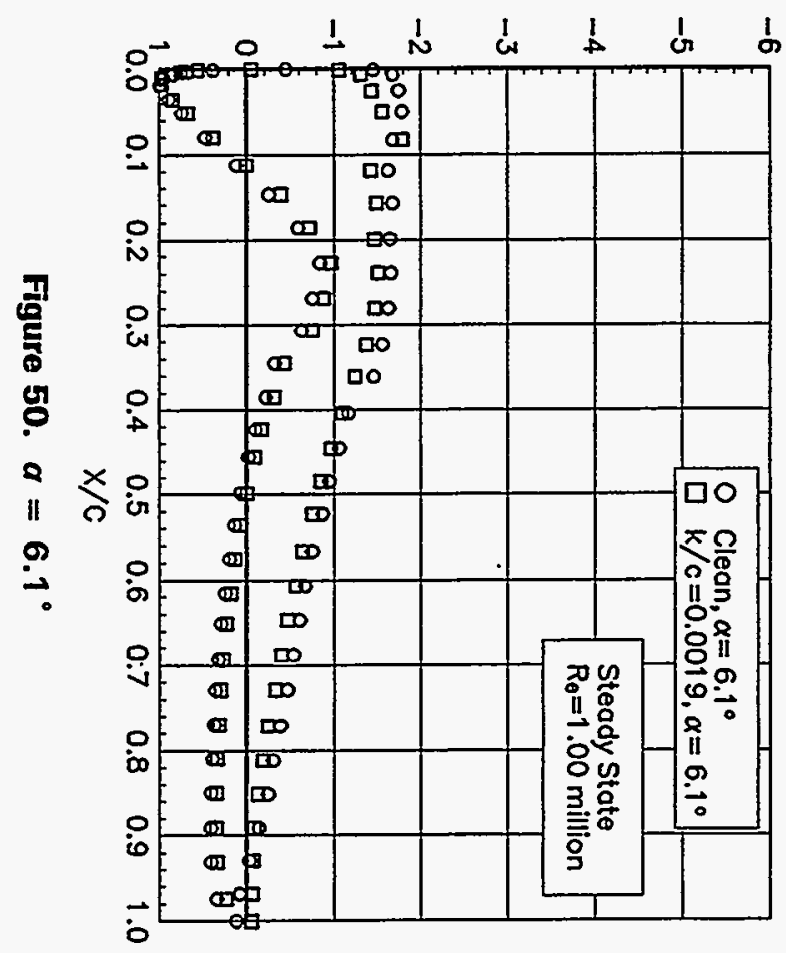




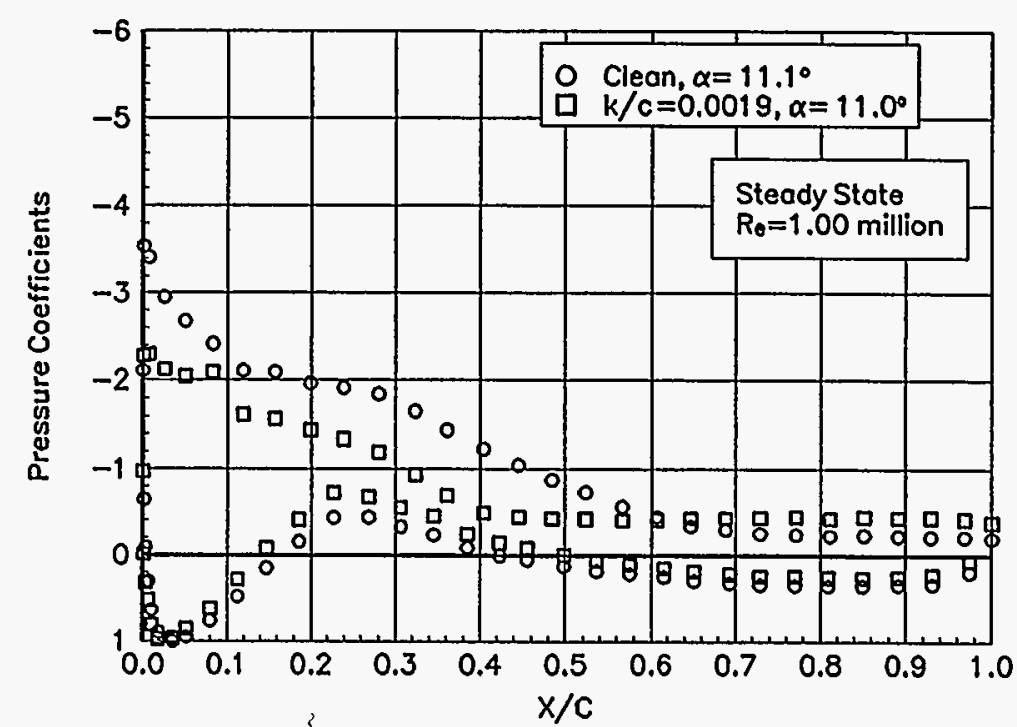

Figure 53. $a=11.1^{\circ}$

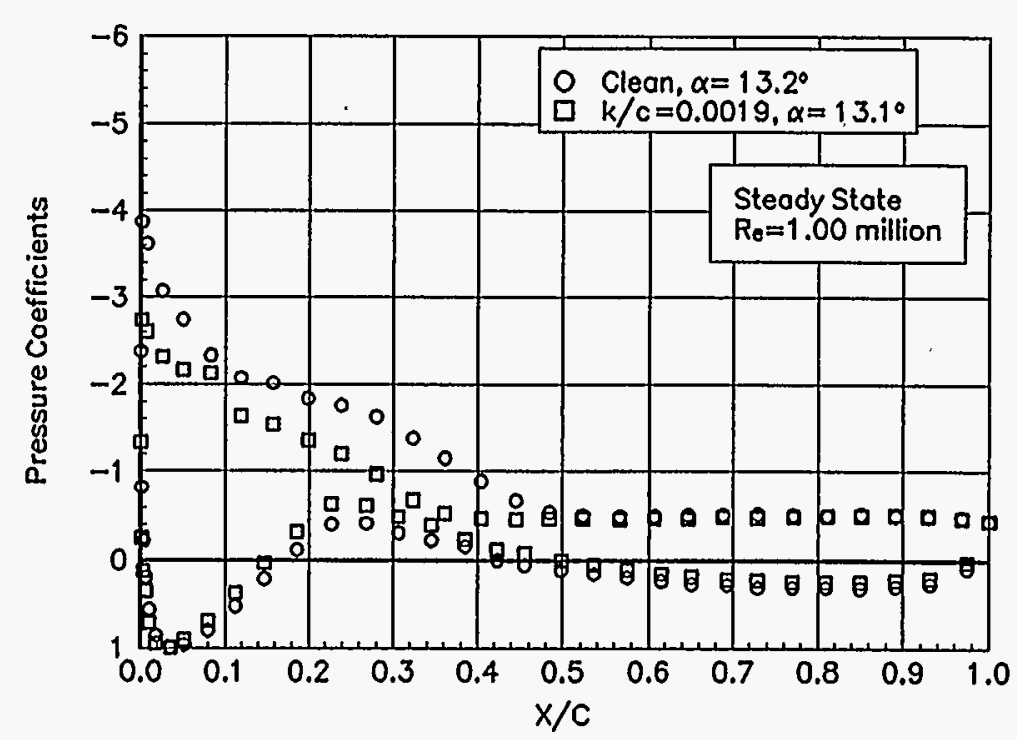

Figure 55. $a=13.2^{\circ}$

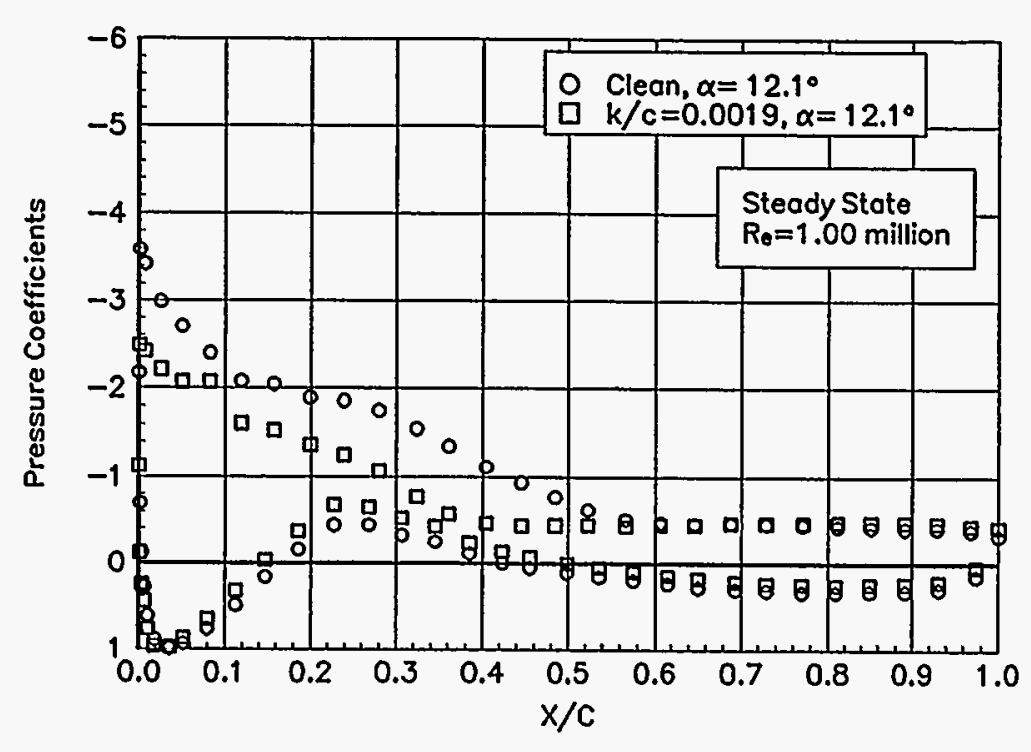

Figure 54. $a=12.1^{\circ}$

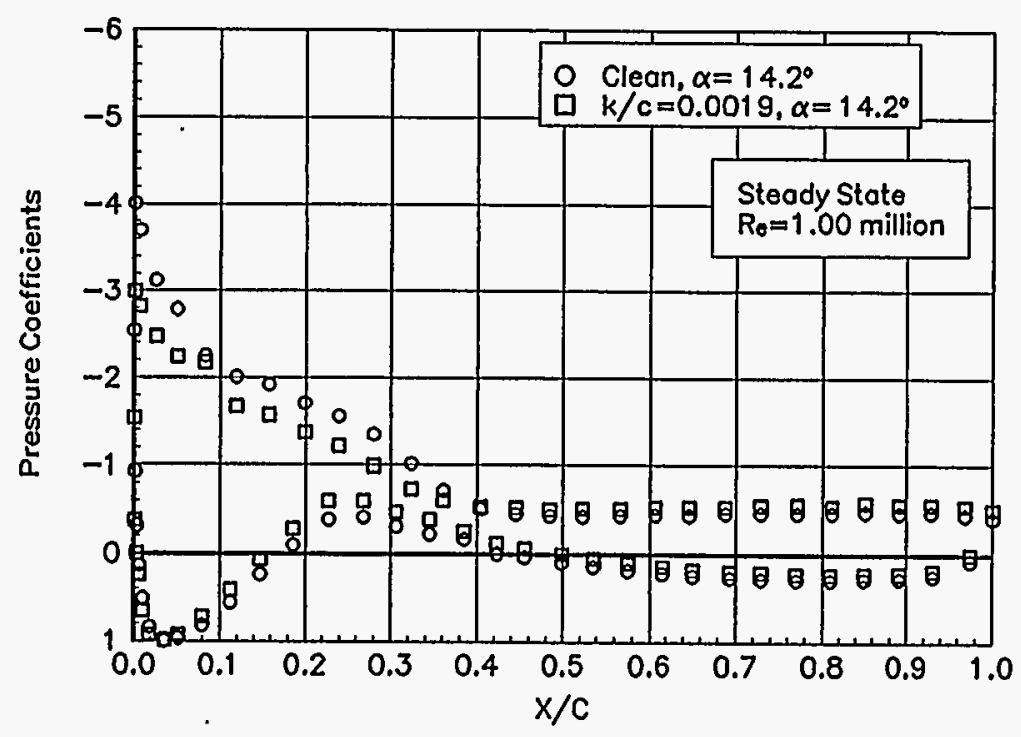

Figure 56. $a=14.2^{\circ}$ 


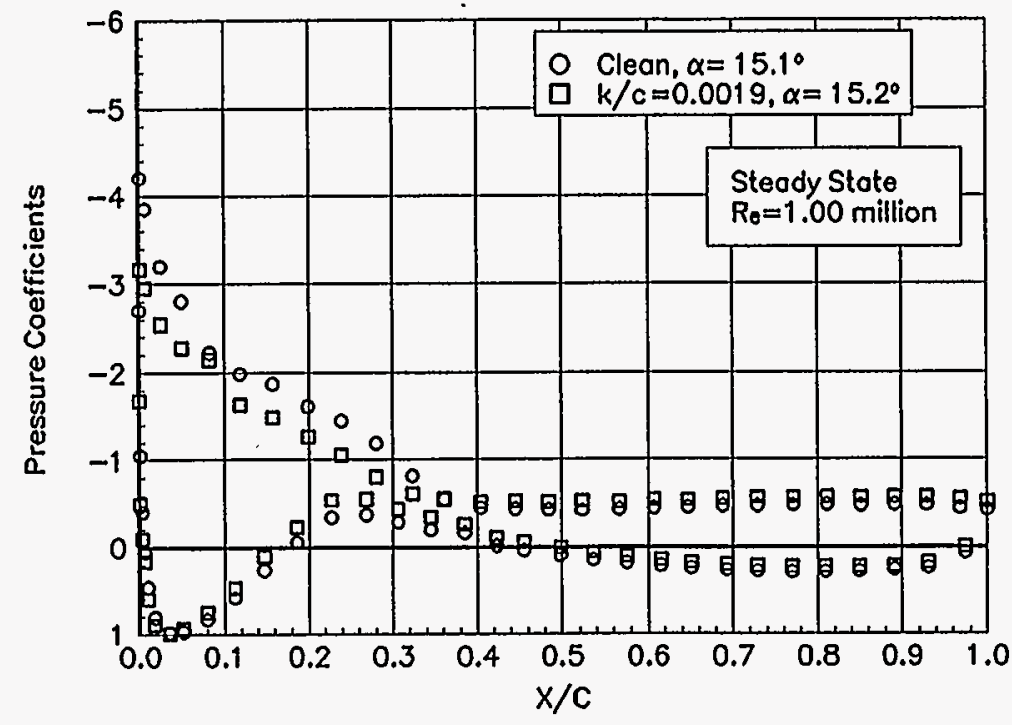

Figure 57. $a=15.1^{\circ}$

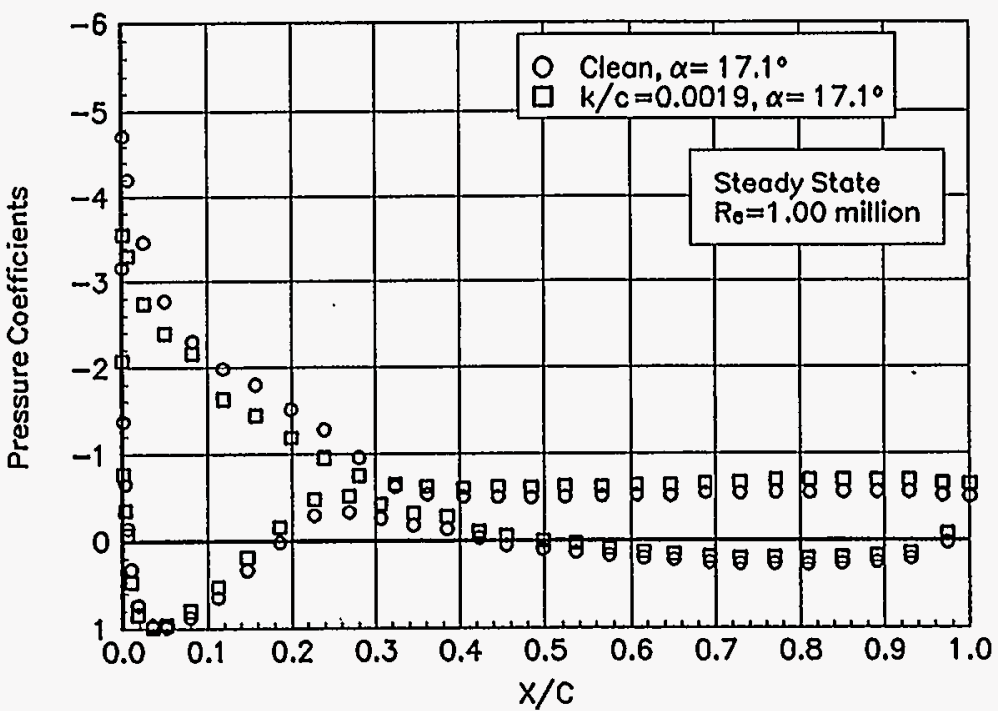

Figure 59. $a=17.1^{\circ}$

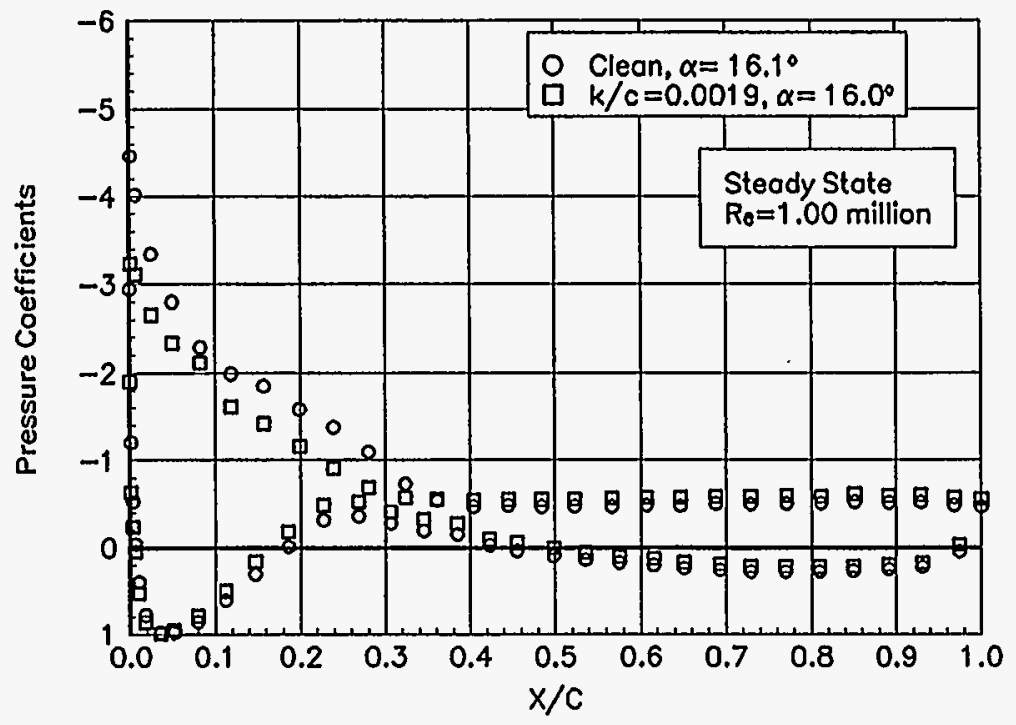

Figure 58. $a=16.1^{\circ}$

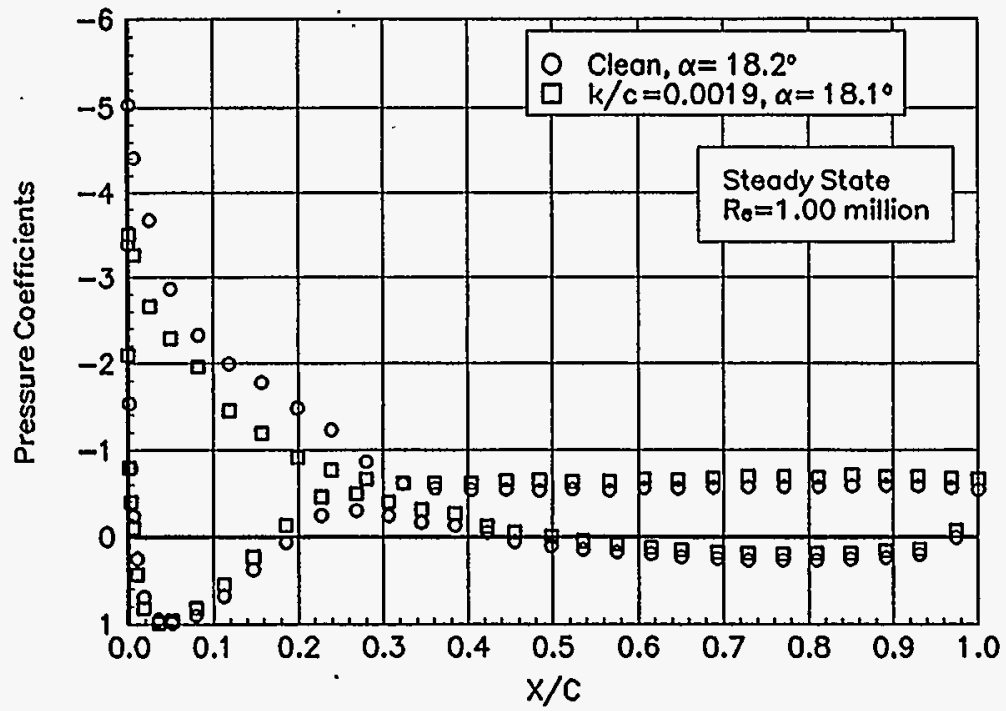

Figure 60. $a=18.2^{\circ}$ 


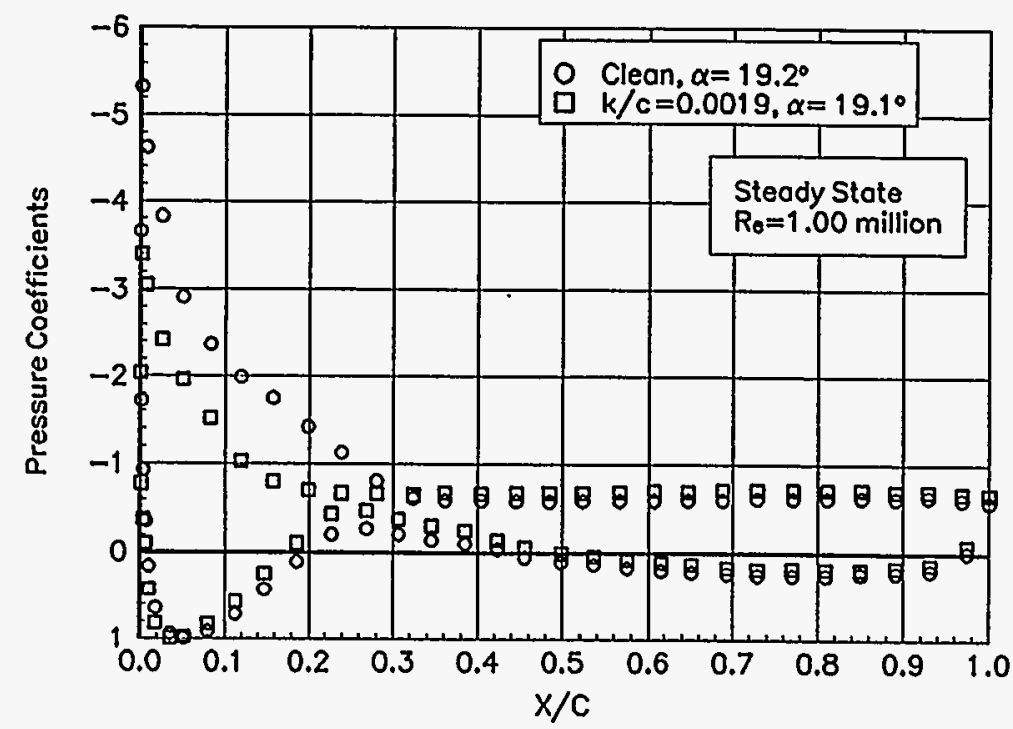

Figure 61. $a=19.2^{\circ}$

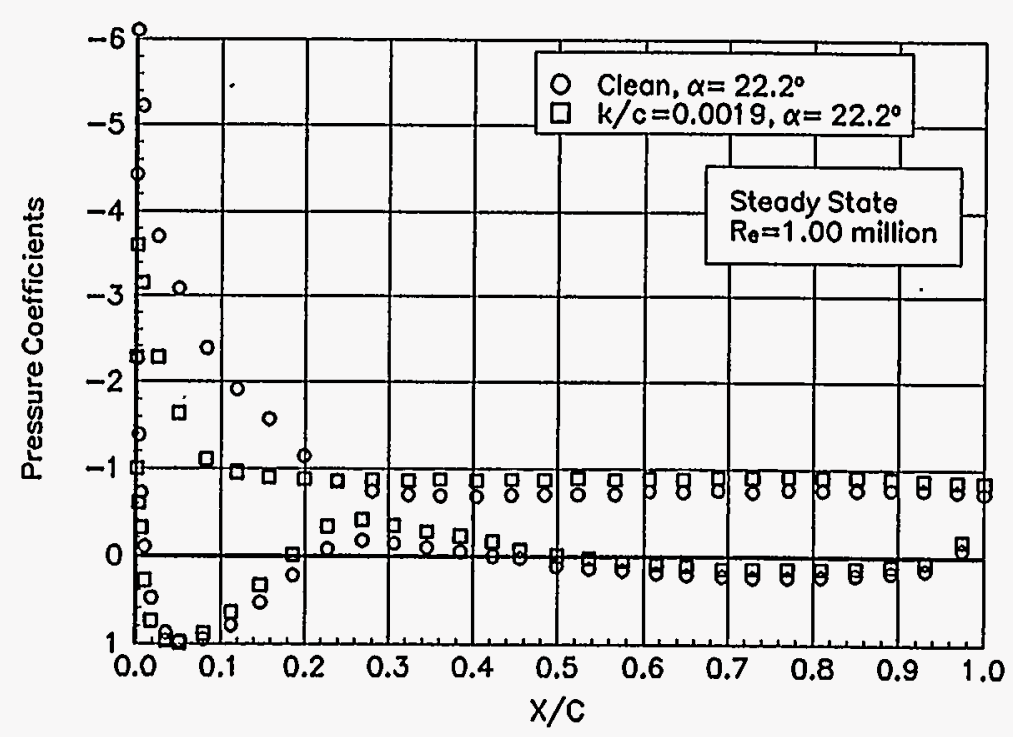

Figure 63. $a=22.2^{\circ}$

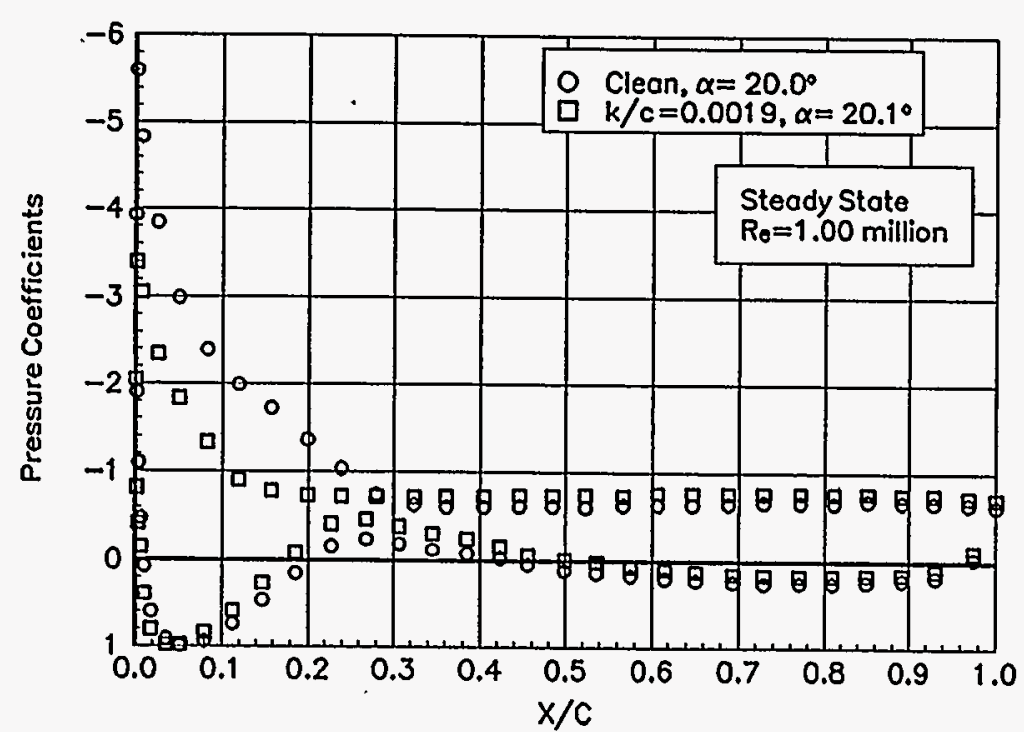

Figure 62. $a=20.0^{\circ}$

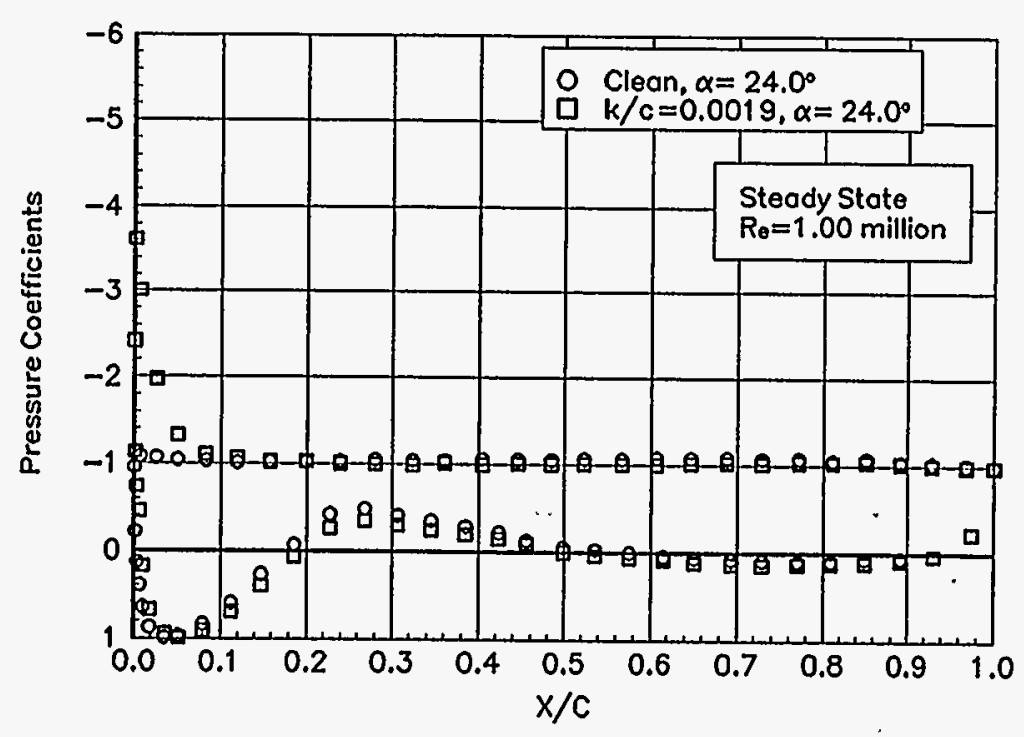

Figure 64. $\alpha=24.0^{\circ}$ 


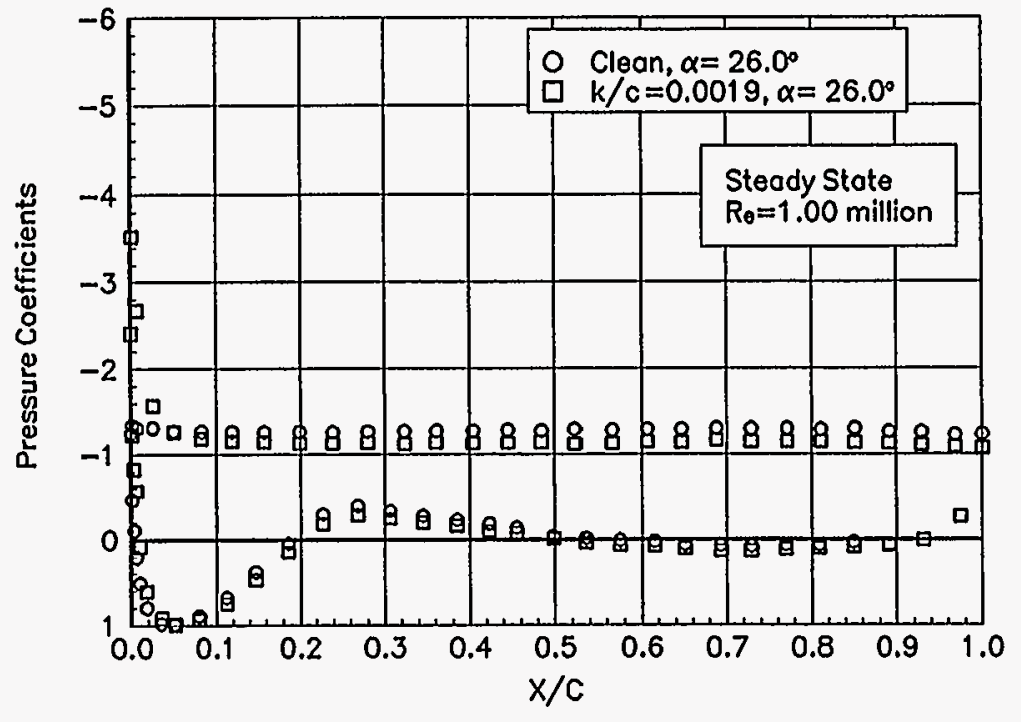

Figure 65. $\alpha=26.0^{\circ}$

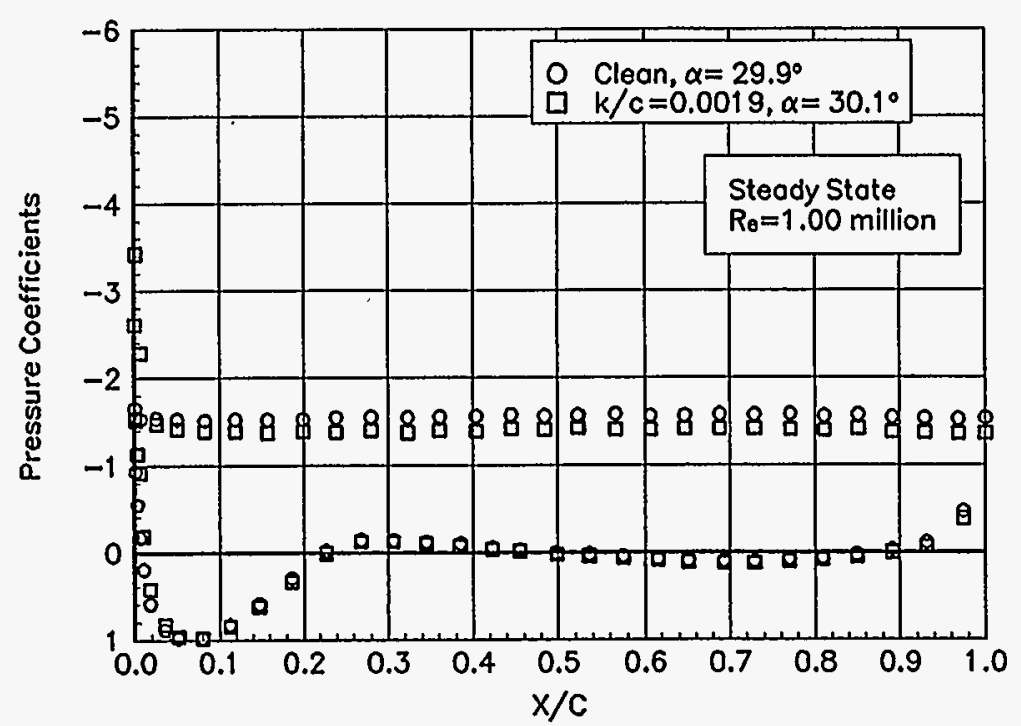

Figure 67. $a=29.9^{\circ}$

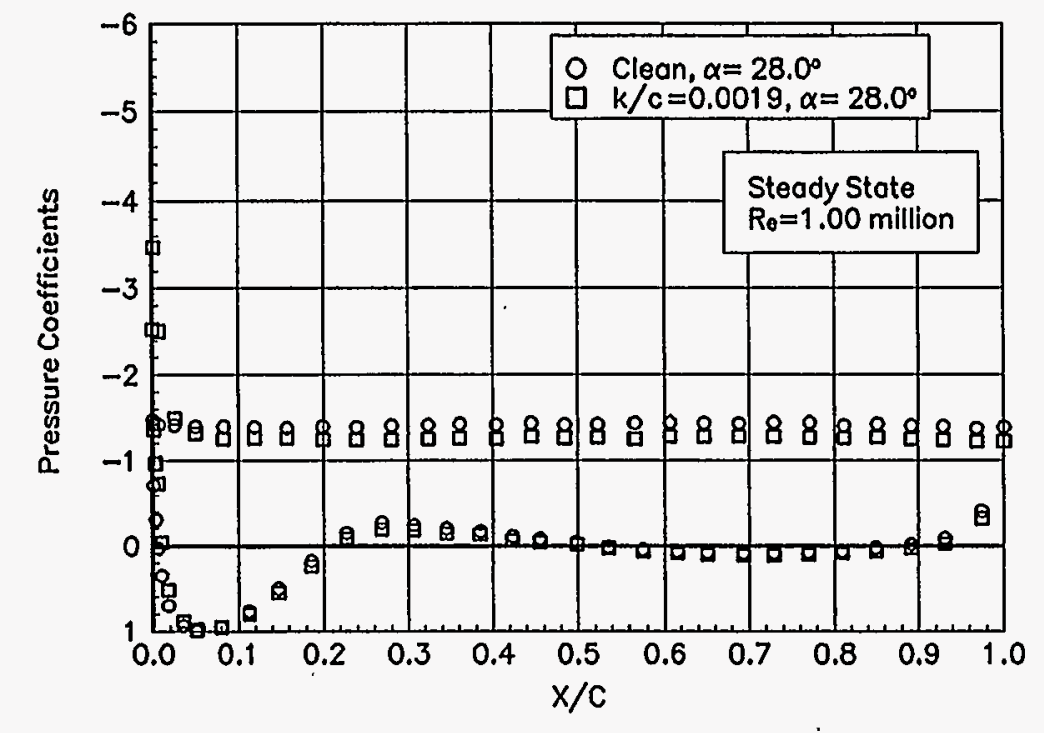

Figure 66. $a=28.0^{\circ}$

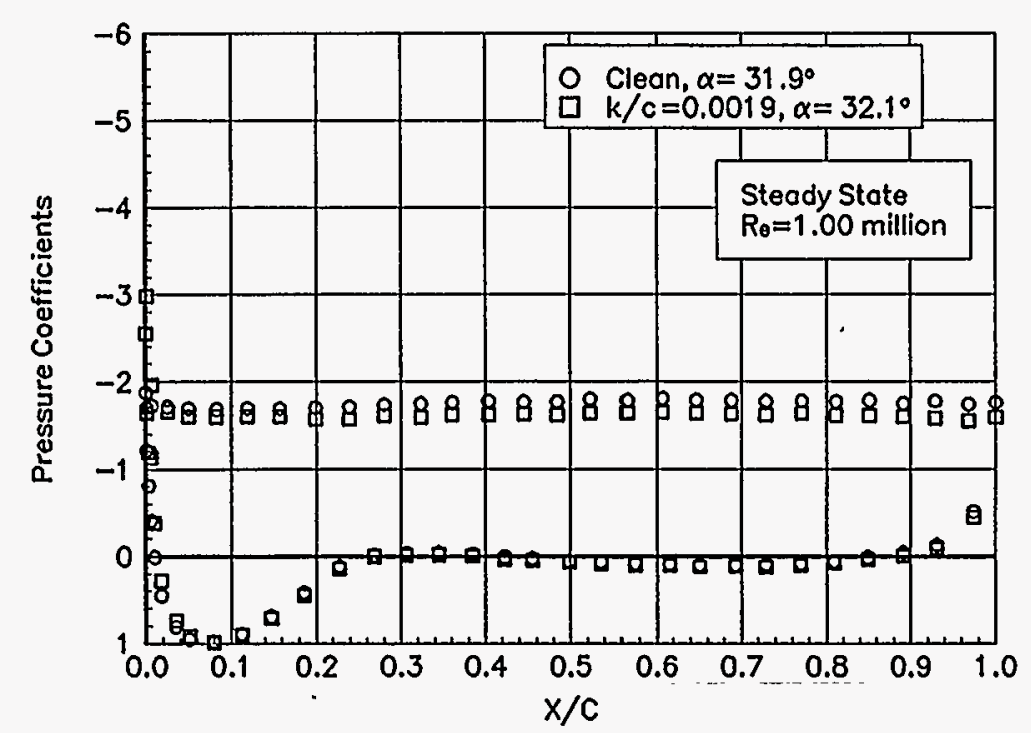

Figure 68. $a=31.9^{\circ}$ 


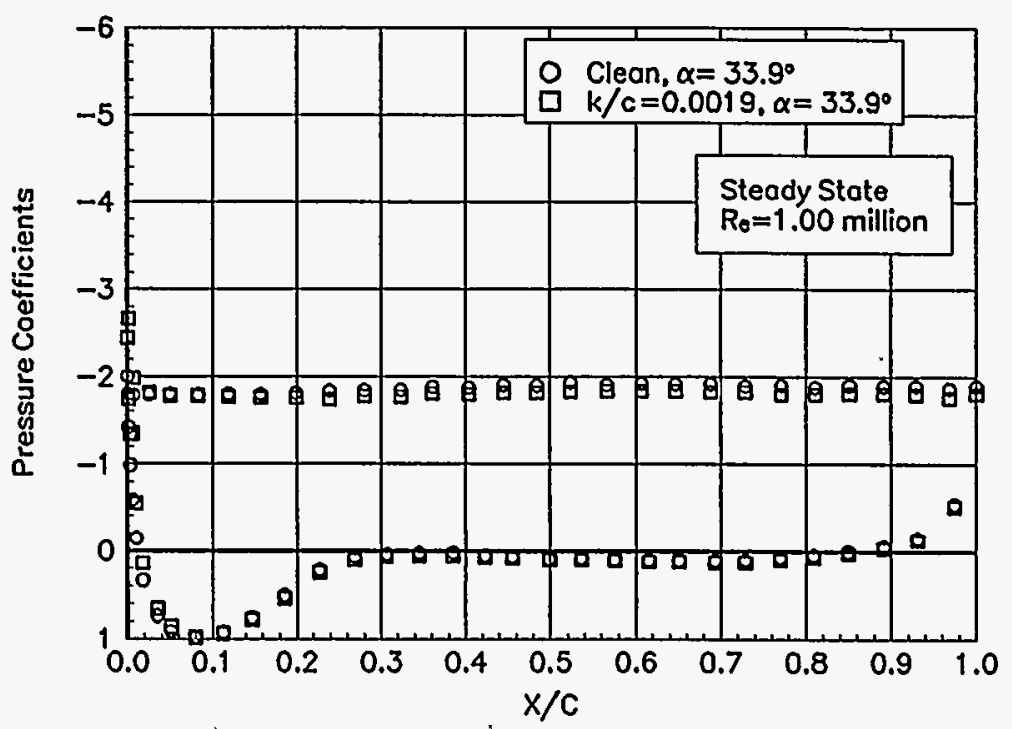

Figure 69. $a=33.9^{\circ}$

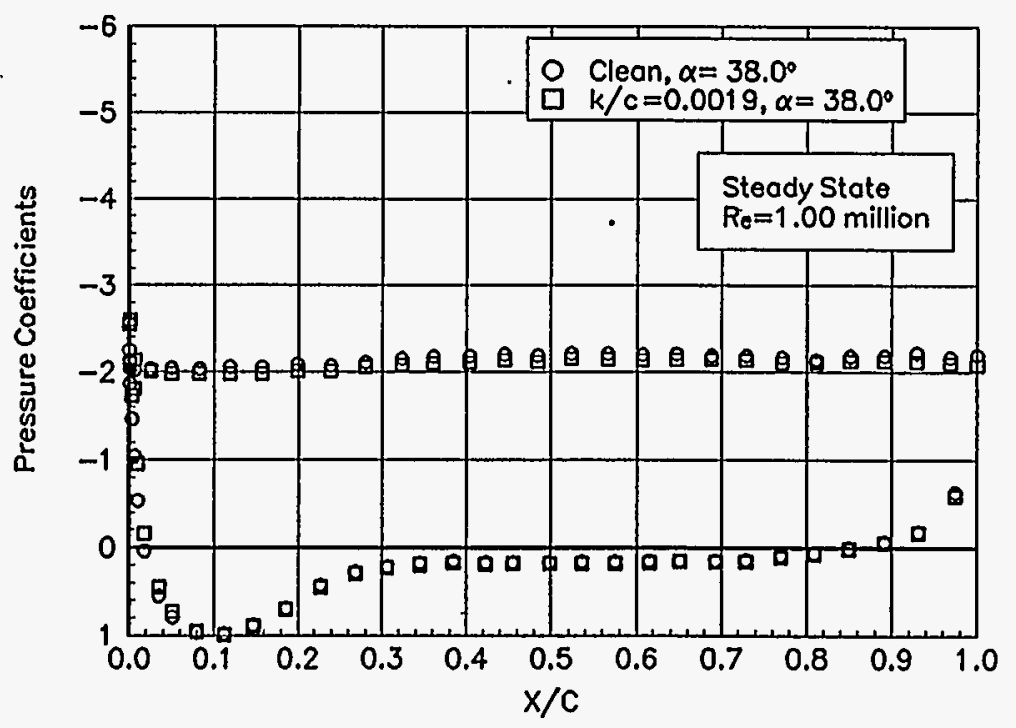

Figure 71. $a=38.0^{\circ}$

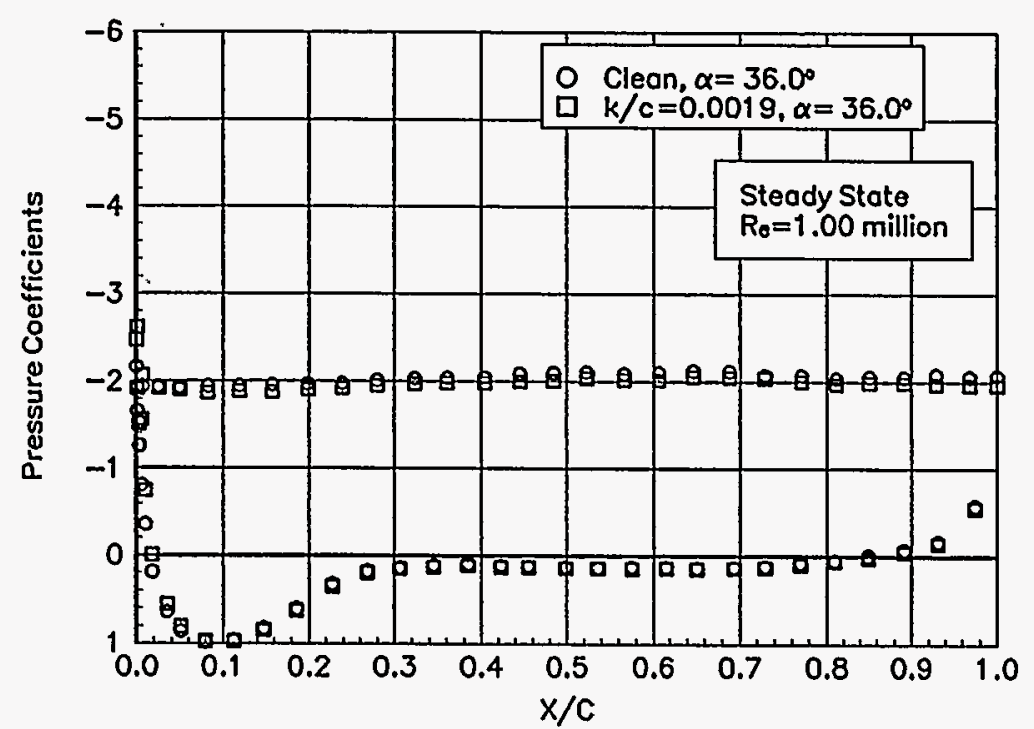

Figure 70. $\alpha=36.0^{\circ}$

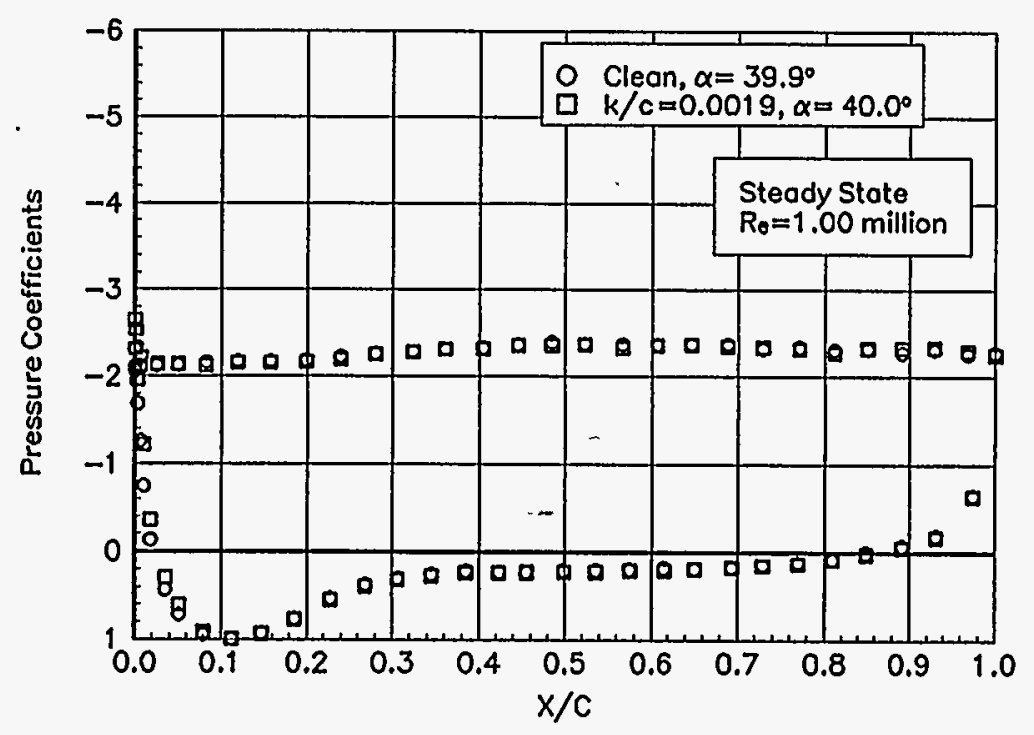

Figure 72. $a=39.9^{\circ}$ 
S815

Pressure Distributions, Steady State, Re $=1.25$ million 

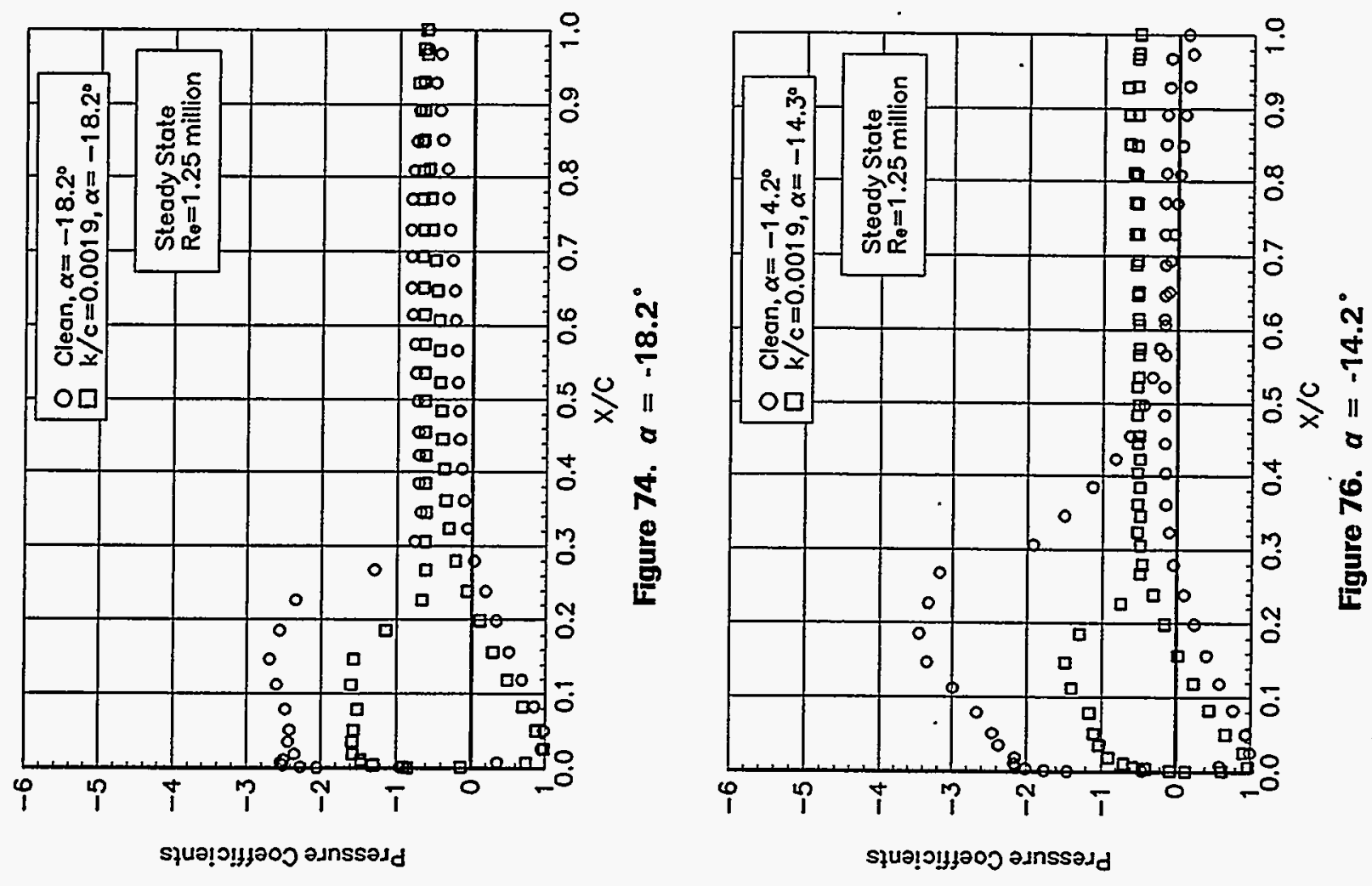

F
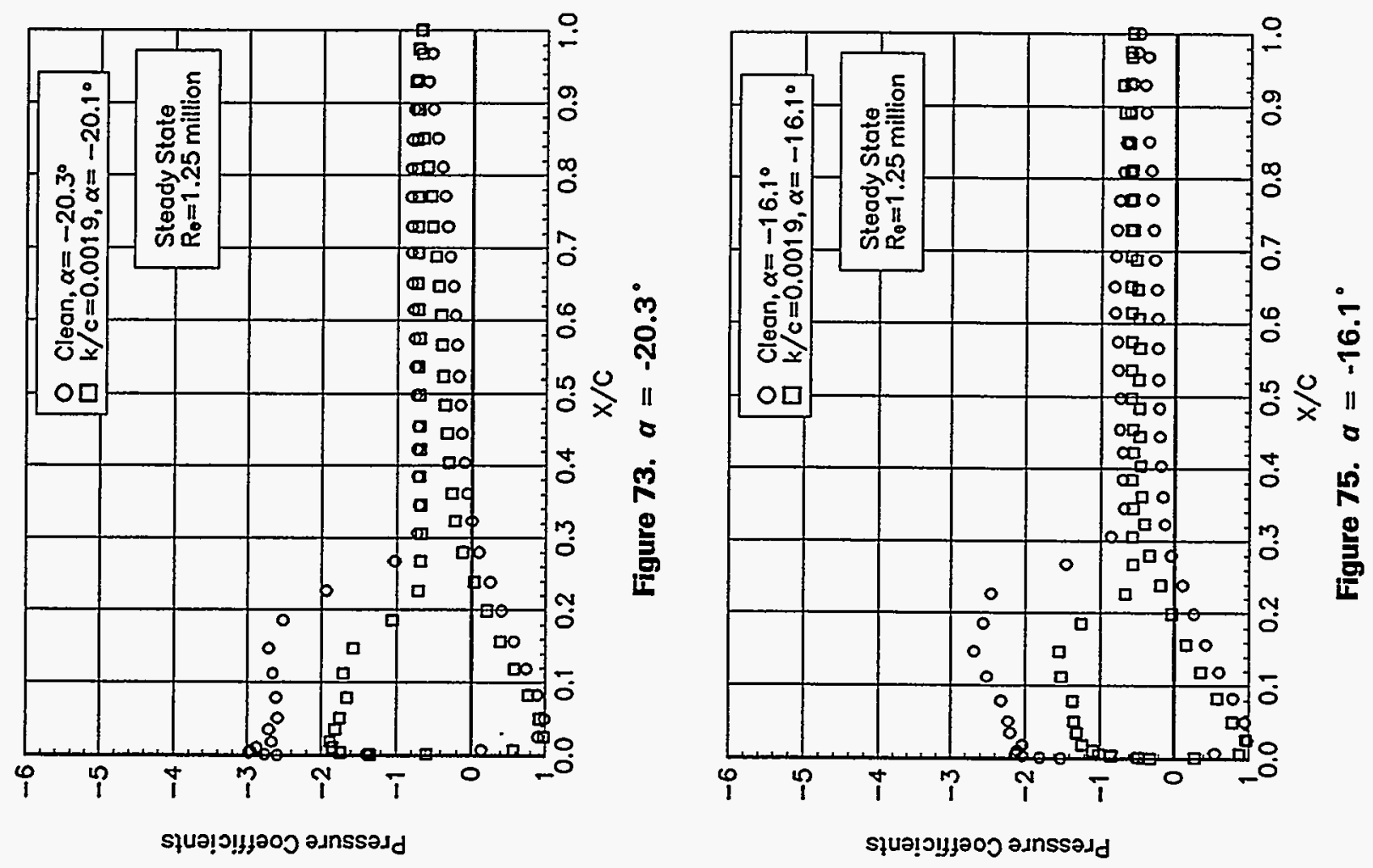


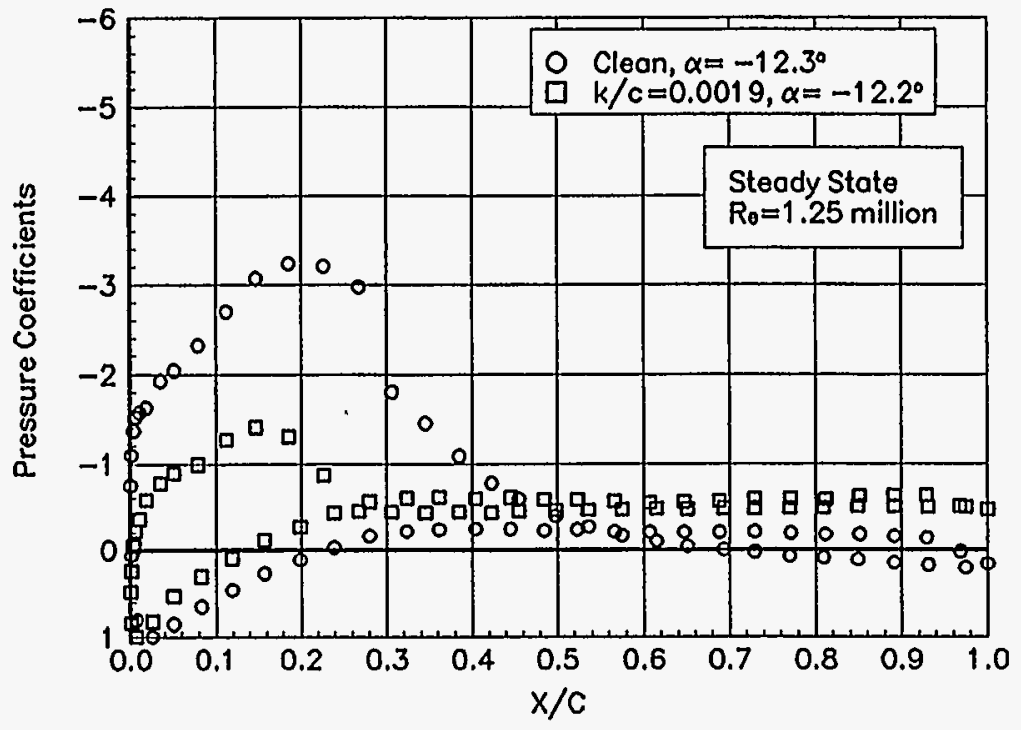

Figure 77. $a=-12.3^{\circ}$

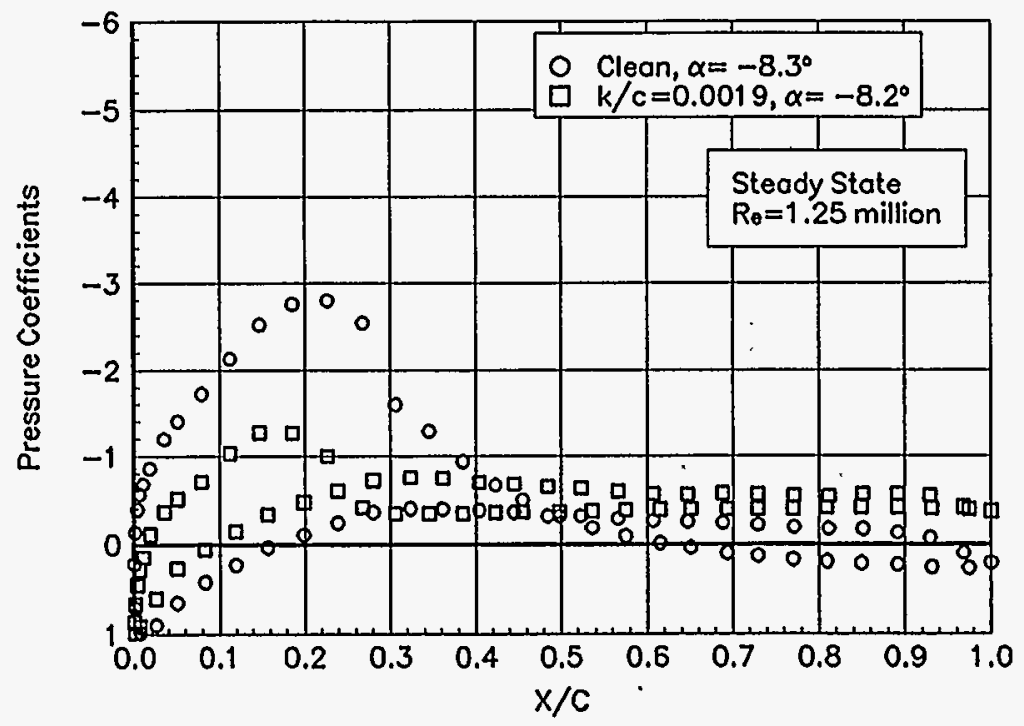

Figure 79. $\alpha=-8.3^{\circ}$

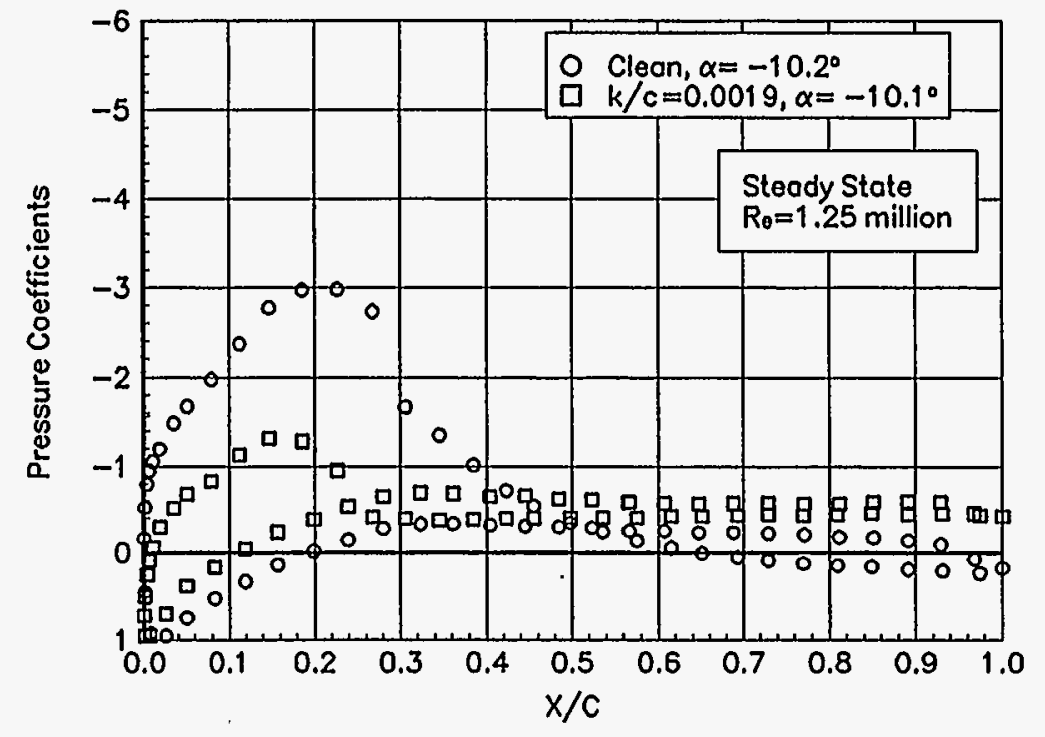

Figure 78. $a=-10.2^{\circ}$

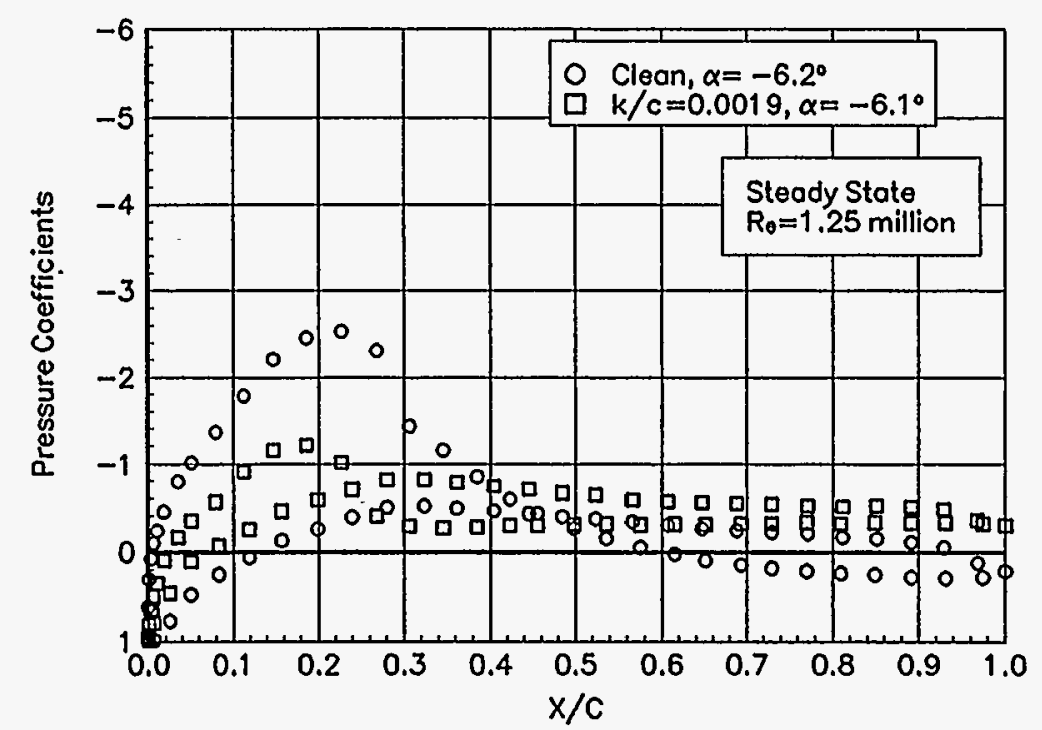

Figure 80. $a=-6.2^{\circ}$ 


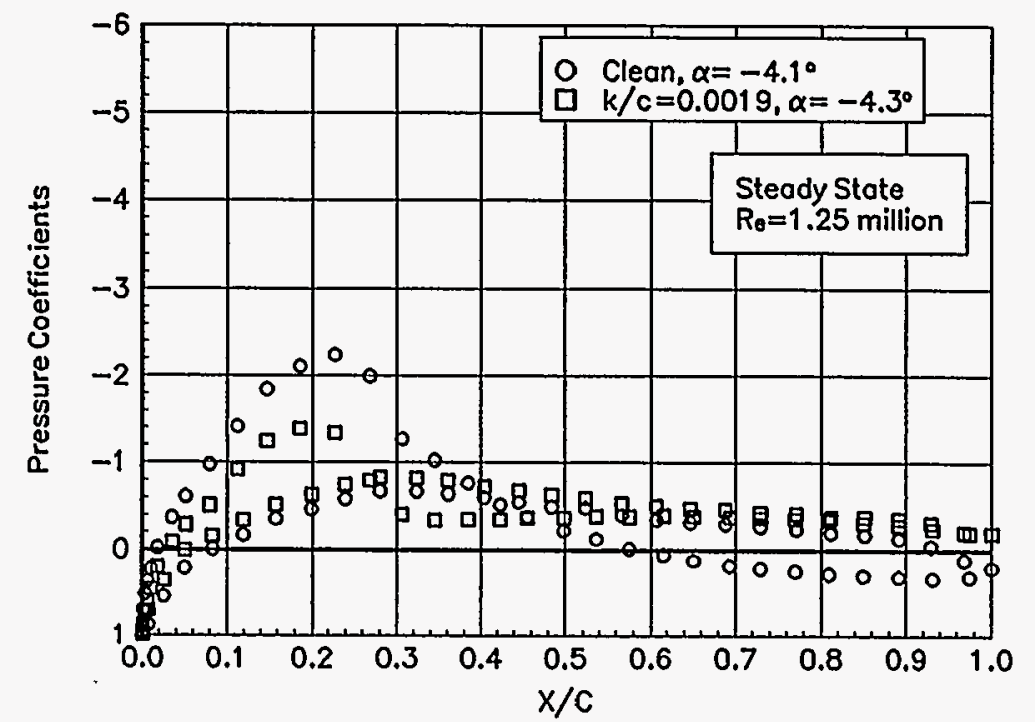

Figure 81. $\alpha=-4.1^{\circ}$

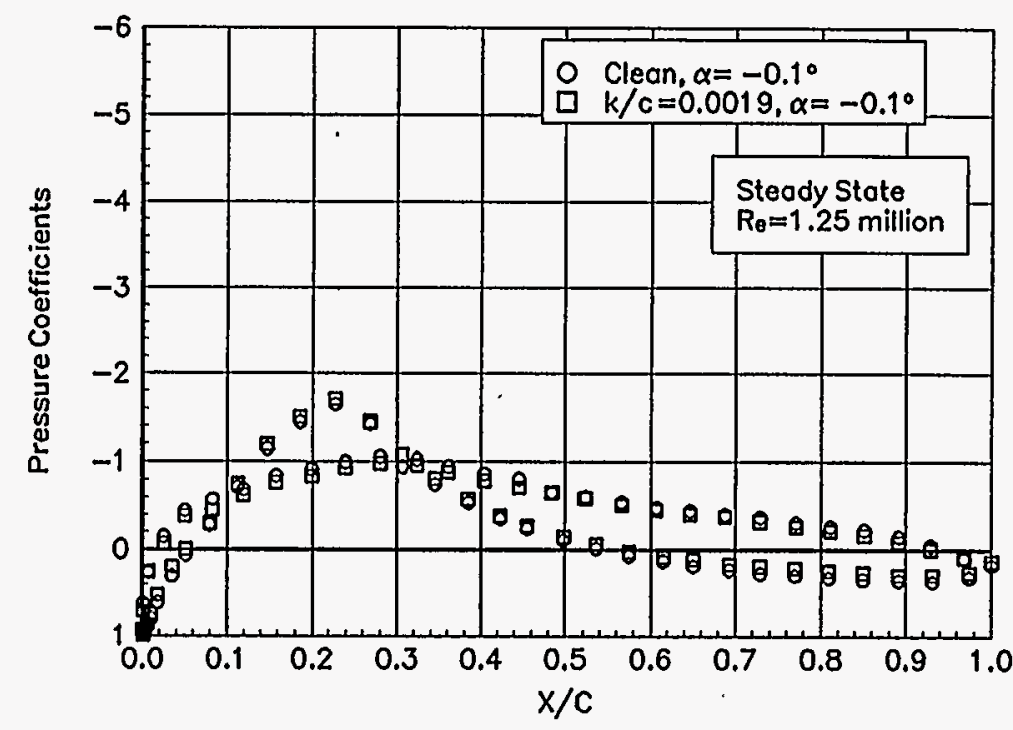

Figure 83. $a=-0.1^{\circ}$

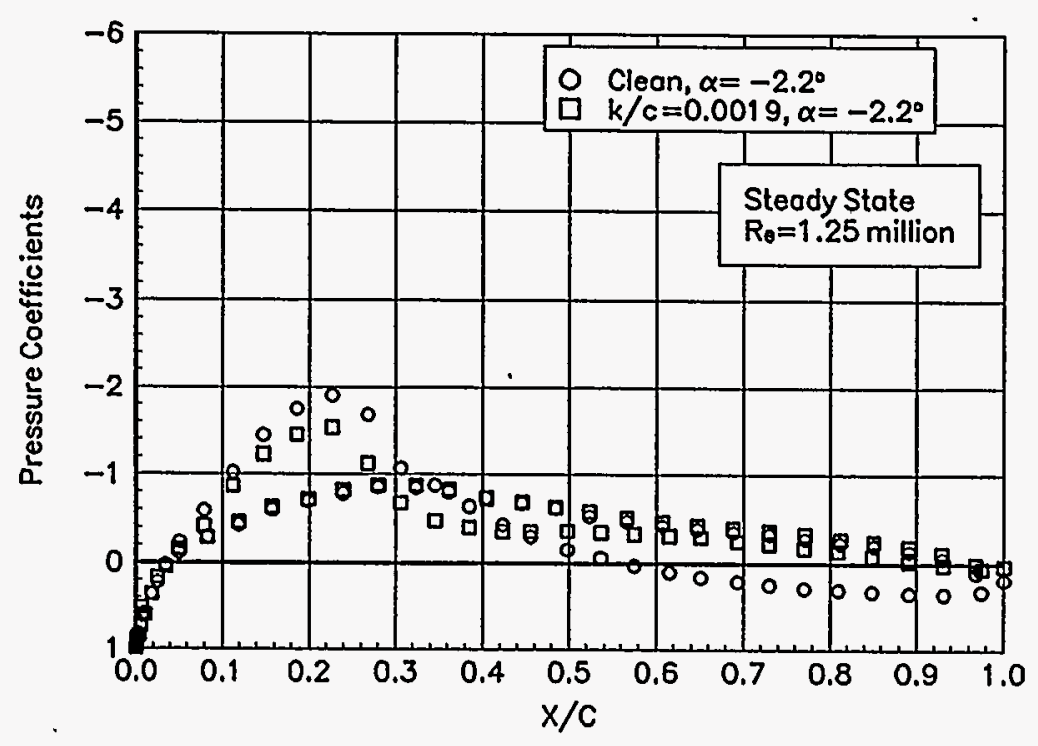

Figure 82. $a=-2.2^{\circ}$

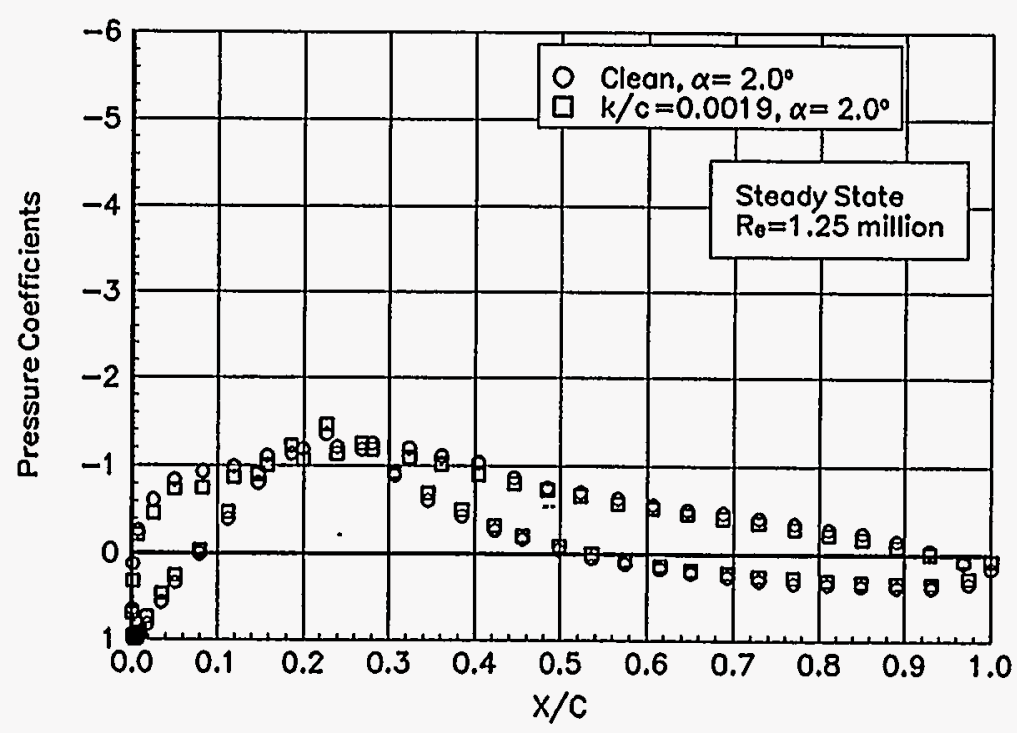

Figure 84. $a=2.0^{\circ}$ 


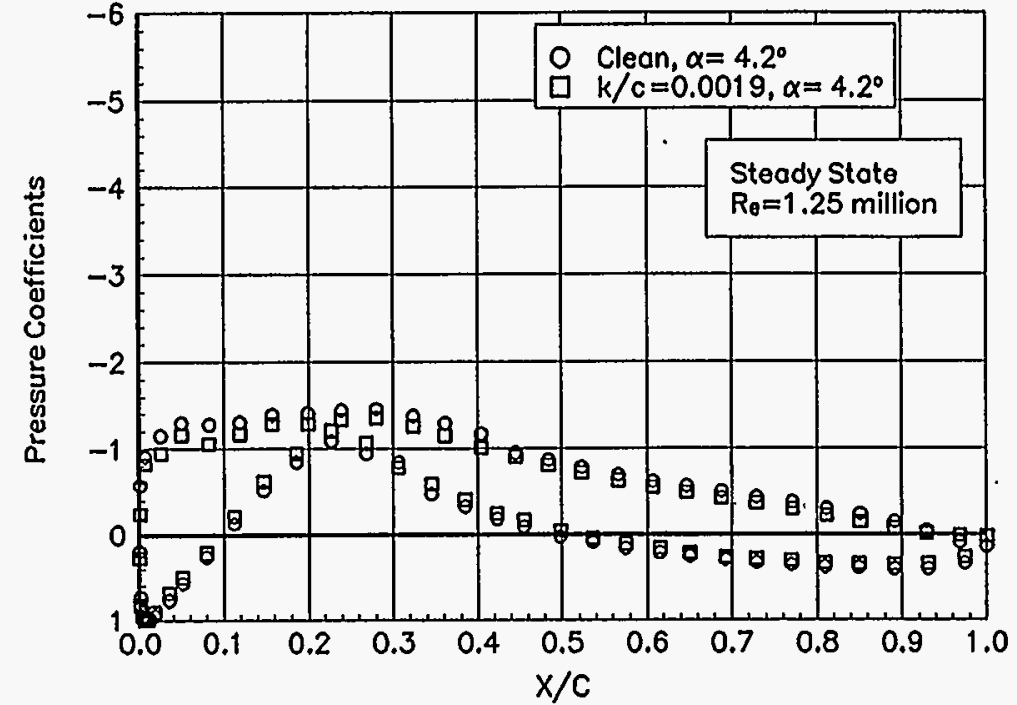

Figure 85. $a=4.2^{\circ}$

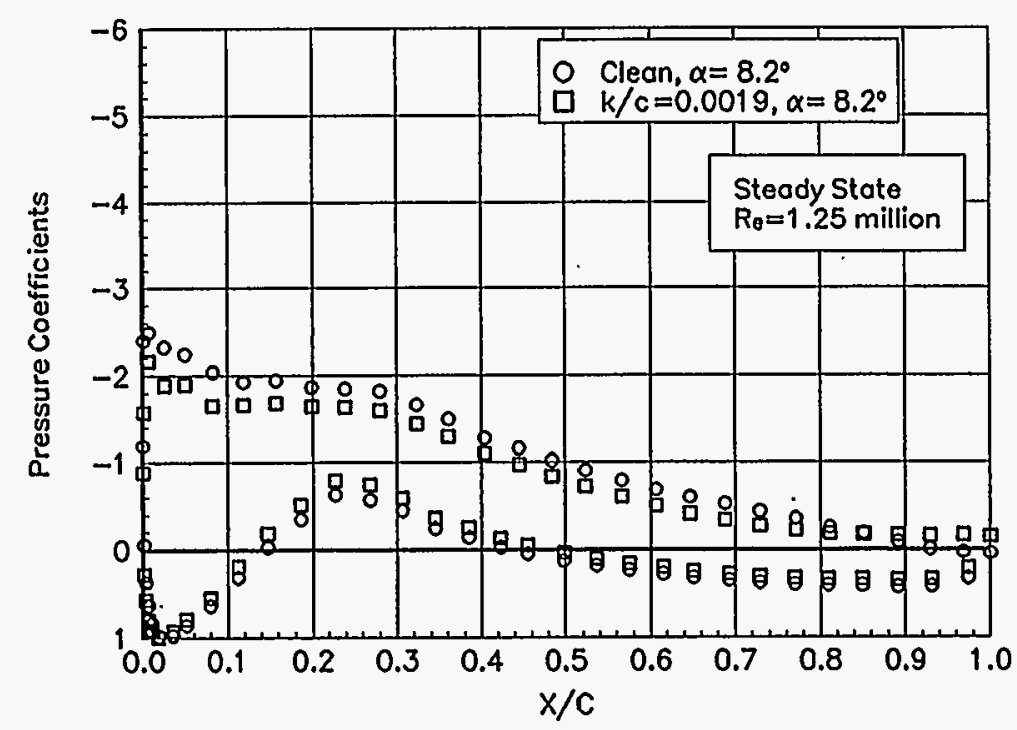

Figure 87. $a=8.2^{\circ}$

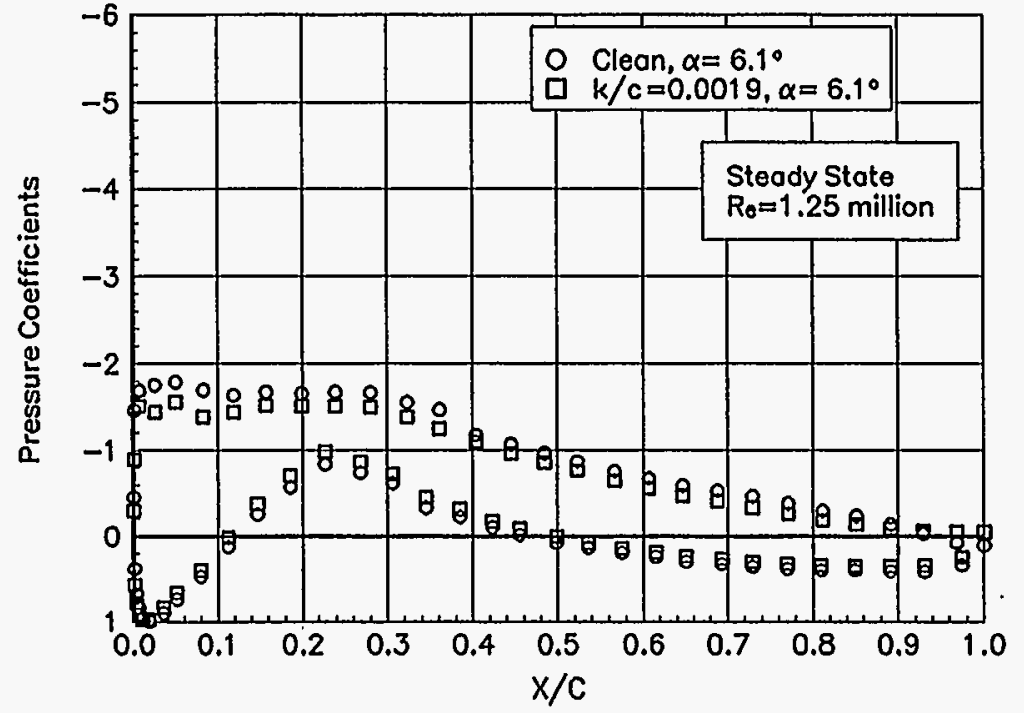

Figure 86. $\alpha=6.1^{\circ}$

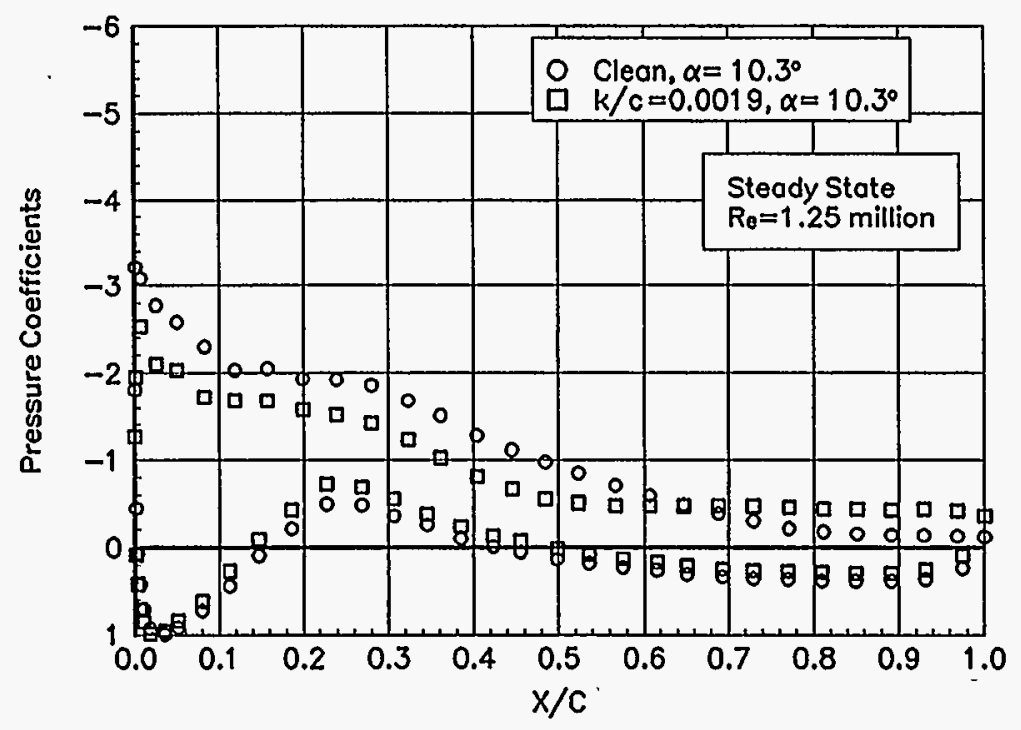

Figure 88. $a=10.3^{\circ}$ 


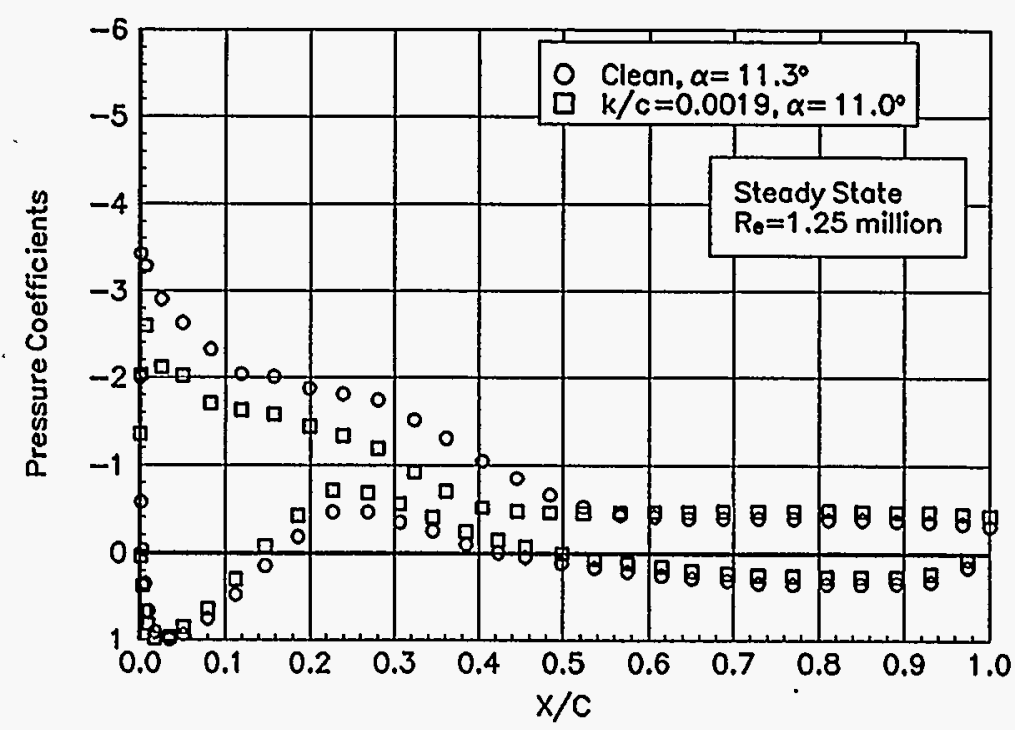

Figure 89. $a=11.3^{\circ}$

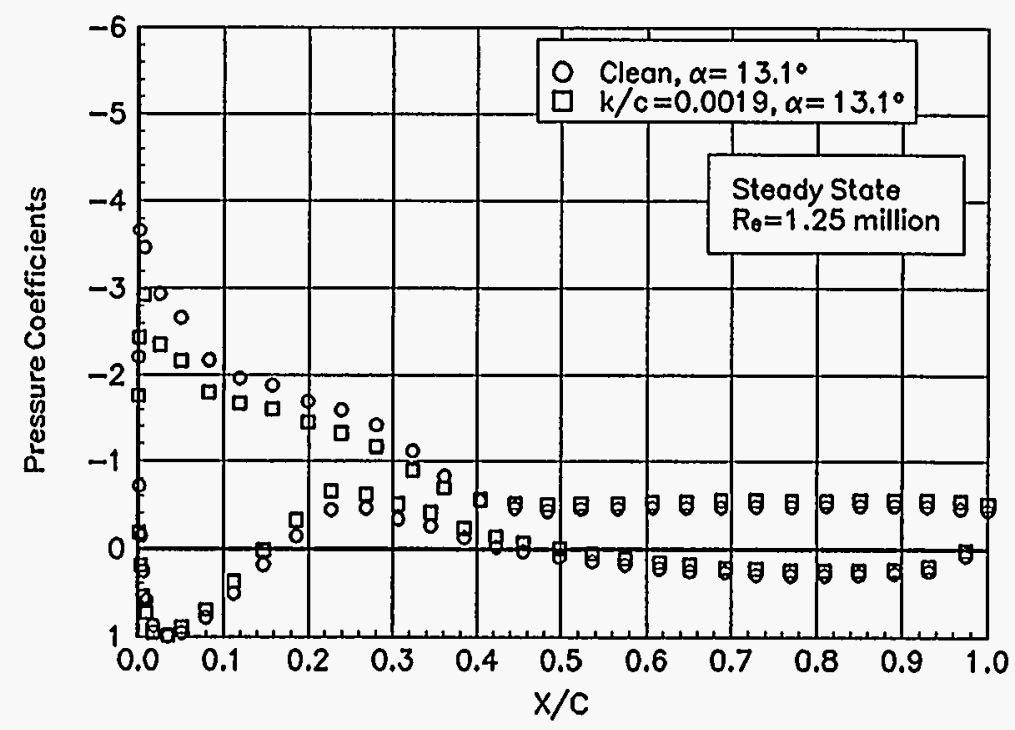

Figure 91. $a=13.1^{\circ}$

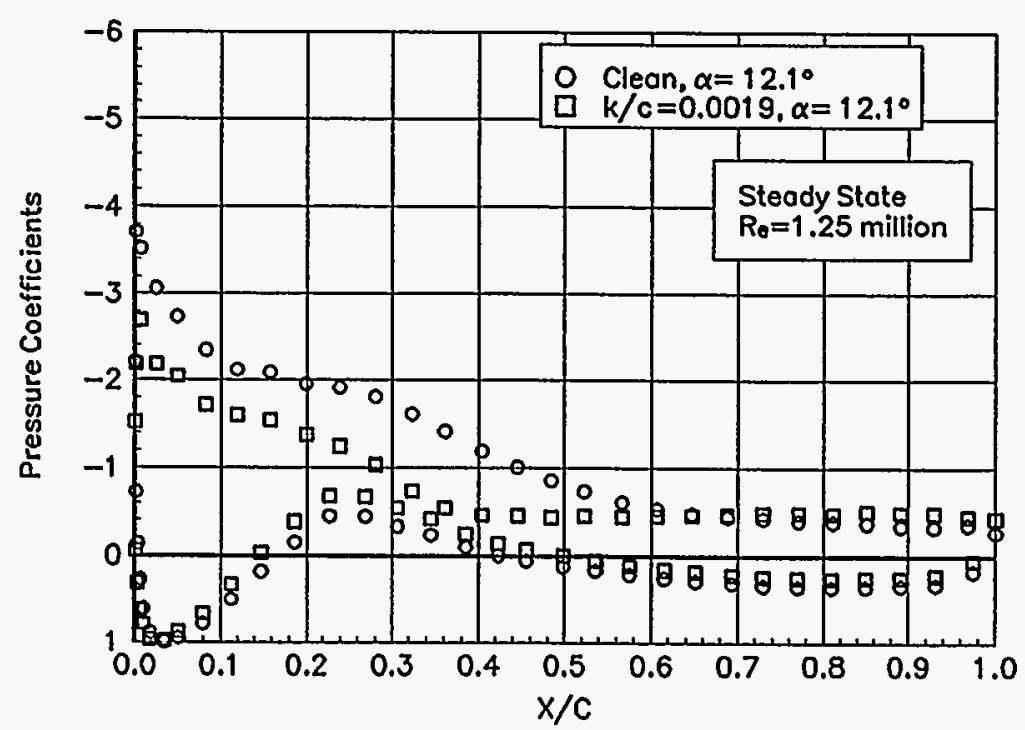

Figure 90. $a=12.1^{\circ}$

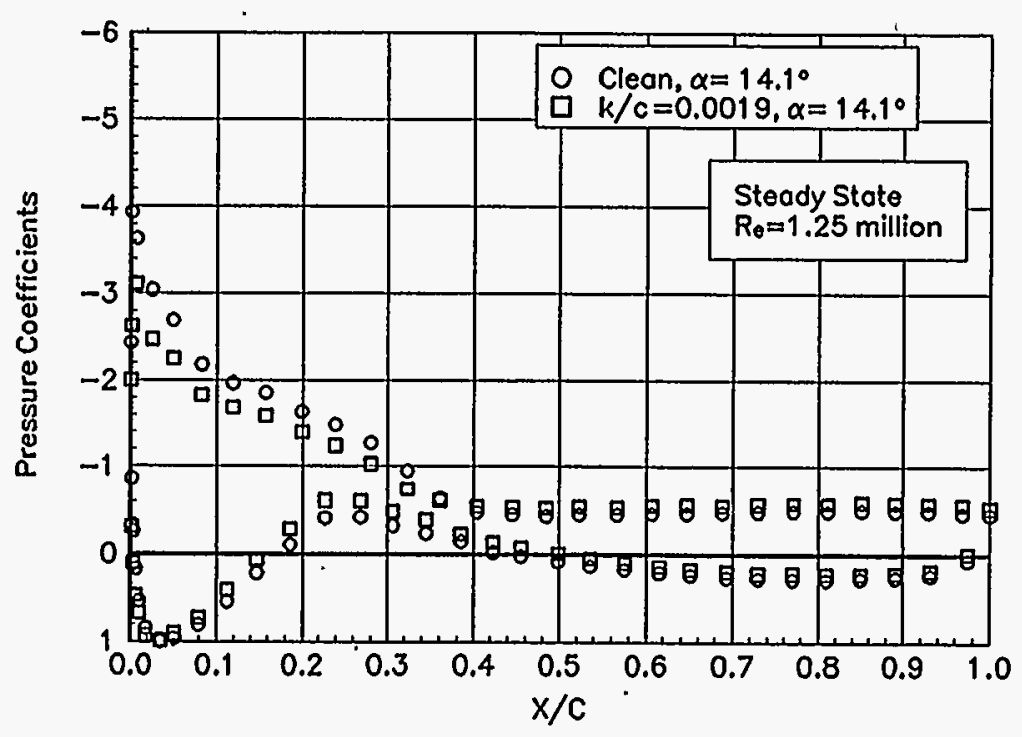

Figure 92. $a=14.1^{\circ}$ 


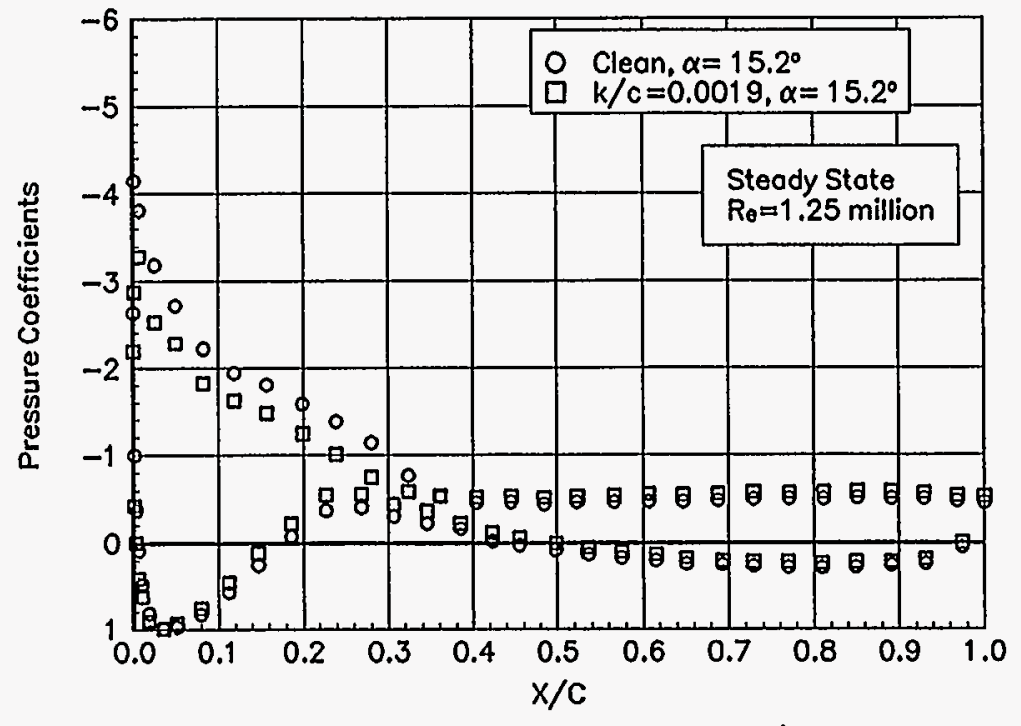

Figure 93. $a=15.2^{\circ}$

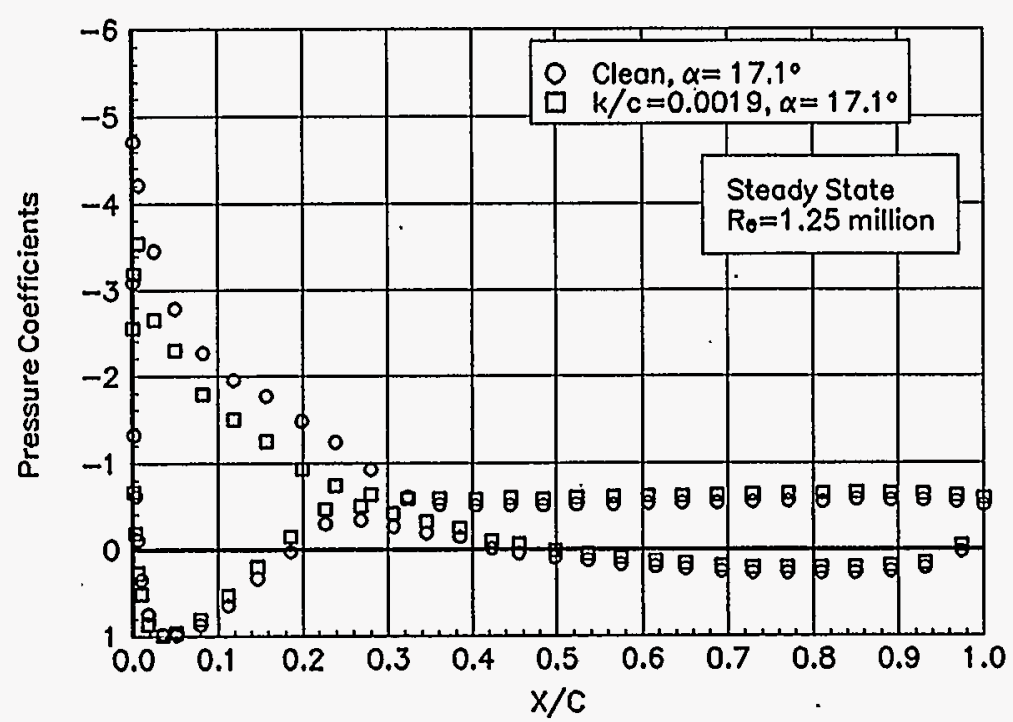

Figure 95. $a=17.1^{\circ}$

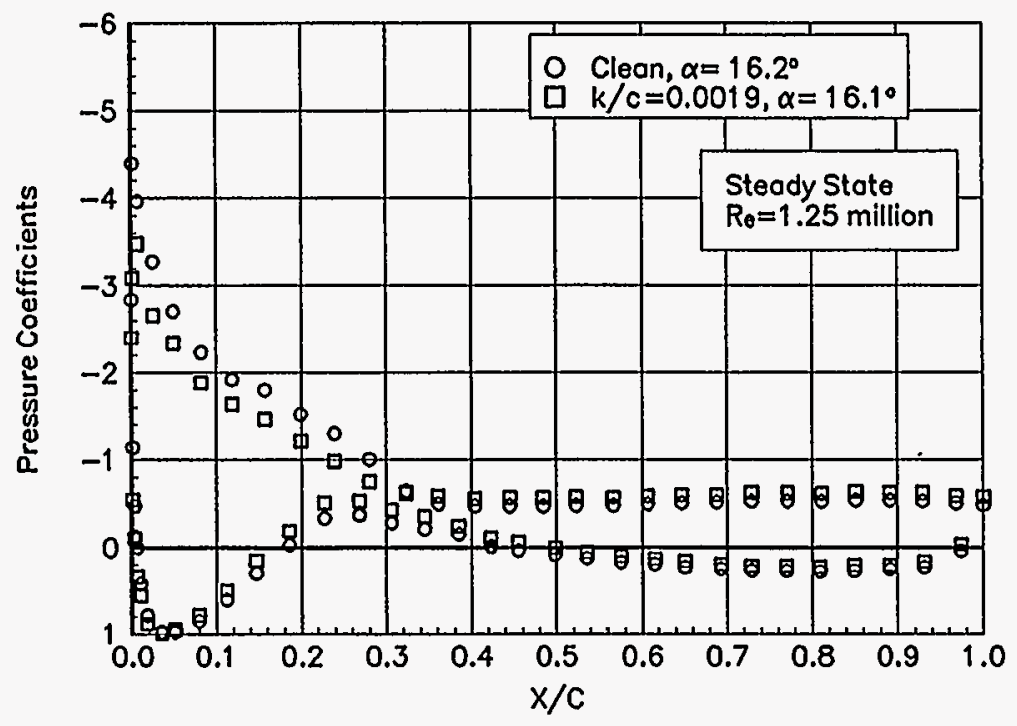

Figure 94. $a=16.2^{\circ}$

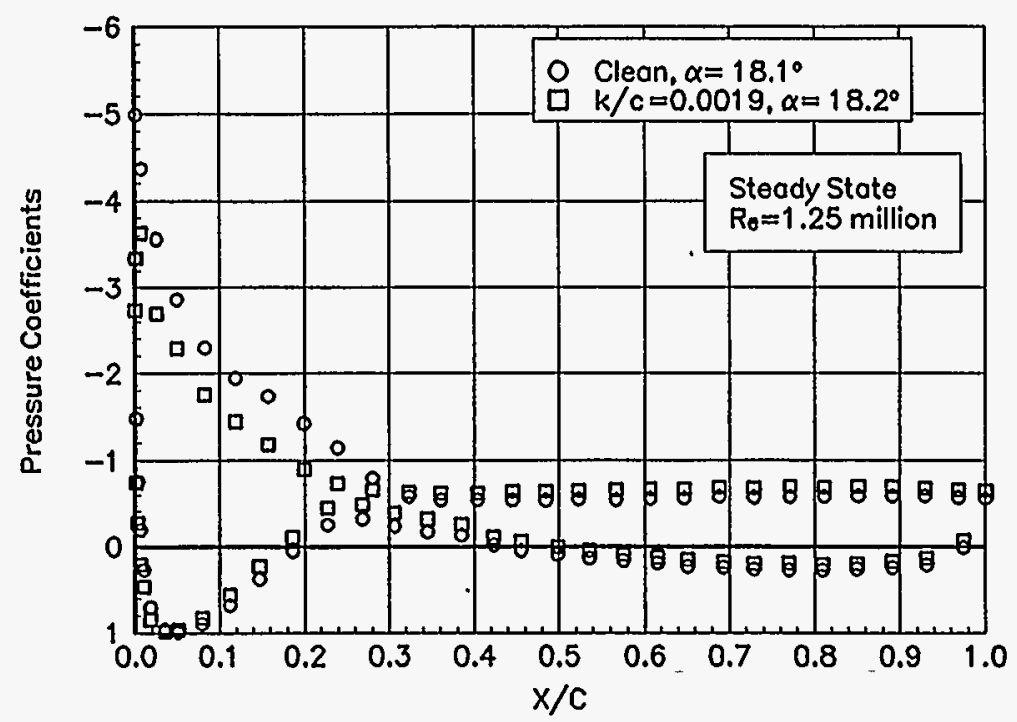

Figure 96. $a=18.1^{\circ}$ 


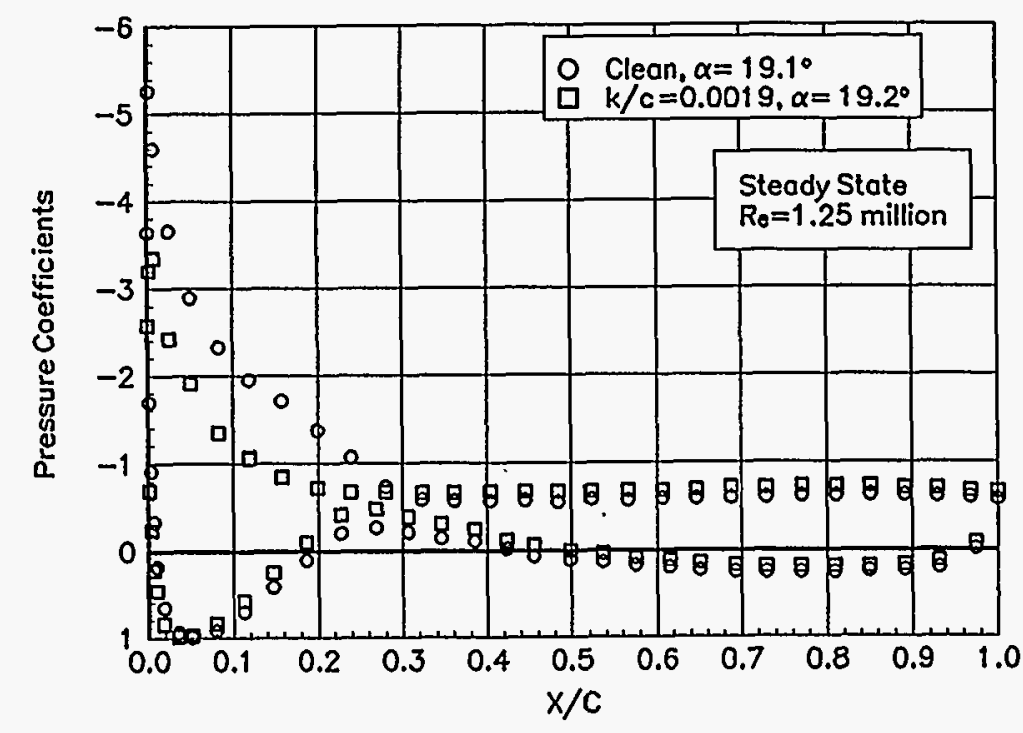

Figure 97. $\alpha=19.1^{\circ}$

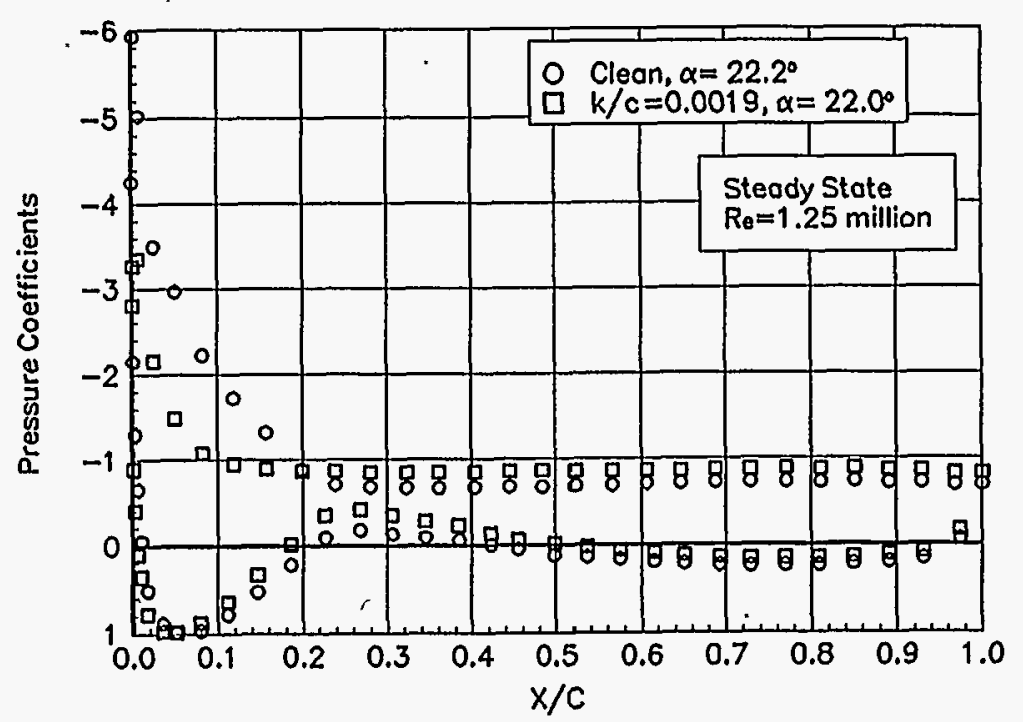

Figure 99. $a=22.2^{\circ}$

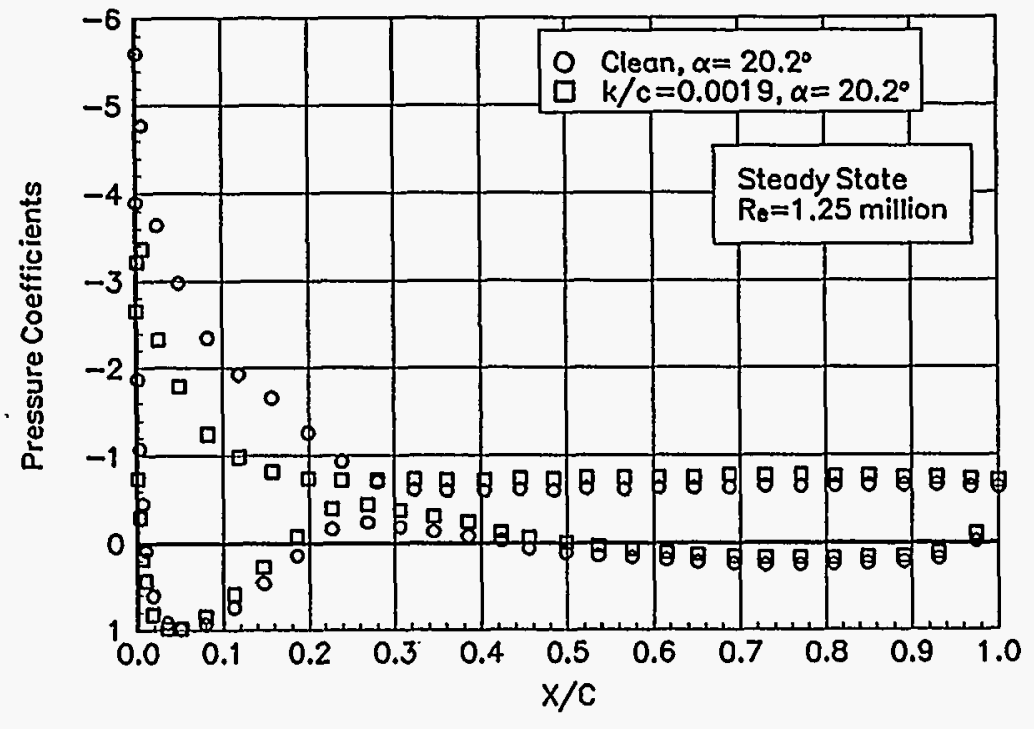

Figure 98. $a=20.2^{\circ}$

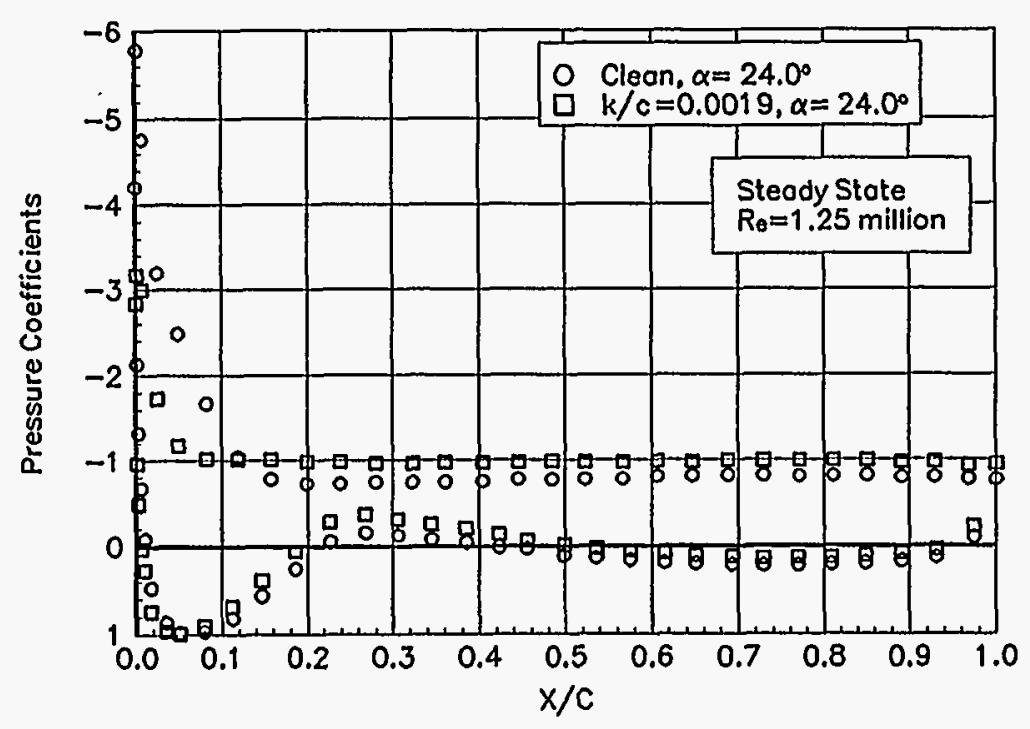

Figure 100. $a=24.0^{\circ}$ 


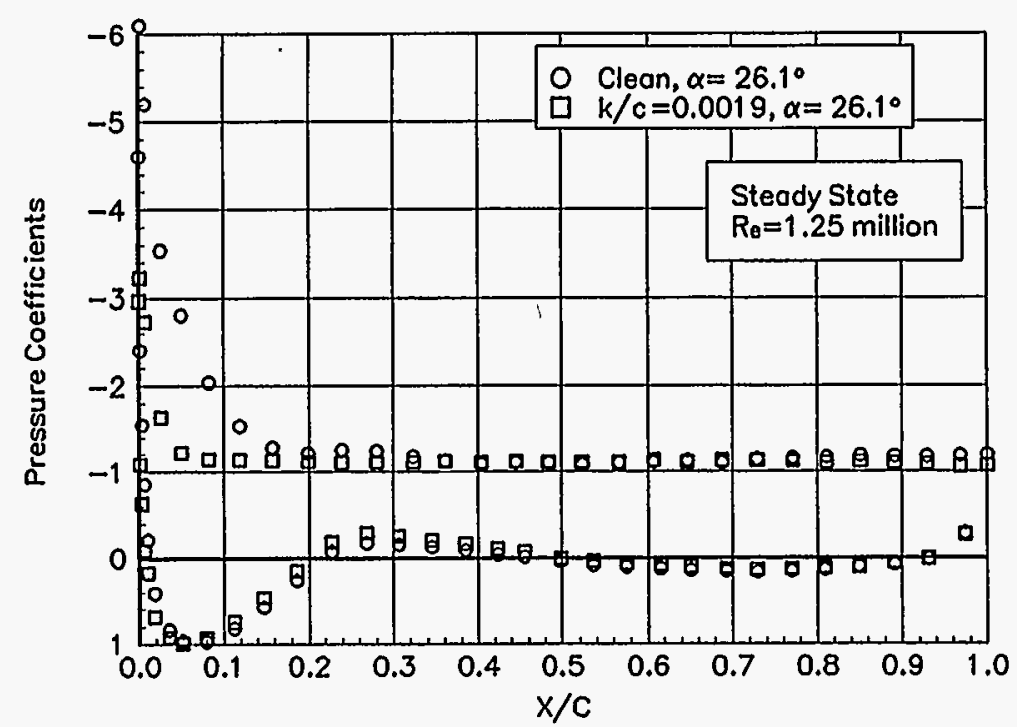

Figure 101. $a=26.1^{\circ}$

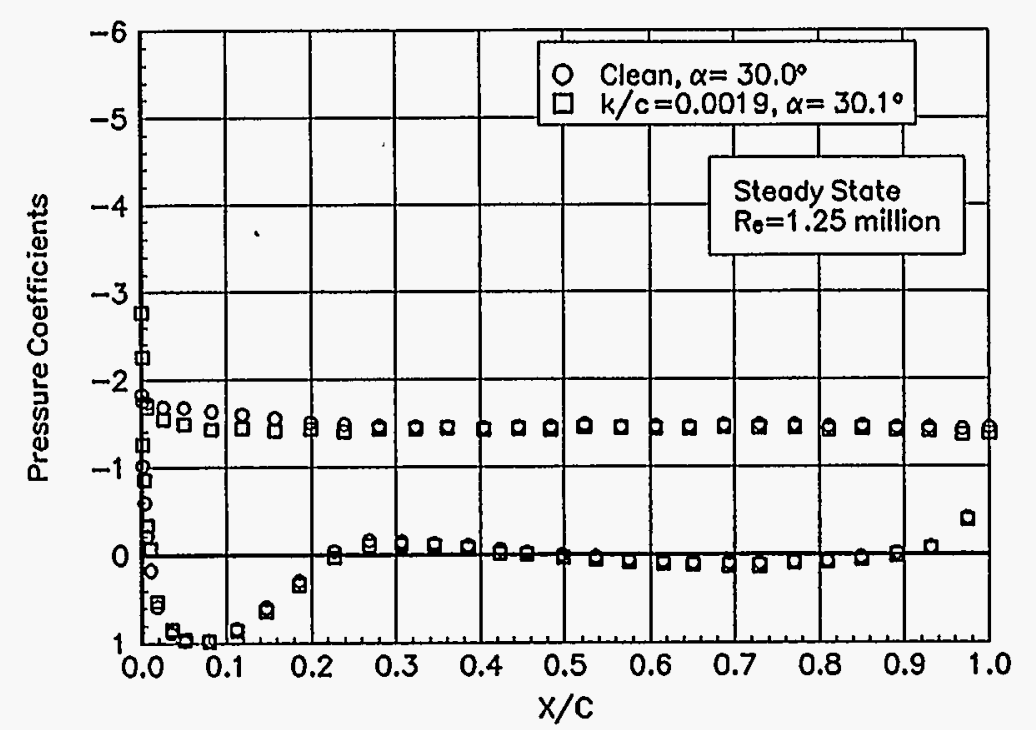

Figure 103. $a=30.0^{\circ}$

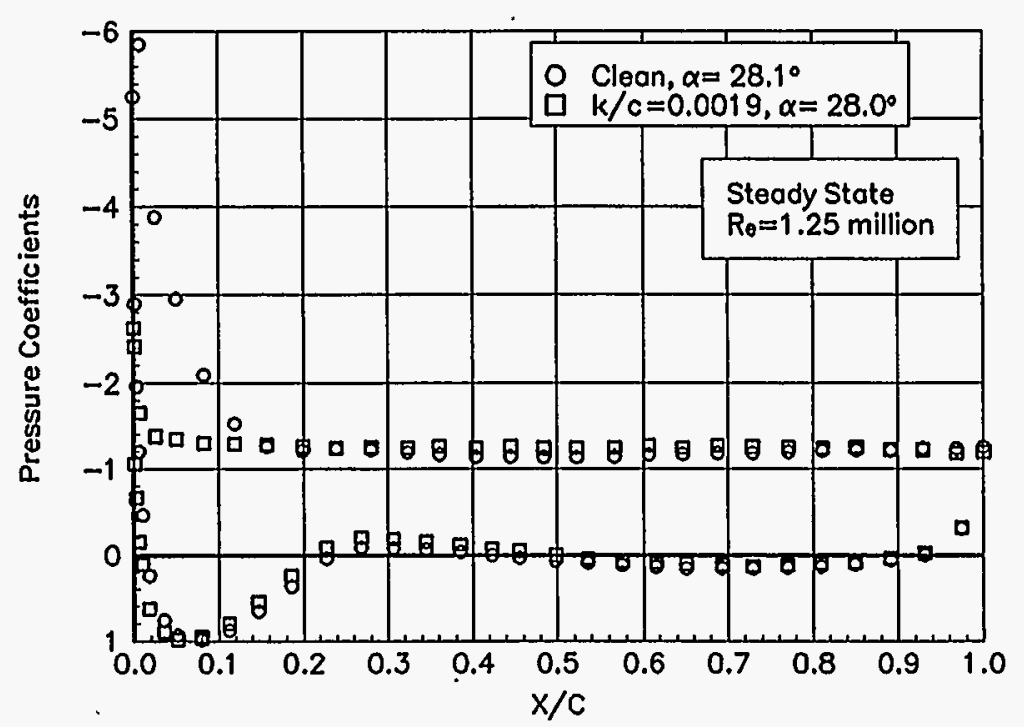

Figure 102. $a=28.1^{\circ}$

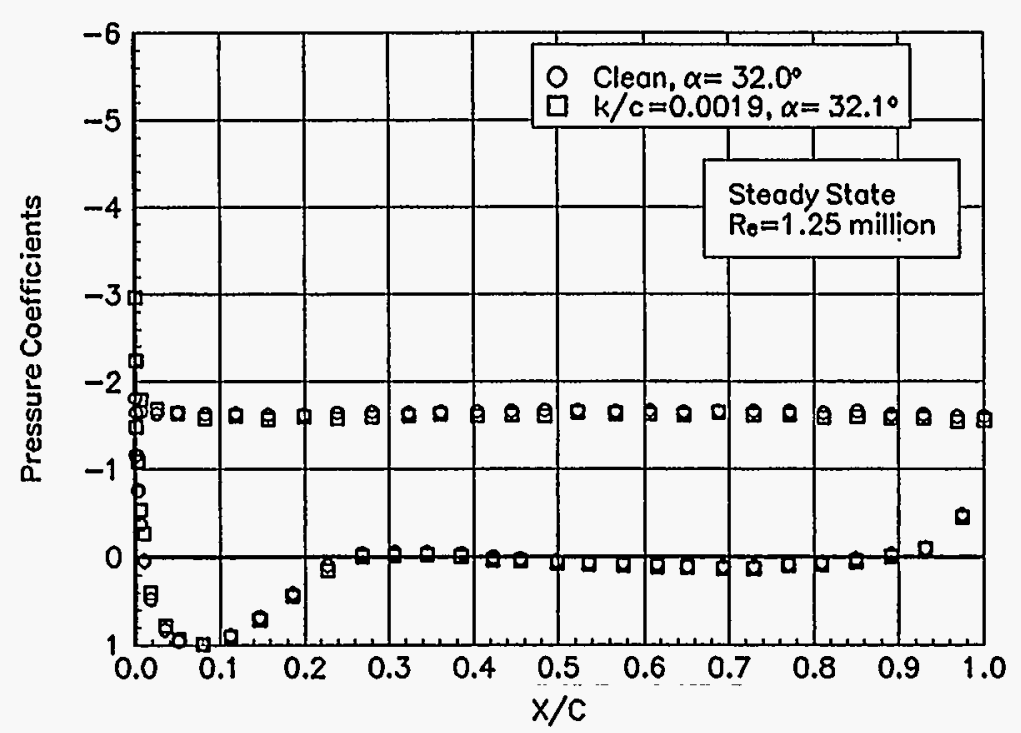

Figure 104. $a=32.0^{\circ}$ 


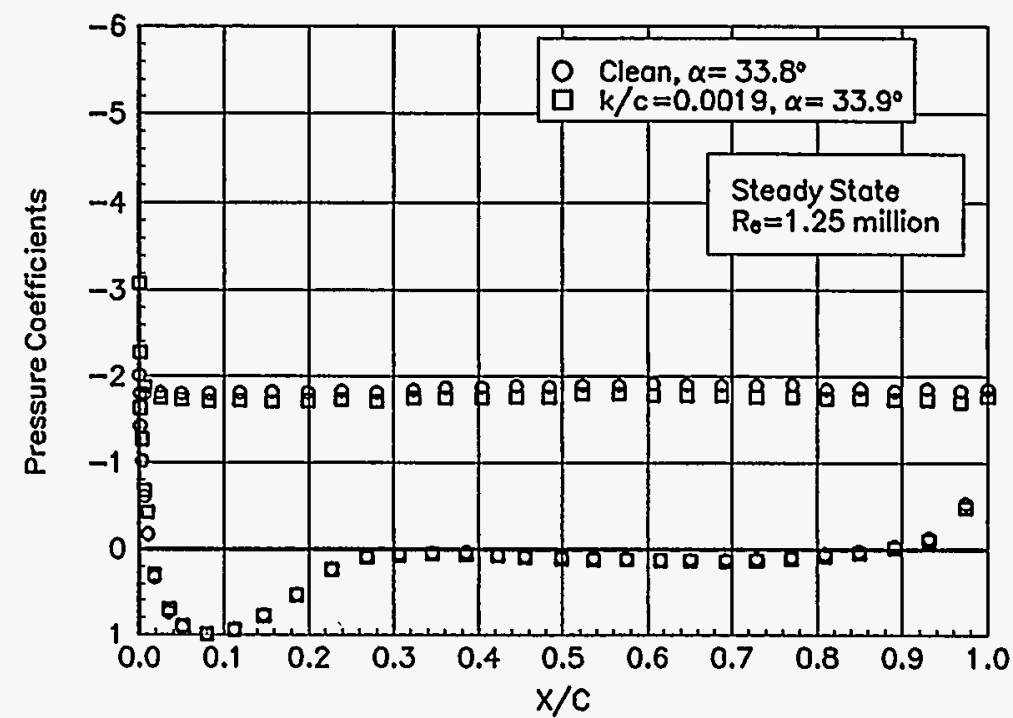

Figure 105. $a=33.8^{\circ}$

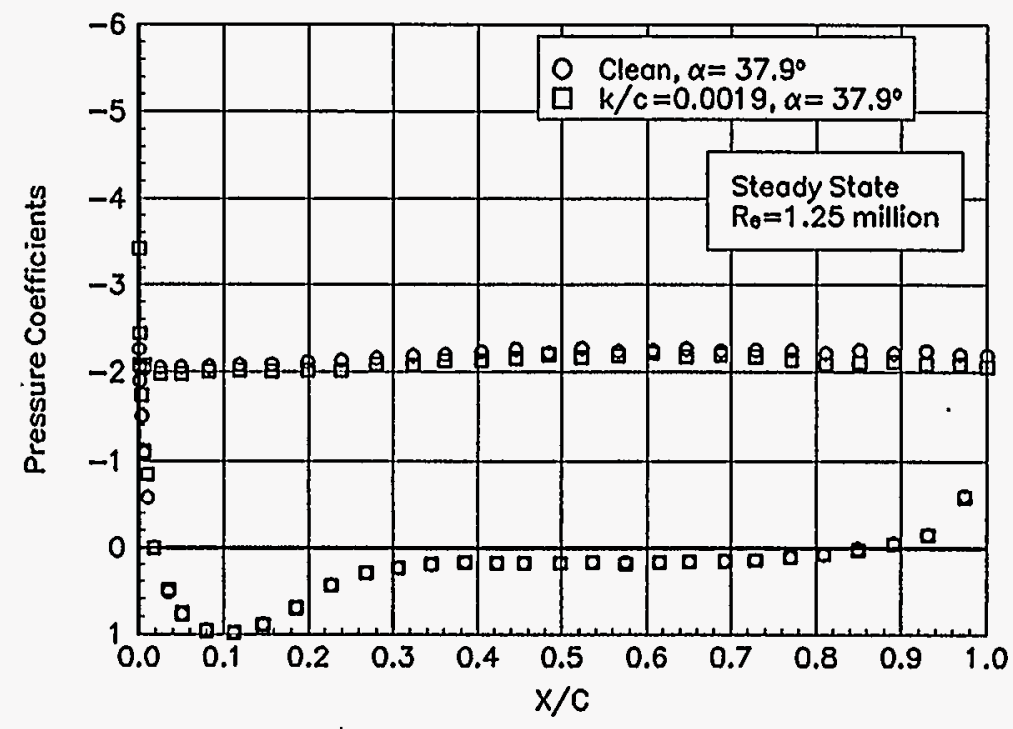

Figure 107. $\alpha=37.9^{\circ}$

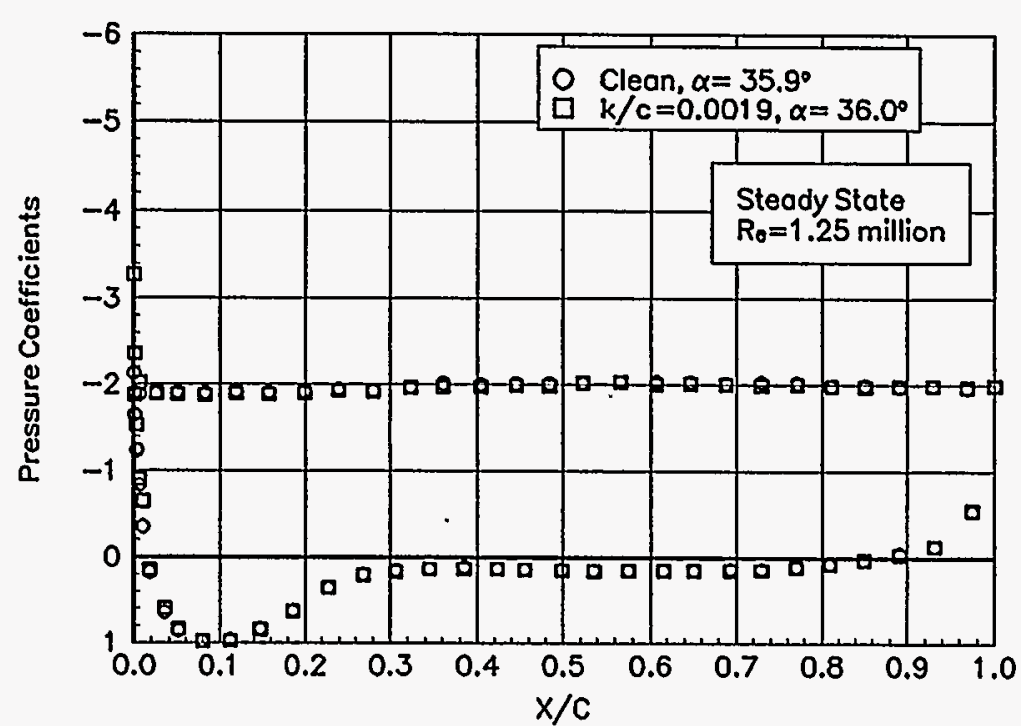

Figure 106. $a=35.9^{\circ}$

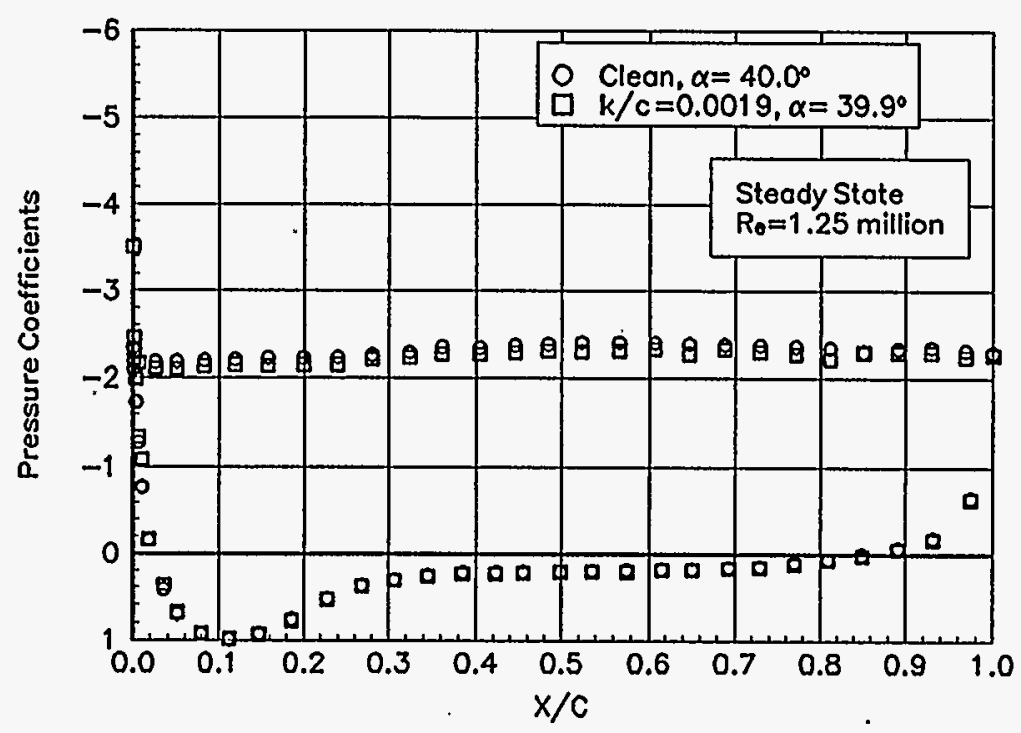

Figure 108. $a=40.0^{\circ}$ 
5815

Pressure Distributions, Steady State, $R e=1.4$ million 
5815

Pressure Coefficient Distribution

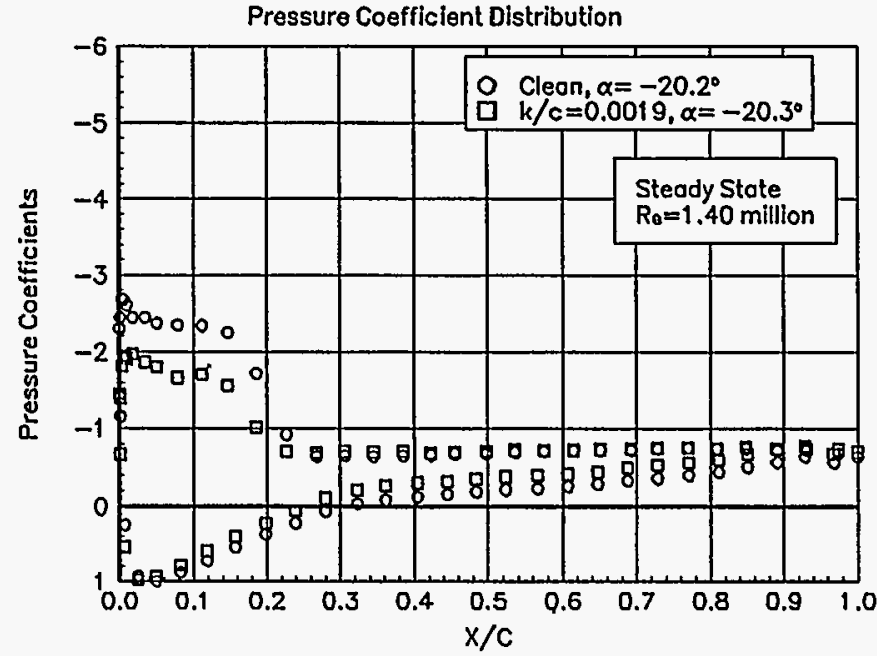

Figure 109. $a=-20.2^{\circ}$

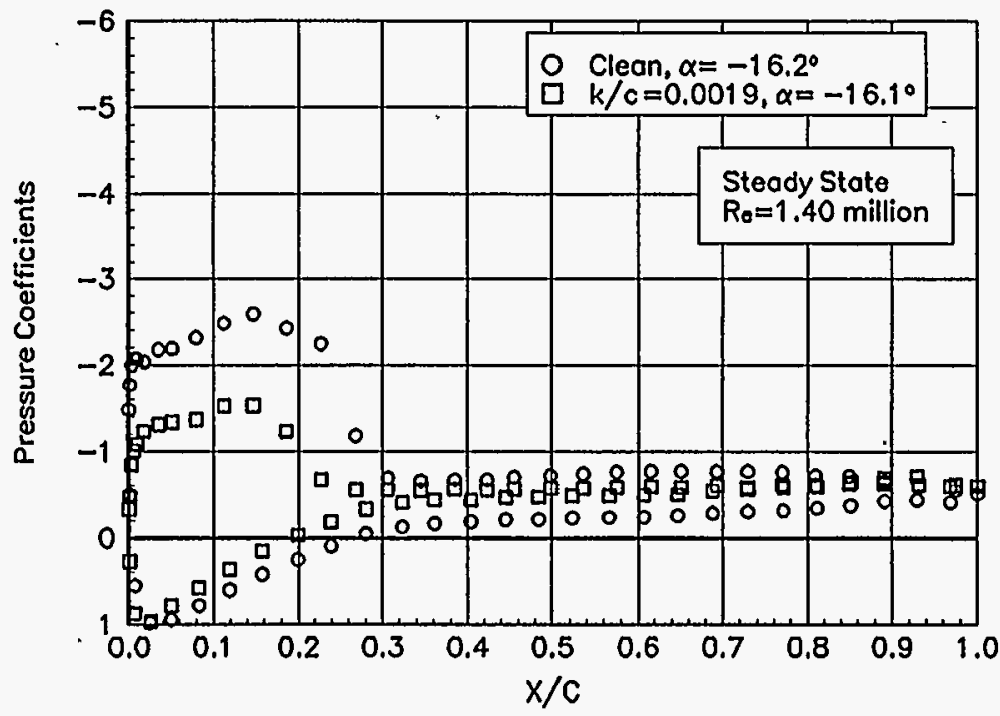

Figure 111. $a=-16.2^{\circ}$

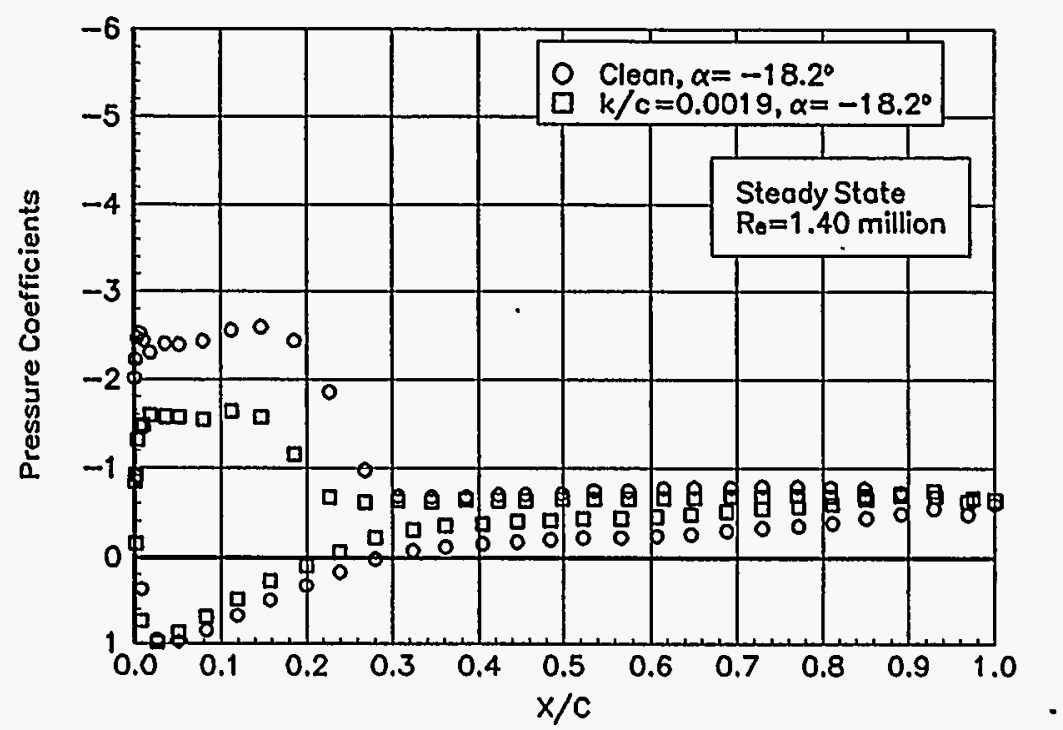

Figure 110. $a=-18.2^{\circ}$

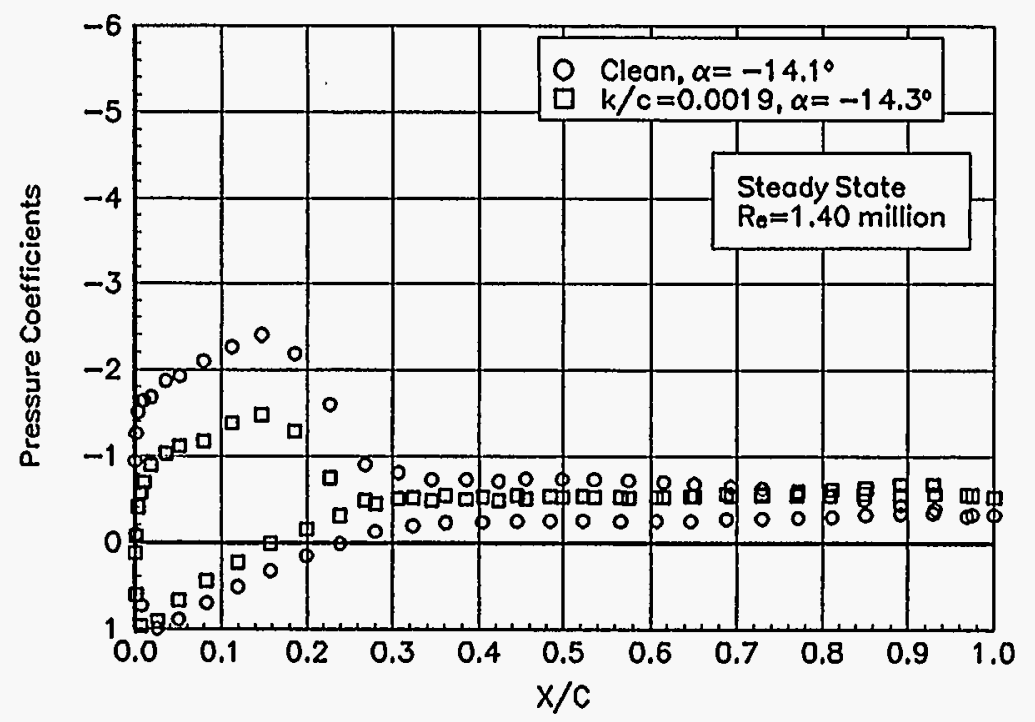

Figure 112. $a=-14.1^{\circ}$ 


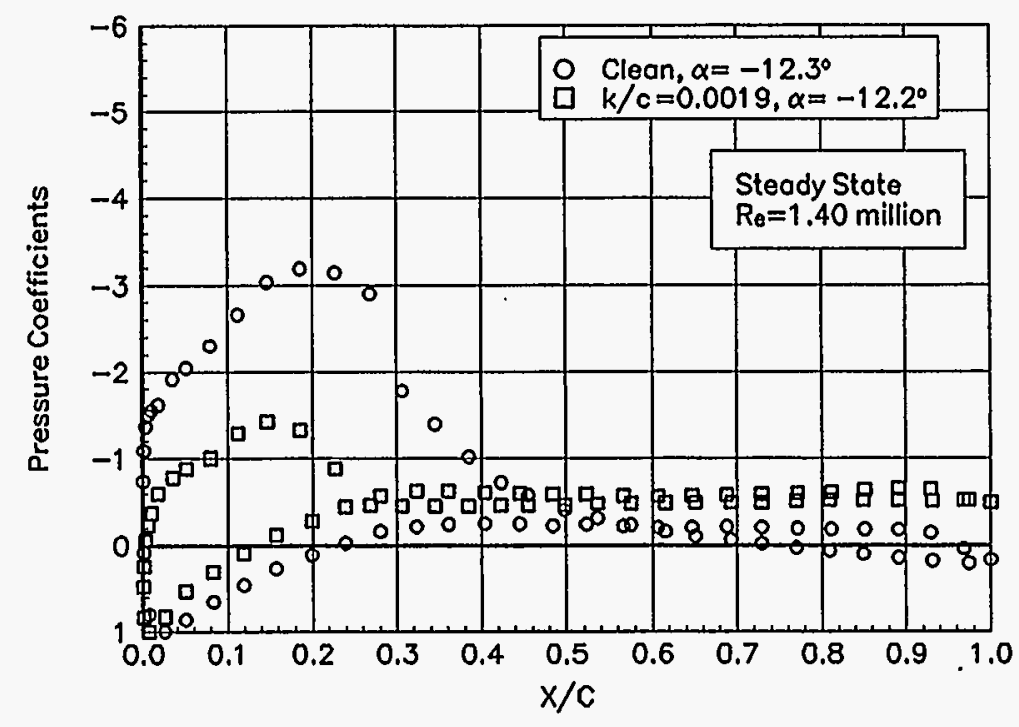

Figure 113. $\alpha=-12.3^{\circ}$

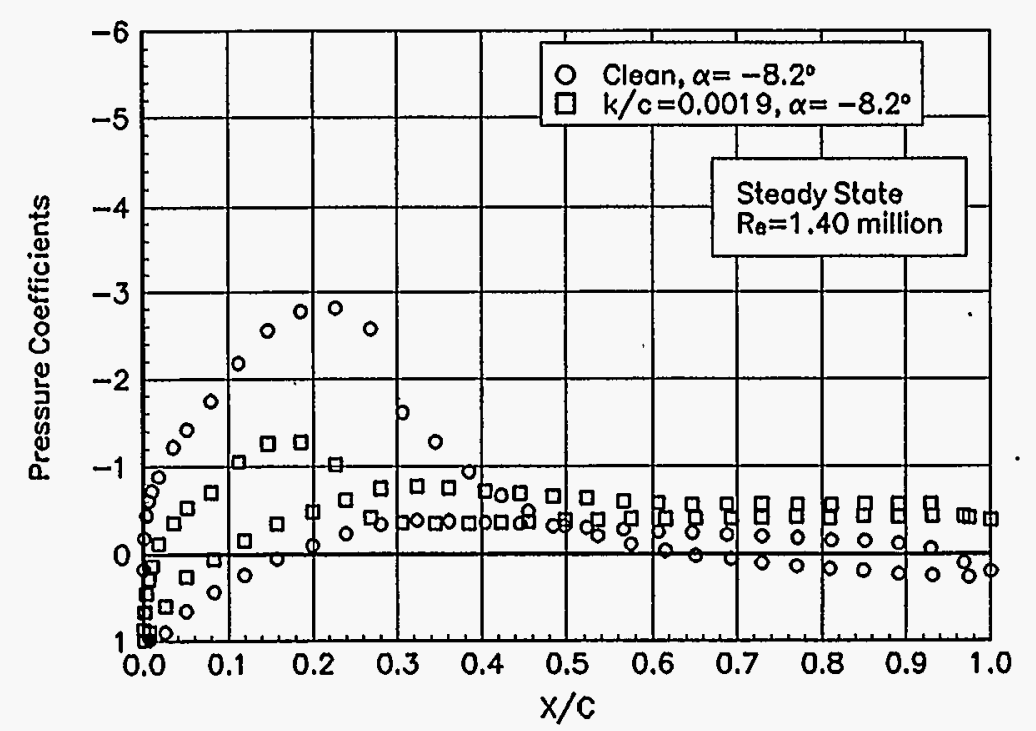

Figure 115. $a=-8.2^{\circ}$

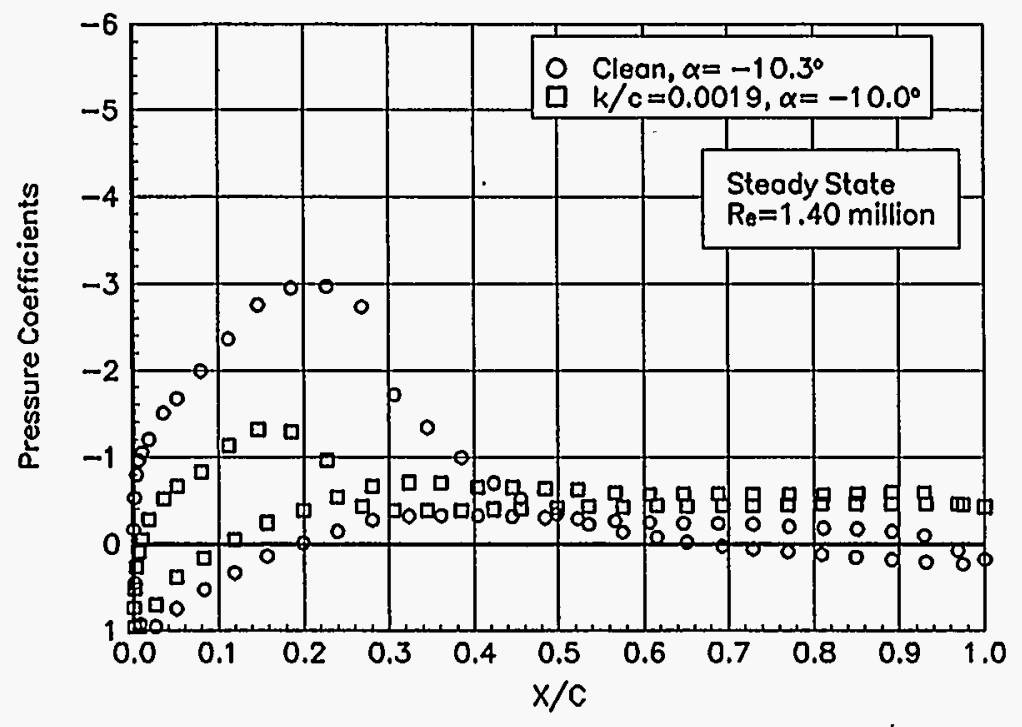

Figure 114. $a=-10.3^{\circ}$

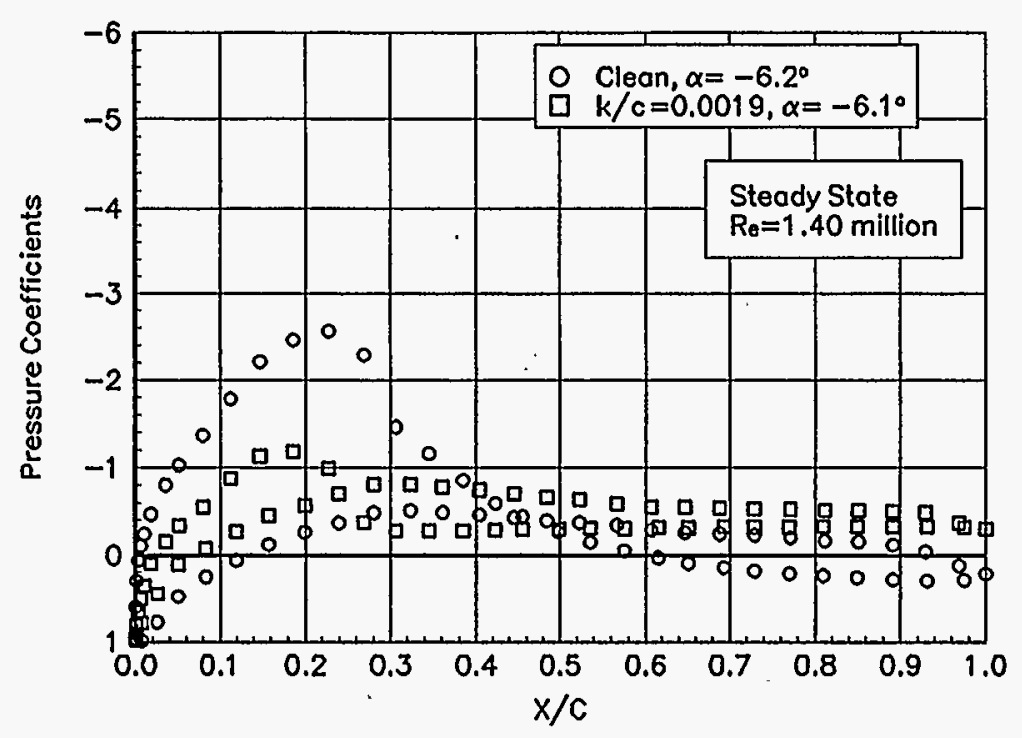

Figure 116. $a=-6.2^{\circ}$ 


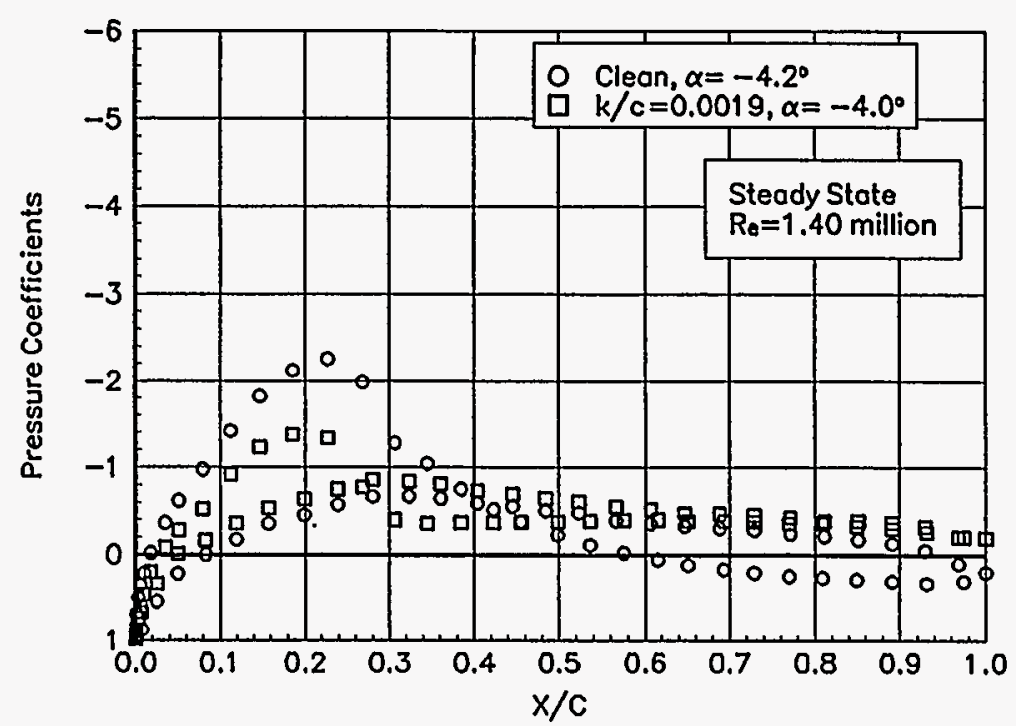

Figure 117. $a=-4.2^{\circ}$

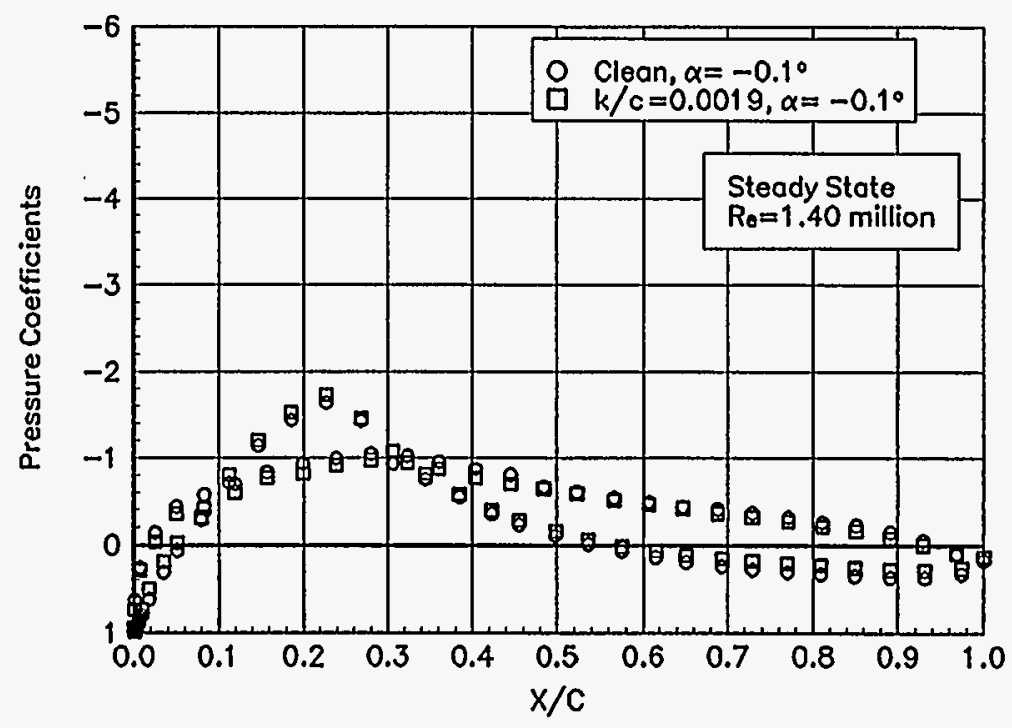

Figure 119. $a=-0.1^{\circ}$

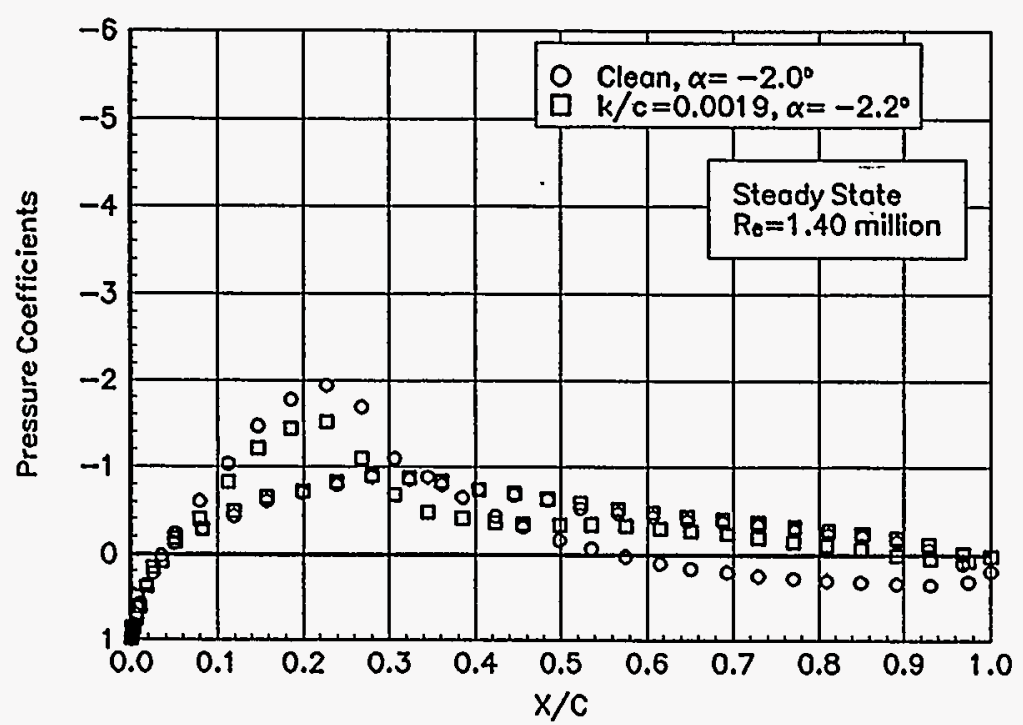

Figure 118. $a=-2.0^{\circ}$

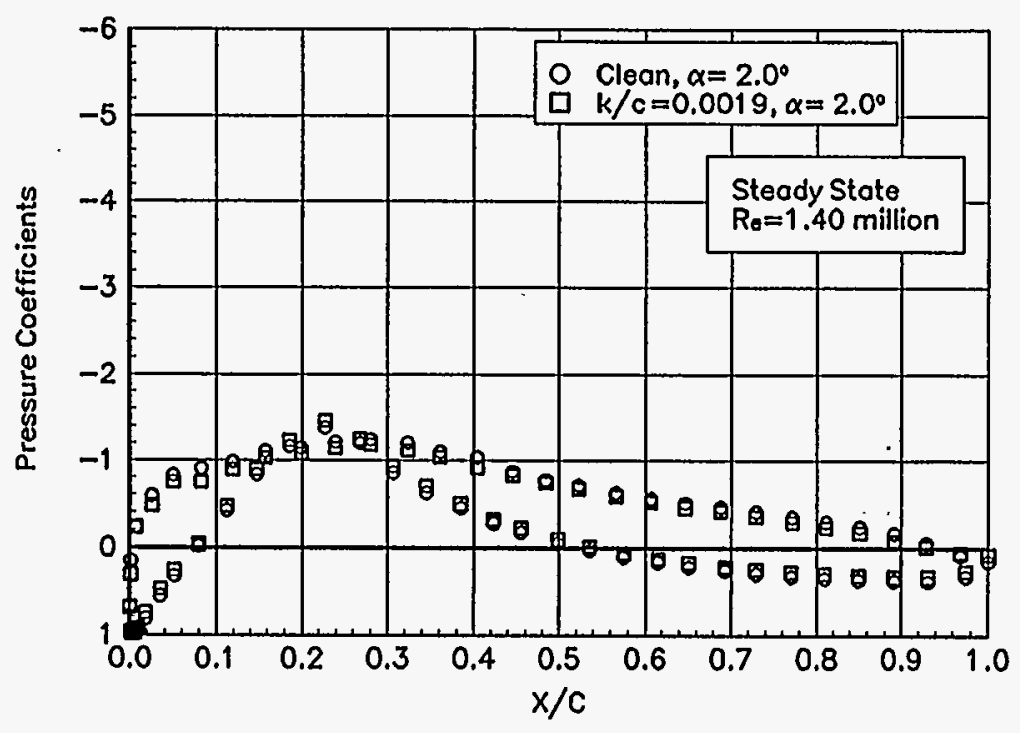

Figure 120. $a=2.0^{\circ}$ 


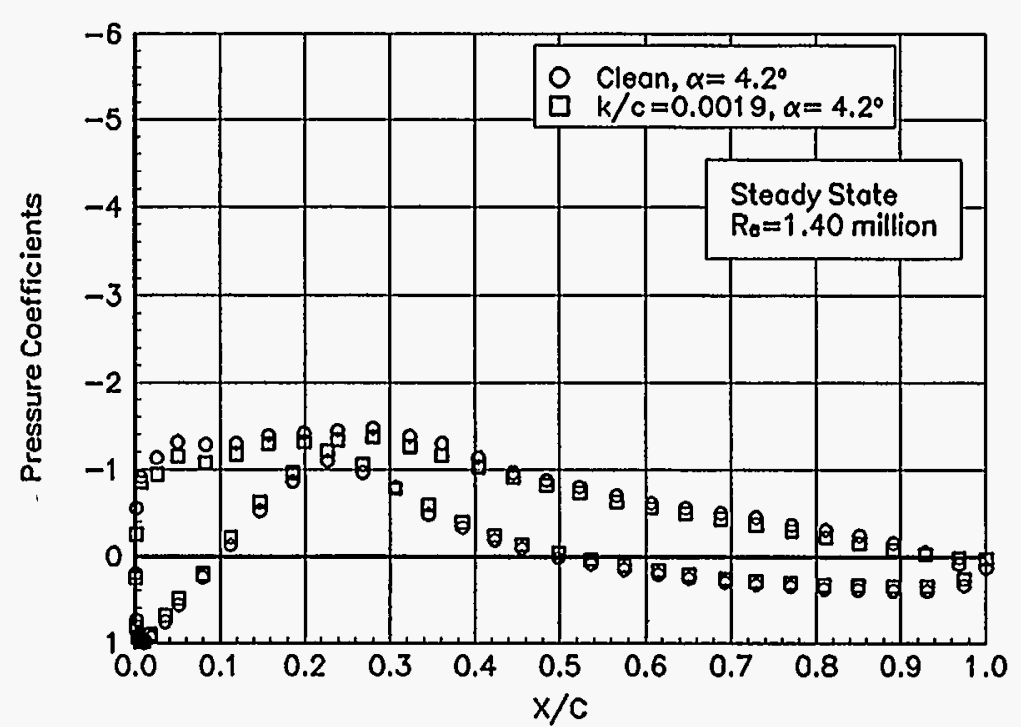

Figure 121. $a=4.2^{\circ}$

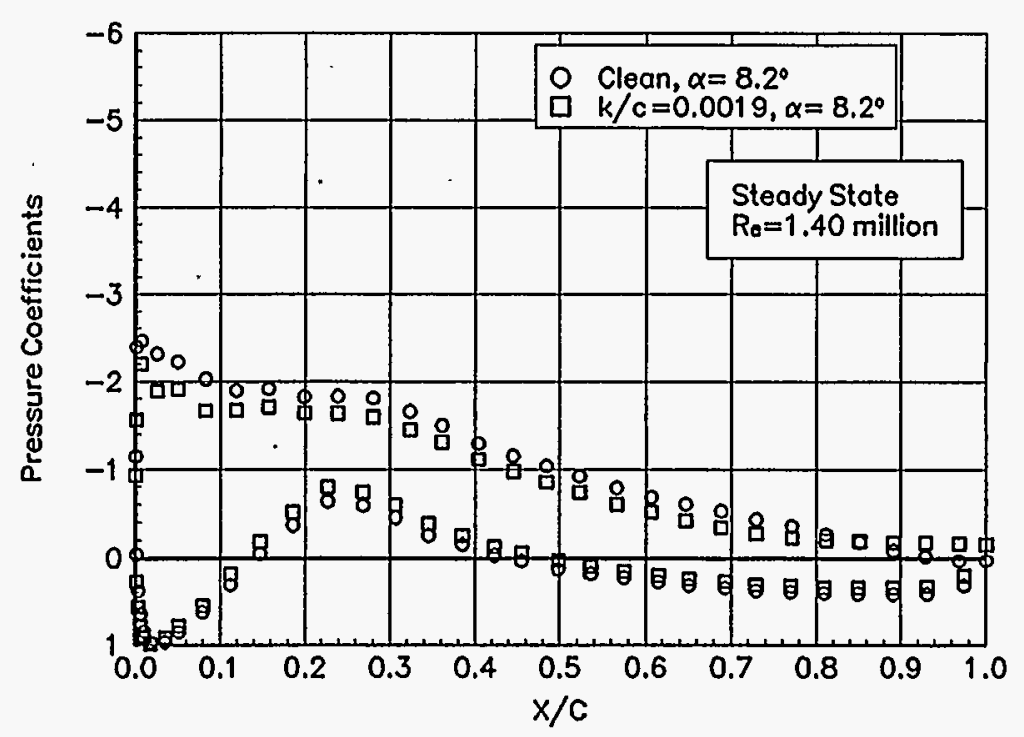

Figure 123. $\alpha=8.2^{\circ}$

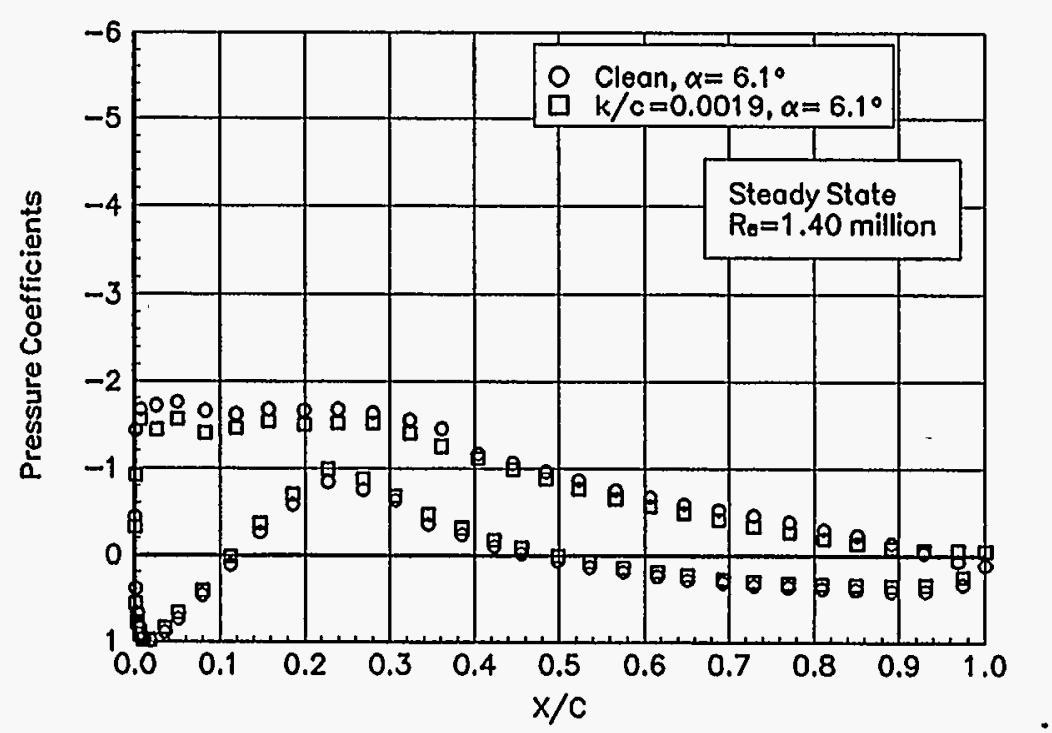

Figure 122. $\alpha=6.1^{\circ}$

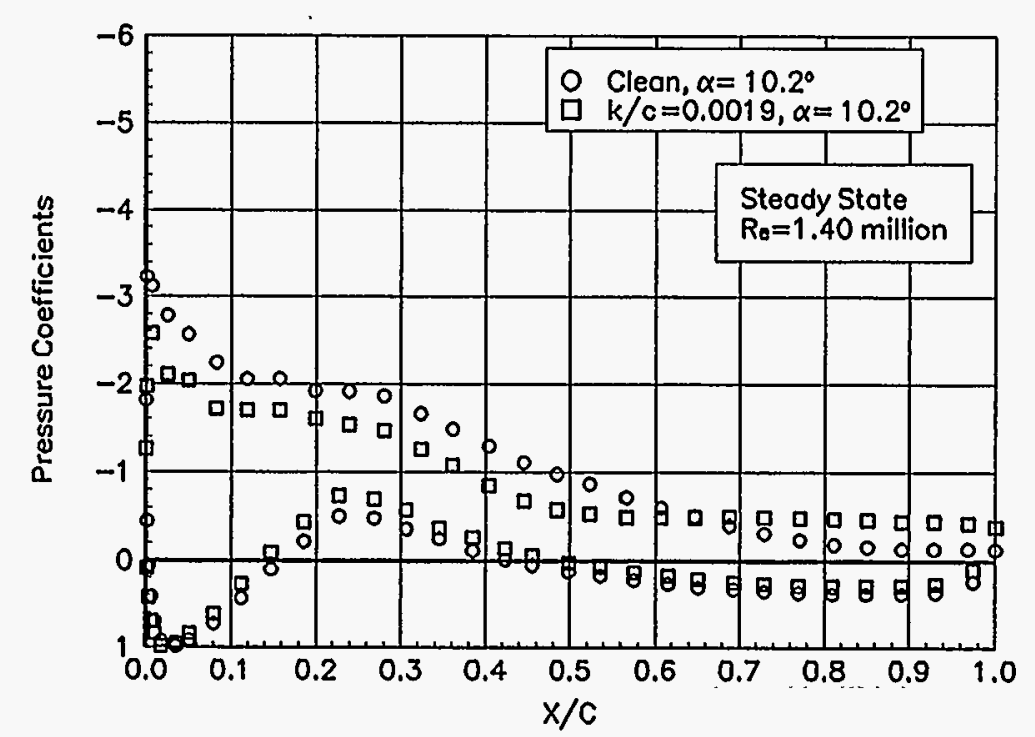

Figure 124. $a=10.2^{\circ}$ 


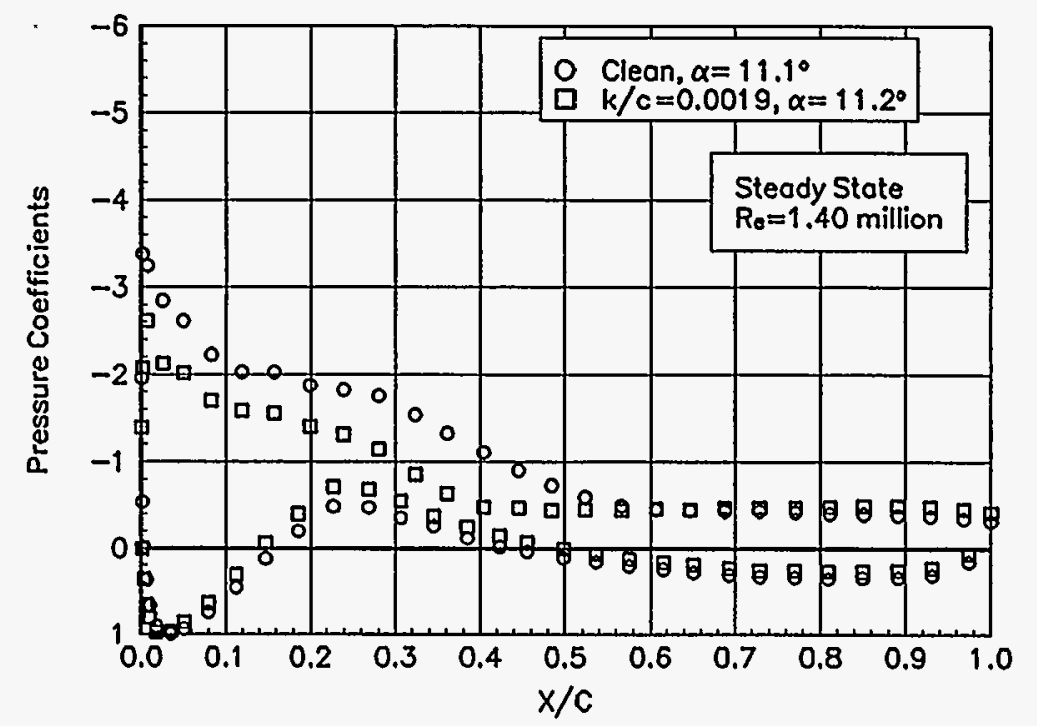

Figure 125. $a=11.1^{\circ}$

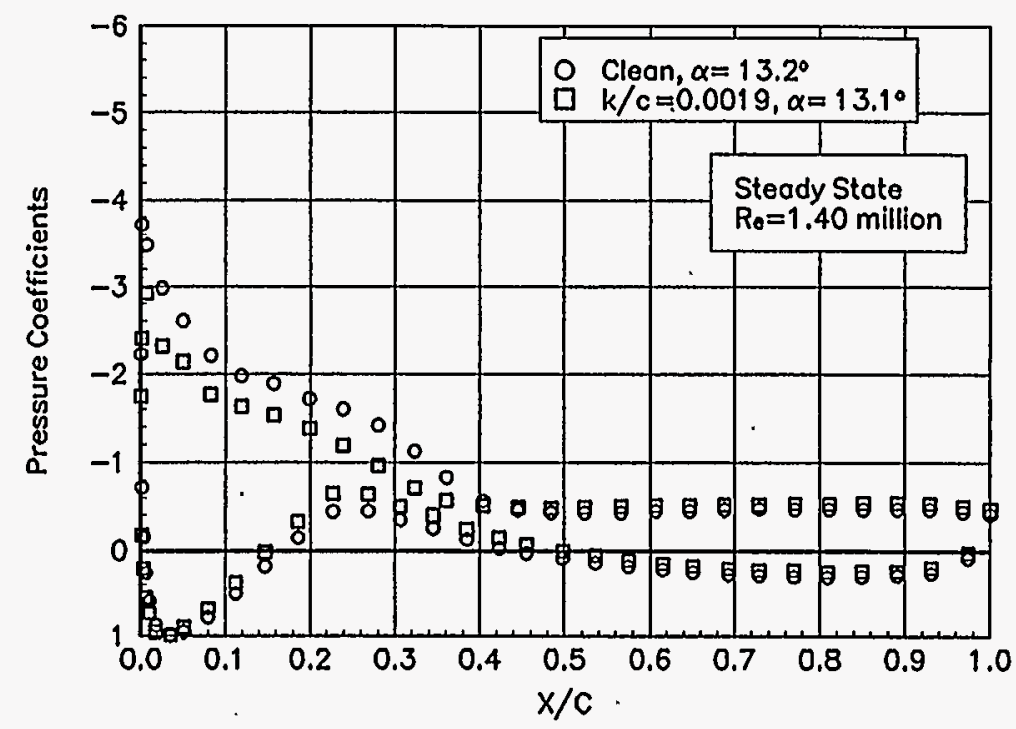

Figure 127. $a=13.2^{\circ}$

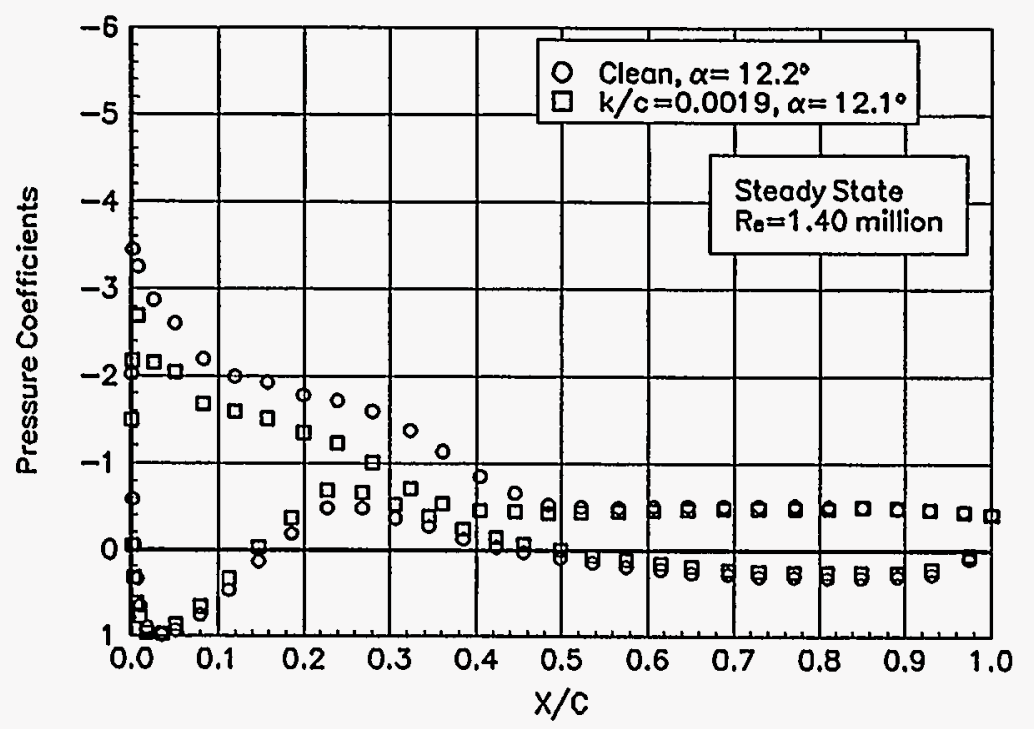

Figure 126. $a=12.2^{\circ}$

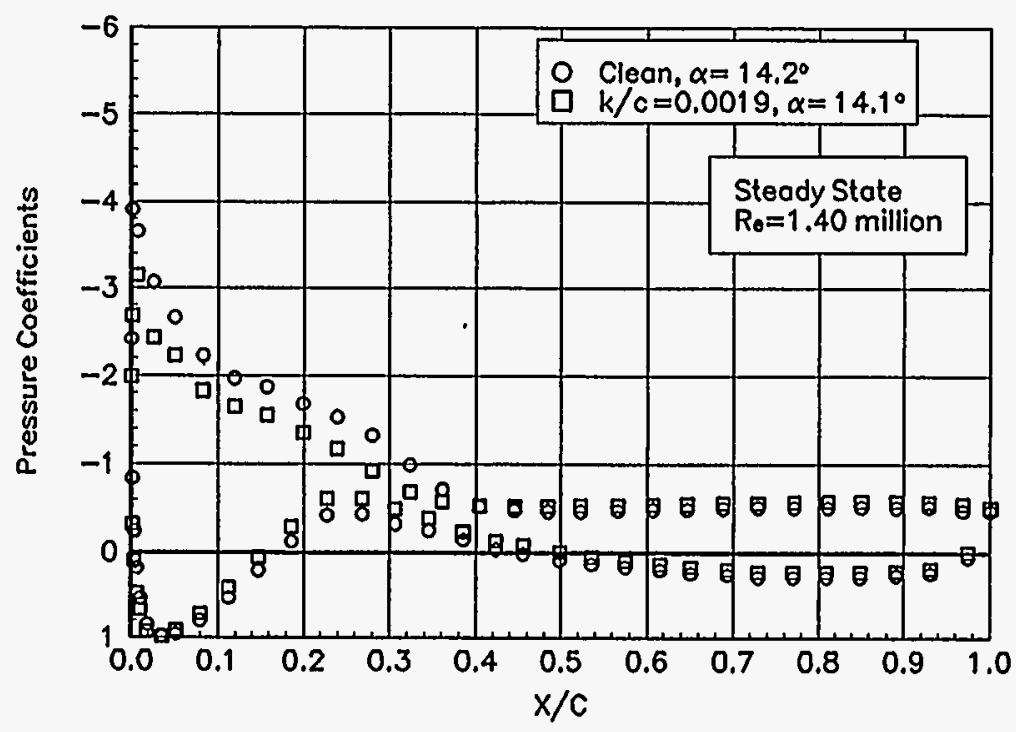

Figure 128. $a=14.2^{\circ}$ 


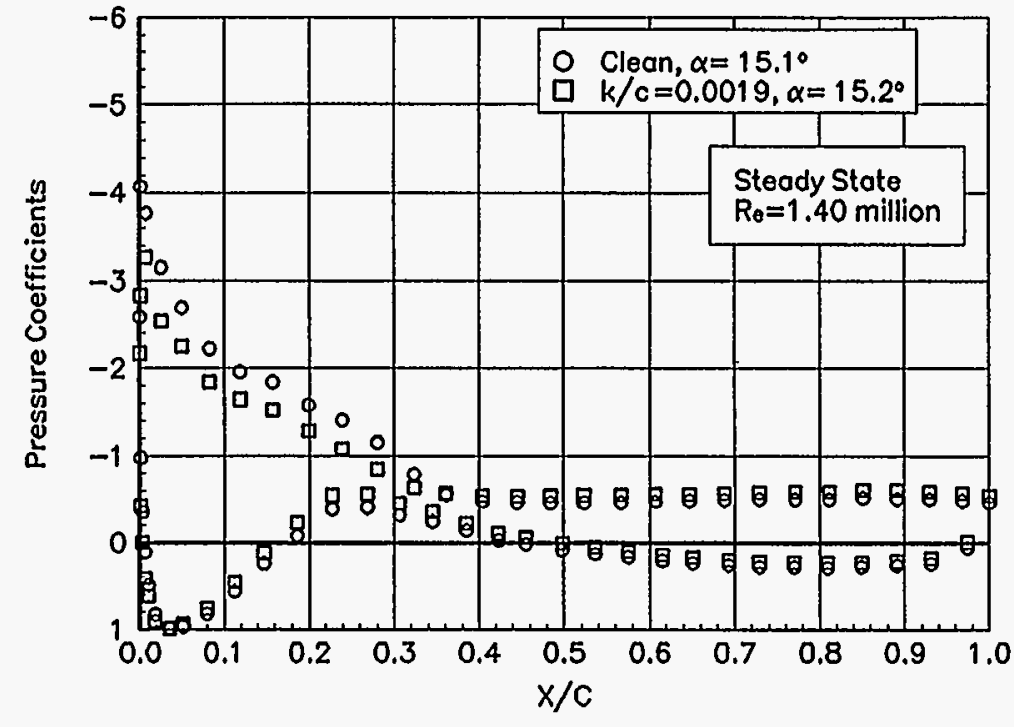

Figure 129. $a=15.1^{\circ}$

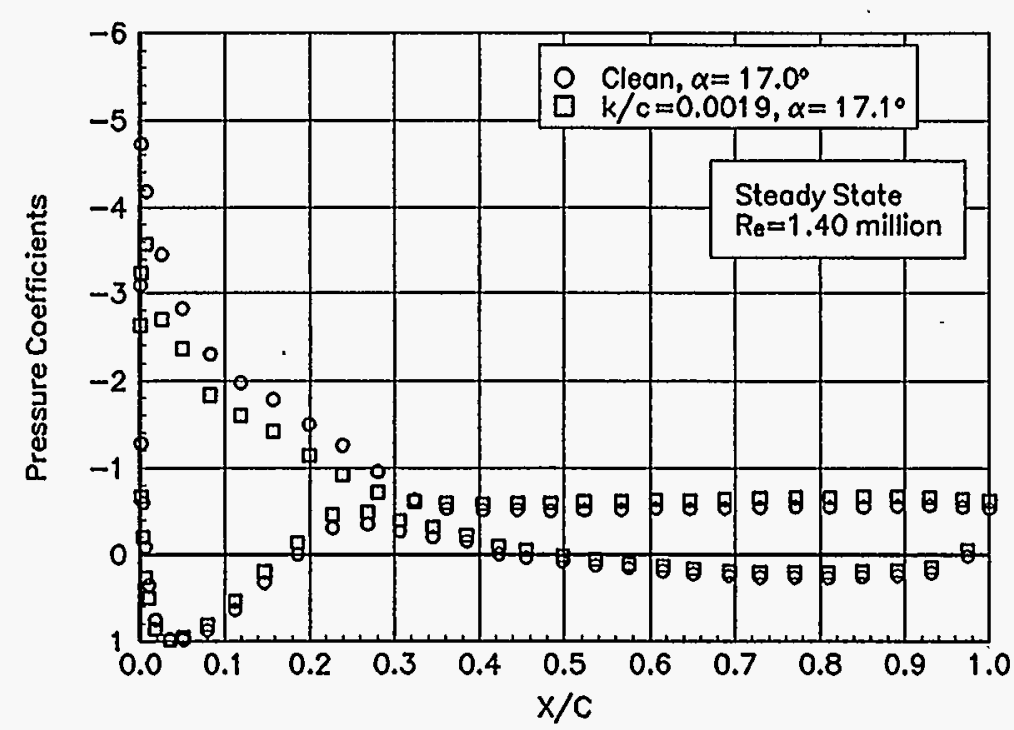

Figure 131. $a=17.0^{\circ}$

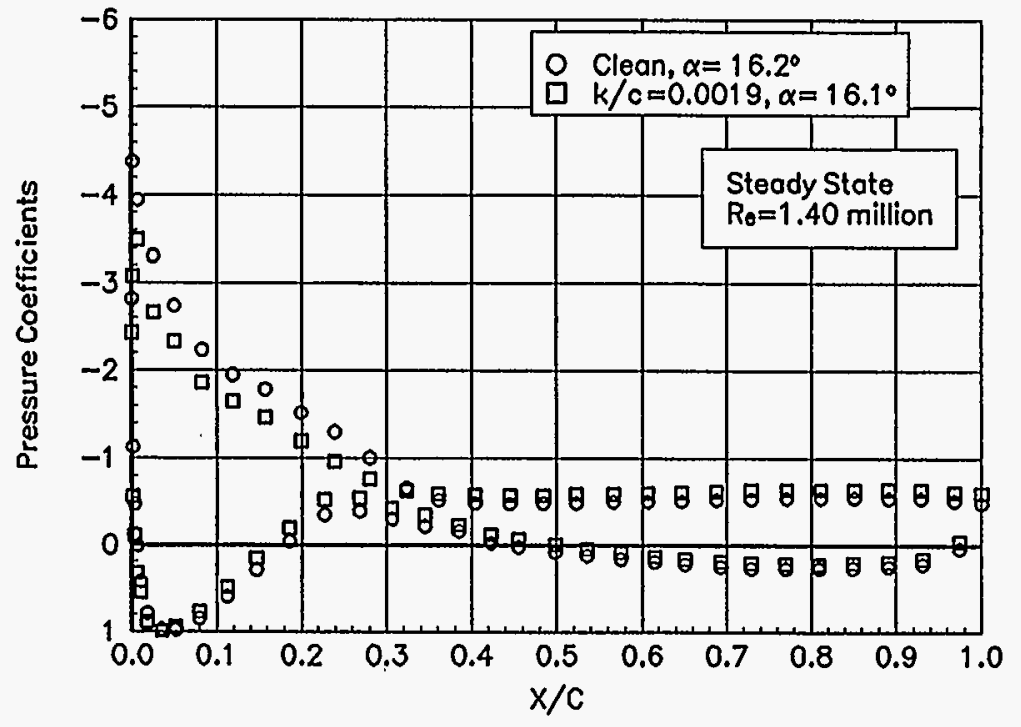

Figure 130. $a=16.2^{\circ}$

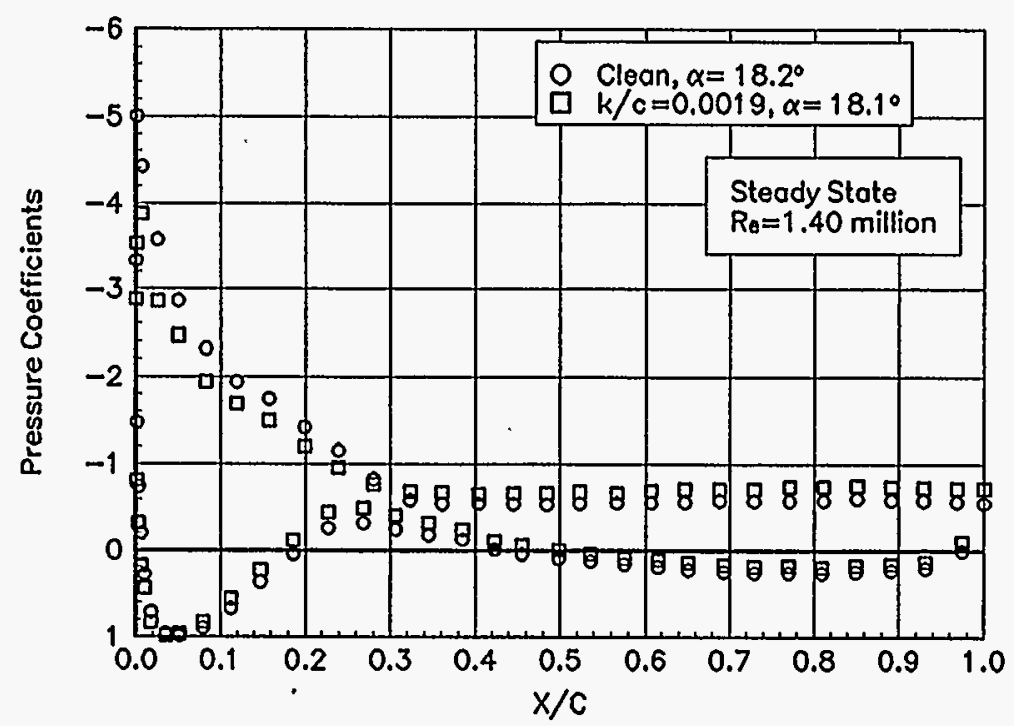

Figure 132. $a=18.2^{\circ}$ 


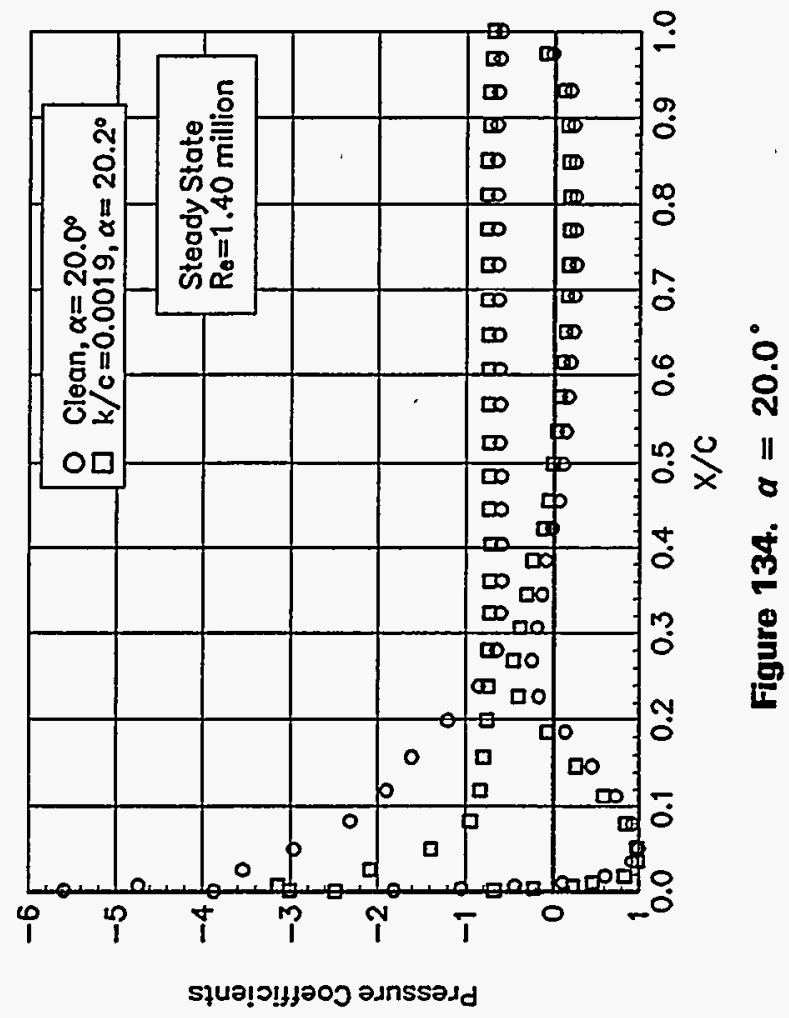

की

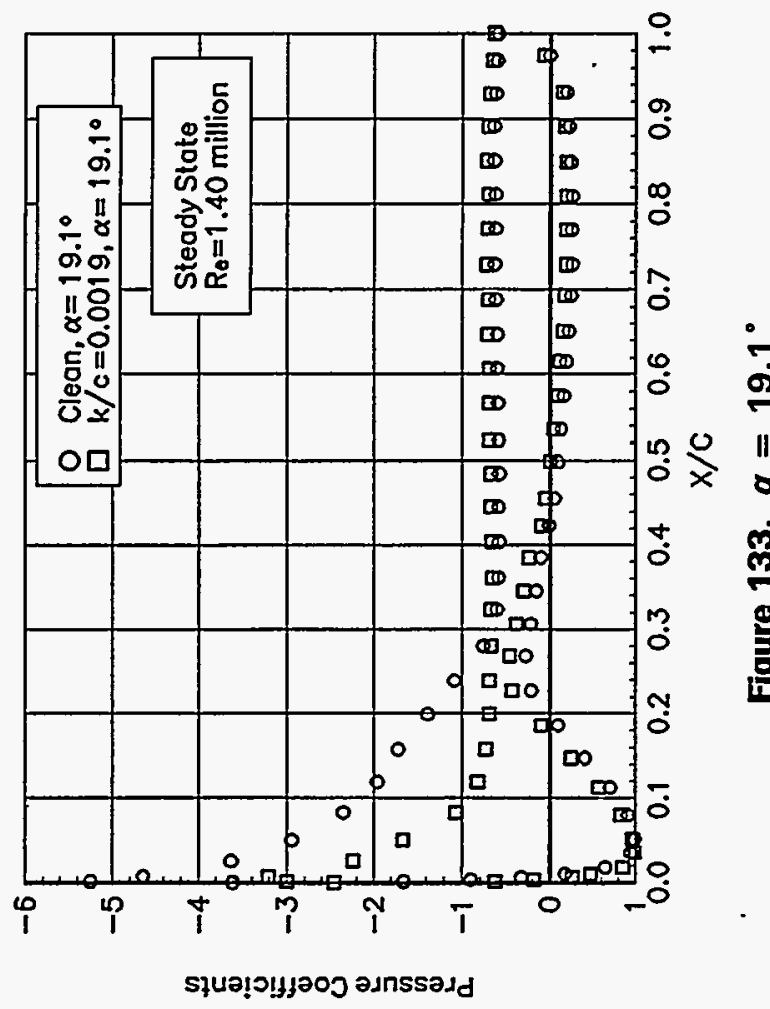



Appendix C: Unsteady Integrated Coefficients 


\section{List of Figures}

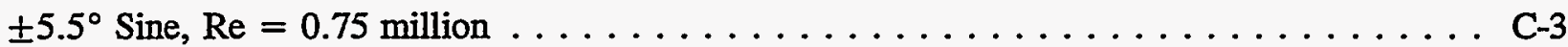

$\pm 5.5^{\circ}$ Sine, $\operatorname{Re}=1$ million $\ldots \ldots \ldots \ldots \ldots \ldots \ldots \ldots \ldots \ldots \ldots \ldots \ldots$

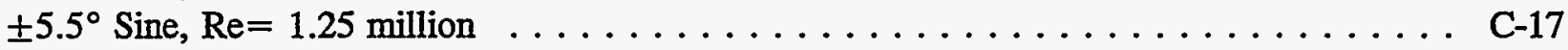

$\pm 5.5^{\circ}$ Sine $\operatorname{Re}=1.4$ million $\ldots \ldots \ldots \ldots \ldots \ldots \ldots \ldots \ldots \ldots \ldots \ldots \ldots \ldots$

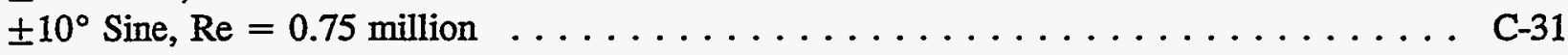

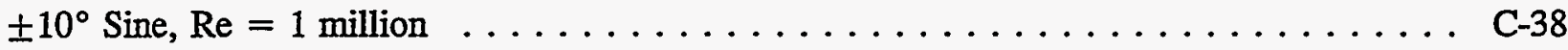

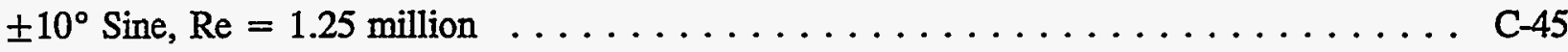

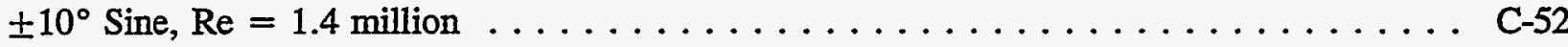




\section{Unsteady Airfoil Characteristics \\ $\pm 5.5^{\circ}$ Sine, $\operatorname{Re}=0.75$ million}



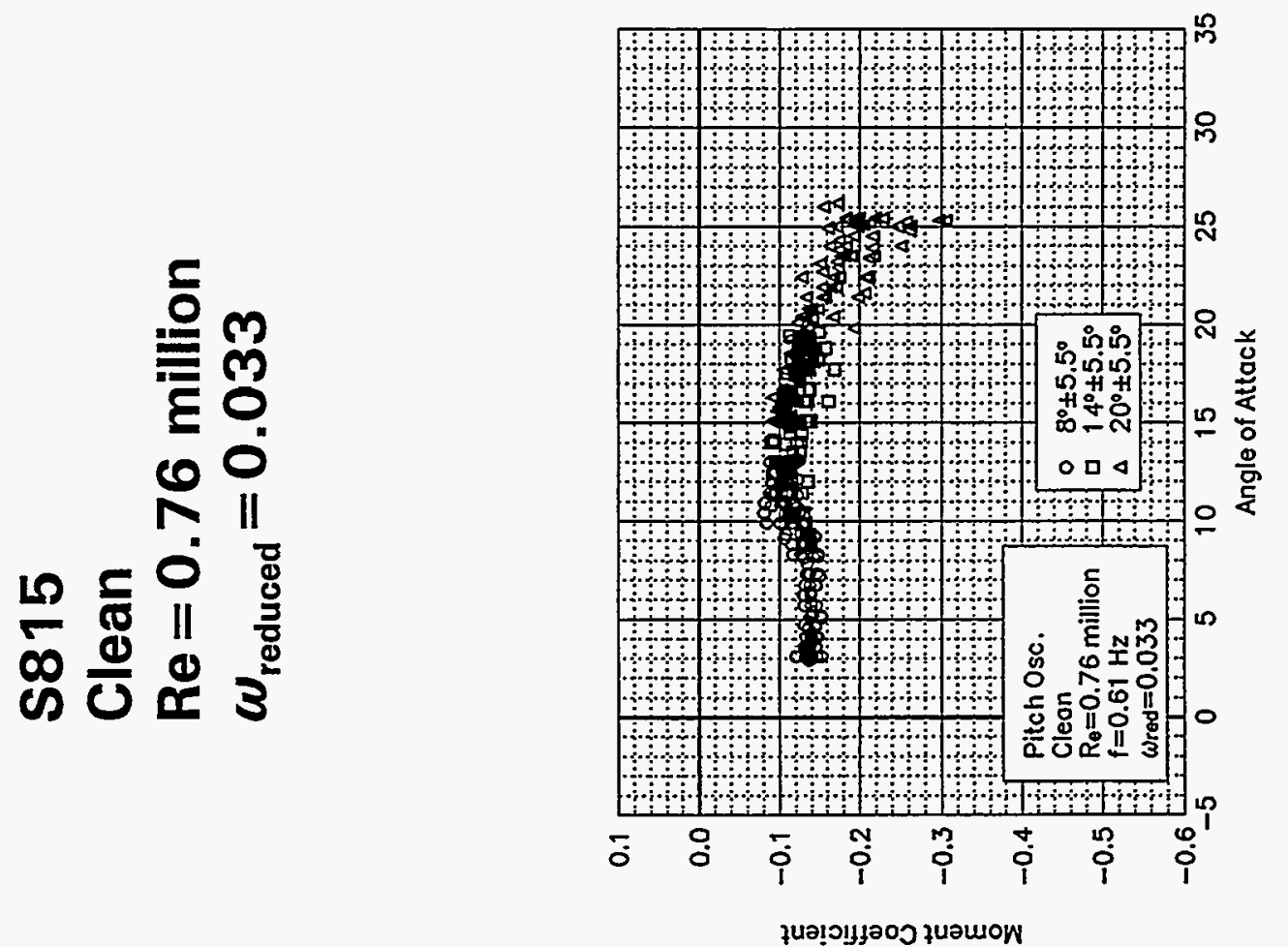

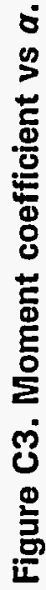
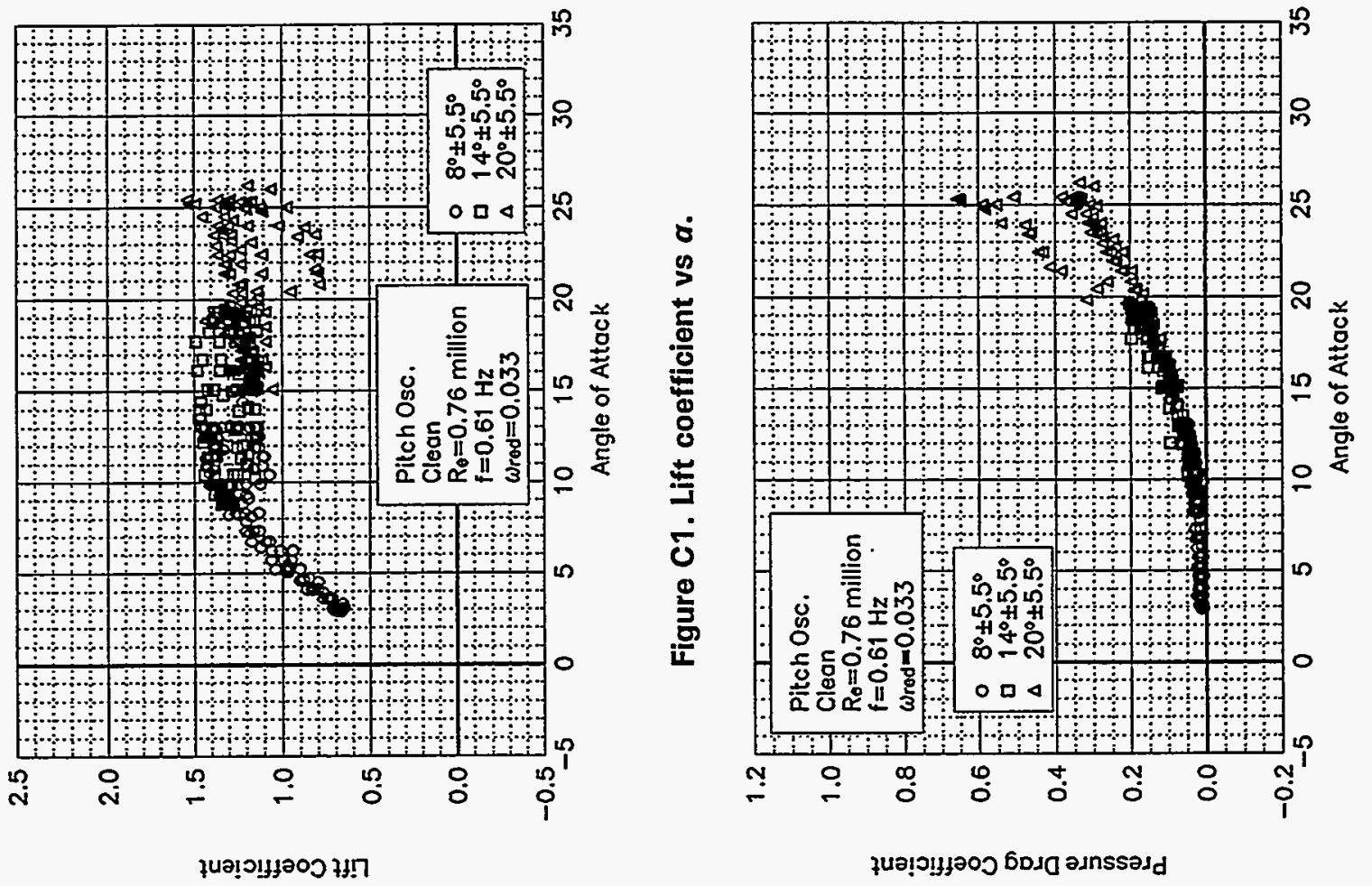

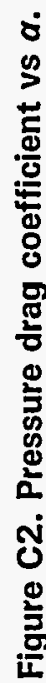

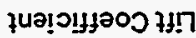

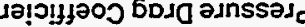



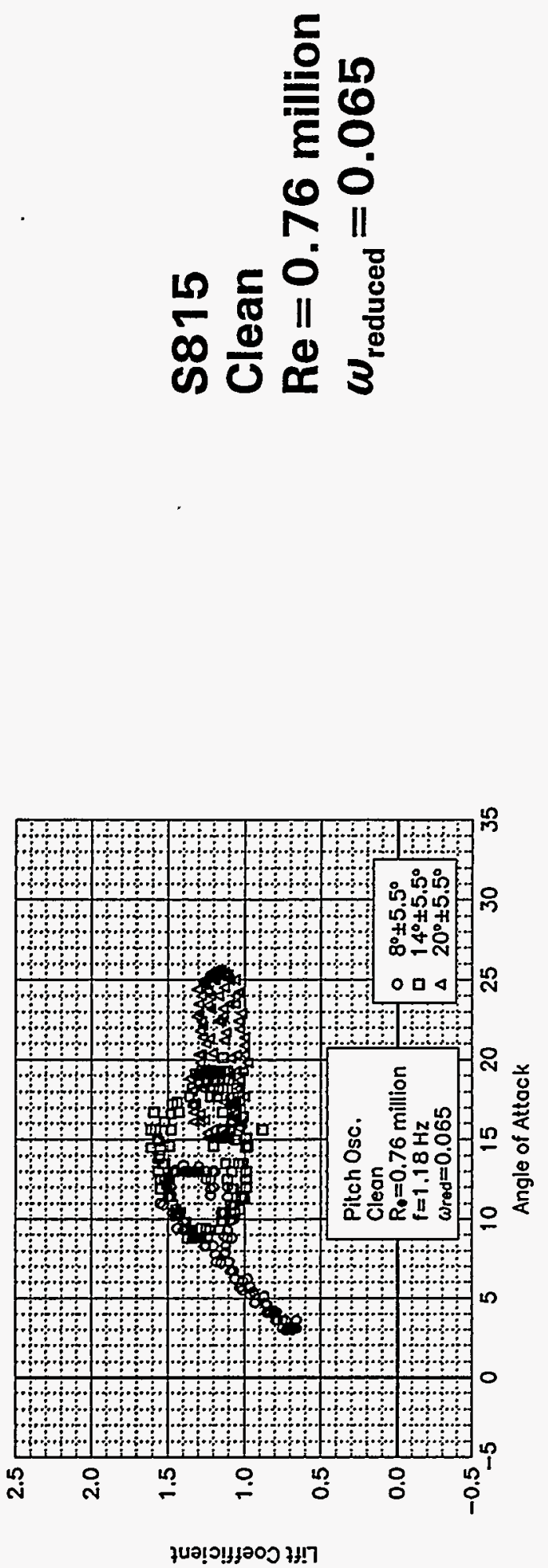

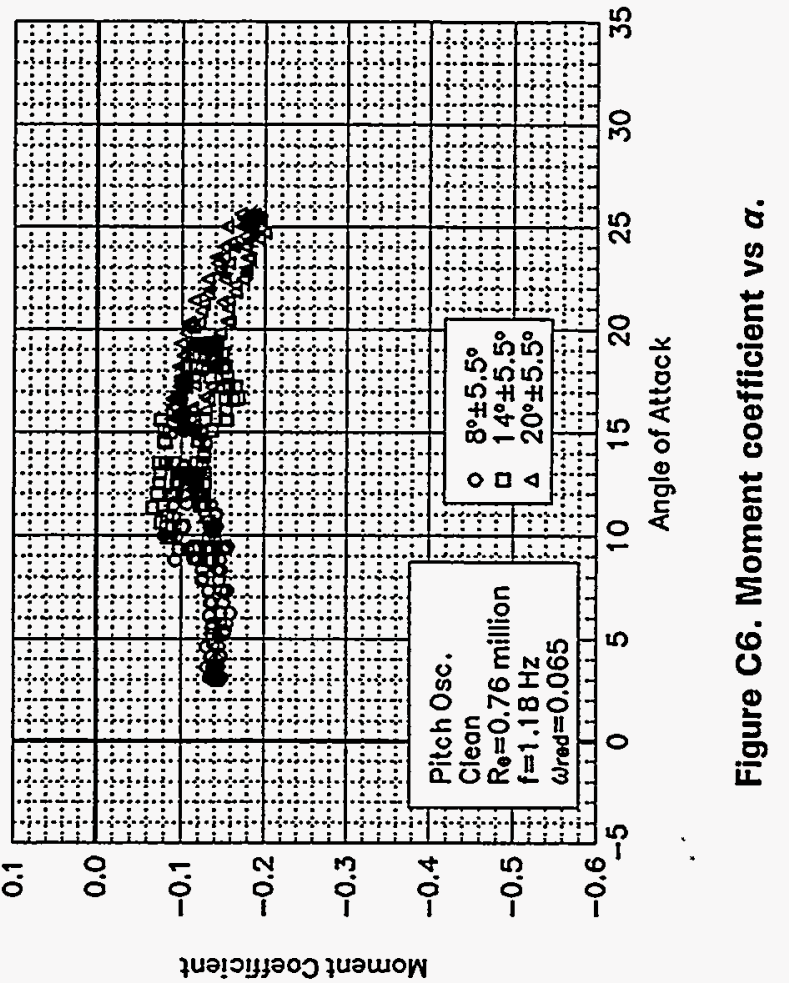

ช

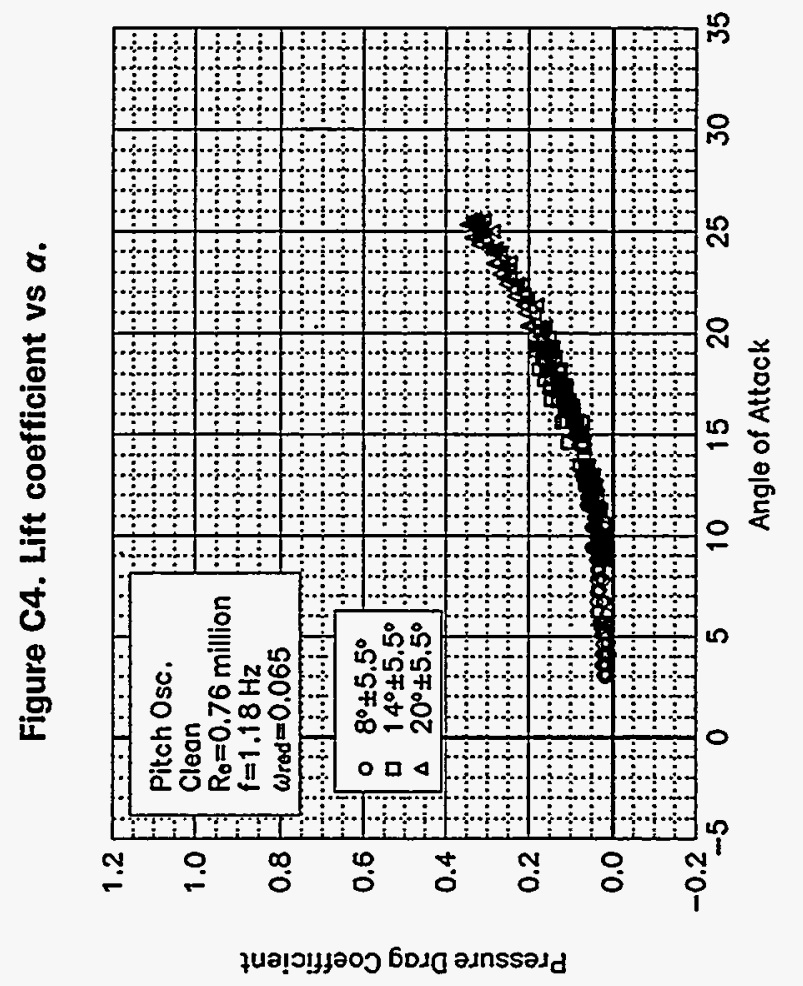

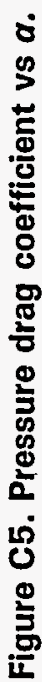



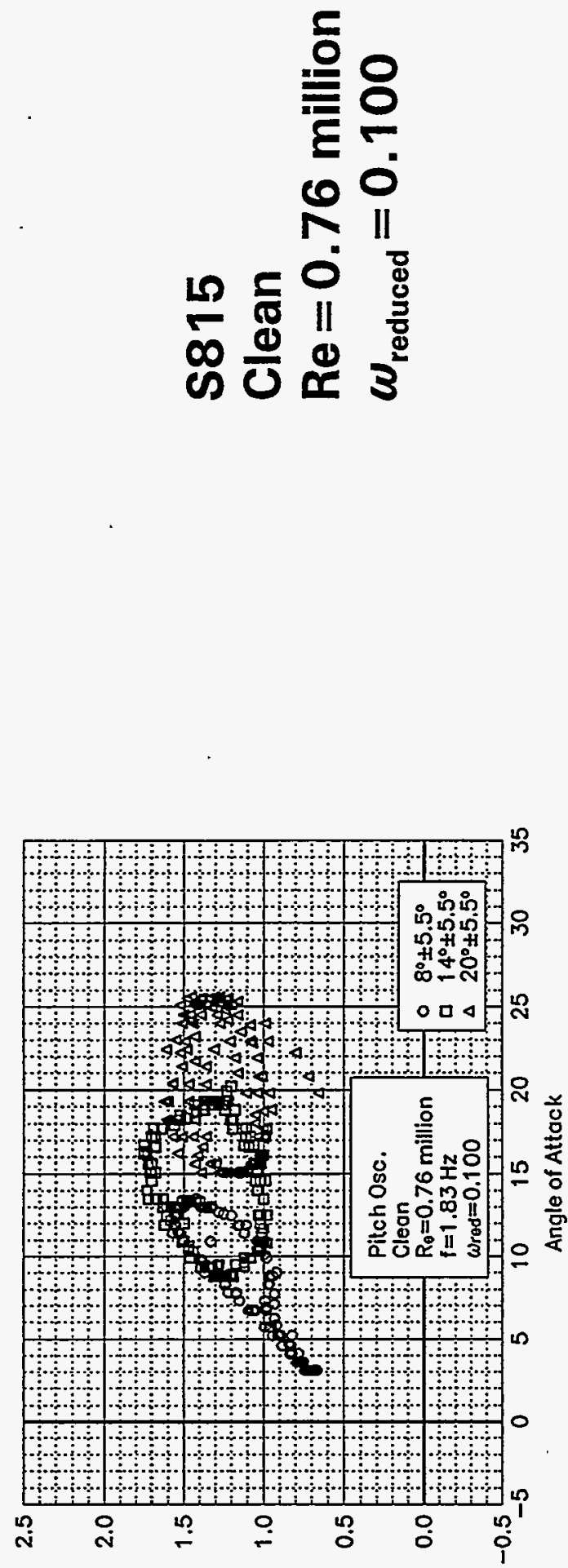

วนข!วแมวัดว $34 ! 7$
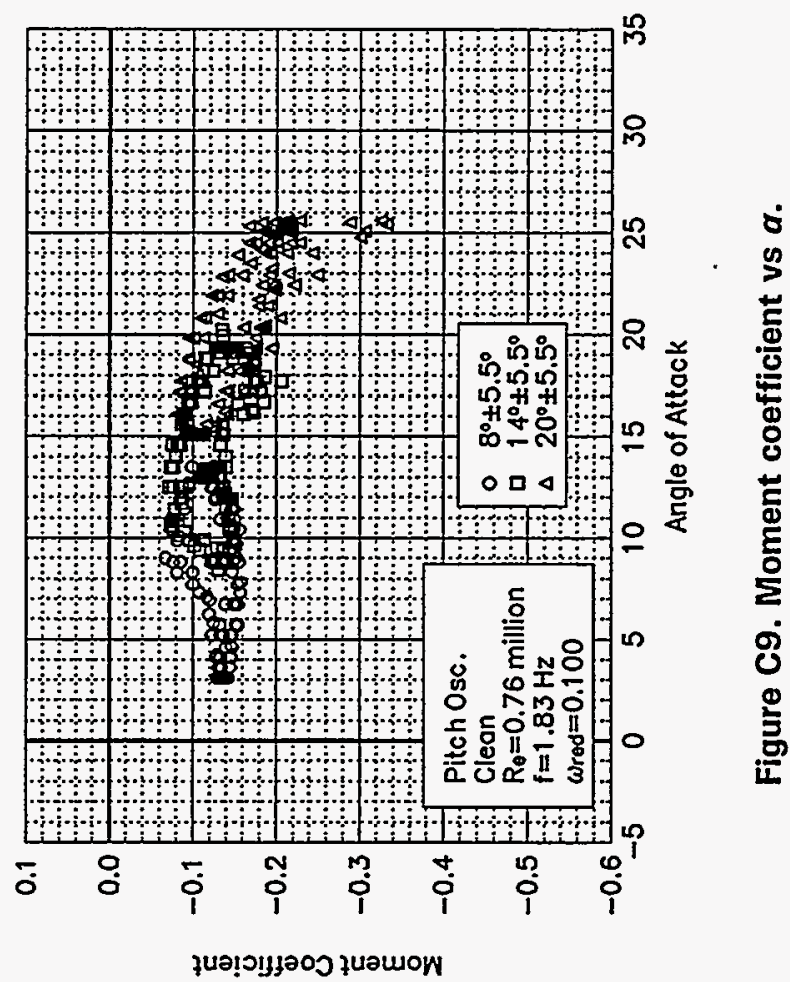

ن

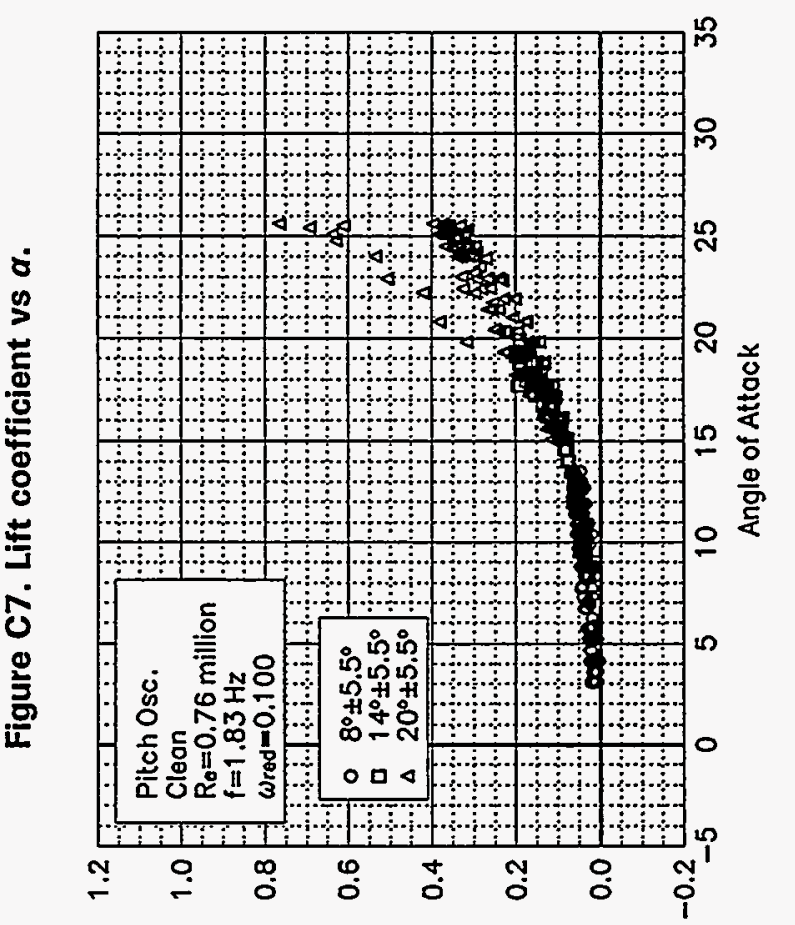

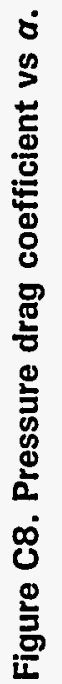


Pressure Drog Coefficient

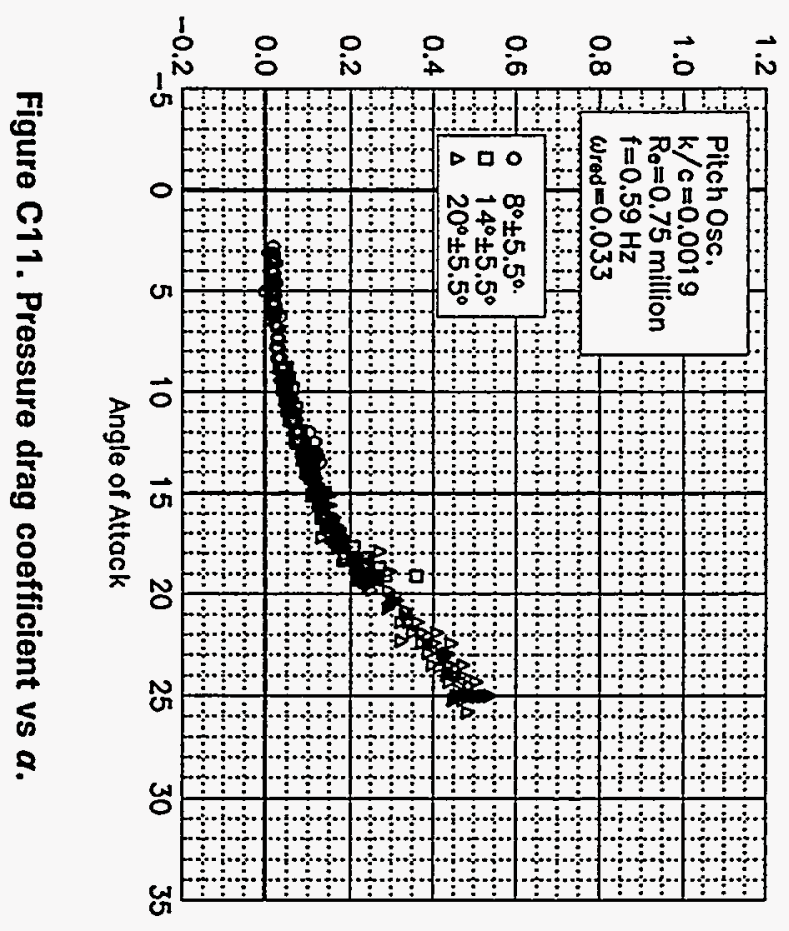

Lift Coefficient

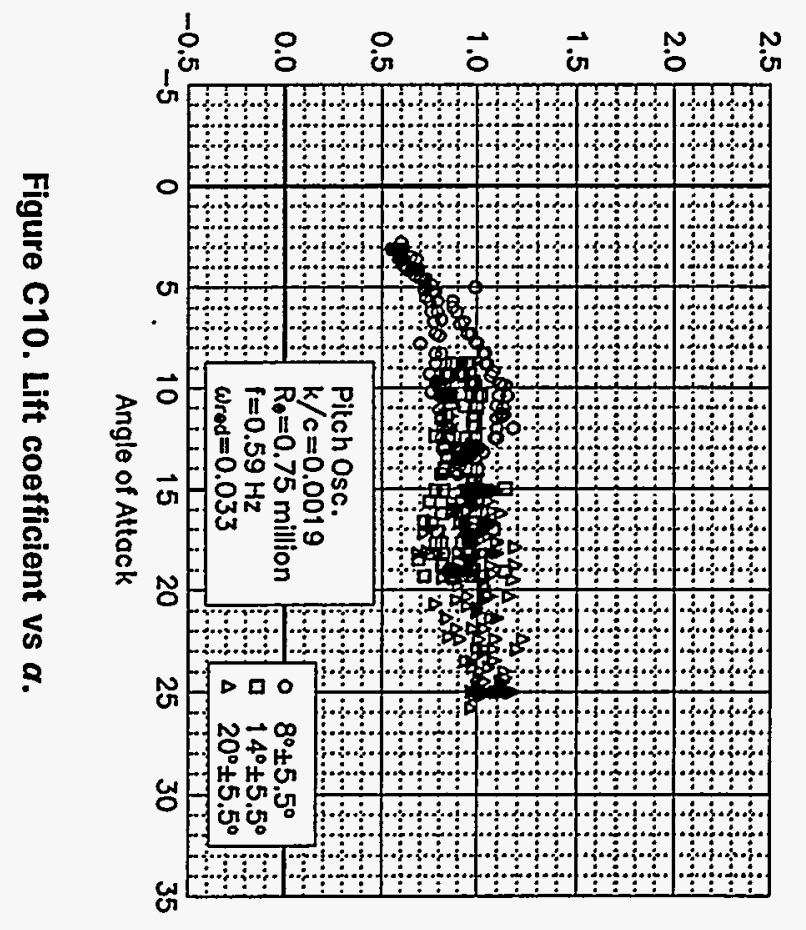

\&
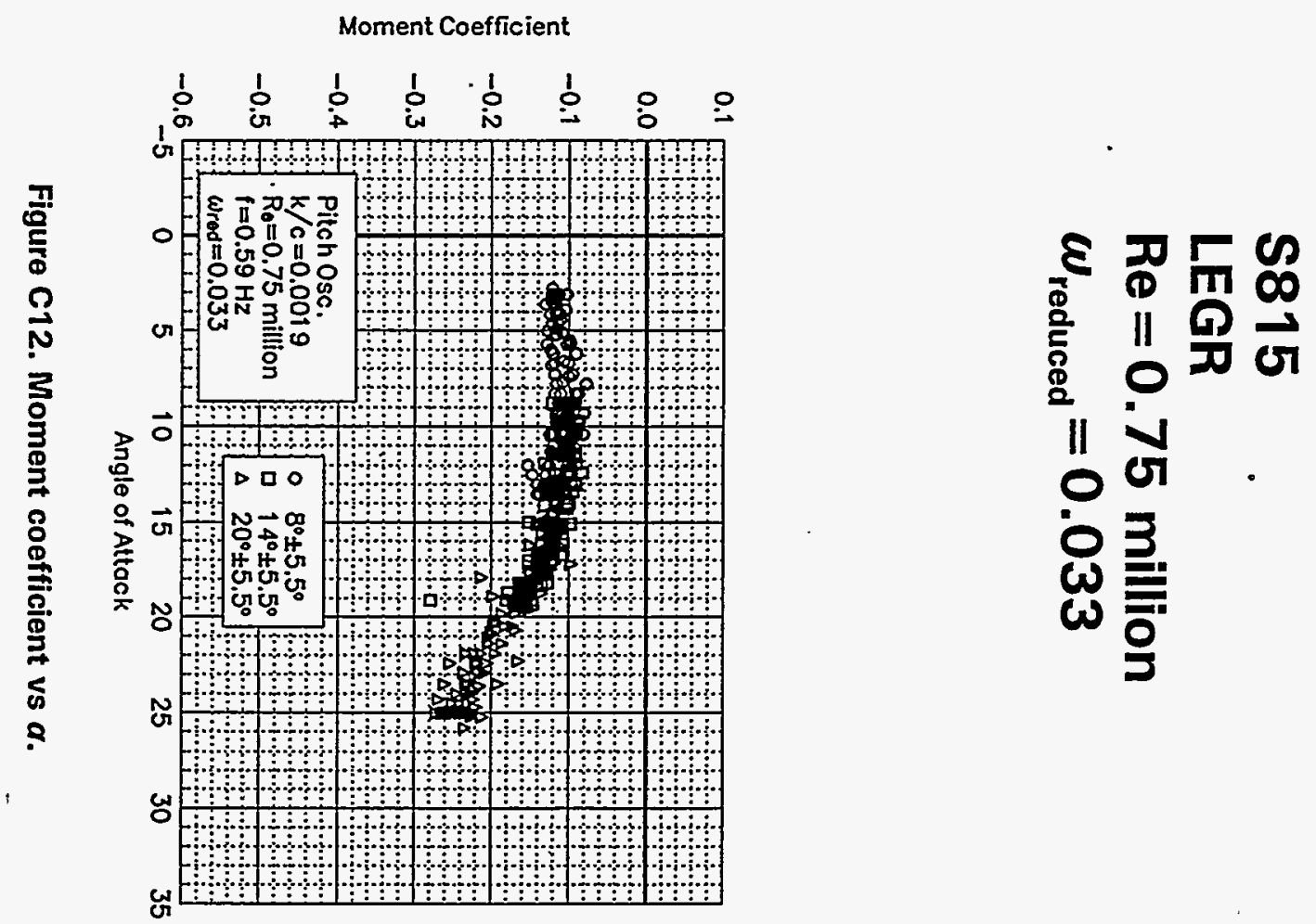

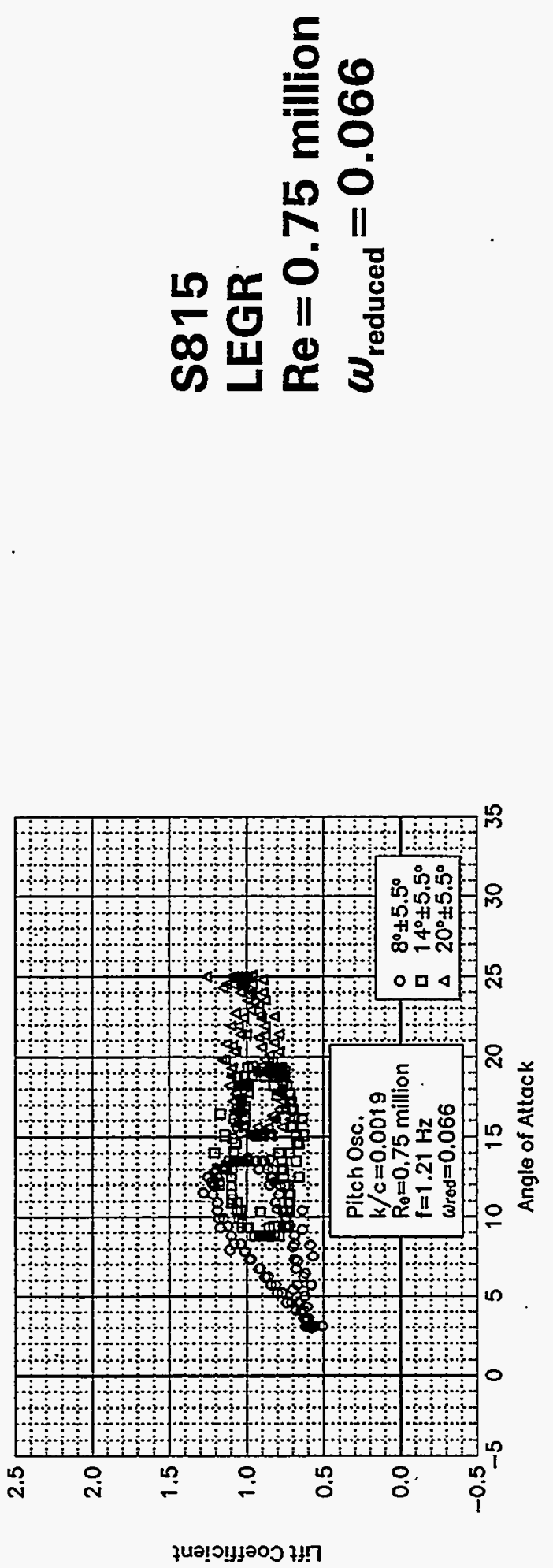

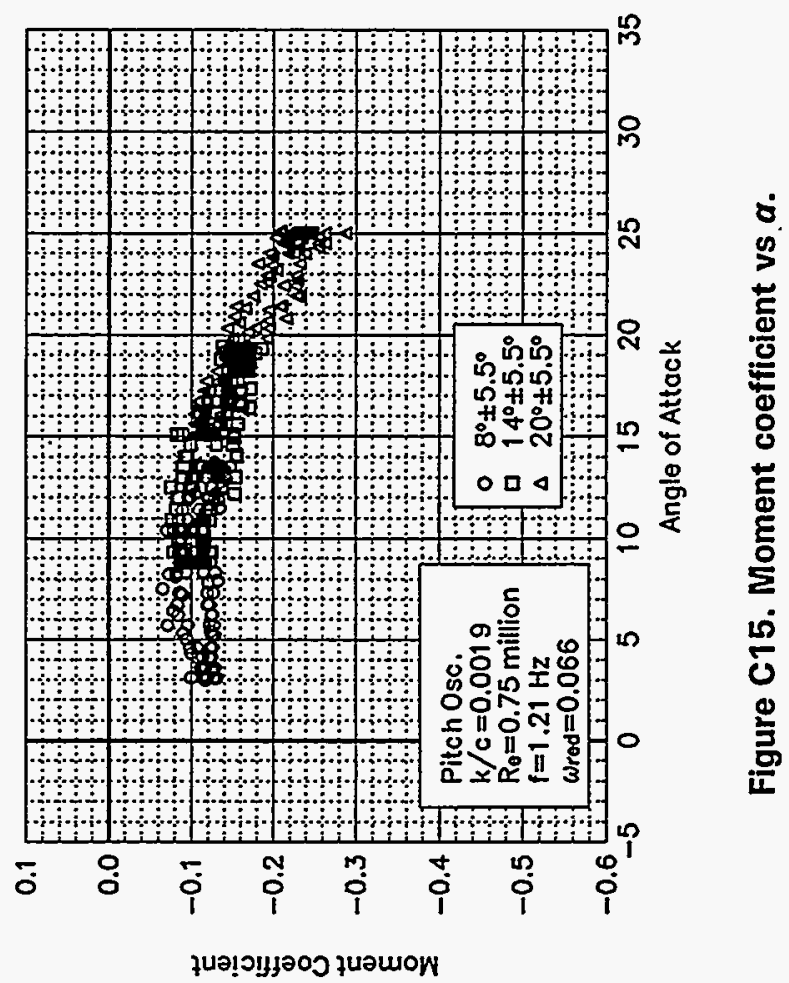

i

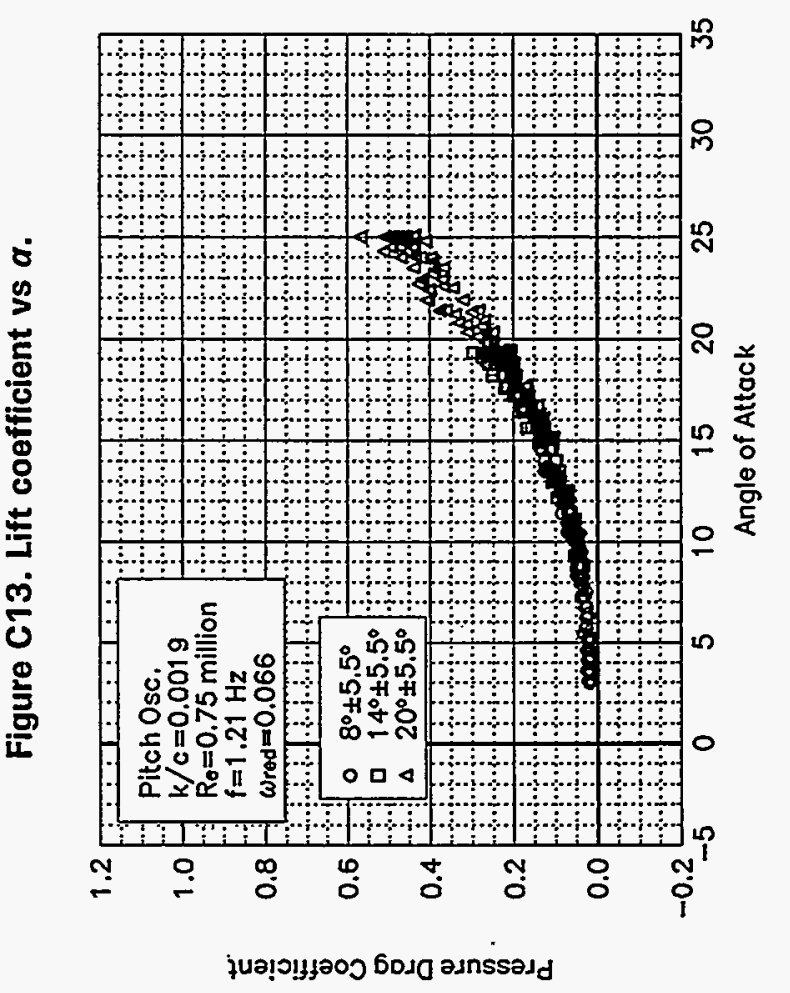

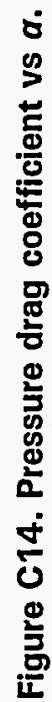



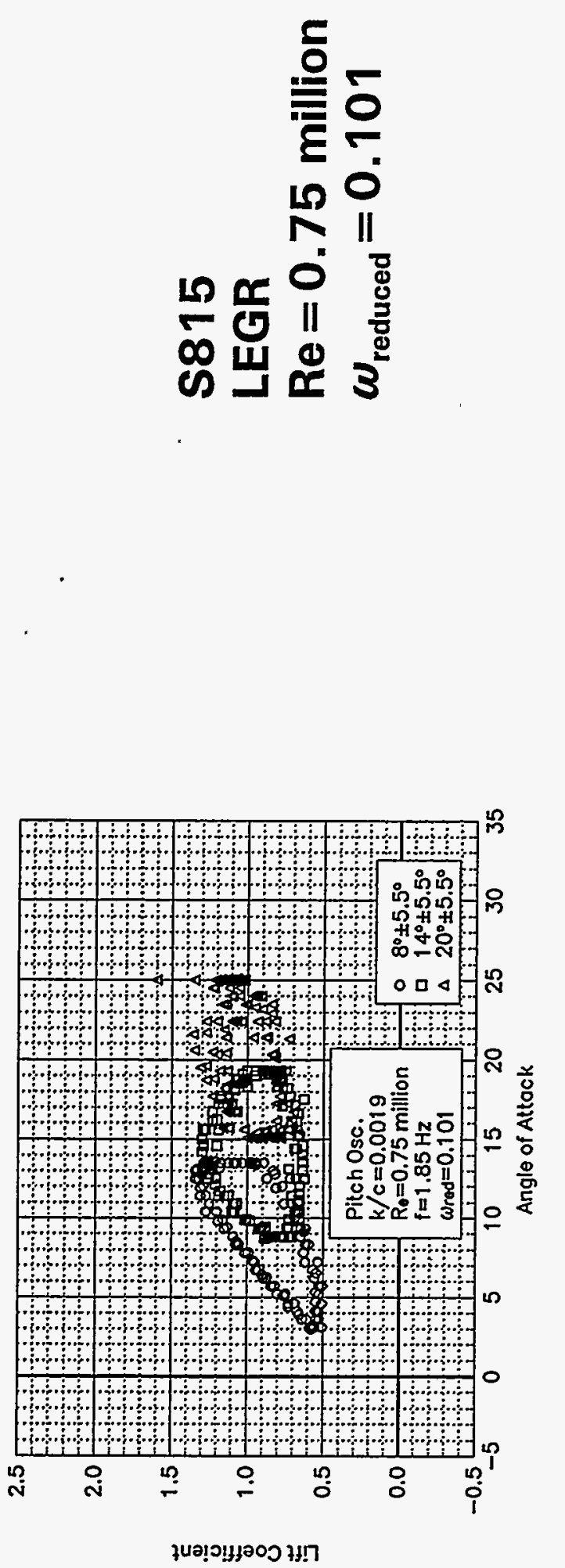

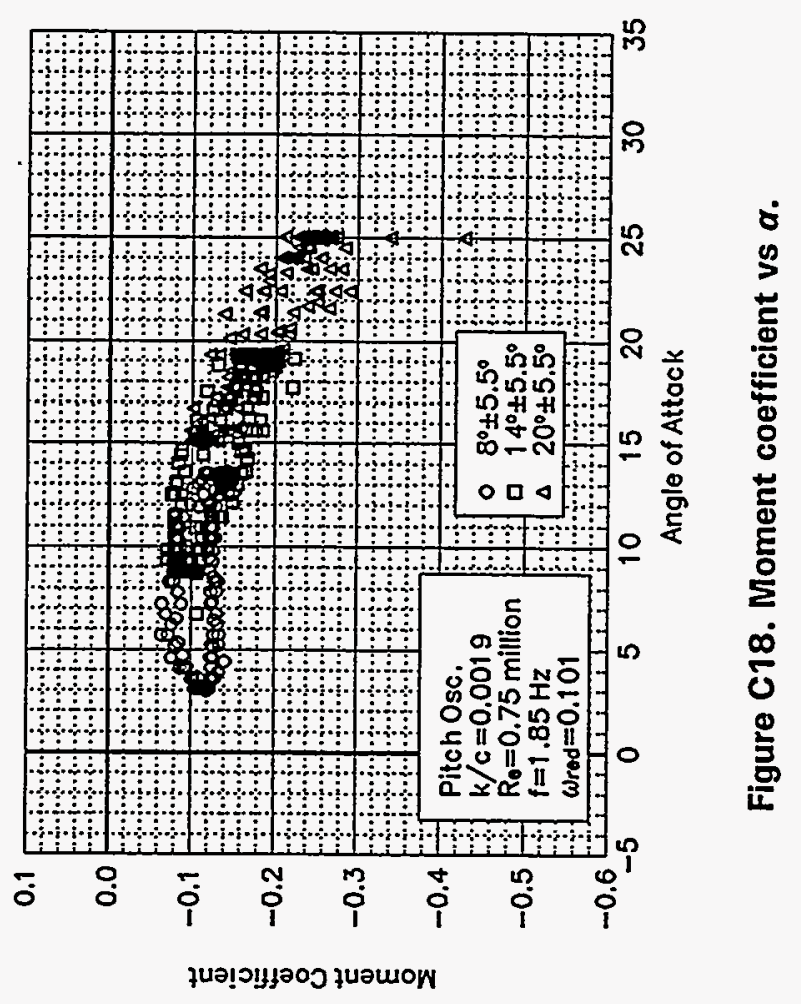

i

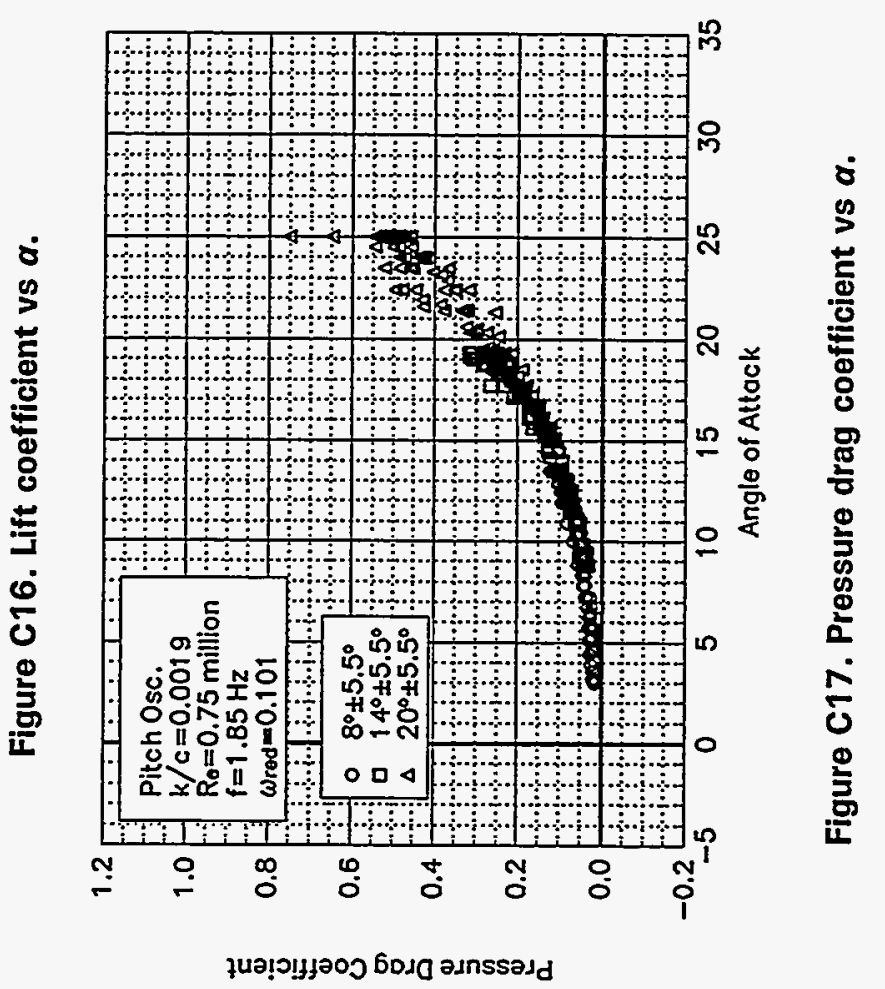


Unsteady Airfoil Characteristics

$\pm 5.5^{\circ}$ Sine, $\operatorname{Re}=1$ million 

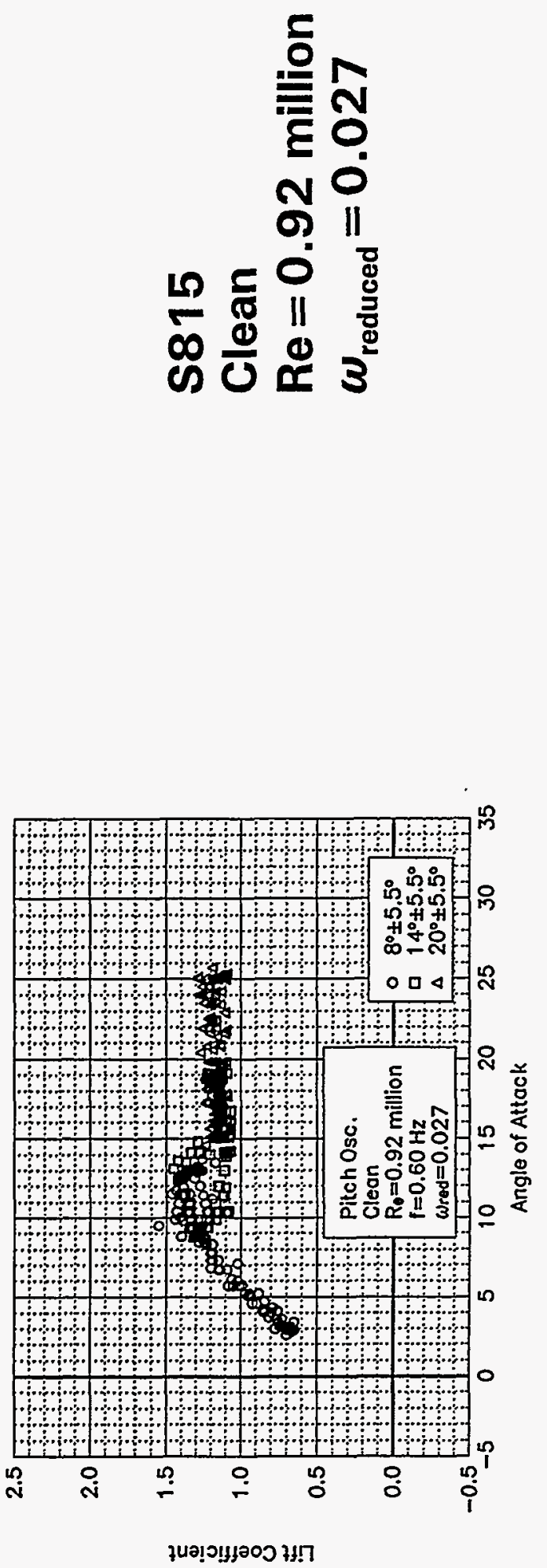

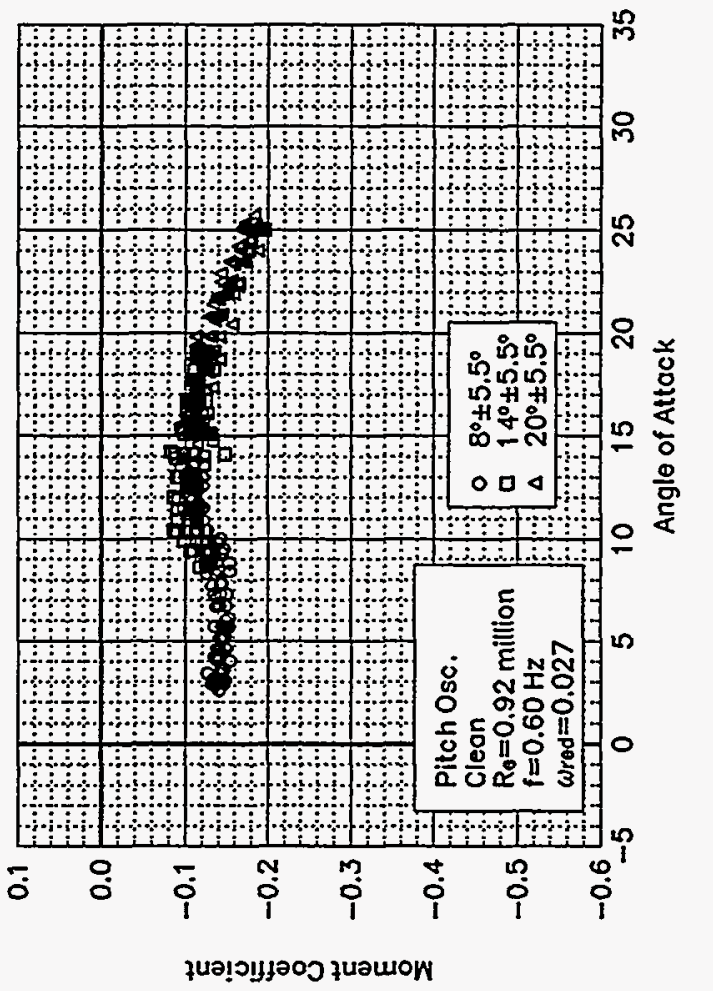

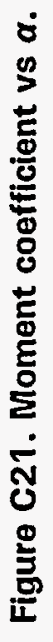

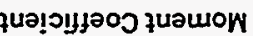

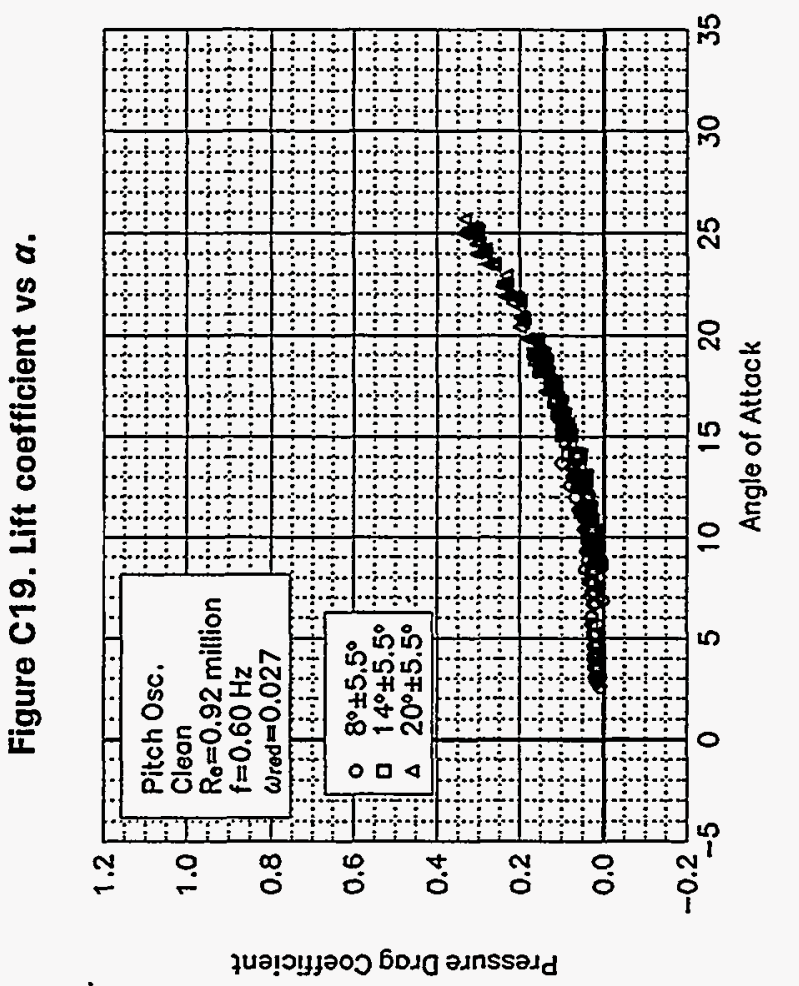

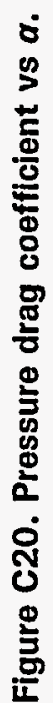



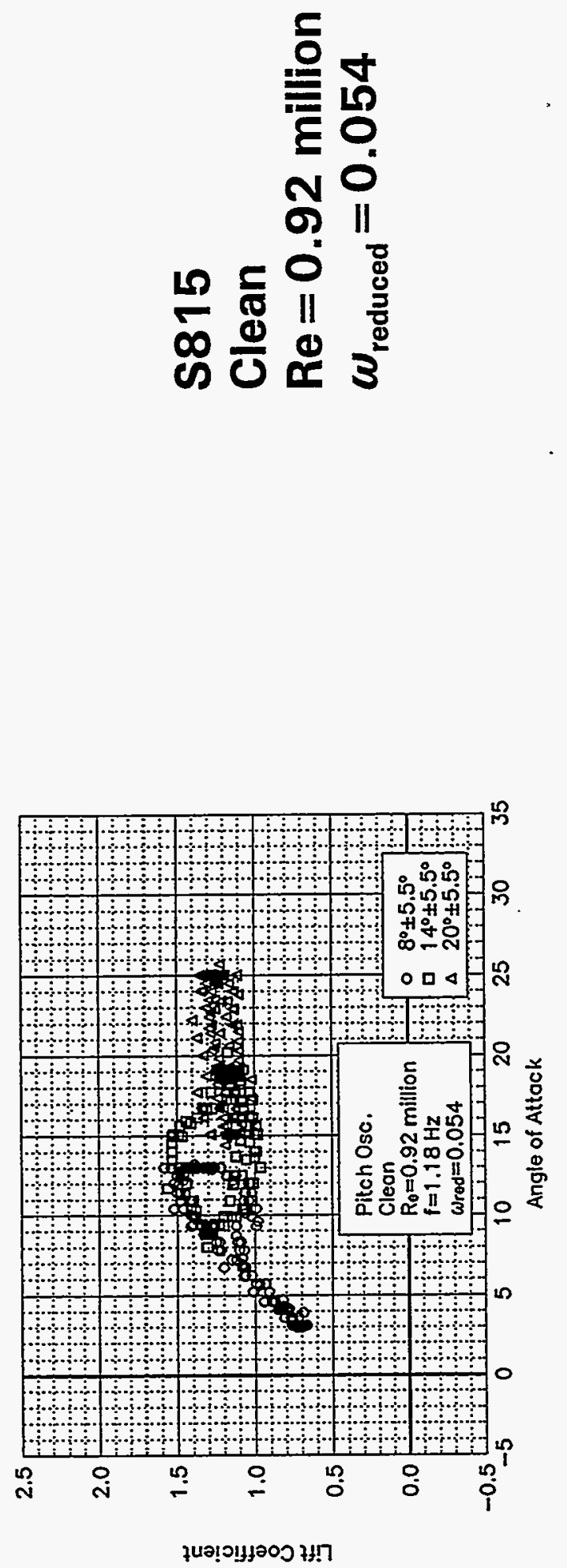

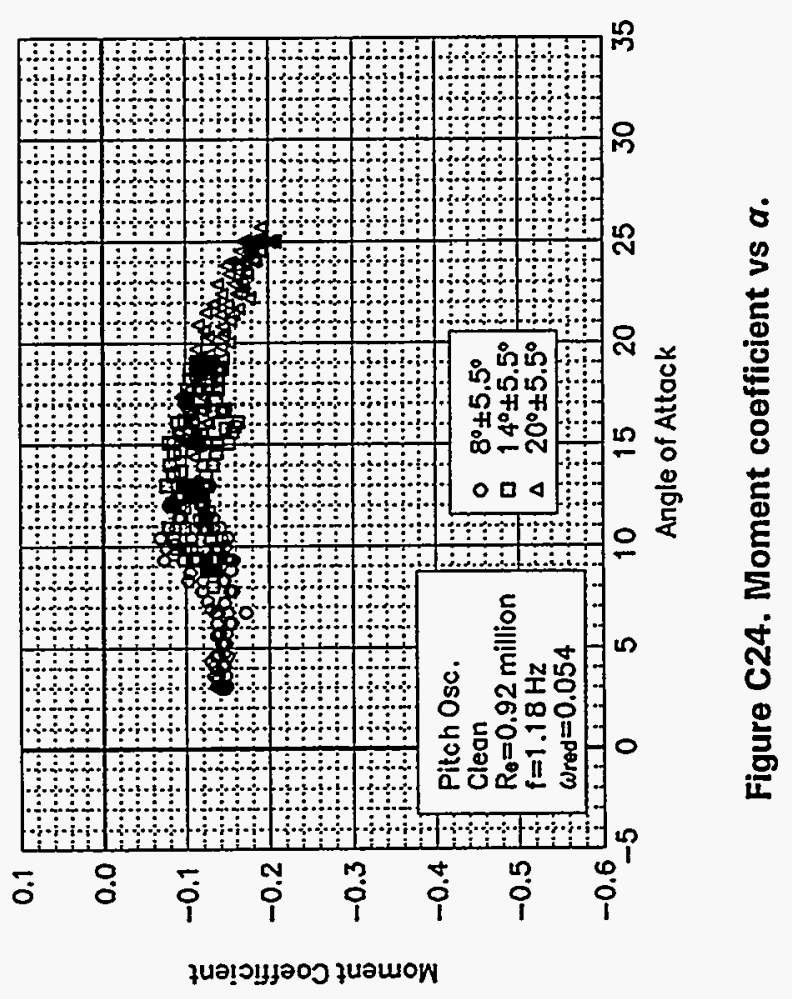

웡

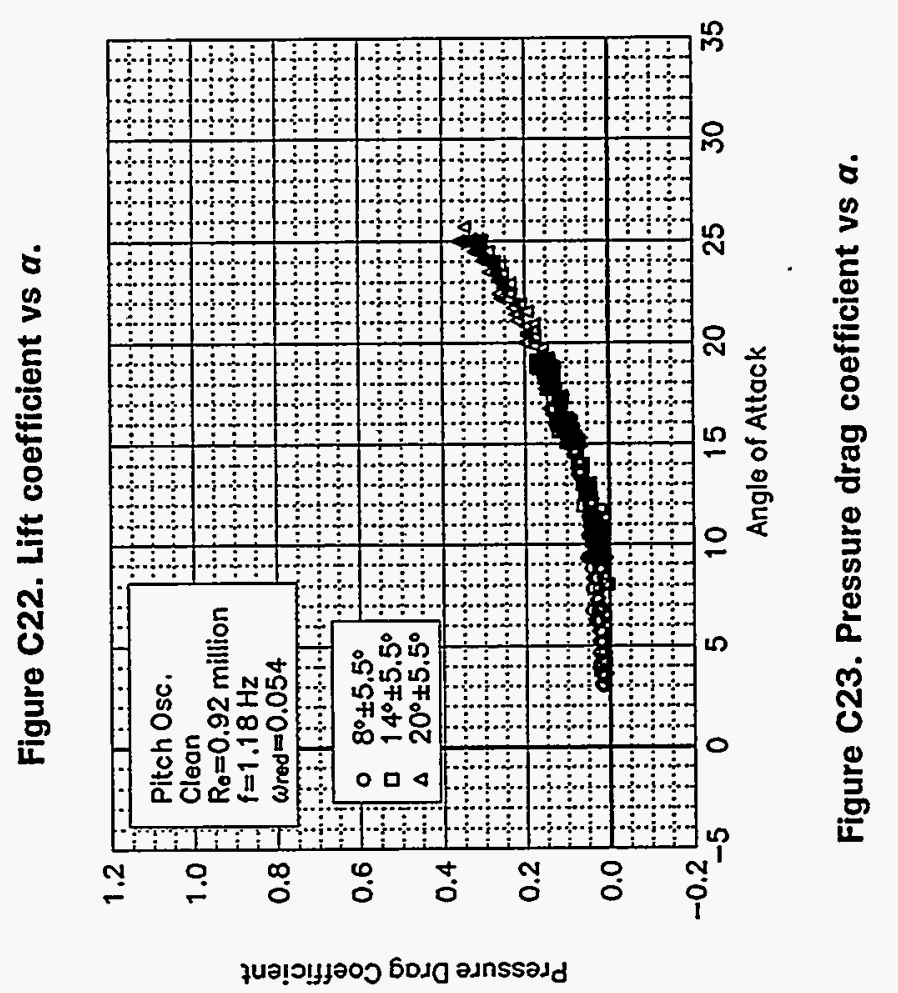



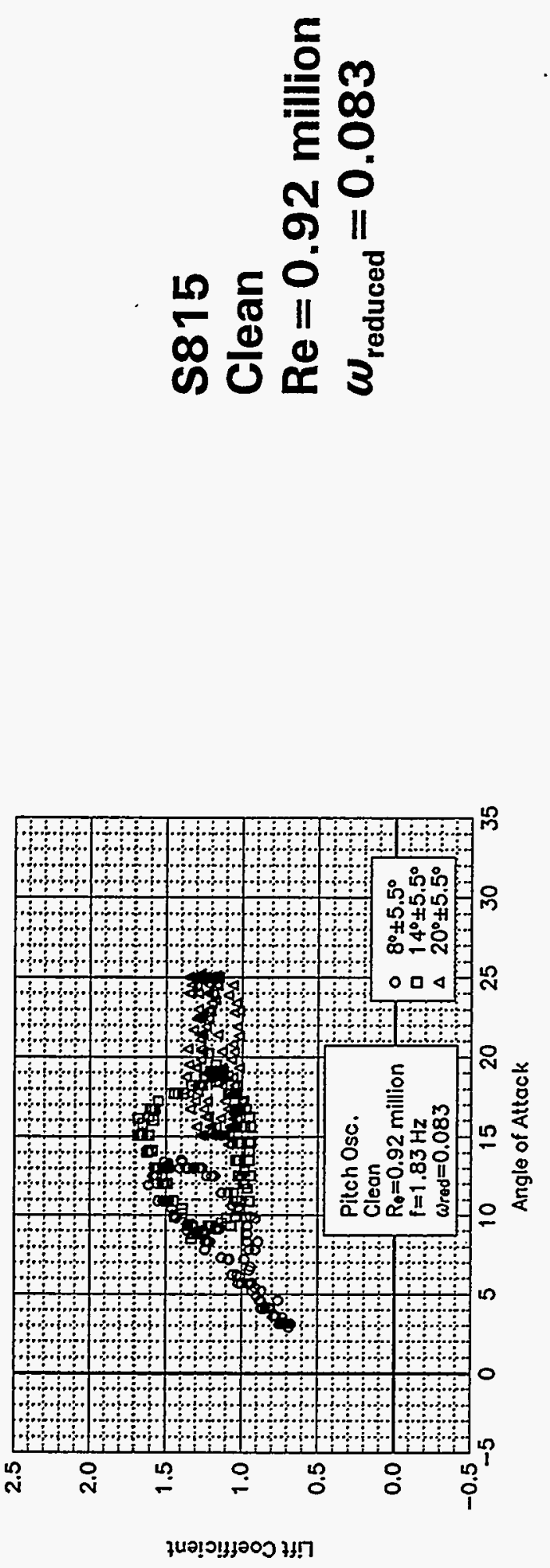

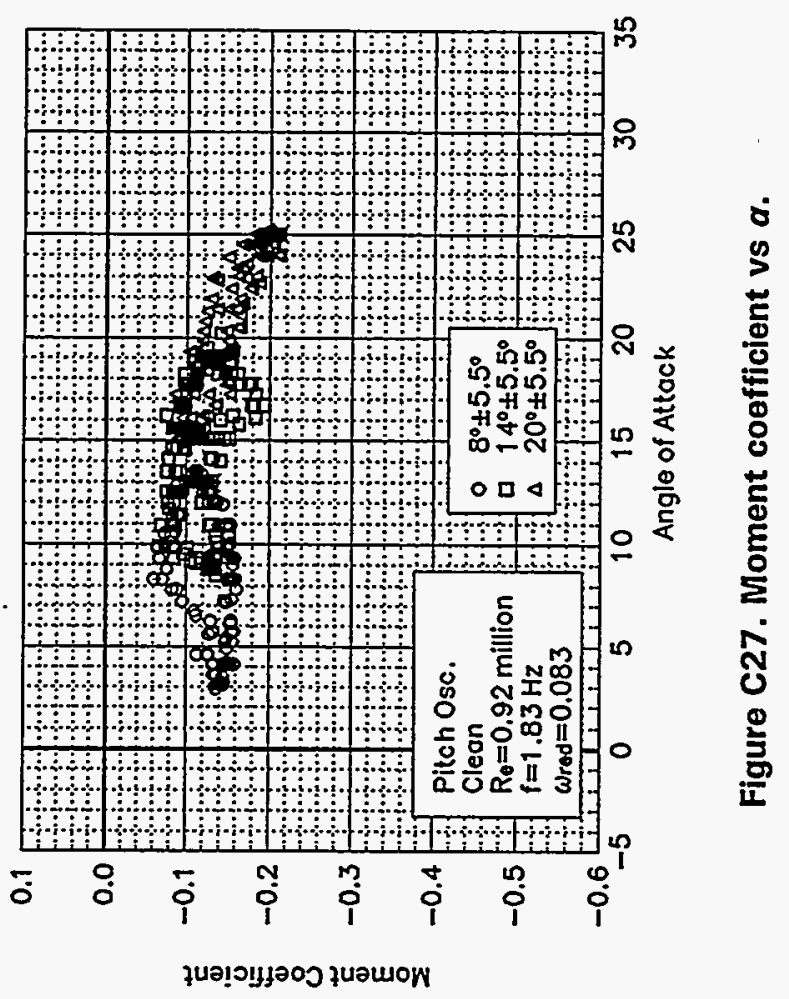

$\frac{9}{3}$

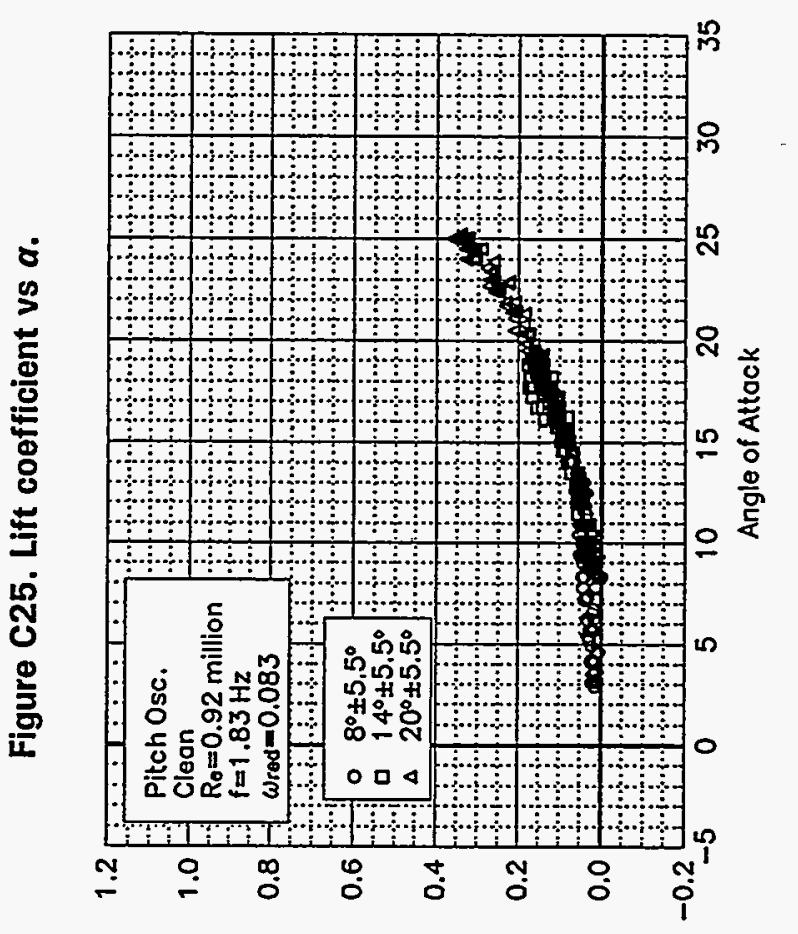

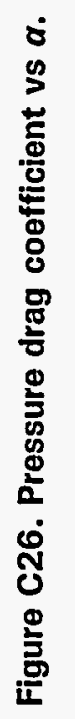



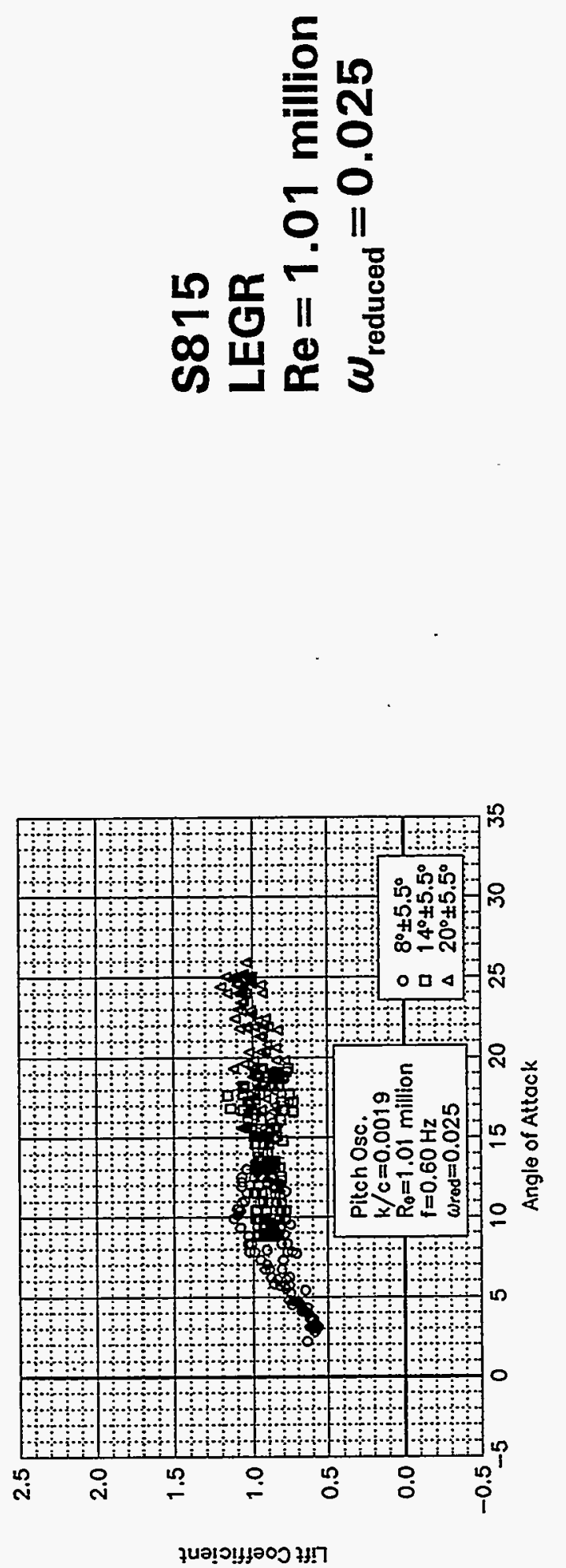

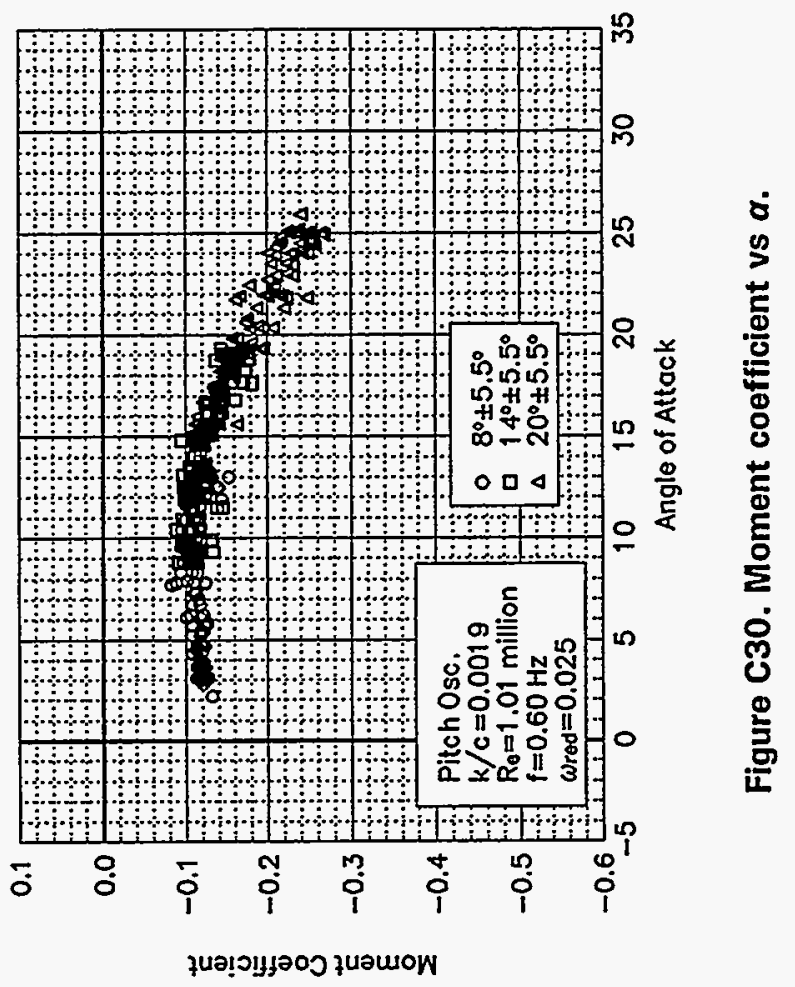

ป

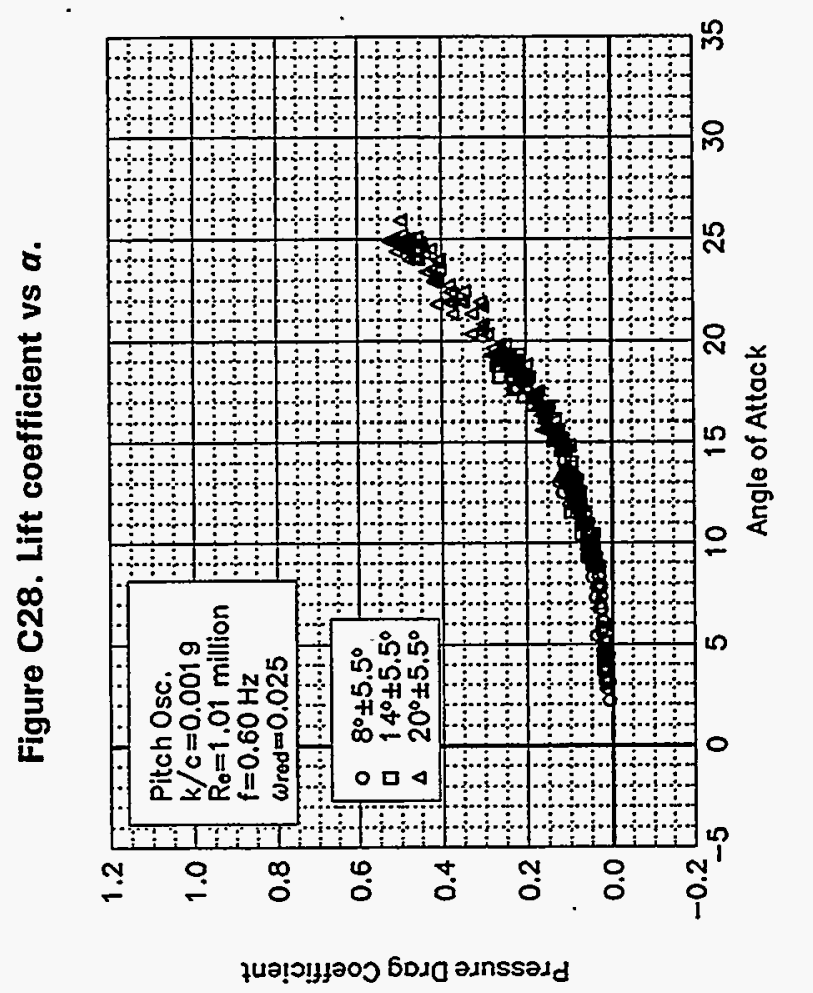

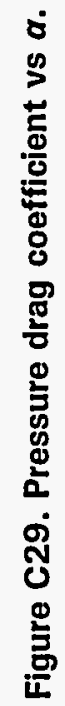




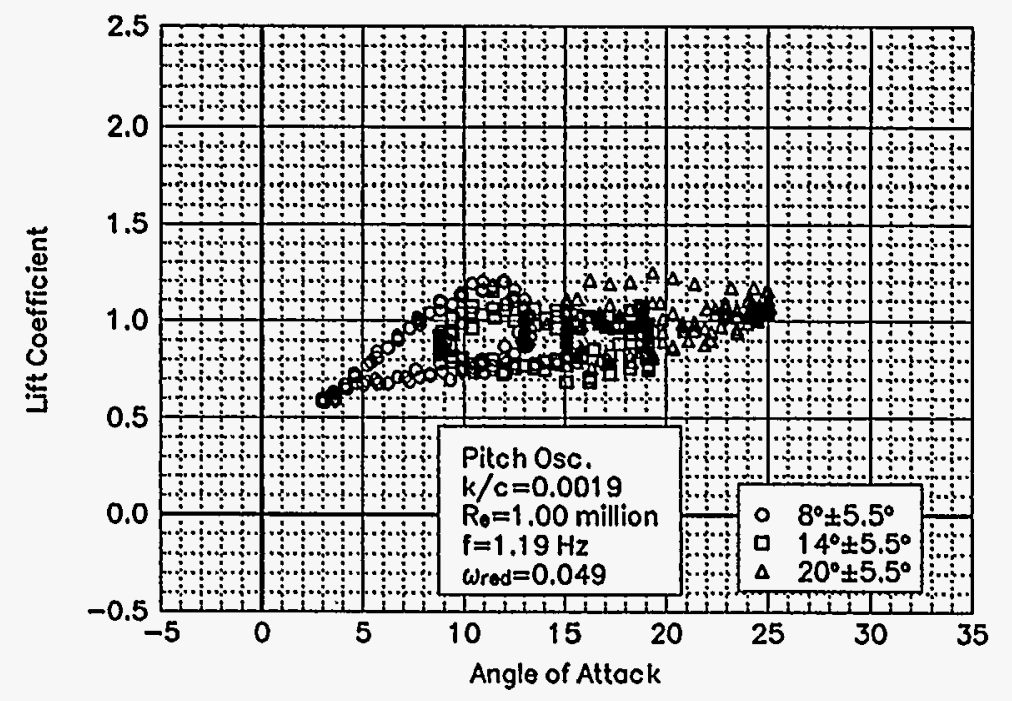

Figure C31. Lift coefficient vs $a$.

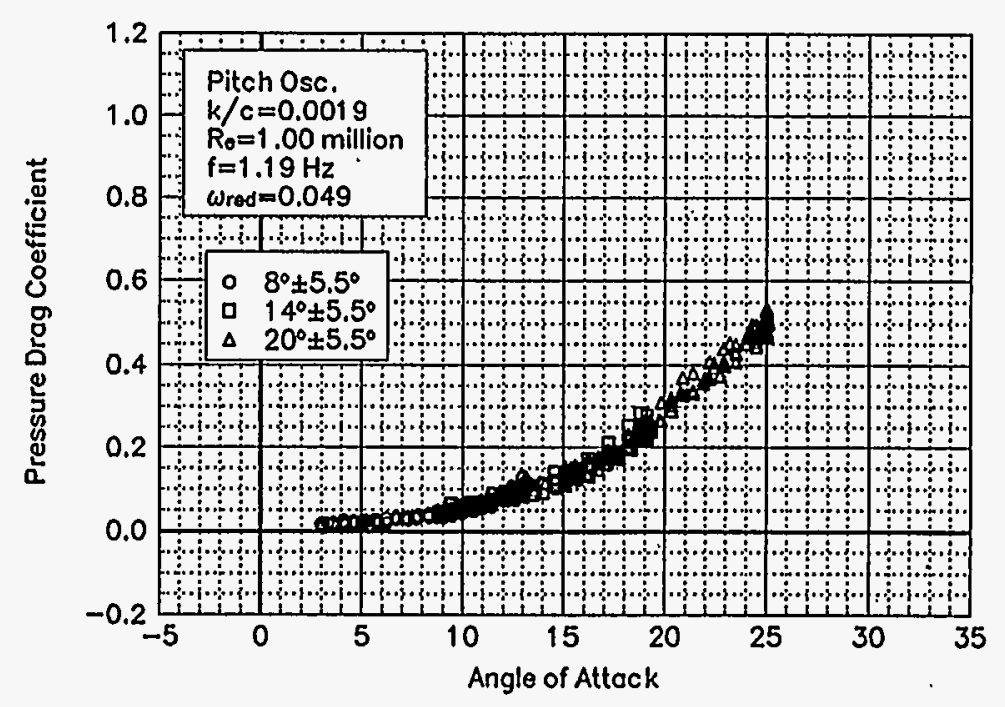

Figure C32. Pressure drag coefficient vs $a$.

\section{S815 LEGR
$\mathrm{Re}=1.00$ million
$\omega_{\text {reduced }}=0.049$

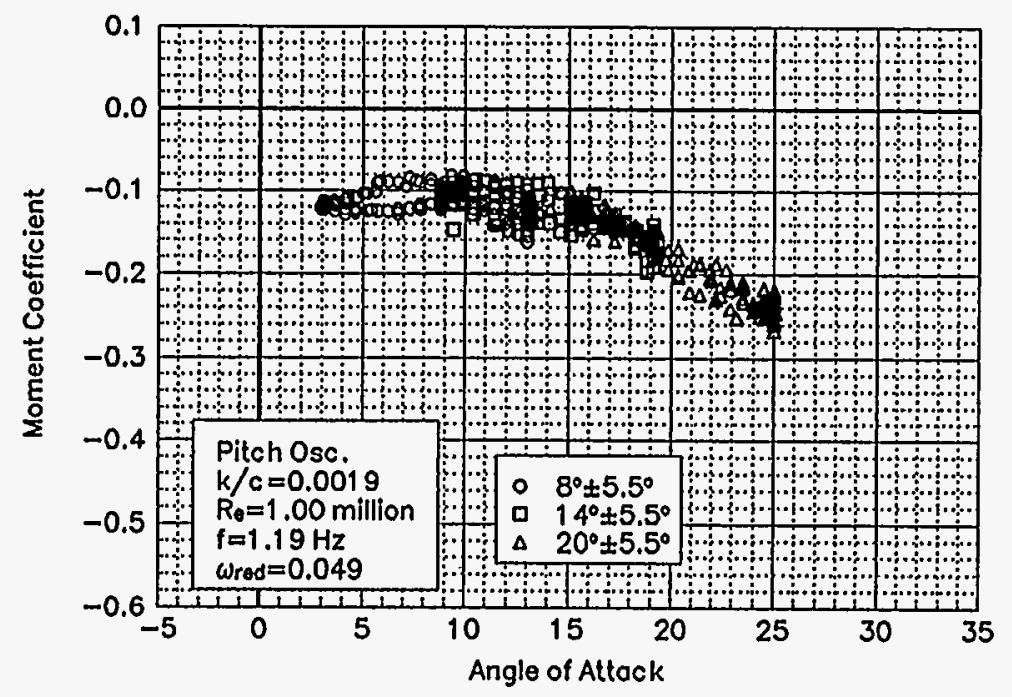

Figure C33. Moment coefficient vs $a$. 

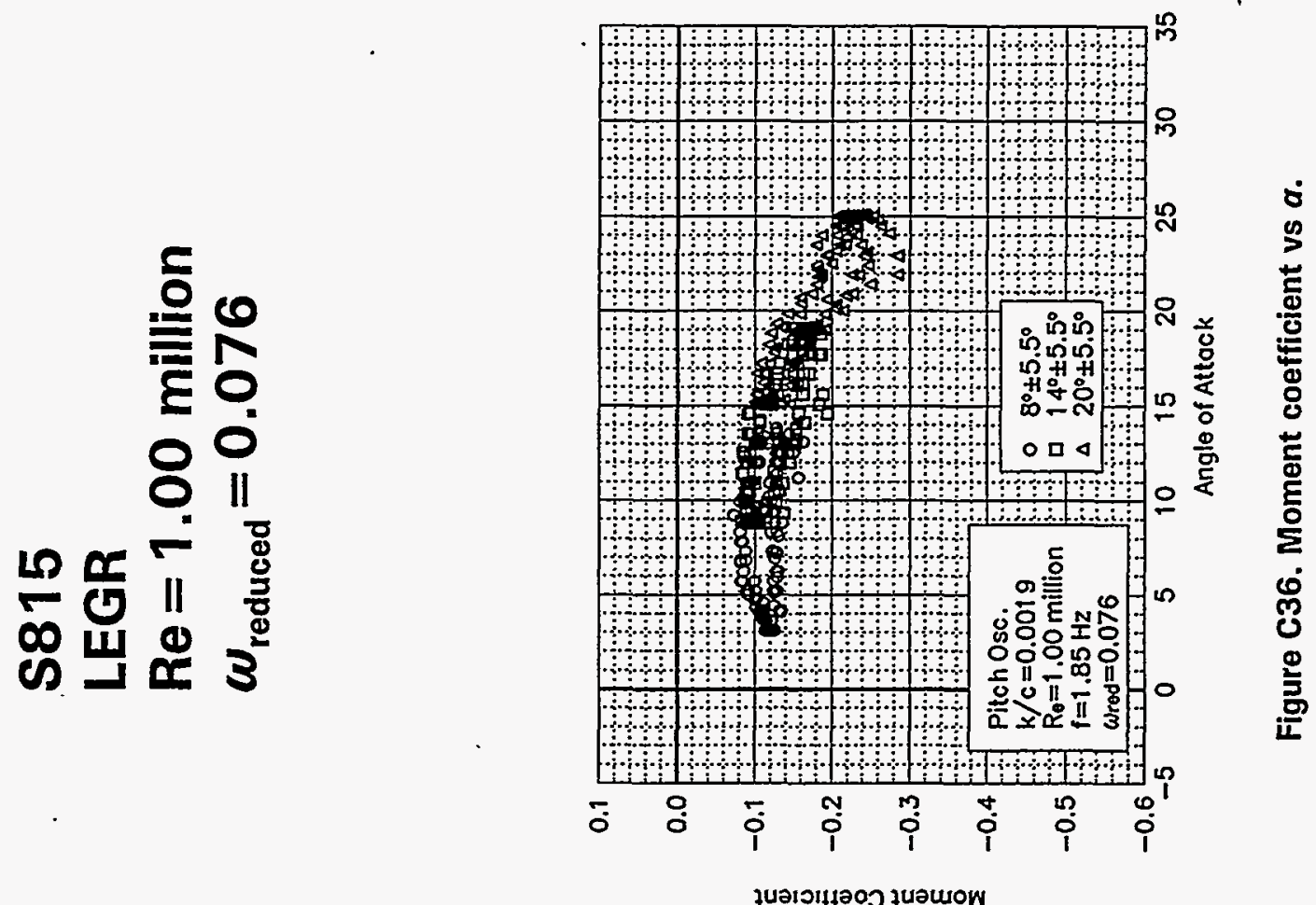

$\frac{6}{0}$

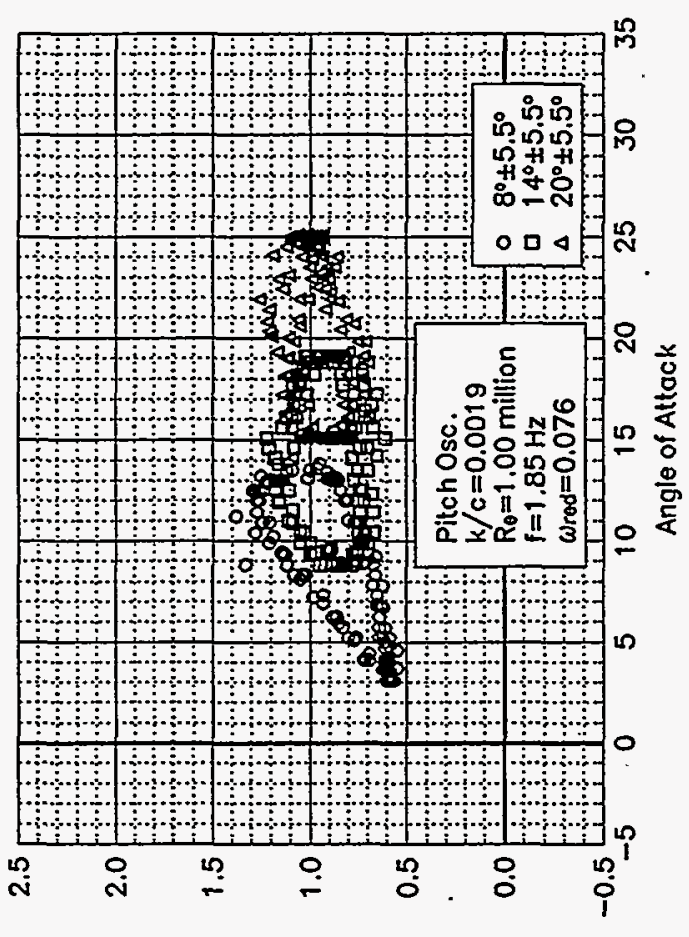

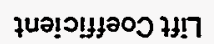

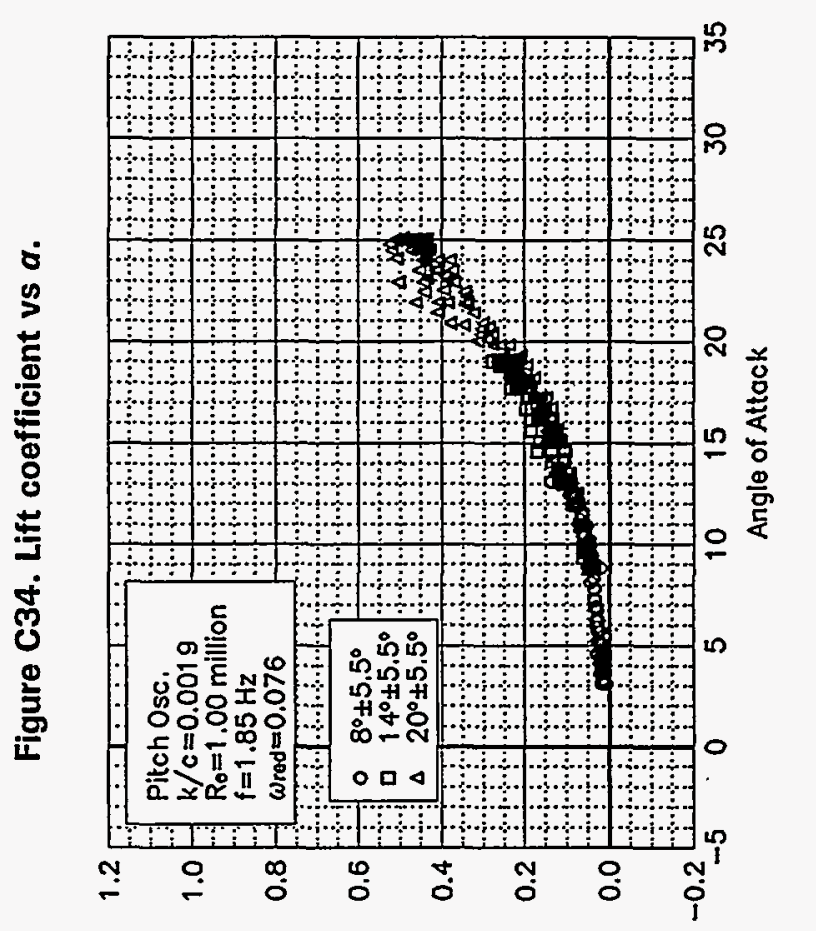

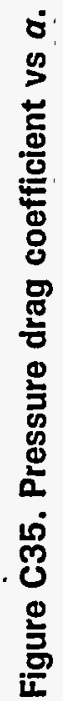




\section{Unsteady Airfoil Characteristics}

$$
\pm 5.5^{\circ} \text { Sine, } \operatorname{Re}=1.25 \text { million }
$$



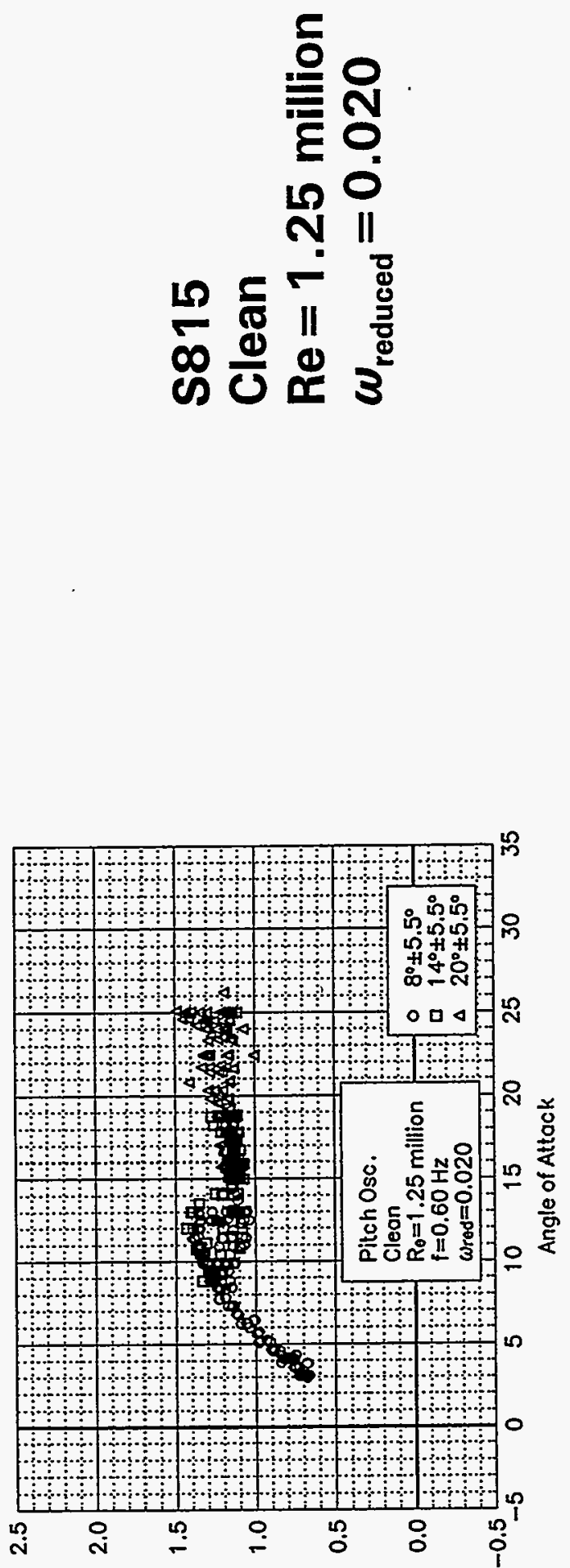

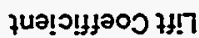

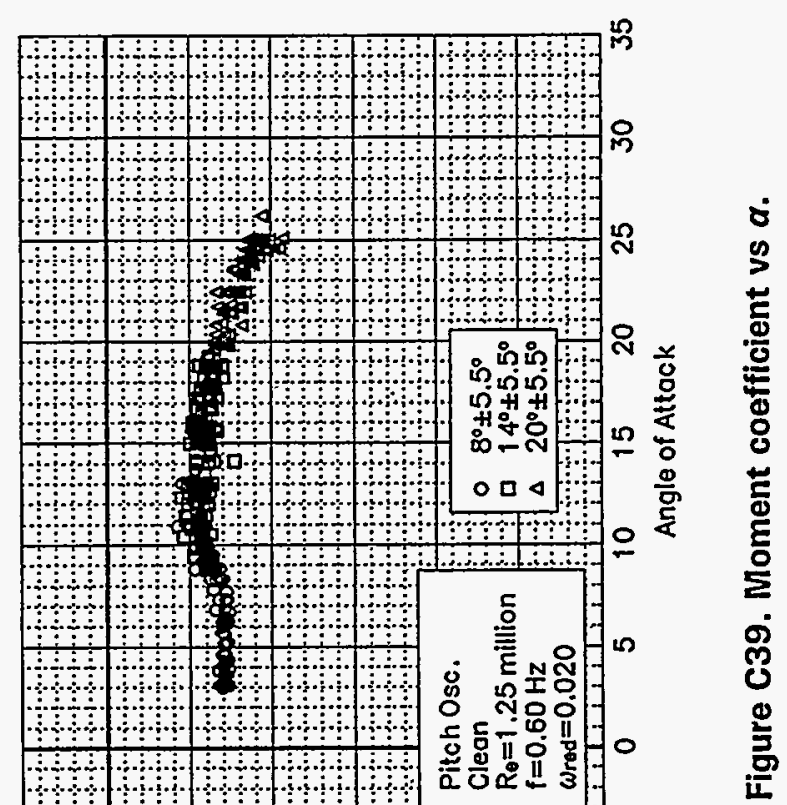

$\frac{\infty}{u}$

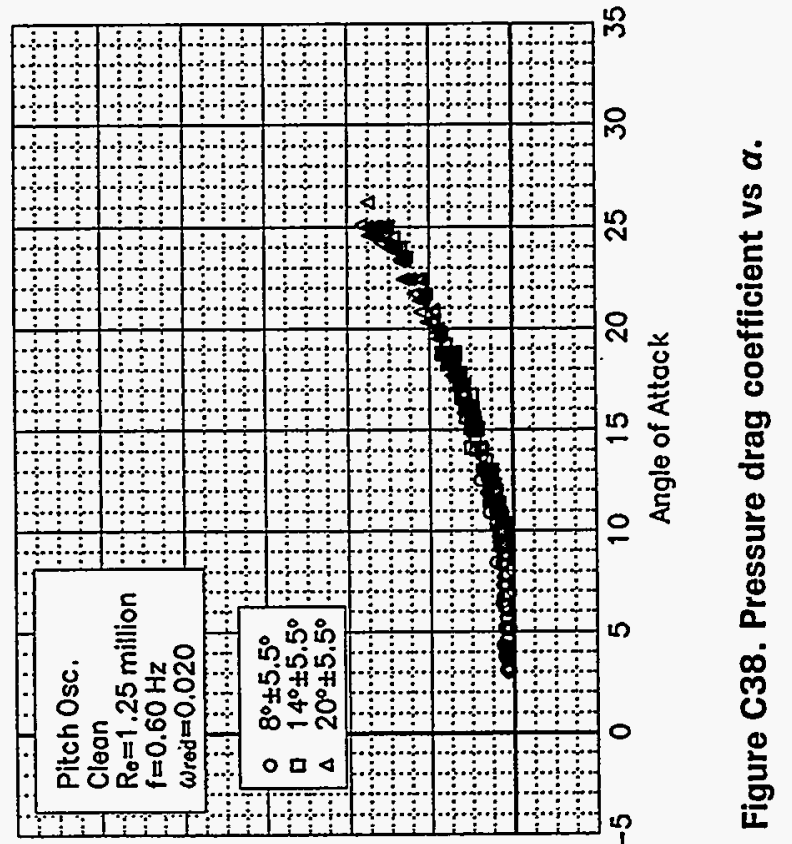

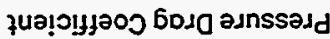



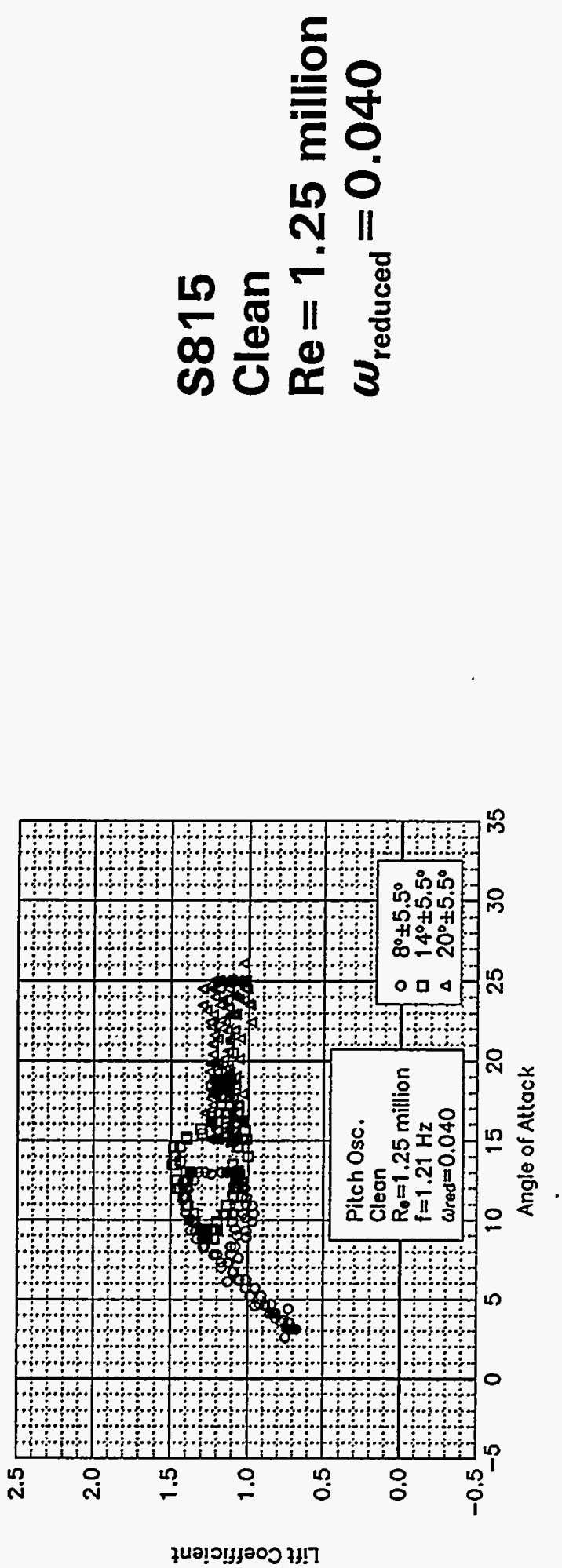

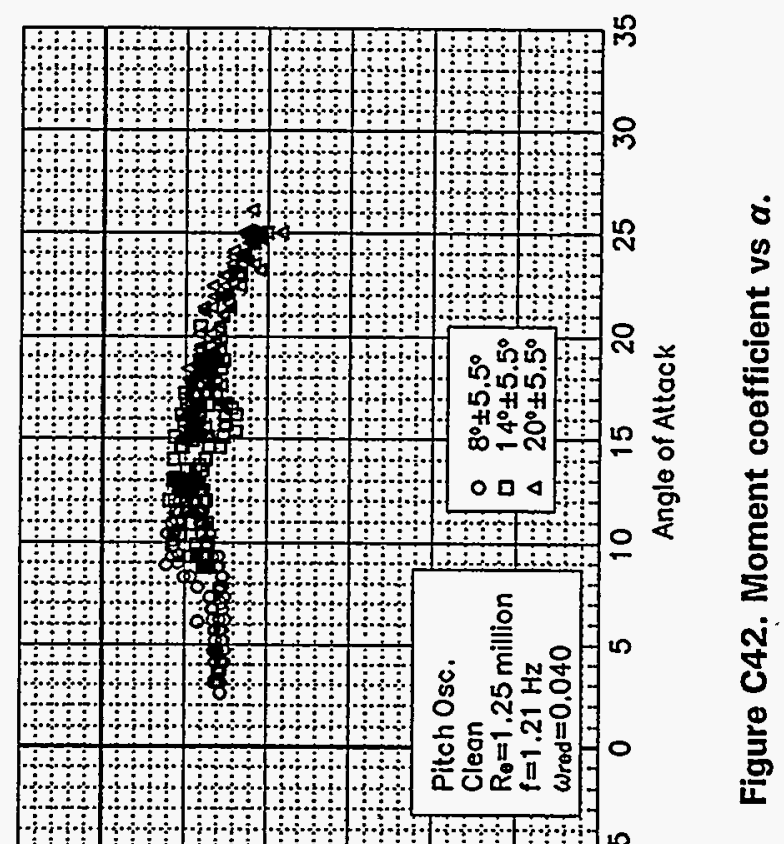

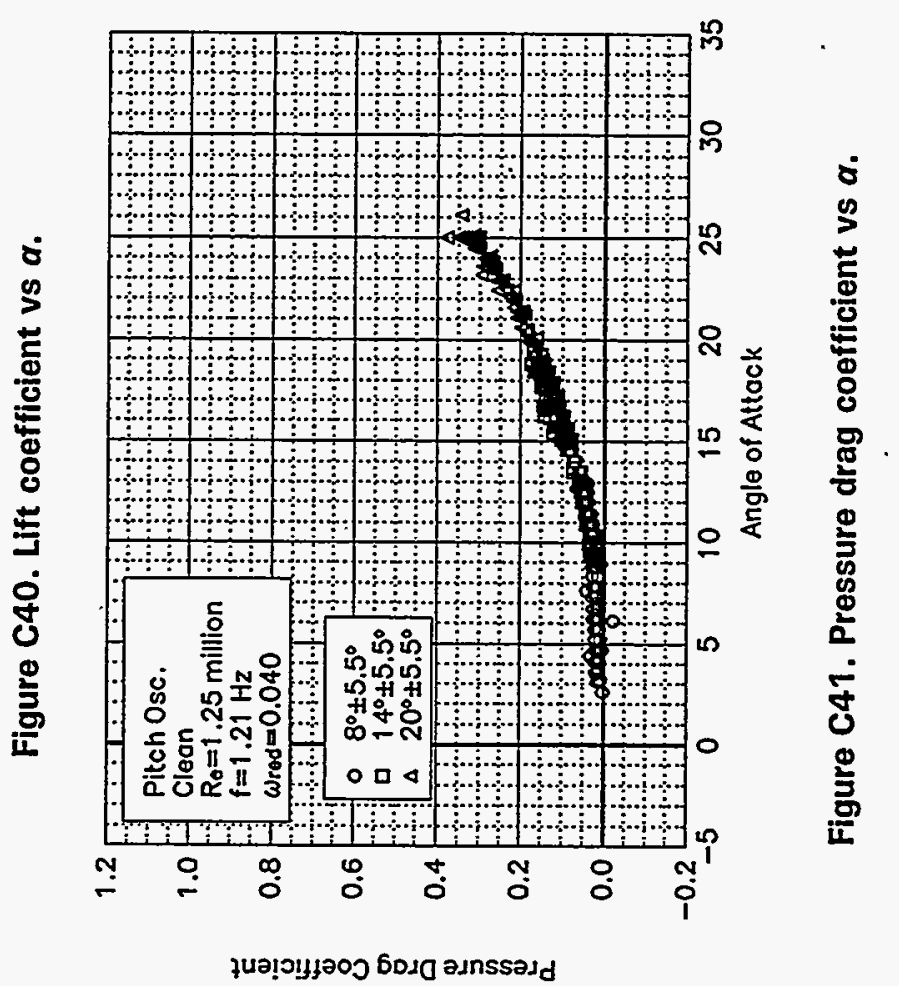



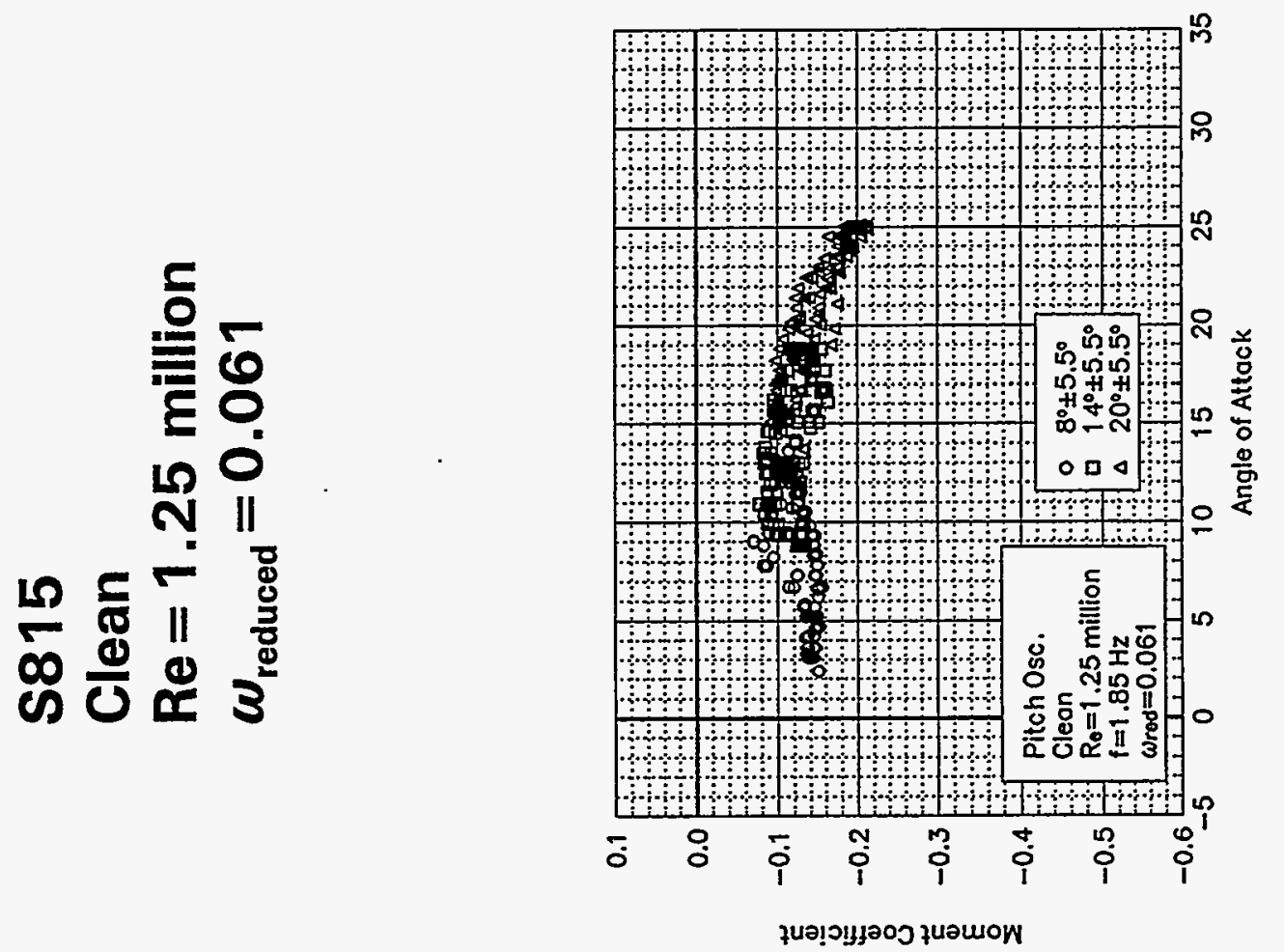

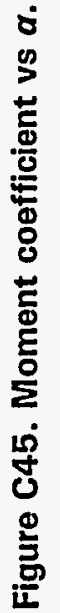
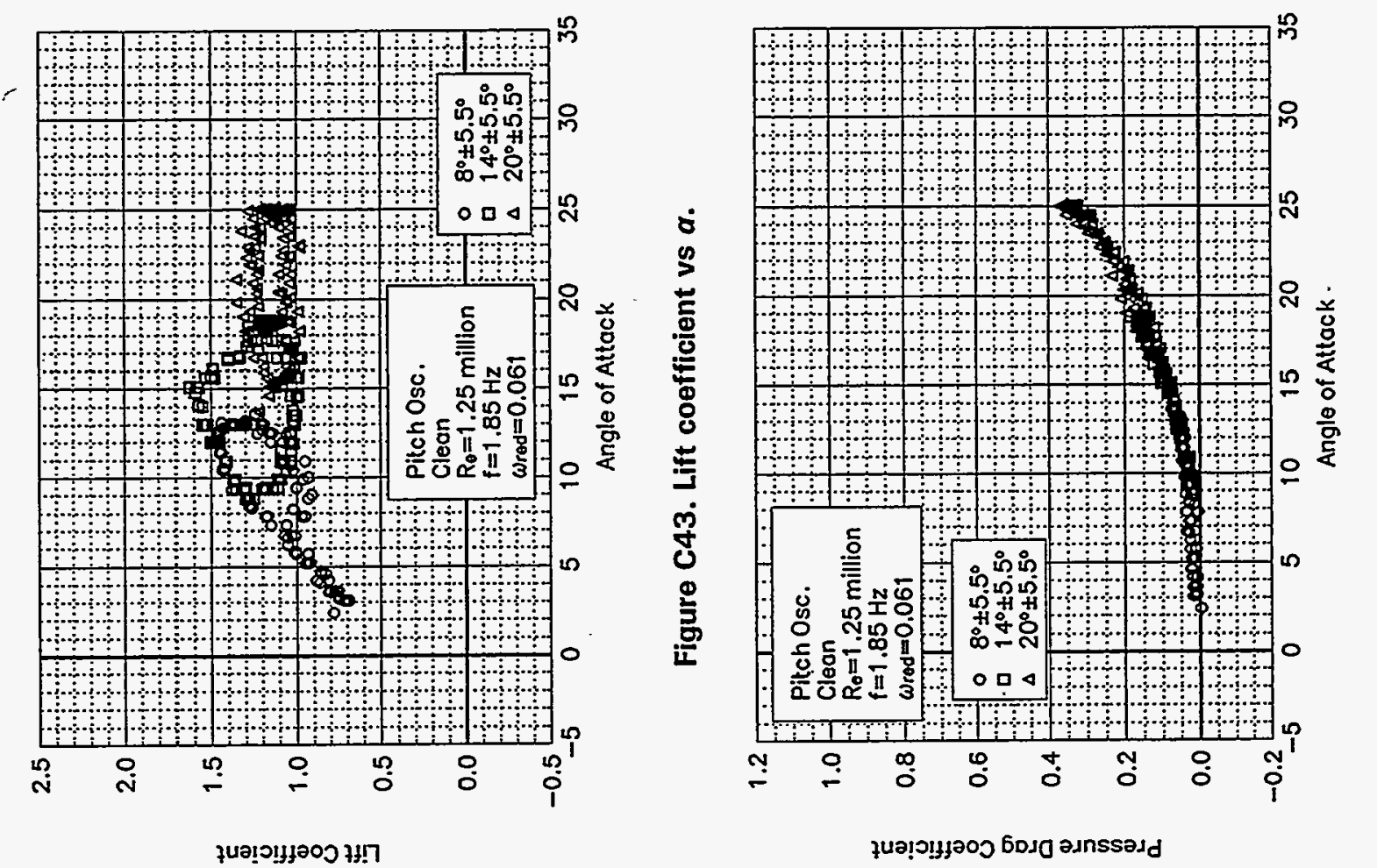

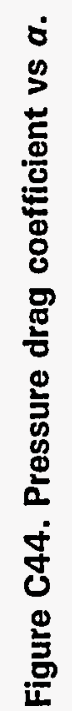

ชัำ 

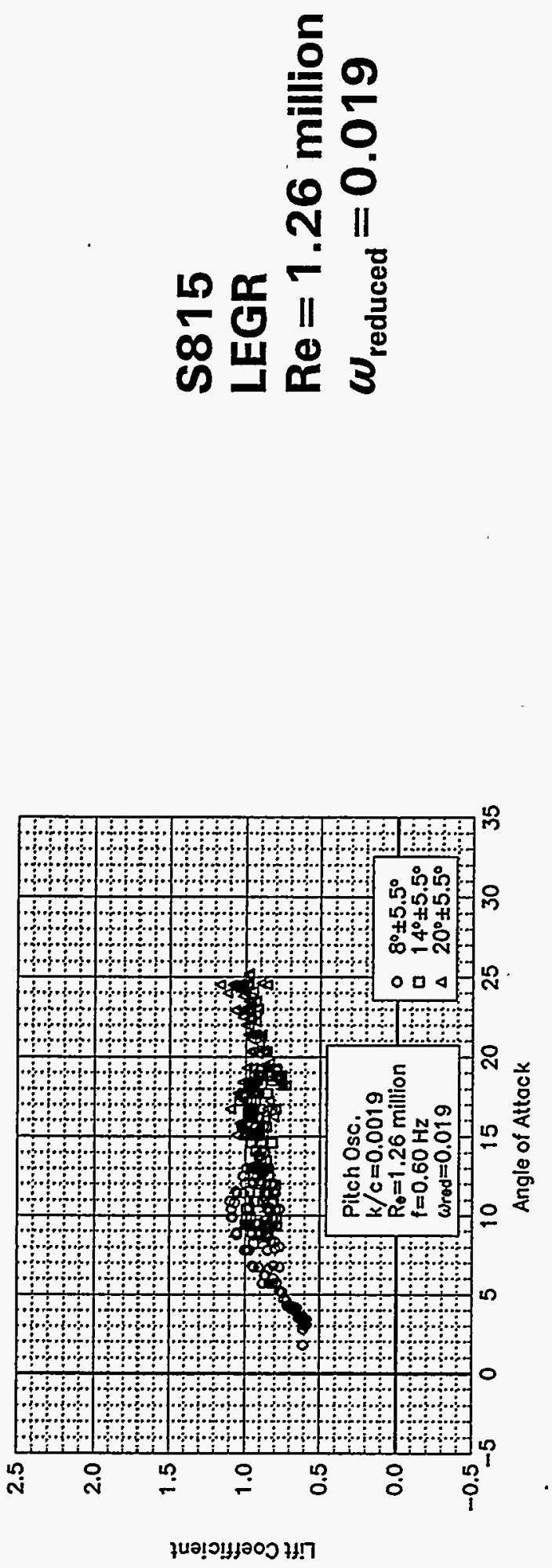

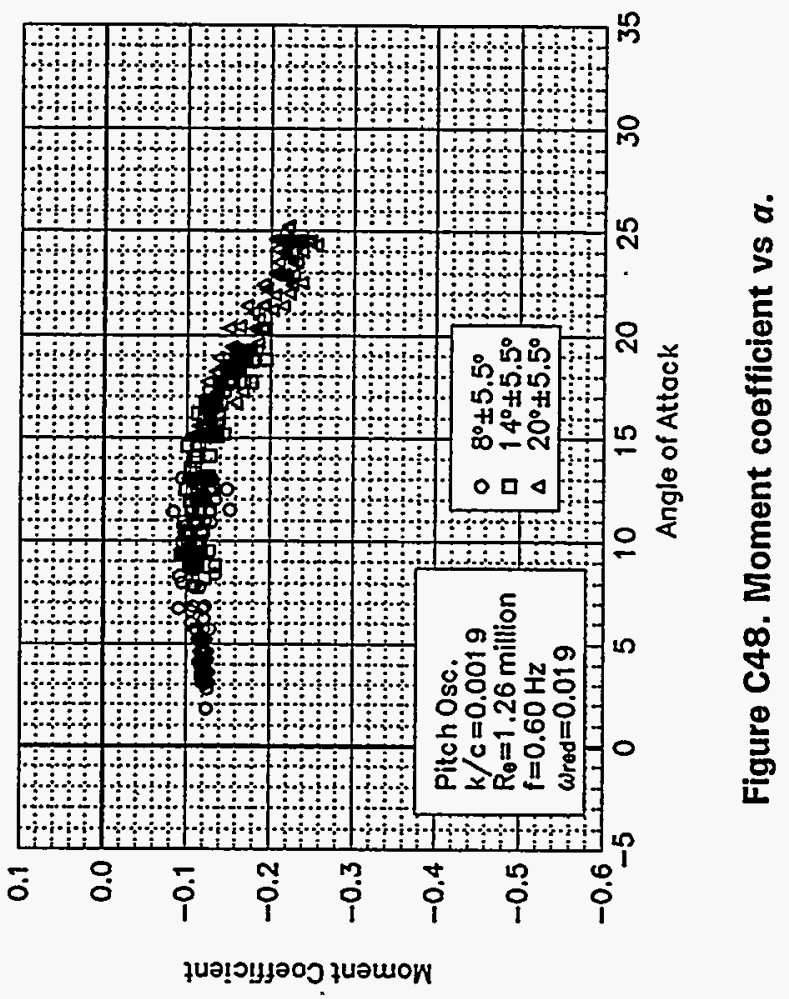

ริ

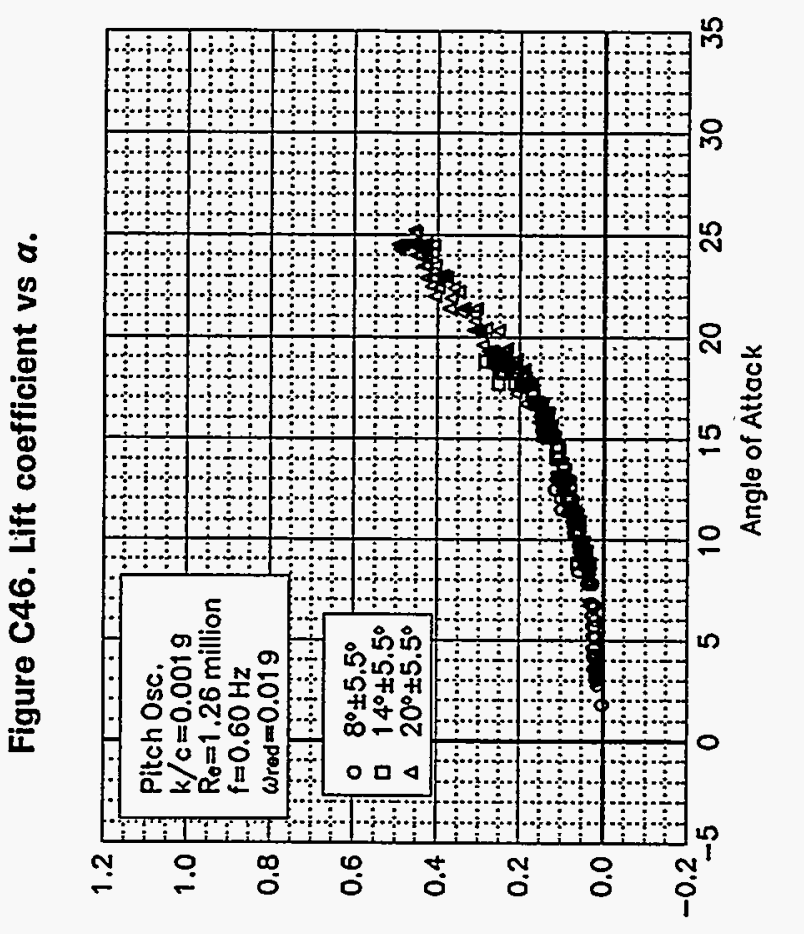

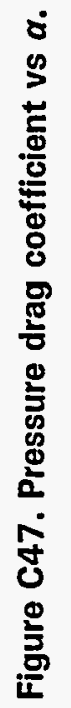



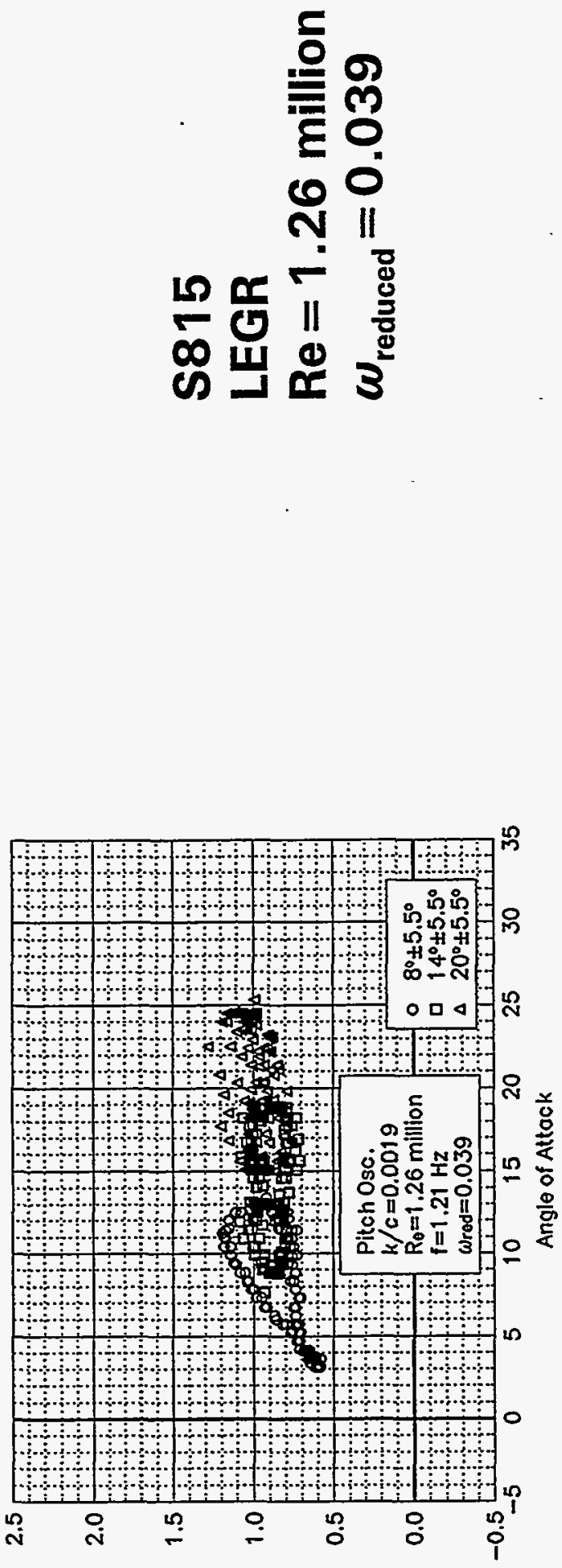

ในข!อเมรคว ห!า

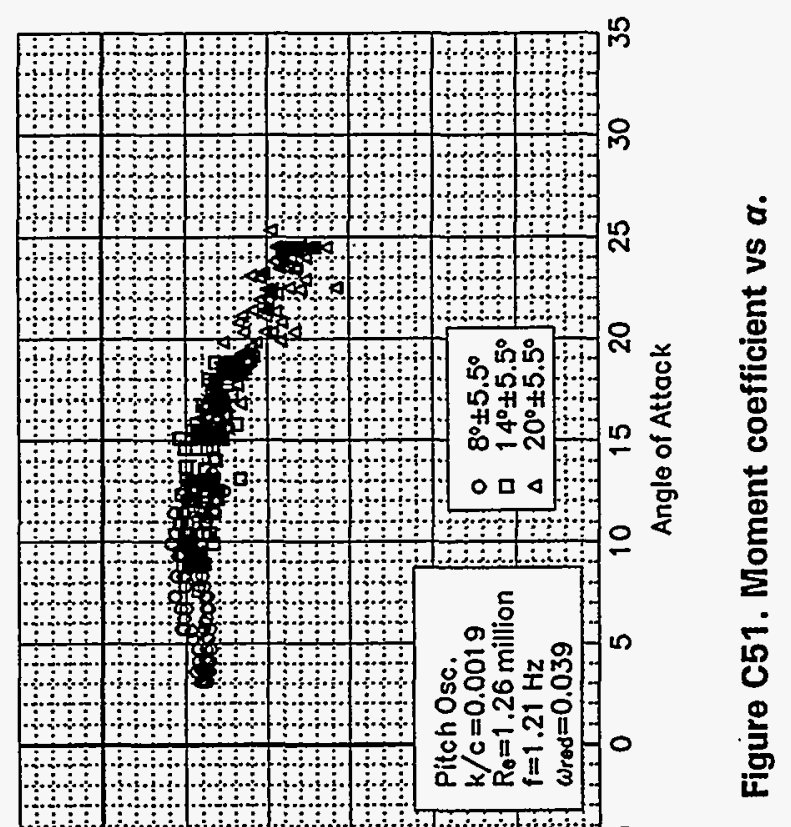

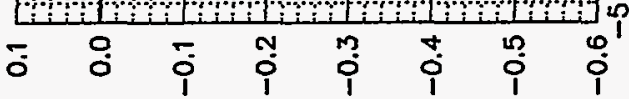

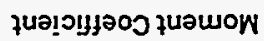

ชิ

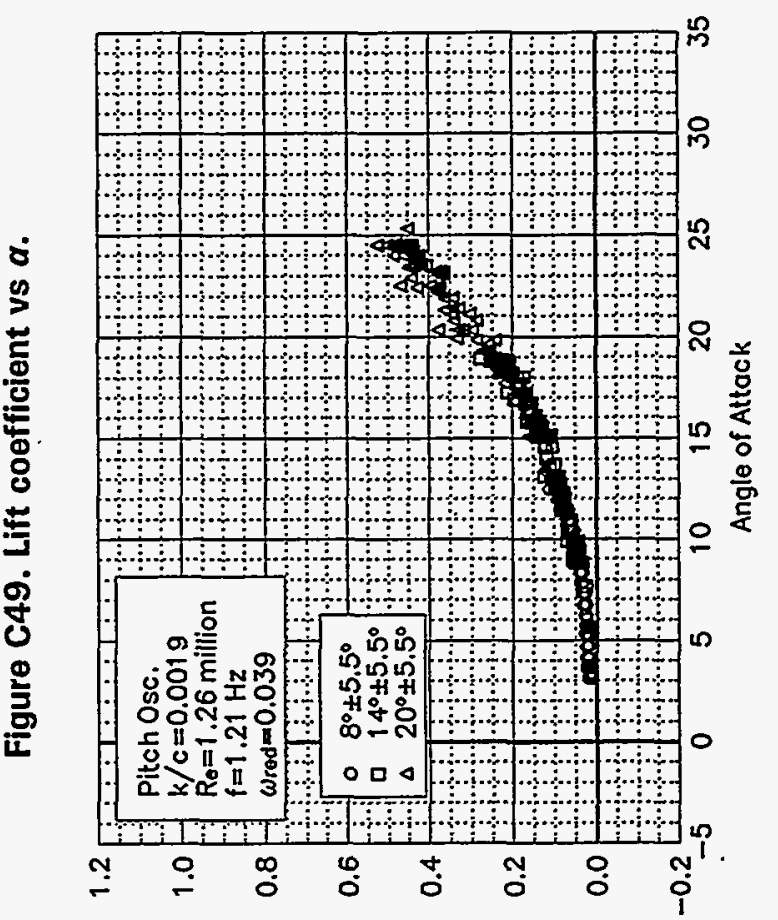

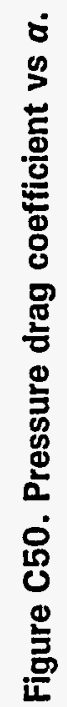

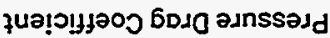



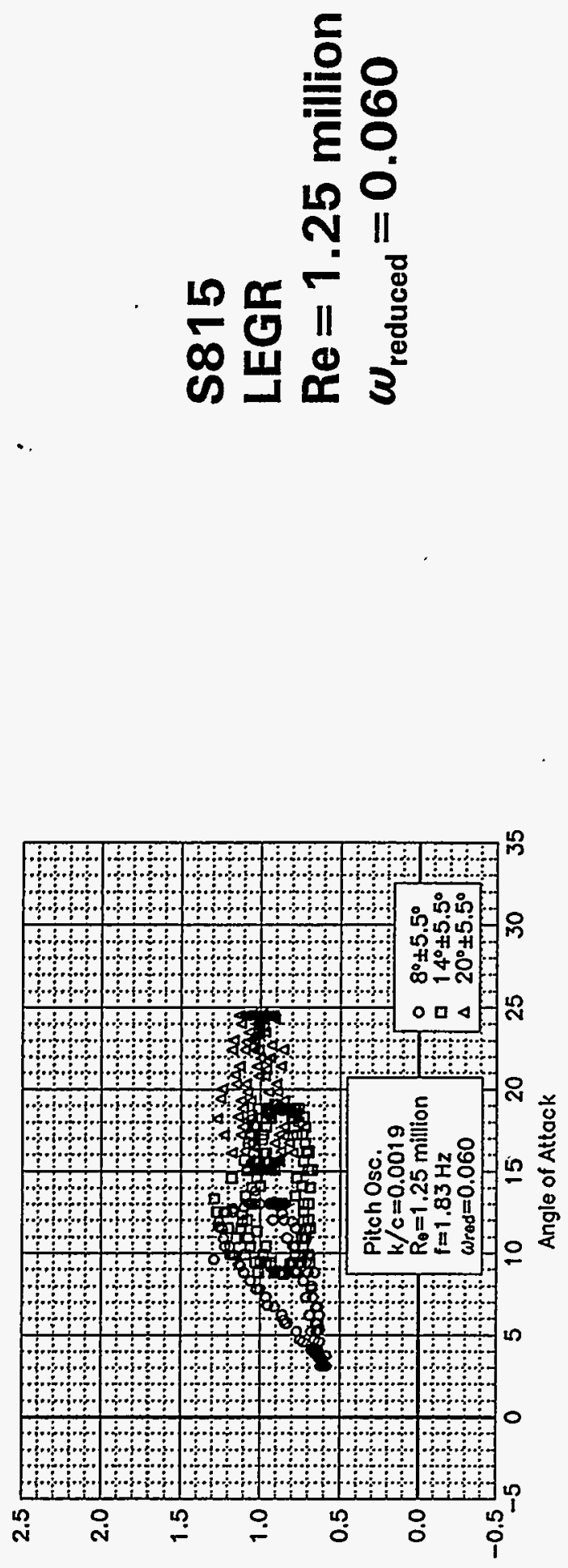

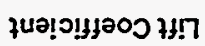

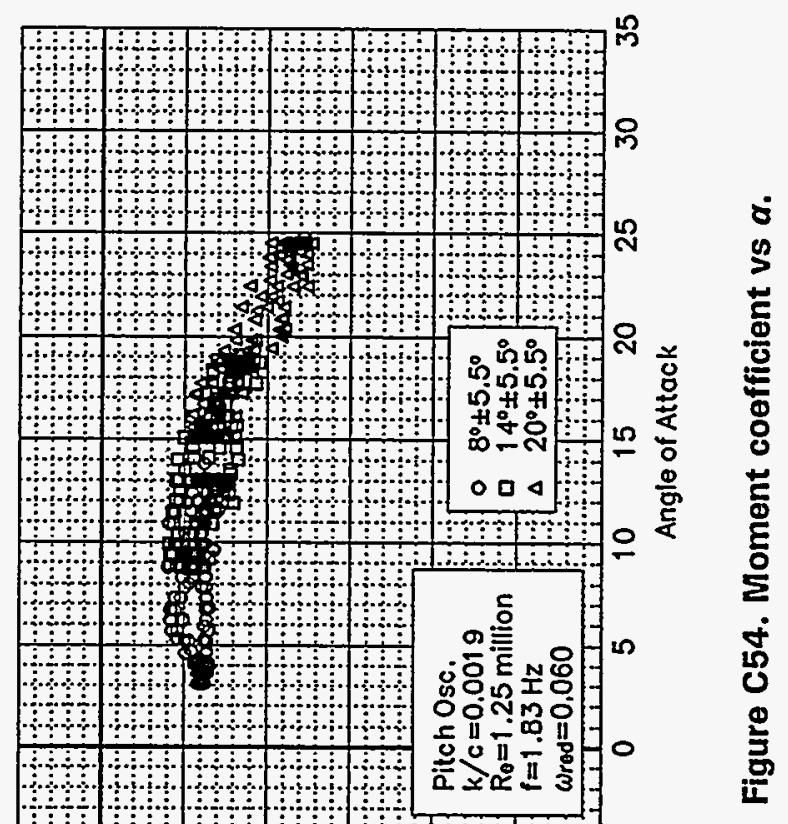

ণั

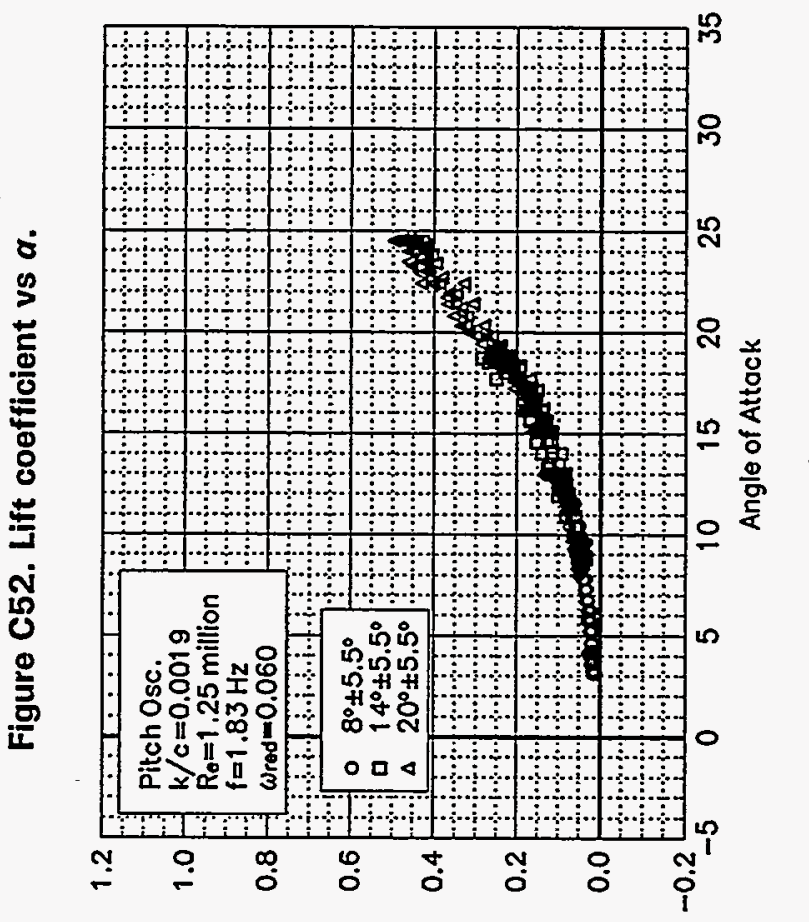

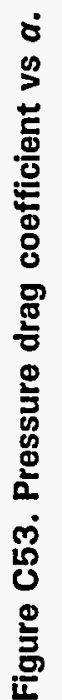

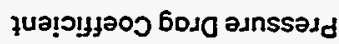




\section{Unsteady Airfoil Characteristics}

$\pm 5.5^{\circ}$ Sine, $\operatorname{Re}=1.4$ million 

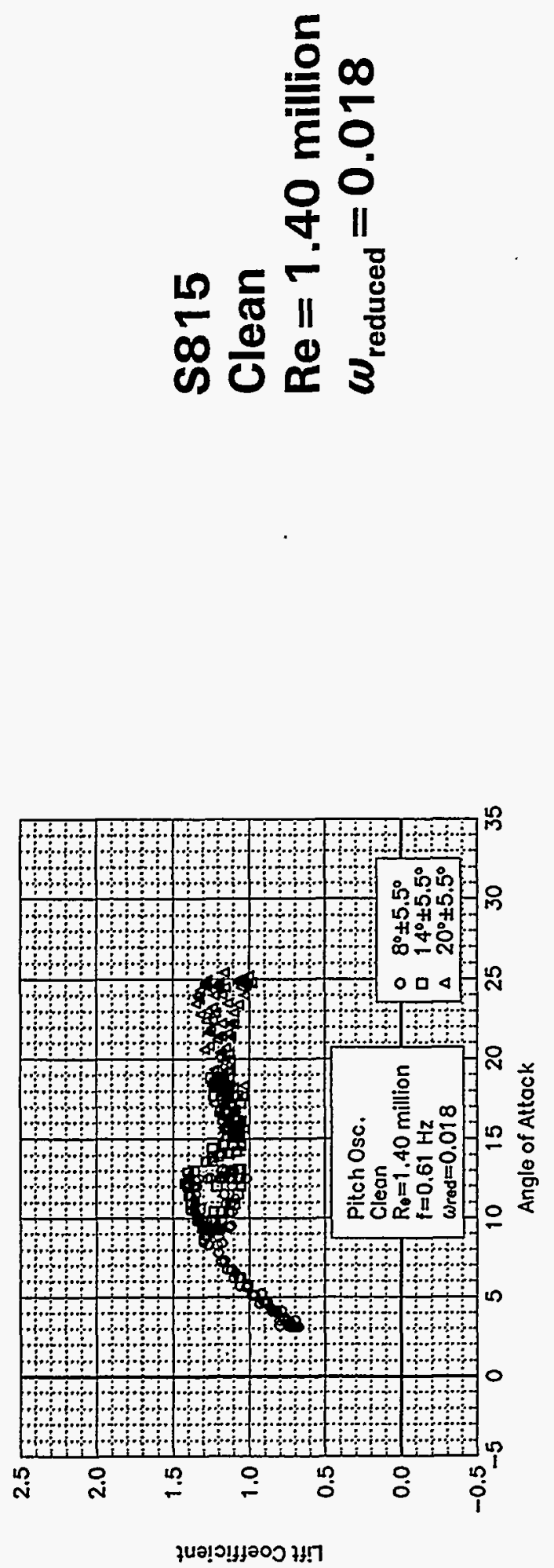

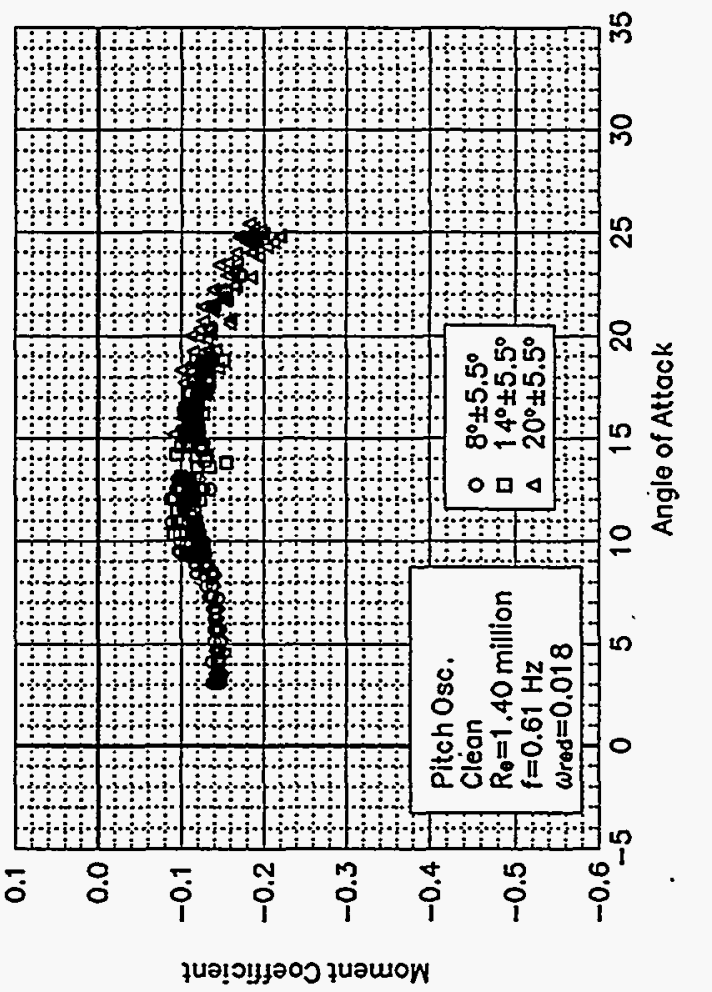

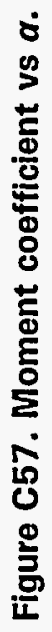

ชัง

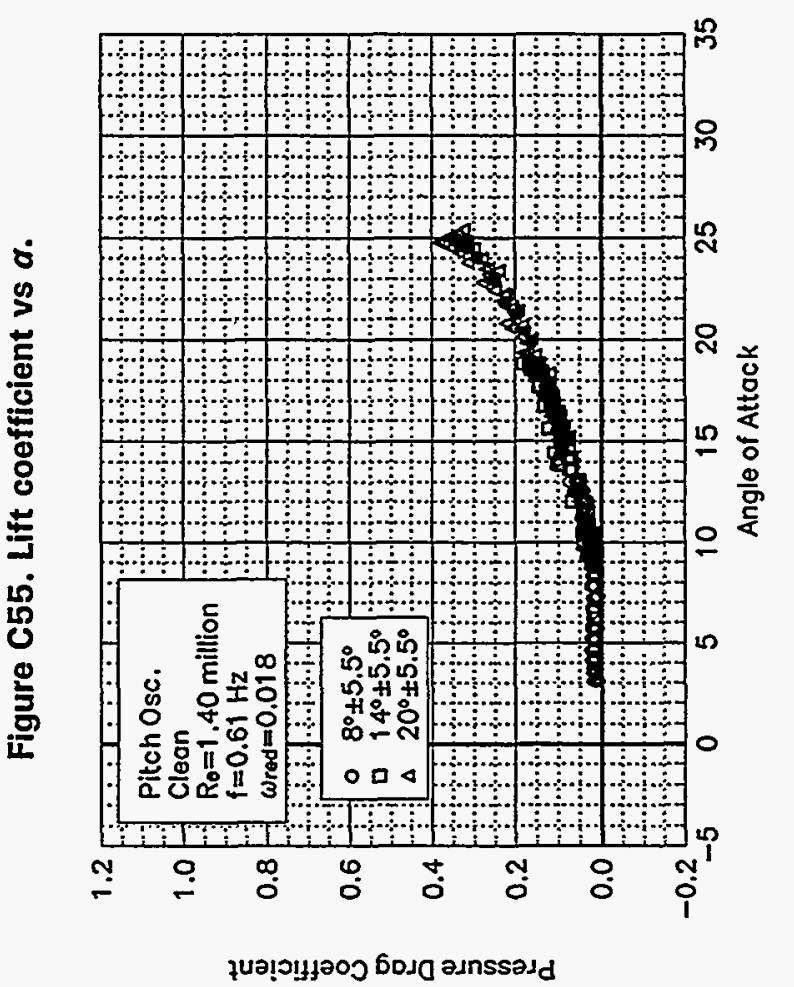

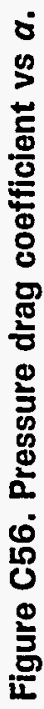



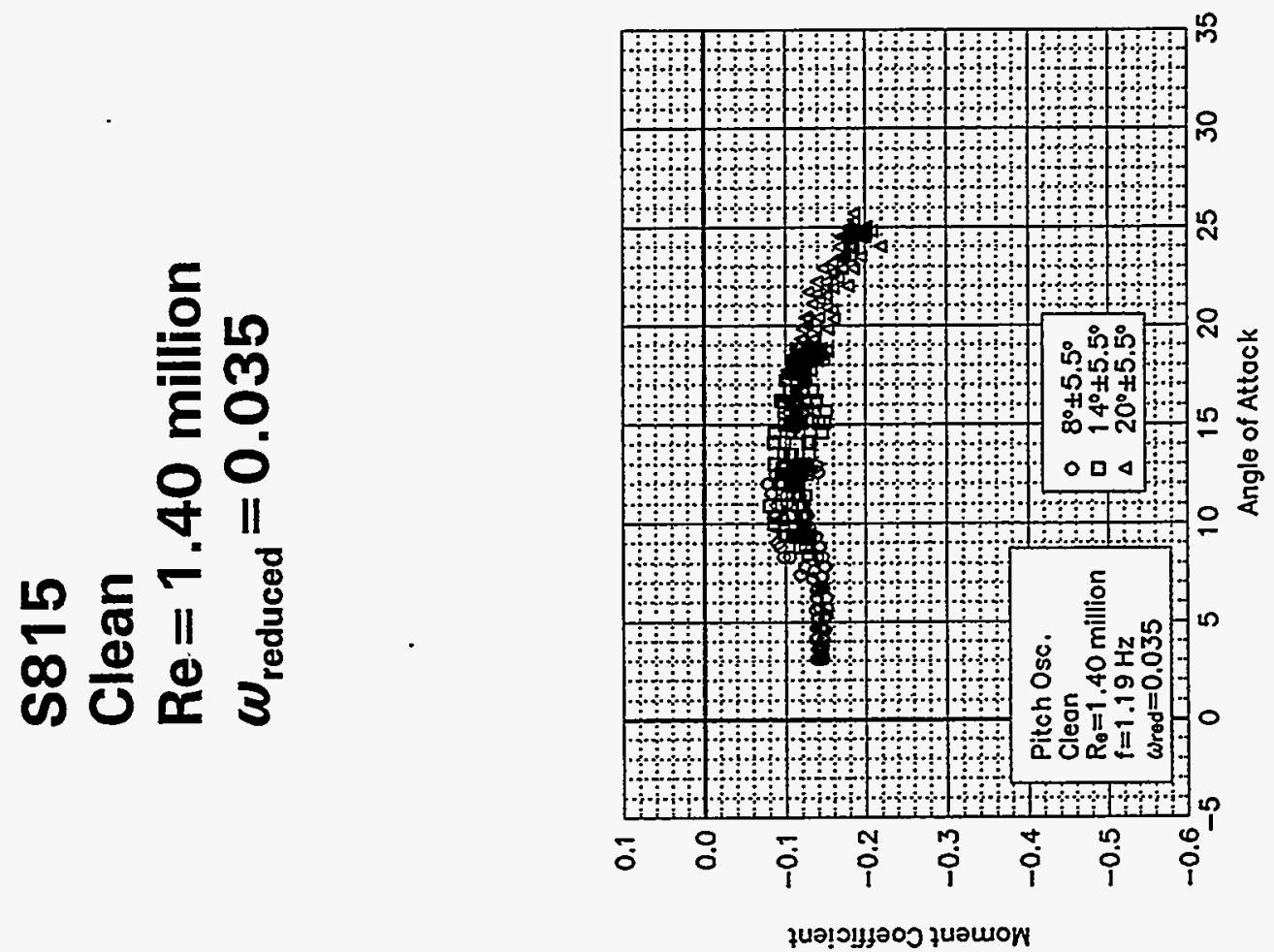

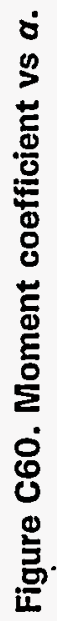
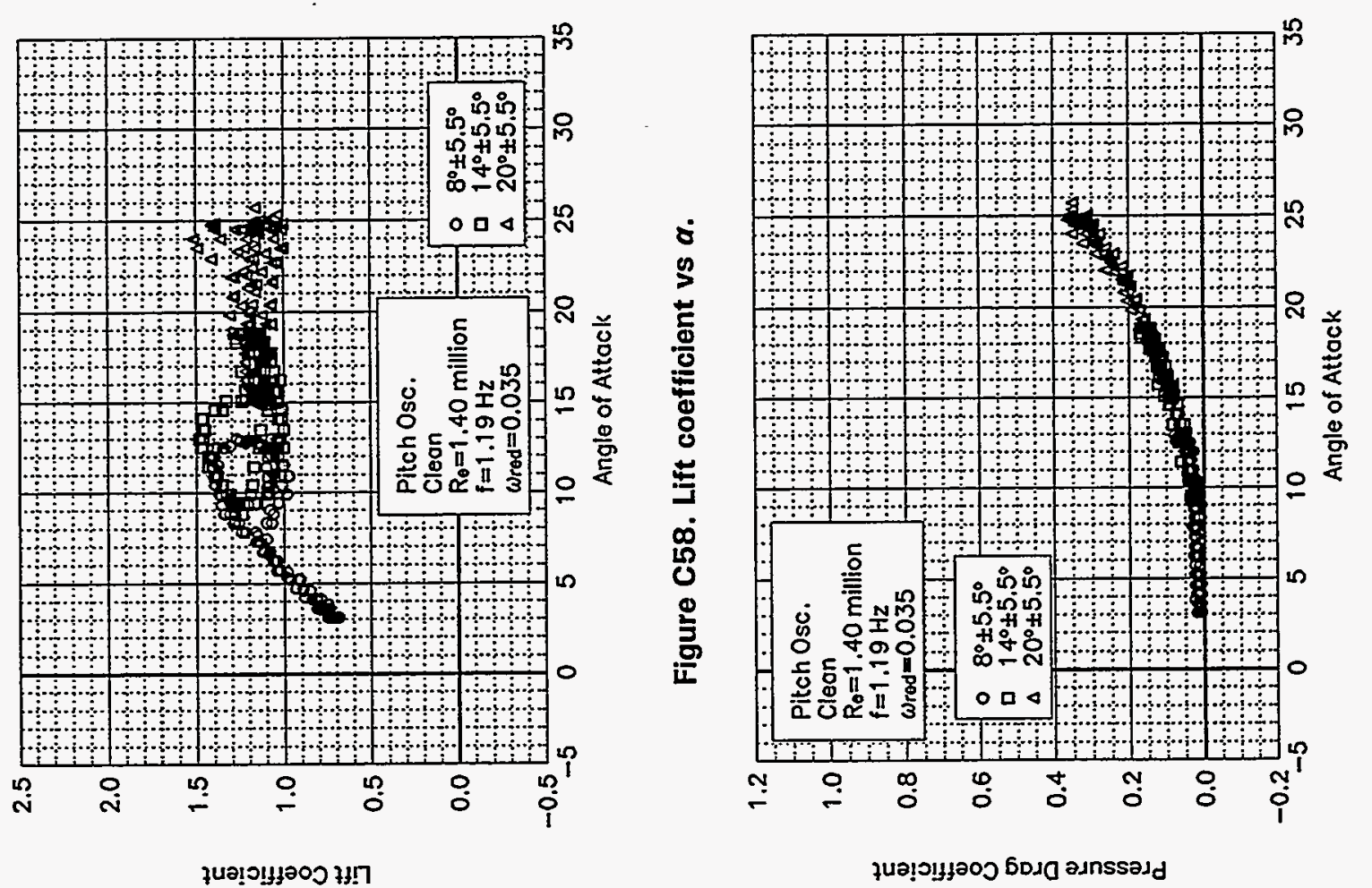

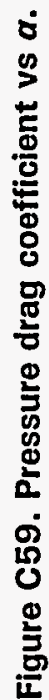



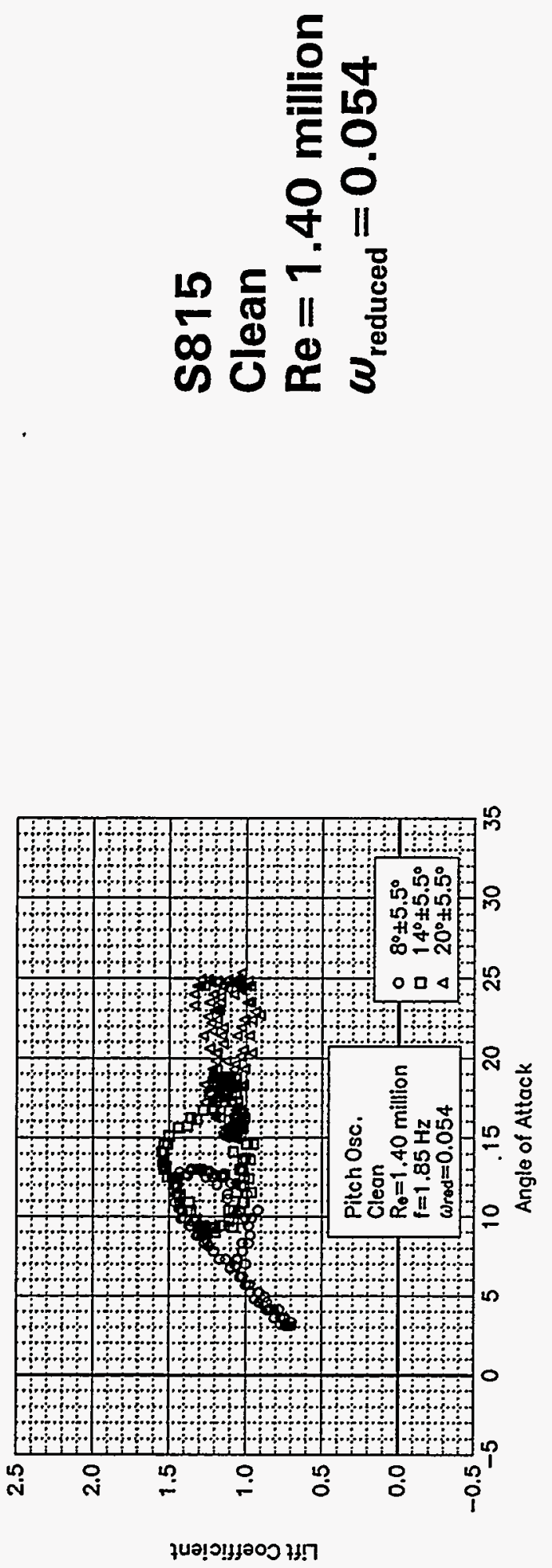

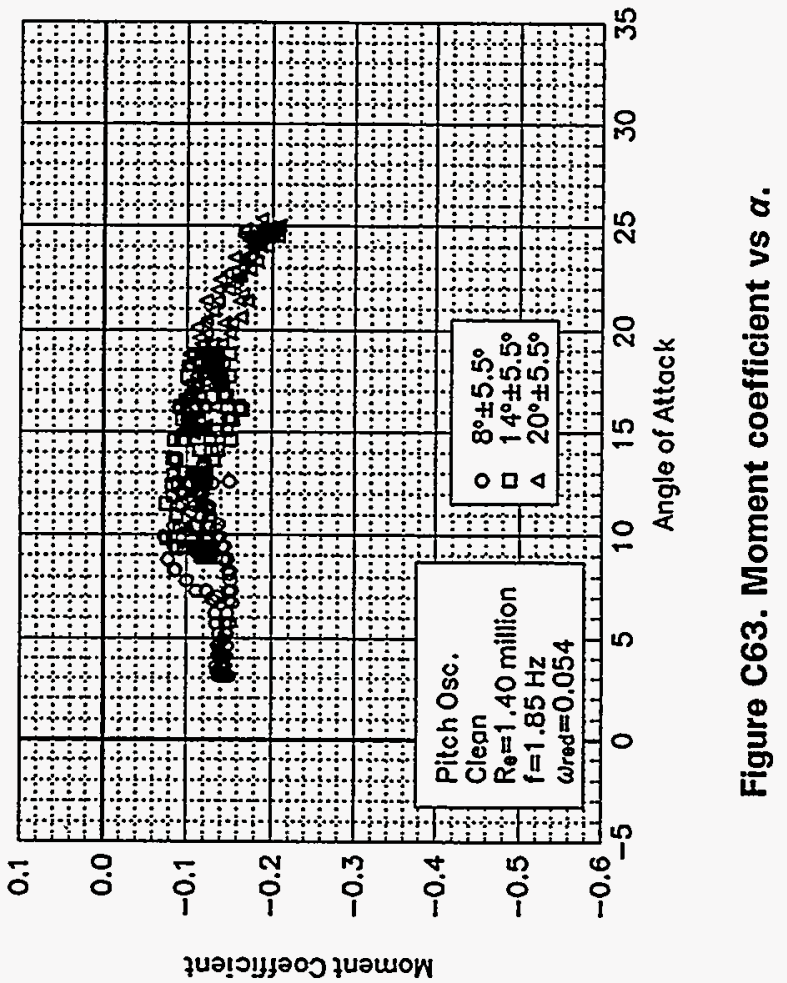

8

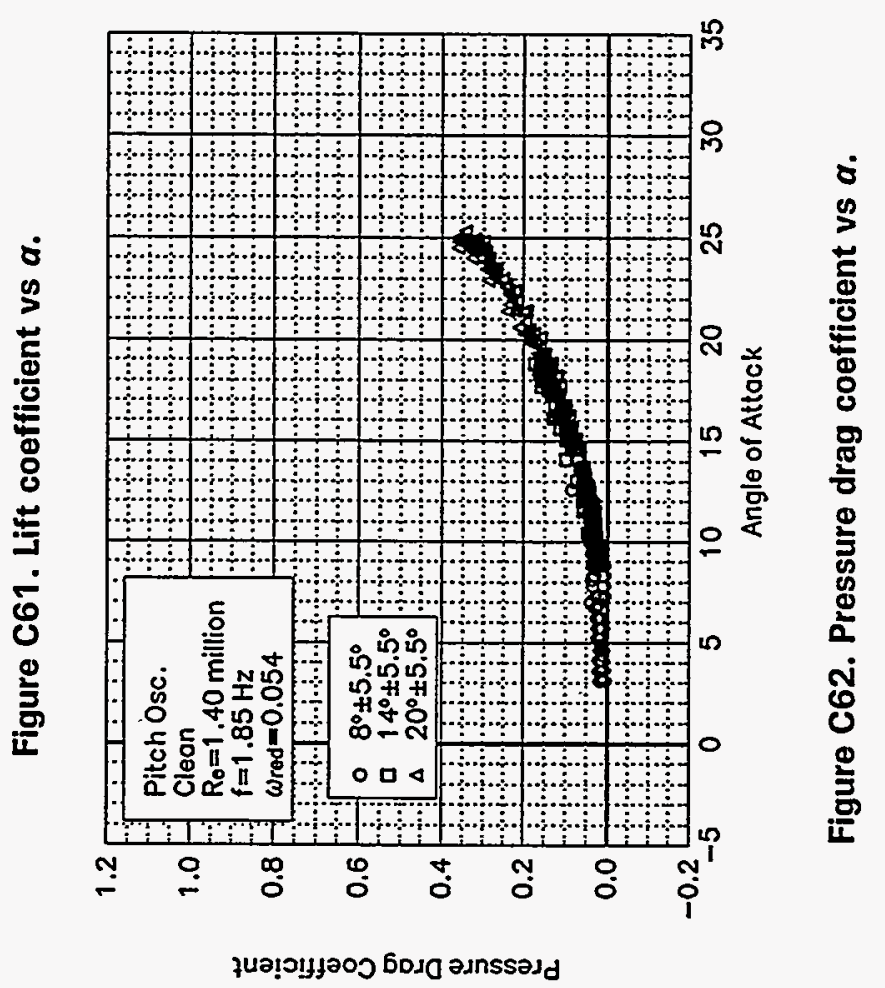



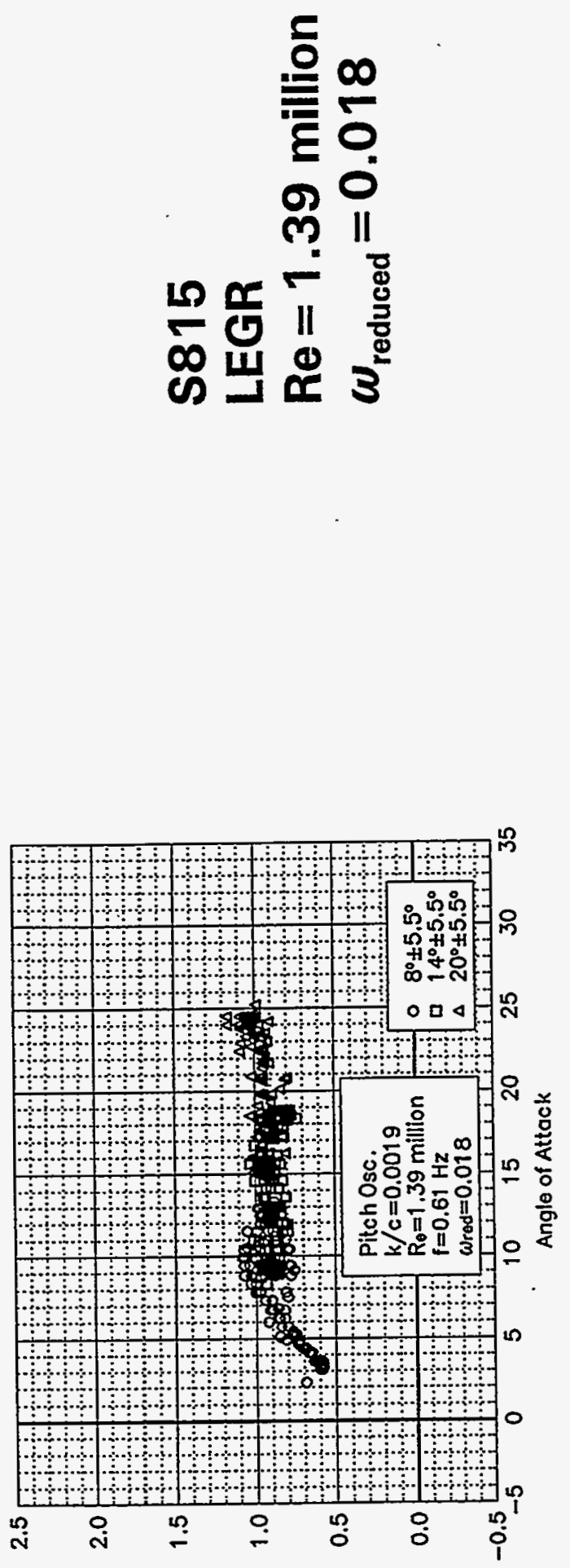

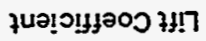

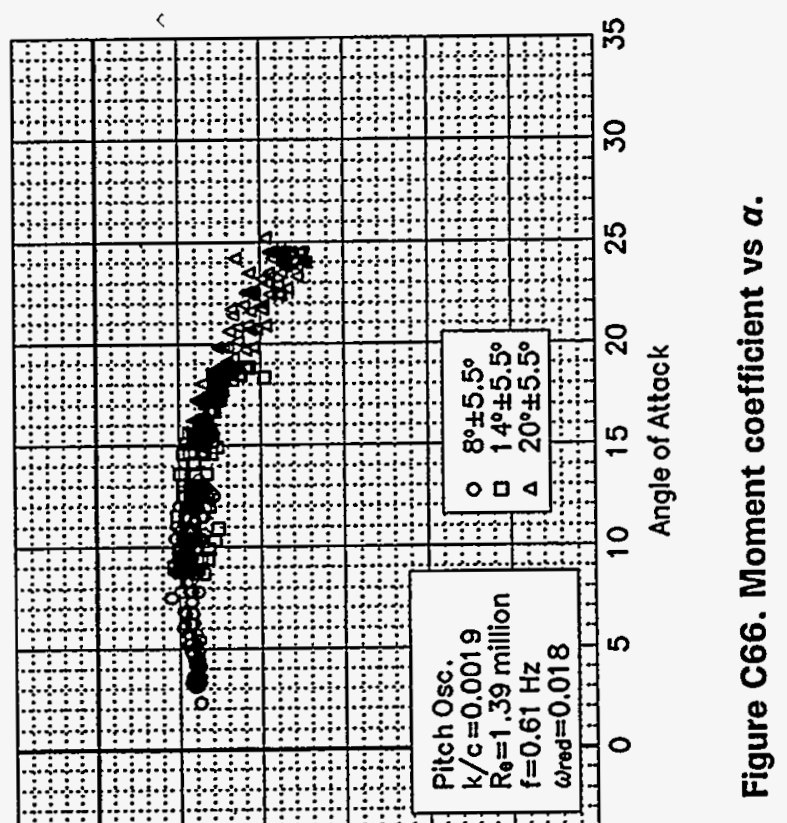

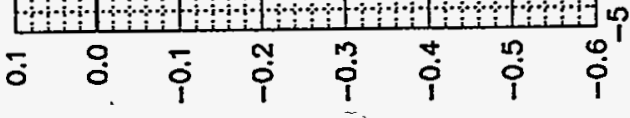

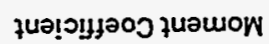

$\stackrel{\infty}{\mathfrak{1}}$

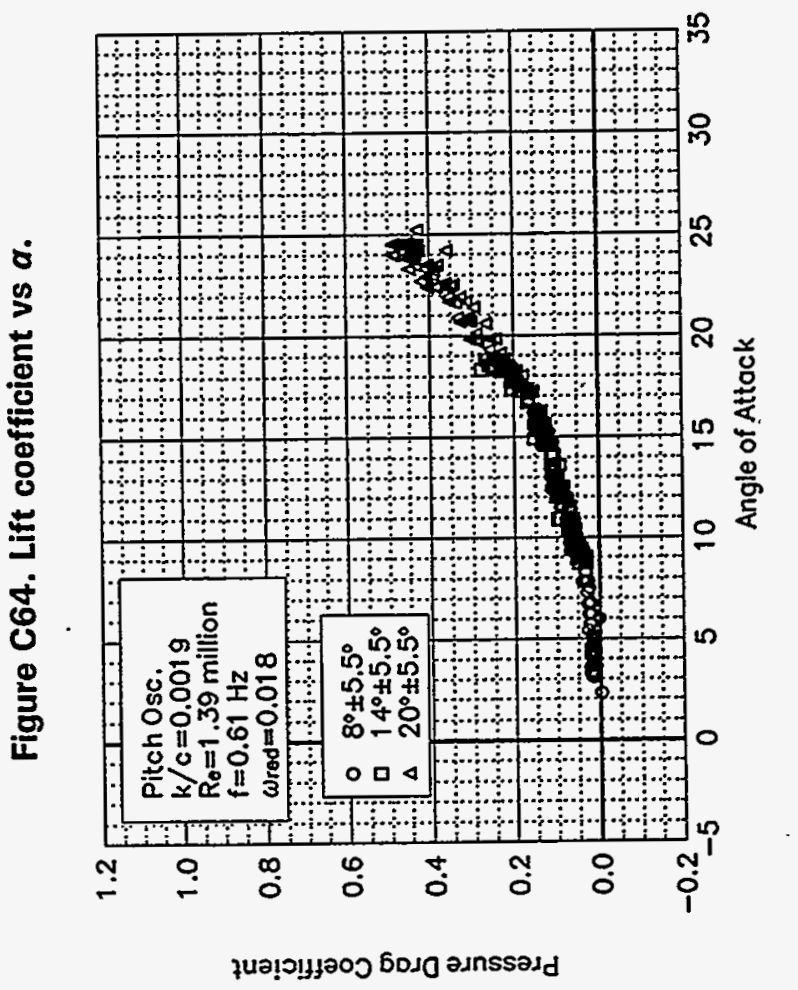

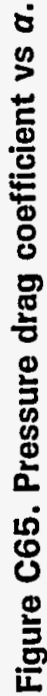



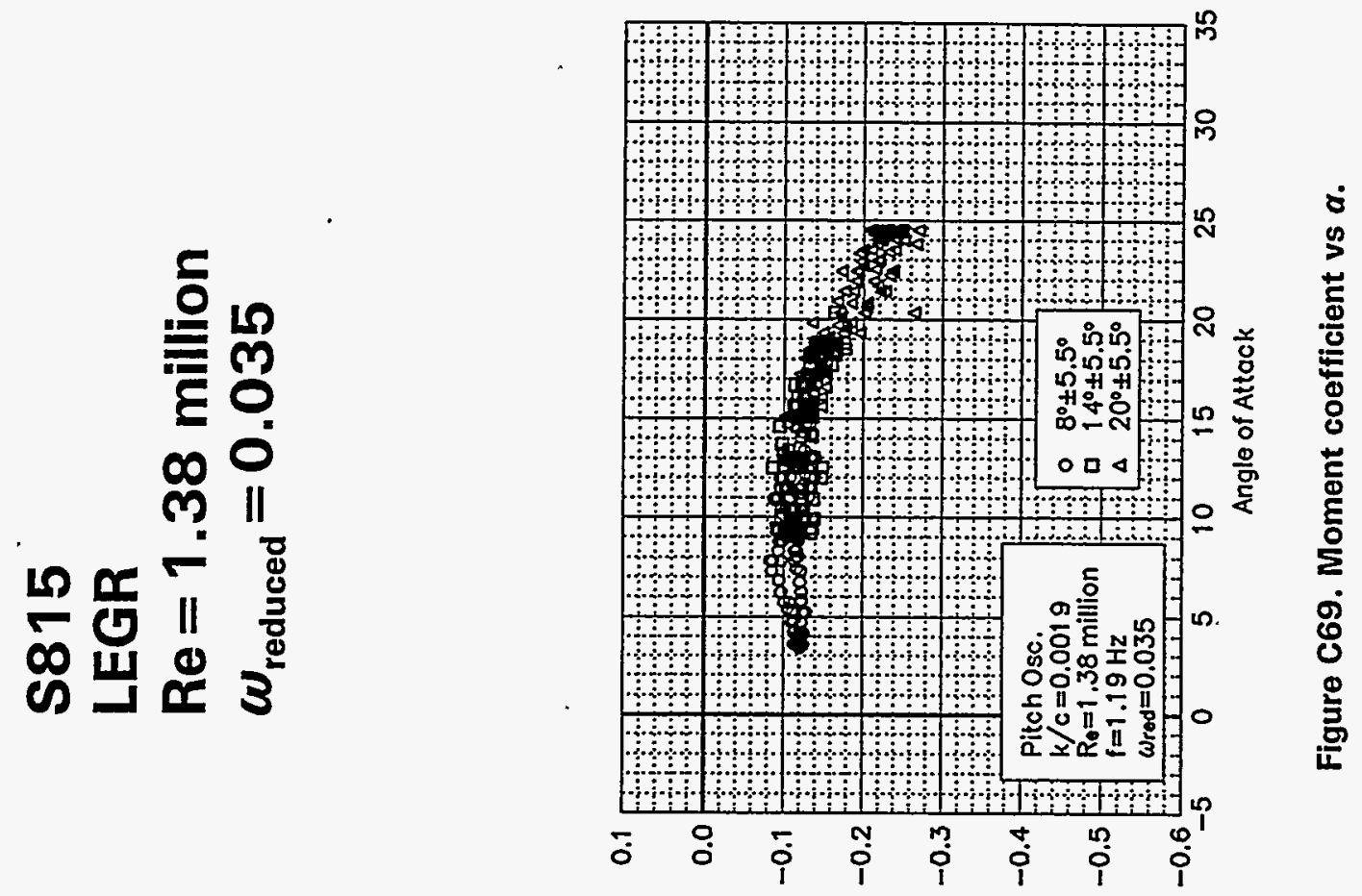

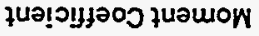

ชิ่
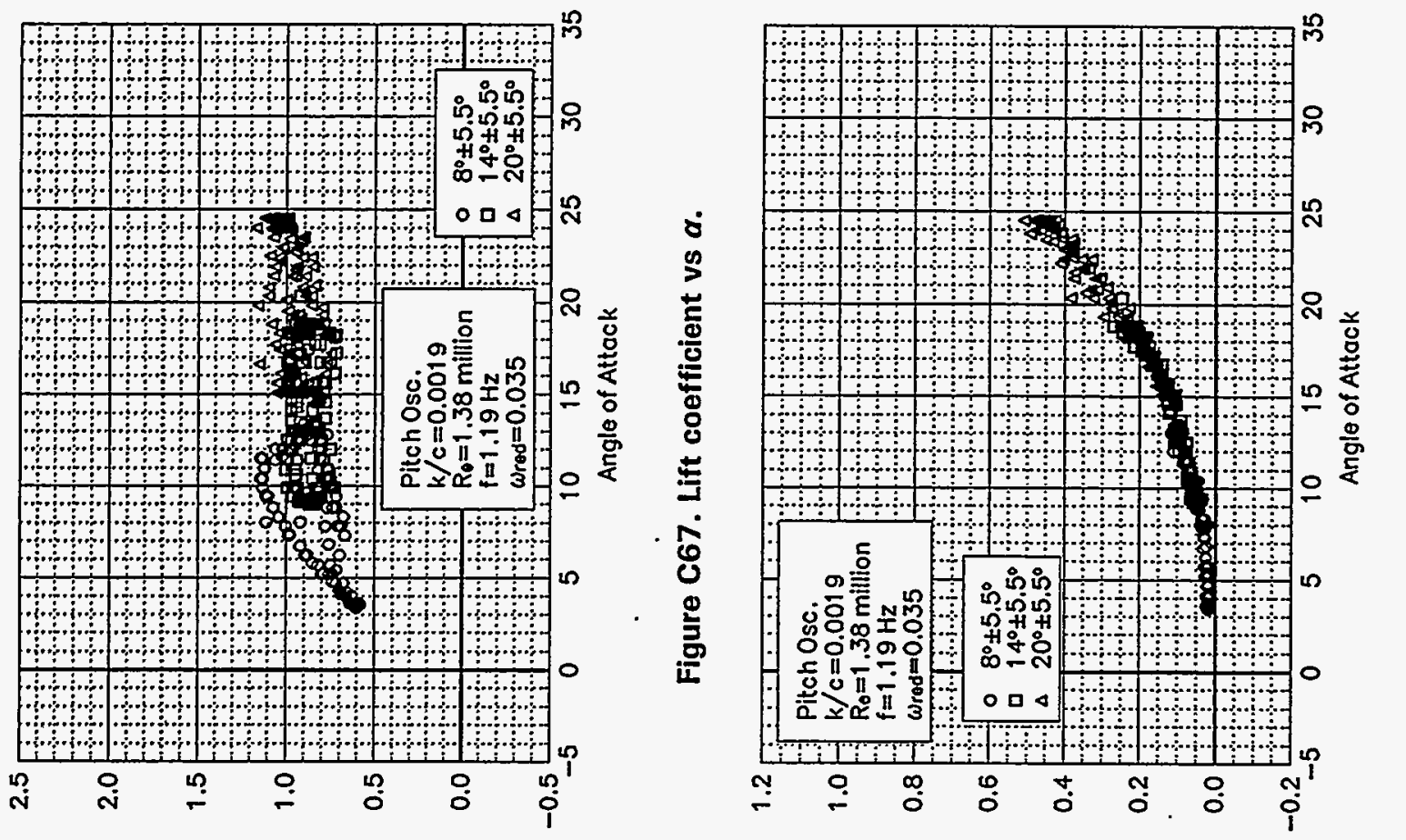

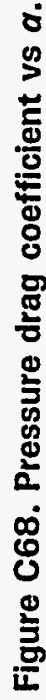

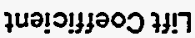

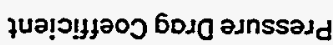



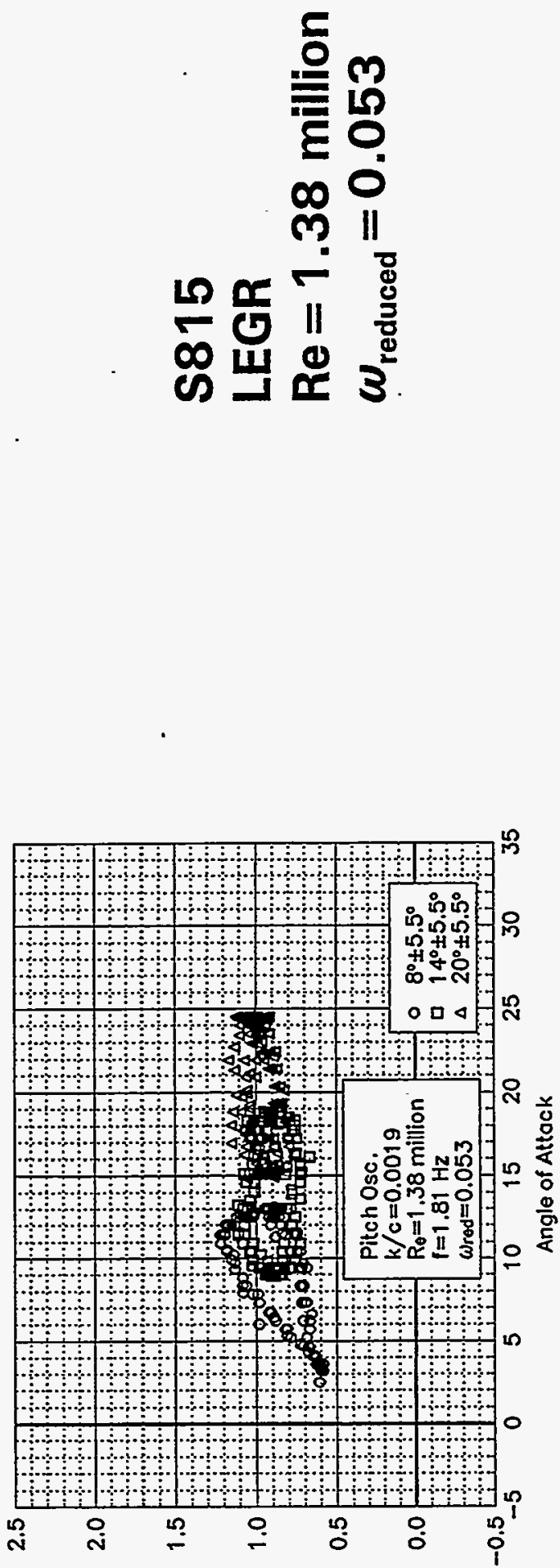

ในอเุวมรค0ว $7 ! ! 7$

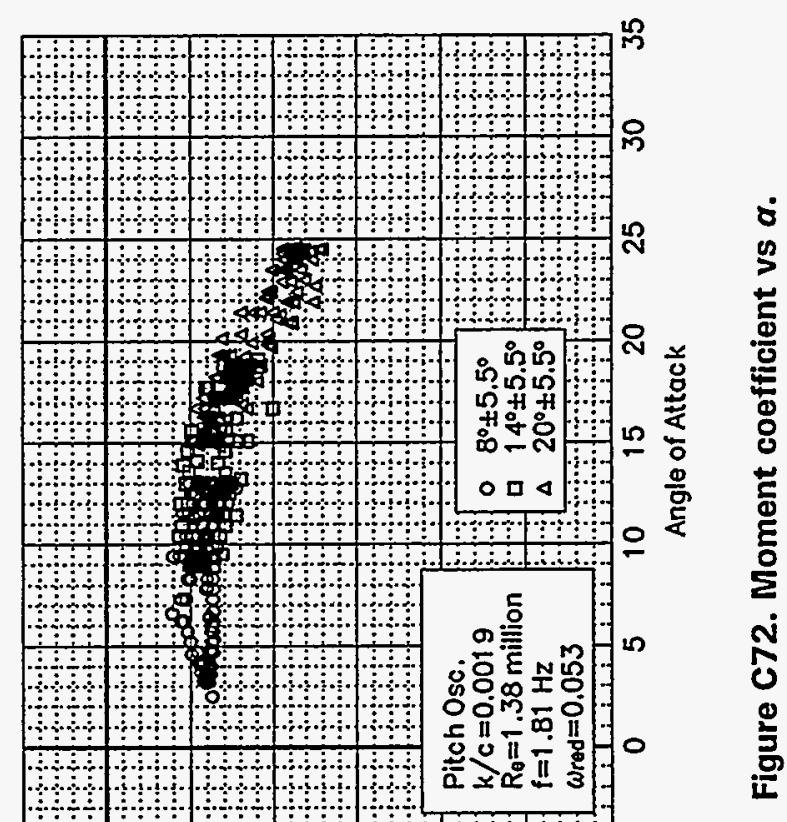

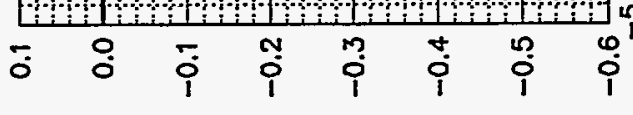

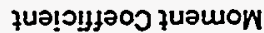

i

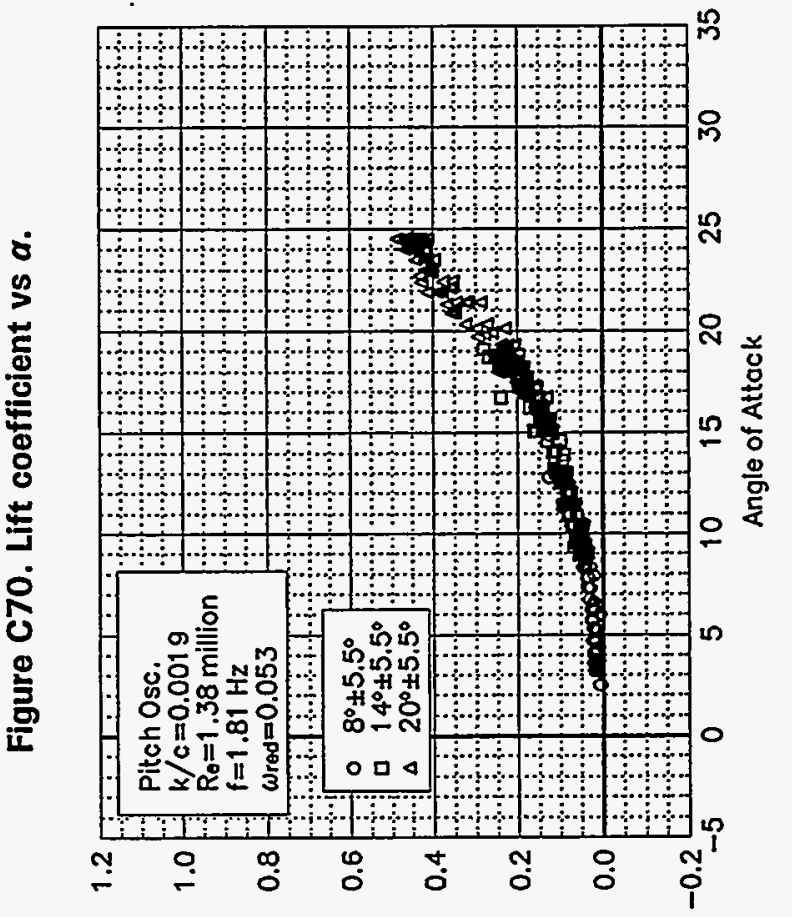

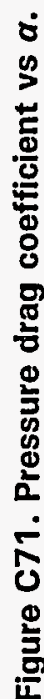

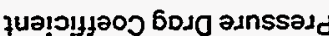




\section{Unsteady Airfoil Characteristics \\ $\pm 10^{\circ}$ Sine, $\operatorname{Re}=0.75$ million}



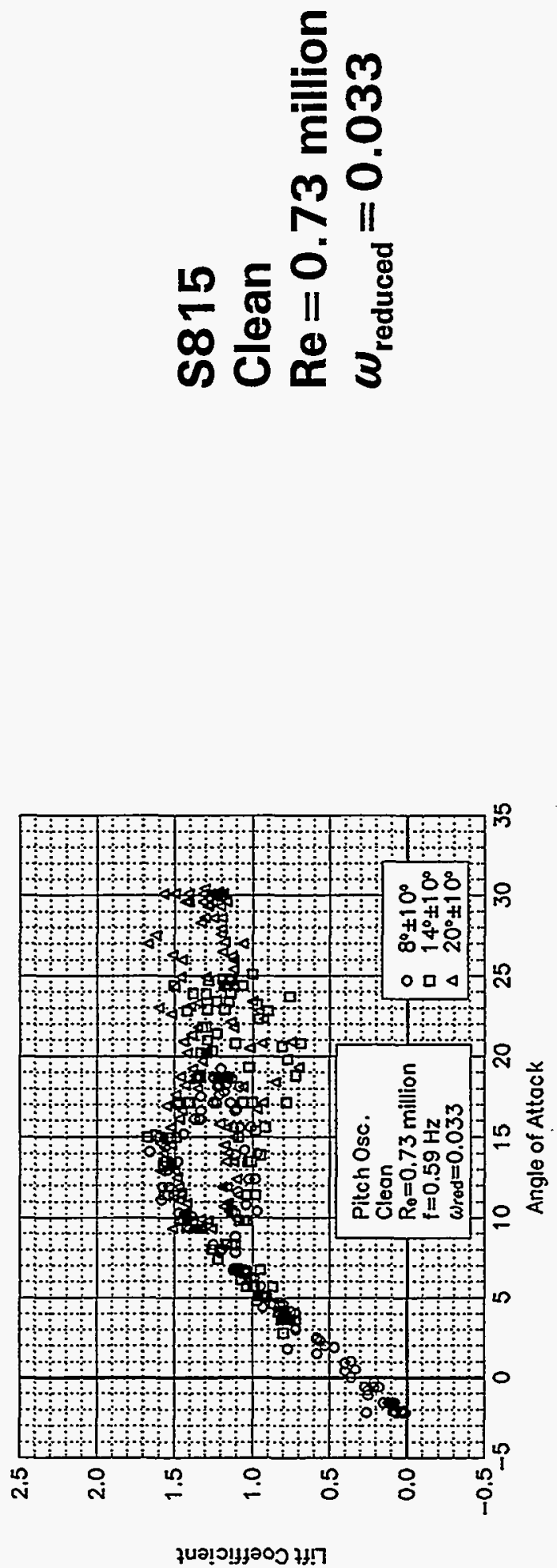

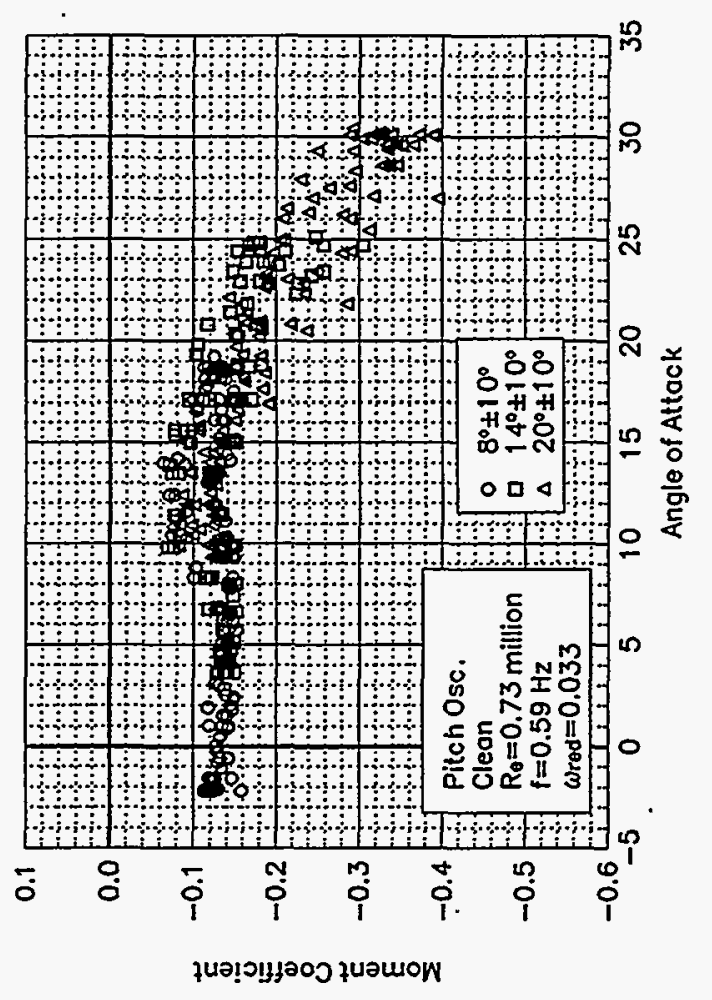

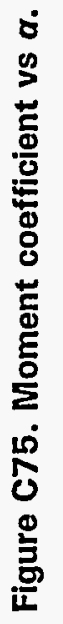

ปั

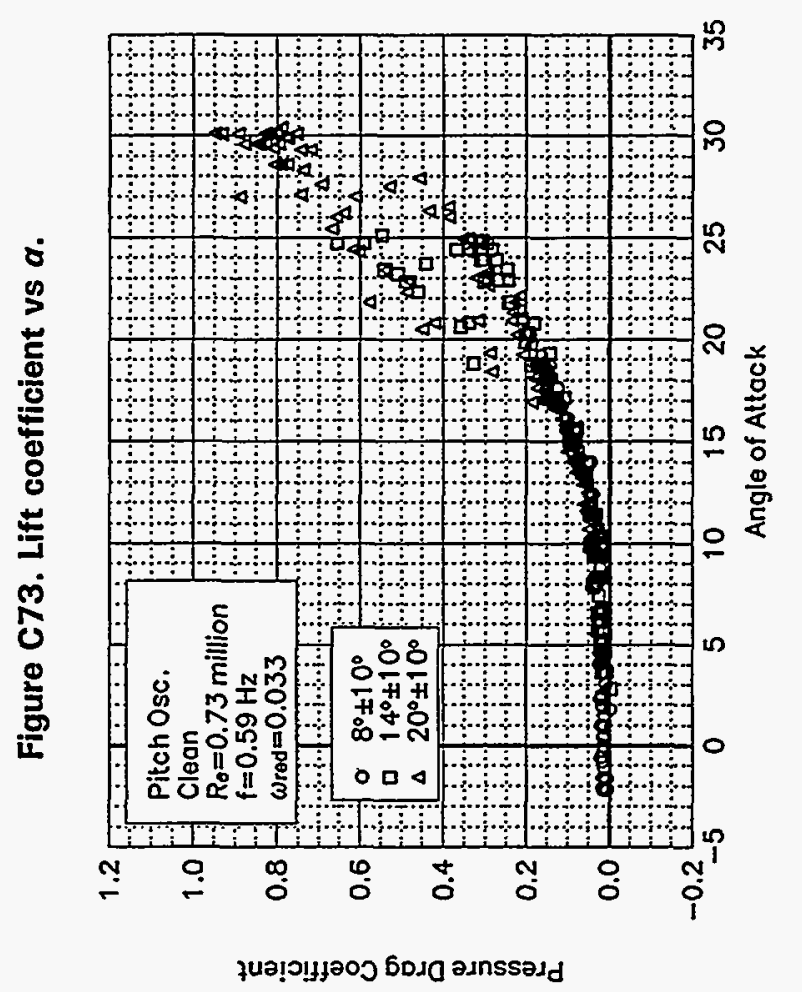

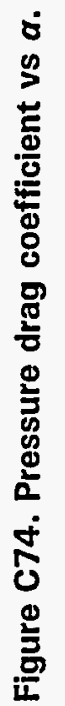



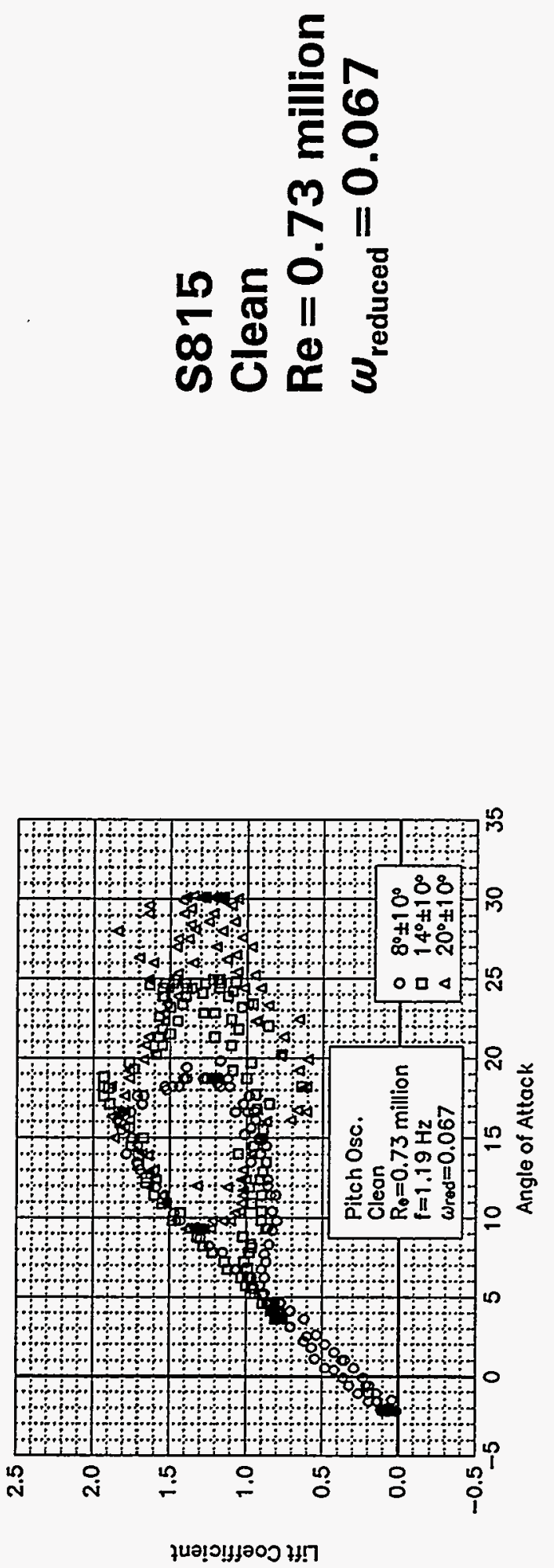

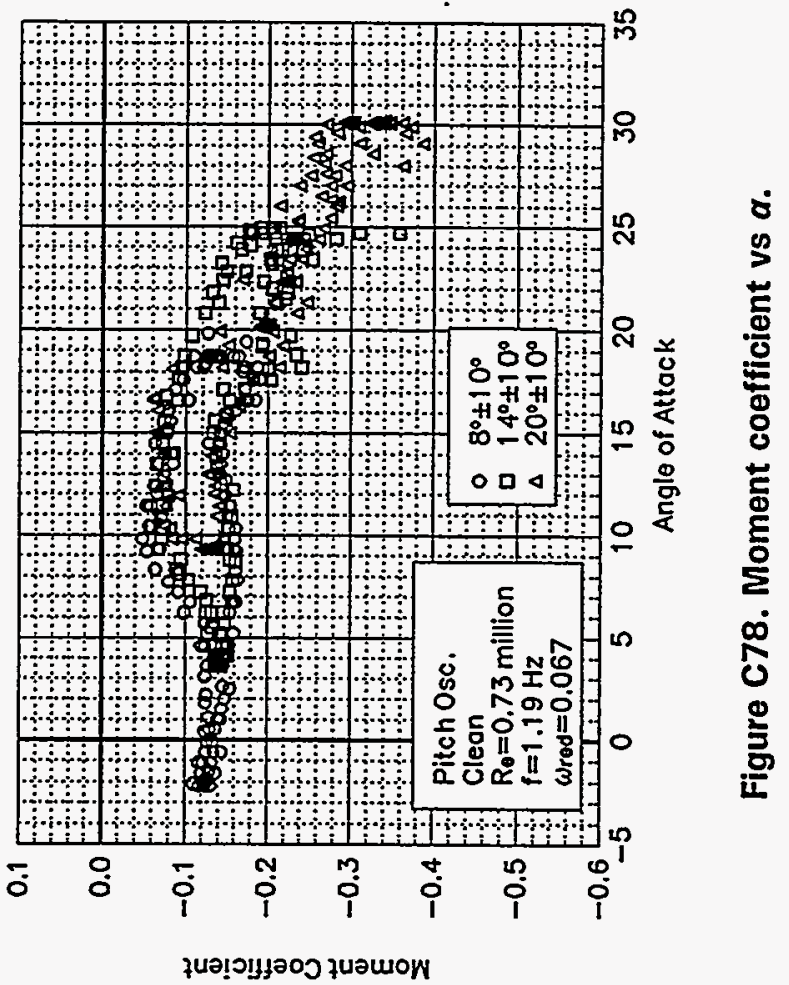

8

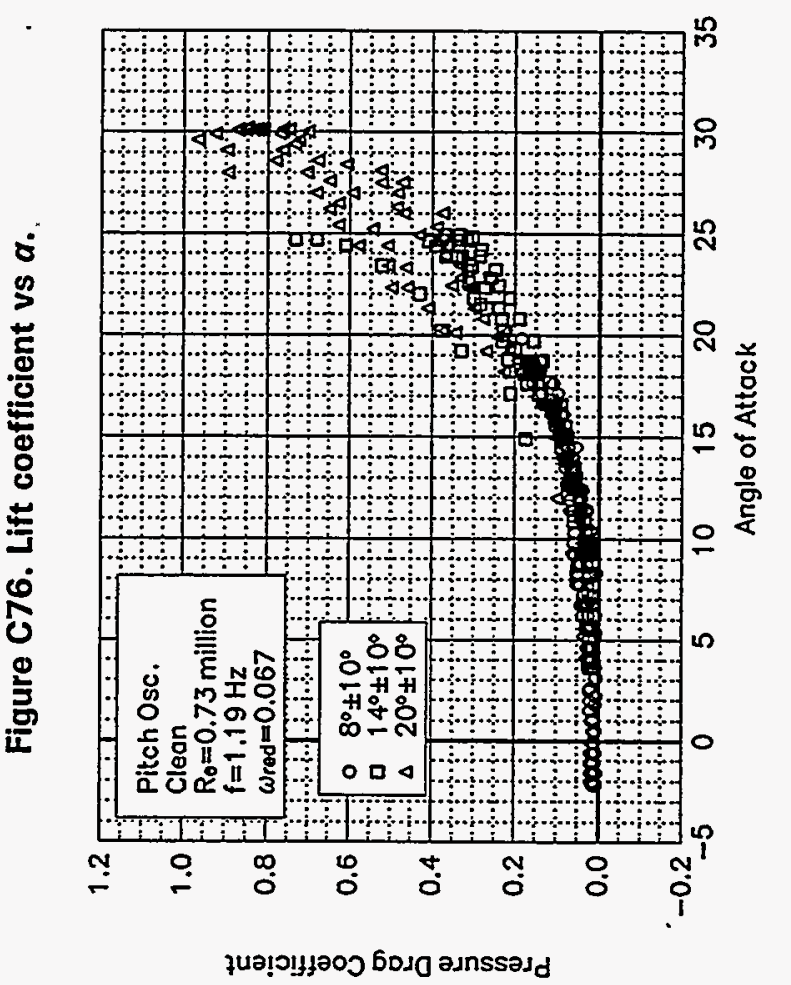



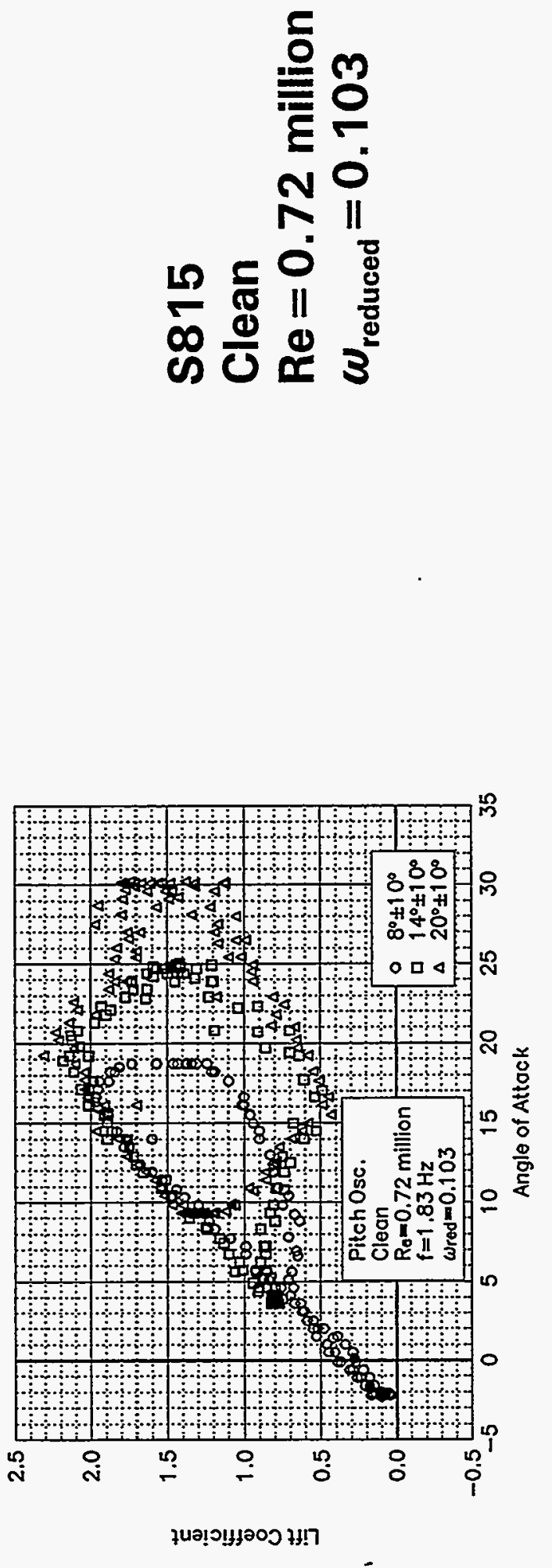

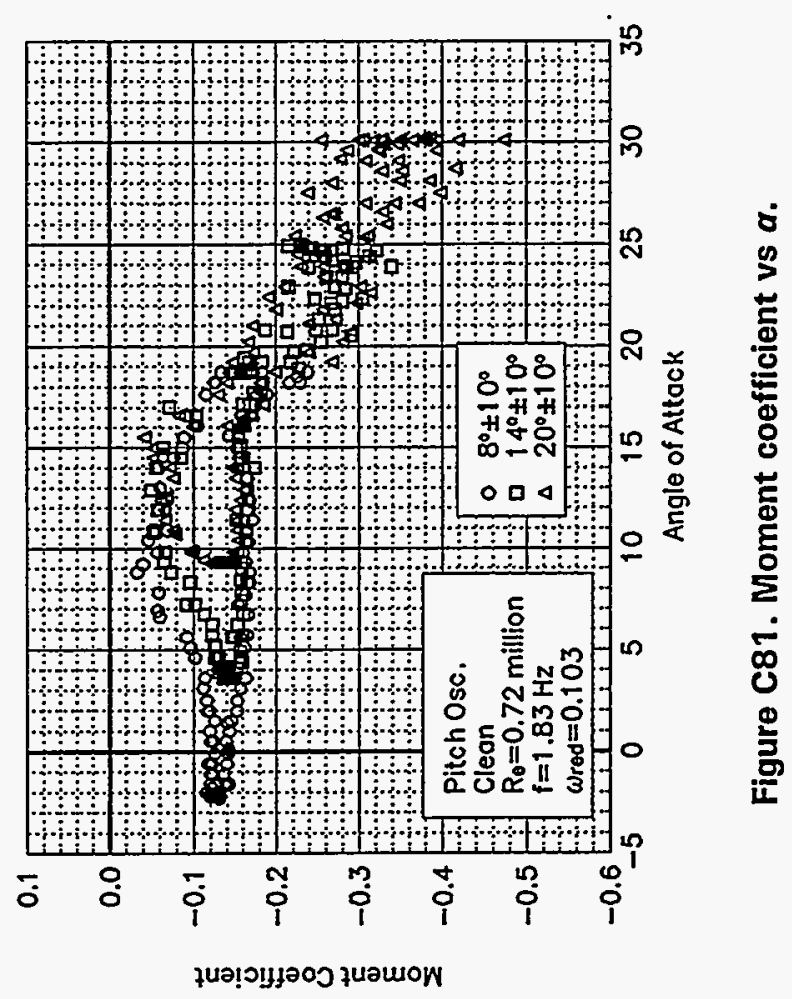

đ̇

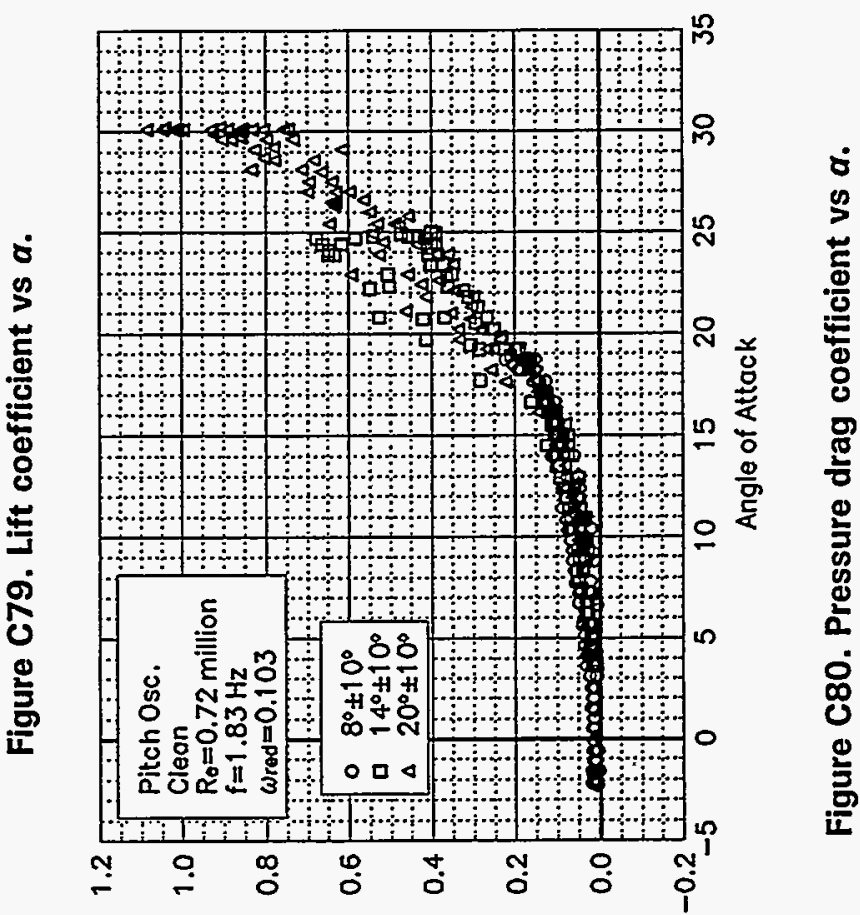

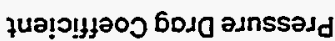



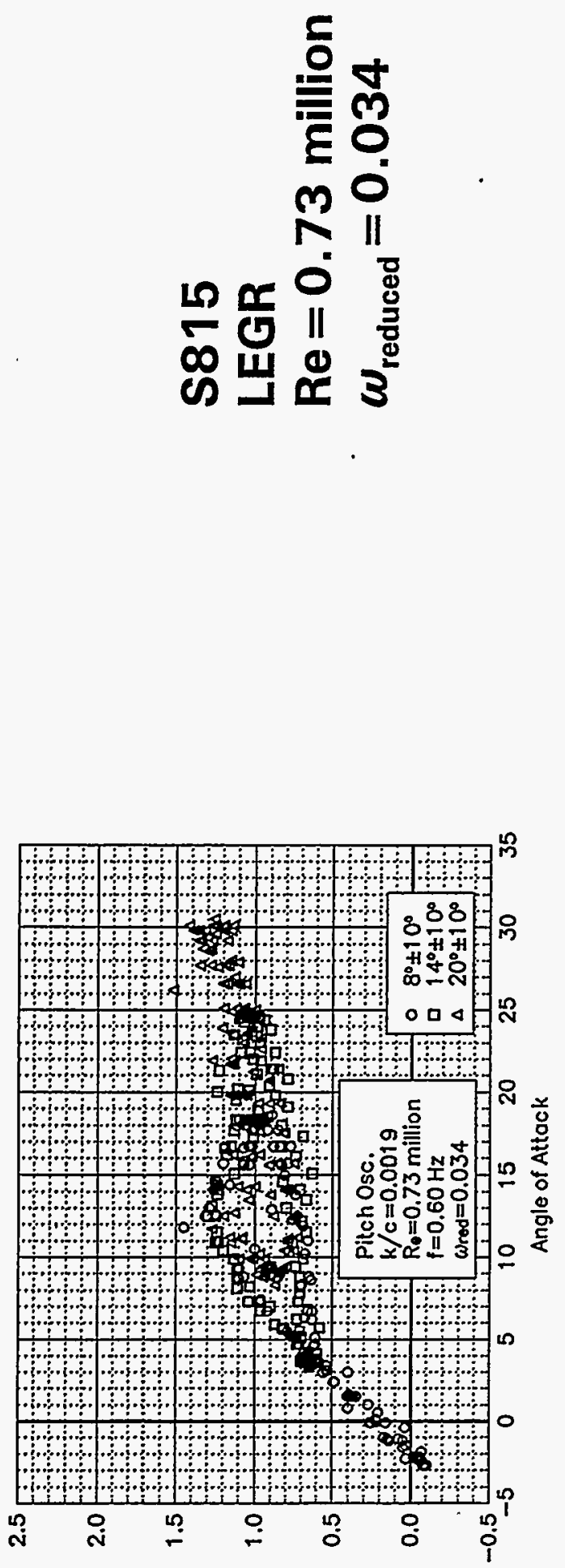

ในอ!วเมุวัว 2117

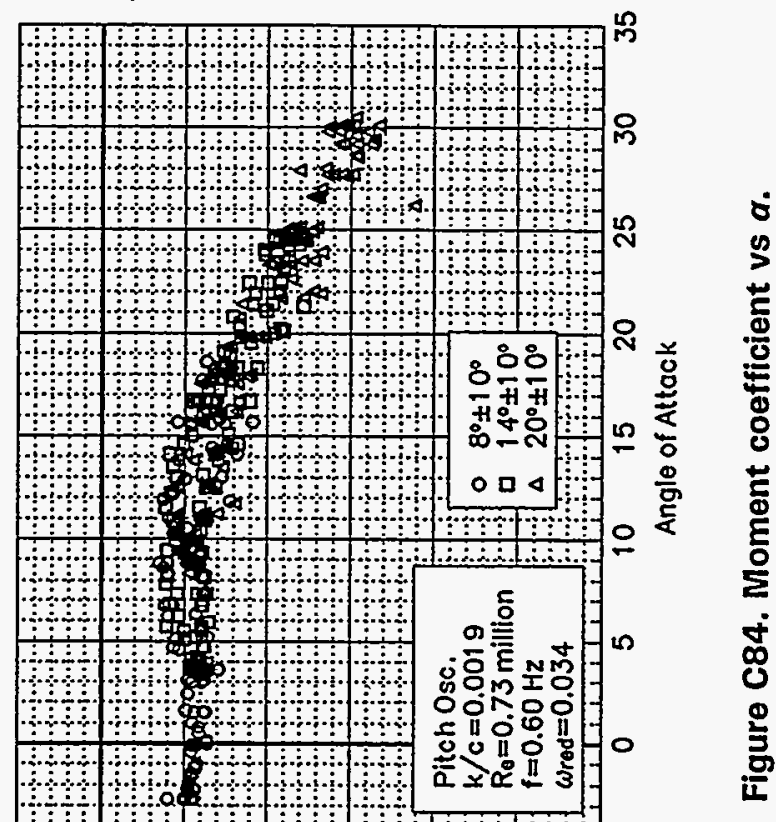

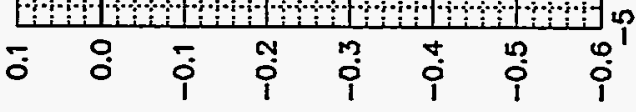

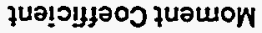

ช

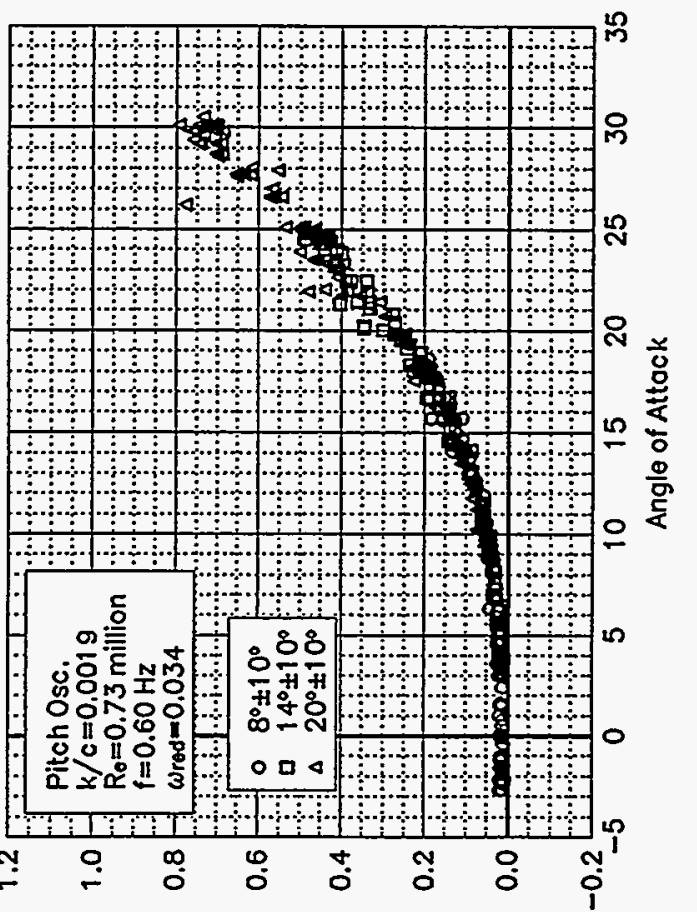

ச

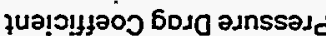



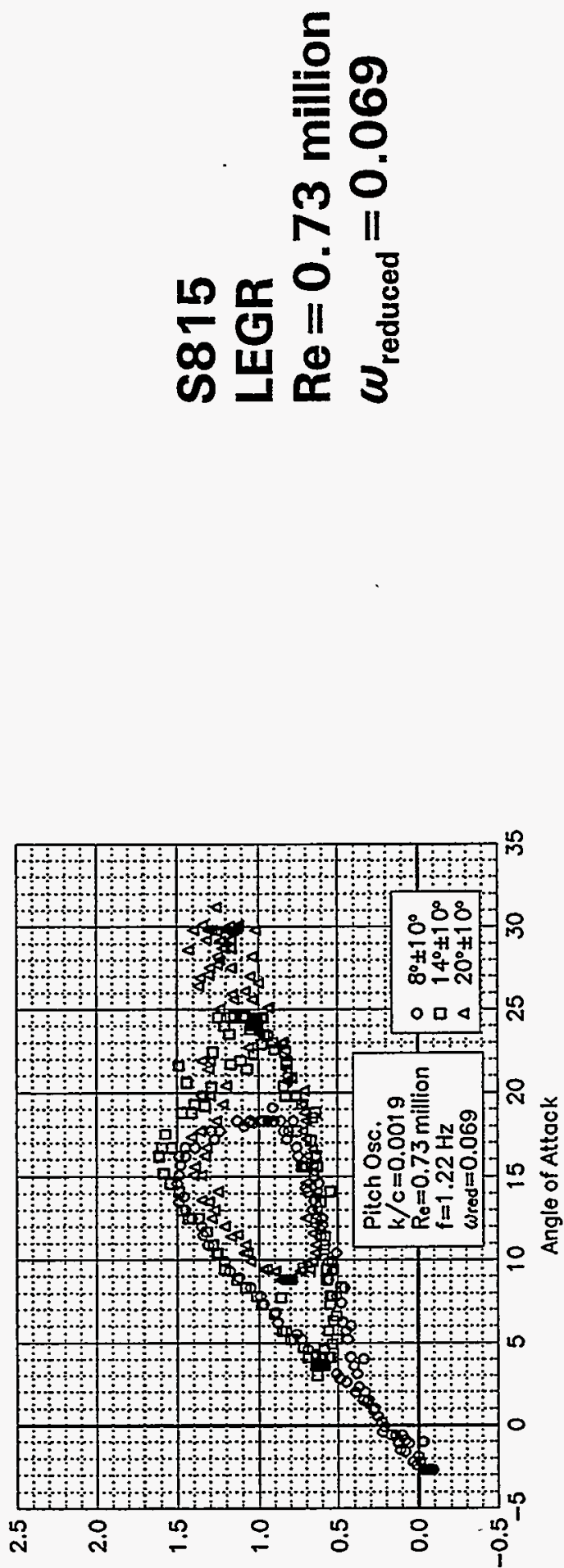

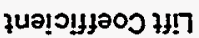

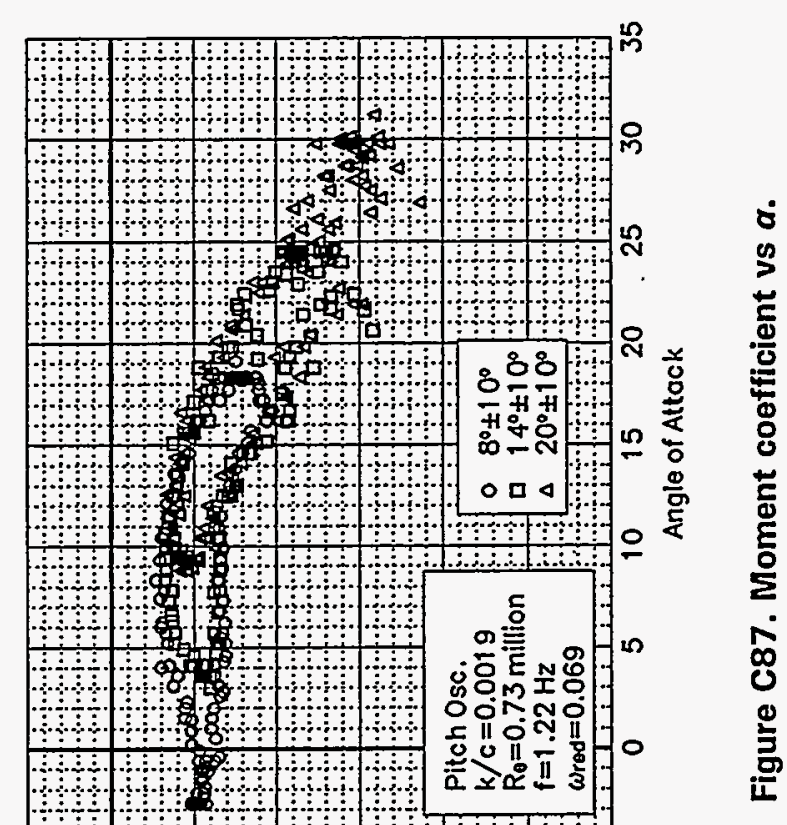

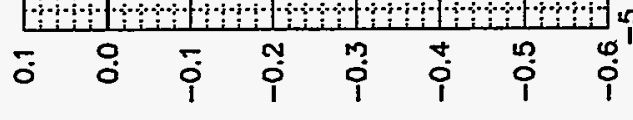

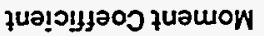

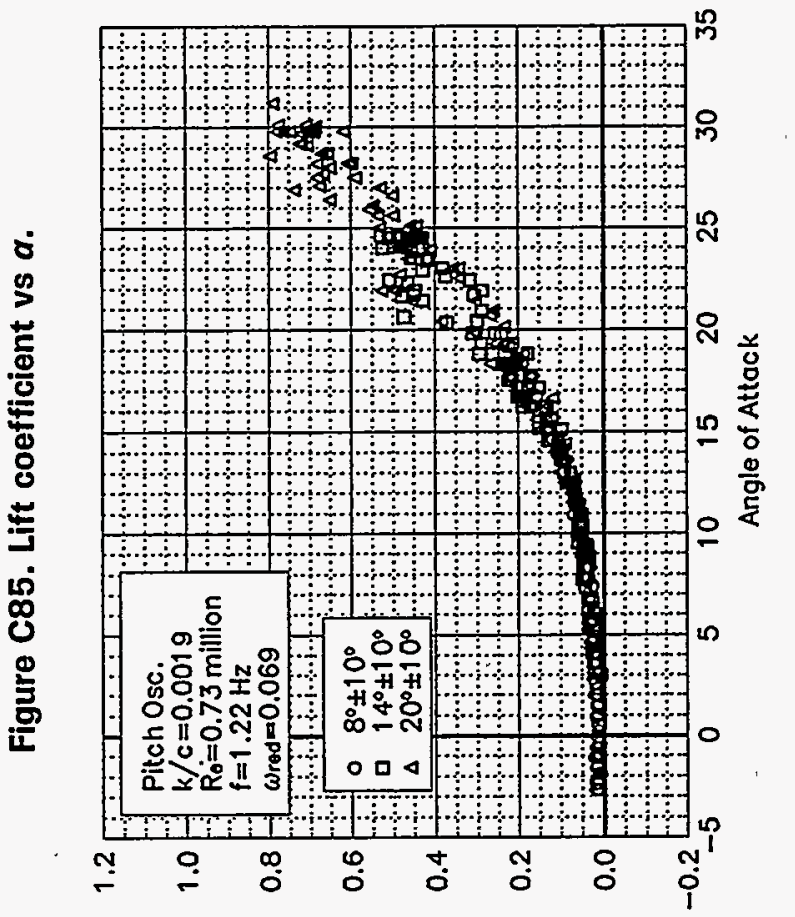

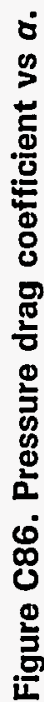

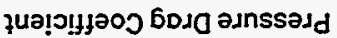



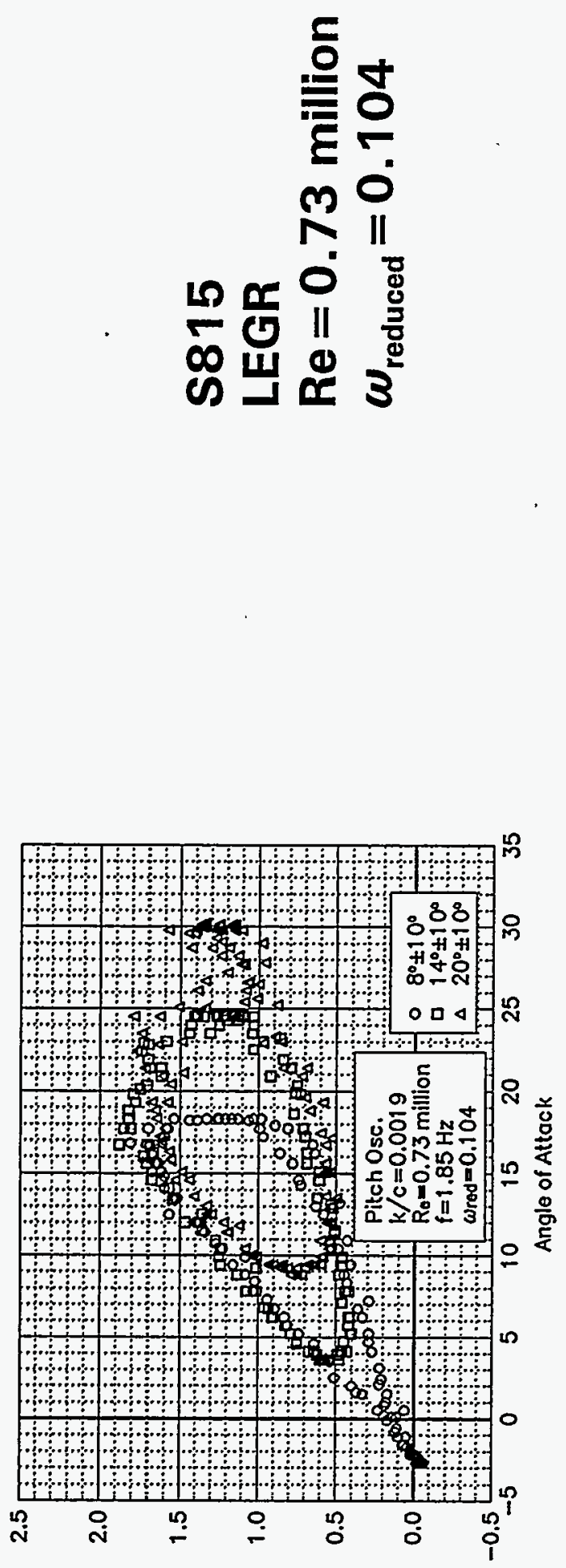

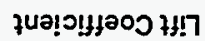

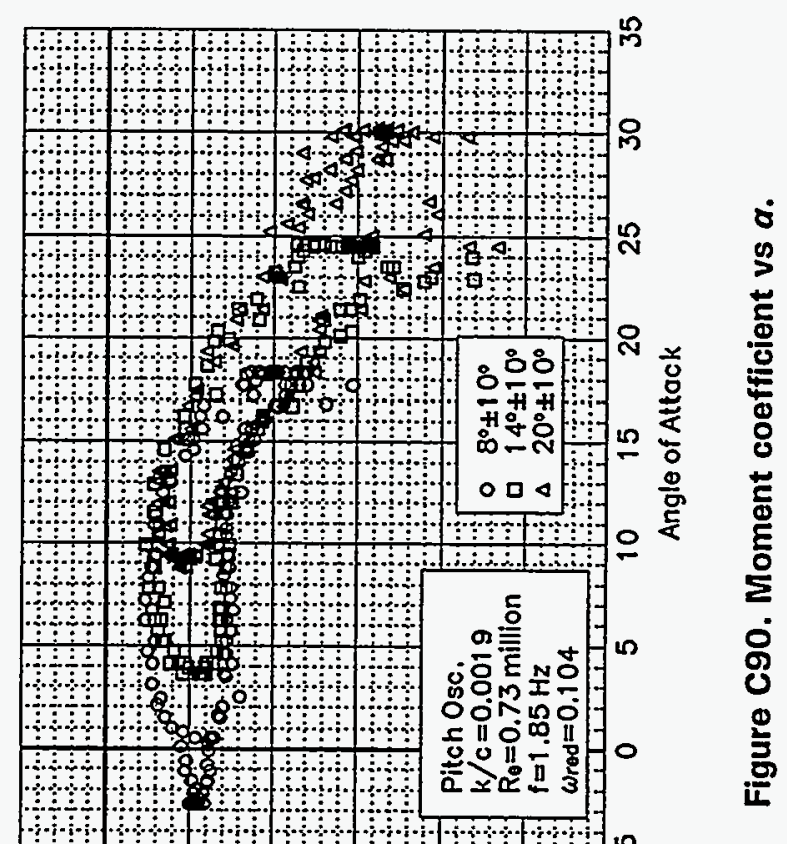

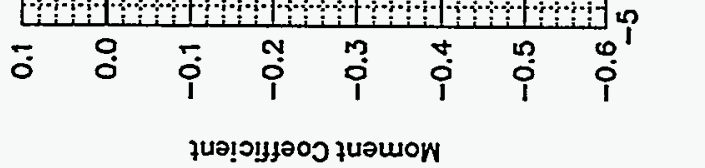

$\sqrt{3}$

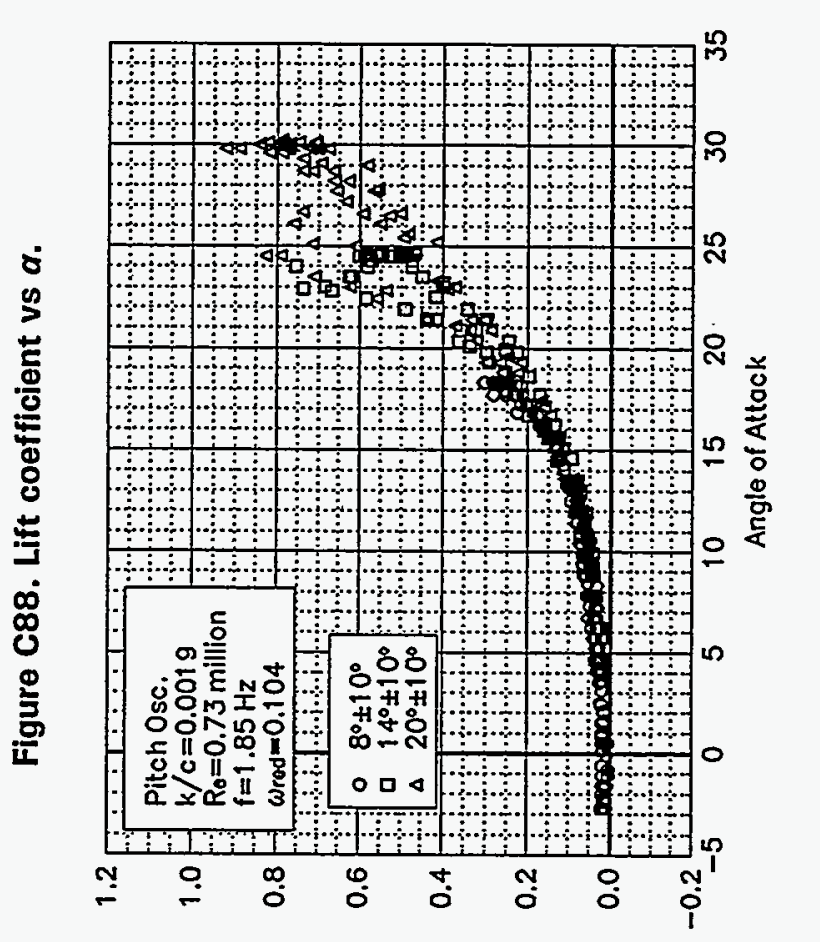

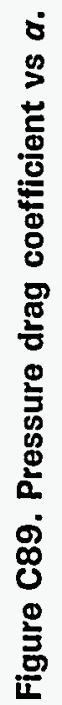

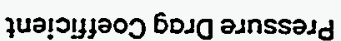


Unsteady Airfoil Characteristics

$\pm 10^{\circ}$ Sinne, $\operatorname{Re}=1$ million 
Pressure Drag Coefficient

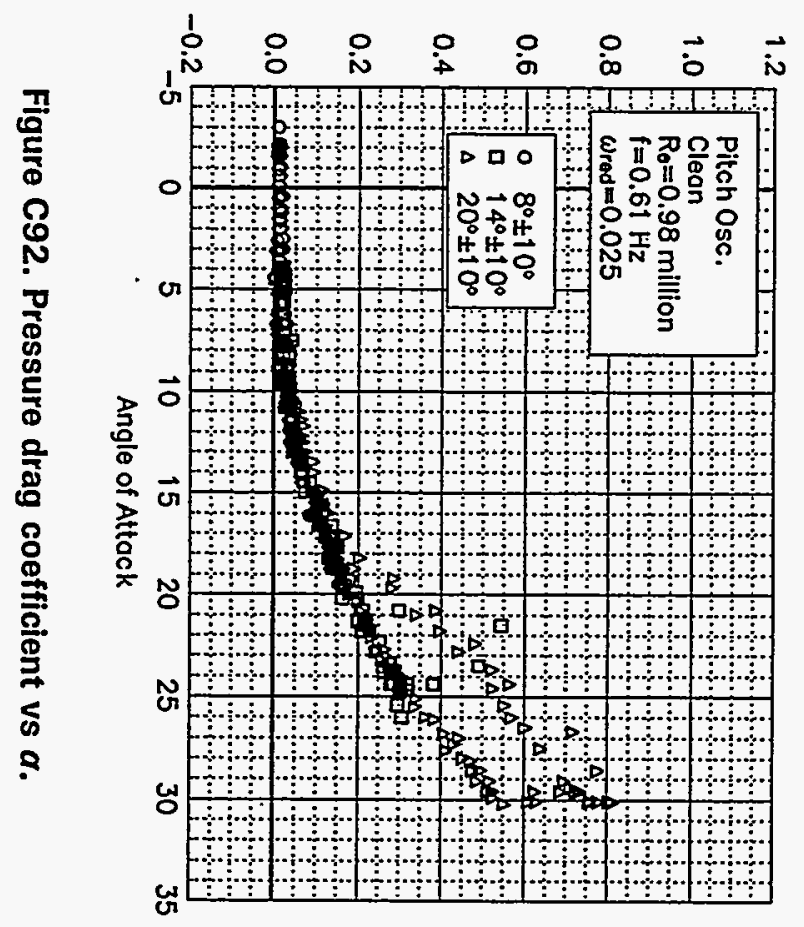

Lift Coefficient

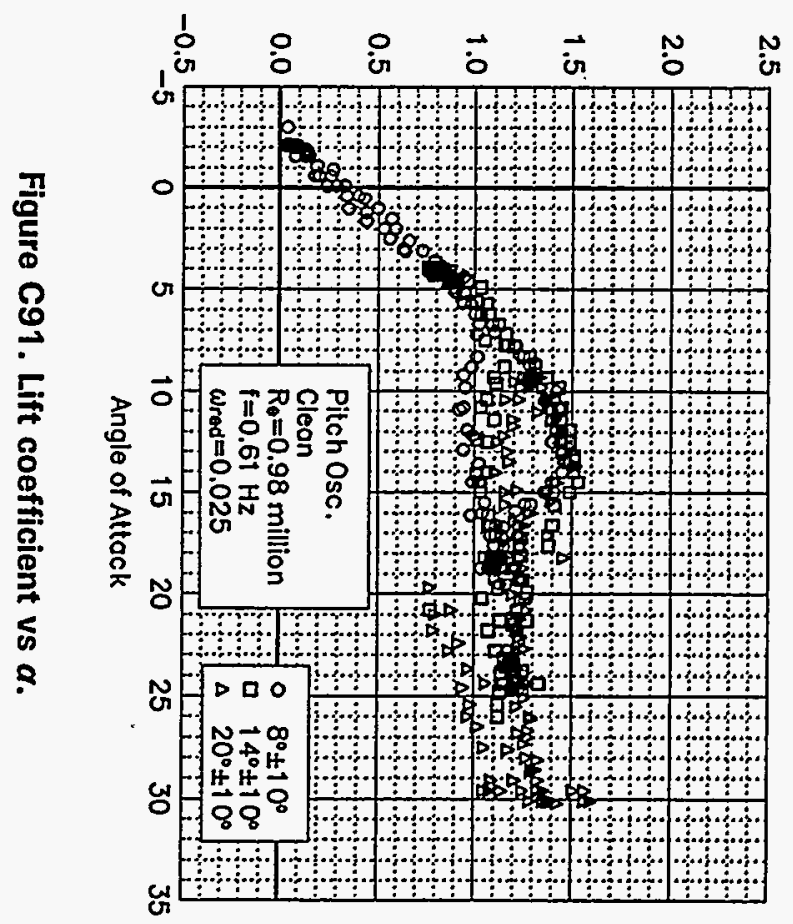

ڤ్ర
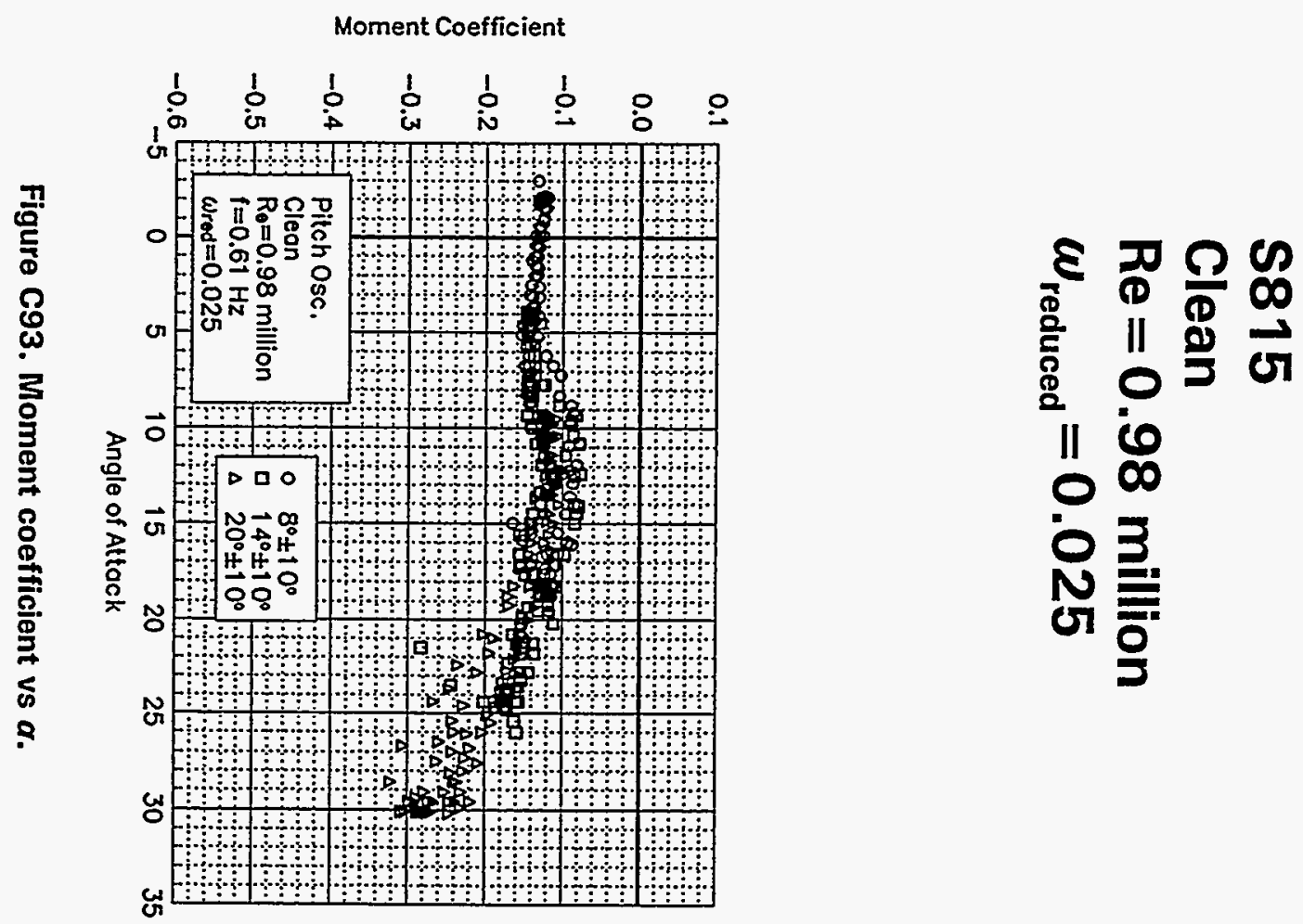


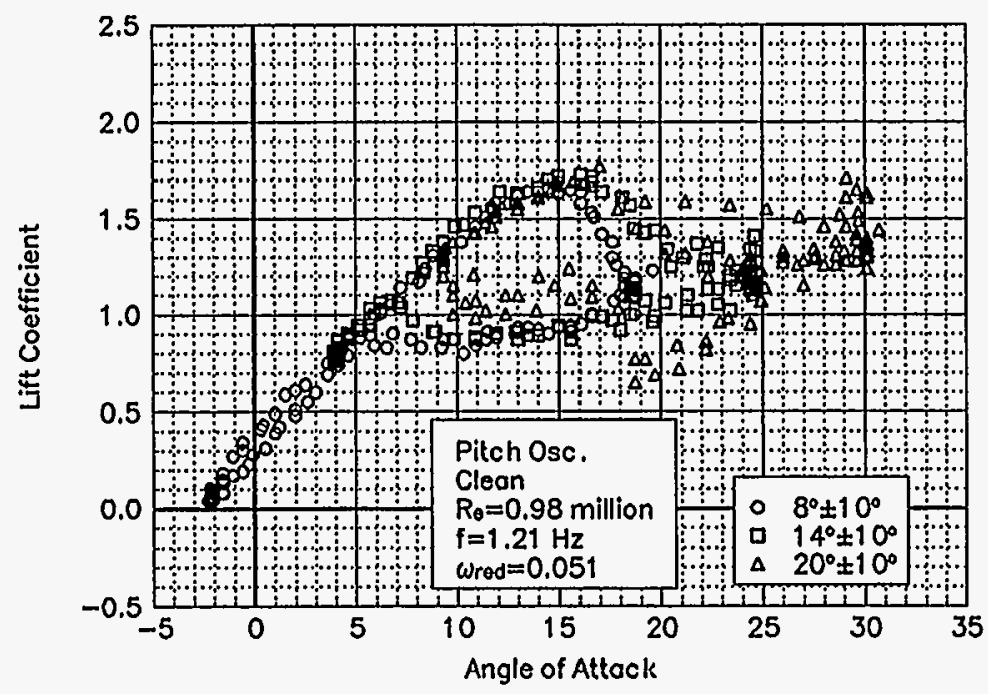

Figure C94. Lift coefficient vs $a$.

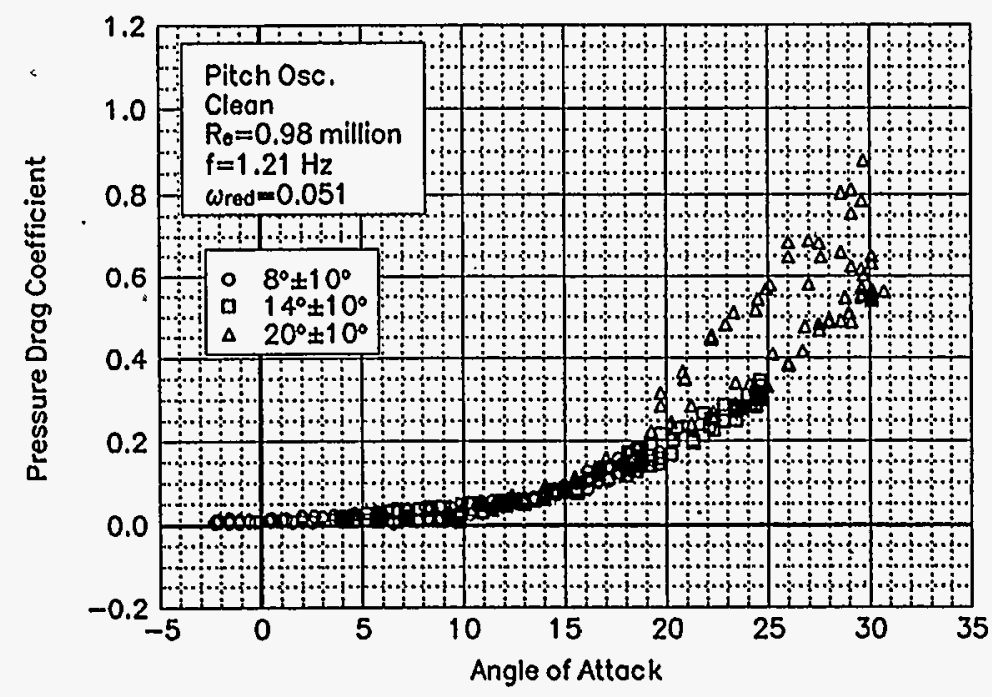

Figure C95. Pressure drag coefficient vs $a$.

\section{S815 \\ Clean \\ $\mathbf{R e}=\mathbf{0 . 9 8}$ million \\ $\omega_{\text {reduced }}=0.051$}

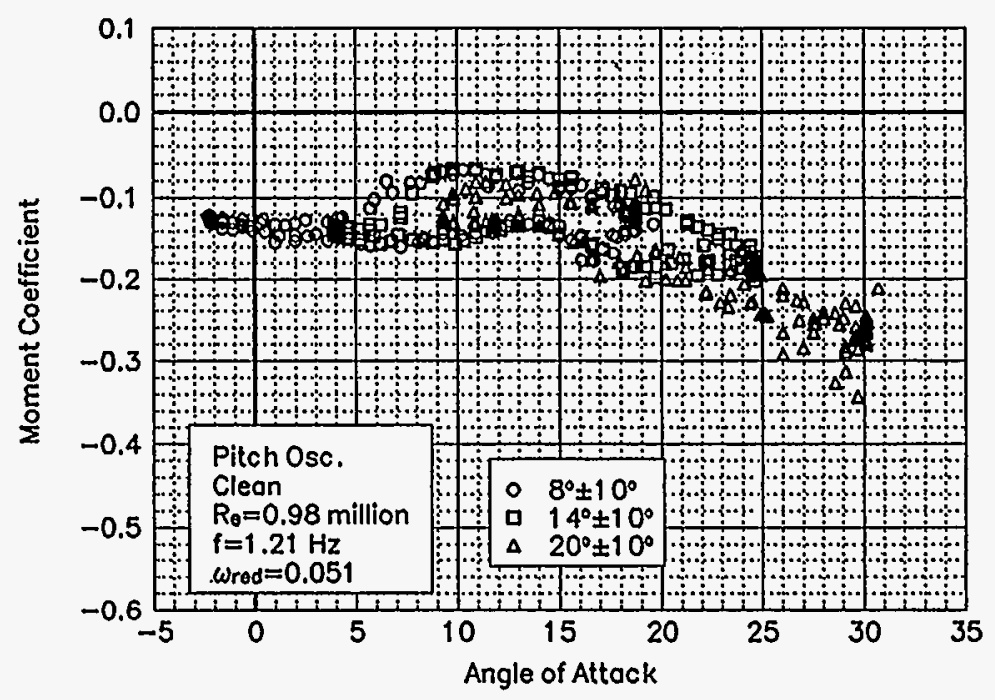

Figure C96. Moment coefficient vs $\alpha$. 

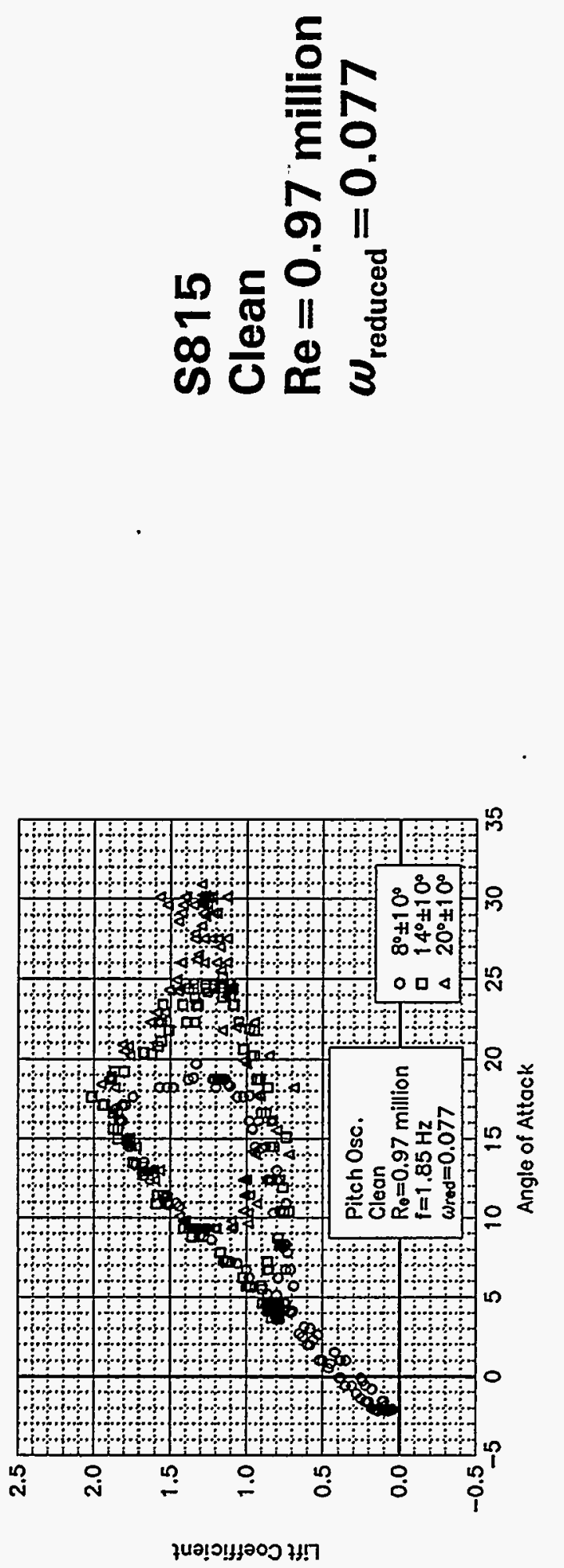

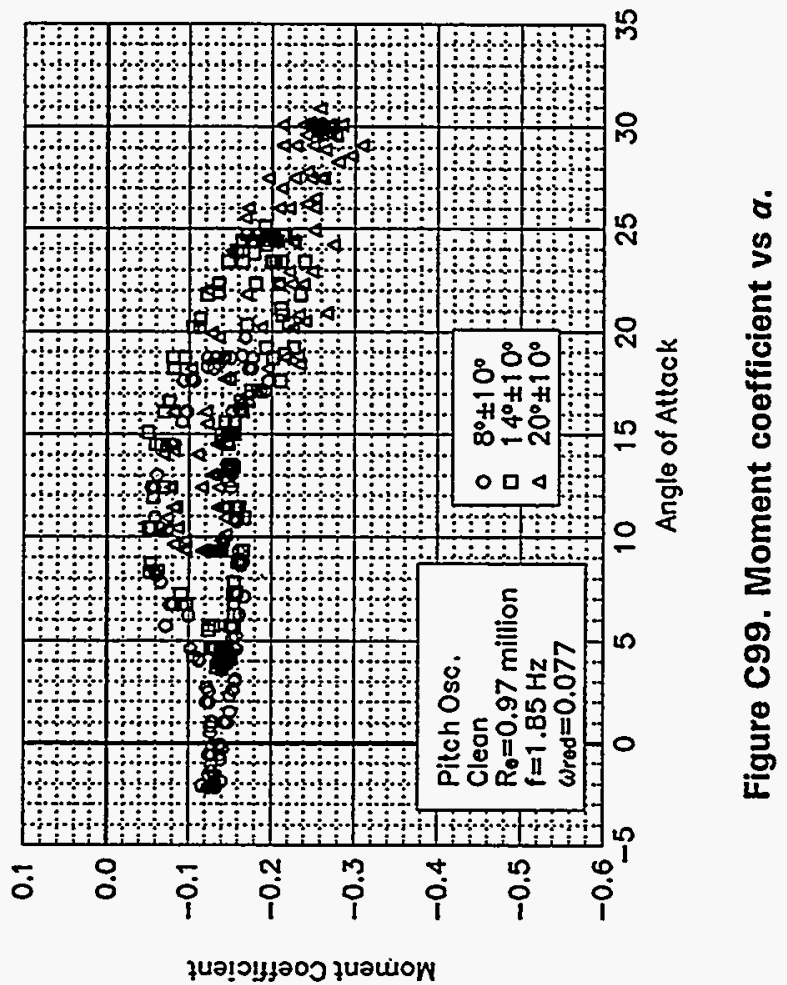

F 

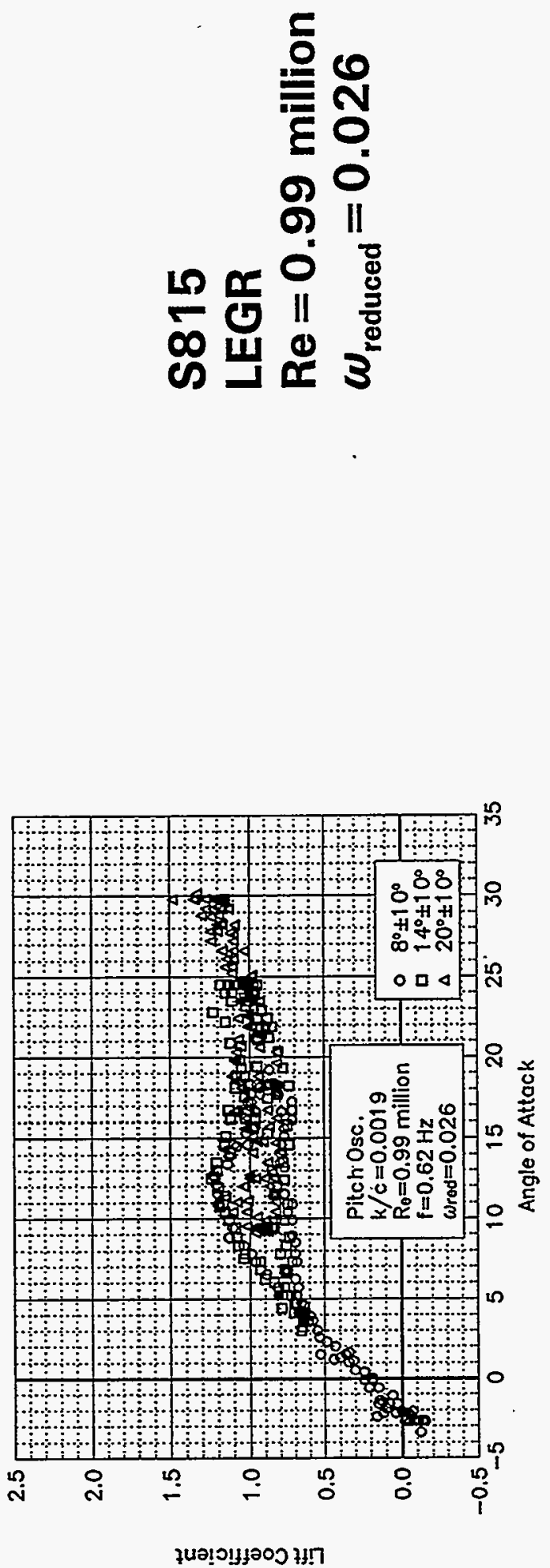

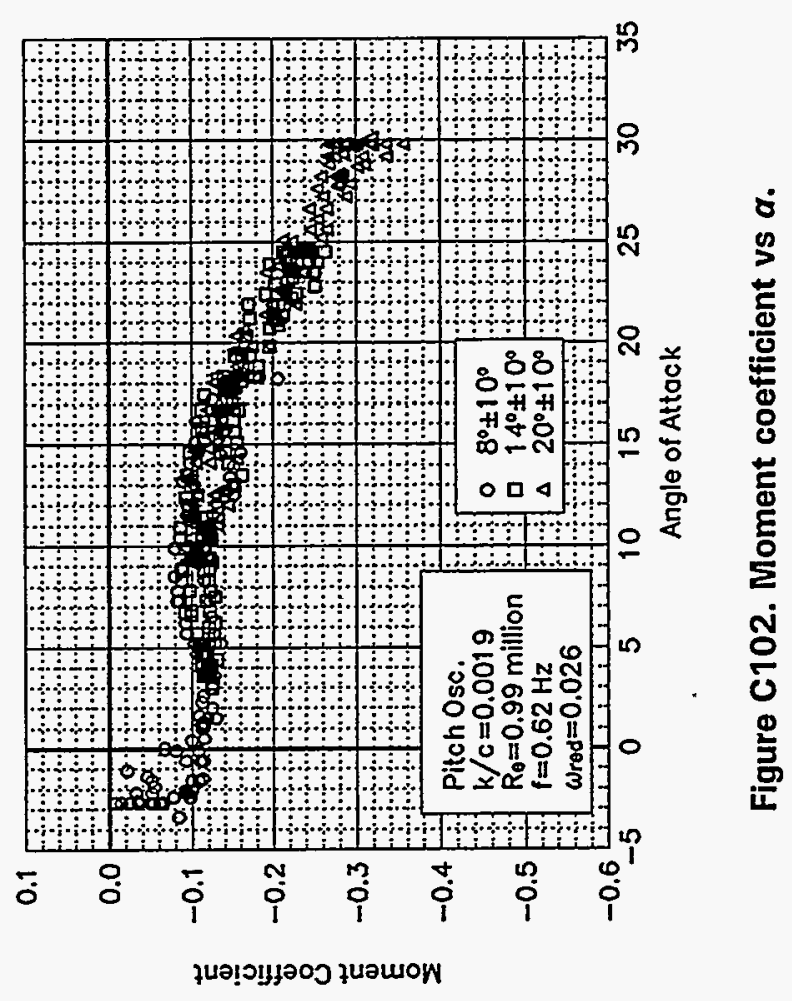

₹

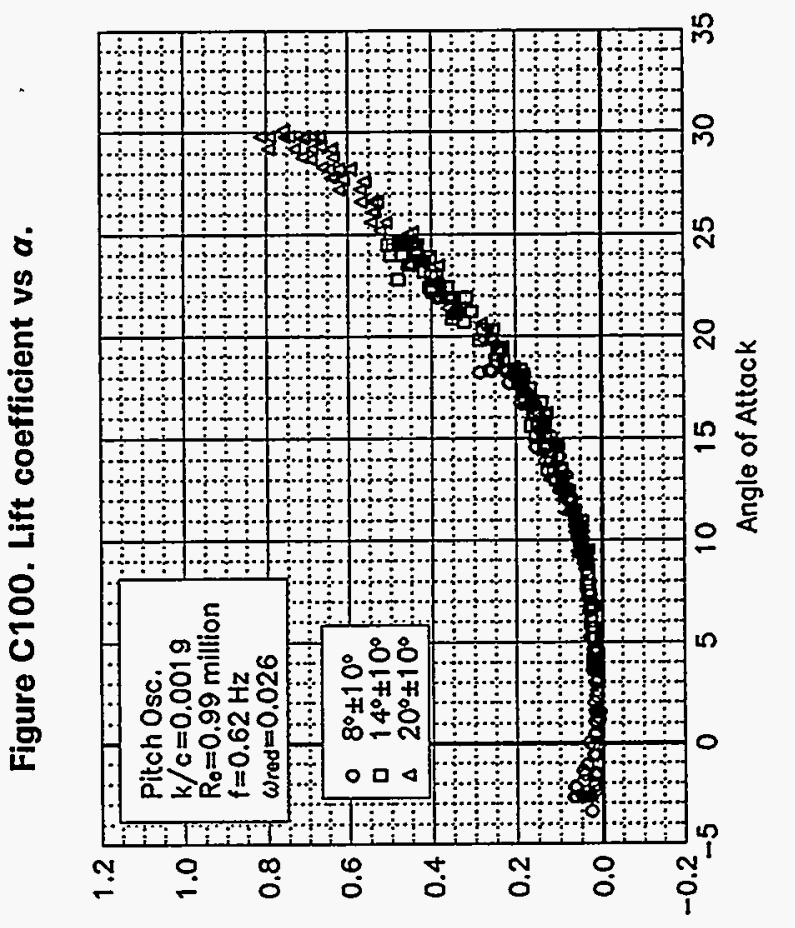

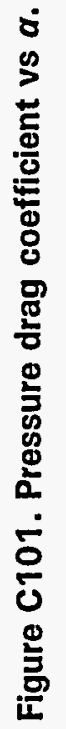

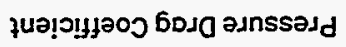




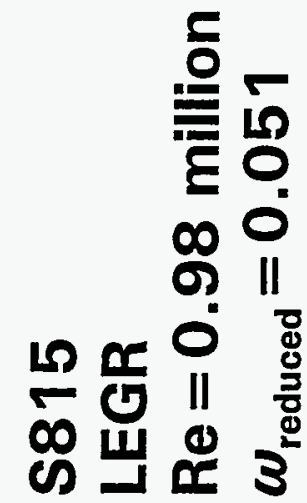

0

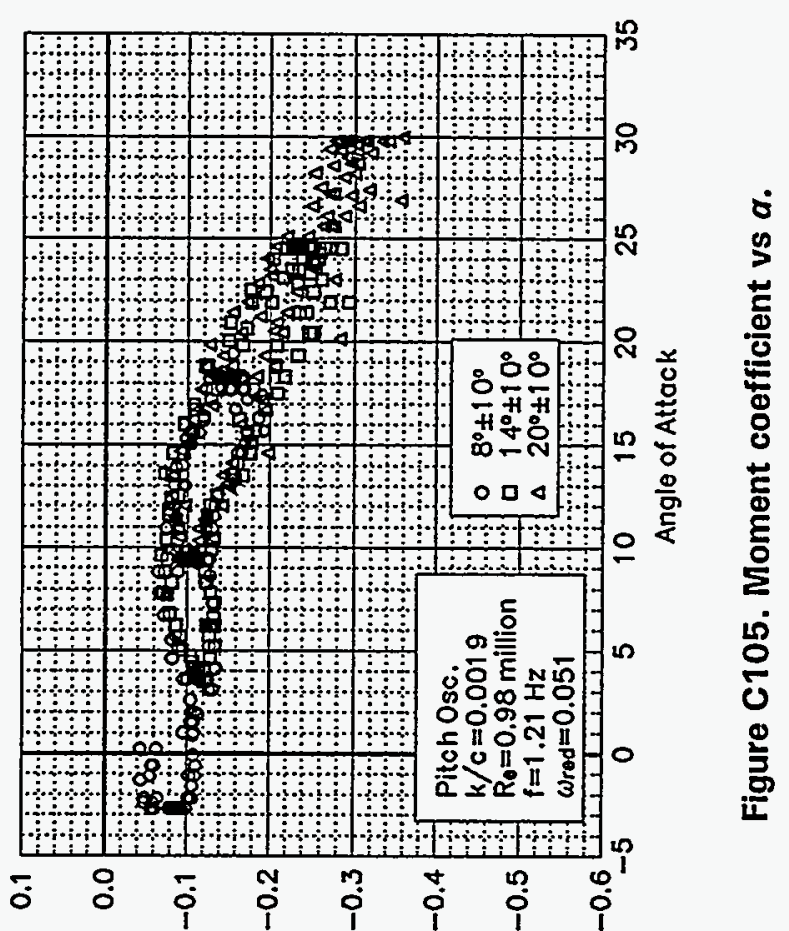

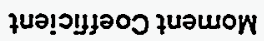

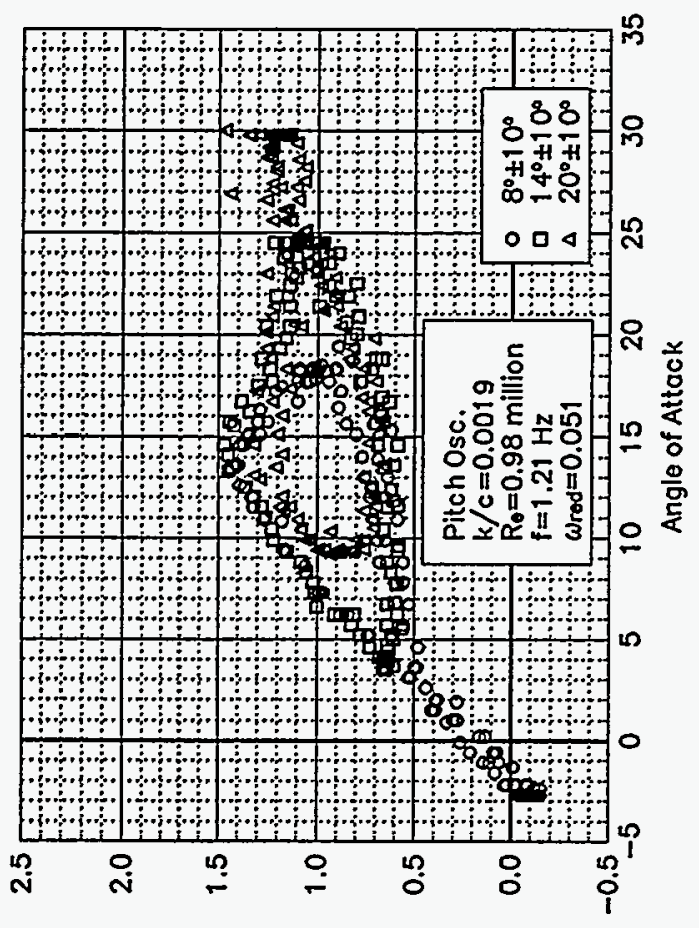

วนอ!วเรมจัว ใน!า

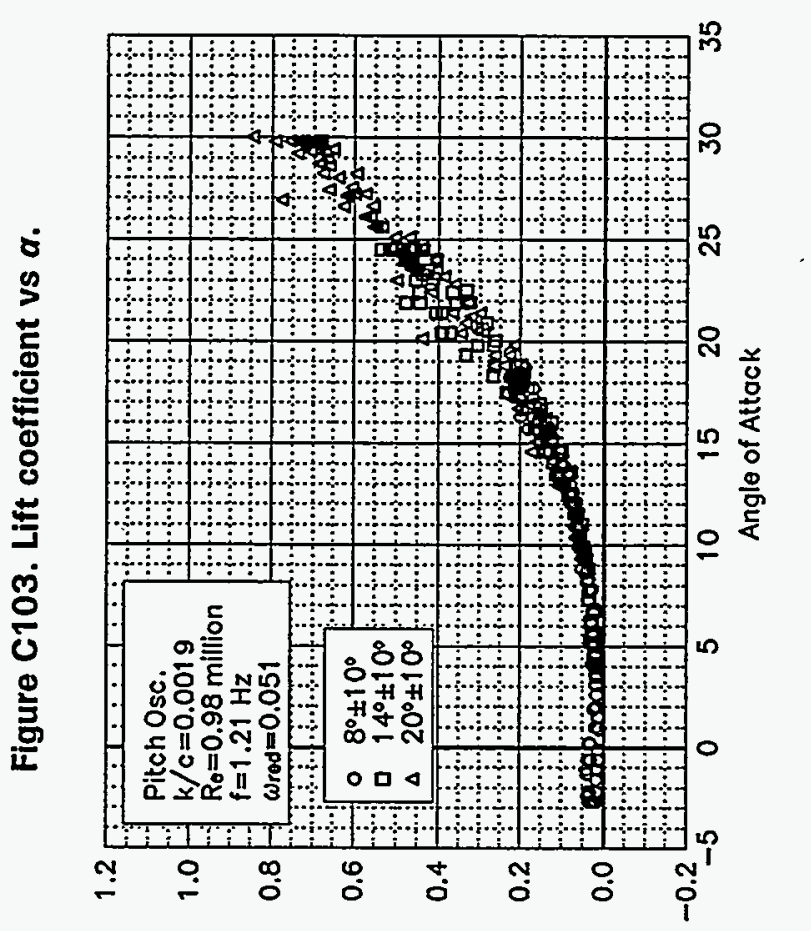

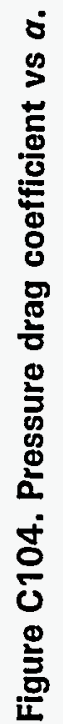

$\stackrel{m}{\mathfrak{j}}$

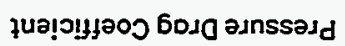



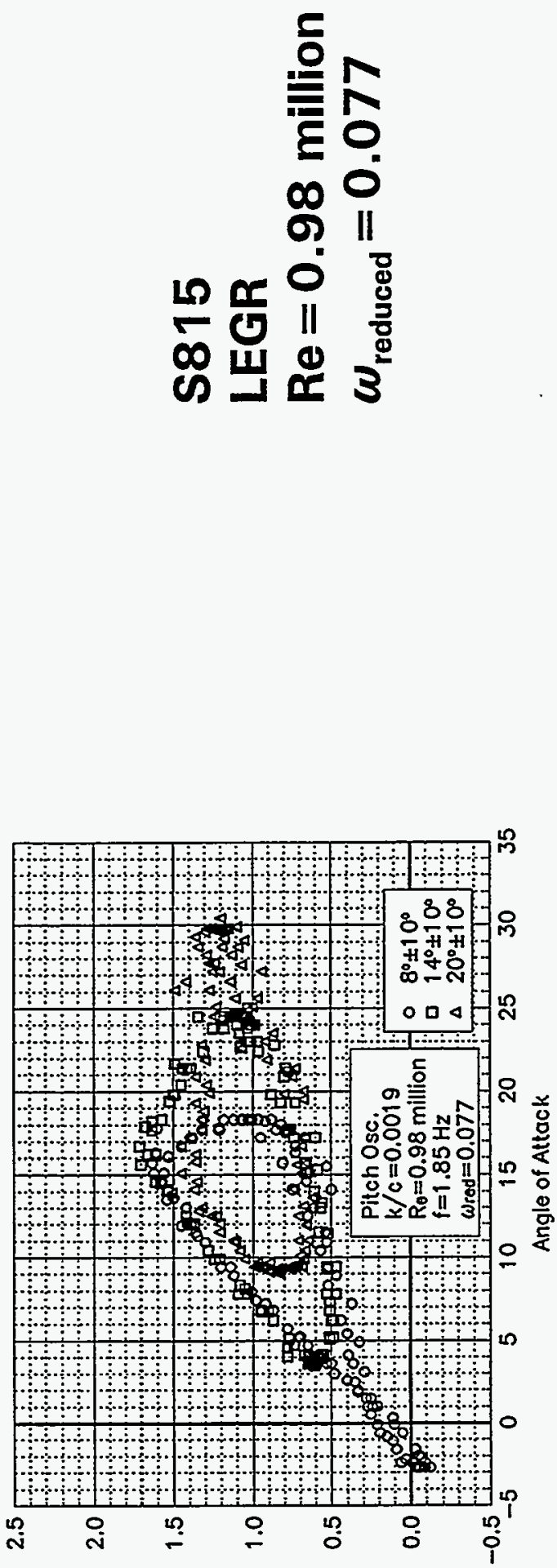

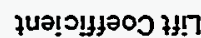

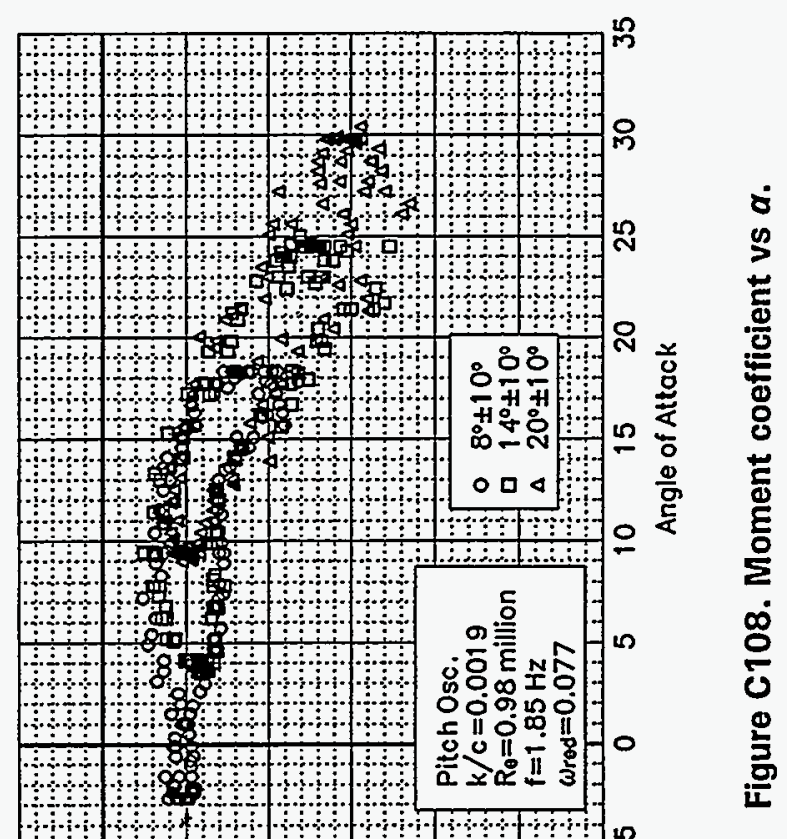

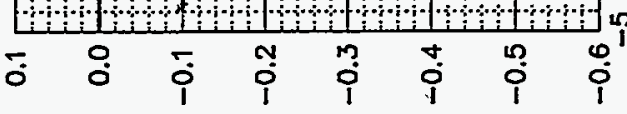

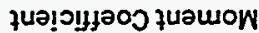

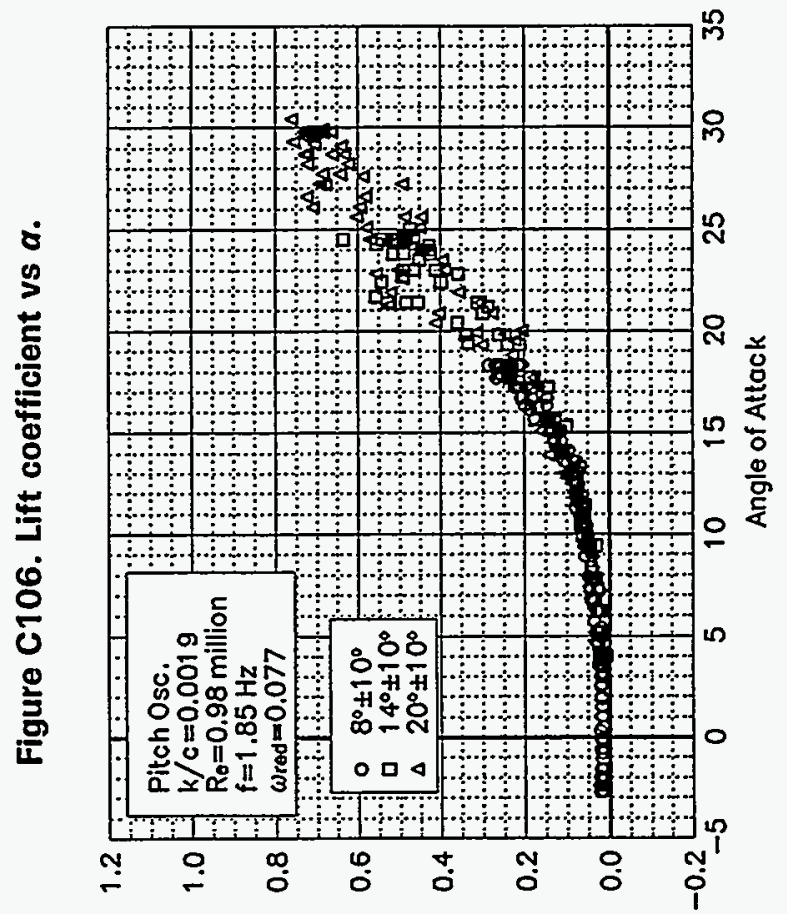

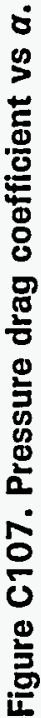

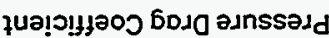




\section{Unsteady Airfoil Characteristics \\ $\pm 10^{\circ}$ Sine, $\operatorname{Re}=1.25$ million}



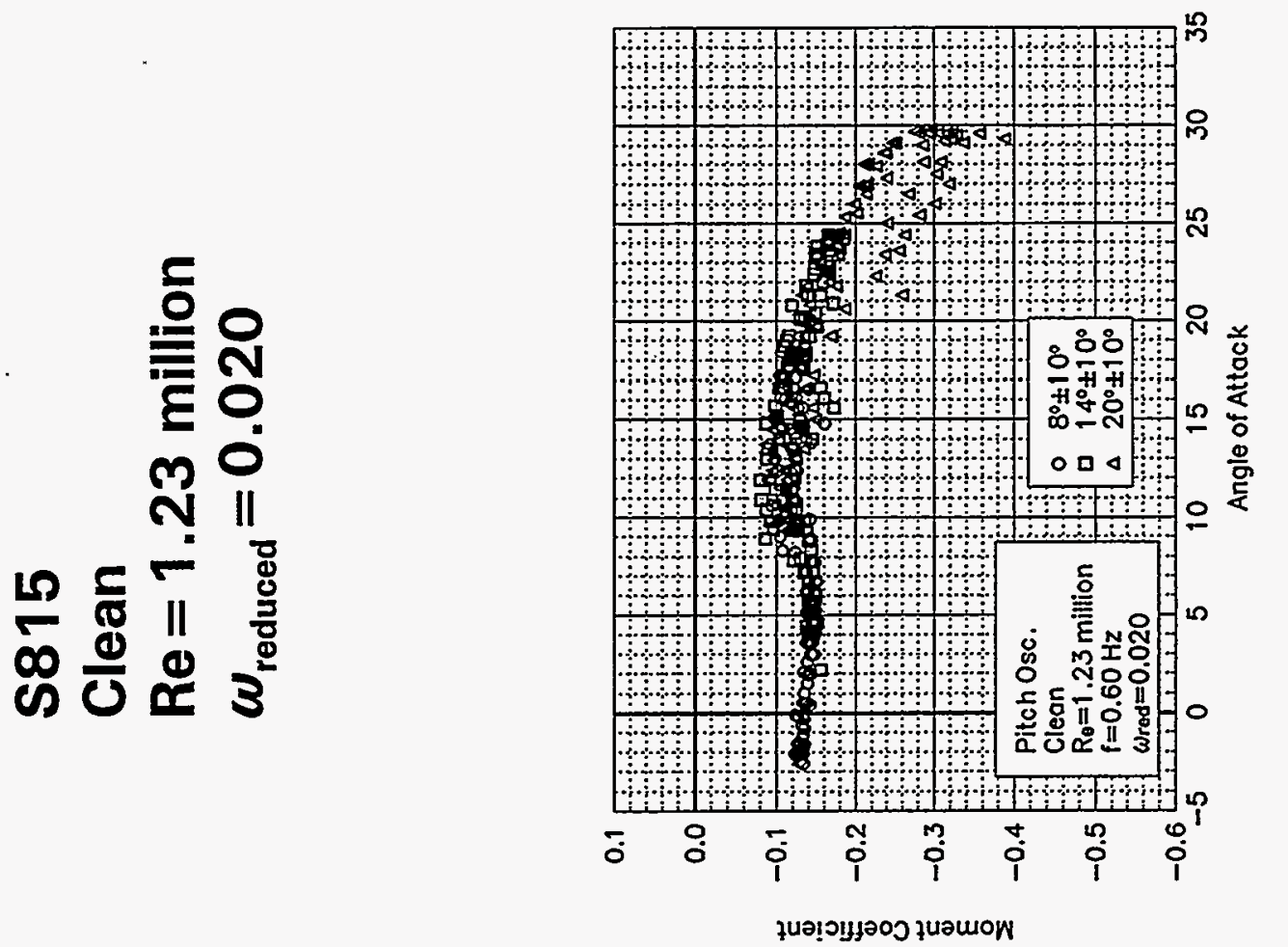

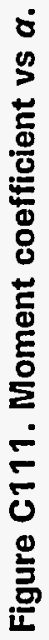
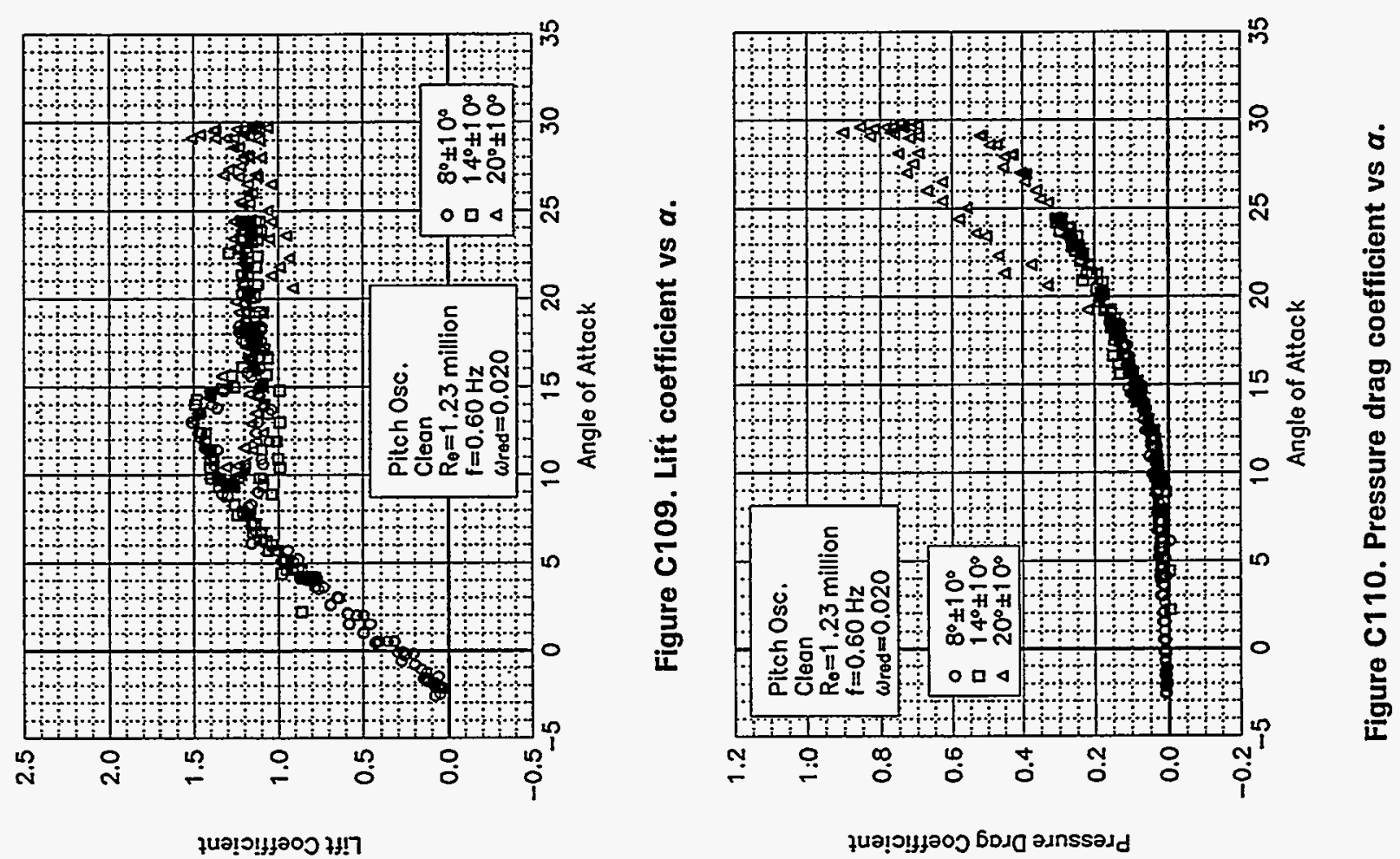

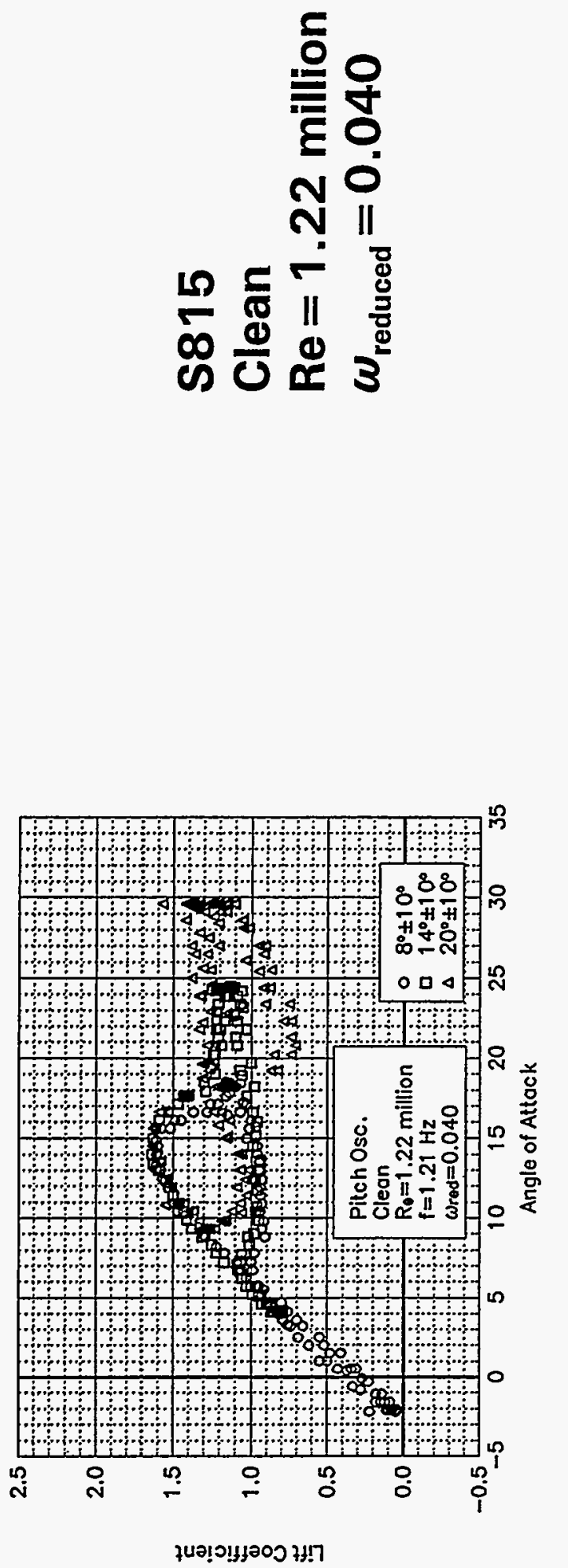

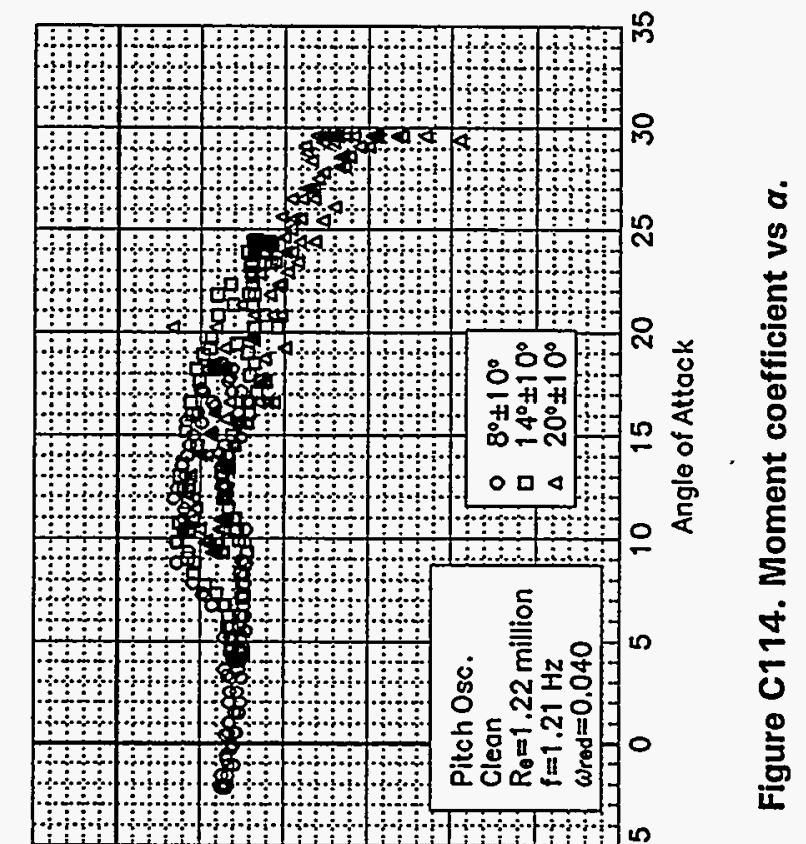

列

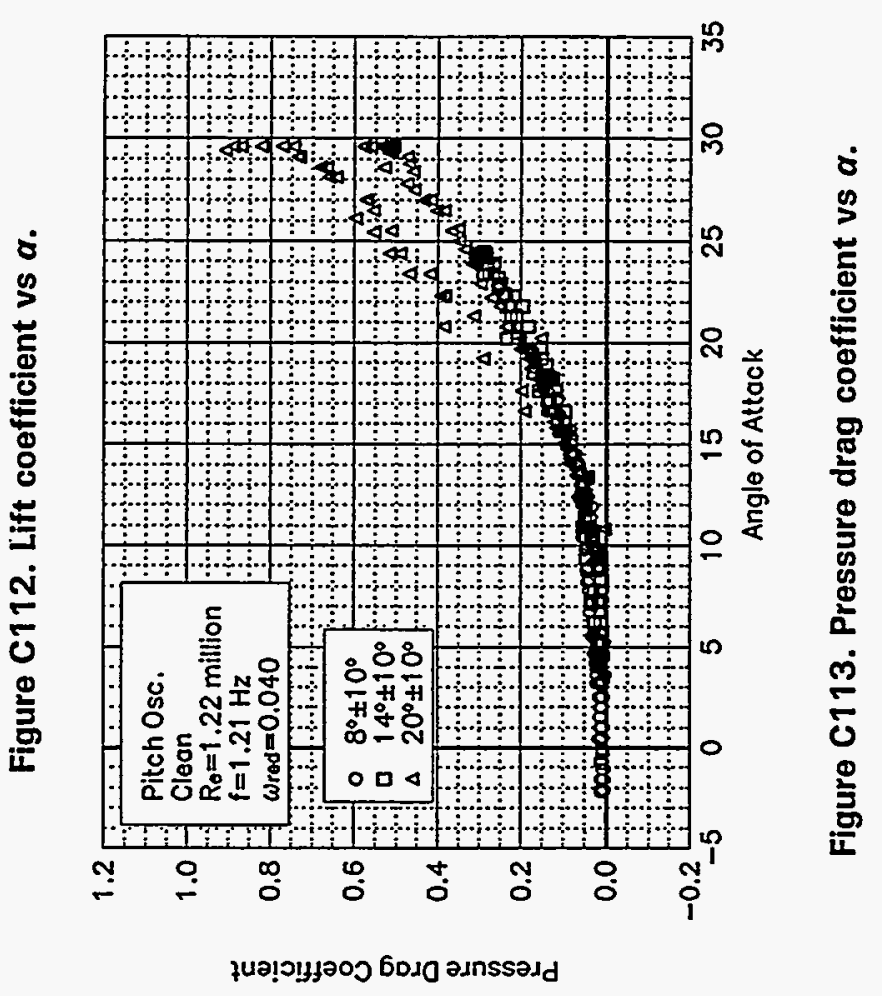



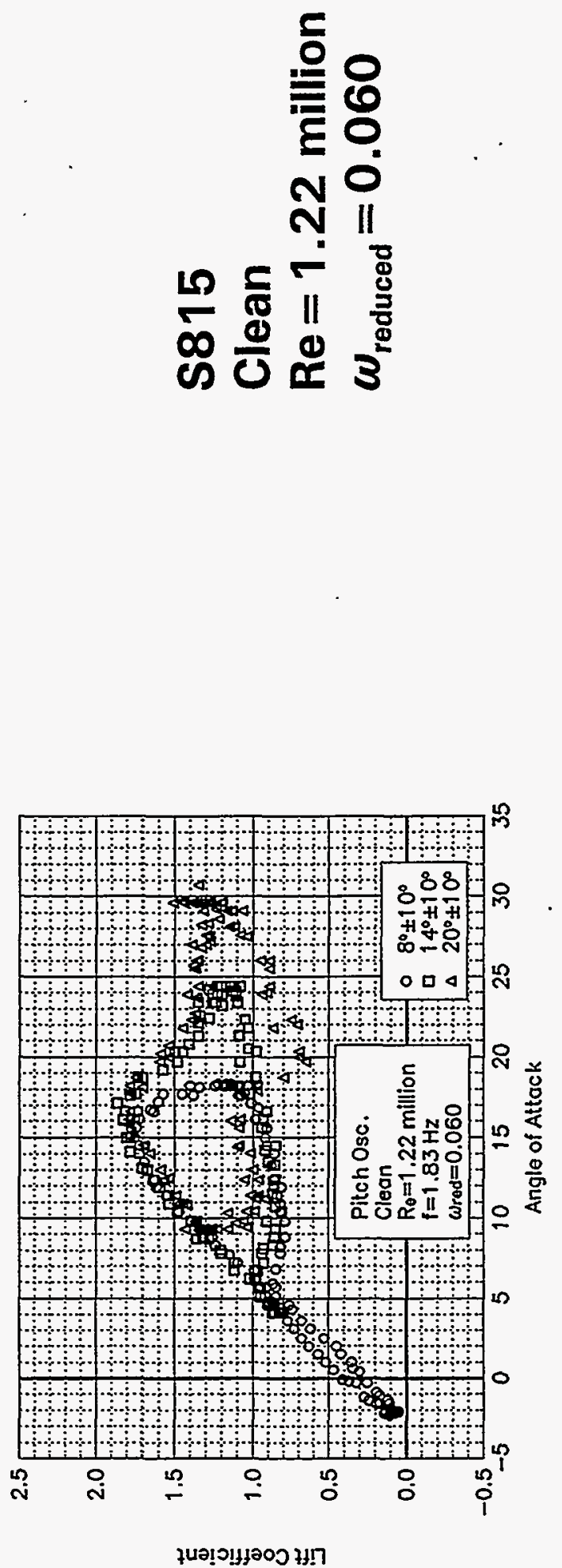

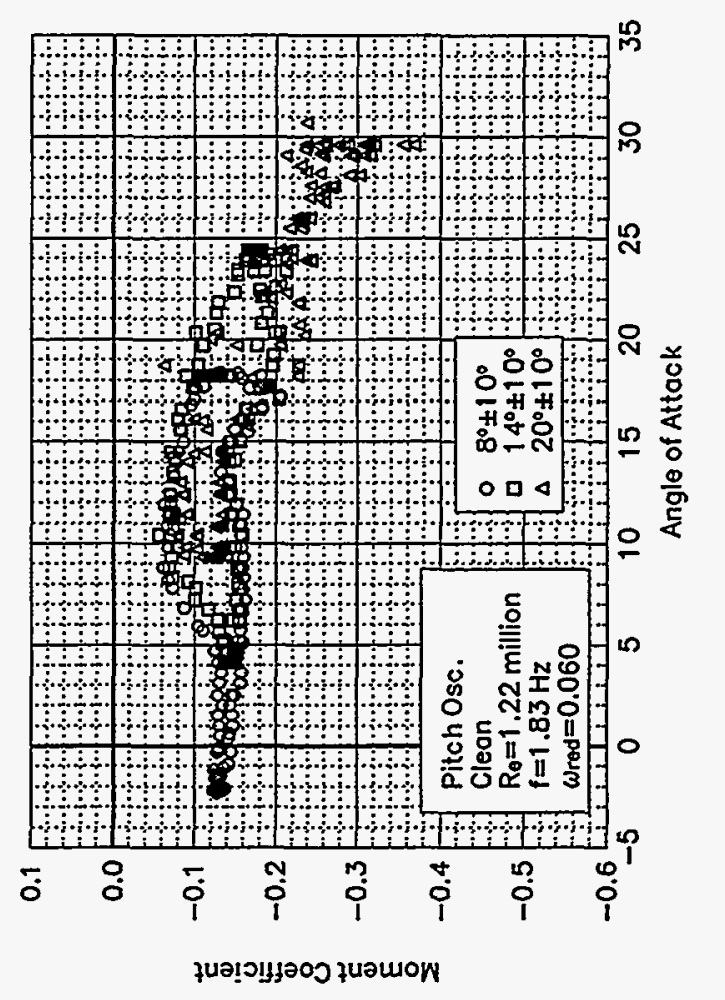



U

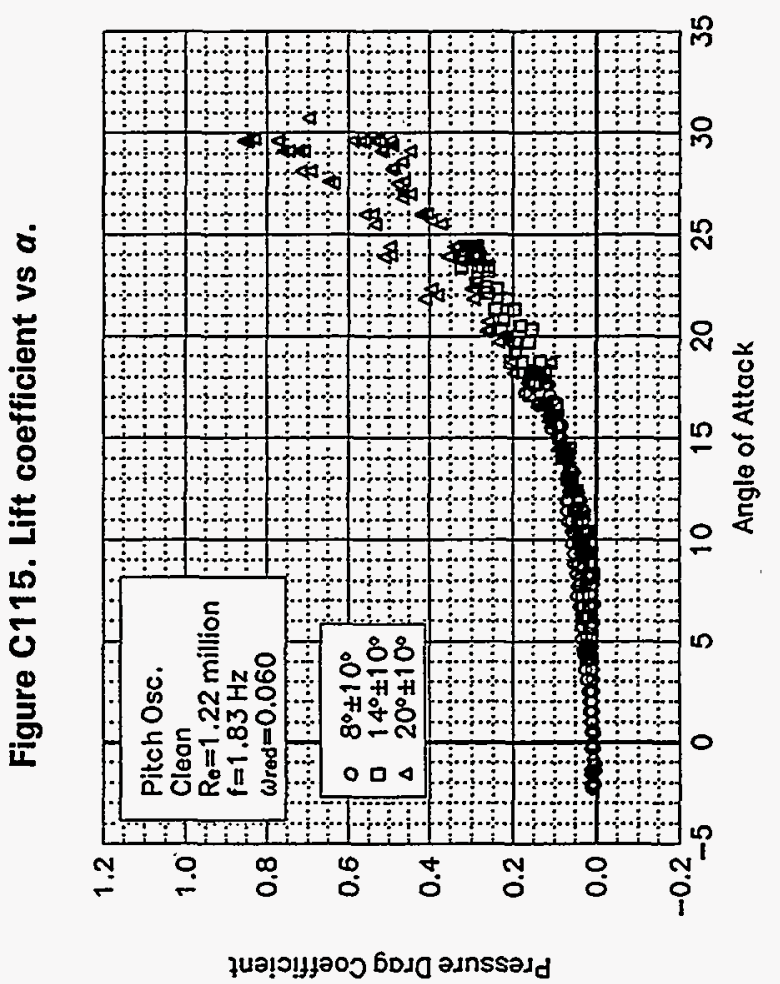

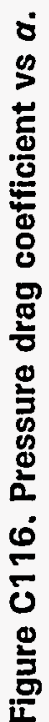



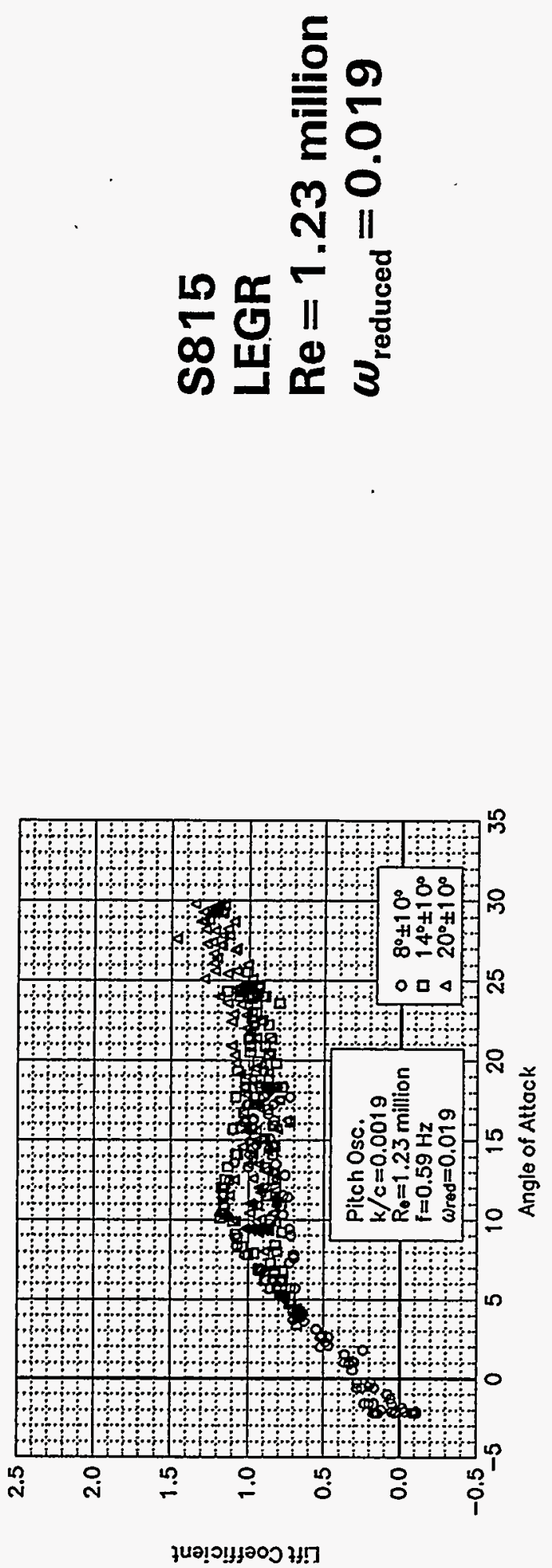

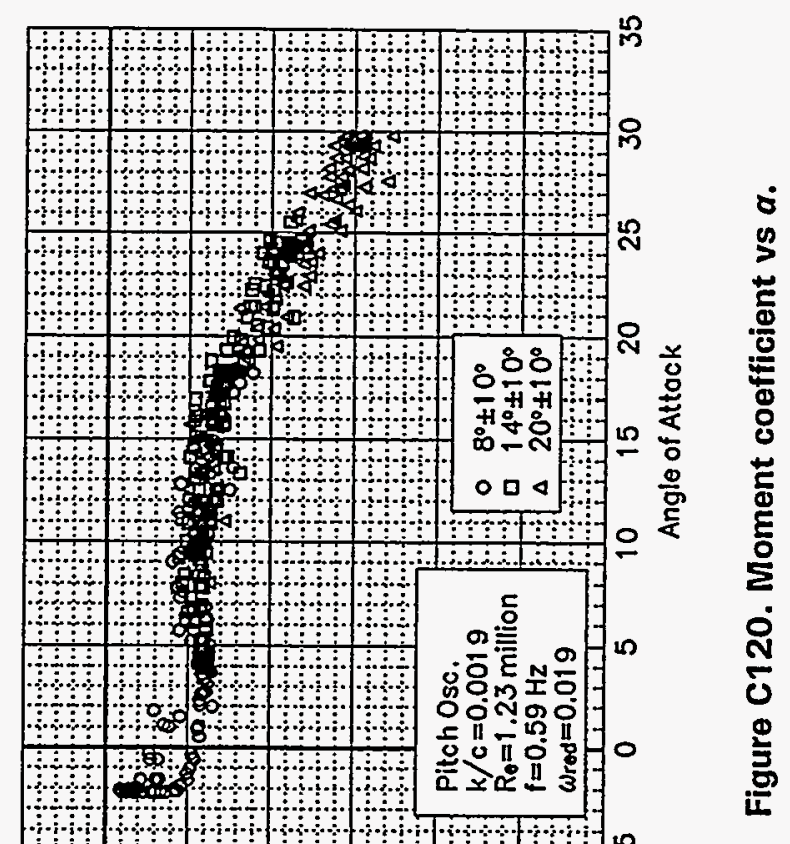

\section{i}

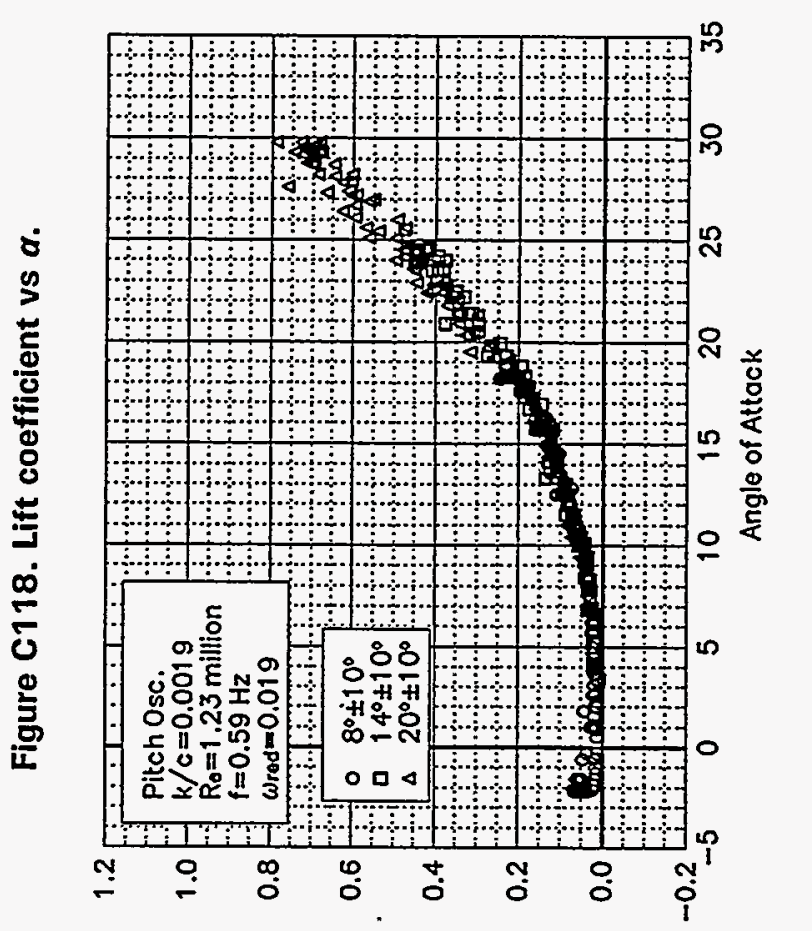

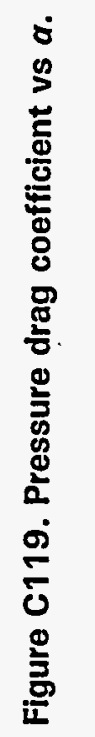



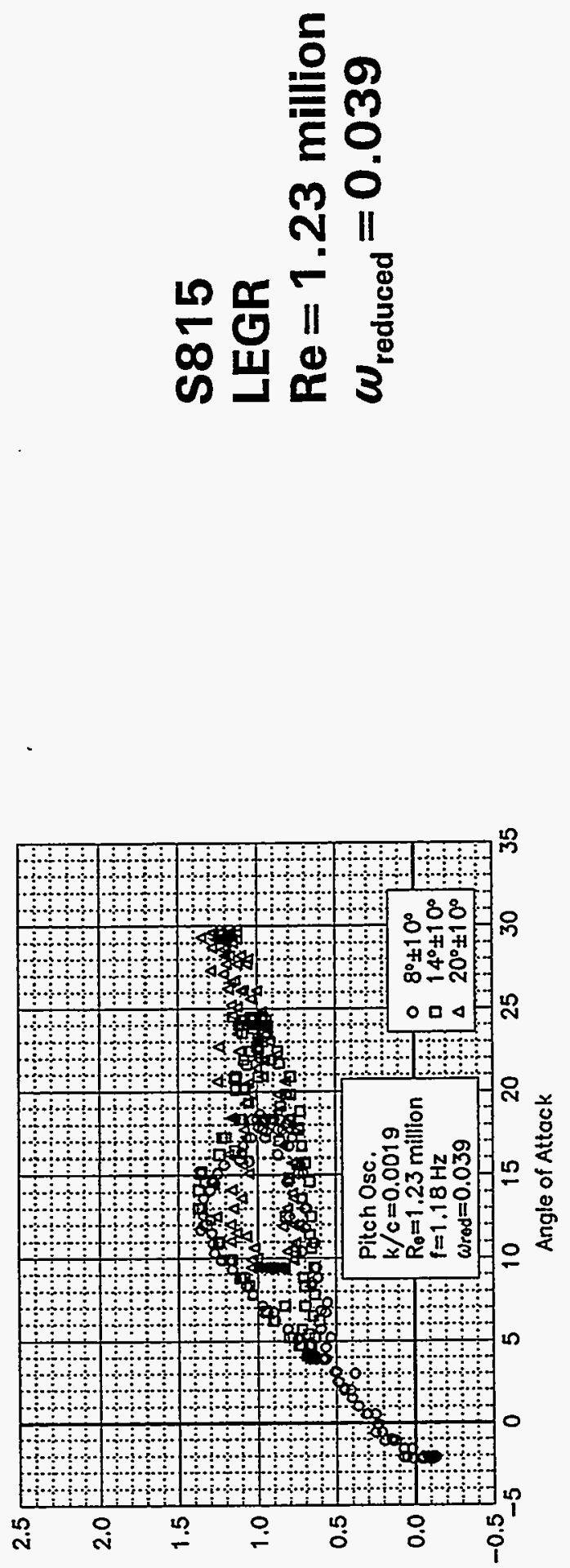

\}บขเว!มมอว

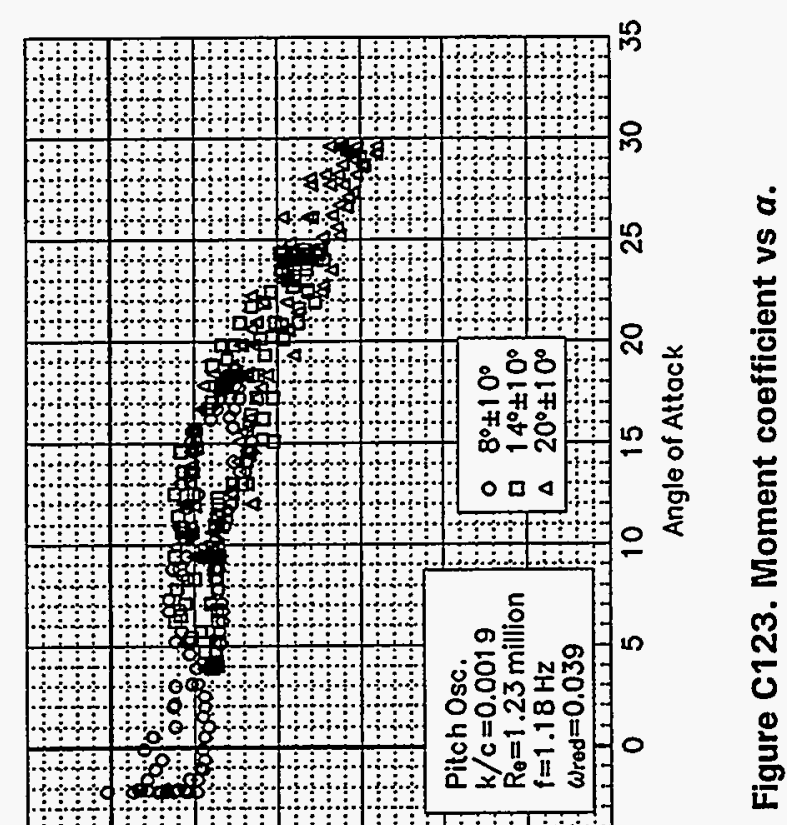

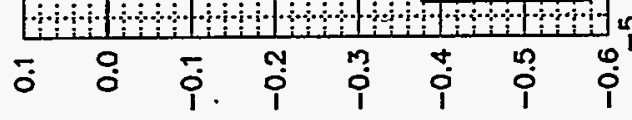

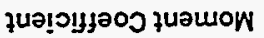

i

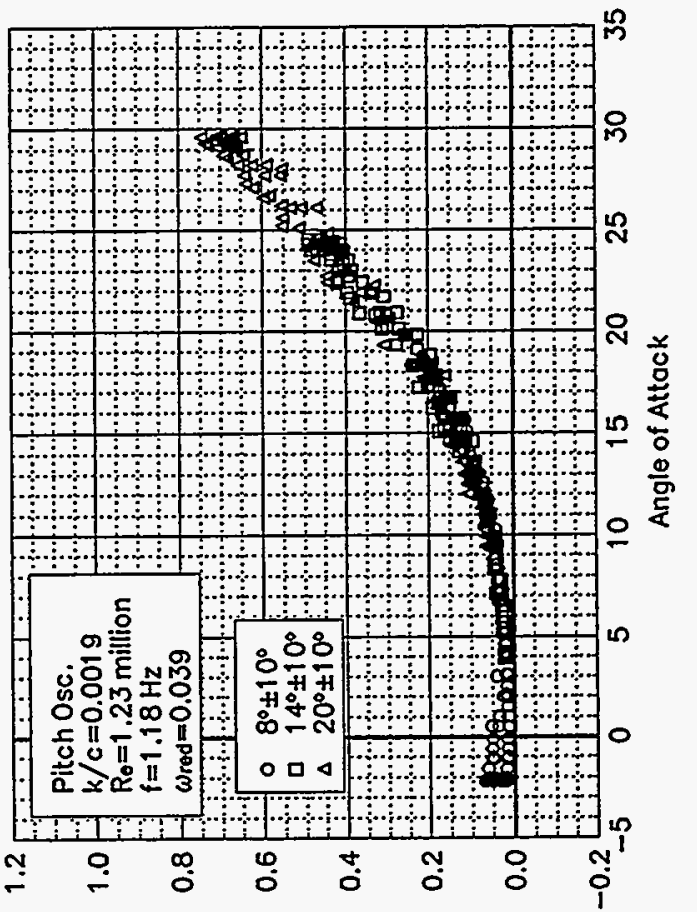

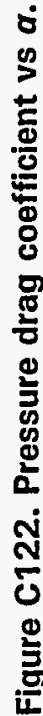

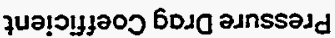




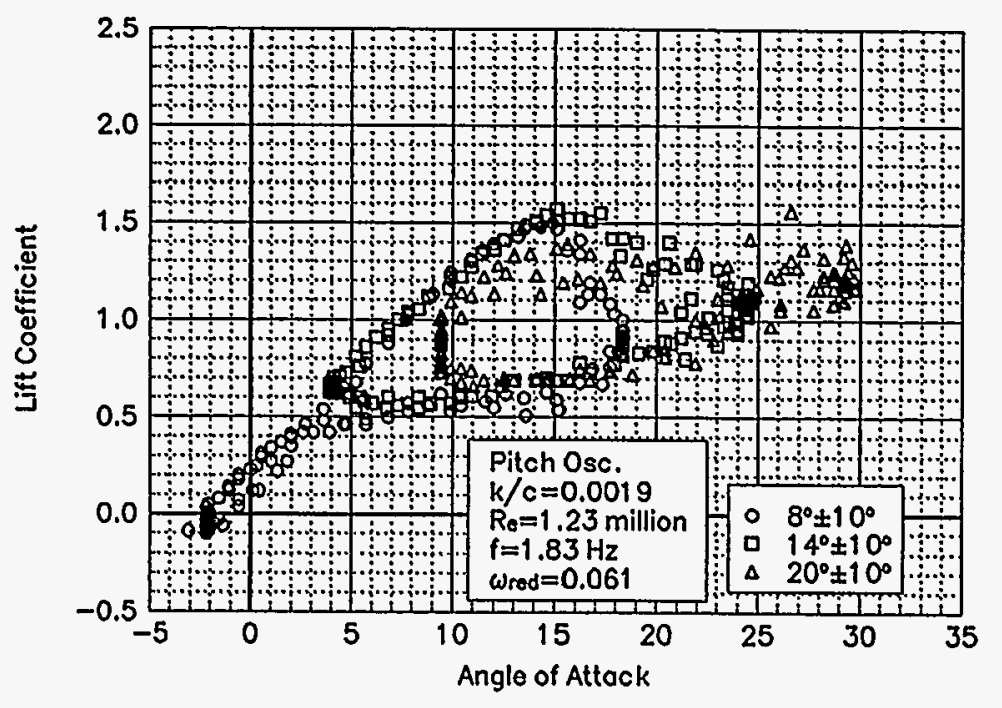

Figure C124. Lift coefficient vs $a$.

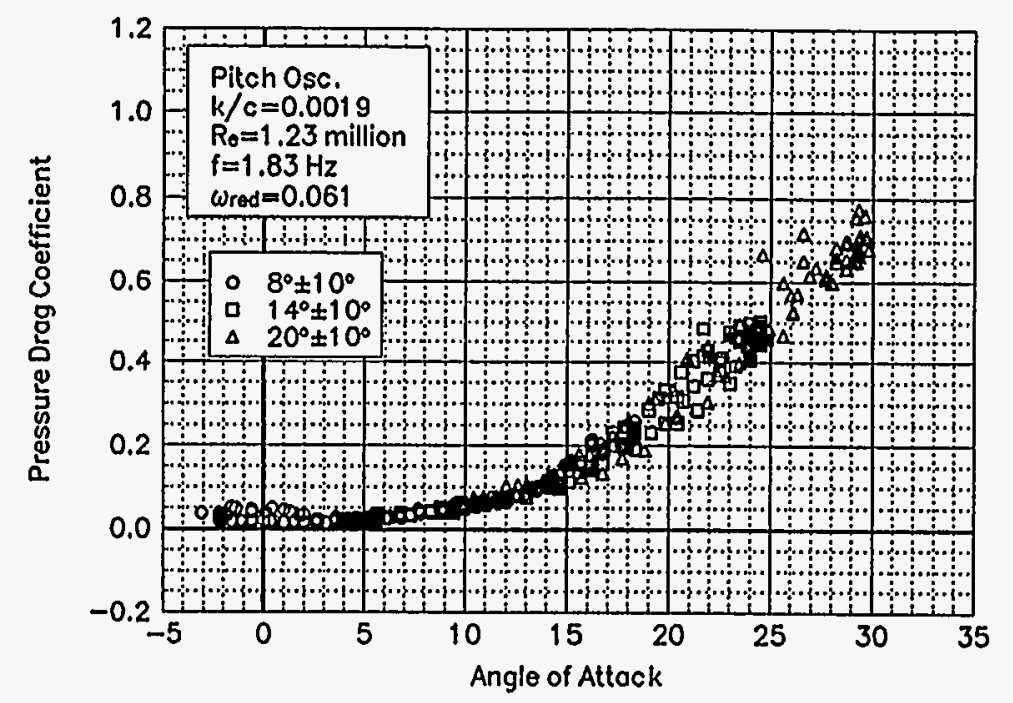

Figure C125. Pressure drag coefficient vs $a$.

\section{S815 LEGR \\ $\operatorname{Re}=1.23$ million \\ $\omega_{\text {reduced }}=0.061$}

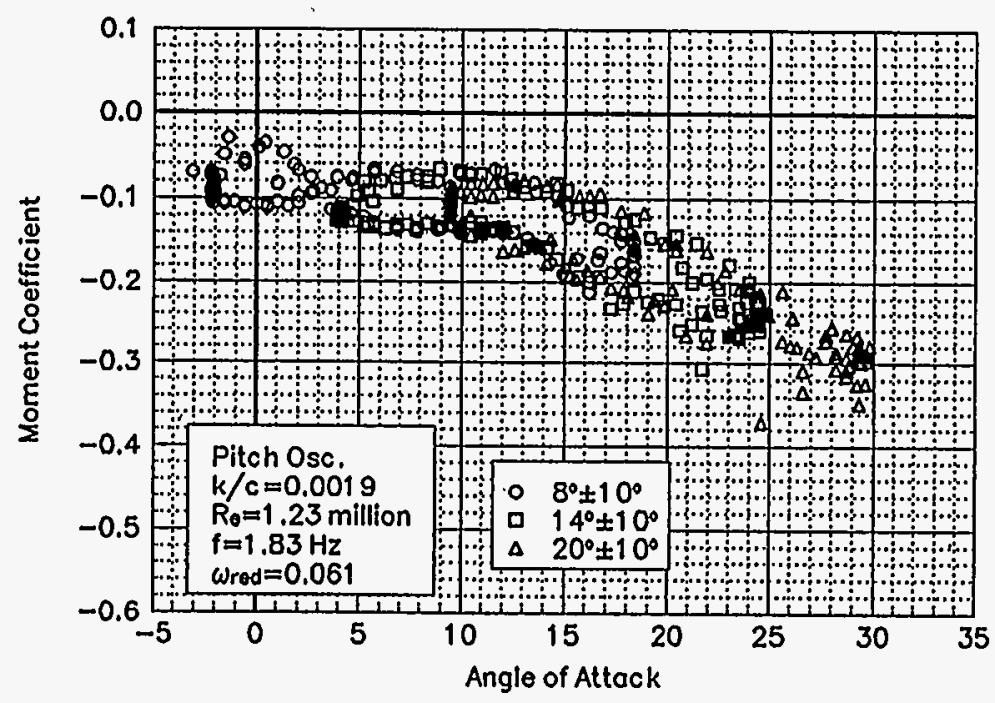

Figure C126. Moment coefficient vs $a$. 


\section{Unsteady Airfoil Characteristics}

$\pm 10^{\circ}$ Sine, $\operatorname{Re}=1.4$ million 
Pressure Drag Coefficient

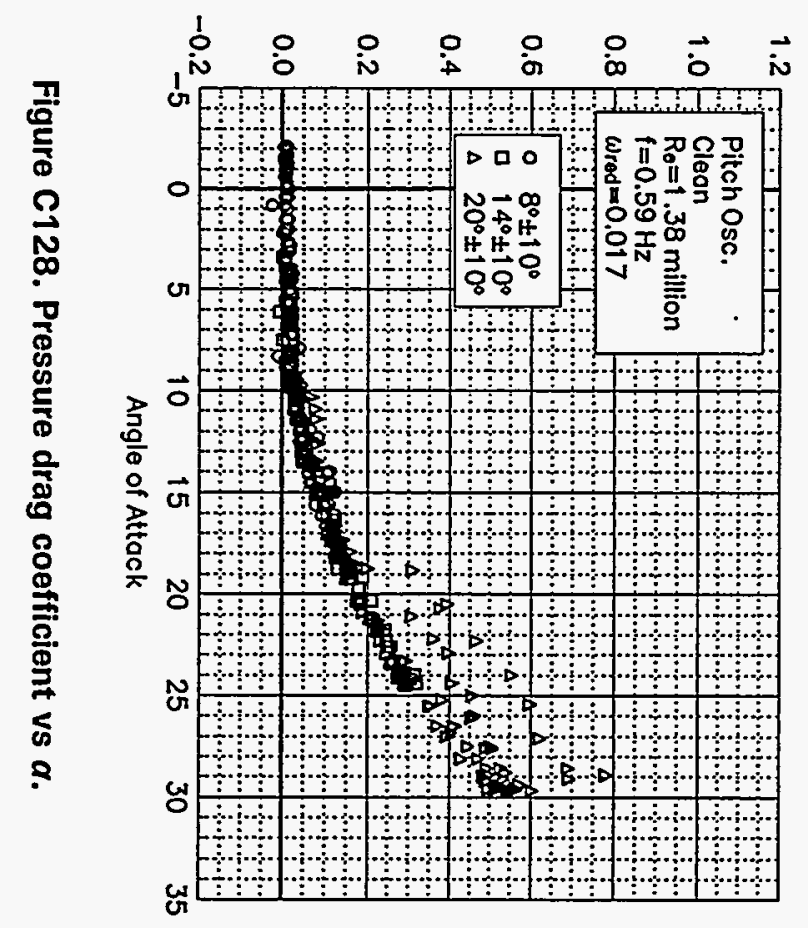

Lift Coefficient

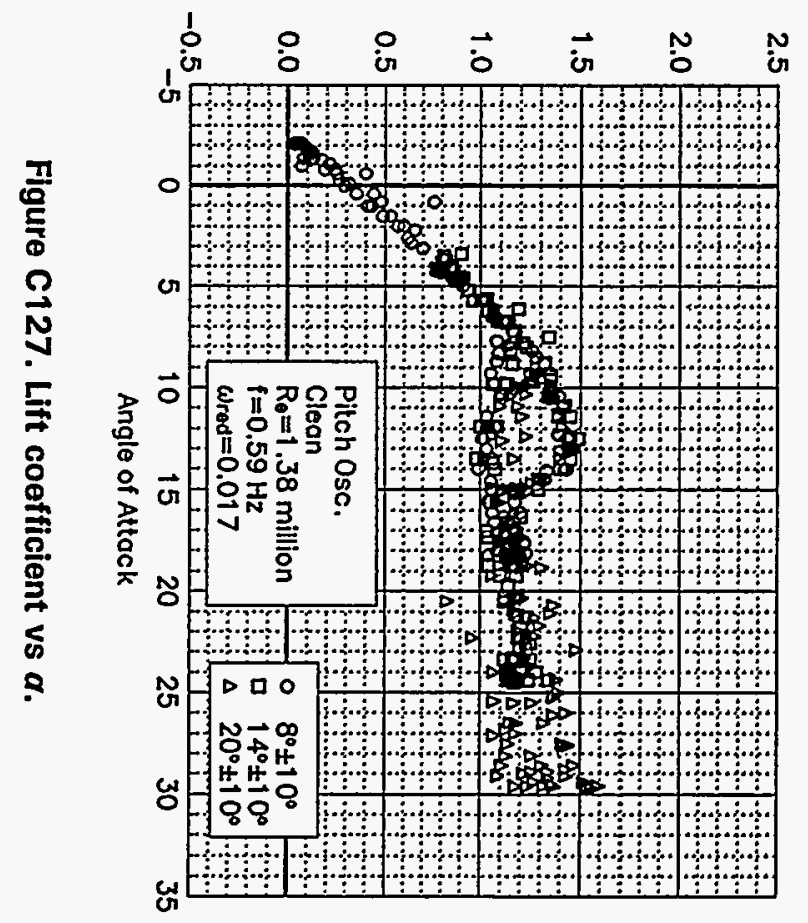

ư
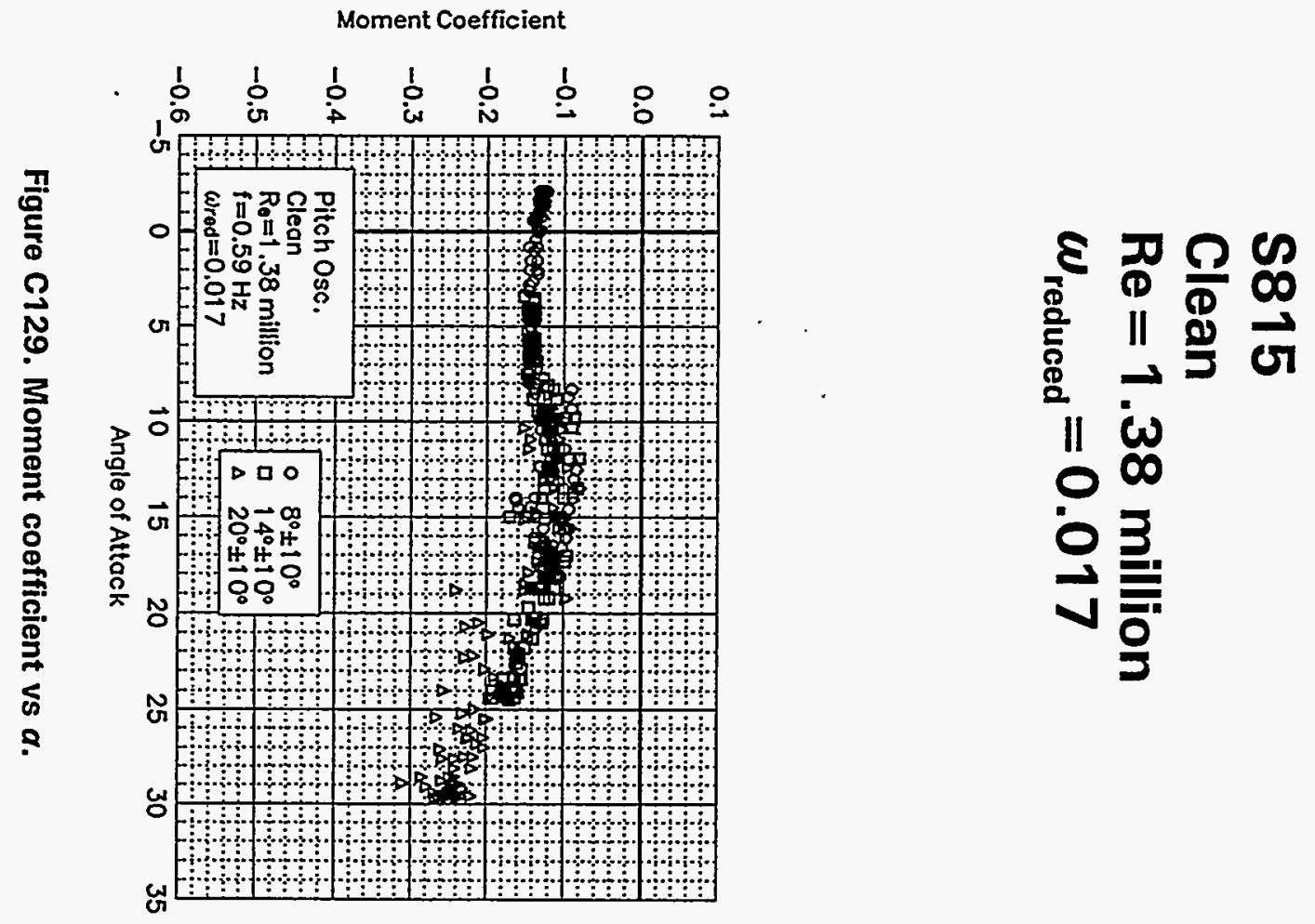

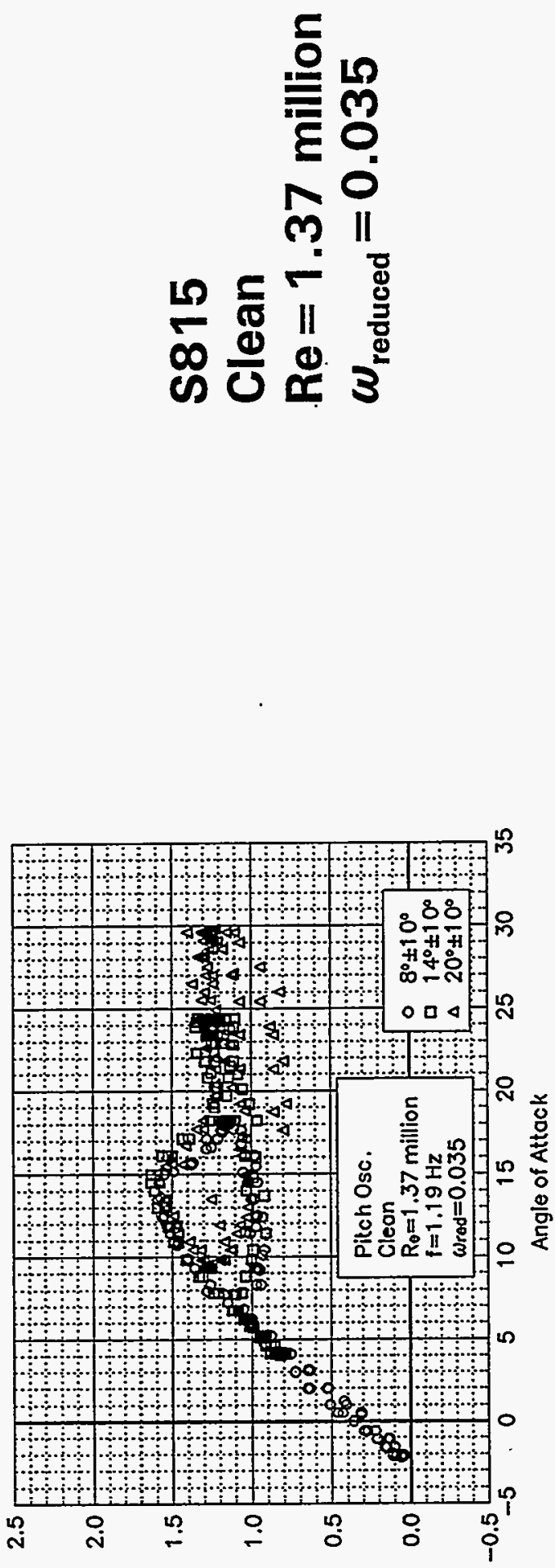

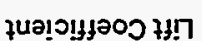

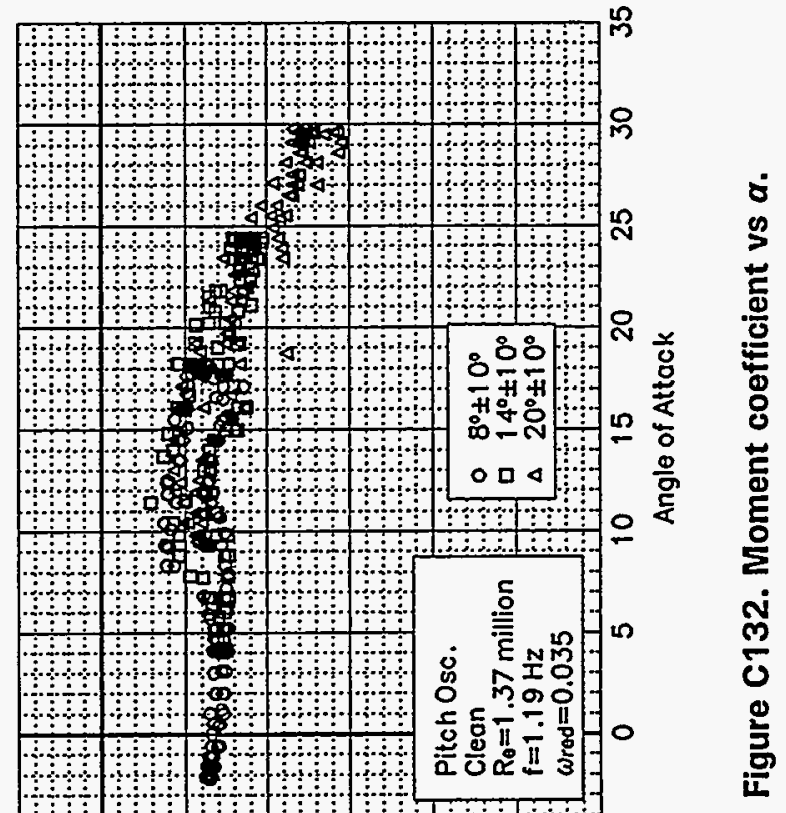

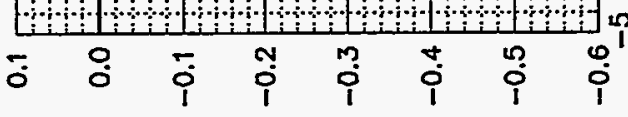

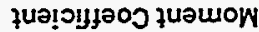

นั

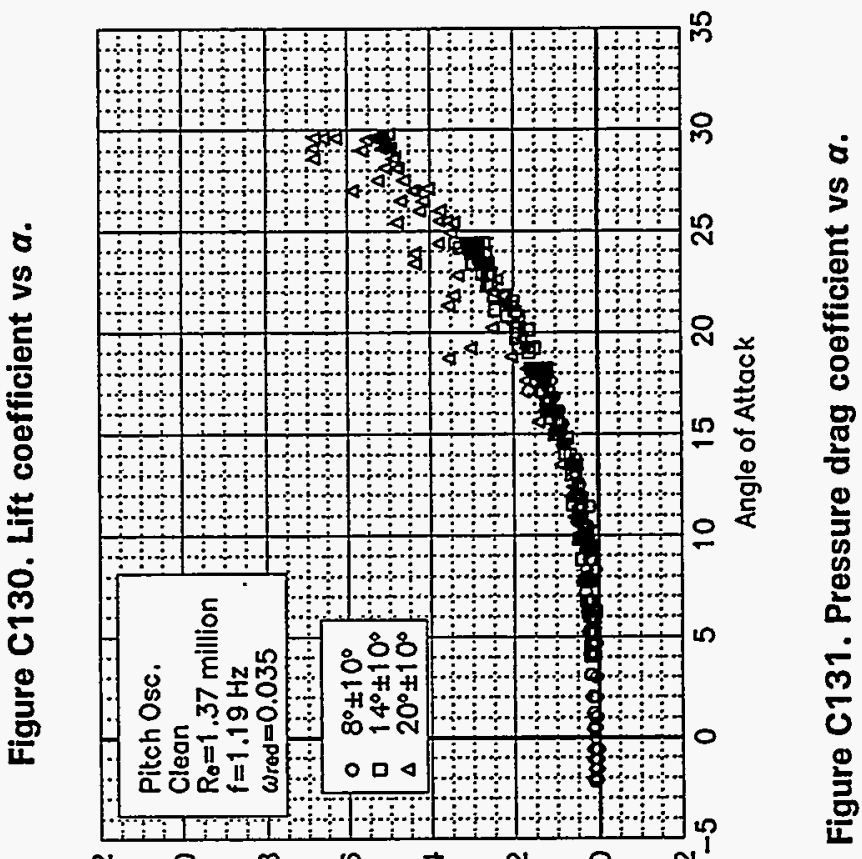

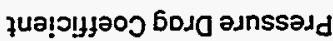



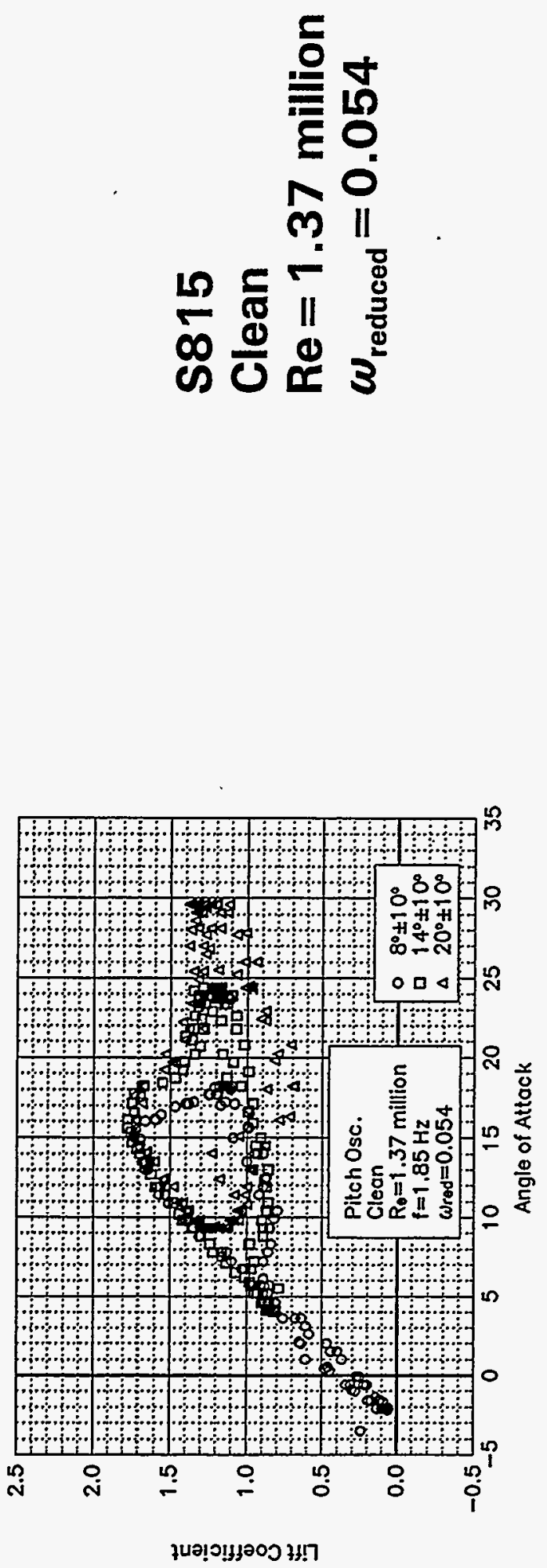

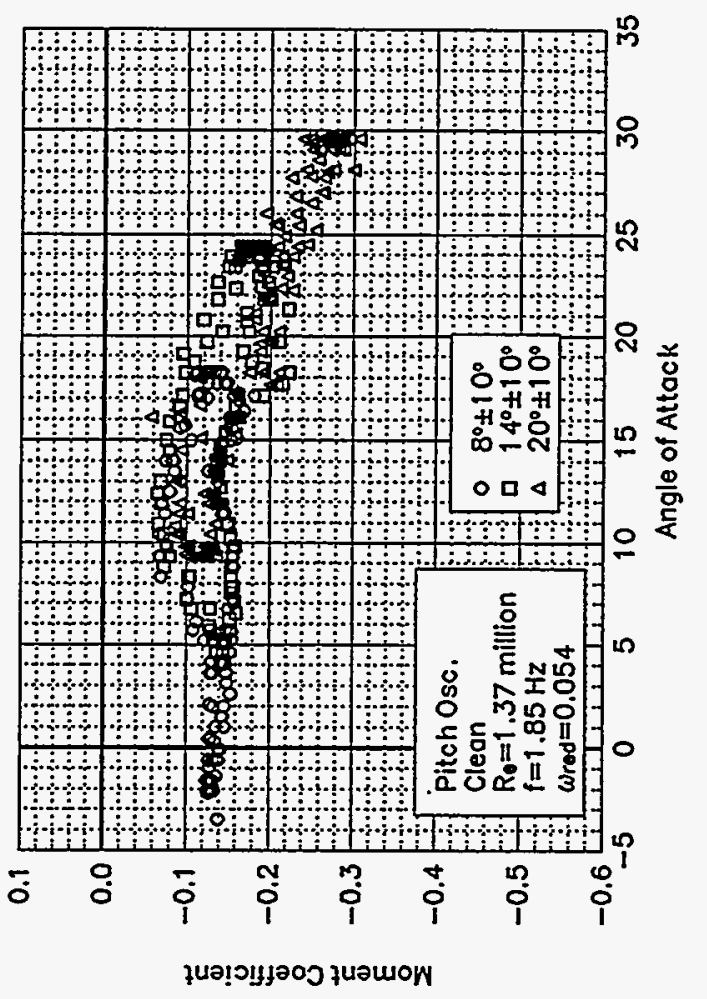

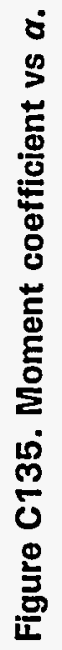

颌

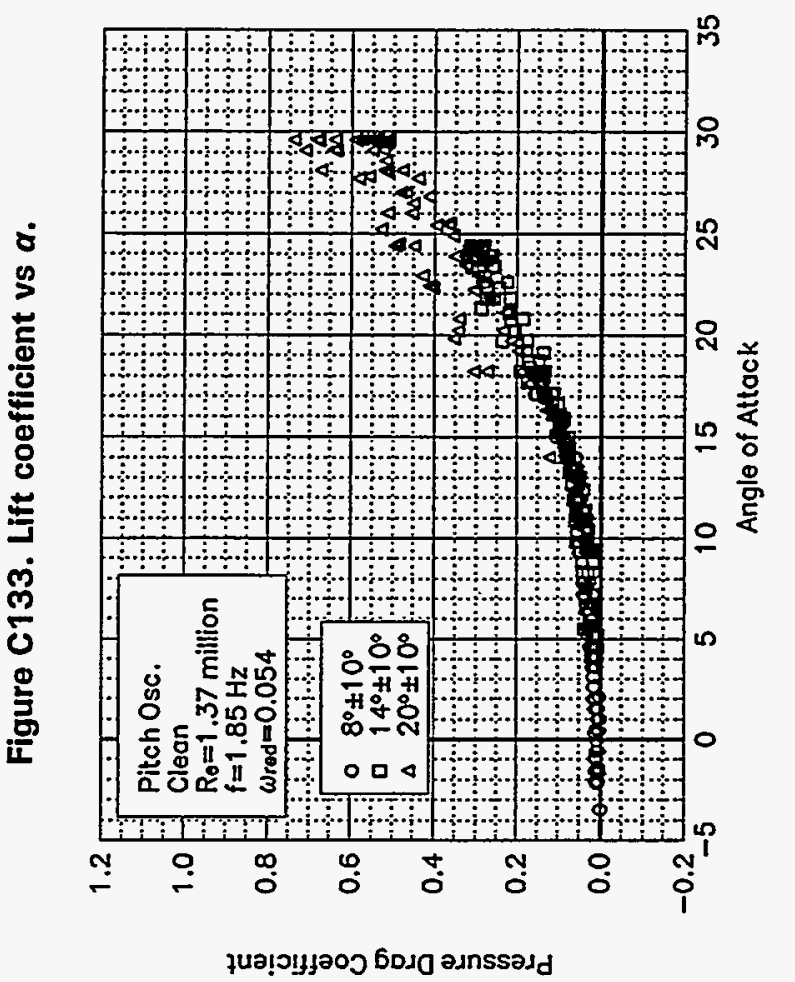

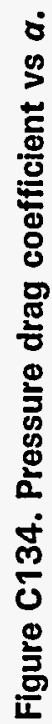




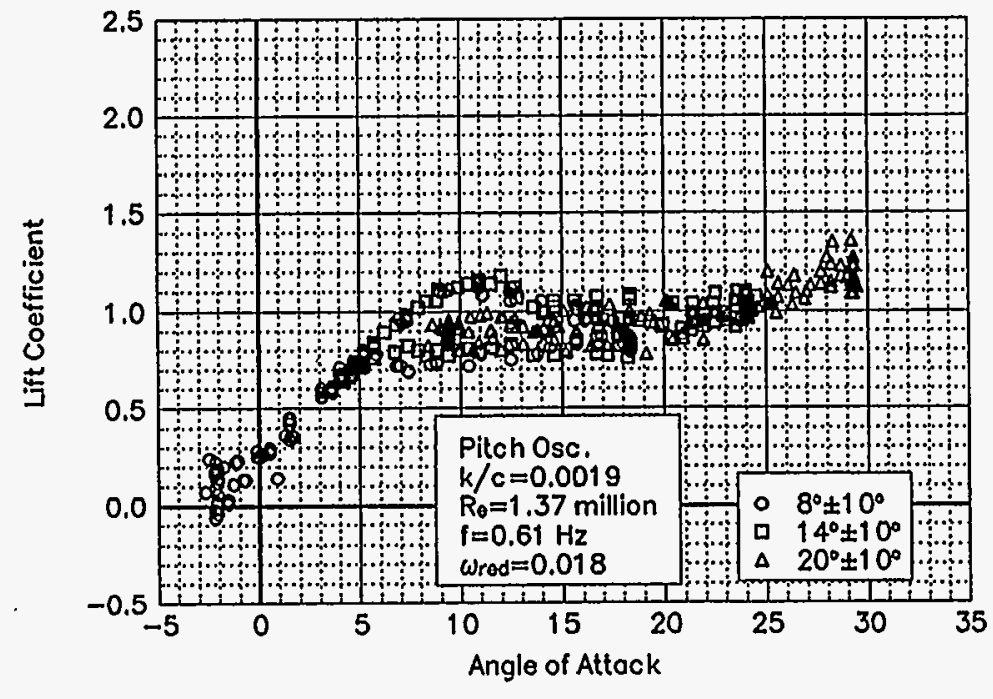

Figure C136. Lift coefficient vs $a$.

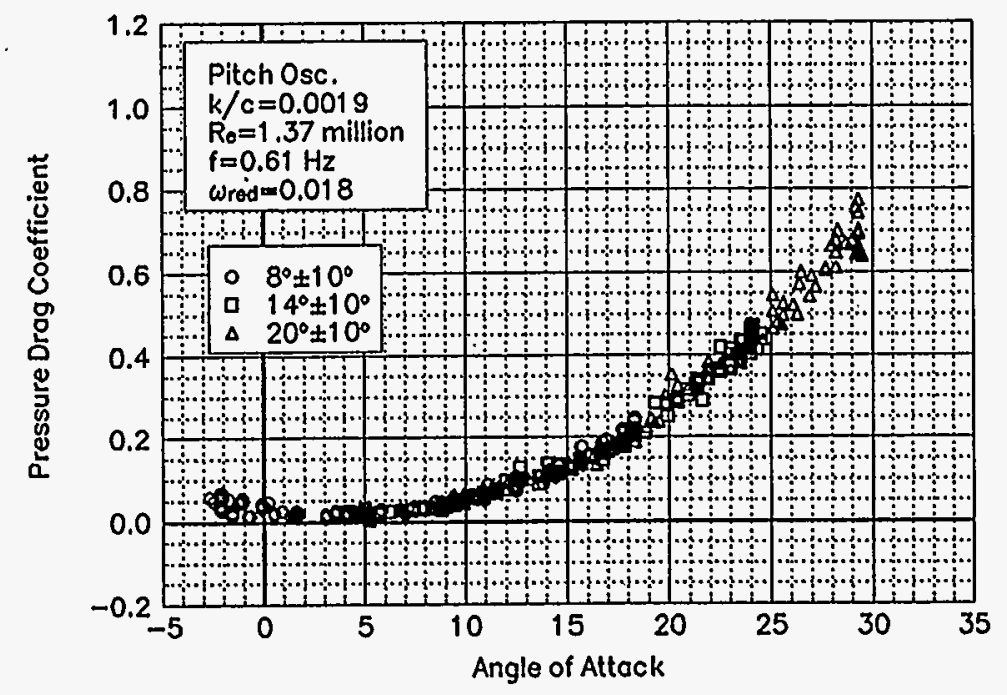

Figure C137. Pressure drag coefficient vs $\dot{a}$.

\section{S815 LEGR \\ $\operatorname{Re}=1.37$ million $\omega_{\text {reduced }}=0.018$}

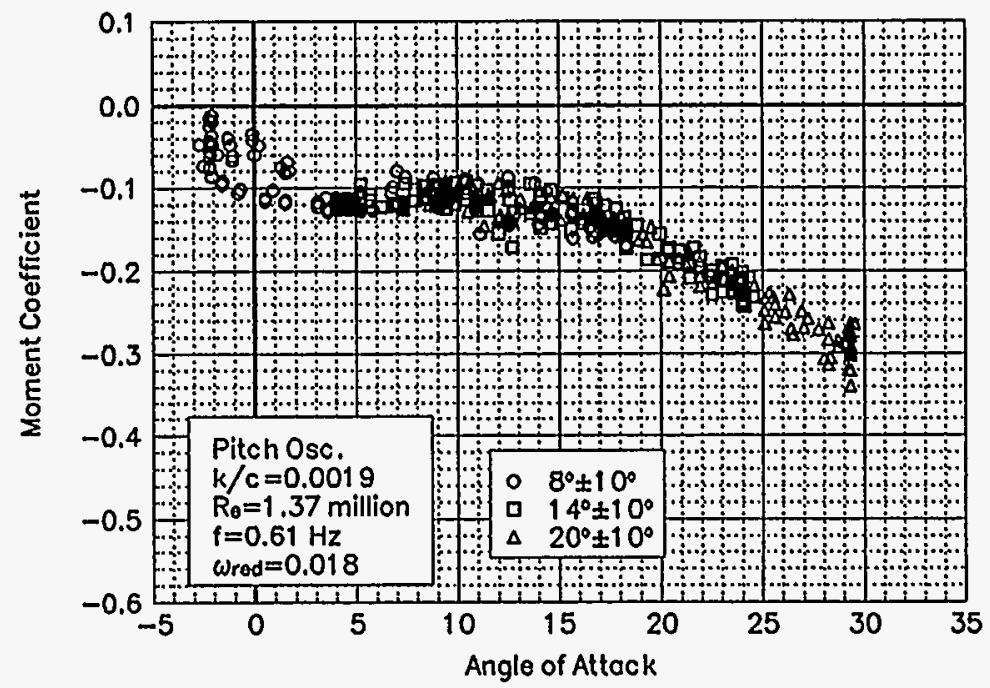

Figure C138. Moment coefficient vs $a$. 

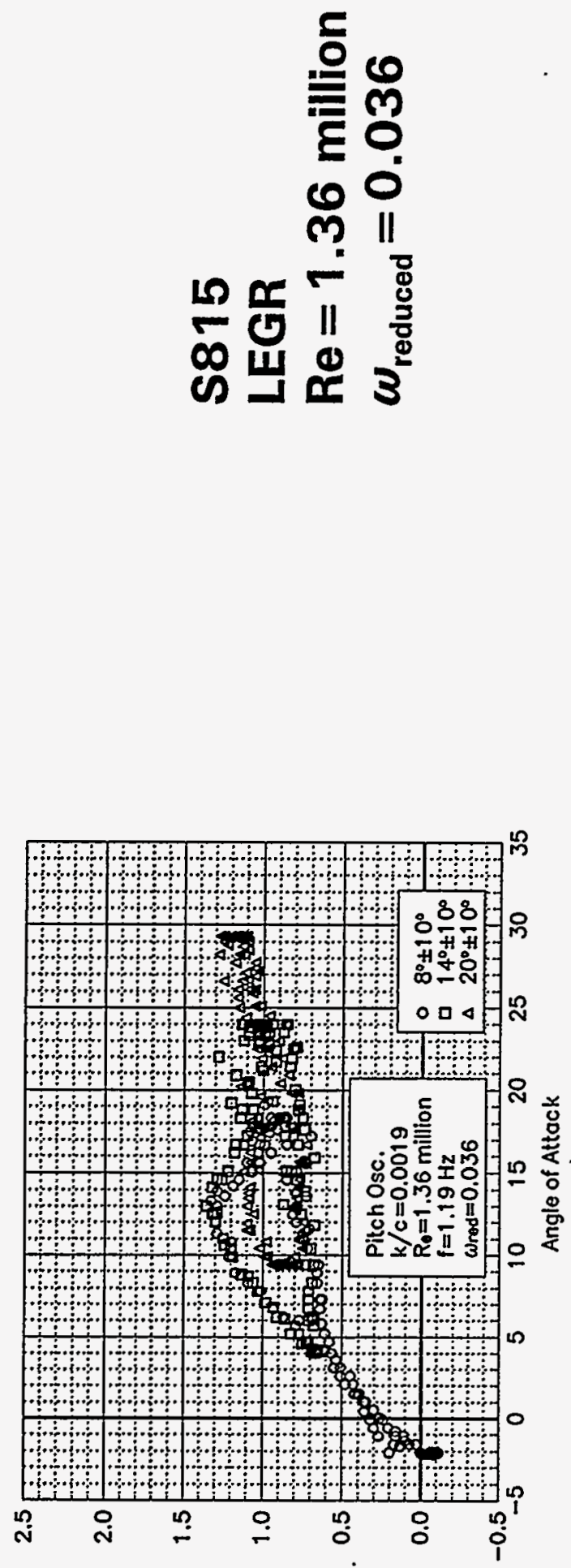

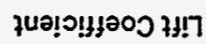

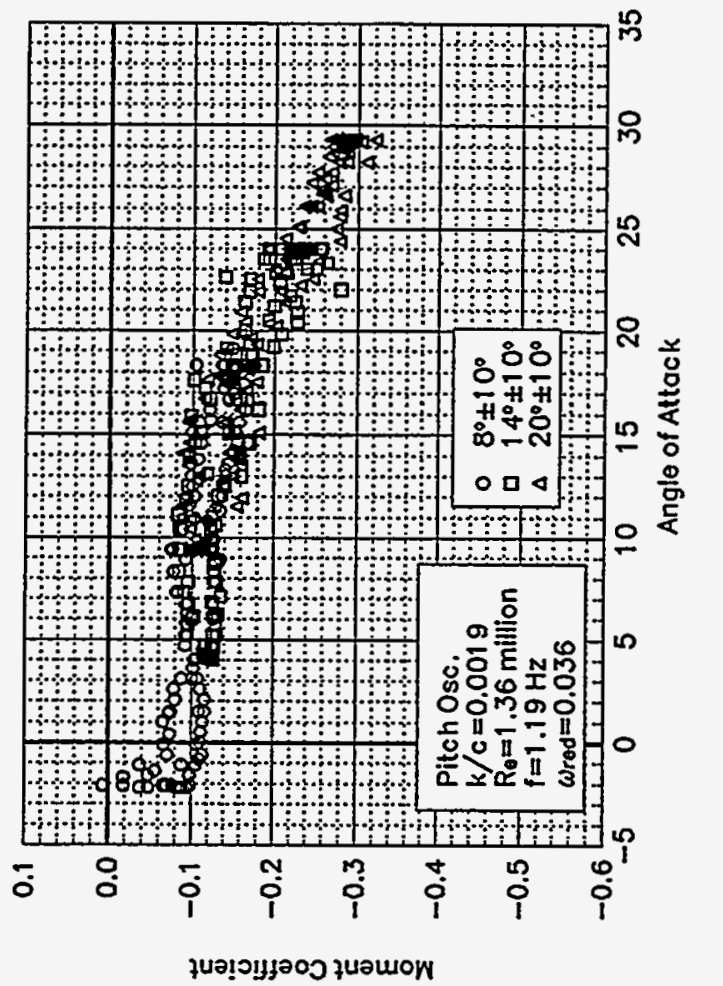

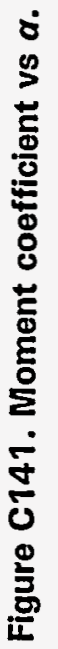

尔

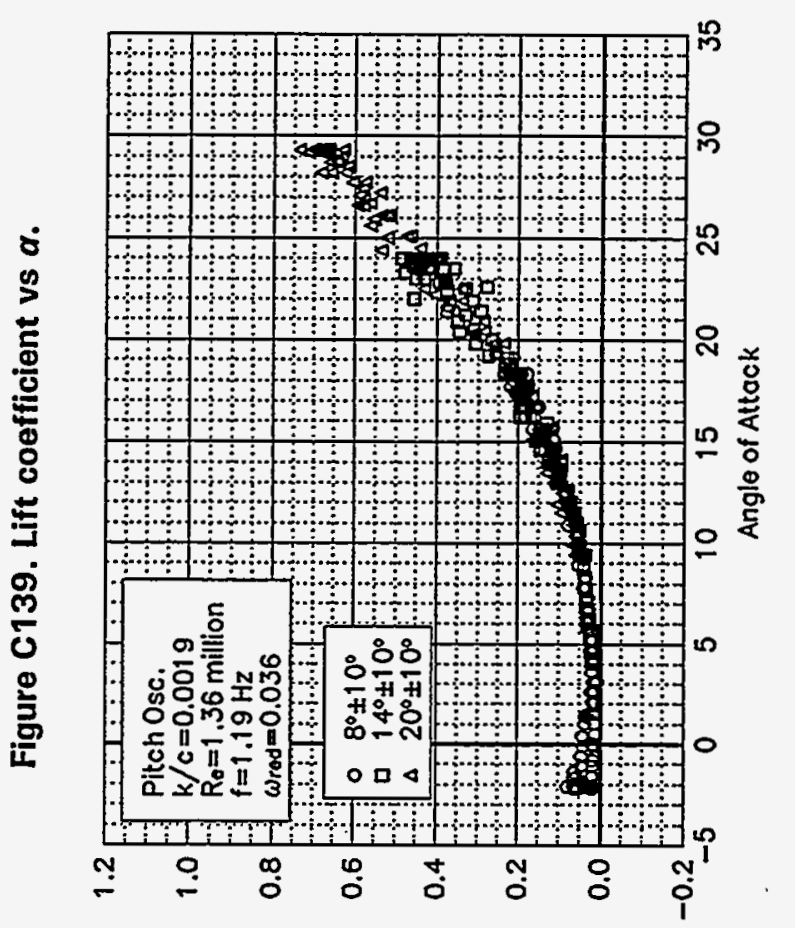

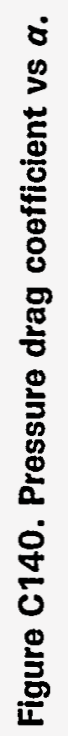

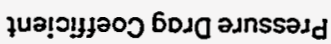



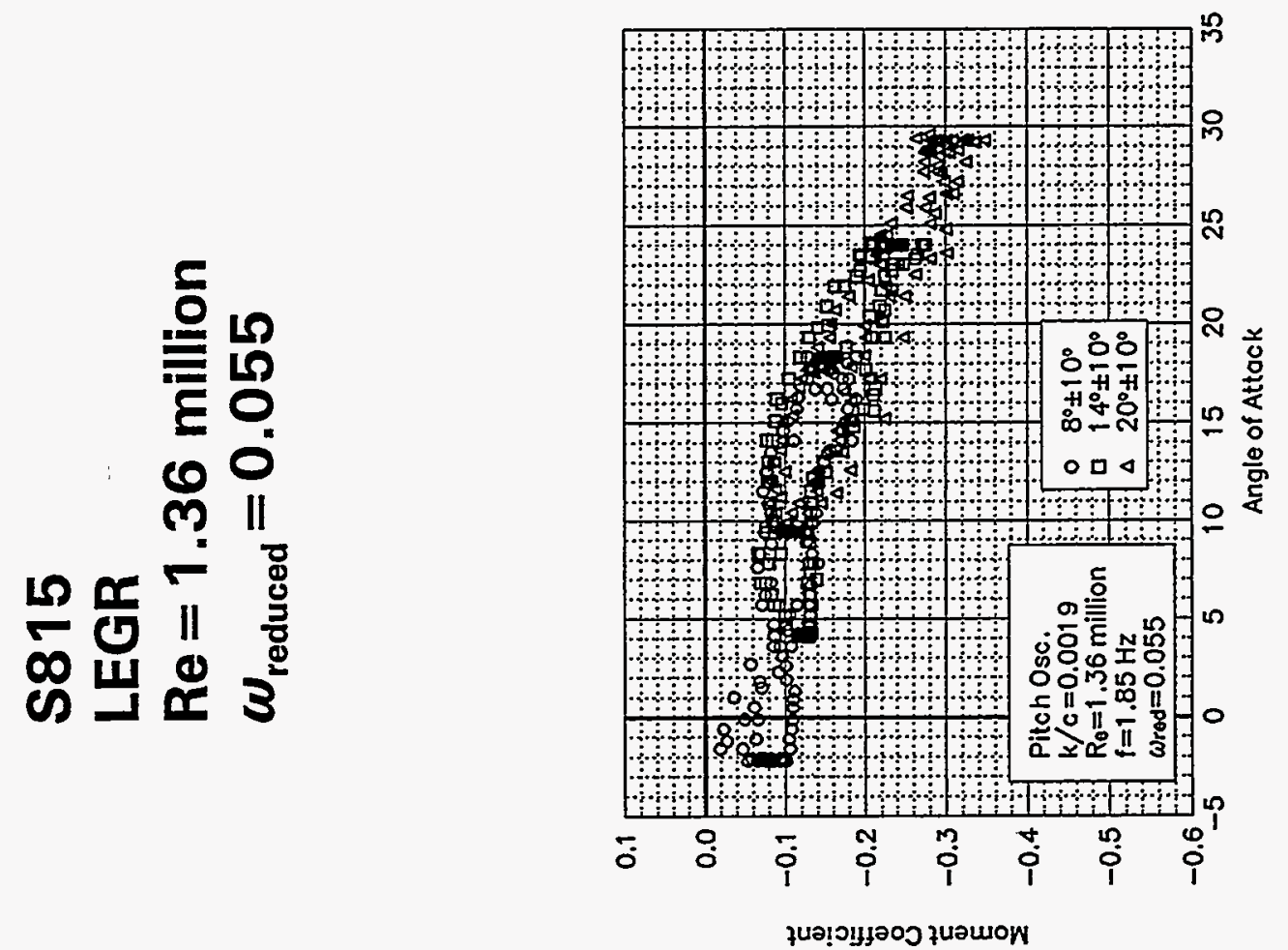

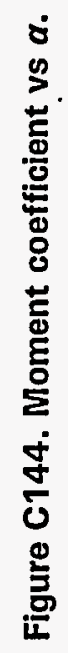
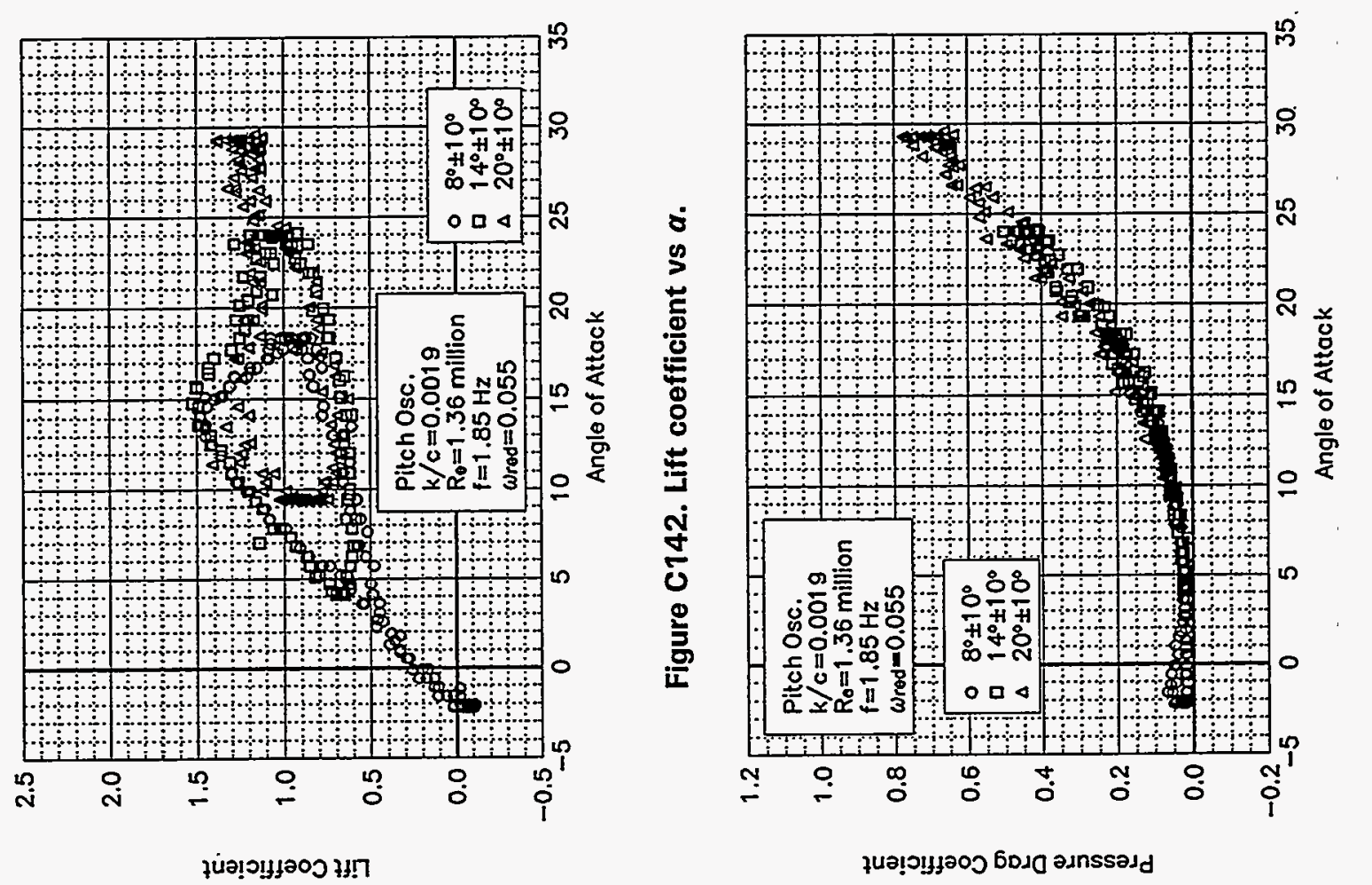

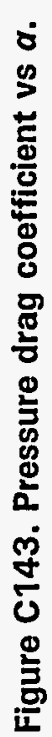


Public reporting burden for this collection of information is estimated to average 1 hour per response, including the time for reviewing instructions, searching existing dat sources, gathering and maintaining the data needed, and completing and reviewing the collection of information. Send comments regarding this burden estimate or any other aspect of this collection of information, including suggestions for reducing this burden, to Washington Headquarters Services, Directorate for Information Operation and Reports, 1215 Jefferson Davis Highway, Suite 1204, Arlington, VA 22202-4302, and to the Office of Management and Budget, Paperwork Reduction Project 107040188), Washington, DC 20503 .

\begin{tabular}{l|l|l}
\hline 1. & $\begin{array}{l}\text { 2. REPORT DATE } \\
\text { July } 1996\end{array}$ & $\begin{array}{l}\text { 3. REPORT TYPE AND DATES COVERED } \\
\text { Subcontract Report }\end{array}$ \\
\hline
\end{tabular}

4. TITLE AND SUBTITLE

Effects of Grit Roughness and Pitch Oscillations on the $\$ 815$ Airfoil

5. FUNDING NUMBERS

6. AUTHOR(S)

R. Reuss Ramsay, M. J. Hoffmann, G. M. Gregorek

C:

\section{TA: WE619030}

7. PERFORMING ORGANIZATION NAME(S) AND ADDRESS(ES)

Dr. Gerald Gregorek

The Ohio State University

Aero \& Astronautical Research

2300 West Case Road

Columbus, Ohio 43220

(614) 292-5491

9. SPONSORING/MONITORING AGENCY NAME(S) AND ADDRESS(ES)

National Renewable Energy Laboratory

1617 Cole Blvd.

Golden, CO 80401-3393

8. PERFORMING ORGANIZATION REPORT NUMBER

11. SUPPLEMENTARY NOTES

NREL Technical Monitor: C. P. Butterfield

12a. DISTRIBUTION/AVAILABILITY STATEMENT

National Technical Information Service

U.S. Department of Commerce

5285 Port Royal Road

Springfield, VA 22161

12b. DISTRIBUTION CODE

UC-1211

\section{ABSTRACT (Maximum 200 words)}

Horizontal axis wind turbine rotors experience unsteady aerodynamics due to wind shear when the rotor is yawed, when rotor blades pass through the support tower wake, and when the wind is gusting. An understanding of this unsteady behavior is necessary to assist in the calculation of rotor performance and loads. The rotors also experience performance degradation due to surface roughness. These surface irregularities are caused by the accumulation of insect debris, ice, and the aging process. Wind tunnel studies that examine both the steady and unsteady behavior of airfoils can help define pertinent flow phenomena, and the resultant data can be used to validate analytical computer codes.

An S815 airfoil model was tested in The Ohio State University Aeronautical and Astronautical Research Laboratory (OSU/AARL) $3 \times 5$ subsonic wind tunnel $(3 \times 5)$ under steady flow and stationary model conditions, as well as with the model undergoing pitch oscillations. To study the possible extent of performance loss due to surface roughness, a standard grit pattern (LEGR) was used to simulate leading edge contamination. After baseline cases were completed, the LEGR was applied for both steady state and model pitch oscillation cases. The Reynolds numbers for steady state conditions were $0.75,1,1.25$, and 1.4 million, while the angle of attack ranged from $-20^{\circ}$ to $+40^{\circ}$. With the model undergoing pitch oscillations, data were acquired at Reynolds numbers of 0.75 , $1,1.25$, and 1.4 million, at frequencies of $0.6,1.2$, and $1.8 \mathrm{~Hz}$. Two sine wave forcing functions were used, $\pm 5.5^{\circ}$ and $\pm 10^{\circ}$, at mean angles of attack of $8^{\circ}, 14^{\circ}$, and $20^{\circ}$. For purposes herein, any reference to unsteady conditions means.that the model was in pitch oscillation about the quarter chord.

14. SUBJECT TERMS

wind energy; horizontal-axis wind turbine; wind tunnel test data; wind turbine airfoil

15. NUMBER OF PAGES

16. PRICE CODE

17. SECURITY CLASSIFICATION

OF REPORT

Unclassified
18. SECURITY CLASSIFICATION OF THIS PAGE

Unclassified
19. SECURITY CLASSIFICATION OF ABSTRACT

Unclassified
20. LIMITATION OF ABSTRACT

UL 
